Aus dem Fachgebiet Pflanzenpathologie und Pflanzenschutz

des Departments für Nutzpflanzenwissenschaften der Georg-August-Universität Göttingen

\title{
Einfluss von Kohlfliegenbefall auf die Infektion und Schadwirkung von Verticillium longisporum und Phoma lingam an Raps
}

\author{
Dissertation \\ zur Erlangung des Doktorgrades \\ der Fakultät für Agrarwissenschaften \\ der Georg-August-Universität Göttingen
}

\author{
vorgelegt von \\ Harald Keunecke \\ geboren in Mettmann
}

Göttingen, im April 2009 
D 7

1. Referent: Prof. Dr. Andreas von Tiedemann

2. Referent: Prof. Dr. Stefan Vidal

Tag der mündlichen Prüfung: 20. Mai 2009 


\section{Inhaltsverzeichnis}

\section{Abkürzungen und Symbole}

1. Einleitung 1

1.1 Kleine Kohlfliege (Delia radicum) 3

1.2 Verticillium longisporum 5

1.3 Wurzelhals- und Stängelfäule (Leptosphaeria maculans/Phoma lingam) 8

2. Material und Methoden $\quad 11$

2.1 Chemikalien und Biochemikalien 11

2.2 Nährmedien, Puffer und Trenngele 12

2.3 Pflanzenmaterial 15

2.4 Vermehrung und Erhaltung von Pilzmaterial 15

2.4.1 Verticillium longisporum 15

2.4.2 Phoma lingam 15

2.5 Herstellung von Inokulum 16

2.5.1 Befallenes Stoppelmaterial 16

2.5.2 Mikrosklerotienherstellung von $V$. longisporum 16

2.5.3 Sporensuspensionsherstellung von $V$. longisporum 17

$\begin{array}{ll}\text { 2.5.4 Sporensuspensionsherstellung von } P \text {. lingam } & 17\end{array}$

2.6 Inokulationsmethoden von $V$. longisporum 18

2.6.1 Bodeninokulation im Freiland 18

2.6.2 Bodeninokulation unter Gewächshausbedingungen 18

2.6.3 Stängelinokulation unter Gewächshausbedingungen 18

2.7 Inokulationsmethoden von P. lingam 19

2.7.1 Hypokotylinokulation im Freiland 19

2.7.2 Hypokotylinokulation unter Gewächshausbedingungen 19

2.8 Erfassung des Befalls der Rapspfanzen mit $V$. longisporum 19

2.8.1 Visuelle Bonitur im Freiland 19

2.8.2 Visuelle Bonitur im Gewächshaus 21

2.8.3 ELISA (Enzyme-linked immunosorbent-assay) 23

2.8.3.1 Probenahme im Feld 26

2.8.3.2 Probenahme im Gewächshaus 26

2.8.4 Real-time PCR (Polymerase Chain Reaction) 27

2.8.5 Druckkammer 28

2.9 Visuelle Erfassung des Befalls der Rapspflanzen mit P.lingam 29

2.9.1 Visuelle Bonitur im Freiland 29

2.9.2 Visuelle Bonitur im Gewächshaus $\quad 30$ 
2.10 Anzucht der Kleinen Kohlfliege im Labor 31

2.11 Simulierung des Befalls mit der Kleinen Kohlfliege 32

2.12 Befallssteuerung mit Kulturschutznetzen und Insektiziden 33

2.13 Erfassung des Befalls mit der Kleinen Kohlfliege 34

2.14 Erfassung pflanzenmorphologischer und ertraglicher Parameter 35

2.15 Feldversuche 36

2.15.1 Standorte 36

2.15.2 Sortenversuch 37

2.15.3 Anbaufaktorenversuch 38

2.15.4 Angabe meteorologischer Daten $\quad 40$

2.16 Monitoring 41

2.17 Halbfreilandversuche $\quad 42$

2.18 Gewächshausversuche $\quad 44$

2.18.1 Anzucht und Haltung der Pflanzen 44

2.18.2 Sortenversuch 45

2.18.3 Inokulationsstufenversuch 46

2.18.4 Befallsdynamikversuch $\quad 46$

$\begin{array}{ll}2.18 .5 \text { Resistenzversuch } & 47\end{array}$

2.19 Mechanismen der Interaktion zwischen der Kleinen Kohlfliege und $V$. longisporum $\quad 47$

2.19.1 Stängelinokulationsversuch 47

2.19.2 Wurzelteilungsversuch 48

2.19.3 Wurzelverletzungsversuch 49

2.20 Einfluss der Kleinen Kohlfliege auf den Befall von Raps mit P. lingam 50

2.21 Statistische Auswertung 51

3. Ergebnisse $\quad 52$

3.1 Feldversuche $\quad 52$

3.1.1 Witterungsverlauf $\quad 52$

3.1.2 Erfassung des Befalls von Raps mit der Kleinen Kohlfliege 55

3.1.2.1 Sortenversuch $\quad 55$

$\begin{array}{ll}\text { 3.1.2.2 Anbaufaktorenversuch } & 58\end{array}$

3.1.3 Erfassung des Befalls von Raps mit V. longisporum $\quad 62$

3.1.3.1 Sortenversuch $\quad 62$

$\begin{array}{ll}\text { 3.1.3.2 Anbaufaktorenversuch } & 67\end{array}$

3.1.4 Erfassung des Befalls von Raps mit P. lingam 72

$\begin{array}{ll}3.1 .5 \text { Ertragsparameter } & 78\end{array}$

3.1.6 Einfluss von Netzabdeckungen auf die Pflanzenmorphologie 82

3.1.7 Monitoring 84 
3.2 Halbfreilandversuche $\quad 87$

3.3 Gewächshausversuche $\quad 91$

3.3.1 Einfluss der Kohlfliege auf den Befall von Raps mit $V$. longisporum 91

3.3.1.1 Sortenversuch $\quad 91$

3.3.1.2 Inokulationsstufenversuch 96

$\begin{array}{ll}\text { 3.3.1.3 Befallsdynamikversuch } & 98\end{array}$

3.3.1.4 Resistenzversuch 103

3.3.2 Mechanismen der Interaktion zwischen der Kleinen Kohlfliege und V. longisporum 108

$\begin{array}{ll}\text { 3.3.2.1 Stängelinokulationsversuch } & 108\end{array}$

$\begin{array}{ll}\text { 3.3.2.2 Wurzelteilungsversuch } & 111\end{array}$

$\begin{array}{ll}\text { 3.3.2.3 Wurzelverletzungsversuch } & 114\end{array}$

3.3.3 Einfluss der Kleinen Kohlfliege auf den Befall von Raps mit P. lingam 117

4. Diskussion $\quad 119$

4.1 Befall und Schadwirkung der Kleinen Kohlfliege 119

4.2 Befall und Schadwirkung von $V$. longisporum 130

4.3 Einfluss von Kohlfliegenbefall auf die Infektion und Schadwirkung von V. longisporum 143

4.4 Mechanismen der Interaktion zwischen der Kleinen Kohlfliege und V. longisporum 151

$\begin{array}{ll}4.5 \text { Befall und Schadwirkung von P. lingam } & 160\end{array}$

4.6 Einfluss von Kohlfliegenbefall auf die Infektion und Schadwirkung von P. lingam 164

$\begin{array}{ll}\text { 5. Schlussfolgerungen } & 169\end{array}$

6. Zusammenfassung $\quad 170$

$\begin{array}{ll}\text { Summary } & 175\end{array}$

$\begin{array}{ll}\text { 7. Literaturverzeichnis } & 179\end{array}$

$\begin{array}{lr}\text { 8. Anhang } & 203\end{array}$ 


\section{Abkürzungen und Symbole}

Abb.

BB

$\mathrm{BBCH}$

$\mathrm{BH}$

BSL

BW

bspw.

bzgl.

bzw.

${ }^{\circ} \mathrm{C}$

ca.

$\mathrm{cm}$

DNA

ELISA

$\mathrm{dt}$

dpi

Fa.

FM

GW

g

$\mathrm{h}$

ha

H2Obidest

i.d.R.

$\mathrm{kg}$

$\mathrm{km}$

1

$\mathrm{m}$

$\mathrm{m}^{2}$

$\min$

$\mathrm{mm}$

MS

MV

ng

$\mathrm{nm}$
Abbildung

Brandenburg

Codierung der phänotypischen Entwicklungsstadien von Raps

Befallshäufigkeit in Prozent

Bundessortenliste

Befallswert

beispielsweise

bezüglich

beziehungsweise

Grad Celsius

zirka

Zentimeter

Desoxyribonukleinsäure

Enzyme-linked immunosorbent assay

Dezitonne

days post inoculation

Firma

Frischmasse

prozentual fraßgeschädigte Wurzeloberfläche

Gramm

Stunde

Hektar

doppelt destilliertes Wasser

in der Regel

Kilogramm

Kilometer

Liter

Meter

Quadratmeter

Minute

Millimeter

Mikrosklerotien

Mecklenburg-Vorpommern

Nanogramm

Nanometer 
n.s.

OD

o.g.

PCR

PFL.

pg

rel.

rel. LF

rpm

SB

$\sec$

$\mathrm{SH}$

SN

Taq

Tab.

TKG

z.B.

$\mu \mathrm{g}$

$\mu 1$

u.a.

$\mathrm{W}: \mathrm{V}$

Wdh

$\%$

zzgl. nicht signifikant

Optische Dichte

oben genannt

Polymerase Chain Reaction

Pflanzenlänge

Pikogramm

relativ

relative Luftfeuchte

Umdrehungen pro Minute

Starkbefall durch die Kohlfliege in Prozent

Sekunde

Schleswig-Holstein

Sachsen

Thermus aquaticus

Tabelle

Tausendkorngewicht

zum Beispiel

Mikrogramm

Mikroliter

unter anderem

weight per volume (Gewichtsanteil zu Volumenanteil)

Wiederholung

Prozent

zuzüglich 


\section{Einleitung}

Die Anbaubedeutung von Raps, insbesondere Winterraps (Brassica napus ssp. oleifera Metzger) hat in der Bundesrepublik Deutschland in den letzten Jahren deutlich zugenommen. Nach einem Tiefstand im Jahr 1956 mit 18.000 Hektar wurde die Anbaufläche stark ausgeweitet und erreichte im Jahr 2008 mit ca. 1,6 Millionen Hektar ihren vorläufigen Höchststand. Damit ist Winterraps nach Winterweizen und Wintergerste die bedeutenste Ackerfrucht in Deutschland und die Bundesrepublik der größte Rapsproduzent in der EU (Anonymus, 2008a).

Als Ergebnis der Anbauausdehnung von Winterraps haben eine Reihe von Krankheiten und Schädlingen an Bedeutung gewonnen. Neben Phoma lingam (P. lingam), dem Erreger der Wurzelhals- und Stängelfäule, sind insbesondere Verticillium longisporum (V. longisporum), der Erreger der Krankhaften Abreife, sowie die Kleine Kohlfliege (Delia radicum) in den letzten Jahren stärker in Erscheinung getreten (Daebeler et al., 1988; Erichsen \& Hünmörder, 2005). Bei $V$. longisporum handelt es sich um ein bodenbürtiges Pathogen, welches in Form von Dauerstadien (Mikrosklerotien) langjährig im Boden überdauern kann. Über keimende Mikrosklerotien dringt $V$. longisporum in die Wurzel ein, von wo aus eine akropetale Ausbreitung im Leitbahnsystem der Pflanze erfolgt (Schreiber \& Green, 1963; Olsson \& Nordbring-Hertz, 1985; Zhou et al., 2006; Eynck et al., 2007). Die Kleine Kohlfliege (Delia radicum) schädigt im Larvenstadium. Die Larven können in drei aufeinander folgenden Generationen im Herbst, Frühjahr und Sommer starke Wurzelfraßschädigungen an Rapspflanzen hervorrufen (Erichsen \& Hünmörder, 2005).

In der Vergangenheit durchgeführte Untersuchungen haben gezeigt, dass Wurzelschädlinge den Befall bodenbürtiger Pathogene begünstigen können. Die meisten Untersuchungen, in denen eine Förderung vaskulärer Pathogene (Verticillium spp., Fusarium spp.) beschrieben worden ist, beziehen sich auf Nematoden (Fielding, 1959; Powell 1971; Mai \& Abawi, 1987; Back et al., 2002). Wurzelschädigungen von Nematoden der Gattung Pratylenchus (P.) spp. werden mit einer Befallsförderung von Verticillium spp. bei einer Vielzahl von Kulturpflanzen (u. a. Kartoffel, Tomate, Minze) in Verbindung gebracht (Back et al., 2002). Untersuchungen zur Bedeutung tierischer Organismen für den Befall von Raps mit $V$. longisporum weisen ebenfalls auf befallsfördernde Effekte von Nematoden (Heterodera schachtii) hin (Inszuna \& Eriksson, 1987). Für die Kleine Kohlfliege lagen diesbezüglich bislang keine Untersuchungen vor. 
Fehlende Kenntnisse über mögliche Interaktionen und die sie determinierenden Faktoren bilden die Grundlage dieser Arbeit, die sich mit dem Einfluss von Kohlfliegenbefall auf die Infektion und Schadwirkung von $V$. longisporum an Raps auseinandersetzt. Im Rahmen von Feld-, Halbfreiland- sowie Gewächshausversuchen wurden die Faktoren Kohlfliegenbefall, Sortenanfälligkeit (gegenüber $V$. longisporum), Bodeninokulum, Saattermin sowie Bodenbearbeitung variiert, um neben der Identifizierung von Interaktionseffekten auch der Frage nachgehen zu können, welche Determinanten hierbei eine Rolle spielen. Neben visuellen Befallsbonituren dienten Nachweismethoden (ELISA, Real-Time PCR) für $V$. longisporum in der Rapspflanze dazu, um Schadwirkungen beteiligter Schaderreger in Abhängigkeit von befallsdynamischen Aspekten (Zeitpunkt, Stärke und Ausbreitung des Pathogens) beurteilen zu können. Zur Untersuchung der Interaktion wurden Gewächshausversuche zu den möglichen zugrunde liegenden Mechanismen durchgeführt, anhand derer die Bedeutung lokaler Wundeffekte bzw. pflanzenphysiologischer Effekte abgeschätzt werden konnte.

Die Untersuchung des Befallskomplexes Kohlfliege/ $V$. longisporum bildete den Schwerpunkt in der vorliegenden Arbeit. Darüber hinaus wurde der Frage nachgegangen, ob Larvenfraß der Kohlfliege auch Auswirkungen auf den Befall von Raps mit P. lingam, dem Erreger der Wurzelhals- und Stängelfäule, hat. Zahlreiche Untersuchungen weisen auf einen positiven Zusammenhang zwischen Insektenbefall (Großer Rapsstängelrüssler, Gefleckter Kohltriebrüssler, Rapserdfloh) und Phoma-Befall am Stängel bzw. Wurzelhals hin (Ndimande, 1976; Krüger, 1982; Newman \& Plumridge, 1983; Schulz \& Daebeler, 1984; Newman, 1984; Schulz, 1992; Ulber, 1994; Hartleb et al., 1998). Über die Bedeutung von Larvenfraß der Kohlfliege für den Befall von Raps mit $P$. lingam lagen bis dato noch keine Untersuchungsergebnisse vor. Vor über hundert Jahren von Quanjer (1907) durchgeführte Feldstudien, in denen ein Zusammenhang zwischen Kohlfliegen- und Phoma-Befall an Kohl aufgezeigt wurde, liefern jedoch bereits erste Hinweise für das möglicheVorhandensein einer Interaktion an Raps. Im Rahmen dieser Arbeit wurden in Feld- und Gewächshausversuchen die Faktoren Kohlfliegenbefall, Sortenanfälligkeit (gegenüber P. lingam) und Inokulum (Pyknidiosporen) variiert, um mögliche Interaktionseffekte in Abhängigkeit vom Befallsdruck zu analysieren. 


\subsection{Kleine Kohlfliege (Delia radicum)}

Die Kleine Kohlfliege (Delia radicum L.) gehört zur Ordnung der Zweiflügler (Diptera) und lässt sich hierbei den Blumenfliegen (Anthomyiidae) zuordnen. Das Hauptverbreitungsgebiet des auf Brassica-Arten spezialisierten Schädlings liegt im westlichen Mittel- und Nordeuropa sowie in Nordamerika, wo D. radicum im 19. Jahrhundert eingeschleppt wurde. Darüber hinaus existieren Vorkommen in Nordafrika, Madeira sowie den Azoren (Hoffmann \& Schmutterer, 1999). Vom Erscheinungsbild her ähnelt die 5-6 mm große Kohlfliege einer Stubenfliege. Charakteristisches Erkennungsmerkmal ist eine silbergraue Stirn mit rotem Fleck. Die Unterscheidung von Geschlechtern kann anhand von Farbgebung, Augenabstand, Körperform sowie Behaarung vorgenommen werden. Männliche Fliegen lassen sich von den Weibchen durch drei auf dem Rücken befindliche schwarze Längsstreifen, einen engeren Augenabstand, ein schmaleres, längeres Abdomen sowie zottig behaarte Innenseiten der Hinterbeine unterscheiden. Die Eier der Kohlfliege sind etwa $1 \mathrm{~mm}$ lang und weißlich gefärbt. Aus den Eiern schlüpfen kopf- und beinlose, etwa 7-8 mm lange Larven, die von weißlich-grauer Erscheinung sind. Die Vorderseite des Körpers weist zwei Mundhaken, das schräg abgestutzte Hinterende zwölf warzenförmige Höcker auf. Tönnchenförmige, bräunlich gefärbte Puppen sind etwa 6-7 mm lang und zeigen eine deutliche Segmentierung an (Zohren, 1968; Hoffmann \& Schmutterer, 1999; Crüger et al., 2002).

Insgesamt werden drei Generationen pro Jahr gebildet. Ab Ende April/Anfang Mai schlüpft die erste Generation, die als Tönnchenpuppe im Boden überwintert hat. Nach etwa einer Woche beginnen die Weibchen mit der Eiablage, wobei pro Individuum etwa 100 Eier in Gelegen von 2 bis 10 Eiern an den Wurzelhals oder in nahe gelegene Bodenrisse abgelegt werden. Nach etwa fünf Tagen schlüpfen die Larven, die zunächst an Wurzelhaaren und Feinwurzeln, später jedoch vorwiegend an der Rinde der Hauptwurzel fressen. Der Reifungsfraß der Larven dauert etwa 3 bis 4 Wochen an, bevor eine Verpuppung im Boden stattfindet. Eine zweite Generation tritt ab Juni/Juli, eine dritte ab Ende August/Anfang September auf. Die aus den Eiern der dritten Generation geschlüpften Larven verpuppen sich nach dem Reifungsfraß und überwintern im Boden (Zohren, 1968; Collier \& Finch, 1983a, 1983b; Coaker, 1987; Erichsen \& Hünmörder, 2005).

Während die Kleine Kohlfliege im Kohlanbau bereits seit vielen Jahren als bedeutender Schädling gilt, wird sie im Rapsanbau erst seit Mitte der 90er Jahre verstärkt wahrgenommen. Bei Winterraps wird der im September/Oktober erscheinenden dritten Kohlfliegengeneration die größte Bedeutung beigemessen, da Larven an jungen Rapspflanzen starken Wurzelfraß 
hervorrufen können, der bei Kappung der Hauptwurzel häufig zum Absterben der Pflanzen führt. Der ab Ende April/Anfang Mai erscheinenden ersten Kohlfliegengeneration im Frühjahr wird nur eine untergeordnete Schadrelevanz zugeschrieben, da sich Winterraps zu Beginn des Zufluges bereits im Stadium der Blüte befindet und i. d. R. in der Lage ist, Fraßschädigungen an der Pfahlwurzel besser zu tolerieren (Erichsen, 2004; Erichsen \& Hünmörder, 2005). Bei Sommerraps liegt eine andere Situation vor. Aufgrund des mit der Jugendphase zusammenfallenden Frühjahrsfluges kommt der ersten Kohlfliegengeneration hier die entscheidende Bedeutung zu (Liu \& Butts, 1982; McDonald \& Sears, 1991; Dosdall et al., 2004). Die Ertragswirkung eines Kohlfliegenbefalls ist schwer vorherzusagen. Unter günstigen Bedingungen kann die Versorgung geschädigter Pflanzen durch neu gebildete Nebenwurzeln weitgehend sichergestellt werden. Einzelpflanzenausfälle in geringem Ausmaß können i. d. R. ebenfalls kompensiert werden. Ein hoher Anteil stark geschädigter Pflanzen (geschädigte Wurzeloberfläche $>50 \%$ ), verbunden mit Herbst- und Frühjahrstrockenheit, kann zu ertragsrelevanten Schäden führen. Falls Bedingungen vorherrschen, die eine Kompensation zusätzlich erschweren, sind Ertragseinbußen in Höhe von bis zu 20\% nach Griffiths $(1986,1991)$ nicht auszuschließen.

Zur Kontrolle von Kohlfliegenbefall stehen verschiedene Möglichkeiten zur Verfügung. Maßnahmen zur Herabsetzung der Befallswahrscheinlichkeit stellen eine indirekte Form der Bekämpfung dar. Eine gezielte Wahl des Saattermins bietet eine Möglichkeit, Kohlfliegenbefall zu vermeiden, indem der Saattermin so gelegt wird, dass das anfällige Entwicklungsstadium einer Wirtspflanze nicht mit dem Höhepunkt der Eiablage zusammenfällt (Maack, 1977; Coaker, 1987; Finch, 1989; Dosdall et al., 1995, 2006). Beobachtungen aus der Praxis haben gezeigt, dass Frühsaaten (Saattermin vor dem 20. August) häufig stärker durch die Kohlfliege geschädigt werden als später gesäte Bestände, da größere Pflanzen bei der Eiablage bevorzugt werden. Neben der Wahl eines nicht zu frühen Saattermins können Bodenbearbeitungsgänge nach dem Anbau von Raps durch eine mechanische Zerstörung der Puppen zu einem verminderten Kohlfliegenschlupf und somit ebenfalls zu einer geringeren Befallswahrscheinlichkeit beitragen.

Kulturschutznetze bieten eine weitere Möglichkeit, Kohlfliegenbefall effektiv zu verhindern. Während Kulturschutznetze im ökologischen Kohlanbau häufig erforderlich sind, um einen wirtschaftlichen Anteil marktfähiger Ware zu produzieren (Crüger et al., 2002; Merz, 2005), stellt ein Einsatz im Rapsanbau aus Kostengründen allerdings keine praktikable Kontrollmaßnahme dar. Neben den angeführten indirekten Kontrollmaßnahmen, die auf eine 
Beeinflussung der Populationsgröße und des Eiablageverhaltens ausgerichtet sind, stellt ein Insektizideinsatz eine direkte Form der Bekämpfung dar. Bisher durchgeführte Versuche zur Kontrolle der Imagines bzw. Larven mittels Spritzapplikation haben dabei i. d. R. nur geringe Wirkungsgrade erzielen können (Erichsen, 2004; Erichsen \& Hünmörder, 2005). Im Kohlanbau wurden Insektizide in der Vergangenheit häufig als Gießapplikationen oder in Granulatform in den Boden eingebracht (Finch, 1989). Eine Saatgutbehandlung mit Insektiziden, die auf eine Bekämpfung der Kohlfliegenlarven abzielt, stellt im Rapsanbau die einzig praktikable Bekämpfungsmaßnahme dar. Einige momentan zugelassene Präparate weisen zumindest eine Teilwirkung gegenüber den Larven der Kohlfliege auf, wodurch das Risiko von Starkbefall verringert werden kann (Erichsen \& Hünmörder, 2005; Haarstrich, 2007).

\subsection{Verticillium longisporum}

V. longisporum gehört wie andere zu Verticillium spp. zählende Pathogene (u.a. V. dahliae, V. albo-atrum, V. tricorpus) zur Formklasse der Deuteromyceten (Fungi imperfecti), einer Gruppe von Pilzen, die durch fehlende oder nicht bekannte sexuelle Hauptfruchtform (Teleomorph) charakterisiert wird (Schwantes, 1996). Die Gattung Verticillium Nees, zu der neben den o.g. noch mehr als 50 Arten gehören, zeichnet sich durch wirtelig verzweigte Konidienträger (Konidiophoren) aus (Pegg \& Brady, 2002). Eine eindeutige Zuordnung kulturpflanzenspezifischer Verticilliosen zu bestimmten Verticillium-Arten war jahrelang durch eine unklare nomenklatorische Abgrenzung geprägt. Bis vor etwa zehn Jahren wurde die bei Raps auftretende Verticilliose auf den Erreger $V$. dahliae Kleb., der über einen sehr weiten Wirtspflanzenkreis verfügt (u. a. Kartoffel, Baumwolle, Leguminosen), zurückgeführt. Stark (1961) isolierte aus Verticillium-befallenem Meerrettich einen Erreger, der zwar einige Merkmale von $V$. dahliae (Mikrosklerotienbildung, farblose Konidienträger) aufwies, sich jedoch durch längere Konidien und ein anderes Verhalten unter UV-Licht abgrenzte. Der Autor schlug vor, dieses Pathogen als eigene Varietät ( $V$. dahliae Kleb. var. longisporum Stark) anzuerkennen.

Dieser Vorschlag fand jedoch bis Mitte der 90er Jahre kaum Beachtung. Erst morphologische sowie molekulare Untersuchungen von Karapapa et al. (1997), die deutliche Unterschiede zwischen Verticillium-Isolaten kruziferer und nicht kruziferer Wirte feststellten, führten zu einer nomenklatorischen Umkehr. Isolate kruziferer Wirte grenzten sich in diesen Untersuchungen durch eine andere Mikrosklerotienform (länglich), längere Konidien, eine unterschiedliche Phialidenzahl an Konidienträgern, sowie fehlende extrazelluläre 
Polyphenoloxidaseaktivität von $V$. dahliae ab. Darüber hinaus wiesen kruzifere Isolate einen fast doppelt so hohen DNA-Gehalt wie haploide $V$. dahliae-Isolate auf, so dass die Autoren kruzifere Isolate als nahezu diploid bezeichneten. Diese Untersuchungen und später von Zeise \& Tiedemann (2002) sowie Eynck et al. (2007) durchgeführte Pathogenitätstests zeigten, dass ausschließlich kruzifere Isolate in der Lage sind, Symptome an Winterraps hervorzurufen. Aufgrund unterschiedlicher Wirtspflanzenkreise unterbreiteten Karapapa et al. (1997) den Vorschlag, kruzifere Isolate nicht nur als eigene Varietät, sondern als eigene Art (V. longisporum Karapapa Stark (1997)) zu beschreiben.

$V$. longisporum ist ein bodenbürtiges Pathogen, welches in Form von Dauerstadien (Mikrosklerotien) langjährig im Boden überdauern kann. Eine Infektion geht von Mikrosklerotien (MS) aus, die durch von der Wirtspflanze abgesonderte Wurzelexsudate bei entsprechenden Bodentemperatur- und Feuchtebedingungen zur Keimung stimuliert werden (Schreiber \& Green, 1963; Olsson \& Nordbring-Hertz, 1985). Wie bei anderen von Verticillium spp. befallenen Kulturpflanzen ist das Pathogen in der Lage, die Wurzel mittels Infektionshyphe direkt zu penetrieren (Zhou et al., 2006; Eynck et al., 2007). Infektionen können allerdings auch über Wunden stattfinden (Karapapa et al., 1997; Steventon et al., 2002). Bei erfolgreicher Passage von peripherem Rindengewebe und Endodermis dringt das Pathogen ins Wurzelxylem ein, von wo aus sich eine akropetale Besiedlung vollziehen kann. Die Ausbreitung in weiter oben gelegene Pflanzenbereiche erfolgt vorwiegend durch im Xylem gebildete und passiv im Transpirationsstrom bewegte Konidien (Karapapa et al., 1997; Johansson et al., 2006; Zhou et al., 2006). Mit beginnender Seneszenz ist $V$. longisporum in der Lage, parenchymatisches Gewebe $\mathrm{zu}$ besiedeln, wodurch erste Symptome, im Feld i. d. R. in Form halbseitiger Stängelverbräunungen, sichtbar werden. Im abgestorbenen Gewebe (Wurzel, Spross, Mark) werden MS gebildet, die über Rapserntereste wieder in den Boden gelangen und somit zu Infektionen anfälliger Pflanzen führen können. Damit ist $V$. longisporum eine typische Fruchtfolgekrankheit (Daebeler et al., 1988). Eine Saatgutübertragbarkeit wird zwar für möglich erachtet, spielt jedoch eine untergeordnete Rolle (Heppner \& Heitefuss, 1995).

Die bereits in den 60er Jahren in Teilen Südschwedens beobachtete Verticilliose an Raps wurde lange Zeit als ein rein schwedisches Problem angesehen (Svensson \& Lerenius, 1987). In Deutschland wird erst seit Mitte der 80er Jahre vermehrt Notiz von dieser Rapskrankheit genommen, wobei das Auftreten zunächst auf dem Gebiet der ehemaligen DDR (Mecklenburg-Vorpommern) sowie in Schleswig-Holstein beobachtet wurde. In einem bei 
Rostock-Biestow seit 1970 angelegten Fruchtfolgeversuch mit 33\%igem Rapsanteil lagen Befallshäufigkeiten von $V$. longisporum an Winterraps 1984 bei 2\%, 1987 jedoch schon bei 44\% (Daebeler et al., 1988). Heute auf dieser Fläche erhobene Befallshäufigkeiten schwanken jahresbedingt zwischen 30 und 100\% (Zeise \& Steinbach, 2004). An anderen durch enge Rapsfruchtfolgen gekennzeichneten Standorten ist ebenfalls ein in den letzten Jahren vermehrtes Auftreten von $V$. longisporum beobachtet worden. Ungeachtet dieser Tatsache existieren nur wenige Untersuchungen, die Befallsauswirkungen von $V$. longisporum näher beleuchten. An Einzelpflanzen wurden Ertragsreduktionen, hervorgerufen durch verringerte Schoten- und Kornausbildung, abgestorbene Nebentriebe sowie ein vermindertes Tausendkorngewicht, von bis zu 85\% ermittelt (Daebeler et al., 1988; Zeise \& Steinbach, 2004). Angaben über mögliche Gesamtertragsverluste reichen von 10-50\%, auch wenn bislang keine entsprechenden Nachweise im Rahmen experimenteller Versuche erbracht worden sind (Dunker et al., 2008).

Während zur Bekämpfung anderer Fruchtfolgekrankheiten Fungizide und Biologische Bekämpfung des Bodeninokulums (Sclerotinia sclerotiorum) bzw. resistente Sorten (Plasmodiophora brassicae) effektive Kontrollinstrumente darstellen, existieren momentan keine vergleichbaren Möglichkeiten gegenüber V. longisporum. Maßnahmen zur Herabsetzung der Infektionswahrscheinlichkeit, die auf eine Reduktion des Bodeninokulums abzielen, basieren auf einer Erweiterung der Fruchtfolge anfälliger Kulturpflanzen sowie einer Bekämpfung kruziferer Unkräuter (Svensson \& Lerenius, 1987; Daebeler \& Seidel, 1989; Amelung et al., 1996; Sadowski \& Zielinski, 1995; Zeise \& Steinbach, 2004). Eine Biologische Bekämpfung mit antagonistisch wirkenden Mikroorganismen wurde zwar untersucht (Berg \& Ballin, 1994; Alström, 2000), lässt sich bislang in der Praxis jedoch noch nicht nutzen. Fungizide, die zur Kontrolle anderer Rapskrankheiten eingesetzt werden, haben in den wenigen angelegten Versuchen (Wohlleben, 2001; Keunecke, 2005) keinen befallsreduzierenden Effekt erkennen lassen. In vitro-Untersuchungen, in denen verschiedene fungizide Wirkstoffe zu einer Hemmung von $V$. longisporum führten (Koopmann, persönliche Mitteilung), ließen sich unter Feldbedingungen nicht wiederfinden. Eine fehlende basipetale Verlagerung in Richtung Wurzel wurde hierbei als Hauptgrund fehlender Wirkung im Feld erachtet.

Vor dem Hintergrund fehlender direkter Bekämpfungsmöglichkeiten wird die Verbesserung von Sortenresistenz als einzige Möglichkeit angesehen, um $V$. longisporum effektiv kontrollieren zu können (Happstadius et al., 2003; Dixelius et al., 2005; Rygulla et al., 2007, 
2008; Eynck, 2008). Das Resistenzniveau derzeit zugelassener Rapssorten gegenüber $V$. longisporum ist jedoch als gering zu bezeichnen, da alle Sorten mehr oder weniger stark besiedelt werden und Symptome ausbilden. Inokulationsversuche im Gewächshaus (Zeise, 1992; Zeise \& Tiedemann, 2002; Steventon et al., 2002; Happstadius et al., 2003; Keunecke, 2005; Eynck, 2008) sowie Befallserhebungen im Feld (Heppner, 1995; Zeise \& Steinbach, 2004; Eynck, 2008) haben jedoch gezeigt, dass es Anfälligkeitsunterschiede zwischen Sorten gibt. In den letzten Jahren sind zudem einige Brassica-Genotypen identifiziert worden, die ein höheres quantitatives Resistenzniveau gegenüber $V$. longisporum aufweisen (Happstadius et al., 2003; Dixelius et al., 2005; Rygulla et al., 2007, 2008; Eynck, 2008).

\subsection{Wurzelhals- und Stängelfäule (Leptosphaeria maculans/Phoma lingam)}

Bei der Wurzelhals- und Stängelfäule handelt es sich um eine weltweit verbreitete Krankheit von Brassica-Arten, die durch den Loculoascomyzeten Leptosphaeria maculans/Leptosphaeria biglobosa (anamorph Phoma lingam) verursacht wird (Smith \& Sutton, 1964; Williams, 1992; Shoemaker \& Brun, 2001). Die Primärinfektion der Blätter im Herbst erfolgt meist über luftbürtige Ascosporen, die in Pseudothezien auf befallenen Rapsstoppeln oder anderen Kreuzblütlern gebildet werden, wo P. lingam saprophytisch lebt (Wood \& Barbetti, 1977; Gladders \& Musa, 1980; West et al., 2002; Huang et al., 2005). Angaben über mögliche Flugdistanzen der Ascosporen variieren von $1500 \mathrm{~m}$ bei Fitt et al. (1999) bis hin zu $8000 \mathrm{~m}$ bei Gladders \& Musa (1980). Temperaturen um $20^{\circ} \mathrm{C}$ und eine Blattnässedauer von mindestens 48 Stunden stellen nach Biddulph et al. (1999) optimale Bedingungen für eine erfolgreiche Blattinfektion dar, bei der $P$. lingam über die Stomata oder Wunden ins Blattgewebe eindringt. Andere mögliche Primärinfektionswege über Myzel oder infiziertes Saatgut spielen eine untergeordnete Rolle (Petrie \& Vanterpool, 1974; Gabrielson, 1983; Wahmhoff, 2000). Die sekundäre Ausbreitung erfolgt durch Pyknidiosporen, die in Pyknidien auf befallenen Blättern gebildet werden und über Regentropfen lokal verbreitet werden (Barbetti, 1977; Fitt et al., 1999; Travadon et al., 2007). Von befallenen Blättern ausgehend wächst $P$. lingam systemisch über den Blattstiel bis in den Wurzelhals, wo Läsionen aufgrund einer langen latenten, biotrophen Phase i. d. R. erst ab Frühjahr sichtbar werden (Hammond et al., 1985; Hammond \& Lewis, 1986b). Infektionen von Wurzelhals und Stängel können allerdings auch direkt, über Wunden erfolgen (Brunin \& Lacoste, 1970; Ndimande, 1976; Newman, 1984; Hammond et al., 1985). 
Die Wurzelhals- und Stängelfäule ist in allen Anbaulagen zu finden, wobei das Befallsvorkommen starken jahreszeitlichen, regionalen und pflanzenspezifischen Schwankungen unterliegt (Hall, 1992; West et al., 2001; Fitt et al., 2006). Das Pathogen ist in der Lage, neben Blättern, Wurzelhals und Stängel auch Schoten sowie Wurzeln zu befallen (Gabrielson, 1983; Sosnowski et al., 2001). Ertragsrelevant ist vor allem Wurzelhalsbefall, der zu Vermorschung, Verkorkung und als Folge zu Lager, Stängelbruch und vorzeitiger Abreife (Notreife) führen kann (Hall, 1992; West et al., 2001; Wherrett et al., 2004). Insbesondere bei frühem, massiven Blattbefall im Herbst und anhaltend warmfeuchten Witterungsbedingungen kann es dabei zu erheblichen Ertragsverlusten kommen, weil $P$. lingam dann optimale Bedingungen vorfindet, um systemisch über den Blattstiel bis zum Wurzelhals vorzudringen. Spätere Blattinfektionen können die Pflanze durch Befall der oberen Stängelregion zwar auch schädigen, üben jedoch i. d. R. nur noch einen geringen Einfluss auf den Wurzelhalsbefall aus (Hammond \& Lewis, 1986b; Fitt et al., 1999; Zhou et al., 1999; West et al., 2002).

Phoma-Isolate lassen sich anhand von Pathogenität, Virulenz sowie morphologischen Merkmalen entweder Leptosphaeria maculans (ehemals A-Typ) oder Leptosphaeria biglobosa (ehemals B-Typ) zuordnen (Williams \& Fitt, 1999; Shoemaker \& Brun, 2001). Isolate (Rassen) von Leptosphaeria maculans werden dabei insbesondere mit ertragsrelevanten Wurzelhalsbefall, Isolate von Leptosphaeria biglobosa dagegen mit weniger schädigenden Symptomen am Stängel in Verbindung gebracht (Rouxel \& Balesdent, 2005).

Die Kontrolle von P. lingam basiert sowohl auf indirekten als auch direkten Maßnahmen. Da es sich bei der Wurzelhals- und Stängelfäule um eine stoppelbürtige Krankheit handelt, die von infizierten Ernteresten initiiert wird, kommt dem Abbau von Stoppelresten eine zentrale Bedeutung zur Verringerung von Inokulum zu (Hall, 1992; Barbetti \& Khangura, 1999; West et al., 2001). Untersuchungen von McGee \& Emmett (1977) sowie Macroft et al. (2003), wonach der größte Anteil freigesetzter Ascosporen von abgeernteten Rapsfeldern stammt, weisen zudem darauf hin, dass bei Einhaltung einer zwei- bis dreijährigen Anbaupause nur noch mit geringen Inokulummengen $\mathrm{zu}$ rechnen ist. Ein weiterer wichtiger Aspekt der Krankheitsprävention ist in der Sortenwahl $\mathrm{zu}$ sehen, da das vorhandene Spektrum zugelassener Rapssorten unterschiedliche Anfälligkeiten gegenüber $P$. lingam aufweist (Anonymus, 2008b).

Die Infektionswahrscheinlichkeit von $P$. lingam kann durch genannte Maßnahmen erheblich reduziert werden, reicht aber in einzelnen Jahren mit hohem Befallsdruck nicht aus, so dass 
Fungizidmaßnahmen erforderlich sind (Gladders \& Musa, 1980; Fitt et al., 1999; West et al., 2002; Fitt et al., 2006). Problematisch ist allerdings, dass die chemische Bekämpfung mit Fungiziden aufgrund der langen möglichen Infektionszeit von P. lingam hinsichtlich Wirkung und ökonomischem Erfolg kaum vorhersehbar ist (Heitefuss et al., 2000). Wegen Fehlens zuverlässiger Bekämpfungsschwellen oder geeigneter Prognosemodelle, die eine Bekämpfungsentscheidung unterstützen könnten, unterliegt der Erfolg von Fungizidmaßnahmen großen Schwankungen. Bisher erarbeitete Befalls-Verlust Relationen beziehen sich auf den Befall im Stadium BBCH 85, nicht jedoch auf den Blattbefall zum möglichen Bekämpfungszeitraum im Herbst und Frühjahr. Bekämpfungsentscheidungen beruhen daher häufig auf Erfahrungen zurückliegender Jahre (Thürwächter, 1995; Wohlleben, 2001). 


\section{Material und Methoden}

\subsection{Chemikalien und Biochemikalien}

Neben den unten aufgeführten Produkten wurden ausschließlich Chemikalien der Firma Merck KGaA, Darmstadt, mit dem Reinheitsgrad p. A. verwendet.

Agar-Agar

Agarose NEEO

Biotin-X-NHS

Czapek-Dox-Agar

Czapek-Dox-Broth

Diethanolamin

Dimethylformamid

Dneasy Plant Mini Kit

dNTP-Mix

EDTA

Ethidiumbromid

Fluorescein

Glyzerin

Kartoffel-Glucose-Agar (PDA)

Loading Dye Solution

$\mathrm{MgCl}_{2}$

PCR-Puffer, 10x

SybrGreen

Taq-Polymerase

PDB-Medium

Natriumnitrat $\left(\mathrm{NaN}_{3}\right)$

Para-Nitrophenylphosphat (PNPP)

Polyvinylpyrrolidone (PVP)

Rinderserumalbumin (RSA)

Streptavidin-alkalische Phosphatase (StrAP)

Streptomycinsulfat

Tris-hydroxymethyl-aminomethan

Tween 20
Merck, Darmstadt

AppliChem, Darmstadt

Sigma-Aldrich, München

Duchefa Biochem, Haarlem, Niederlande

Scharlau, Barcelona, Spanien

Fluka, Neu-Ulm

Serva, Heidelberg

Qiagen, Hilden

Fermentas, St.Leon-Rot

Amresco, Solon, USA

Fluka, Neu-Ulm

Roche, Mannheim

Roth, Karlsruhe

Duchefa Biochem, Haarlem, Niederlande

Fermentas, St.Leon-Rot

Fermentas, St.Leon-Rot

Fermentas, St.Leon-Rot

Roche, Mannheim

Fermentas, St.Leon-Rot

Scharlau, Barcelona, Spanien

Serva, Heidelberg

Serva, Heidelberg

Serva, Heidelberg

Roche, Mannheim

Roche, Mannheim

Fluka, Neu-Ulm

Roth, Karlsruhe

Scharlau, Barcelona, Spanien 


\subsection{Nährmedien, Puffer und Trenngele}

Der pH Wert unten aufgelisteter Nährmedien wurde vor dem Autoklavieren (15 Minuten bei $\left.121^{\circ} \mathrm{C}\right)$ mit $\mathrm{NaOH}$ bzw. HCL eingestellt.

Potato Dextrose Agar (PDA): $\mathrm{pH} 5,5$

PDB $24 \mathrm{~g}$

Agar $15 \mathrm{~g}$

Aqua bidest. ad $1000 \mathrm{ml}$

Potato Dextrose Broth (PDA): $\mathrm{pH} \mathrm{5,1}$

PDB

$24 \mathrm{~g}$

Aqua bidest. ad $1000 \mathrm{ml}$

Czapek-Dox-Agar: pH 5,5

Czapek-Dox Broth $33,5 \mathrm{~g}$

Agar

$12 \mathrm{~g}$

Aqua bidest. ad $1000 \mathrm{ml}$

Czapek-Dox Broth: pH 6,8

Czapek-Dox Broth $33,5 \mathrm{~g}$

Aqua bidest. ad $1000 \mathrm{ml}$

Für den ELISA-Test wurden wurden folgende Puffer verwendet:

Carbonatpuffer: $\mathrm{pH} 7,5$

$\mathrm{NaHCO}_{3}$ Natriumhydrogencarbonat

$\mathrm{NaCl}$ Natriumchlorid

$10 \mathrm{~g}$

Aqua bidest. ad $1000 \mathrm{ml}$

Waschpuffer: pH 7,4 (nach Casper \& Meyer, 1981)

PPK (s.u.)

$1000 \mathrm{ml}$

Tween 20

$0,5 \mathrm{ml}$

$\mathrm{NaN}_{3}$

Natriumazid

$0,2 \mathrm{~g}$ 
Beschichtungspuffer: pH 9,6 (nach Casper \& Meyer, 1981)

$\begin{array}{llr}\mathrm{Na}_{2} \mathrm{CO}_{3} & \text { Natriumcarbonat } & 1,59 \mathrm{~g} \\ \mathrm{NaHCO}_{3} & \text { Natriumhydrogencarbonat } & 2,93 \mathrm{~g} \\ \mathrm{NaN}_{3} & \text { Natriumazid } & 0,2 \mathrm{~g} \\ \text { Aqua bidest. } & & \text { ad } 1000 \mathrm{ml}\end{array}$

Phosphatgepufferte physiologische Kochsalzlösung (PPK): pH 7,4 (Casper \& Meyer, 1981)

$\begin{array}{llr}\mathrm{NaCl} & \text { Natriumchlorid } & 8 \mathrm{~g} \\ \mathrm{KH} 2 \mathrm{PO} 4 & \text { Kaliumhydrogenphosphat } & 0,2 \mathrm{~g} \\ \mathrm{Na} 2 \mathrm{HPO} 4 \times 12 \mathrm{H} 2 \mathrm{O} & \text { Dinatriumhydrogenphosphat } & 2,9 \mathrm{~g} \\ \mathrm{KCL} & \text { Kaliumchlorid } & 0,2 \mathrm{~g} \\ \mathrm{NaN}_{3} & \text { Natriumazid } & 0,2 \mathrm{~g}\end{array}$

Aqua bidest.

ad $1000 \mathrm{ml}$

Extraktionspuffer: pH 7,4 (nach Casper \& Meyer, 1981)

PPK (s.o.)

$1000 \mathrm{ml}$

Tween 20 (s.o.)

PVP Polyvinylpyrrolidon

$0,5 \mathrm{ml}$

$\mathrm{NaN}_{3}$

Natriumazid

$2 \mathrm{~g}$

$0,2 \mathrm{~g}$

Konjugatpuffer: pH 7,4 (nach Casper \& Meyer, 1981)

PPK (s.o.)

$1000 \mathrm{ml}$

Tween 20 (s.o.)

$0,5 \mathrm{ml}$

Rinderserumalbumin

$2 \mathrm{~g}$

Substratpuffer: pH 9,8 (nach Clark \& Adams, 1977)

Diethanolamin

$97 \mathrm{ml}$

Aqua bidest.

$600 \mathrm{ml}$

$\mathrm{NaN}_{3}$

$0,2 \mathrm{~g}$

Aqua bidest.

$303 \mathrm{ml}$

Nach Zusammenführen von $600 \mathrm{ml}$ Aqua bidest., $97 \mathrm{ml}$ Diethanolamin sowie 0,2 g Natriumazid wurde durch Zugabe von 1N HCL 8 (Salzsäure) ein pH von 9,8 eingestellt und anschließend mit Aqua bidest. auf $1000 \mathrm{ml}$ aufgefüllt. 
Für die molekularen Untersuchungen wurden folgende Puffer und Lösungen verwendet:

TBE-Puffer 10x (Tris-Borat-EDTA-Puffer): $\mathrm{pH} 8,3$

TRIS

Borsäure

$108 \mathrm{~g}$

0,5 M EDTA $55 \mathrm{~g}$

Aqua bidest.

$40 \mathrm{ml}$

ad $1000 \mathrm{ml}$

TE-Puffer: $\mathrm{pH} 8$

TRIS

$0,1 \mathrm{M}$

EDTA

$10 \mathrm{mM}$

Agarose-Trenngel (1\%ig)

Agarose

$1 \mathrm{~g}$

TBE-Puffer

$100 \mathrm{ml}$

Ethidiumbromid

$3 \mathrm{ml}$

Für die Extraktion von DNA aus Pflanzenmaterial wurden ausschließlich Puffer des DNeasy Plant Mini Kits (Fa. Quiagen) verwendet. Eine genaue Zusammensetzung einzelner Bestandteile wurde vom Hersteller nicht angegeben. 


\subsection{Pflanzenmaterial}

Die im Rahmen dieser Arbeit verwendeten Rapssorten bzw. -linien sind in Tab. 1 zusammengestellt.

Tab.1: Verwendete Rapssorten/Rapslinien mit Herkunfts- und Züchternachweis.

\begin{tabular}{lll}
\hline Rapssorten/Rapslinien & Herkunftsland & Züchter \\
\hline Aviso & Schweden & Danisco Seed GmbH \\
Caiman & Frankreich & Monsanto SAS \\
Express & Deutschland & NPZ KG \\
Heros & Deutschland & Raps GbR \\
Laser & Deutschland & Syngenta Seeds GmbH \\
Lion & Deutschland & DSV AG \\
NK Fair & Deutschland & Syngenta Seeds GmbH \\
Oase & Deutschland & DSV AG \\
SEM 05-500256 & Schweden & Svalöf Weibull AG \\
Smart & Deutschland & Syngenta Seeds GmbH \\
Trabant & Deutschland & NPZ KG \\
Viking & Deutschland & NPZ KG \\
\hline
\end{tabular}

\subsection{Vermehrung und Erhaltung von Pilzmaterial}

\subsubsection{Verticillium longisporum}

Die Inokulumherstellung für Gewächshausversuche erfolgte mit den $V$. longisporum-Isolaten VL 40 und VL 43. Beide Isolate stammen aus Mecklenburg-Vorpommern (1990 aus Raps isoliert) und haben sich in bisher durchgeführten Versuchen (Zeise, 1992, 1995; Keunecke, 2005) als aggressiv gegenüber Brassica napus erwiesen. Zur Erhaltung wurden die verwendeten Isolate in einer Glycerinstocklösung in einer Konzentration von 1-3 x $10^{6}$ Sporen $/ \mathrm{ml}$ bei $-80^{\circ} \mathrm{C}$ aufbewahrt. Die Anzucht und Vermehrung der Isolate erfolgte auf PDA bzw. als Schüttelkultur in PDB.

\subsubsection{Phoma lingam}

Für Inokulationen im Gewächshaus wurden mehrere Isolate von P. lingam verwendet, die sich anhand ihrer Pathogenitätsgruppe in aggressive bzw. nicht aggressive Isolate unterteilen lassen (Koch et al., 1989). Die von befallenem Stoppelmaterial gewonnenen Isolate (Tab. 2) wurden auf Hafermehlagarschrägröhrchen unter dickflüssigem Parafinöl bei $4^{\circ} \mathrm{C}$ im 
Kühlschrank gelagert. Sporensuspensionen wurden in einer Konzentration von $1-2 \times 10^{7}$ Sporen $/ \mathrm{ml}$ für einige Monate bei $-20^{\circ} \mathrm{C}$ aufbewahrt. Für Inokulationen im Freiland kam ein Sporensuspensionsgemisch aggressiver Isolate der Pathogenitätsgruppen A1, A2 und A5 zur Anwendung, welches von der Prophyta GmbH, Malchow/Poel, hergestellt worden war.

Tab. 2: Klassifizierung der verwendeten P. lingam-Isolate in Pathogenitätsgruppen (PG) aufgrund der Reaktion an Kotyledonen der Rapssorten Lirabon, Glacier, Quinta und Jet Neuf [S = anfällig; $\mathrm{R}=$ resistent; I = intermediäre Reaktion] (Kuswinanti, 1996).

\begin{tabular}{llcccc}
\hline PG & Isolatbezeichnung & Lirabon & Glacier & Quinta & Jet Neuf \\
\hline A1 & T20bc66 & S & S & S & $\mathrm{S}$ \\
A2 & RF 108 & S & S & I/R & S \\
A5 & T12aB07 & S & S & S & R \\
NA* & IBCN 78 & R & R & R & R \\
NA $*$ & IBCN 79 & R & R & R & R \\
\hline
\end{tabular}

*nicht aggressiv

\subsection{Herstellung von Inokulum}

\subsubsection{Befallenes Stoppelmaterial}

Für die Bodeninokulation kamen Verticillium-befallene Stoppelreste zur Anwendung, die nach der Rapsernte von einem künstlich inokulierten Feldversuchsstandort bei Göttingen (Weende) entnommen worden waren. Die mit Mikrosklerotien durchsetzten Erntereste wurden nach der Entnahme klein gehäckselt bzw. für einige Versuche klein gemahlen und bis zur weiteren Verwendung in Kunststoffsäcken im Gewächshaus aufbewahrt.

\subsubsection{Mikrosklerotienherstellung von $V$. longisporum}

Die Herstellung von Mikrosklerotien (MS) für die Bodeninokulation eines Gewächshausversuches (vgl. 2.15.2) erfolgte in Anlehnung an Heppner (1995). Hierzu wurden $20 \mathrm{ml}$ eines Czapek-Dox Flüssigmediums mit zwei Myzelstücken (Ø $5 \mathrm{~mm}$ ) der auf PDA angezogenen $V$. longisporum-Isolate VL 40 bzw. VL 43 beimpft und für vierzehn Tage auf einem Rotationsschüttler $(100 \mathrm{rpm})$ bei $20^{\circ} \mathrm{C}$ inkubiert. Die weitere Anzucht der MS erfolgte in $300 \mathrm{ml}$ Erlenmeyerkolben. 225 g einer sterilen Roggenmehl-Quarzsand (fein, Fa. Vitakraft)Mischung (1:14; w/w) zzgl. 9\% (v/w) Aqua bidest. wurden mit der vierzehn Tage alten Sporensuspension versetzt und gründlich vermischt. Insgesamt dreißig Kolben, jeweils 
fünfzehn mit VL 40 bzw. VL 43 versetzt, wurden mit Parafilm verschlossen und anschließend für fünf Wochen bei $20^{\circ} \mathrm{C}$ im Dunkeln inkubiert.

Das MS-Substrat wurde nach der Inkubationszeit in flache Aluschalen überführt, in einem Lichtthermostat unter Zuhilfenahme eines Gebläses für zwei Tage getrocknet und anschließend mit einem Pistill pulverisiert. Zur Bestimmung der MS-Konzentration im Anzuchtsubstrat erfolgte eine stichprobenweise Isolierung von MS mit 70\%iger Saccharoselösung (w/w). In Zentrifugenröhrchen (14 ml, Fa. Sarstedt) wurden Aliquots von $2 \mathrm{~g}$ eingewogen, mit Saccharoselösung $(1: 2,5 ; \mathrm{w} / \mathrm{w})$ versetzt, gründlich geschüttelt und bei $10^{\circ} \mathrm{C}$ für zehn Minuten mit 1500 x $g$ zentrifugiert (4K10 Rose, Fa. Sigma). Die im Überstand angereicherten MS wurden mit einem Papierrundfilter (Ø 110 mm, Fa. Schleicher \& Schüll) dekantiert und unter Vakuum mit Aqua bidest. gespült. Zur Isolierung nahezu aller MS war eine dreimalige Zentrifugation notwendig. Das Gewicht der trockenen MS wurde durch Differenzwägung von Filter ohne bzw. Filter mit MS nach zwölfstündiger Trocknung bei $105^{\circ} \mathrm{C}$ mit einer Feinwaage ermittelt. Das Anzuchtsubstrat der insgesamt dreißig Kolben wurde $\mathrm{zu}$ isolatspezifischen Mischproben à drei Kolben vereint, so dass jeweils fünf Mischproben mit Isolat VL 40 bzw. VL 43 entstanden. Je Mischprobe wurden fünf Aliquots à $2 \mathrm{~g}$ für MS-Konzentrationsbestimmung untersucht. Die aus den Stichproben isolierten MS wurden aufgrund der für die Gewichtsfeststellung notwendigen Trocknung (bei $105^{\circ} \mathrm{C}$ ) nicht zur Topfbodeninokulation im Gewächshaus herangezogen. Nach Ermittlung der MSAusbeute (mg MS/g Substrat) in den einzelnen Mischproben wurde das gesamte Anzuchtsubstrat gründlich vermischt, um eine einheitliche MS-Dichte zu erhalten.

\subsubsection{Sporensuspensionsherstellung von $V$. longisporum}

Für die Herstellung einer Sporensuspension von $V$. longisporum wurden $500 \mathrm{ml}$ PDBMedium mit $500 \mu$ l Glycerolstocklösung der V. longisporum-Isolate VL 40 bzw. VL 43 beimpft und für vierzehn Tage bei $23^{\circ} \mathrm{C}$ auf einem Schüttelinkubator $(100 \mathrm{rpm})$ im Dunkeln inkubiert. Nach der Inkubation wurde die Sporendichte der Suspension unter Verwendung einer Thomakammer bestimmt und durch Zugabe von Aqua bidest. auf 1 x $10^{6}$ Sporen $/ \mathrm{ml}$ eingestellt. Anschließend wurden die Sporensuspensionen der Isolate VL 40 und VL 43 im Verhältnis 1:1 vermischt. 


\subsubsection{Sporensuspensionsherstellung von $P$. lingam}

Für Inokulationen im Gewächshaus wurde ein Sporensuspensionsgemisch aggressiver bzw. nicht aggressiver $P$. lingam-Isolate hergestellt. Hierzu wurden Sporensuspensionen der in Tab. 2 aufgeführten Isolate auf eine Dichte von $1 \times 10^{6}$ Sporen/ml eingestellt und im Anschluss zu einem aggressiven und einem nicht aggressiven Isolatgemisch vereinigt. Für Inokulationen im Freiland wurde das von der Prophyta $\mathrm{GmbH}$ produzierte Sporensuspensionsgemisch $\left(5 \times 10^{7}\right.$ Sporen/ml) durch Zugabe von Wasser auf eine Dichte von 5 × $10^{5}$ Sporen $/ \mathrm{ml}$ eingestellt.

\subsection{Inokulationsmethoden von $V$. longisporum}

\subsubsection{Bodeninokulation im Freiland}

Die Bodeninokulation mit $V$. longisporum erfolgte an den Feldversuchsstandorten mit Verticillium-befallenen Rapsstoppeln (vgl. 2.5.1). Kurz vor der Aussaat des Winterrapses wurde das Inokulummaterial per Hand in Inokulationsblöcken gleichmäßig ausgestreut (ca. $15 \mathrm{~g} / \mathrm{m}^{2}$ ) und im Anschluss mit Kreiselegge und Walze flach (ca. 5-8 cm Tiefe) eingearbeitet. In den Halbfreilandversuchen (vgl. 2.17) erfolgte die Bodeninokulation mit klein gemahlenem Stoppelmaterial. Neben einer Kontrolle wurden im Jahr 2006 entweder 15 g oder 100 g, im Jahr 2007 entweder $10 \mathrm{~g}$ oder 50 g Inokulummaterial per Hand in die Kleinparzellen $\left(1 \mathrm{~m}^{2}\right)$ ausgestreut und anschließend mit einer Harke flach eingemischt. Zur Vermeidung von verzerrenden Düngungseffekten wurde eine Ausgleichsdüngung mit autoklaviertem Stoppelmaterial in entsprechender Höhe durchgeführt.

\subsubsection{Bodeninokulation unter Gewächshausbedingungen}

Für die Bodeninokulation im Gewächshaus kam i. d. R. Verticillium-befallenes, klein gemahlenes Stoppelmaterial zur Anwendung (vgl. 2.5.1), welches vor der Saat bzw. Pflanzung in den Boden eingebracht wurde. Im Sortenversuch (vgl. 2.15.2) erfolgte die Bodeninokulation mit künstlich angezogenen MS (vgl. 2.5.2), die mit dem Anzuchtsubstrat in den Boden eingemischt wurden. In einem Gewächshausversuch (vgl. 2.19.3) wurde der Topfboden mit einer Sporensuspension inokuliert, die sich zu je 50\%igem Volumenanteil aus den $V$. longisporum-Isolaten VL 40 und VL 43 zusammensetzte. Hierbei wurden $100 \mathrm{ml}$ Sporensuspension ( 1 x $10^{5}$ Sporen $/ \mathrm{ml}$ ) im Bereich der Stängelbasis auf der Bodenoberfläche ausgebracht. Die Rapspflanzen befanden sich zu diesem Zeitpunkt im BBCH-Stadium 60. 
Zur Vermeidung von verzerrenden Düngungseffekten erfolgte in allen Versuchen eine Ausgleichsdüngung mit inokulumfreiem Stoppel- bzw. Anzuchtsubstrat.

\subsubsection{Stängelinokulation unter Gewächshausbedingungen}

Die Stängelinokulation von Rapspflanzen wurde in Anlehnung an eine von Bugbee \& Presley (1967) beschriebene Methode durchgeführt. Zu BBCH 60 wurde der direkt oberhalb des Hypokotyls befindliche untere Stängelbereich mit einer sterilen Injektionsnadel (Ø 0,7 mm) in einem Winkel von ca. 45 Grad an zwei Stellen durchstoßen, bis die Nadelspitze auf der gegenüber liegenden Stängelseite zu sehen war. Anschließend wurden mit einer Pipette im Bereich der beiden Einstichstellen jeweils $5 \mu$ l einer Sporensuspension aufgetragen, die unmittelbar vom Stängel aufgenommen wurde. Die hier verwendete Sporensuspension, ein Gemisch der beiden $V$. longisporum-Isolate VL 40 und VL 43, wies eine Dichte von $1 \times 10^{6}$ Sporen/ml auf, so dass jede Pflanze mit ca. 10.000 Sporen inokuliert wurde. Behandlungen von Kontrollpflanzen erfolgten mit inokulumfreien PDB-Medium in entsprechender Weise.

\subsection{Inokulationsmethoden von $P$. lingam}

\subsubsection{Hypokotylinokulation im Freiland}

Für die Inokulation im Freiland wurde ein Gemisch aggressiver P. lingam-Isolate (vgl. 2.5.4) in einer Konzentration von 5 x $10^{5}$ Sporen/ml mittels Rückenspritze an den Hypokotylbereich der Rapspflanzen appliziert. Eine mechanische Verletzung erfolgte nicht. Im Versuchsjahr 2005/2006 gab es ausschließlich eine Herbstvariante, bei der Rapspflanzen zu BBCH 15 inokuliert wurden. Im zweiten Versuchsjahr 2006/2007 gab es zusätzlich eine Frühjahrsvariante, bei der die Inokulation zu BBCH 63 durchgeführt wurde.

\subsubsection{Hypokotylinokulation unter Gewächshausbedingungen}

Bei der Inokulation im Gewächshaus wurden im BBCH-Stadium 55 entweder $1 \mathrm{ml}$ eines aggressiven oder $1 \mathrm{ml}$ eines nicht aggressiven $P$. lingam-Isolatgemischs in einer Konzentration von $1 \times 10^{6}$ Sporen $/ \mathrm{ml}$ mit einer Pipette $2 \mathrm{~cm}$ oberhalb des Wurzelhalses aufgetragen. Zur besseren Haftung auf der Pflanzenoberfläche wurde der Sporensuspension Methylzellulose $[1,5 \%(\mathrm{v} / \mathrm{w})]$ zugesetzt. Kontrollpflanzen wurden mit inokulumfreier Suspension behandelt. 


\subsection{Erfassung des Befalls der Rapspflanzen mit V. longisporum}

\subsubsection{Visuelle Bonitur im Freiland}

Eine visuelle Befallsermittlung von $V$. longisporum an Raps erfolgte bei den Freilandversuchen in Form einer Stoppelbonitur nach der Ernte in BBCH 92. Nach Entnahme der Pflanzen und Reinigung des Wurzelbereiches wurden die Stoppeln im Labor mit Hilfe eines Binokulars auf Verticillium-Befall untersucht. Die ungefähr $40 \mathrm{~cm}$ langen Stoppeln, bestehend aus Wurzel und unterem Stängelabschnitt, wurden längs aufgeschnitten, um neben äußerlich erkennbaren Symptomen auch Mark- und Wurzelbefall erfassen zu können. Nach Orientierung an 9-stufigen Boniturskalen von Holtschulte (1992) sowie Krüger (1989) kam ein vereinfachtes Schema der Befallserfassung zur Anwendung, bei dem Verticillium-Befall in vier Klassen unterteilt wurde.

$1=$ Kein Befall (keine Mikrosklerotien (MS))

$2=$ Schwacher Befall (wenige MS)

$3=$ Mittlerer Befall (viele MS)

$4=$ Starker Befall (sehr viele MS)

Das Vorhandensein und die Besatzdichte von MS (Ø 30-50 $\mu \mathrm{m})$ wurden als alleinige Kriterien für Befallsnachweis bzw. Befallsstärke herangezogen (Abb. 1), da andere mögliche Symptome wie bspw. blauschwarz verfärbte Wurzeln oder halbseitige Stängelverbräunungen auch durch andere Pathogene (P. lingam, Alternaria brassicae, Rhizoctonia solani) oder allgemeine Rotteprozesse hervorgerufen werden können (Daebeler et al., 1985; Krüger, 1989, Zeise \& Steinbach, 2004, Steinbach et al., 2005). Im Unterschied zu den oben erwähnten Boniturskalen wurde $V$. longisporum getrennt nach Haupttrieb-, Mark- und Wurzelbefall bonitiert, da Befall an Rapspflanzen nicht immer homogen auftritt. Neben der Erhebung der Befallshäufigkeit (prozentualer Anteil von Pflanzen mit Verticillium-Befall) wurde der Befallswert (1-4) einer jeden Versuchsvariante nach folgender Formel errechnet:

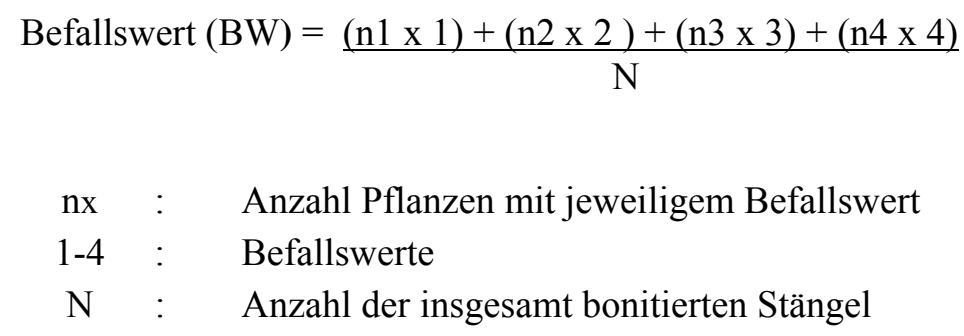



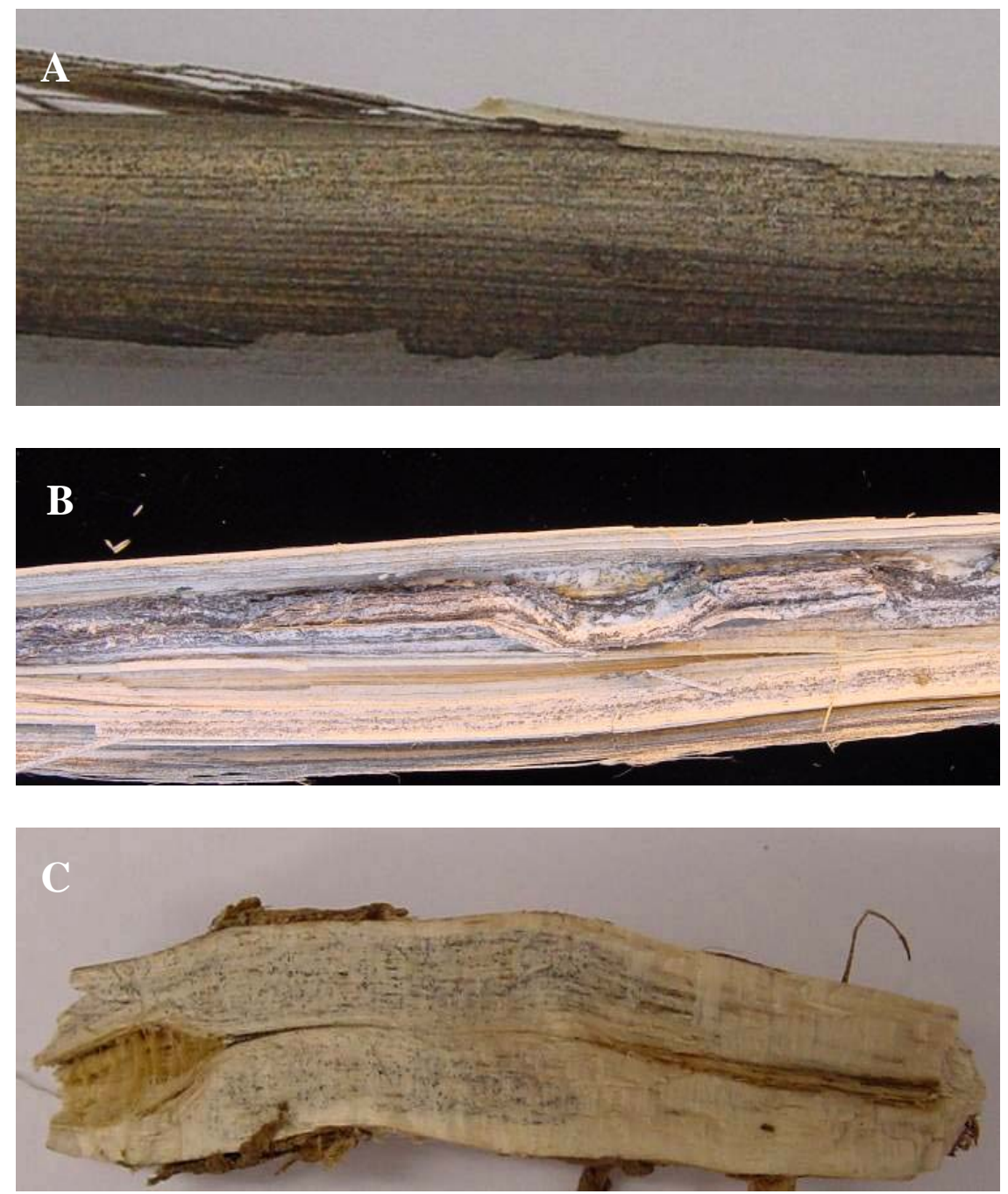

Abb. 1: Besatz mit Mikrosklerotien von V. longisporum in Epidermis (A), Mark (B) und Wurzel (C).

\subsubsection{Visuelle Bonitur im Gewächshaus}

In Abhängigkeit vom jeweiligen Entwicklungszustand der zu bonitierenden Rapspflanzen wurde entweder ein nach Zeise (1992) oder das nach Krüger (1989) und Holtschulte (1992) abgewandelte Boniturschema verwendet. Bei dem auf Blattsymptomen basierenden Boniturschema nach Zeise (1992), welches vorwiegend $\mathrm{zu}$ frühen Boniturterminen Anwendung fand, wurden nur Pflanzen mit eindeutigen Blattsymptomen, zumindest einer beginnenden Schwarzadrigkeit, als Verticillium-positiv bonitiert (Abb. 2). Unspezifische Blattvergilbungen, die bei einigen Resistenzprüfungen (i. d. R. kurzer Prüfungszeitraum) mit bonitiert werden, fanden bei der Befallsermittlung keine Berücksichtigung, da sonst keine klare Abgrenzung zu nicht befallenen Pflanzen über einen langen Zeitraum möglich gewesen wäre. Das am MS-Besatz ausgerichtete Boniturschema entsprach dem der Freilandversuche (Abb. 3). 
Tab. 3: Boniturskala zur Ermittlung der Befallswerte (BW) von $V$. longisporum anhand von Blattsymptomen unter Gewächshausbedingungen (modifiziert nach Zeise, 1992).

\begin{tabular}{ll}
\hline BW & Symptombeschreibung \\
\hline 1 & Keine Symptome \\
2 & Leichte Symptome am ältesten Blatt \\
3 & Leichte Symptome an nächst jüngeren Blättern \\
4 & Etwa $50 \%$ der Blätter mit Symptomen \\
5 & Mehr als $50 \%$ der Blätter mit Symptomen \\
6 & Bis zu 50\% der Blätter abgestorben \\
7 & Mehr als 50\% der Blätter abgestorben \\
8 & Nur Vegetationskegel ist noch vital \\
9 & Pflanze ist abgestorben \\
\hline
\end{tabular}

Befallswert $(\mathrm{BW})=\frac{(\mathrm{n} 1 \times 1)+(\mathrm{n} 2 \times 2)+\ldots \ldots(\mathrm{n} 9 \times 9)}{\mathrm{N}}$

nx : Anzahl Pflanzen mit jeweiligem Befallswert

1-9 : Befallswerte

$\mathrm{N}$ : Anzahl der insgesamt bonitierten Pflanzen
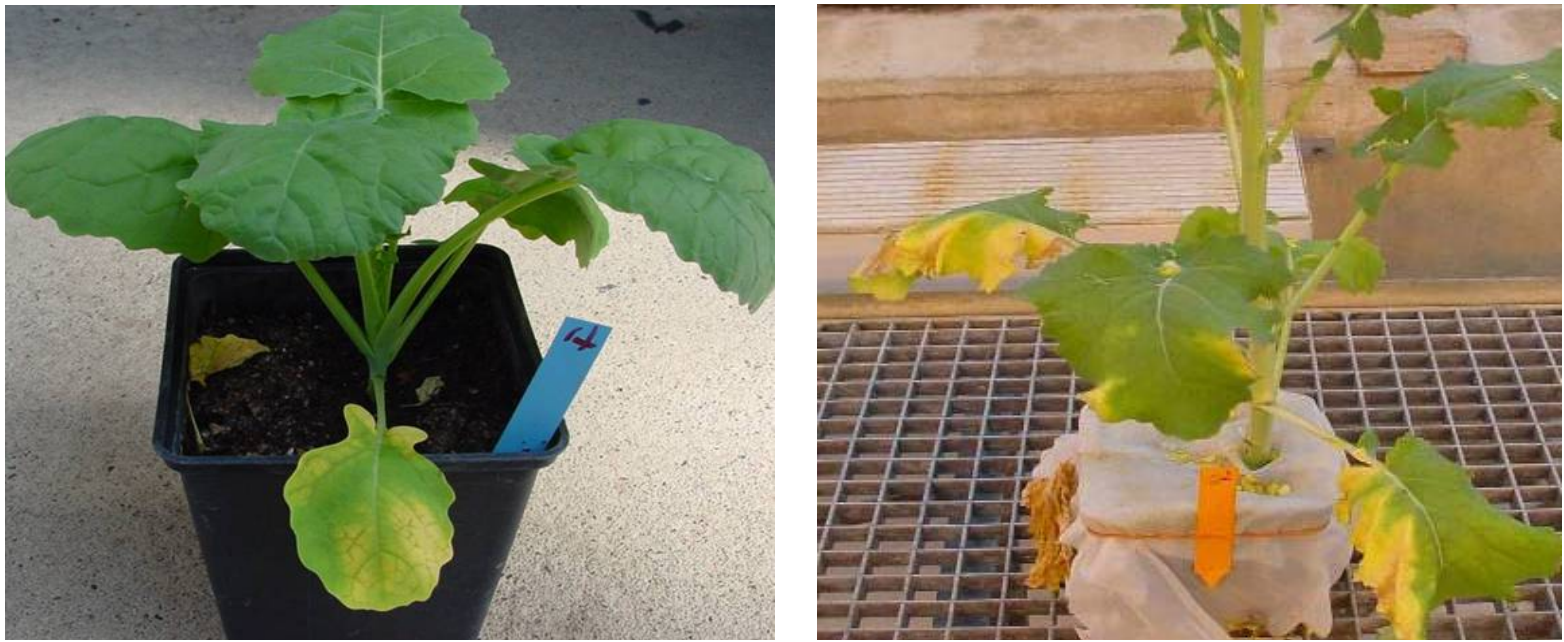

Abb. 2: Blattsymptome von $V$. longisporum mit beginnender Schwarzadrigkeit.
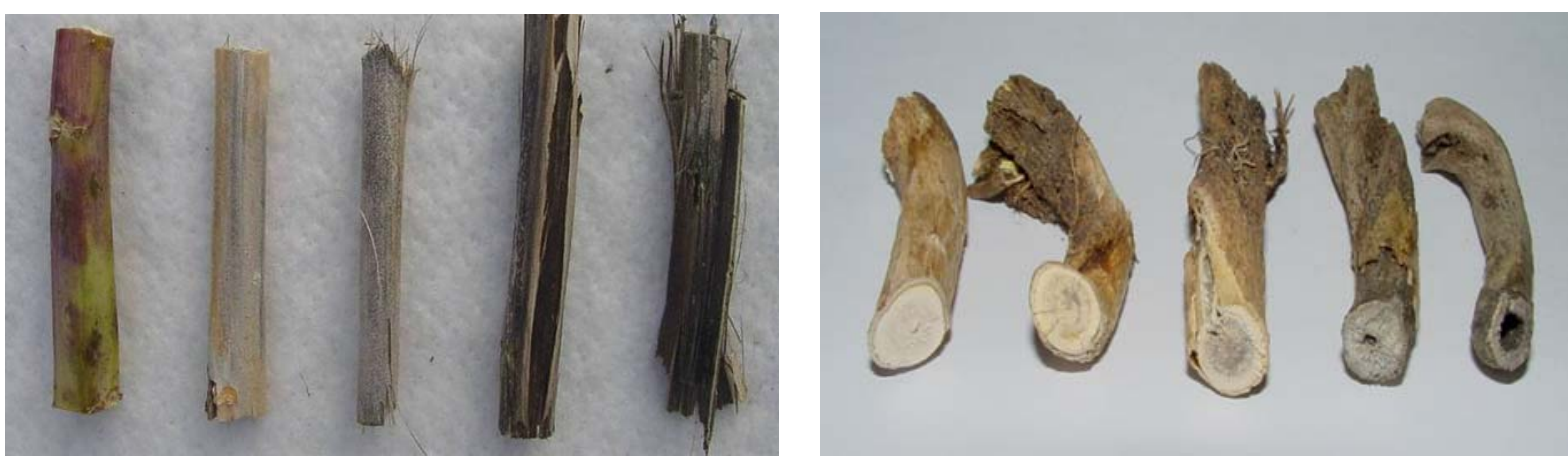

Abb. 3: Besatz mit Mikrosklerotien von V. longisporum im Stängel- und Hypokotylbereich. 


\subsubsection{ELISA (Enzyme-linked-immunosorbent-assay)}

Zum Nachweis von $V$. longisporum in der Rapspflanze wurde in zwei Versuchen ein direkter ELISA mit biotinylierten Detektionsantikörpern (BA-ELISA) verwendet, der speziell für Verticillium an Raps entwickelt worden war (Cernusco, 1996). Diese serologische Methode ermöglicht durch den Einsatz geeigneter Antikörper einen spezifischen, quantitativen Nachweis von Proteinkonzentrationen (Antigen) im Pflanzengewebe (Clark \& Adams, 1977). Die zur Durchführung des BA-ELISA erforderlichen Verticillium-spezifischen Antikörper sowie das Verticillium-Standardprotein wurden freundlicherweise von Herrn Prof. G. Wolf, Abteilung Allgemeine Pflanzenpathologie und Pflanzenschutz des Fachgebietes Pflanzenpathologie und Pflanzenschutz, Universität Göttingen, zur Verfügung gestellt.

Die Durchführung des ELISA-Verfahrens lässt sich in mehrere Schritte einteilen: Zunächst werden die im Beschichtungspuffer gelösten Antikörper durch Adsorption an die Innenwände der Mikrotiterplattenvertiefungen angelagert. Nach Zugabe des Antigens in Form der zu überprüfenden Probenlösung bildet sich ein fester Komplex aus Antigen und Antikörper. Durch Hinzufügen von biotinylierten Antikörpern als Detektionsantikörper erfolgt eine weitere Bindung mit dem bereits vorhandenen Komplex. Im nächsten Schritt hinzu gegebene Streptavidin-alkalische Phosphatase (Streptavidin-Enzymkonjugat) geht mit dem Biotin der Detektionsantikörper eine nicht kovalente Bindung ein (Bieber, 1990). Im letzten Schritt des ELISA-Verfahrens erfolgt eine Zugabe von para-Nitrophenylphosphat (pnPP), welches von der alkalischen Phosphatase des Streptavidin-Enzymkonjugats gespalten wird. Das hierbei entstehende Spaltprodukt, Nitrophenol, nach Substratinkubation durch eine Gelbfärbung sichtbar, wird mit dem Photometer gemessen. Die Intensität dieser Färbung bzw. der photometrisch gemessene Extinktionswert (OD-Wert) ist dabei umso höher, je mehr Moleküle an den Komplex aus Antikörper-Antigen-biotinylierten Antikörpern gebunden sind. Eine Komplexbildung findet allerdings nur statt, wenn Antigen (Protein von Verticillium) in der Probe vorhanden ist. Je mehr Antigen vom Komplex gebunden wird, desto mehr Anhaftstellen sind für biotinylierte Antikörper vorhanden. Die mit dem Photometer messbare Gelbfärbung verhält sich somit proportional zur Menge Pilzprotein in der jeweiligen Probe (Casper \& Meyer, 1981). 
Einzelne Schritte des ELISA-Tests sind unten aufgeführt:

\section{Tag:}

Beschichten mit spezifischen Antikörpern (IgG)

Die Immunglobuline-G wurden im Verhältnis 1:1000 in Beschichtungspuffer verdünnt $(1 \mu \mathrm{l} / \mathrm{ml})$ und je $100 \mu \mathrm{l}$ dieser Lösung in Mikrotiterplattenvertiefungen (MTP) einpipettiert (1. Reihe der MTP bleibt frei). Anschließend wurden die MTP mit einem Deckel versehen und über Nacht bei $4^{\circ} \mathrm{C}$ inkubiert.

\section{Probenaufbereitung}

Getrocknete, gemahlene Pflanzenproben wurden in Schnappdeckelgläsern im Verhältnis 1:20 mit Extraktionspuffer versetzt $(0,5 \mathrm{~g} / 10 \mathrm{ml})$ und über Nacht im Kühlraum auf einem Rüttler geschüttelt.

2.Tag:

Probenaufbereitung

Je $1 \mathrm{ml}$ der über Nacht gerüttelten Probenlösungen wurden in 1,5 $\mathrm{ml}$ e-cups umpipettiert und für zehn Minuten bei 13.000 x $g$ zentrifugiert (Biofuge fresco, Fa. Heraeus). Der Überstand der Pflanzprobenlösungen wurde im ELISA-Testansatz verwendet.

\section{Waschen}

Die über Nacht inkubierten MTP wurden ausgeschüttet und für 3 x 3 Minuten mit Waschpuffer gespült. Im Anschluss erfolgte ein manuelles Trockenschlagen der MTP.

\section{$\underline{\text { Blocken }}$}

Beschichtungspuffer wurde mit 0,2\% Rinderserumalbumin (RSA) versetzt und davon $200 \mu 1$ je Mikrotiterplattenvertiefung einpipettiert (1. Reihe der MTP bleibt frei). Die MTP wurden im Anschluss zugedeckt für $1 \mathrm{~h}$ im Wasserbad bei $37^{\circ} \mathrm{C}$ inkubiert.

\section{$\underline{\text { Ansetzen verschiedener Proteinkonzentrationen für die Eichreihe }}$}

Während der Inkubation der MTP im Wasserbad wurden aus der Stammlösung des Standardproteins (für Verticillium) durch entsprechende Verdünnung mit Extraktionspuffer verschiedene Proteinkonzentrationen für die Eichreihe hergestellt.

$\underline{\text { Waschen }}$

Die MTP wurden nach einstündiger Inkubation aus dem Wasserbad entnommen und gewaschen (s.o.). 
Auftragen von Proteinstandardkonzentrationen und Pflanzprobenlösungen

Je $100 \mu \mathrm{l}$ der verschiedenen Proteinstandards sowie Pflanzprobenlösungen wurden in MTPVertiefungen mit jeweils einer Wiederholung einpipettiert. Die erste Reihe der MTP blieb unbesetzt; der übrige, äußere Randbereich wurde mit Extraktionspuffer (100 $\mu 1)$ gefüllt. Neben den eigentlich zu testenden Pflanzproben wurden immer drei im Voraus untersuchte Kontrollen mitgeprüft, um gemessene Extinktionswerte mit diesen vergleichen zu können. Dabei handelt es sich um zwei Negativkontrollen (Wurzel- bzw. Stängelmaterial), die nachweislich keinen Verticillium-Befall aufwiesen, sowie um eine Positivkontrolle (Stängelmaterial), die stark Verticillium-befallen war. Nach dem Befüllen wurden die MTP mit einem Deckel versehen und über Nacht bei $4^{\circ} \mathrm{C}$ inkubiert.

\section{Tag:}

Waschen

Die MTP wurden aus Kühlschrank genommen und gewaschen (s.o.).

$\underline{\text { Beschichten mit Detektionsantikörpern (biotinylierte Antikörper) }}$

Biotinylierte Immunglobuline-G wurden im Verhältnis 1:100 in Konjugatpuffer verdünnt und $100 \mu 1$ in MTP- Vertiefungen einpipettiert (1. Reihe blieb frei). Zugedeckt wurden die MTP über Nacht bei $4^{\circ} \mathrm{C}$ inkubiert.

4. Tag:

Waschen

Die MTP wurden aus Kühlschrank genommen und gewaschen (s.o.).

$\underline{\text { Beschichten mit Streptavidin-alkalischer-Phosphatase }}$

Die Streptavidin-alkalische-Phosphatase wurde im Verhältnis 1:10.000 $(1 \mu \mathrm{l} / \mathrm{ml})$ in Konjugatpuffer verdünnt und $100 \mu 1$ in MTP-Vertiefungen einpipettiert (1. Reihe blieb frei). MTP wurden mit Deckel versehen und für $1 \mathrm{~h}$ im Wasserbad bei $37^{\circ} \mathrm{C}$ inkubiert.

\section{Waschen}

Die MTP wurden aus Wasserbad genommen und gewaschen (s.o.).

Beschichten mit para-Nitrophenylphosphat (pnPP)

Das pnPP wurde in Substratpuffer im Verhältnis $1 \mathrm{mg} / \mathrm{ml}$ verdünnt und jeweils $100 \mu 1$ dieser Lösung in MTP-Vertiefungen einpipettiert (gesamte MTP). Anschließend wurden die MTP mit Deckel versehen und abgedunkelt bei Raumtemperatur neben dem Photometer inkubiert. 


\section{Messung}

Nach 1, 2 und 3 h erfolgte eine Messung der Gelbfärbung des Spaltproduktes Nitrophenol mit einem Photometer (Spectra II; SLT Labinstruments) bei $405 \mathrm{~nm}$ und einer Referenzwellenlänge von $592 \mathrm{~nm}$. Die Dauer der Inkubation war vom Zeitpunkt abhängig, an dem der 1000er Proteinstandard einen Extinktionswert (OD-Wert) von ungefähr 1,8 erreicht hatte.

\section{Auswertung}

Nach Überprüfung der aus den Proteinstandardkonzentrationen gebildeten Eichreihe erfolgte eine Analyse der gemessenen Extinktionswerte (OD-Werte). Dazu wurden die Pflanzprobenmesswerte um die OD-Werte der mit geprüften Negativkontrollen (Wurzel bzw. Stängel) bereinigt. Die Netto-OD-Werte wurden zur Quantifizierung des Verticillium-Befalls in Stängel bzw. Wurzel herangezogen.

\subsubsection{Probenahme im Feld}

Aus den Feldversuchsparzellen des Anbaufaktorenversuchs (vgl. 2.15.3) wurden im Versuchsjahr 2005/2006 in vierwöchigem Abstand (April-August) jeweils fünf Rapspflanzen zufällig entnommen. Für die ELISA-Untersuchung wurde neben der Wurzel ein ca. $25 \mathrm{~cm}$ langer Abschnitt des unteren Rapsstängels verwendet. Nach Reinigung der Pflanzenproben wurden diese zur Trocknung in der Vegetationshalle des Gewächshauses gelagert und im Anschluss am Institut für Pflanzenbau und Pflanzenzüchtung gemahlen (Mühle, Fa. Retsch). Wurzel- und Stängelabschnitte einer jeden Parzelle wurden getrennt voneinander gemahlen, zu jeweils einer Mischprobe vereinigt und bis zur weiteren Verwendung in beschrifteten Quarkschalen aufbewahrt.

\subsubsection{Probenahme im Gewächshaus}

Der ELISA-Test wurde zur Quantifizierung des $V$. longisporum-Befalls im Sortenversuch (vgl. 2.18.2) herangezogen. Im BBCH-Stadium 90 wurden alle Pflanzen destruktiv bonitiert und im Anschluss für die ELISA-Untersuchung weiterverarbeitet. Es erfolgte keine Einzelpflanzenuntersuchung, sondern nach Orientierung an der visuellen Befallsbonitur (vgl. 2.8.1) wurden innerhalb der einzelnen Versuchsvarianten Mischgruppen aus jeweils zwei Rapspflanzen mit gleicher Boniturnote gebildet. Bei den Kontrollpflanzen erfolgte eine zufällige Mischgruppenbildung aus jeweils vier Rapspflanzen. Zur besseren Mahlbarkeit wurden die luftgetrockneten Pflanzproben für $12 \mathrm{~h}$ bei $30^{\circ} \mathrm{C}$ in einen Trockenschrank gestellt und im Anschluss gemahlen (s.o.). 


\subsubsection{Real-Time PCR (Polymerase Chain Reaction)}

In mehreren Gewächshausversuchen wurde eine quantitative Real-time PCR-Analyse durchgeführt, um befallsdynamische Aspekte eines $V$. longisporum-Befalls genau erfassen zu können. Diese molekulare Methode ermöglicht durch den Einsatz geeigneter Primer einen spezifischen, hochempfindlichen, quantitativen Nachweis von Verticillium-DNA im Pflanzengewebe. Die zur Durchführung der PCR erforderlichen Primer wurden freundlicherweise von Herrn Prof. Karlovsky, Abteilung Molekulare Pflanzenpathologie und Mykotoxinforschung des Fachgebietes Pflanzenpathologie und Pflanzenschutz, Universität Göttingen, zur Verfügung gestellt.

Je nach Versuchsansatz wurden Wurzel-, Hypokotyl- sowie Stängelabschnitte zu den jeweiligen Boniturterminen entnommen und im Anschluss mittels Real-Time PCR untersucht. Nach Reinigung der Pflanzenproben wurden diese in Polyethylenbeutel transferiert, für $72 \mathrm{~h}$ gefriergetrocknet (Fa. Christ, Osterode) und im Anschluss mit einer Kugelmühle (Fa. Retsch) fein vermahlen. Mit Ausnahme des unter Punkt 2.19.1 aufgeführten Stängelinokulationsversuches erfolgte keine Einzelpflanzen- sondern eine Mischprobenanalyse, wobei sich eine Mischprobe inokulierter Varianten aus jeweils zwei Pflanzen zusammensetzte. Kontrollpflanzen wurden zu Mischgruppen aus je vier Pflanzen vereinigt. Für die DNA-Extraktion, die mit Hilfe des DNeasy Plant Mini Kits der Firma Quiagen erfolgte, wurden je Probe $30 \mathrm{mg}$ gefriergetrocknetes Material herangezogen. Nach der Extraktion wurden $5 \mu \mathrm{l}$ der Proben auf ein Agarosegel aufgetragen und elektrophoretisch aufgetrennt, um Quantität und Qualität der extrahierten DNA beurteilen zu können. Bis zur weiteren Verwendung wurden die Proben bei $-20^{\circ} \mathrm{C}$ gelagert.

Für die PCR-Untersuchung wurden die Verticillium-spezifischen Primer OLG 70 (CAGCGAAA CGCGATATGTAG) und OLG 71 (GGCTTGTAGGGGGTTTAGA) verwendet, die in der Lage sind, ein sowohl in $V$. longisporum als auch in $V$. dahliae vorkommendes DNAFragment zu amplifizieren (Eynck et al., 2007). Die fehlende Differenzierung zwischen beiden Verticillium-Arten war in der vorliegenden Arbeit nicht relevant, da das $\mathrm{zu}$ untersuchende Pflanzenmaterial ausschließlich mit $V$. longisporum inokuliert worden war. Für Amplifikation und Schmelzkurvenanalyse wurde ein iCycler- System (Fa. BioRad, Hercules, CA, USA) verwendet. Die Filtereinstellung für Anregung bzw. Emission des Fluoreszenzfarbstoffes SybrGreen lagen bei $490 \pm 10 \mathrm{~nm}$ bzw. $530 \pm 15 \mathrm{~nm}$. Die Komponenten des PCR-Reaktionsmix sowie der Ablauf des PCR-Programms sind in Tab. 4 und 5 aufgeführt. 
Tab. 4: Zusammensetzung des PCR-Reaktionsmix zum Nachweis von Verticillium-DNA in Rapspflanzen [Gesamtvolumen pro Reaktion $25 \mu 1$ ].

\begin{tabular}{llll}
\hline Chemikalien & Konzentration & Endkonzentration & $\mu 1 /$ Reaktion \\
\hline $\mathrm{H} 2 \mathrm{O}$ & & & 15,8 \\
$10 \mathrm{x}$ Puffer & $10 \mathrm{x}$ & 1 & 2,5 \\
$\mathrm{MgCl}_{2}$ & $25 \mathrm{mM}$ & $3 \mathrm{mM}$ & 3 \\
$\mathrm{dNTP}$ & $10 \mathrm{mM}$ & $200 \mathrm{mM}$ & 0,5 \\
F- Primer OLG 70 & $10 \mu \mathrm{M}$ & $0,3 \mu \mathrm{M}$ & 0,75 \\
R- Primer OLG 71 & $10 \mu \mathrm{M}$ & $0,3 \mu \mathrm{M}$ & 0,75 \\
Taq Polymerase & $5 \mathrm{U} / \mu \mathrm{l}$ & $1 \mathrm{U} / \mu \mathrm{l}$ & 0,2 \\
SybrGreen & $10 \mathrm{x}$ & 0,1 & 0,25 \\
Fluorescein & $1 \mu \mathrm{M}$ & $10 \mathrm{nM}$ & 0,25 \\
Probe DNA & & $\mathrm{x} \mathrm{ng}$ & 1 \\
\hline
\end{tabular}

Tab. 5: Programmfolge der Real-Time PCR zum Nachweis von Verticillium-DNA im Pflanzengewebe.

\begin{tabular}{cllc}
\hline Programm & Phase & Zeit & Temperatur $\left[{ }^{\circ} \mathrm{C}\right]$ \\
\hline 1 & Initiale Denaturierung & $2 \mathrm{~min}$ & 94 \\
2 & Denaturierung & $20 \mathrm{sec}$ & 94 \\
3 & Primer Hybridisierung (Annealing) & $30 \mathrm{sec}$ & 59 \\
4 & PCR-Synthese & $40 \mathrm{sec}$ & 72 \\
& (36-fache Wdh. der Schritte 2-4) & & 72 \\
5 & Elongation & $5 \mathrm{~min}$ & 7 \\
\hline
\end{tabular}

Eine Quantifizierung von Verticillium-DNA wird durch die Messung von Fluoreszenzsignalen ermöglicht. Die mit dem Fluoreszenzdetektor des Thermocyclers messbare Fluoreszenz nimmt dabei proportional zur Menge an Verticillium-DNA in der Probe zu. Anhand von Fluoreszenzsignalen bekannter Verticillium-DNA Standards (0,5, 1, 2, 4, 8, 16, 32, 64 pg), die als Bezugsgröße dienten, ließen sich die Verticillium-DNA Mengen in den jeweiligen Proben bestimmen. 


\subsubsection{Gewinnung von Xylemsaft mit der Druckkammer}

In den Halbfreilandversuchen (vgl. 2.17) wurden neben einer visuellen Befallsbonitur auch Untersuchungen von Xylemflüssigkeit durchgeführt, um $V$. longisporum, bei dem es sich um ein xylembesiedelndes Pathogen handelt (Heale \& Karapapa, 1999), aus Rapspflanzen isolieren zu können. Die Gewinnung von Xylemflüssigkeit erfolgte mit einer der Scholanderbombe (Scholander et al., 1965) ähnlichen Druckkammer (Typ 600, pms instruments co, Corvallis, Oregon, USA). Es sollte geklärt werden, zu welchem Entwicklungsstadium sich $V$. longisporum im Pflanzengewebe im Freiland nachweisen lässt. In der Vegetationsperiode wurden von Mai bis Ende August in vierwöchigem Abstand jeweils acht Pflanzen pro Variante aus der Versuchsanlage entnommen. Direkt nach den Probenahmen wurde der gesamte untere Pflanzenbereich bestehend aus Wurzel, Hypokotyl sowie Sprossbasis für die Gewinnung von Xylemflüssigkeit verwendet.

Hierzu wurde der zu untersuchende Pflanzenabschnitt durch einen Dichtungsring geschoben, bis ca. $3 \mathrm{~cm}$ von der Sprossbasis oben herausragten. Der Hypokotylbereich wurde in einem Kompressionsring mit drehverstellbarem Deckel luftdicht eingespannt, mit diesem auf die Druckkammer gesetzt und verschlossen. Die nach unten hinausragende Wurzelbereich wurde dabei in ein Gefäß mit sterilem Wasser getaucht, welches auf dem Boden der Druckkammer platziert worden war. Über die oben herausragende Sprossbasisschnittfläche wurde ein ca. $1 \mathrm{~cm}$ langes Schlauchstück gestülpt, um austretende Xylemflüssigkeit mit einer Pipette auffangen zu können. Das aus einer Gasflasche zugeleitete Stickstoffgas erzeugte in der Druckkammer einen stetig steigenden Überdruck und führte ab einem bestimmten Zeitpunkt (Druck) dazu, das Wasser aus dem Gefäß durch das Xylem nach oben gedrückt wurde. Je Pflanzenabschnitt wurden $300 \mu 1$ der austretenden Flüssigkeit mit einer Pipette aufgefangen und in $1,5 \mathrm{ml}$ e-cups pipettiert. Im Anschluss wurden $100 \mu \mathrm{l}$ jeder Probe in einer Wiederholung auf eine Petrischale mit Czapek-Dox-Agar aufgetragen und mit einem Drigalskyspatel gleichmäßig verteilt. Nach Abtrocknen der Agaroberfläche wurden die Petrischalen bei $20^{\circ} \mathrm{C}$ für vier Wochen im Dunkeln inkubiert. Zur Auswertung wurden die inkubierten Petrischalen unter fließendem Wasser mit Hilfe eines Objektträgers vorsichtig gereinigt und auf $V$. longisporum Kolonien untersucht. Im Vordergrund stand dabei ein qualitativer Nachweis von $V$. longisporum. Eine Quantifizierung des Befalls, wie bei PCR oder ELISA, ist hiermit nicht möglich. 


\subsection{Visuelle Erfassung des Befalls der Rapspflanzen mit P. lingam}

\subsubsection{Visuelle Bonitur im Freiland}

Die Erfassung des Befalls mit P. lingam erfolgte gleichzeitig mit der Bonitur des Kohlfliegenbefalls zu BBCH 85 (vgl. 2.13). Die Befallsbeurteilung orientierte sich an einem von Krüger (1982) entwickelten 9-stufigen Boniturschema, welches sich auf Symptome am Stängel und Wurzelhals bezieht (Tab. 6). Je Parzelle wurden dazu 25 Pflanzen zufällig entnommen und nach Reinigung mit Hilfe eines Binokulars auf $P$. lingam-Befall untersucht. Der Befallswert [1-9] einer jeden Versuchsvariante wurde nach u. a. Formel errechnet:

Tab. 6.: Boniturschlüssel für Phoma lingam nach Krüger (1982), unterteilt in Wurzelhals- und Stängelbefall.

\begin{tabular}{|c|c|c|}
\hline Befallswert & Wurzelhals & Stängel \\
\hline 1 & Kein Befall & Kein Befall \\
\hline 2 & Kleine Flecke an der Oberfläche & Kleine Flecke an der Oberfläche \\
\hline 3 & $\begin{array}{l}\text { Kleine Flecke mit geringer } \\
\text { Verkorkung und/oder } \\
\text { Verbräunungen im Wurzelhals }\end{array}$ & $\begin{array}{c}\text { Größere Flecke an der Oberfläche } \\
\text { mit geringer Verkorkung }\end{array}$ \\
\hline 4 & Zwischenstufe & Zwischenstufe \\
\hline 5 & $\begin{array}{l}\text { Umfassende oberflächliche Verkorkung } \\
\text { (bis } 50 \% \text { des Wurzelhalses befallen) }\end{array}$ & Tiefere Befallsstellen am Stängel \\
\hline 6 & Zwischenstufe & Zwischenstufe \\
\hline 7 & $\begin{array}{c}\text { Über } 50 \% \text { des Wurzelhalses } \\
\text { tief verkorkt }\end{array}$ & Tiefe Befallsstellen mit Pyknidien \\
\hline 8 & Zwischenstufe & Zwischenstufe \\
\hline 9 & $\begin{array}{l}\text { Pflanze abgestorben, } \\
\text { starke Verkorkung }\end{array}$ & $\begin{array}{l}\text { Pflanze abgestorben, } \\
\text { tiefe Befallsstellen }\end{array}$ \\
\hline
\end{tabular}

Befallswert $(\mathrm{BW})=\frac{(\mathrm{n} 1 \times 1)+(\mathrm{n} 2 \times 2)+\ldots \ldots(\mathrm{n} 9 \times 9)}{\mathrm{N}}$

nx $\quad: \quad$ Anzahl Pflanzen mit jeweiligem Befallswert

1-9 : Befallswerte

N : : Anzahl der insgesamt bonitierten Pflanzen 


\subsubsection{Visuelle Bonitur im Gewächshaus}

Die Beurteilung der durch $P$. lingam hervorgerufenen Krankheitssymptome erfolgte im Gewächshausversuch 49 Tage nach Inokulation (vgl. 2.7.2), wobei der Befall des Wurzelhalses anhand der Läsionen (Länge, Tiefe und Umfang) bonitiert wurde (Tab. 7). Zur Anwendung kam ein Boniturschema von Volke (2000), welches sich an Koch et al. (1989) bzw. Kutscher et al. (1993) orientierte.

Tab. 7: Boniturnoten (BN) für P. lingam Läsionen am Wurzelhals modifiziert von Volke (2000) nach Koch et al. (1989) und Kutscher et al. (1993).

\begin{tabular}{cccc}
\hline BN & Läsionslänge $(\mathrm{L})[\mathrm{mm}]$ & Läsionsumfang $(\mathrm{U})[\%]$ & Läsionstiefe $(\mathrm{T})[\%]$ \\
\hline 0 & keine Läsion & keine Läsion & keine Läsion \\
1 & $1-4$ & $1-11$ & $1-11$ \\
2 & $5-8$ & $12-22$ & $12-22$ \\
3 & $9-12$ & $23-33$ & $23-33$ \\
4 & $13-16$ & $34-44$ & $34-44$ \\
5 & $17-20$ & $45-55$ & $45-55$ \\
6 & $21-24$ & $56-66$ & $56-66$ \\
7 & $25-28$ & $67-77$ & $67-77$ \\
8 & $29-32$ & $78-88$ & $78-88$ \\
9 & $>32$ & $>88$ & $>88$ \\
\hline
\end{tabular}

Anhand von Boniturnoten für Länge, Umfang und Tiefe der Phoma-Läsionen wurden zwei Befallsparameter abgeleitet, die die Läsionsgröße (GBW) bzw. das Volumen erkrankten Gewebes (VDT) charakterisieren:

Gesamtboniturwert $\left(\mathrm{GBW}_{\mathrm{m}} 0-9\right)=(\mathrm{L} \times \mathrm{U})^{1 / 2}$

Volume of Diseased Tissue-Wert $\left(\operatorname{VDT}_{\mathrm{m}} 0-9\right)=\left(\left(1-\mathrm{HR}^{2}\right) \times \mathrm{U} / 9 \times \mathrm{L}\right) \quad(\mathrm{HR}=1-\mathrm{T} / 9)$

\subsection{Anzucht der Kleinen Kohlfliege im Labor}

Für die Simulierung von Kohlfliegenbefall (vgl. 2.11) kamen Kohlfliegeneier zur Anwendung, die aus der Laborzucht der entomologischen Abteilung des Fachgebietes Pflanzenpathologie und Pflanzenschutz stammten. Die Anzucht der Kohlfliege orientierte sich dabei an einer von Zohren (1968) beschriebenen Methode. Hierbei wurden die Kohlfliegen in einem Zuchtkäfig $(30 \mathrm{~cm}$ x $30 \mathrm{~cm}$ x $30 \mathrm{~cm})$ bei $18-22^{\circ} \mathrm{C}$ und $16 \mathrm{~h}$ Photoperiode gehalten. Als Nahrung stand sowohl Trockenfutter (10 g Traubenzucker, $10 \mathrm{~g}$ Magermilchpulver, $1 \mathrm{~g}$ Sojamehl, 1 g Bierhefe) als auch Nassfutter (5 g Honig, 5 g Sojamehl, 1 g Bierhefe) ad 
libitum zur Verfügung. Die Wasserversorgung wurde über eine Tellertränke sichergestellt. Zur Produktion von Eiern bzw. Puppen wurde, je nach Bedarf, eine unterschiedliche Anzahl von Puppen, die sich in einer Petrischale befanden, in den Zuchtkäfig eingestellt. Etwa fünf bis sechs Tage nach dem Schlupf der Fliegen setzte die Eiablage ein. Eine mit Sand und einem Stück Kohlrübe versehene Petrischale, die alle zwei Tage durch eine neue ersetzt wurde, diente dabei als Eiablageschale. Zur Eigewinnung wurde der Sand aus der Eiablageschale in ein Becherglas transferiert und im Anschluss mit Wasser aufgefüllt. Die im Überstand aufgeschwemmten Kohlfliegeneier wurden mit Hilfe eines Kaffeefilters abfiltriert, so dass die Eier am Filterpapier anhafteten. Der Vorgang des Aufschwemmens und Abfiltrierens wurde so oft wiederholt, bis sich keine Eier mehr im Überstand befanden. Die so gewonnenen Eier wurden entweder direkt für Versuche eingesetzt (vgl. 2.11) oder zur Puppenproduktion weiter verwendet. Zur Produktion von Kohlfliegenpuppen wurde ein mit Kohlfliegeneiern besetzter Kaffeefilter auf einer ca. $3 \mathrm{~cm}$ dicken Sandschicht einer Quarkschale platziert, wobei die mit Eiern besetzte Seite nach oben zeigte. Im Anschluss wurde eine Kohlrübenscheibe entsprechender Größe auf den Kaffeefilter mit der Schnittfläche nach unten gelegt, um den schlüpfenden Larven als Nahrung zu dienen. Die mit Sand verfüllte Schale wurde mit einem Deckel versehen und bis zur Gewinnung der Puppen bei ca. $22^{\circ} \mathrm{C}$ für 30 Tage gelagert. Für die darauf folgende Auswaschung der Puppen wurden zwei Siebe mit den Maschenweiten 1,4 bzw. 3,15 mm verwendet, um Puppen unterschiedlicher Größe vom Sand trennen zu können. Anschließend wurden die Puppen in Petrischalen transferiert und bis zur weiteren Verwendung im Kühlraum bei $1^{\circ} \mathrm{C}$ aufbewahrt.

\subsection{Simulierung des Befalls mit der Kleinen Kohlfliege}

Der Befall der Rapspflanzen mit der Kleinen Kohlfliege wurde in den Halbfreilandversuchen sowie im Gewächshaus durch das Ansetzen von Kohlfliegeneiern, die aus der Laborzucht stammten, gezielt gesteuert. Im Freiland wurden zu BBCH 15 zehn Kohlfliegeneier mit einem feinen Haarpinsel an den vorher von Erde befreiten Wurzelhals gesetzt (Abb. 4). Zur Vermeidung von Doppelbelegungen wurden die besetzten Pflanzen nach Wiederaufhäufelung der Erde durch einen seitlich im Boden steckenden Zahnstocher markiert. Im Gewächshaus erfolgte die Simulierung des Kohlfliegenbefalls in ähnlicher Weise. Je nach Versuchsansatz wurden Kohlfliegeneier zu unterschiedlichen Entwicklungsstadien des Rapses an den Wurzelhals angesetzt, um den Zuflug der Herbst- bzw. Frühjahrsgeneration simulieren zu können. Etwa drei Wochen nach dem Ansetzten von Eiern wurde der 
Topfboden mit einem dünnen Netz (Maschenweite $1 \mathrm{~mm}$ ) abgedeckt, um unkontrollierten Zuflug der nächsten Kohlfliegengeneration auszuschließen.

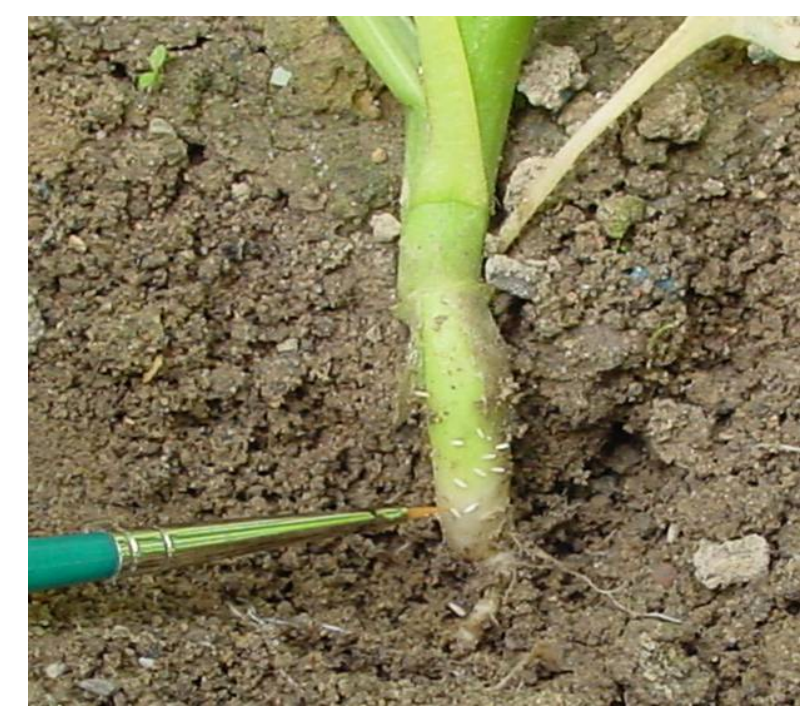

Abb. 4: Ansatz von Eiern der Kleinen Kohlfliege an den Wurzelhals junger Sommerrapspflanzen.

\subsection{Befallssteuerung mit Kulturschutznetzen und Insektiziden}

An den Feldversuchsstandorten wurde versucht, Kohlfliegenbefall mit Hilfe von Kulturschutznetzen bzw. Insektiziden abzustufen. Für die Netzabdeckung von Parzellen wurden Kulturschutznetze des Typs Rantai K (Maschenweite 1,35 mm x 1,35 mm; Fa. Schachttrupp, Hamburg) verwendet, die auch zur Abwehr von Kohlfliegen im Gemüsebau zum Einsatz kommen. Zur Vermeidung von Kohlfliegenbefall im Herbst wurden Kulturschutznetze eine Woche nach der Saat des Winterrapses auf den entsprechenden Parzellen ausgebreitet und im Anschluss an den Rändern mit Erde fixiert (Abb. 5). Nach Beendigung des Zufluges im Herbst, etwa Mitte Oktober, wurden die Netze abgenommen, getrocknet, gereinigt und dann bis zur weiteren Verwendung in einem kühlen Lagerraum aufbewahrt. In Varianten, wo zusätzlich zur Herbstgeneration auch der Befall der Frühjahrsgeneration ausgeschlossen werden sollte, wurden Mitte April (ca. BBCH 55), kurz vor Beginn des Zufluges der Frühjahrsgeneration, Netzkäfige errichtet (Abb. 5). Der Abbau dieser Käfige erfolgte Mitte Juni, kurz vor Abreifebeginn des Rapses. 

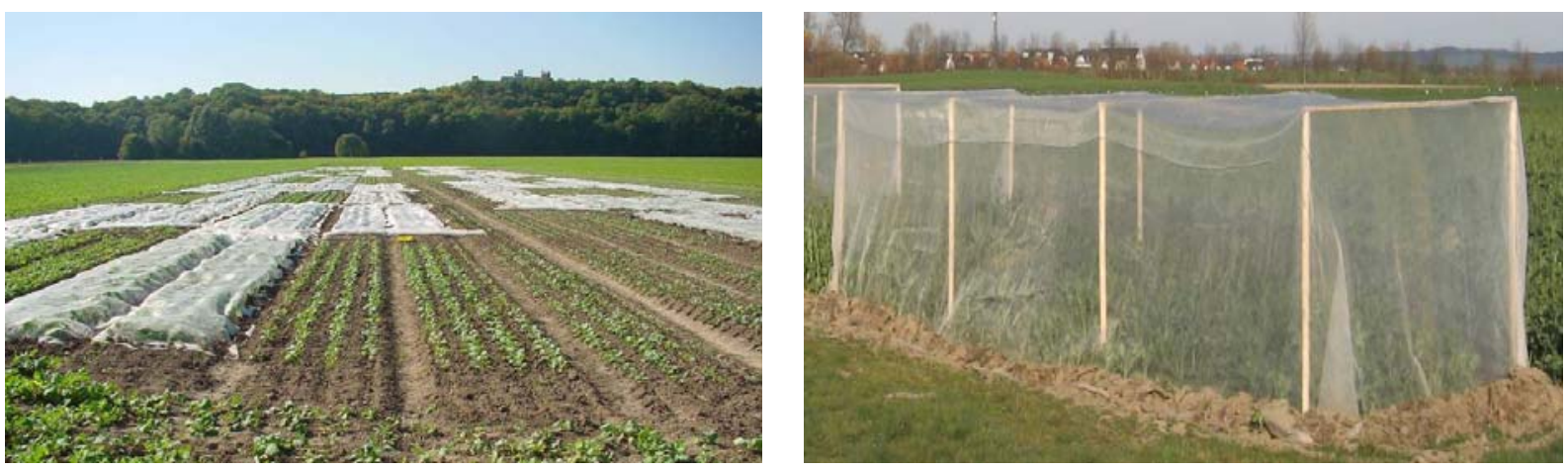

Abb. 5: Netzabdeckung im Herbst (Foto links). Netzabdeckung im Frühjahr (Foto rechts): Die Netzkäfigkonstruktion (10 m Länge; 2,5 m Breite; 1,6 m Höhe) besteht aus acht Pflanzpfählen, die $40 \mathrm{~cm}$ im Boden verankert sind. Vier an das obere Ende der Pflanzpfähle verschraubte Dachlatten dienen als Querverbindung. Die Längsseiten sind an der oberen Kante mit wetterfester Nylonschnur bespannt, um als Netzauflage zu fungieren.

Neben dem Einsatz von Kulturschutznetzen, mit denen Kohlfliegenbefall im Herbst und Frühjahr gänzlich ausgeschlossen werden sollte, sahen einige Versuche Insektizidvarianten vor, um unterschiedlich hohen Kohlfliegenbefall zu generieren. Im Rahmen der vorliegenden Arbeit kamen drei verschiedene insektizide Saatgutbehandlungsmittel zum Einsatz, wobei entweder das Präparat Chinook (Imidacloprid + Betacyfluthrin) mit Elado (Clothianidin + Betacyfluthrin) oder mit Oftanol T (Isofenphos: Präparat seit 2003 nicht mehr zugelassen) verglichen wurde. Mit Hilfe von Elado bzw. Oftanol T sollte im Vergleich zu Chinook ein deutlich geringerer Kohlfliegenbefall, zumindest im Herbst, erzielt werden. In einigen Varianten, bei denen Saatgut mit den Präparaten Elado bzw. Oftanol T behandelt worden war, wurde zusätzlich, einen Tag nach der Aussaat, das insektizide Streumittel Nexion Neu (Chlorpyriphos) ausgestreut $\left(10 \mathrm{~g} / \mathrm{m}^{2}\right)$, um eine weitere Reduktion des Kohlfliegenbefalls herbeiführen zu können. Eine Zuordnung der verschiedenen Netz/Insektizidvarianten zu einzelnen Versuchen bzw. Jahren wird in den Kapiteln 2.15.2 und 2.15.3 vorgenommen.

\subsection{Erfassung des Befalls mit der Kleinen Kohlfliege}

Der Kohlfliegenbefall wurde durch eine visuelle Bonitur des Larvenfraßes an der Wurzel erfasst (Abb. 6). In den Feldversuchen wurden zur Untersuchung des Kohlfliegenbefalls der Herbst- und Frühjahrsgeneration im November (BBCH 18) bzw. Juni (BBCH 85) je Parzelle 25 Pflanzen zufällig entnommen und nach Reinigung der Wurzeln im Labor auf Fraßschädigungen untersucht. Neben dem Anteil fraßgeschädigter Pflanzen (Befallshäufigkeit [\%]) wurden die Parameter fraßgeschädigte Wurzeloberfläche [\%] sowie der Anteil von Pflanzen mit Starkbefall (fraßgeschädigte Wurzeloberfläche $\geq 50 \%$ ) erhoben. Abgesehen von 
abweichenden Boniturzeitpunkten erfolgte die Erfassung des Kohlfliegenbefalls in den Halbfreiland- und Gewächshausversuchen in entsprechender Weise.

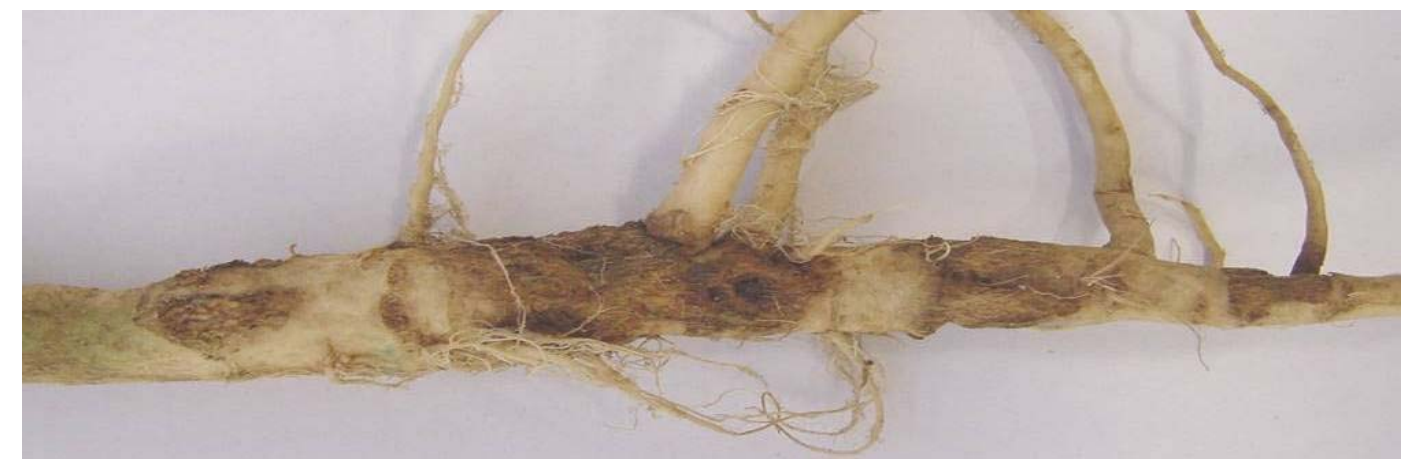

Abb. 6: Wurzelfraß durch Larven der Kleinen Kohlfliege an Winterraps

\subsection{Erfassung pflanzenmorphologischer und ertraglicher Parameter}

Neben der Erfassung von Kohlfliegen-, Phoma- und Verticillium-Befall wurden eine Reihe von pflanzenmorphologischen und ertraglichen Parametern erhoben, um Schadwirkungen durch beteiligte Schaderreger genauer beurteilen zu können. In den Feldversuchen dienten die Parameter Kornertrag sowie Tausendkorngewicht (TKG) als Indikatoren etwaiger Schadwirkungseffekte. Im Sortenversuch (vgl. 2.15.2) wurden die bereits Ende Juni/Anfang Juli gescheitelten Parzellen nach Abreife einzeln mit einem Mähdrescher (Modell Farmliner, Fa. Deutz-Fahr, Köln) beerntet. Beim Anbaufaktorenversuch (vgl. 2.15.3) erfolgte die Ertragserhebung mittels Kerndrusch, wobei je Parzelle eine Mähdruschbreite (2,7 m) auf der gesamten Parzellenlänge abgeerntet wurde. Die Trockensubstanzbestimmung des Erntegutes erfolgte durch Trocknung eines abgewogenen Äquivalents der Ernteproben bei $105^{\circ} \mathrm{C}$ für $12 \mathrm{~h}$ und anschließender Rückwiegung. Parzellenerträge wurden im Anschluss auf einen handelsüblichen Wassergehalt von 9\% umgerechnet. Der Fremdbesatz wurde durch Differenzwägung vor und nach Reinigung der Ernteproben bestimmt; das TKG durch Auszählen (Saatgutzählgerät) und Wiegen von 1000 Körnern ermittelt. Zusätzlich zu den Ertragsparametern wurde im Sortenversuch 2006/2007 bzw. im Anbaufaktorenversuch 2007/2008 überprüft, ob Netzabdeckungen im Herbst (Mitte August bis Mitte Oktober) Auswirkungen auf die Wurzel- und Sprossentwicklung von Raps ausüben. Hierzu wurden die für die Kohlfliegenbonitur im November entnommenen Pflanzen (25 Pflanzen je Parzelle) nach Reinigung der Wurzeln als Parzellenmischgruppe gewogen, um die Pflanzenfrischmasse zu bestimmen. Nach der Kohlfliegenbonitur wurden die Wurzeln bei $105^{\circ} \mathrm{C}$ für $24 \mathrm{~h}$ getrocknet und anschließend zur Bestimmung der Wurzeltrockenmasse herangezogen. 
Im Gewächshaus erfolgte eine Erfassung von Spross- und Wurzelparametern zu den jeweiligen Boniturterminen, die auch für die visuelle Befallsermittlung sowie ELISA/PCRProbenahmen vorgesehen waren. Alle Pflanzen eines jeweiligen Boniturtermins wurden entnommen und im Rahmen einer destruktiven Endbonitur auf pflanzenmorphologische Parameter untersucht. Neben der Pflanzenlänge (Bodenoberfläche bis Hauptfluoreszenz in cm) wurden i. d. R. die Sprossfrisch- bzw. Sprosstrockenmasse sowie die Wurzeltrockenmasse ermittelt. Für die Bestimmung der Trockenmasse wurde der oberirdische Sprossbereich sowie der von Erde befreite Wurzelbereich (inklusive Hypokotyl) in Briefumschläge platziert und im Anschluss für drei Tage bei $35^{\circ} \mathrm{C}$ in einen Trockenschrank eingestellt. Beim Inokulationsstufenversuch (vgl. 2.18.3) wurden zusätzlich zu den o. a. Parametern auch die Ertragsparameter Kornertrag/Pflanze sowie das TKG erhoben. Die abgereiften Rapspflanzen wurden hierbei zunächst per Hand vorgedroschen und im Anschluss mit einer Dreschmaschine (Fa. Linca, Tel-Aviv, Israel) ausgedroschen. Nach Entfernung des Restbesatzes erfolgte die Bestimmung von Ertrag und TKG.

\subsection{Feldversuche}

\subsubsection{Standorte}

Die Feldversuche wurden in den Versuchsjahren 2005 bis 2008 mit Ausnahme eines Versuchs (Anbaufaktorenversuch 2006/2007) auf Flächen der Versuchswirtschaft Reinshof der Universität Göttingen durchgeführt. Der Standort liegt am nordwestlichen Stadtrand von Göttingen zwischen den Ortsteilen Holtensen-Ost und Weende in der Talaue des Leinegrabens (Gemarkung Weende, Flur 12). Hier wurden die Versuche auf den benachbarten Schlägen „Große Breite“ (2005/2006), „Große Lage“ (2006/2007) und „Dragoneranger“ (2007/2008) angelegt. Das Gebiet liegt im Schwemmkegelbereich der Lutter, eines weiter südlich in die Leine mündenden Baches, dessen stark kalkhaltiges Wasser zu Wiesenkalkanlagerungen geführt hat (Wildhagen, 1972). Der vorliegende Bodentyp ist Auenboden, der aus jungen Flusssedimentablagerungen des Holozäns entstanden ist. Oberhalb der im Unterboden befindlichen Wiesenkalkablagerungen liegen toniger Schluff über schluffigem Lehm über lehmigem Kies. Nach Klassifizierung durch Reichsbodenschätzung bzw. deren Anpassungen handelt es sich in den Versuchsflächenbereichen um einen Lehmboden der Zustandsstufe 2, aus Alluvialböden mit der Bodenzahl 86 und der Ackerzahl 89 (L 2 Al 86/89) (Anonymus, 2005). 
Üblicherweise unterliegt der Versuchsstandort einem Produktionsverfahren mit dreigliedriger Fruchtfolge, in der W-Weizen - W-Gerste - Zw.-Frucht Ölrettich - Z-Rüben angebaut werden. Im Versuchsflächenbereich der Schläge „Große Breite“ und „Große Lage“ wurde erstmals W-Raps anstatt Z-Rüben angebaut; der Versuchsflächenbereich des Schlages „Dragoneranger“ wurde nach 2004/2005 zum zweiten Mal mit W-Raps bestellt.

\subsubsection{Sortenversuch}

Im Rahmen eines Sortenversuchs sollten in den Versuchsjahren 2005/2006 bis 2007/2008 Auswirkungen unterschiedlich hohen Kohlfliegenbefalls auf die Infektion und Schadwirkung von $V$. longisporum und P. lingam an Raps untersucht werden. Im Vordergrund der Untersuchungen stand dabei die Beantwortung der Frage, ob Schäden durch Larvenfraß einen Einfluss auf Verticillium- bzw. Phoma-Befall haben, und wenn ja, inwieweit sich hierbei anfällige (gegenüber den Pathogenen) von weniger anfälligen Sorten unterscheiden. Darüber hinaus sollte überprüft werden, ob etwaige Interaktionseffekte vom Zeitpunkt des Erscheinens der Kohlfliege abhängen. Eine Abstufung des Kohlfliegenbefalls erfolgte dabei mit Insektiziden oder Kulturschutznetzen (vgl. 2.12). In Tab. 8 sind die einzelnen Versuchsparameter für alle drei Jahre zusammengefasst. Die Versuchsflächen wurden nach Ernte der Vorfrucht (W-Gerste) gepflügt und nach der Verticillium-Bodeninokulation (vgl. 2.6.1) mit Raps eingesät. Die Aussaat erfolgte dabei zu einem frühen Zeitpunkt (11.-14. August), um einen möglichst starken Kohlfliegenzuflug zu gewährleisten. Düngung und Pflanzenschutz wurden mit Ausnahme von Einkürzungsmaßnahmen praxisüblich durchgeführt. Auf eine Applikation von azolhaltigen Fungiziden im Herbst bzw. Frühjahr wurde dabei verzichtet, um mögliche Wirkungen auf $P$. lingam auszuschließen. Stattdessen erfolgten Einkürzungsmaßnahmen mit CCC + Moddus. Im Anhang ist neben den Versuchsplänen (Tab. 1A-3A) auch eine detaillierte Auflistung durchgeführter acker-und pflanzenbaulicher Maßnahmen (Tab. 6A-8A) zu finden. 
Versuchsflächenbereich nach der Wintergerstenernte streifenweise gepflügt bzw. gegrubbert und vor der Aussaat mit Verticillium-befallenem Stoppelmaterial inokuliert (vgl. 2.6.1). Winterraps der Sorte Oase (2005/2006) bzw. Smart (2006/2007) wurde entweder früh oder vergleichsweise spät, ausgesät. Im dritten Versuchsjahr (2007/2008) sollten Effekte variierender Saattermine auf den Befall von Raps mit $V$. longisporum bei unterschiedlich starkem Kohlfliegenbefall untersucht werden, um eine differenzierte Risikoabschätzung bzgl. $V$. longisporum abgeben zu können. Der Faktor Bodenbearbeitung wurde hier nicht mehr variiert. Winterraps der Sorte Trabant wurde entweder früh, oder vergleichsweise spät, in Einzelkornsaat in Kontroll- bzw. Verticillium-inokulierte Parzellen ausgesät. Der Versuch sah dabei verschiedene Insektizid/Netzvarianten vor, um Effekte von Saatzeit bzw. Kohlfliegenbefall auf $V$. longisporum sowohl in Kombination, als auch einzeln betrachten zu können. Bei der Netzabdeckungsvariante „Netz-Herbst (teilweise offen)“ handelt es sich um eine Variante mit Abdeckung im Herbst, bei der die Netze in der Hauptzuflugphase der Kleinen Kohlfliege für zwei Wochen entfernt wurden. Durch die Kombination von Netz mit Kohlfliegenbefall sollten mögliche, indirekte Effekte der Netzabdeckung auf den Verticillium-Befall identifiziert werden. Abgesehen von einer Erhebung des Kohlfliegen- und Verticillium-Befalls wurden zusätzlich Messungen von Bodentemperatur, Bodenfeuchte, Lufttemperatur sowie Luftfeuchte durchgeführt, um einen möglichen Einfluss klimatischer Parameter auf die Infektion mit $V$. longisporum erfassen zu können. Düngung und Pflanzenschutz erfolgten praxisüblich und sahen im Gegensatz zum Sortenversuch auch eine Fungizidkontrolle von P. lingam vor. Acker- und pflanzenbauliche Maßnahmen (Tab. 9A11A), sowie eine Versuchsskizze (Tab. 4A-5A) sind im Anhang aufgeführt. 
Tab. 9: Versuchsparameter des Anbaufaktorenversuchs in den Jahren 2005 bis 2008.

\begin{tabular}{|c|c|c|c|}
\hline & $2005 / 2006$ & $2006 / 2007$ & $2007 / 2008$ \\
\hline Sorten ${ }^{1)}$ & Oase (Vert.: I) & Smart (Vert.: I) & Trabant (Vert.: S) \\
\hline $\begin{array}{l}\text { Inokulations- } \\
\text { varianten }\end{array}$ & Verticillium-Inokulation & Verticillium-Inokulation & $\begin{array}{l}\text { Verticillium-Inokulation } \\
\text { Kontrolle }\end{array}$ \\
\hline Bodenbearbeitung & $\begin{array}{l}\text { Pflug } \\
\text { Grubber }\end{array}$ & $\begin{array}{l}\text { Pflug } \\
\text { Grubber }\end{array}$ & Pflug \\
\hline Aussaat & $\begin{array}{l}\text { 12. August } 2005 \\
\text { 25. August } 2005 \\
\text { Drillsaat } 60 \mathrm{kf} \mathrm{K} / \mathrm{m}^{2}\end{array}$ & $\begin{array}{l}\text { 17. August } 2006 \\
\text { 01. September } 2006 \\
\text { Drillsaat } 60 \mathrm{kf} \mathrm{K} / \mathrm{m}^{2}\end{array}$ & $\begin{array}{l}\text { 14. August } 2007 \\
\text { 31. August } 2007 \\
\text { Einzelkornsaat } 52 \mathrm{kf} \mathrm{K} / \mathrm{m}^{2}\end{array}$ \\
\hline Insektizide $^{2)}$ & Chinook & Chinook & $\begin{array}{l}\text { Chinook } \\
\text { Oftanol T } \\
\text { Oftanol T (+ Nexion Neu) }\end{array}$ \\
\hline Netzabdeckung ${ }^{3)}$ & ohne Netz & ohne Netz & $\begin{array}{l}\text { ohne Netz } \\
\text { Netz im Herbst } \\
\text { Netz im Herbst (teilweise offen) } \\
\text { Netz im Herbst + Frühjahr }\end{array}$ \\
\hline Anlage & $\begin{array}{l}\text { Streifenversuch } \\
\text { Parzellen } 30 \mathrm{~m} \text { x } 30 \mathrm{~m} \\
2 \text { Wiederholungen }\end{array}$ & $\begin{array}{l}\text { Streifenversuch } \\
\text { Parzellen } 15 \text { m x } 15 \text { m } \\
2 \text { Wiederholungen }\end{array}$ & $\begin{array}{l}\text { Randomisierte Blockanlage } \\
\text { Parzellen 2,5 m x 8,5 m } \\
4 \text { Wiederholungen }\end{array}$ \\
\hline Standort & Große Breite (Weende) & Angerstein & Dragoneranger (Weende) \\
\hline
\end{tabular}

1) Vert.: (S) anfällig; (I) moderat anfällig; (I/R) gering anfällig gegenüber $V$. longisporum

2) Bei den Insektizid- Präparaten handelt es sich mit Ausnahme von Nexion Neu (Streumittel) um Saatgutbehandlungsmittel.

3) Varianten mit Netzabdeckung kamen ausschließlich in der Insektizidvariante Chinook vor.

\subsubsection{Angabe meteorologischer Daten}

Angaben zum Witterungsverlauf während des Versuchszeitraumes (August 2005-August 2008) als auch im langjährigen Mittel (1951-1980) basieren auf meteorologischen Aufzeichnungen des Deutschen Wetterdienstes (DWD), Messstation Göttingen. Zusätzlich erfolgten im Anbaufaktorenversuch 2007/2008 Messungen von Bodentemperatur, Bodenfeuchte, Lufttemperatur sowie Luftfeuchte, um einen möglichen Einfluss von klimatischen Faktoren auf $V$. longisporum erfassen zu können. Zwischen dem 28.08. und dem 09.10.2007 
wurden in wöchentlichem Abstand Bodentemperaturmessungen durchgeführt, wobei jeweils acht Messungen ( $5 \mathrm{~cm}$ Bodentiefe) in einer offenen bzw. einer mit einem Kulturschutznetz abgedeckten Parzelle vorgenommen wurden. Zur Bestimmung der Bodenfeuchtigkeit wurden aus den beiden Parzellen jeweils vier Bodenproben (0-30 cm Tiefe) mit einem Bohrstock entnommen, in Plastikbeutel transferiert und im Anschluss gewogen. Der Wassergehalt wurde nach Trocknung der Proben durch Differenzwägung bestimmt. Die Parameter Luftfeuchte sowie Lufttemperatur wurden jeweils in einer offenen bzw. einer abgedeckten Parzelle mit im Feld installierten Dataloggern (Fa. Escort) stündlich aufgezeichnet.

\subsection{Monitoring}

Abgesehen von eigenen Feldversuchen am Standort Göttingen, an denen Untersuchungen auf Grundlage von künstlichen Inokulationen erfolgten, wurden von 2005 bis 2007 zusätzlich Befallserhebungen von Kohlfliege und $V$. longisporum an einigen Standorten innerhalb Deutschlands durchgeführt, wo beide Schaderreger natürlicherweise auftreten. Im Versuchsjahr 2005/2006 wurden insgesamt fünf Versuchsstandorte [Schackendorf (SH), Veelböken (MV), Nesow (MV), Dedelow (BB) sowie Leipzig (SN)] eines Kohlfliegenringversuchs, bei dem die Wirksamkeit verschiedener insektizider Saatgutbehandlungsmittel gegenüber den Larven der Kleinen Kohlfliege überprüft wurde, beprobt. Bei dem an allen Standorten gleichen Versuchsaufbau wurde die Hybridsorte Talent in verschiedenen insektiziden Saatgutbehandlungsvarianten angebaut. Eine Erfassung des Kohlfliegenbefalls wurde im Herbst 2005 von den jeweiligen Versuchsanstellern vorgenommen. Aus den Chinook bzw. Elado behandelten Varianten wurden nach der Ernte je Wiederholung 25 Pflanzen zufällig entnommen und anschließend in Göttingen im Labor auf Verticillium- Befall hin untersucht (vgl. 2.8.1).

Im Versuchsjahr 2006/2007 wurden Befallserhebungen auf vier Praxisflächen in Prohnsdorf (SH), Veelböken (MV), Nesow (MV) sowie Dedelow (BB) durchgeführt, die nur unweit von den vorjährigen Schlägen entfernt waren. Zum partiellen Kohlfliegenausschluss wurde nach der Saat des Rapses eine etwa 15 m vom Schlagrand entfernte Parzelle (6 m x 14 m) mit einem Kulturschutznetz abgedeckt. Im Frühjahr wurde auf einer Teilparzelle dieser bereits im Herbst abgedeckten Fläche jeweils eine Netzkäfigkonstruktion (10 m x 2 m x 2 m) errichtet, um Kohlfliegenbefall der ersten Generation ausschließen zu können. In Übereinstimmung zum Sortenversuch (vgl. 2.15.2) ergaben sich somit drei Netzabdeckungsvarianten. Eine Erfassung des Kohlfliegenbefalls wurde im Herbst vorgenommen. Nach der Ernte wurden aus jedem Parzellenbereich 100 Rapsstoppeln zufällig entnommen und in Göttingen im Labor 
auf Verticillium-Befall hin untersucht. Düngung und Pflanzenschutz erfolgten praxisüblich. Der Rapsanteil in der Fruchtfolge betrug an allen Standorten 25\%. Einzelne Versuchsparameter des zweijährigen Monitorings sind in Tab. 10 aufgeführt.

Tab. 10: Versuchsparameter des Monitorings in den Jahren 2005 bis 2007.

\begin{tabular}{|c|c|c|}
\hline & $2005 / 2006$ & $2006 / 2007$ \\
\hline Standorte/Sorten ${ }^{1)}$ & $\begin{array}{l}\text { Prohnsdorf (SH)/ Talent } \\
\text { Veelböken (MV)/ s.o. } \\
\text { Nesow (MV)/ s.o. } \\
\text { Dedelow (MV)/ s.o. } \\
\text { Leipzig (SA)/ s.o. }\end{array}$ & $\begin{array}{l}\text { Prohnsdorf (SH)/ Taurus } \\
\text { Veelböken (MV)/ PR46W31 } \\
\text { Nesow (MV)/ Titan } \\
\text { Dedelow (MV)/ Artus }\end{array}$ \\
\hline Insektizide & $\begin{array}{l}\text { Chinook } \\
\text { Elado }\end{array}$ & Chinook \\
\hline Netzabdeckung & ohne & $\begin{array}{l}\text { ohne } \\
\text { Netz im Herbst } \\
\text { Netz im Herbst + Frühjahr }\end{array}$ \\
\hline Bodenbearbeitung & Pflug & Pflug, Grubber \\
\hline Aussaat & $\begin{array}{l}\text { 15. - 20. August } 2005 \\
\text { Drillsaat, } 50 \mathrm{kf} \mathrm{K} / \mathrm{m}^{2}\end{array}$ & $\begin{array}{l}\text { 27. August - 06. September } 2006 \\
\text { Drillsaat, } 40-50 \mathrm{kf} \mathrm{K} / \mathrm{m}^{2}\end{array}$ \\
\hline Anlage & $\begin{array}{l}\text { Randomisierte Blockanlage } \\
\text { Parzellen } 2,5 \mathrm{~m} \times 8,5 \mathrm{~m} \\
4 \text { Wiederholungen }\end{array}$ & $\begin{array}{l}\text { Praxisschläge } \\
\text { Parzelle } 8 \mathrm{~m} \text { x } 14 \mathrm{~m} \\
\text { ohne Wiederholung }\end{array}$ \\
\hline
\end{tabular}

1) Anfälligkeit der Sorten gegenüber $V$. longisporum war mit Ausnahme von Talent (moderat anfällig) nicht bekannt.

\subsection{Halbfreilandversuche}

In Halbfreilandversuchen wurden in den Jahren 2006 und 2007 am Standort „Institutsgarten“ in Göttingen Weende Interaktionsuntersuchungen zwischen der Kohlfliege und $V$. longisporum bei gezieltem Kohlfliegenbesatz durchgeführt. Im Versuchsjahr 2006 wurde Chinook gebeizter Sommerraps der Sorte Heros (moderat anfällig gegenüber $V$. longisporum) in einer Betonkastenrahmenanlage (Abb. 7), die aus $25 \times 1 \mathrm{~m}^{2}$ Parzellen besteht, per Hand in Einzelkornsaat $\left(40 \mathrm{kf} \mathrm{K} / \mathrm{m}^{2}\right)$ im April ausgesät. Neben einer nicht inokulierten Kontrolle wurden vor der Aussaat entweder 15 g oder 100 g stark mit Verticillium befallenes, klein gemahlenes Stoppelmaterial in die Parzellen flach eingemischt. Zur Vermeidung von verzerrenden Düngungseffekten erfolgte eine Ausgleichsdüngung mit autoklaviertem Stoppel- 
material in entsprechender Höhe. Jede Inokulationsstufe kam einmal in einer Variante ohne und einmal in einer Variante mit Kohlfliegenbefall vor. Bei den Varianten mit Kohlfliege wurden zu BBCH 15 zehn Kohlfliegeneier aus der Labor-Dauerzucht mit einem Pinsel an den Wurzelhals jeder Pflanze platziert. Zur Verhinderung des natürlichen Zufluges wurde eine Rahmenkonstruktion mit Kulturschutznetz über der Anlage errichtet. Der Versuch war als randomisierter Blockversuch aufgebaut, in dem jede der sechs Versuchsvarianten in vierfacher Wiederholung vorkam. Düngung und Pflanzenschutz erfolgten praxisüblich (Tab. 12A-13A). Nach Abreife des Sommerrapses Ende August wurden alle Pflanzen einzeln entnommen und im Rahmen einer Masterarbeit von Müller (2007) u. a. auf Kohlfliegen- bzw. Verticillium-Befall hin untersucht.

Nach einem Bodenaustausch der oberen $40 \mathrm{~cm}$ wurde dieser Versuch im Jahr 2007 mit leichten Modifikationen erneut angelegt, um die Ergebnisse des ersten Jahres überprüfen zu können. Verändert gegenüber 2006 wurden die Inokulationsstufen. Neben einer nicht inokulierten Kontrolle wurden entweder $10 \mathrm{~g}$ (anstatt $15 \mathrm{~g}$ ) oder $50 \mathrm{~g}$ (anstatt $100 \mathrm{~g}$ ) Inokulummaterial in die Parzellen flach eingemischt.

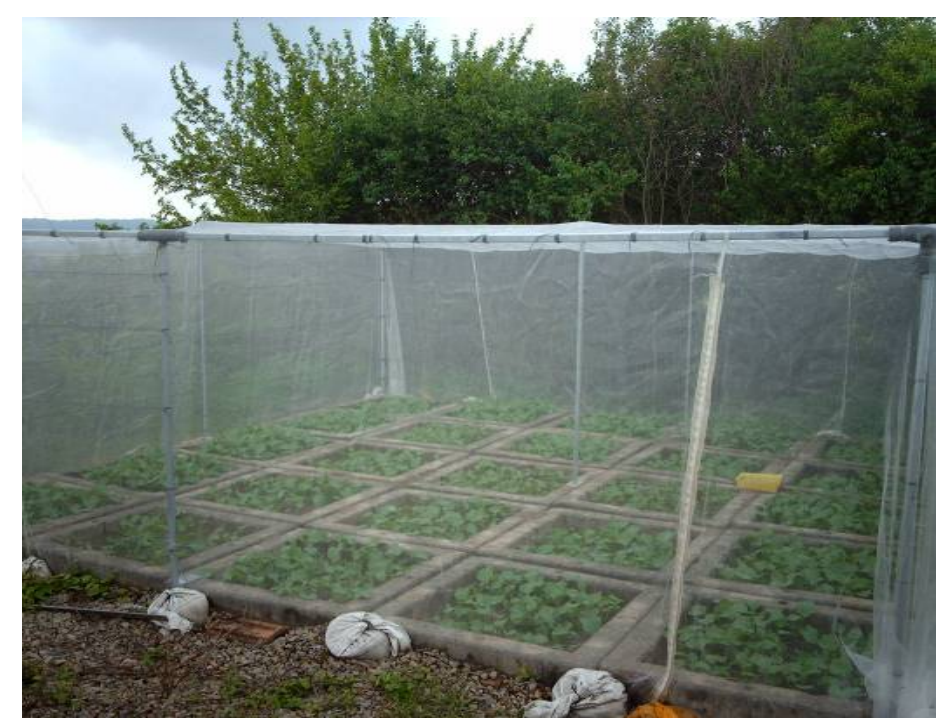

Abb. 7: Betonkastenrahmenanlage am Standort Institutsgarten (Göttingen) einen Monat nach Aussaat von Sommerraps (BBCH 14) im Jahr 2006. Die Parzellen sind durch $1 \mathrm{~m}$ tiefe und 0,15 m breite Wände voneinander abgegrenzt. Bei der Bodenart handelte es sich nach Korngrößenbestimmung und Zuordnung nach Krahmer et al. (1995) um einen sandigen Lehm der Zustandstufe 3 (sL3). 


\subsection{Gewächshausversuche}

\subsubsection{Anzucht und Haltung der Pflanzen}

Die Untersuchungen im Gewächshaus wurden sowohl an Winterraps als auch an Sommerraps durchgeführt. Für Versuche mit Winterraps wurde das Saatgut zunächst in Multitopfplatten (51 Töpfe mit $\varnothing 5 \mathrm{~cm}$ ) ausgesät und unter einem Lichtthermostat bei $18^{\circ} \mathrm{C}$ und $16 \mathrm{~h}$ Photoperiode bis zur Entfaltung des ersten Laubblattes (BBCH 11) angezogen. Nach der Anzucht wurden die in den Multitopfplatten befindlichen Pflanzen in eine Klimakammer eingestellt und bei $5^{\circ} \mathrm{C}$ für eine Dauer von acht Wochen vernalisiert. Im Anschluss wurden die etwa zehn Wochen alten Pflanzen (BBCH 12-13) samt Wurzelballen vorsichtig aus den Vertiefungen der Multitopfplatte präpariert und in die unterschiedlich inokulierten (vgl. 2.6.2) Kunststofftöpfe (13 cm x $13 \mathrm{~cm}$ x $13 \mathrm{~cm})$ gepflanzt. Bei Versuchen mit Sommerraps erfolgte eine direkte Saat in die vorbereiteten Töpfe. Der in den Versuchen verwendete Boden (ca. $1050 \mathrm{~g} /$ Topf) bestand aus den Komponenten Sand (30\% v/w), gedämpfter Komposterde $(20 \% \mathrm{v} / \mathrm{w})$ und Torf $(50 \% \mathrm{v} / \mathrm{w})$, die vorher gründlich vermischt worden waren.

Die Rapspflanzen wurden auf Gewächshaustischen (82 cm Bodenhöhe), deren Stellfläche mit Gießfilz und perforierter Kunststofffolie ausgekleidet worden war, gehalten. Zu Anfang erfolgte ausschließlich eine Bewässerung in die Töpfe, später, nachdem Wurzeln aus dem Topfboden in den Gießfilz eingewachsen waren, wurde die Wasserversorgung der Pflanzen vornehmlich über Gießfilzbewässerung sichergestellt. Die Rapspflanzen wurden in ausreichendem Maße mit Wasser versorgt und vor starker Sonneneinstrahlung von außen durch Dachvorhänge geschützt. Es sollte kein Trockenstress aufgrund unzureichender Wasserversorgung induziert werden. Während des Versuchszeitraumes betrug die Temperatur in den Gewächshauskabinen $25 \pm 10^{\circ} \mathrm{C}$ bei einer relativen Luftfeuchte von 35$40 \%$. Eine automatische Temperaturregelung bei über- oder unterschreiten der eingestellten Sollwerttemperatur von $25^{\circ} \mathrm{C}$ erfolgte durch Öffnen von Dachfenstern bzw. Zuschalten von Heizkörpern. In einer Höhe von 1,3 m über den Gewächshaustischen installierte Lampen gewährleisteten bei einer sechzehnstündigen Photoperiode eine Beleuchtungsstärke von mindestens 10.000 Lux unabhängig von der Strahlung, die durch von außen einfallendes Licht erzeugt wurde.

Die Gewächshausversuche wurden in Blockform angelegt, wobei eine räumliche Trennung von Boniturterminen erfolgte, um möglichst homogene Bedingungen für gleichzeitig destruktiv bonitierte Pflanzen zu gewährleisten. Im Rahmen der Versuche durchgeführte 
Düngungs- und Pflanzenschutzmaßnahmen zielten darauf ab, den neben $V$. longisporum, $P$. lingam und der Kleinen Kohlfliege verursachten biotischen sowie abiotischen Stress möglichst gering zu halten. Nach Berücksichtigung der im Topfboden bereits vorhandenen Nährstoffe war die Düngungshöhe darauf ausgerichtet, eine ausreichende Pflanzenversorgung sicherzustellen und ertragsbildende Prozesse zu ermöglichen. Eine bedarfsgerechte Flüssigdüngung erfolgte etwa alle vier Wochen mit Hakaphos $\left(15 \% \mathrm{~N} ; 15 \% \mathrm{~K}_{2} \mathrm{O} ; 11 \% \mathrm{P}_{2} \mathrm{O} 5 ; 1 \%\right.$ $\mathrm{MgO})$ sowie Bittersalz (16\% MgO; 13\% S). Regelmäßige Applikationen von Netzschwefel dienten der Vorbeugung gegen Echtem Mehltau (Erysiphe chicoracearum). Insektizide (Confidor (Imidacloprid); Karate Zeon (Lambda-Cyhalothrin) wurden in Form von Spritzapplikationen vornehmlich zur Kontrolle von Mehliger Kohlblattlaus (Brevicoryne brassicae) und Thripsen (Thrips tabaci) eingesetzt.

\subsubsection{Sortenversuch}

In einem Gewächshausversuch wurden 2006 kontrollierte Interaktionsuntersuchungen zwischen der Kleinen Kohlfliege und $V$. longisporum bei Winterraps der Sorten Laser und Lion durchgeführt. Im Vordergrund der Untersuchungen stand dabei die Beantwortung der Frage, ob Schädigungen durch Larvenfraß einen Einfluss auf den Befall und die Schadwirkung von $V$. longisporum haben, und wenn ja, inwieweit sich hierbei eine anfällige (Laser) von einer moderat anfälligen Sorte (Lion) unterscheidet. Darüber hinaus sollte überprüft werden, ob etwaige Interaktionseffekte vom Zeitpunkt des Erscheinens der Kohlfliege, sowie der Höhe des Bodeninokulums, abhängen. Für die Bodeninokulation kamen künstlich angezogene MS zur Anwendung, mit denen, neben einer Kontrolle, Inokulationsstärken von 0,05 oder $0,25 \mathrm{mg} \mathrm{MS} / \mathrm{g}$ Boden eingestellt wurden (vgl. 2.5.2). Jede Inokulationsvariante kam in drei verschiedenen Kohlfliegenvarianten vor. Abgesehen von einer Kontrolle (ohne Kohlfliege) wurden acht Kohlfliegeneier entweder zu BBCH 15 (früh) oder zu BBCH 60-61 (spät) mit einem Haarpinsel am Wurzelhals angesetzt (vgl. 2.11). Mit den gewählten Entwicklungsstadien sollte der Zuflug der dritten Generation im Herbst, bzw. der ersten Generation im Frühjahr simuliert werden. Der Versuch war als randomisierter Blockversuch angelegt, in dem jede Versuchsvariante in 15-facher Wiederholung vorkam. Nach Abreife des Rapses erfolgte eine destruktive Endbonitur, bei der neben der Beurteilung von Verticillium-Befall (visuell bzw. ELISA) und Kohlfliegenbefall auch einige pflanzenmorphologische Parameter erhoben wurden. 


\subsubsection{Inokulationsstufenversuch}

In einem weiteren Gewächshausversuch wurden 2006 kontrollierte Interaktionsuntersuchungen zwischen der Kleinen Kohlfliege und $V$. longisporum an Sommerraps der Sorte Heros (moderat anfällig gegenüber $V$. longisporum) durchgeführt. Es sollte überprüft werden, ob eine etwaige durch Kohlfliegen bedingte Förderung des Verticillium-Befalls von der Höhe des Bodeninokulums abhängt. Neben einer Kontrolle wurden entweder 0,25 g, 0,5 g, 1 g, 2 g oder $4 \mathrm{~g}$ stark mit Verticillium befallenes Stoppelmaterial vor der Saat in den Boden (1050 g/Topf) eingemischt. Jede Bodeninokulationsstufe kam einmal in einer Variante ohne und einmal in einer Variante mit Kohlfliegenbefall vor. Bei der zuletzt genannten Variante wurden zu BBCH 15 acht Kohlfliegeneier mit einem Haarpinsel an den Wurzelhals der Pflanzen gesetzt. Jede Versuchsvariante wurde 12-fach wiederholt. Nach Abreife des Rapses erfolgte eine destruktive Endbonitur, bei der neben der visuellen Beurteilung des Verticillium-Befalls auch einige Ertrags- sowie pflanzenmorphologische Parameter erhoben wurden, um Schadwirkungseffekte quantifizieren zu können.

\subsubsection{Befallsdynamikversuch}

Im Befallsdynamikversuch wurde 2007 überprüft, inwieweit Wurzelfraß durch Larven der Kohlfliege Einfluss auf die Ausbreitungsdynamik von $V$. longisporum in der Pflanze nimmt und welche Rolle hierbei die Höhe des Bodeninokulums spielt. In Übereinstimmung zum Inokulationsstufenversuch (vgl. 2.18.3) wurden die Interaktionsuntersuchungen an Sommerraps der Sorte Heros durchgeführt. Neben einer Kontrolle erfolgte eine Bodeninokulation mit 0,2 g, 1 g oder 5 g Inokulum je Topf (1050 g Boden). Varianten mit (acht Kohlfliegeneier zu $\mathrm{BBCH}$ 15) und ohne Kohlfliegenbefall entsprachen denen des Inokulationsstufenversuchs. Eine Quantifizierung von Verticillium-DNA im Pflanzengewebe erfolgte zu drei unterschiedlichen Terminen (BBCH 65, 75 und 90). Jede Versuchsvariante kam dabei 12-fach wiederholt vor. $\mathrm{Zu}$ den jeweiligen Boniturterminen erfolgte eine destruktive Bonitur, bei der zunächst pflanzenmorphologische Parameter sowie Kohlfliegenbefall erhoben wurden. Im Anschluss wurden die Pflanzenproben weiter verarbeitet, um mittels Real-Time PCR den Befall von $V$. longisporum in der Pflanze genau quantifizieren zu können (vgl. 2.8.4). Je Pflanze wurden hierbei zwei Bereiche, der untere Hypokotyl- sowie der untere Sprossbereich, für die Untersuchung herangezogen. 


\subsubsection{Resistenzversuch}

Im Jahr 2007 wurden Interaktionsuntersuchungen zwischen der Kleinen Kohlfliege und $V$. longisporum bei einer Winterrapssorte mit moderater Verticillium-Anfälligkeit (Express) und einer Rapslinie mit hoher Verticillium-Resistenz (Sem 05-500256) durchgeführt. Es sollte überprüft werden, ob der Larvenfraß der Kohlfliege zu einer Abschwächung von Sortenresistenz gegenüber $V$. longisporum führt. Neben einer Kontrolle erfolgte eine Bodeninokulation mit $1 \mathrm{~g}$ Verticillium-befallenem Stoppelmaterial. Varianten mit (acht Kohlfliegeneier zu BBCH 15) und ohne Kohlfliegenbefall entsprachen denen des Inokulationsstufenversuchs (vgl. 2.18.3). Der Versuch sah drei Boniturtermine (BBCH 65, 75, 85) vor, zu denen je Variante zwölf Pflanzen auf Kohlfliegenbefall, pflanzenmorphologische Parameter sowie Verticillium-Befall untersucht wurden. In Übereinstimmung mit dem Befallsdynamikversuch (vgl. 2.18.4) wurde der Befall von $V$. longisporum mittels Real-Time PCR erhoben, wobei neben dem Hypokotyl- und Sprossabschnitt zusätzlich auch eine Untersuchung des Wurzelbereichs erfolgte.

\subsection{Mechanismen der Interaktion zwischen der Kleiner Kohlfliege und V. longisporum}

\subsubsection{Stängelinokulationsversuch}

In einem 2008 durchgeführten Gewächshausversuch wurde der Einfluss von Kohlfliegen- auf Verticillium-Befall bei räumlicher Trennung beider Schaderreger untersucht, um mögliche pflanzenphysiologische Effekte identifizieren zu können. Mit der moderat anfälligen Sorte Express und der resistenten Linie Sem 05-500256 wurden dieselben Sorten wie beim Resistenzversuch (vgl. 2.18.5) ausgewählt, um Effekte mit und ohne räumliche Trennung miteinander vergleichen zu können. Der Versuch sah insgesamt vier Versuchsvarianten vor (Kontrolle, Kohlfliegenbefall, Verticillium-Befall, Kombination von Kohlfliegen- und Verticillium-Befall bei räumlicher Trennung beider Schaderreger), die jeweils 12-fach wiederholt wurden. Bei Varianten mit Kohlfliegenbefall wurden zu BBCH 55 acht Kohlfliegeneier an den Wurzelhals angesetzt. Die Verticillium-Inokulation des direkt oberhalb des Hypokotyls befindlichen unteren Stängelbereichs (vgl. 2.6.3) erfolgte zehn Tage später. Die Rapspflanzen befanden sich zu diesem Zeitpunkt im BBCH-Stadium 60 bis 61 . Eine visuelle Erfassung des Verticillium-Befalls erfolgte 7, 14, 21 und 28 dpi anhand von Blattsymptomen. Nach dem letzten Boniturtermin (28 dpi) wurden zusätzlich Real-Time PCR- Untersuchungen durchgeführt, um den Befall von $V$. longisporum im Pflanzengewebe quantifizieren zu können. Für die Untersuchungen wurden jeweils zwei $5 \mathrm{~cm}$ lange 
Stängelabschnitte aus den Bereichen 5-10 cm sowie 30-35 cm oberhalb der Inokulationsstelle herangezogen.

\subsubsection{Wurzelteilungsversuch}

Im Rahmen eines 2008 durchgeführten Wurzelteilungsversuchs wurden Interaktionen zwischen der Kleinen Kohlfliege und $V$. longisporum bei Sommerraps der moderat anfälligen Sorte Heros untersucht. Es sollte überprüft werden, ob eine etwaige durch Kohlfliegen bedingte Förderung des Verticillium-Befalls eher auf lokale Wundeffekte oder pflanzenphysiologische Effekte zurückzuführen ist. Zur Überprüfung beider Hypothesen erfolgten die Untersuchungen an Rapspflanzen, deren Wurzelsystem in Anlehnung an Laine et al. (1994) in zwei Hälften geteilt worden waren. Hierzu wurde der Sommerraps zunächst in eine mit Quarzsand gefüllte Kunststoffschale ausgesät und für zehn Tage bei $18^{\circ} \mathrm{C}$ und $16 \mathrm{~h}$ Photoperiode angezogen. Danach wurde die Wurzelspitze der vom Sand befreiten Keimblattpflanzen mit einer Schere gekappt und die so behandelten Pflanzen in mit Quarzsand gefüllte Multitopfplatten $(\varnothing 7 \mathrm{~cm})$ pikiert. Diese wurden für weitere 30 Tage o. a. Bedingungen ausgesetzt, so dass sich zwei laterale Wurzelsysteme entwickeln konnten. Anschließend wurden die 40 Tage alten Rapspflanzen (BBCH 13-14) vom Quarzsand befreit und in ein Doppeltopfsystem pikiert (Abb. 8). Hierbei wurden ausschließlich Pflanzen mit zwei gleichmäßig entwickelten Wurzelhälften berücksichtigt. Der Versuch umfasste insgesamt fünf Varianten, die in Tab. 11 angegeben sind.
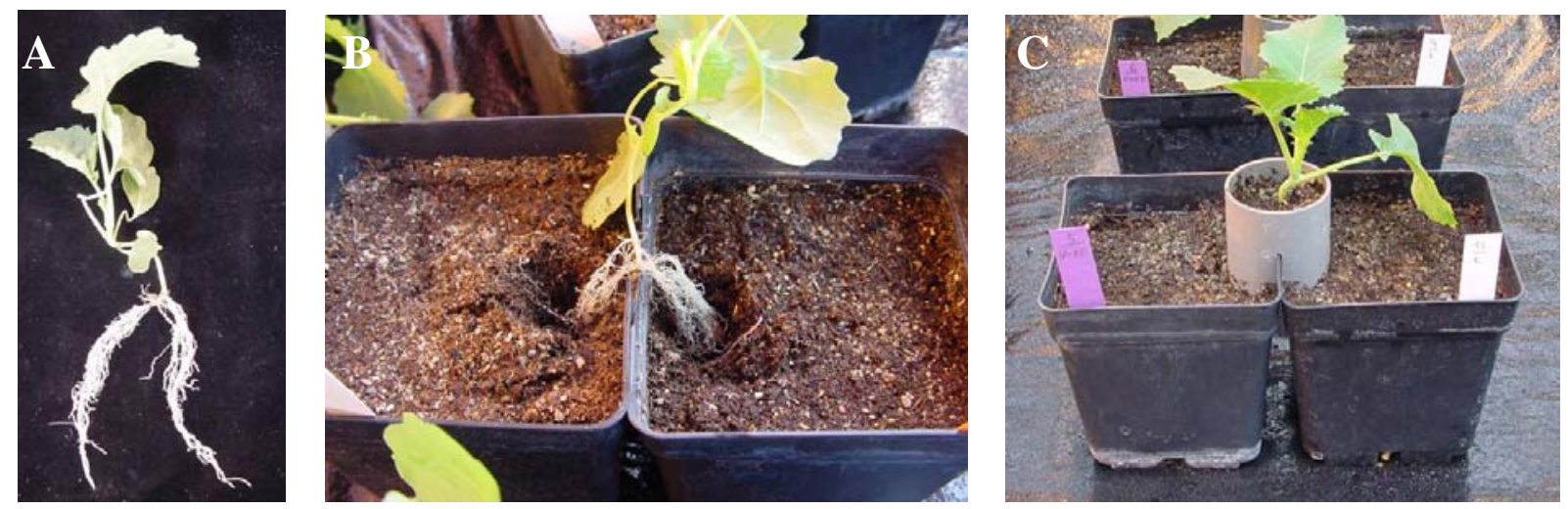

Abb. 8: (A) Geteiltes Wurzelsystem bei einer Rapspflanze der Sorte Heros. (B) Rapspflanze der Sorte Heros wird in ein Doppeltopfsystem, welches aus zwei aneinander befestigten Kunststoffpflanztöpfen besteht, pikiert. (C) Ein mit inokulumfreier Erde verfüllter $5 \mathrm{~cm}$ tiefer PVC-Zylinder $(\varnothing 5 \mathrm{~cm})$ wird zwischen den Doppeltopfhälften fixiert, um die Pflanze zu stabilisieren und zudem zu verhindern, dass es zu einer Verschleppung von Inokulum zur gegenüber liegenden Seite kommt. 
Tab. 11: Versuchsvarianten beim Wurzelteilungsversuch (Sorte Heros).

\begin{tabular}{ll}
\hline Behandlung (links/rechts) $^{1)}$ & Varianten \\
\hline $0 / 0$ & Kontrolle \\
$0 / \mathrm{KF}$ & Kohlfliege (KF) auf einer Wurzelhälfte \\
$\mathrm{V} / 0$ & Verticillium $(\mathrm{V})$ auf einer Wurzelhälfte \\
$\mathrm{V} / \mathrm{KF}$ & Verticillium $(\mathrm{V})$ und Kohlfliege (KF) separat \\
$\mathrm{V}+\mathrm{KF} / 0$ & Verticillium $(\mathrm{V})$ und Kohlfliege (KF) zusammen \\
\hline
\end{tabular}

1) Kürzel (linke Topf- bzw. Wurzelhälfte / rechte Topf- bzw. Wurzelhälfte)

Bei Varianten, die eine Verticillim-Inokulation vorsahen, wurde 1 g stark mit Verticillium befallenes Stoppelmaterial vor dem Pikieren in die entsprechende Topfhälfte eingemischt. Bei Varianten mit Kohlfliegenbefall wurden zu BBCH 17 bis 18 fünf Kohlfliegeneier im mittleren Bereich der zu besetzenden Wurzelhälfte platziert. Es gab zwei Boniturtermine (BBCH 65, 85), zu denen je Variante 12 Pflanzen auf Kohlfliegenbefall, pflanzenmorphologische Parameter sowie Verticillium-Befall hin untersucht wurden. Neben einer visuellen Befallserfassung erfolgten Real-Time PCR-Untersuchungen, um den Befall von $V$. longisporum im Wurzel-, Hypokotyl- und Sprossbereich quantifizieren zu können.

\subsubsection{Wurzelverletzungsversuch}

Ergänzend zu den unter Punkt 2.19.1 und 2.19.2 beschriebenen Interaktionsuntersuchungen wurde in einem weiteren Gewächshausversuch im Jahr 2008 überprüft, welche Rolle einer mechanischen Wurzelverletzung im Vergleich zu einer Kohlfliegen bedingten Wurzelschädigung zukommt. Die Untersuchungen wurden an Winterraps der Sorte Express (moderat anfällig gegenüber $V$. longisporum) durchgeführt. Der Versuch umfasste insgesamt sechs Varianten (Tab. 12), die sich jeweils aus 12 Pflanzen zusammensetzten. Bei Varianten mit Kohlfliegenbefall wurden $\mathrm{zu}$ BBCH 55 acht Kohlfliegeneier an den Wurzelhals angesetzt. Die mechanische Verletzung wurde zehn Tage später (BBCH 60) durchgeführt, in dem der Wurzelbereich unterhalb des Hypokotyls mit einem sterilen Skalpell auf einer Länge von $2 \mathrm{~cm}$ und einer Breite von 0,5 cm oberflächlich (ca. 0,2 cm tief) abgeschnitten wurde. Zusätzlich wurde der Boden im Bereich der Stängelbasis mit einer sterilen Nadel (Ø 0,7 mm) in einer Tiefe von 0 bis $5 \mathrm{~cm}$ an insgesamt acht Stellen perforiert, um eine mechanische Verletzung der Feinwurzeln herbeizuführen. Direkt im Anschluss erfolgte die VerticilliumBodeninokulation, wobei $100 \mathrm{ml}$ einer Sporensuspension im Bereich der Stängelbasis auf der Bodenoberfläche ausgebracht wurden (vgl. 2.6.2). Eine visuelle Erfassung des Verticillium- 
Befalls wurde 7, 14, 21, 28 und 35 dpi anhand von Blattsymtomen vorgenommen. Die nach dem letzten Boniturtermin (35 dpi) erhobene Wurzeltrockenmasse diente als Schadwirkungsparameter.

Tab. 12: Versuchsvarianten beim Wurzelverletzungsversuch (Sorte Express).

\begin{tabular}{ll}
\hline Kürzel & Variante \\
\hline $\mathrm{K}$ & Kontrolle $(\mathrm{K})$ \\
$\mathrm{KF}$ & Kohlfliege $(\mathrm{KF})$ \\
$\mathrm{M}$ & Mechanische Wuzelverletzung $(\mathrm{M})$ \\
$\mathrm{V}$ & Verticillium $(\mathrm{V})$ \\
$\mathrm{KF}+\mathrm{V}$ & Kohlfliege $(\mathrm{KF})+\operatorname{Verticillium}(\mathrm{V})$ \\
$\mathrm{M}+\mathrm{V}$ & Mechanische Wuzelverletzung $(\mathrm{M})+\operatorname{Verticillium}(\mathrm{V})$ \\
\hline
\end{tabular}

\subsection{Einfluss der Kleinen Kohlfliege auf den Befall von Raps mit P. lingam}

Im Versuchsjahr 2007 wurden in einem Gewächshausversuch Interaktionen zwischen der Kleinen Kohlfliege und $P$. lingam an Winterraps untersucht. Im Vordergrund der Untersuchungen stand dabei die Beantwortung der Frage, ob Wurzelfraß der Kleinen Kohlfliege einen Einfluss auf den Phoma-Befall hat und inwieweit sich hierbei eine anfällige (Oase) von einer resistenten Sorte (Caiman) unterscheidet. Darüber hinaus sollte überprüft werden, ob die Interaktion von der Aggressivität der Phoma-Isolate abhängt und wie der Kohlfliegenfraß im Vergleich zu einer nicht biotisch verursachten, mechanischen Schädigung im Hinblick auf Phoma-Befall zu bewerten ist. Neben einer Kontrolle ohne Verletzung setzte sich der Versuch aus einer Kohlfliegen- sowie einer mechanischen Verletzungsvariante zusammen. Bei den Varianten mit Kohlfliegenbefall wurden zu BBCH 39 acht Kohlfliegeneier an den Wurzelhals der Pflanzen angesetzt. Bei der mechanischen Verletzungsvariante wurde die Stängeloberfläche oberhalb des Wurzelhalses unmittelbar vor der Inokulation mit einer sterilen Nadel auf einer Länge von $1 \mathrm{~cm}$ flach eingeritzt. Neben einer nicht inokulierten Kontrolle gab es zwei verschiedene Phoma-Inokulationsvarianten. Zu $\mathrm{BBCH} 55$ wurden entweder $1 \mathrm{ml}$ eines aggressiven oder $1 \mathrm{ml}$ eines weniger aggressiven Phoma-Isolatgemischs mit einer Pipette oberhalb des Wurzelhalses aufgetragen (vgl. 2.7.2). Der Versuch war als randomisierter Blockversuch angelegt, in dem jede Versuchsvariante in 15-facher Wiederholung vorlag. Im BBCH-Stadium 85 erfolgte eine destruktive Endbonitur, bei der der P. lingam-Befall des Wurzelhalses anhand von verschiedenen Läsionsparametern (Länge, Tiefe und Umfang) bonitiert wurde (vgl. 2.9.2). 


\subsection{Statistische Auswertung}

Die statistische Auswertung der aus den Feld- und Gewächshausversuchen erhobenen Daten erfolgte mit Hilfe des Statistikprogramms Statgraphics Plus 5.1 (Manugistics Inc., Rockville, Maryland, USA). Nach der varianzanalytischen Verrechnung der Daten wurde ein multipler Mittelwertevergleich mit dem Fischer Least Significant Difference Test (LSD-Test) durchgeführt. Bei nicht normal verteilten Daten bzw. ordinal skalierten Variablen wurden Unterschiede zwischen den Stichproben mit dem Kruskal-Wallis-Test (Median-Test) und anschließendem Paarwertvergleich (Mann-Whitney-Test) berechnet. Unterschiedliche Buchstaben kennzeichnen signifikante Unterschiede bei einer Irrtumswahrscheinlichkeit von $5 \%(\mathrm{p} \leq 0,05)$. 


\section{Ergebnisse}

\subsection{Feldversuche}

\subsubsection{Witterungsverlauf}

In Abb. 9 a sowie Abb. 9 b ist der Witterungsverlauf für die Versuchsjahre 2005/2006, 2006/2007 und 2007/2008 (Standort Göttingen) dargestellt. Im Versuchsjahr 2005/2006 sorgten günstige Aussaatbedingungen mit anschließend wüchsiger Herbstwitterung für eine zügige Entwicklung des Winterrapses. Nach einem kühl-feuchten November folgte ein vergleichsweise kalter Winter, der im Januar relativ trocken und Ende März relativ feucht war. Nennenswerte Auswinterungsverluste waren nicht zu verzeichnen, auch wenn massiver Blattverlust auftrat. Ab Ende März stiegen die Temperaturen bei überdurchschnittlichen Niederschlagsmengen stetig an, wodurch das Wachstum der Bestände gefördert wurde. Die Ernte konnte nach einer trocken-warmen Abreifeperiode unter günstigen Bedingungen erfolgen, wobei das allgemeine Ertragsniveau überdurchschnittlich war.

Im Versuchsjahr 2006/2007 war die Aussaatperiode durch feuchte Witterung geprägt, wodurch die früh gesäten Bestände relativ zügig aufliefen. Aufgrund einer von Anfang September bis Mitte Oktober anhaltenden Trockenperiode kam es am Standort Angerstein in der Spätsaatvariante des Anbaufaktorenversuchs zu einem sehr lückenhaften Auflaufen des Rapses. Erst Ende Oktober einsetzende Niederschläge hatten keinen weiteren Nachauflauf zur Folge, so dass die Bestandesdichte mit 15 Pflanzen $/ \mathrm{m}^{2}$ sehr gering war. Die Witterung im Spätherbst und Winter (November bis März) war durch außergewöhnlich warm-feuchte Bedingungen geprägt, die keine Vegetationsruhe zuließen. Ab Ende März bis Anfang Mai kam es zu einer Trockenperiode. Von Mai bis zur Ernte Mitte Juli führten anhaltend warme Temperaturen in Verbindung mit relativ hohen Niederschlagsmengen zu einer beschleunigten Abreife des Winterrapses, wobei die Erträge auf relativ geringem Niveau lagen. Zusammenfassend kann das Versuchsjahr 2006/2007 mit einer kumulierten Niederschlagsmenge von $996 \mathrm{~mm}$ und einer Durchschnittstemperatur von 11,2 ${ }^{\circ} \mathrm{C}$ (langjährige Mittel: $645 \mathrm{~mm}$ bzw. $8,7^{\circ} \mathrm{C}$ ) als Extremjahr bezeichnet werden.

Im Versuchsjahr 2007/2008 führten feuchte Witterungsbedingungen im August und September zu einer zügigen Herbstentwicklung der Bestände. Bis Ende Dezember entsprachen die Klimabedingungen dem langjährigen Mittel, auch wenn die Verteilung der Niederschlagsmengen variierte. In Übereinstimmung zum Versuchsjahr 2006/2007 waren die Temperaturen im Januar und Februar vergleichsweise hoch, was zu einem vorzeitigen Ende 
der Vegetationsruhe führte. Im Zeitraum Mai bis Mitte Juni kam es zu einer sechs Wochen anhaltenden Trockenperiode, bei der die Temperaturen ebenfalls überdurchschnittlich hoch waren. Häufige Niederschläge während der Abreife zögerten die Rapsernte bis Ende Juli hinaus. Eine Ertragserfassung wurde nicht vorgenommen, da ein Hagelereignis vom 20.07.2008 keine Variantenvergleiche zuließ.
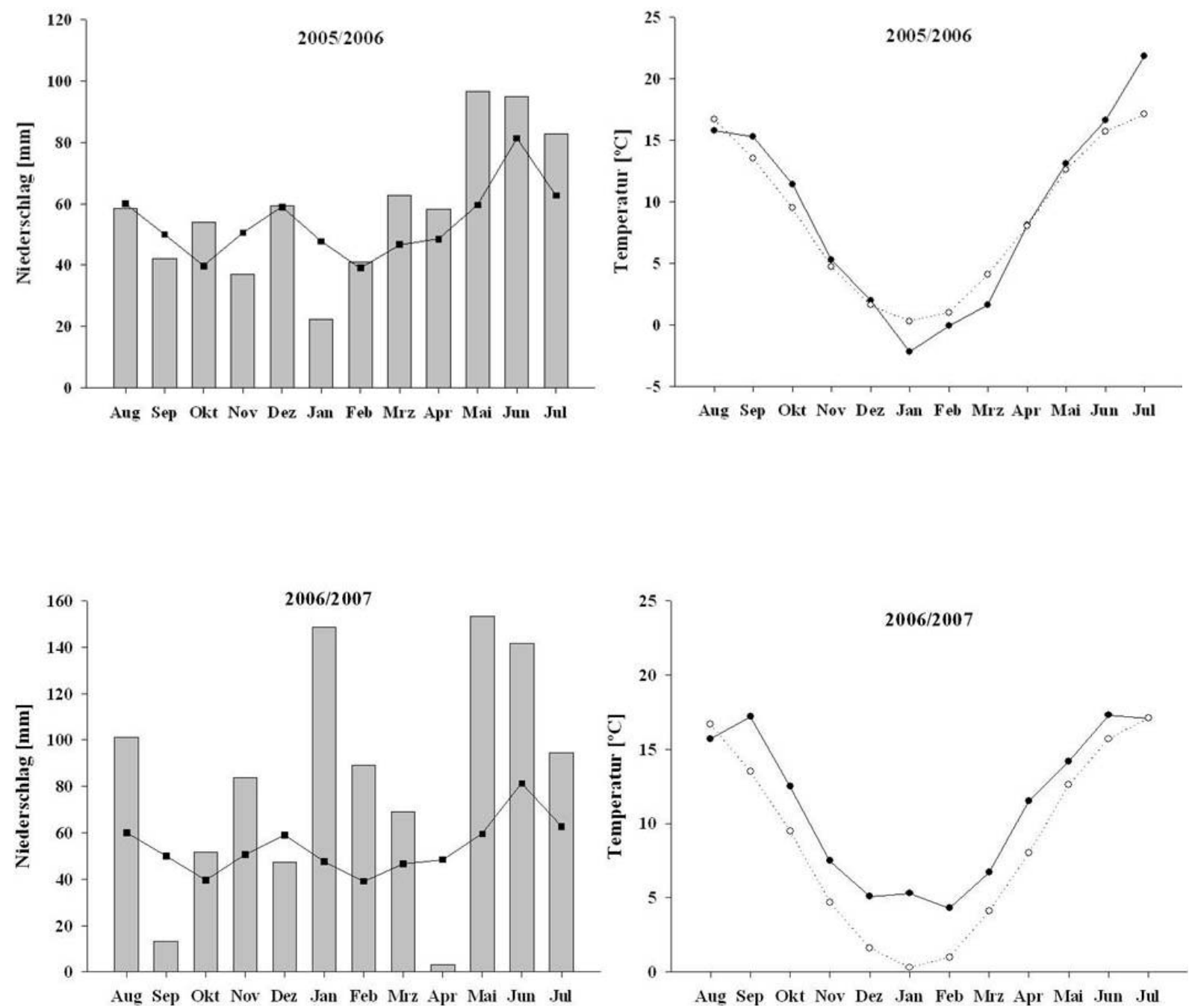

Abb. 9 a: Monatliche Niederschlagsmengen $\left[\sum \mathrm{mm}\right]$ bzw. Lufttemperaturdurchschnittswerte $\left[{ }^{\circ} \mathrm{C}\right]$ am Standort Göttingen für die Versuchsjahre 2005/2006, 2006/2007 von August bis Juli im Vergleich zum langjährigen Mittel (1960-1990). Datenaufzeichnung vom Deutschen Wetterdienst (DWD), Messstation Göttingen. 

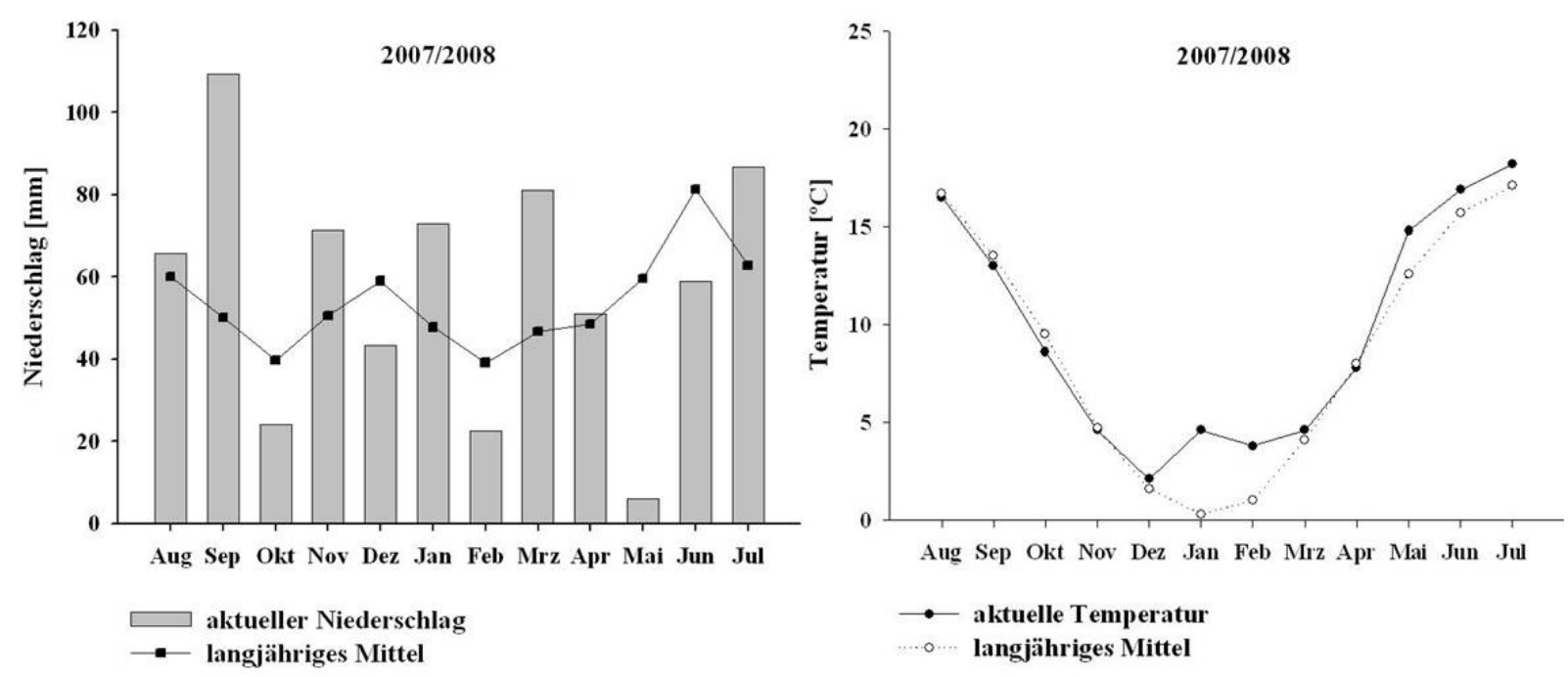

Abb. 9 b: Monatliche Niederschlagsmengen $\left[\sum \mathrm{mm}\right]$ bzw. Lufttemperaturdurchschnittswerte $\left[{ }^{\circ} \mathrm{C}\right]$ am Standort Göttingen für das Versuchsjahr 2007/2008 von August bis Juli im Vergleich zum langjährigen Mittel (1960-1990). Datenaufzeichnung vom Deutschen Wetterdienst (DWD), Messstation Göttingen.

Im Rahmen des Anbaufaktorenversuchs wurden im Versuchsjahr 2007/2008 Messungen von Bodentemperatur, Bodenfeuchte, Lufttemperatur sowie Luftfeuchte durchgeführt, um mögliche Klimaeffekte der Netzabdeckung zu erfassen. In Abb. 10 sind die zwischen dem 28.08. und 09.10.2007 wöchentlich erhobenen Mittelwerte für die Bodentemperatur $\left[{ }^{\circ} \mathrm{C}\right]$ sowie den Bodenwassergehalt [\%] dargestellt. In der Abbildung ist ein Einfluss der Netzabdeckung auf die Bodentemperatur, nicht jedoch auf den Bodenwassergehalt zu erkennen. Im sechswöchigen Untersuchungszeitraum lag die durchschnittliche Bodentemperatur in der mit einem Kulturschutznetz abgedeckten Parzelle im Vergleich zur offenen Parzelle um $1,1^{\circ} \mathrm{C}$ höher. Unterschiede variierten zwischen $1,87^{\circ} \mathrm{C}$ und $0,65^{\circ} \mathrm{C}$.

Die mit Hilfe von im Feld installierten Dataloggern stündlich erhobenen Parameter Lufttemperatur und Lufteuchte zeigten im betreffenden Untersuchungszeitraum keine Unterschiede zwischen den Parzellen mit oder ohne Netzabdeckung (Ø 13,2 ${ }^{\circ} \mathrm{C}, 81 \%$ rel. LF). Um klimatische Unterschiede zwischen Früh- und Spätsaat (Saattermin 14.08. bzw. 31.08.07) erfassen zu können, wurde die Lufttemperatursumme von Aussaat bis Vegetationsende im Herbst, wiedergegeben in Gradtagen $\left(\sum\right.$ Tage $\left.\mathrm{x} \geq 10^{\circ} \mathrm{C}\right)$, berechnet. Die Frühsaatvariante verzeichnete dabei im Vergleich zur Spätsaatvariante eine um 249 Gradtage höhere Temperatursumme. 

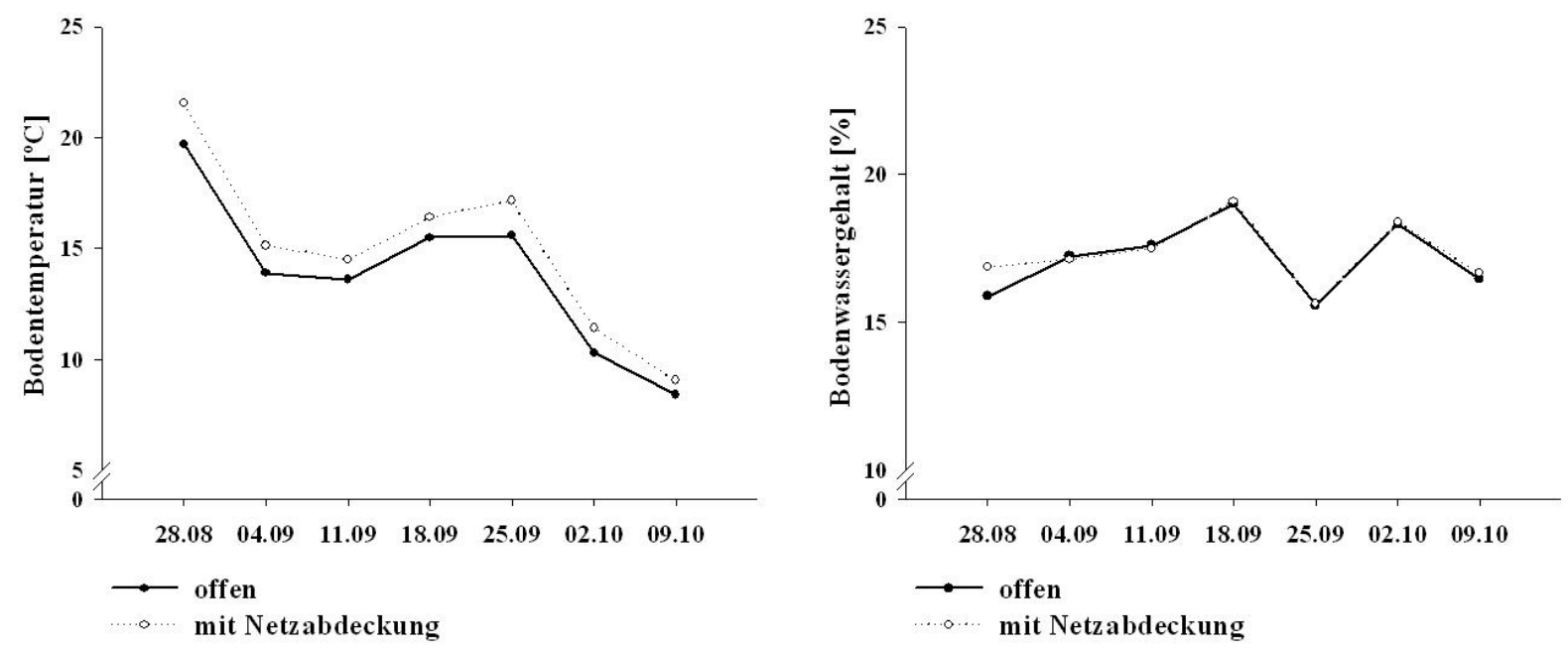

Abb. 10: Bodentemperatur $\left[{ }^{\circ} \mathrm{C}\right]$ sowie Bodenwassergehalt [\%] am Standort Dragoneranger (Göttingen-Weende) im Anbaufaktorenversuch, Versuchsjahr 2007/2008. Dargestellt sind Mittelwerte von zwischen dem 28.08. und 09.10.2007 wöchentlich durchgeführten Messungen $(n=8)$. Zu den unterschiedlichen Terminen wurden aus jeweils einer offenen und einer mit einem Kulturschutznetz abgedeckten Parzelle des frühen Saattermins (14.08.2007, Sorte Trabant) an acht über die Parzelle verteilten Punkten Bodentemperaturmessungen (in $5 \mathrm{~cm}$ Bodentiefe) vorgenommen und im Anschluss Bodenproben aus dem Bereich 0-30 cm Bodentiefe für die Wassergehaltsbestimmung entnommen.

\subsubsection{Erfassung des Befalls von Raps mit der Kleinen Kohlfliege}

\subsubsection{Sortenversuch}

Im Rahmen des Sortenversuchs wurden in den Versuchsjahren 2005 bis 2008 Auswirkungen von Kohlfliegenbefall auf die Infektion und Schadwirkung von $V$. longisporum und $P$. lingam an Raps untersucht. Zur Beantwortung der Frage, ob Larvenfraß der Kohlfliege einen Einfluss auf Verticillium- und Phoma-Befall hat, war es notwendig, unterschiedlich hohen Kohlfliegenbefall zu generieren. Eine Abstufung sollte mit Hilfe von Insektiziden oder Kulturschutznetzen erreicht werden. In Tab. 13-15 sind die Ergebnisse der im Herbst und Frühjahr durchgeführten Kohlfliegenbefallsbonitur für die einzelnen Versuchsjahre aufgeführt. Bei der Darstellung der Befallsparameter wird ausschließlich eine Differenzierung zwischen den einzelnen Insektizid-/Netzvarianten vorgenommen, da zwischen den Inokulationsvarianten keine und zwischen den Sorten (Tab. 14A-16A) nur geringe Unterschiede im Kohlfliegenbefall zu verzeichnen waren.

Im ersten Versuchsjahr 2005/2006 sollte mit Hilfe des Saatgutbehandlungsmittels Elado in Kombination mit dem insektiziden Streumittel Nexion Neu ein im Vergleich zur Saatgutbehandlungsvariante Chinook deutlich geringerer Kohlfliegenbefall, zumindest im Herbst, 
erzielt werden, um anschließend überprüfen $\mathrm{zu}$ können, ob unterschiedlich hoher Kohlfliegenbefall Einfluss auf den Befall von Raps mit $V$. longisporum und P. lingam hat. Ein anhand von Gelbschalenfängen beobachteter starker Kohlfliegenzuflug im Herbst führte $\mathrm{zu}$ einem insgesamt hohen Kohlfliegenbefallsniveau. Zwischen den beiden Insektizidvarianten traten entgegen den Erwartungen nur geringe Unterschiede bei den Parametern fraßgeschädigte Wurzeloberfläche sowie beim Starkbefall auf. Der Anteil durch Kohlfliegen geschädigte Pflanzen zeigte keine Unterschiede auf. Im Frühjahr, nach dem Zuflug der ersten Kohlfliegengeneration, waren nahezu alle untersuchten Wurzeln fraßgeschädigt. Beim Vergleich beider Insektizidvarianten wies Elado + Nexion Neu gegenüber Chinook hier nur noch beim Starkbefall einen leicht reduzierten Wert auf.

Tab. 13: Mittlere Befallshäufigkeit [BH \%], prozentual geschädigte Wurzeloberfläche [GW \%] sowie Anteil stark befallener Pflanzen mit GW $\geq 50 \%$ [SB \%] von Winterraps mit der Kleinen Kohlfliege nach visueller Bonitur im Herbst (November) 2005 bzw. Frühjahr (Juni) 2006 am Standort Weende (Schlag Große Breite) bei Göttingen. Dargestellt sind die über alle Sorten (Laser, Lion, Caiman, Oase) und Inokulationsvarianten (Kontrolle, Verticillium-Inokulation, Phoma-Herbstinokulation) gemittelten Boniturwerte (je Variante 48 Parzellenmittelwerte bestehend aus jeweils 25 Pflanzen). Unterschiedliche Buchstaben kennzeichnen statistisch signifikante Differenzen zwischen den Insektizidvarianten im Herbst bzw. Frühjahr (LSD p $\leq 0,05)$.

\begin{tabular}{|c|c|c|c|c|c|c|}
\hline \multirow[b]{2}{*}{ Insektizidvarianten ${ }^{1)}$} & \multicolumn{3}{|c|}{ Herbst } & \multicolumn{3}{|c|}{ Frühjahr } \\
\hline & $\mathrm{BH}[\%]$ & $\mathrm{GW}[\%]$ & $\mathrm{SB}[\%]$ & $\mathrm{BH}[\%]$ & GW [\%] & $\mathrm{SB}[\%]$ \\
\hline Chinook & $70,50 \mathrm{a}$ & $25,56 \mathrm{~B}$ & $18,48 \beta$ & $98,58 \mathrm{a}$ & $37,88 \mathrm{~A}$ & $25,17 \beta$ \\
\hline Elado + Nexion Neu & $67,75 \mathrm{a}$ & $21,96 \mathrm{~A}$ & $13,31 \alpha$ & $98,50 \mathrm{a}$ & $36,37 \mathrm{~A}$ & $22,58 \alpha$ \\
\hline GD LSD $p \leq 0,05$ & 4,04 n.s. & 2,15 & 3,09 & 1,34 n.s. & 2,4 n.s. & 2,31 \\
\hline
\end{tabular}

1) Insektizidvarianten: Saatgutbehandlung mit Chinook bzw. Saatgutbehandlung mit Elado + Austreuen des insektiziden Granulats Nexion Neu nach der Saat $\left(10 \mathrm{~g} / \mathrm{m}^{2}\right)$.

Nachdem sich das insektizide Saatgutbehandlungsmittel Elado (+ Nexion Neu) im Versuchsjahr 2005/2006 als unzureichend erwiesen hatte, den Kohlfliegenbefall abzustufen, wurde im Versuchsjahr 2006/2007 versucht, Kohlfliegenbefall mit Kulturschutznetzen gezielt auszuschließen. Neben einer Variante ohne Netzabdeckung gab es eine alleinige Herbstabdeckung sowie eine kombinierte Herbst- und Frühjahrsabdeckung. Die Ergebnisse der Kohlfliegenbefallsbonitur sind in Tab. 14 aufgeführt. Nach einem starken Kohlfliegenzuflug im Herbst wiesen Varianten ohne Netz hohen Kohlfliegenbefall, mit Kulturschutznetzen abgedeckte Varianten hingegen nur sehr geringen Kohlfliegenbefall auf. Nach dem Zuflug der ersten Kohlfliegengeneration im Frühjahr zeigten nahezu alle untersuchten Wurzeln, die aus den nicht abgedeckten Varianten stammten, Kohlfliegenbefall auf. Mit 
Kulturschutznetzen konnte die vorgesehene Abstufung des Kohlfliegenbefalls (Herbst + Frühjahrsbefall, Frühjahrsbefall, Befallsausschluss) sehr gut erreicht werden.

Tab. 14: Mittlere Befallshäufigkeit [BH \%], prozentual geschädigte Wurzeloberfläche [GW \%] sowie Anteil stark befallener Pflanzen mit GW $\geq 50 \%$ [SB \%] von Winterraps mit der Kleinen Kohlfliege nach visueller Bonitur im Herbst (November) 2006 bzw. Frühjahr (Juni) 2007 am Standort Weende (Schlag Große Lage) bei Göttingen. Dargestellt sind die über alle Sorten (Laser, Lion, Caiman, Viking) und Inokulationsvarianten (Kontrolle, Verticillium-Inokulation, Phoma-Herbstinokulation, Phoma-Frühjahrsinokulation) gemittelten Boniturwerte (je Variante 40 Parzellenmittelwerte bestehend aus jeweils 25 Pflanzen). Unterschiedliche Buchstaben kennzeichnen statistisch signifikante Differenzen zwischen den Netzabdeckungsvarianten im Herbst bzw. Frühjahr (LSD p $\leq$ $0,05)$.

\begin{tabular}{lcccccccc}
\hline & \multicolumn{3}{c}{ Herbst } & & \multicolumn{3}{c}{ Frühjahr } \\
\cline { 2 - 4 } \cline { 8 - 10 } Netzvarianten ${ }^{1)}$ & BH [\%] & GW [\%] & SB [\%] & & BH [\%] & GW [\%] & SB [\%] \\
\hline ohne Netz & $68,97 \mathrm{~b}$ & $25,59 \mathrm{~B}$ & $16,98 \beta$ & & $98,23 \mathrm{~b}$ & $35,24 \mathrm{~B}$ & $16,48 \beta$ \\
Netz im Herbst & $7,34 \mathrm{a}$ & $1,87 \mathrm{~A}$ & $0,41 \alpha$ & & $97,85 \mathrm{~b}$ & $33,53 \mathrm{~B}$ & $16,02 \beta$ \\
Netz im Herbst + Frühjahr & $6,84 \mathrm{a}$ & $1,50 \mathrm{~A}$ & $0,30 \alpha$ & & $5,80 \mathrm{a}$ & $1,18 \mathrm{a}$ & $0,10 \alpha$ \\
\hline GD LSD p $\leq 0,05$ & 3,6 & 1,58 & 2,36 & & 2,51 & 2,35 & 4,56 \\
\hline
\end{tabular}

1) Netzvarianten: ohne Netz; Netz im Herbst: Auflage eines Kulturschutznetzes von Mitte August bis Mitte Oktober 2006; Netz im Herbst + Frühjahr: Netz im Herbst + Netzkäfigkonstruktion von April bis Mitte Juni 2007.

Im Versuchsjahr 2007/2008 erfolgte die Abstufung des Kohlfliegenbefalls sowohl durch Insektizidbehandlungen, als auch durch Kulturschutznetze. Mit der Insektizidvariante Oftanol T (+ Nexion Neu) sollte, zumindest im Herbst, ein im Vergleich zur Chinook-Variante deutlich geringerer Kohlfliegenbefall erzielt werden. In Übereinstimmung mit dem Versuchsjahr 2006/2007 sah der Versuch eine weitere Variante vor, bei der Kohlfliegenbefall im Herbst mit Hilfe von Kulturschutznetzen ausgeschlossen werden sollte. Die Ergebnisse der Kohlfliegenbefallsbonitur sind in Tab. 15 zusammengefasst. Kohlfliegenzuflug und Befallsniveau lagen im Vergleich zu den Vorjahren auf einem etwas niedrigeren Niveau. Mit Hilfe von Oftanol T + Nexion Neu konnten alle Befallsparameter gegenüber Chinook um etwa 50\% gesenkt werden. Die mit Kulturschutznetzen abgedeckten Parzellen wiesen erwartungsgemäß den geringsten Kohlfliegenbefall auf. Der Befall im Frühjahr war nicht mit der Befallssituation der Vorjahre zu vergleichen, wo nahezu alle Wurzeln nicht abgedeckter Parzellen durch Kohlfliegen geschädigt waren. Trotz eines vergleichbar starken Zufluges der Kohlfliege im Mai 2008 kam es nur zu einer geringen Zunahme der Befallswerte gegenüber der Situation im Herbst. Die mit dem Kohlfliegenflug im Mai koinzidierende sechs Wochen anhaltende Trockenperiode kann hier als möglicher Grund für 
eine hohe Eimortalität und einen demzufolge geringen Larvenfraß angeführt werden. In der Gesamtbetrachtung aller Versuchsjahre war die erzielte Abstufung des Kohlfliegenbefalls zur Untersuchung von Interaktionseffekten im ersten Versuchsjahr unzureichend, in den beiden letzten Versuchsjahren hingegen zufriedenstellend.

Tab. 15: Mittlere Befallshäufigkeit [BH \%], prozentual geschädigte Wurzeloberfläche [GW \%] sowie Anteil stark befallener Pflanzen mit GW $\geq 50 \%$ [SB \%] von Winterraps mit der Kleinen Kohlfliege nach visueller Bonitur im Herbst (November) 2007 bzw. Frühjahr (Juni) 2008 am Standort Weende (Schlag Dragoneranger) bei Göttingen. Dargestellt sind die über alle Sorten (Laser, Lion, Caiman, NK Fair, Aviso) und Inokulationsvarianten (Kontrolle, Verticillium-Inokulation) gemittelten Boniturwerte (je Variante 40 Parzellenmittelwerte bestehend aus jeweils 25 Pflanzen). Unterschiedliche Buchstaben kennzeichnen statistisch signifikante Differenzen zwischen den Netz-/Insektizidvarianten im Herbst bzw. Frühjahr (LSD p $\leq 0,05)$.

\begin{tabular}{lcccccccc}
\hline & \multicolumn{3}{c}{ Herbst } & & \multicolumn{3}{c}{ Frühjahr } \\
\cline { 2 - 4 } \cline { 7 - 9 } Netz-/Insektizidvarianten ${ }^{1)}$ & BH [\%] & GW [\%] & SB [\%] & & BH [\%] & GW [\%] & SB [\%] \\
\hline ohne Netz/Chinook & $61,70 \mathrm{c}$ & $18,56 \mathrm{C}$ & $12,87 \beta$ & & $62,59 \mathrm{c}$ & $20,90 \mathrm{C}$ & $11,20 \beta$ \\
ohne Netz/Oftanol T + Nexion Neu & $32,34 \mathrm{~b}$ & $8,36 \mathrm{~B}$ & $6,40 \alpha$ & & $42,33 \mathrm{~b}$ & $11,81 \mathrm{~B}$ & $7,12 \alpha$ \\
Netz im Herbst/Chinook & $8,33 \mathrm{a}$ & $1,47 \mathrm{~A}$ & $1,23 \alpha$ & & $26,66 \mathrm{a}$ & $7,88 \mathrm{~A}$ & $1,67 \alpha$ \\
\hline GD LSD p $\leq 0,05$ & 5,99 & 2,61 & 3,13 & & 5,61 & 2,47 & 4,17 \\
\hline
\end{tabular}

1) Netz/Insektizidvarianten = ohne Netz/Chinook: Saatgutbehandlung mit Chinook); ohne Netz/Oftanol $\mathrm{T}+$ Nexion Neu: Saatgutbehandlung mit Oftanol T + Austreuen des insektiziden Granulats Nexion Neu nach der Saat $\left(10 \mathrm{~g} / \mathrm{m}^{2}\right)$; Netz im Herbst/Chinook: Auflage eines Kulturschutznetzes von Mitte August bis Mitte Oktober 2007/Saatgutbehandlung mit Chinook.

\subsubsection{Anbaufaktorenversuch}

Im Rahmen des Anbaufaktorenversuchs wurden in den Versuchsjahren 2005 bis 2008 Auswirkungen unterschiedlicher Bodenbearbeitung sowie Saattermine auf Kohlfliegen- und Verticillium-Befall untersucht. In den ersten beiden Versuchsjahren wurden die beiden Versuchsfaktoren Bodenbearbeitung (Pflug bzw. Grubber) und Saattermin (früh bzw. spät) auf einer einheitlich mit Verticillium-befallenem Stoppelmaterial inokulierten Versuchsfläche variiert. Die Ergebnisse der im Herbst und Frühjahr durchgeführten Kohlfliegenbefallsbonitur sind für das Versuchsjahr 2005/2006 in Tab. 16 dargestellt. Bei dem durch die dritte Kohlfliegengeneration verursachten Wurzelfraß im Herbst zeigte die früh gesäte Pflugvariante eine signifikant höhere Befallshäufigkeit, Fraßschädigung sowie Starkbefallswerte als die übrigen Varianten. Der im Frühjahr bonitierte Kohlfliegenbefall, der sich aus dem Herbst- und Frühjahrsbefall zusammensetzt, wies geringere Unterschiede zwischen den Varianten im Vergleich zur Herbstsituation auf, wobei sich auch hier nach wie vor die 
früh gesäte Pflugvariante bei der prozentual geschädigten Wurzeloberfläche und dem Starkbefall von den anderen Varianten absetzte.

Tab. 16: Mittlere Befallshäufigkeit [BH \%], prozentual geschädigte Wurzeloberfläche [GW \%] sowie Anteil stark befallener Pflanzen mit GW $\geq 50 \%$ [SB \%] von Winterraps (Sorte Oase) mit der Kleinen Kohlfliege nach visueller Bonitur im Herbst (November) 2005 bzw. Frühjahr (Juni) 2006 am Standort Weende (Schlag Große Breite) bei Göttingen. Je Variante wurden 100 Pflanzen untersucht. Unterschiedliche Buchstaben kennzeichnen statistisch signifikante Differenzen zwischen den Bodenbearbeitungs-/Saatterminvarianten ${ }^{1)}$ im Herbst bzw. Frühjahr (LSD $\left.p \leq 0,05\right)$.

\begin{tabular}{lcccccccc}
\hline & \multicolumn{3}{c}{ Herbst } & & \multicolumn{3}{c}{ Frühjahr } \\
\cline { 2 - 4 } \cline { 8 - 10 } Varianten & BH [\%] & GW [\%] & SB [\%] & & BH [\%] & GW [\%] & SB [\%] \\
\hline Pflug/ Frühsaat & $71 \mathrm{~b}$ & $21,4 \mathrm{~B}$ & $12 \beta$ & & $88 \mathrm{~b}$ & $34,6 \mathrm{C}$ & $34 \gamma$ \\
Pflug/ Spätsaat & $21 \mathrm{a}$ & $3,7 \mathrm{~A}$ & $0 \alpha$ & & $77 \mathrm{ab}$ & $23,3 \mathrm{~B}$ & $17 \beta$ \\
Grubber/ Frühsaat & $30 \mathrm{a}$ & $5,6 \mathrm{~A}$ & $0 \alpha$ & & $74 \mathrm{a}$ & $20,7 \mathrm{AB}$ & $14 \alpha \beta$ \\
Grubber/ Spätsaat & $20 \mathrm{a}$ & $2,8 \mathrm{~A}$ & $0 \alpha$ & & $70 \mathrm{a}$ & $18,9 \mathrm{~A}$ & $9 \alpha$ \\
\hline GD LSD p $\leq 0,05$ & 13,13 & 3,5 & 2,95 & & 12,38 & 3,82 & 7,86 \\
\hline
\end{tabular}

1) Bodenbearbeitung: Pflug bzw. Grubber; Saattermine: 12.08. bzw. 25.08.2005

Im zweiten Versuchsjahr (2006/2007), in dem der Anbaufaktorenversuch auf einem ca. 10 km von Göttingen entfernten Standort (Angerstein) angelegt worden war, wiesen die früh gesäten Varianten geringen, die später gesäten Varianten kaum Kohlfliegenbefall auf (Tab. 17). Nach dem Zuflug der ersten Generation im Frühjahr nahm der Anteil durch Kohlfliegen geschädigte Pflanzen deutlich zu, wobei die später gesäten Varianten im Vergleich zu den früh gesäten Varianten hierbei höheren Befall verzeichneten. Ein bei den Spätsaatvarianten zu beobachtender lückiger Bestand, der eine Bestandesdichte von etwa 15 Pflanzen $/ \mathrm{m}^{2}$ (bei Frühsaat etwa 50 Pflanzen $/ \mathrm{m}^{2}$ ) aufwies, führte zu vergleichsweise kräftigen Einzelpflanzen, wodurch die Eiablage der Kohlfliege vermutlich gefördert wurde. 
Tab. 17: Mittlere Befallshäufigkeit [BH \%], prozentual geschädigte Wurzeloberfläche [GW \%] sowie Anteil stark befallener Pflanzen mit GW $\geq 50 \%$ [SB \%] von Winterraps (Sorte Smart) mit der Kleinen Kohlfliege nach visueller Bonitur im Herbst (November) 2006 bzw. Frühjahr (Juni) 2007 am Standort Angerstein bei Göttingen. Je Variante wurden 100 Pflanzen untersucht. Unterschiedliche Buchstaben kennzeichnen statistisch signifikante Differenzen zwischen den Bodenbearbeitungs-/ Saatterminvarianten im Herbst bzw. Frühjahr (LSD p $\leq 0,05)$.

\begin{tabular}{lcccccccc}
\hline & \multicolumn{3}{c}{ Herbst } & & \multicolumn{3}{c}{ Frühjahr } \\
\cline { 2 - 4 } \cline { 7 - 9 } Varianten ${ }^{1)}$ & BH [\%] & GW [\%] & SB [\%] & & BH [\%] & GW [\%] & SB [\%] \\
\hline Pflug/ Frühsaat & $24 \mathrm{~b}$ & $7,8 \mathrm{~B}$ & $3,5 \beta$ & & $60 \mathrm{a}$ & $17,1 \mathrm{~A}$ & $4 \alpha$ \\
Pflug/ Spätsaat & $6 \mathrm{a}$ & $1,0 \mathrm{~A}$ & $0 \alpha$ & & $83 \mathrm{~b}$ & $23,9 \mathrm{~A}$ & $3 \alpha$ \\
Grubber/ Frühsaat & $16 \mathrm{ab}$ & $5,1 \mathrm{~B}$ & $1 \alpha \beta$ & & $73 \mathrm{ab}$ & $20,4 \mathrm{~A}$ & $2 \alpha$ \\
Grubber/ Spätsaat & $4 \mathrm{a}$ & $1,2 \mathrm{~A}$ & $1 \alpha \beta$ & & $83 \mathrm{~b}$ & $24,6 \mathrm{~A}$ & $7,5 \alpha$ \\
\hline GD LSD p $\leq 0,05$ & 12,52 & 3,93 & 2,85 & & 19,83 & 5,4 n.s. & 6,2 n.s. \\
\hline
\end{tabular}

1) Bodenbearbeitung: Pflug bzw. Grubber; Saattermine: 17. 08. bzw. 01.09.2006

Im dritten Versuchsjahr (2007/2008) sollten Effekte variierender Saattermine auf den Befall von Raps mit $V$. longisporum bei unterschiedlich hohem Kohlfliegenbefall untersucht werden, um eine differenzierte Risikoabschätzung bzgl. $V$. longisporum abgeben zu können. Der Faktor Bodenbearbeitung wurde hier nicht mehr variiert (nur Pflugsaat). Der Versuch sah verschiedene Insektizid-/Netzvarianten vor, um Effekte von Saatzeit und Kohlfliegenbefall auf $V$. longisporum sowohl in Kombination, als auch einzeln betrachten zu können. Die im Rahmen von Bonituren im Herbst und Frühjahr erhobenen Kohlfliegenbefallsparameter sind in Tab. 18 angegeben. Früh gesäte Varianten (14.08.2007) ohne Netzabdeckung zeigten im Vergleich zu den später gesäten Varianten (31.08.2007) deutlich höheren Kohlfliegenbefall im Herbst. In Übereinstimmung mit dem Sortenversuch, der im Versuchsjahr 2007/2008 an den Anbaufaktorenversuch angrenzte, führte der Einsatz von Oftanol T gegenüber Chinook zu einer signifikanten Verringerung des Kohlfliegenbefalls. Die während des Herbstzufluges mit Kulturschutznetzen abgedeckten Parzellen wiesen erwartungsgemäß nur sehr geringen Kohlfliegenbefall auf. Eine zweiwöchige Entfernung der Netzauflage in der Variante „Netz im Herbst (teilweise offen)“ führte zu einem Kohlfliegenbefall, der den Oftanol TVarianten entsprach.

Im Frühjahr kam es wie beim Sortenversuch nur zu einer geringen Zunahme der Befallswerte, was möglicherweise auf eine durch Trockenheit bedingte höhere Eimortalität zurückzuführen ist. Zusammenfassend lässt sich für alle drei Versuchsjahre feststellen, dass eine frühe Aussaat in der ersten Augusthälfte Kohlfliegenbefall im Herbst begünstigt. Dieser Effekt wurde durch eine Grundbodenbearbeitung mit dem Pflug gegenüber einer Grubber- 
bearbeitung noch verstärkt. Eine für die Untersuchung von möglichen Interaktionseffekten zwischen der Kohlfliege und $V$. longisporum notwendige Abstufung des Kohlfliegenbefalls konnte in zwei von drei Versuchsjahren erreicht werden.

Tab. 18: Mittlere Befallshäufigkeit [BH \%], prozentual geschädigte Wurzeloberfläche [GW \%] sowie Anteil stark befallener Pflanzen mit GW $\geq 50 \%$ [SB \%] von Winterraps (Sorte Trabant) mit der Kleinen Kohlfliege nach visueller Bonitur im Herbst (November) 2007 bzw. Frühjahr (Juni) 2008 am Standort Weende (Schlag Dragoneranger) bei Göttingen. Dargestellt sind die über beide Inokulationsvarianten (Kontrolle, Verticillium-Inokulation) gemittelten Boniturwerte (je Variante 8 Parzellenmittelwerte bestehend aus jeweils 25 Pflanzen). Unterschiedliche Buchstaben kennzeichnen statistisch signifikante Differenzen zwischen den Netz-/Insektizidvarianten bei Frühsaat bzw. Spätsaat. (+/-) zeigen signifikante Unterschiede zwischen Frühsaat (14.08.07) und Spätsaat (31.08.07) bei den jeweiligen Netz-/Insektizidvarianten an (LSD $p \leq 0,05)$.

\begin{tabular}{|c|c|c|c|c|c|c|}
\hline \multirow{2}{*}{$\begin{array}{l}\text { Herbstbonitur } \\
\text { Netz-/ Insektizidvarianten }{ }^{1)}\end{array}$} & \multicolumn{2}{|c|}{$\mathrm{BH}[\%]$} & \multicolumn{2}{|c|}{$\mathrm{GW}[\%]$} & \multicolumn{2}{|c|}{ SB [\%] } \\
\hline & Frühsaat & Spätsaat & Frühsaat & Spätsaat & Frühsaat & Spätsaat \\
\hline ohne Netz/Chinook & $61,5 \mathrm{~d}+$ & $20,8 \mathrm{~B}-$ & $20,7 \mathrm{~d}+$ & $4,1 \mathrm{~B}-$ & $12,5 \mathrm{c}+$ & $0,8 \mathrm{~A}-$ \\
\hline ohne Netz/ Oftanol T & $45,0 \mathrm{c}+$ & $7,5 \mathrm{~A}-$ & $14,8 \mathrm{~cd}+$ & $1,0 \mathrm{~A}-$ & $2,5 \mathrm{ab}$ & $0 \mathrm{~A}$ \\
\hline ohne Netz/ Oftanol T + Nexion Neu & $34,0 \mathrm{bc}+$ & $7,5 \mathrm{~A}-$ & $10,5 \mathrm{bc}+$ & $1,1 \mathrm{~A}-$ & $2,5 \mathrm{ab}$ & $0 \mathrm{~A}$ \\
\hline Netz im Herbst/ Chinook & $12,5 \mathrm{a}+$ & $10,0 \mathrm{~A}-$ & $0,9 \mathrm{a}$ & $0,9 \mathrm{~A}$ & $0,0 \mathrm{a}$ & $0 \mathrm{~A}$ \\
\hline Netz im Herbst (teilw. offen)/ Chinook & $38,0 \mathrm{bc}+$ & $10,8 \mathrm{~A}-$ & $16,7 \mathrm{~cd}+$ & $1,3 \mathrm{~A}-$ & $8,3 \mathrm{bc}+$ & $0,8 \mathrm{~A}-$ \\
\hline Netz im Herbst + Frühjahr/ Chinook & $12,5 \mathrm{a}$ & $10,8 \mathrm{~A}$ & $0,9 \mathrm{a}$ & $1,5 \mathrm{~A}$ & $0,0 \mathrm{a}$ & $0 \mathrm{~A}$ \\
\hline GD LSD $p \leq 0,05$ & 13,81 & 9,31 & 6,28 & 1,67 & 5,95 & 1,37 n. s. \\
\hline \multirow{2}{*}{$\begin{array}{l}\text { Frühjahrsbonitur } \\
\text { Netz-/ Insektizidvarianten }{ }^{1)}\end{array}$} & \multicolumn{2}{|c|}{$\mathrm{BH}[\%]$} & \multicolumn{2}{|c|}{ GW [\%] } & \multicolumn{2}{|c|}{$\mathrm{SB}[\%]$} \\
\hline & Frühsaat & Spätsaat & Frühsaat & Spätsaat & Frühsaat & Spätsaat \\
\hline ohne Netz/ Chinook & $64,2 \mathrm{e}+$ & $25,8 \mathrm{~B}-$ & $29,2 \mathrm{c}+$ & $8,1 \mathrm{~B}-$ & $18,3 \mathrm{c}+$ & $1,7 \mathrm{~A}-$ \\
\hline ohne Netz/ Oftanol T & $48,2 \mathrm{~cd}+$ & $24,2 \mathrm{~B}-$ & $20,2 b+$ & $5,6 \mathrm{AB}-$ & $12,5 \mathrm{bc}+$ & $0 \mathrm{~A}-$ \\
\hline ohne Netz/ Oftanol T + Nexion Neu & $36,5 \mathrm{bc}+$ & $22,9 \mathrm{~B}-$ & $16,9 b+$ & $5,5 \mathrm{AB}-$ & $7,5 \mathrm{ab}$ & $1 \mathrm{~A}$ \\
\hline Netz im Herbst/ Chinook & $25,8 \mathrm{~b}$ & $24,8 \mathrm{~B}$ & $7,4 \mathrm{a}$ & $8,3 \mathrm{~B}$ & $0,0 \mathrm{a}$ & $1,9 \mathrm{~A}$ \\
\hline Netz im Herbst (teilw. offen)/ Chinook & $40,8 \mathrm{c}+$ & $25,8 \mathrm{~B}-$ & $20,2 b+$ & $7,8 \mathrm{~B}-$ & $14,7 \mathrm{c}+$ & $2,5 \mathrm{~A}-$ \\
\hline Netz im Herbst + Frühjahr/ Chinook & $10,8 \mathrm{a}$ & $9,2 \mathrm{~A}$ & $2,3 \mathrm{a}$ & $2,5 \mathrm{~A}$ & $1,0 \mathrm{a}$ & $0 \mathrm{~A}$ \\
\hline GD LSD $p \leq 0,05$ & 13,45 & 11,81 & 5,73 & 4,21 & 6,3 & 3,73 n.s. \\
\hline
\end{tabular}

1) Netz/Insektizidvarianten: ohne Netz/Chinook (Saatgutbehandlung mit Chinook); ohne Netz/Oftanol T (Saatgutbehandlung mit Oftanol T); ohne Netz/Oftanol T + Nexion Neu (Saatgutbehandlung mit Oftanol T + Austreuen des insektiziden Granulats Nexion Neu nach der Saat $\left(10 \mathrm{~g} / \mathrm{m}^{2}\right)$; Netz im Herbst/Chinook (Auflage eines Kulturschutznetzes von Mitte August bis Mitte Oktober 2007/Saatgutbehandlung mit Chinook); Netz im Herbst (teilweise offen)/Chinook (Auflage eines Kulturschutznetzes von Mitte August bis Anfang September und Mitte September bis Mitte Oktober 2007)/Saatgutbehandlung mit Chinook); Netz im Herbst + Frühjahr/Chinook (Netz im Herbst + Netzkäfigkonstruktion von Ende April bis Mitte Juni 2008/ Saatgutbehandlung mit Chinook). 


\subsubsection{Erfassung des Befalls von Raps mit V. longisporum}

\subsubsection{Sortenversuch}

In den Feldversuchen erfolgte die visuelle Erfassung des Verticillium-Befalls in Form einer Stoppelbonitur nach der Ernte. Bei der folgenden Darstellung der Befallsparameter fanden ausschließlich Varianten Berücksichtigung, in denen vor der Aussaat eine Bodeninokulation mit Verticillium-befallenem Stoppelmaterial durchgeführt worden war. In den Kontrollparzellen lag die Befallshäufigkeit i. d. R. nicht über $20 \%$, so dass auf eine vergleichende Darstellung verzichtet wurde. Im ersten Versuchsjahr 2005/2006 zeigten sich erste Symptome von $V$. longisporum erst relativ spät in der Vegetationsperiode. Mit beginnender Abreife des Winterrapses konnten vereinzelt Pflanzen mit halbseitiger Stängelverbräunung beobachtet werden, die in Wurzel, Stängelmark und/oder unter der Epidermis MS aufwiesen. Im weiteren Verlauf der Abreife nahm der Anteil symptomatischer Rapspflanzen kontinuierlich zu. In Abb. 11 sind die im Rahmen der Stoppelbonitur ermittelten Befallshäufigkeiten (BH) sowie Befallswerte (BW) dargestellt. Bei moderatem Befallsniveau zeigten die Sorten Laser und Caiman signifikant höhere Befallsparameter im Vergleich zu Lion und Oase auf. Beim Vergleich beider Insektizidvarianten waren keine Befallsunterschiede festzustellen. Mögliche Effekte von Kohlfliegenbefall auf $V$. longisporum ließen sich vor dem Hintergrund eines indifferenten Kohlfliegenbefalls (vgl. 3.1.2.1) nicht ableiten. 

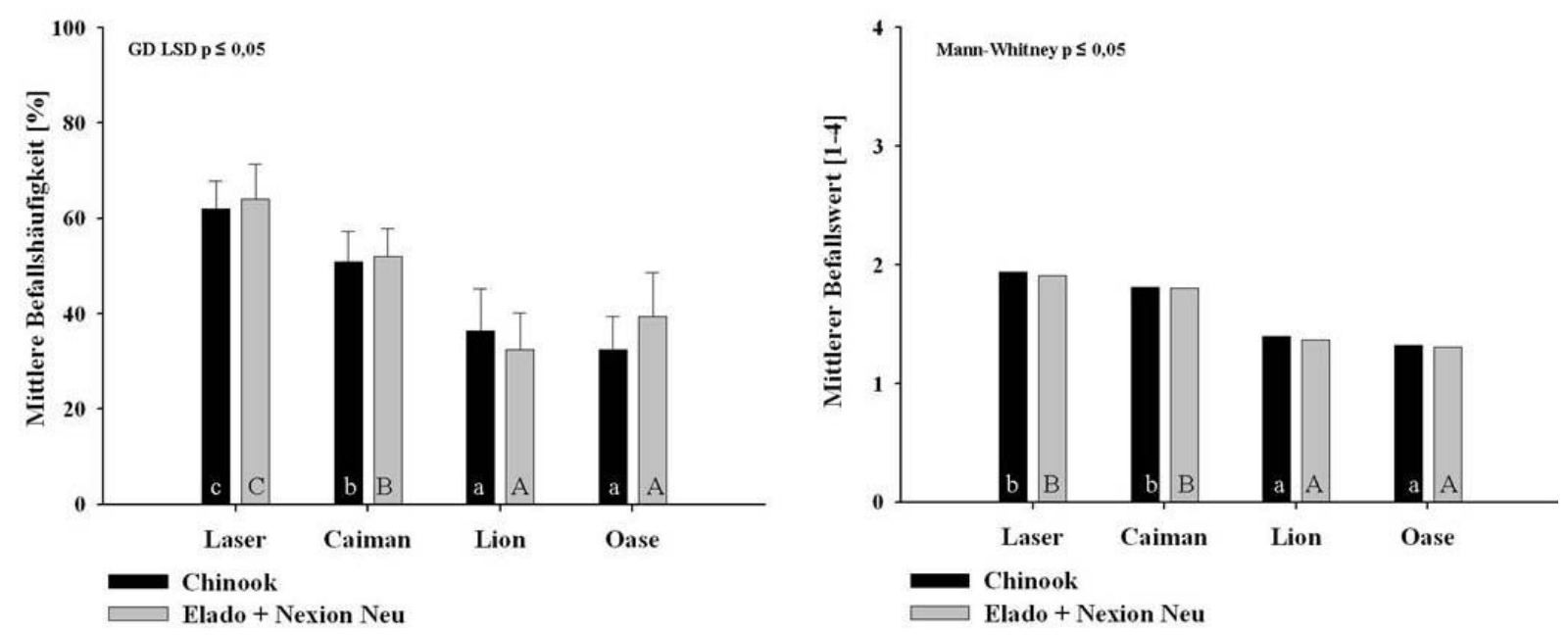

Abb. 11: Auftreten von $V$. longisporum an Winterraps bei verschiedenen Sorten am Standort Weende (Schlag Große Breite) nach visueller Bonitur in BBCH 92; Versuchsjahr 2005/2006. Aufgeführt sind mittlere Befallshäufigkeiten [\%] sowie mittlere Befallswerte [1 (kein Befall) - 4 (sehr starker Befall)] von Varianten mit Verticillium-Inokulation ${ }^{1)}$ ( $\mathrm{n}=4$ bestehend aus jeweils 50 Pfanzen). Unterschiedliche Buchstaben kennzeichnen statistisch signifikante Befallshäufigkeits- (LSD p $\leq 0,05$ ) bzw. Befallswertunterschiede (Mann-Whitney Median-Test $\mathrm{p} \leq 0,05$ ) zwischen den Sorten bei den jeweiligen Insektizidvarianten (Saatgutbehandlung mit Chinook bzw. Saatgutbehandlung mit Elado sowie zusätzliches Ausstreuen von Nexion Neu $\left(10 \mathrm{~g} / \mathrm{m}^{2}\right)$ nach der Saat. 1) Vorsaat-Bodeninokulation mit stark Verticillium-befallenem Stoppelmaterial in Höhe von $15 \mathrm{~g} / \mathrm{m}^{2}$.

Im zweiten Versuchsjahr 2006/2007, welches durch eine außergewöhnlich milde Witterung geprägt war (vgl. 3.1.1), zeigten sich erste Symptome von $V$. longisporum bereits früh in der Vegetationsperiode. Ab Anfang Juni (BBCH 79) konnten Pflanzen mit halbseitiger Stängelverbräunung beobachtet werden, die MS aufwiesen. Da dem Zeitpunkt des Symptomauftretens möglicherweise eine entscheidende Bedeutung für die Schadwirkung von $V$. longisporum zukommt, wurde zusätzlich zur visuellen Bonitur in $\mathrm{BBCH} 92$ bereits vier Wochen vor der Ernte (BBCH 85), im Rahmen der Kohlfliegen- bzw. Phoma-Bonitur eine Befallsfeststellung vorgenommen (Abb. 12). Die Verticillium-anfällige Sorte Laser wies hierbei deutlich höheren Verticillium- Befall als die moderat anfällige Sorte Lion auf. 


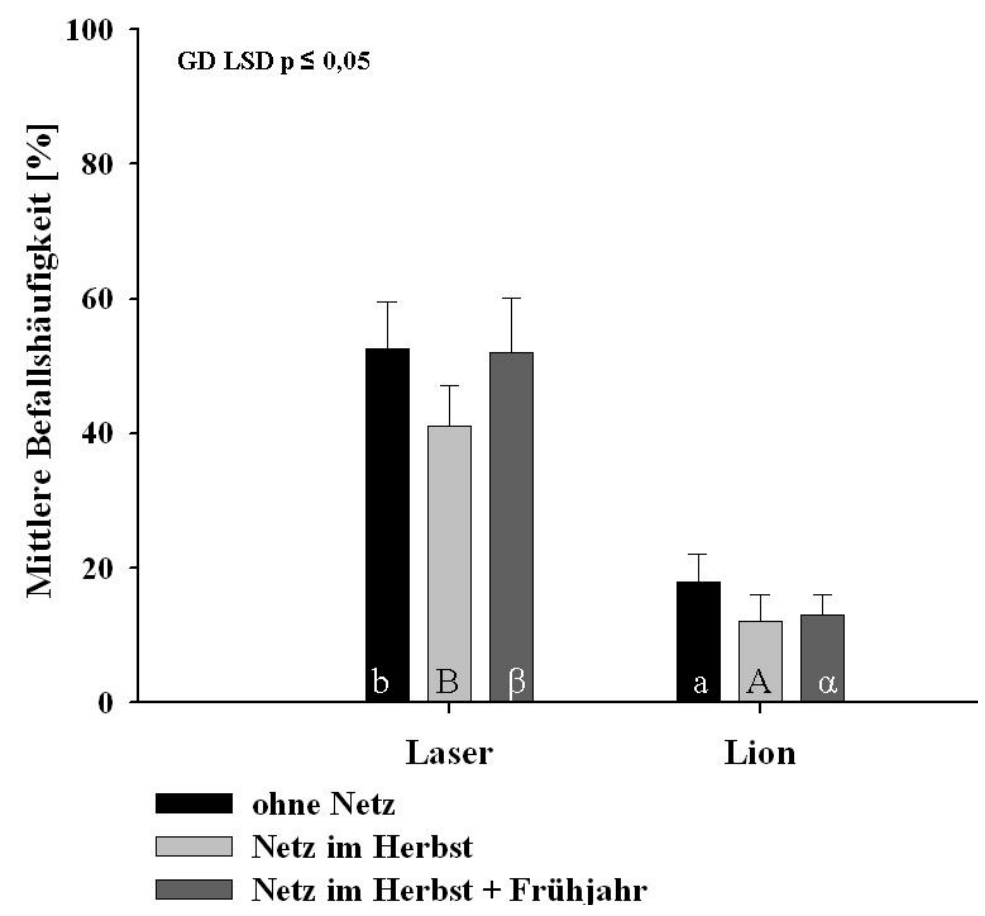

Abb. 12: Auftreten von $V$. longisporum an Winterraps der Sorten Laser und Lion am Standort Weende (Schlag Große Lage) nach visueller Bonitur zu BBCH 85; Versuchsjahr 2006/2007. Aufgeführt sind mittlere Befallshäufigkeiten [\%] von Varianten mit Verticillium-Inokulation ${ }^{1)}(\mathrm{n}=4$ bestehend aus jeweils 25 Pfanzen). Unterschiedliche Buchstaben kennzeichnen statistisch signifikante Befallshäufigkeitsunterschiede (LSD $\mathrm{p} \leq 0,05$ ) zwischen den Sorten bei den jeweiligen Netzabdeckungsvarianten. 1) Vorsaat-Bodeninokulation mit stark Verticillium-befallenem Stoppelmaterial in Höhe von $15 \mathrm{~g} / \mathrm{m}^{2}$ ).

Bei beiden Sorten kam es bis zur Ernte zu einer deutlichen Zunahme symptomatischer Pflanzen, was sich in den Befallsparametern der Stoppelbonitur widerspiegelt (Abb. 13). Ein Effekt der Netzabdeckungsvarianten (Kohlfliegenbefall) auf $V$. longisporum war bei Lion, nicht jedoch bei Laser auszumachen. Die nicht abgedeckte, bereits im Herbst stark durch Kohlfliegen geschädigte Variante der Sorte Lion verzeichnete zur Ernte einen signifikant höheren, als auch stärkeren Verticillium-Befall im Vergleich zu den Netzvarianten, bei denen Kohlfliegenbefall im Herbst nahezu ausgeschlossen werden konnte. Signifikante Befallsunterschiede zwischen Laser und Lion waren im BBCH-Stadium 92 nur noch bei den Varianten mit Netzabdeckung festzustellen. Die Tatsache, dass eine Verhinderung des Zufluges der ersten Generation im Frühjahr in der Variante „Netz im Herbst + Frühjahr“ keine weitere Reduktion des Verticillium-Befalls gegenüber der Variante „Netz im Herbst“ herbeiführen konnte, deutet darauf hin, dass der Herbstgeneration der Kohlfliege in der Befallsförderung von $V$. longisporum die größte Bedeutung beizumessen ist. 

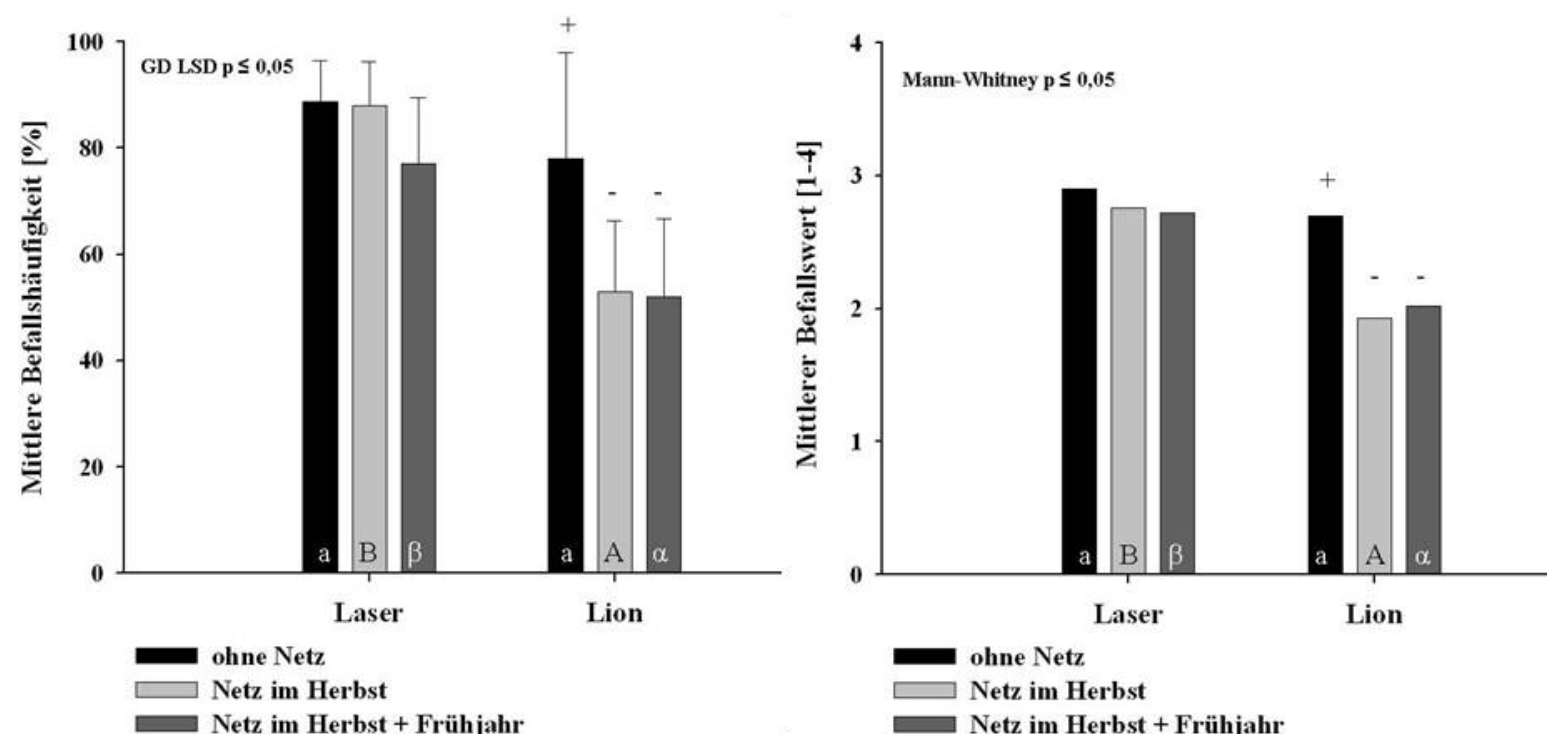

Abb. 13: Auftreten von $V$. longisporum an Winterraps der Sorten Laser und Lion am Standort Weende (Schlag Große Lage) nach visueller Bonitur in BBCH 92; Versuchsjahr 2006/2007. Aufgeführt sind mittlere Befallshäufigkeiten [\%] sowie mittlere Befallswerte [1 (kein Befall) - 4 (sehr starker Befall)] von Varianten mit Verticillium-Inokulation ${ }^{1)}(n=4$ bestehend aus jeweils 50 Pfanzen). Unterschiedliche Buchstaben kennzeichnen statistisch signifikante Befallshäufigkeits- (LSD p $\leq 0,05$ ) bzw. Befallswertunterschiede (Mann-Whitney Median-Test $\mathrm{p} \leq 0,05$ ) zwischen den Sorten bei den jeweiligen Netzabdeckungsvarianten. (+/-) zeigen signifikante Unterschiede zwischen den Netzabdeckungsvarianten der jeweiligen Sorten an. 1) Vorsaat-Bodeninokulation mit stark Verticillium-befallenem Stoppelmaterial in Höhe von $15 \mathrm{~g} / \mathrm{m}^{2}$.

Im dritten Versuchsjahr 2007/2008, welches ebenfalls durch einen vergleichsweise milden Winter geprägt war, entsprach die im Feld zu beobachtende Dynamik der Symptomentwicklung der des ersten Versuchsjahres (2005/2006). Zum Zeitpunkt von Kohlfliegen- bzw. Phoma-Bonitur (BBCH 85) waren nur vereinzelt Pflanzen mit Verticillium-Symptomen zu beobachten. Im weiteren Verlauf der Abreife nahm der Anteil symptomatischer Pflanzen jedoch deutlich zu, so dass das im Rahmen der Stoppelbonitur erhobene Befallsniveau vergleichbar mit dem des Vorjahres (2006/2007) war. Aus Abb. 14 a sowie Abb. 14 b ist ersichtlich, dass die Sorte Aviso den mit Abstand niedrigsten Verticillium-Befall aufwies. Die Sorte Laser verzeichnete wie in den Vorjahren höchste Befallswerte, die sich auch gegenüber Lion und Aviso absichern ließen. Zwischen den Netz-/Insektizidvarianten, die auch gleichzeitig unterschiedlich hohen Kohlfliegenbefall repräsentieren, waren i.d. R. nur tendenzielle Befallsunterschiede festzustellen. In der Variante „ohne Netz/Oftanol + Nexion Neu“, bei der Kohlfliegenbefall im Herbst gegenüber der Variante „ohne Netz/Chinook“ Variante um etwa 50\% reduziert werden konnte (vgl. 3.1.2.1 ), ging die Reduktion des Kohlfliegenbefalls bei den Sorten Laser, Caiman, NK Fair und Lion mit einer Senkung der Verticillium-Befallsparameter einher, was sich allerdings aufgrund einer relativ hohen 
Variabilität nur bei der BH der Sorte Lion absichern ließ. Bei der Sorte Aviso, wo zum Zeitpunkt der Bonitur noch ca. 65\% der untersuchten Stoppeln grün waren, ließen sich keine Variantenunterschiede erkennen. In der Variante „Netz im Herbst“, bei der Kohlfliegenbefall im Herbst effektiv ausgeschlossen werden konnte, kam es zu ähnlichen Effekten wie bei der Variante „ohne Netz/Oftanol + Nexion Neu“. Bei Betrachtung der Abbildung fällt allerdings auf, dass die Variante „Netz im Herbst“ trotz Kohlfliegenausschlusses im Vergleich zur Variante „ohne Netz/Oftanol + Nexion Neu“ keinen geringeren sondern tendenziell sogar höheren Verticillium-Befall aufwies. Dieses Ergebnis deutet darauf hin, dass Netzeffekte den Befall mit $V$. longisporum fördern können.

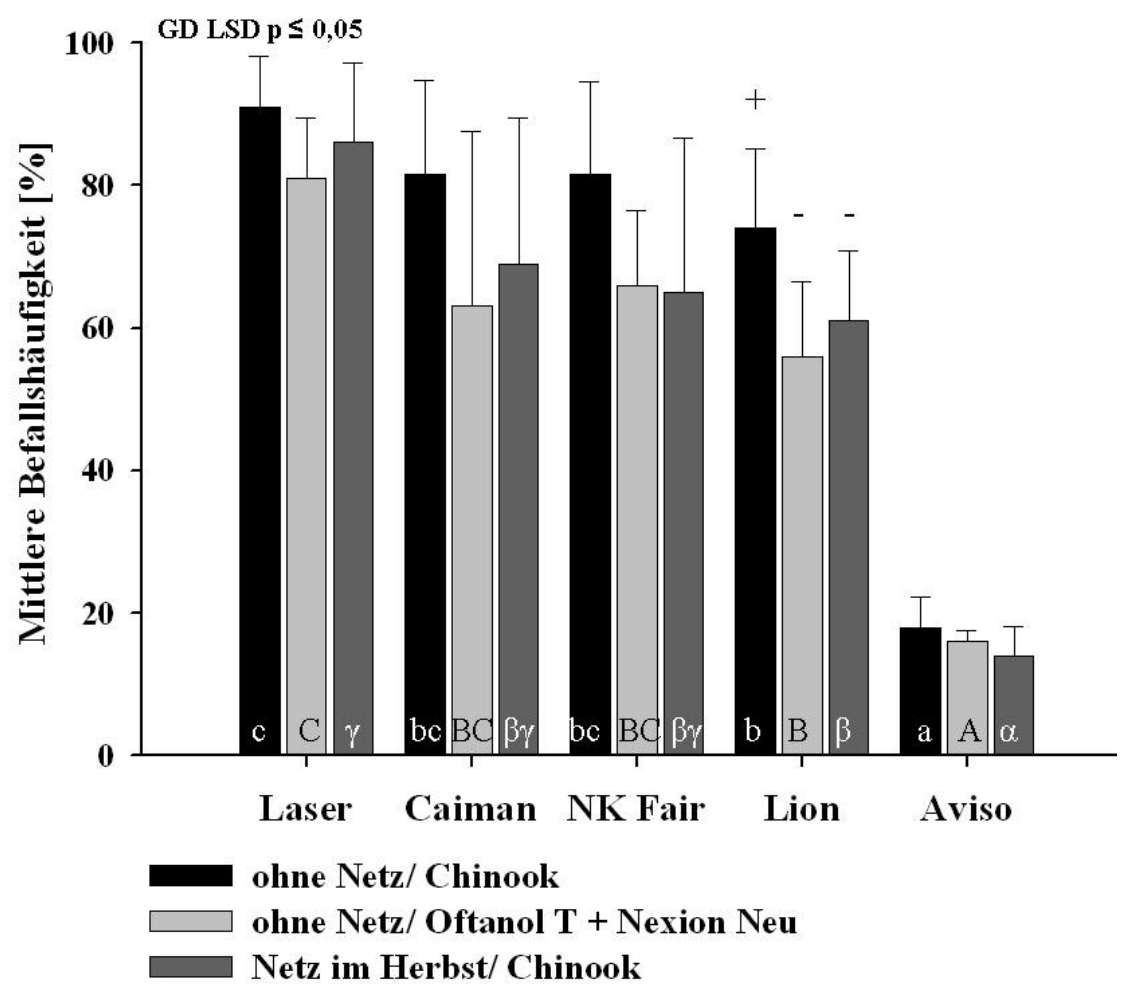

Abb. 14 a: Auftreten von $V$. longisporum an Winterraps bei verschiedenen Sorten am Standort Weende (Schlag Dragoneranger) nach visueller Bonitur in BBCH 92; Versuchsjahr 2007/2008. Aufgeführt sind mittlere Befallshäufigkeiten [\%] von Varianten mit Verticillium-Inokulation ${ }^{1)}(\mathrm{n}=4$ bestehend aus jeweils 50 Pfanzen). Unterschiedliche Buchstaben kennzeichnen statistisch signifikante Befallshäufigkeitsunterschiede zwischen den Sorten bei den jeweiligen Netz-/Insektizidvarianten (LSD p $\leq 0,05$ ). 1) Vorsaat-Bodeninokulation mit stark Verticillium-befallenem Stoppelmaterial in Höhe von $15 \mathrm{~g} / \mathrm{m}^{2}$ ). 


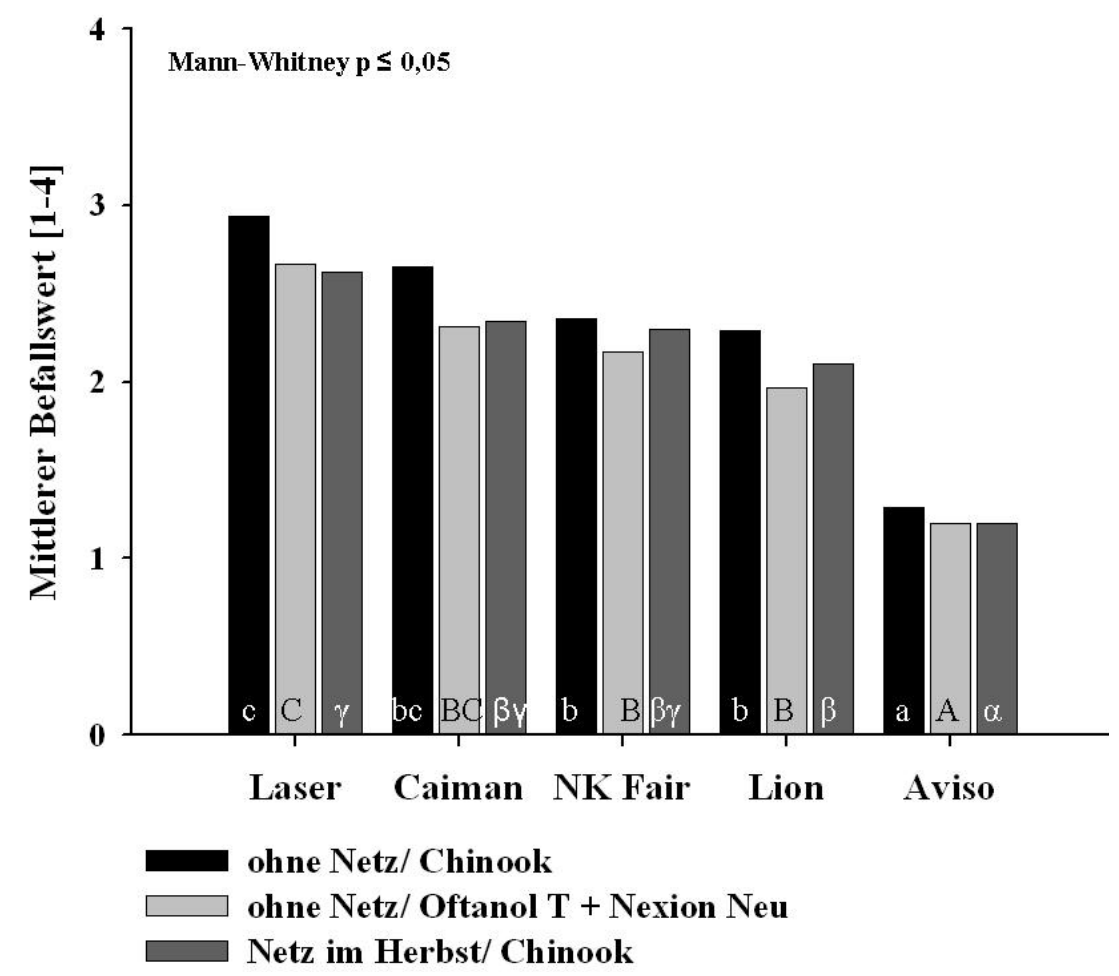

Abb. 14 b: Auftreten von $V$. longisporum an Winterraps bei verschiedenen Sorten am Standort Weende (Schlag Dragoneranger) nach visueller Bonitur in BBCH 92; Versuchsjahr 2007/2008. Aufgeführt sind mittlere Befallswerte [1 (kein Befall) - 4 (sehr starker Befall)] von Varianten mit Verticillium-Inokulation ${ }^{1)}$ ( $\mathrm{n}=4$ bestehend aus jeweils 50 Pfanzen). Unterschiedliche Buchstaben kennzeichnen statistisch signifikante Befallswertunterschiede zwischen den Sorten bei den jeweiligen Netz-/Insektizidvarianten (Mann-Whitney Median-Test $p \leq 0,05$ ). 1) Vorsaat-Bodeninokulation mit stark Verticillium-befallenem Stoppelmaterial in Höhe von $15 \mathrm{~g} / \mathrm{m}^{2}$ ).

\subsubsection{Anbaufaktorenversuch}

In den ersten beiden Versuchsjahren wurden die Versuchsfaktoren Bodenbearbeitung (Pflug bzw. Grubber) und Saattermin (früh bzw. spät) auf einer einheitlich mit Verticilliumbefallenem Stoppelmaterial inokulierten Versuchsfläche variiert, um Auswirkungen auf den Befall mit Kohlfliege bzw. $V$. longisporum untersuchen zu können. In Übereinstimmung mit dem Sortenversuch, der an den Anbaufaktorenversuch angrenzte, zeigten sich erste Symptome von $V$. longisporum im Versuchsjahr 2005/2006 erst spät in der Vegetationsperiode. Die Ergebnisse der Stoppelbonitur sind in Abb. 15 zusammengefasst. Hierbei wies mit der früh gesäten Pflugvariante diejenige Variante den signifikant höchsten VerticilliumBefall auf, die auch gleichzeitig den signifikant höchsten Kohlfliegenbefall verzeichnete. Bei Betrachtung der Befallsstärke, ausgedrückt im Befallswert, wird allerdings deutlich, dass das Befallsniveau insgesamt gering war. Wie im Sortenversuch konnten bei der Sorte Oase bei 
Vorliegen von Verticillium-Befall MS häufig nur in der Wurzel, nicht jedoch im Stängelbereich, gefunden werden.
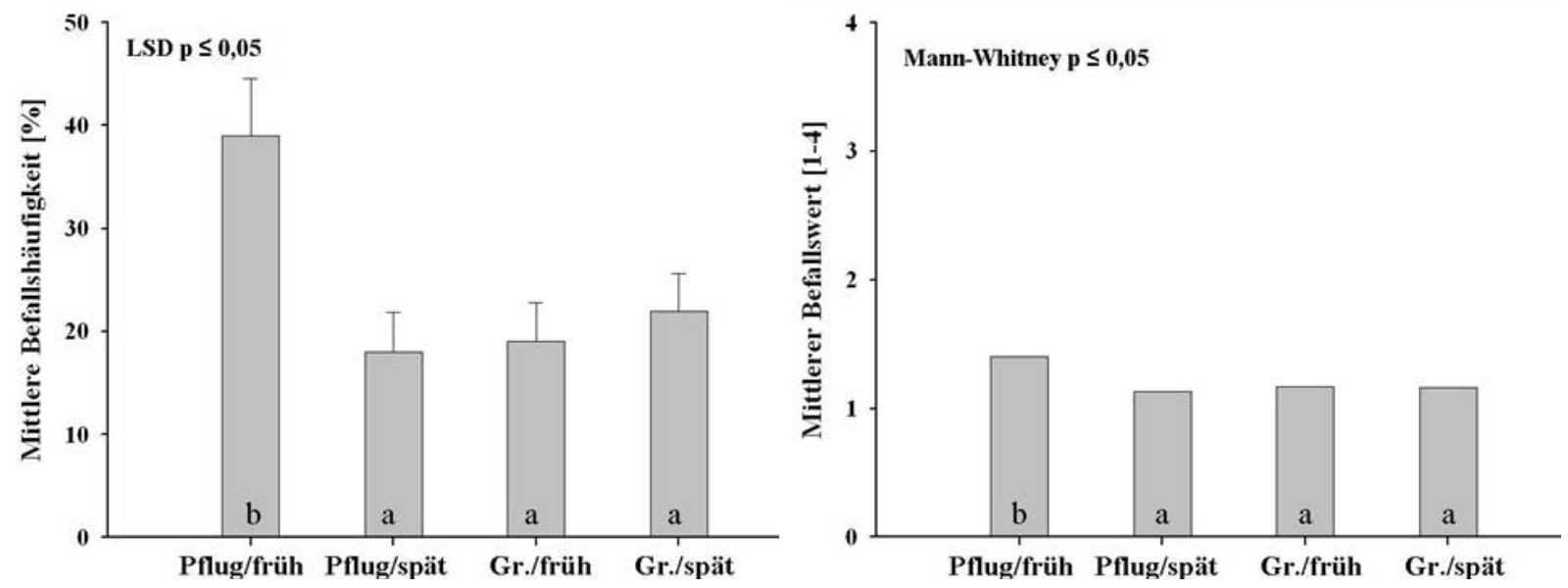

Abb.15: Auftreten von $V$. longisporum an Winterraps der Sorte Oase (Saatgutbehandlung mit Chinook) am Standort Weende (Schlag Große Breite) nach visueller Bonitur in BBCH 92; Versuchsjahr 2005/2006. Aufgeführt sind mittlere Befallshäufigkeiten [\%] sowie mittlere Befallswerte [1 (kein Befall) - 4 (sehr starker Befall)] der verschiedenen Bodenbearbeitungs-/Saatterminvarianten $^{1)}$ ( $\mathrm{n}=4$ bestehend aus jeweils 50 Pfanzen). Unterschiedliche Buchstaben kennzeichnen statistisch signifikante Befallshäufigkeits- (LSD p $\leq 0,05$ ) bzw. Befallswertunterschiede (MannWhitney Median-Test $\mathrm{p} \leq 0,05)$ zwischen den Bodenbearbeitungs-/Saatterminvarianten. Die gesamte Versuchsfläche wurde vor der Aussaat mit stark Verticillium-befallenem Stoppelmaterial in Höhe von $15 \mathrm{~g} / \mathrm{m}^{2}$ inokuliert. 1) Bodenbearbeitung: Pflug bzw. Grubber (Gr.); Saattermine: 12.08. (früh) bzw. 25.08.2005 (spät).

Zusätzlich zur visuellen Befallserfassung wurde der Befallsverlauf von $V$. longisporum mittels ELISA untersucht, um auch latenten Befall ohne das Vorhandensein von Symptomen detektieren und quantifizieren zu können. In Übereinstimmung mit der späten Symptomentwicklung konnte mit dem ELISA erst zum letzten Beprobungstermin (BBCH 87) eindeutig Verticillium-Befall nachgewiesen werden (Abb. 16). Früh gesäte Varianten zeigten hierbei im Vergleich zu den später gesäten Varianten eine deutlich stärkere Besiedlung des Pflanzengewebes. 


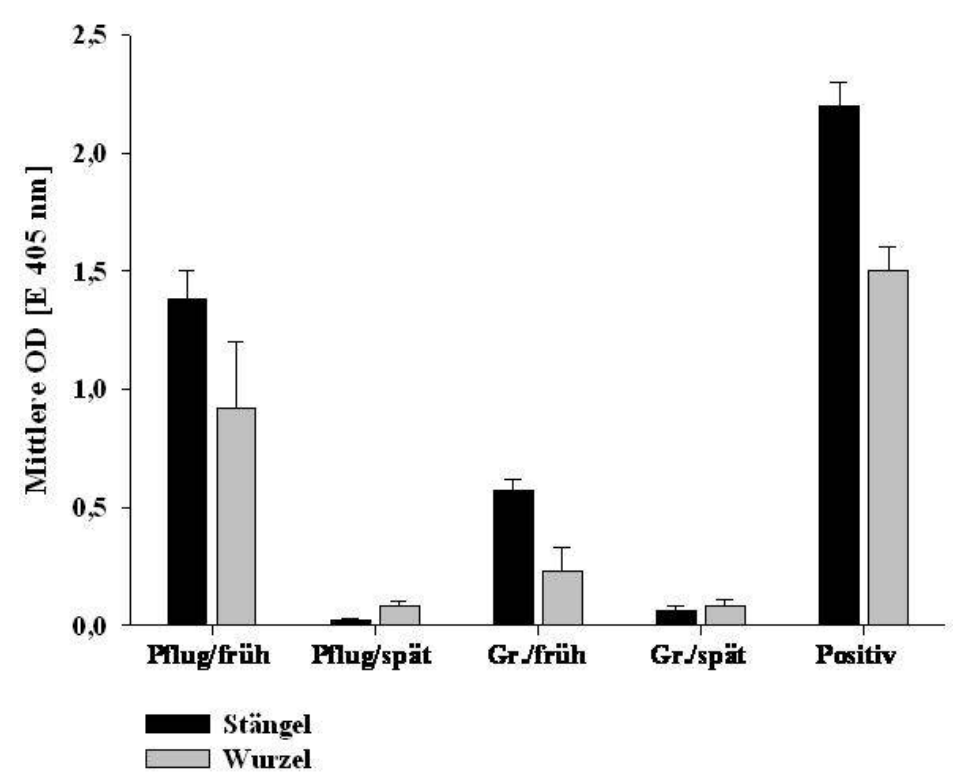

Abb. 16: Mittlere mit dem ELISA gemessene OD (Optische Dichte)-Werte [Extinktion (E) $405 \mathrm{~nm}$ ] in Rapsstängel bzw. Wurzel der Sorte Oase am Standort Weende in BBCH 87 (29.07.06). Dargestellt sind die nach drei Stunden Inkubationszeit mit einem Photometer gemessenen mittleren Extinktionswerte bereinigt um Negativkontrollwerte. Je Versuchsvariante ${ }^{1)}$ wurden zehn zufällig entnommene Rapspflanzen in Mischproben ( 2 x 5) getrennt nach Wurzel und Stängelabschnitt untersucht. Als Positivkontrolle dienten stark befallene Rapspflanzen des Sortenversuchs (Sorte Laser). Die gesamte Versuchsfläche wurde vor der Aussaat mit Verticillium-befallenem Stoppelmaterial in Höhe von $15 \mathrm{~g} / \mathrm{m}^{2}$ inokuliert. 1) Bodenbearbeitung: Pflug bzw. Grubber (Gr.); Saattermine: 12.08. (früh) bzw. 25.08.2005 (spät)).

Der Anbaufaktorenversuch wurde zur Überprüfung der Vorjahresergebnisse mit leichten Modifikationen (Sorte Smart) auf einem anderen Versuchsstandort nördlich von Göttingen (Angerstein) im Versuchsjahr 2006/2007 erneut angelegt. Erste Symptome von V. longisporum konnten etwa zwei Wochen vor der Ernte beobachtet werden. Nach den Ergebnissen der Stoppelbonitur, die in Abb. 17 dargestellt sind, wiesen die Spätsaatvarianten bei insgesamt niedrigem Befallsniveau höheren Verticillium-Befall als die Frühsaatvarianten auf. Die spät gesäte Grubbervariante setzte sich von der früh gesäten Pflugvariante mit signifikant höherem Befall ab. Bei der Befallsstärke waren keine Variantenunterschiede auszumachen. Aufgrund des geringen Kohlfliegenbefalls im Herbst sowie der trockenheitsbedingt geringen Bestandesdichte bei den Spätsaatvarianten lässt sich anhand der vorliegenden Ergebnisse nicht eindeutig schließen, inwieweit Kohlfliegenbefall und/oder kräftigere Einzelpflanzen mit stärkerer Durchwurzelung zu höherem Verticillium-Befall beigetragen haben könnten. 

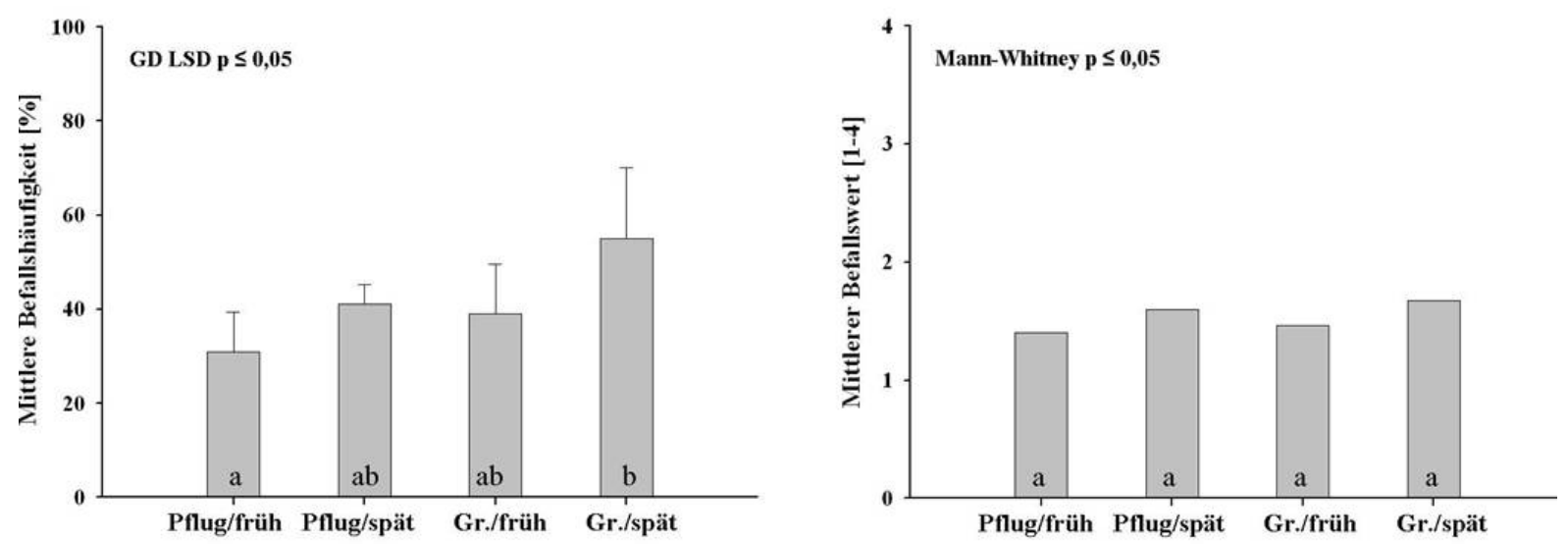

Abb. 17: Auftreten von V. longisporum an Winterraps der Sorte Smart (Saatgutbehandlung mit Chinook) am Standort Angerstein nach visueller Bonitur in BBCH 92; Versuchsjahr 2006/2007. Aufgeführt sind mittlere Befallshäufigkeiten [\%] sowie mittlere Befallswerte [1 (kein Befall) - 4 (sehr starker Befall)] der verschiedenen Bodenbearbeitungs-/Saatterminvarianten ${ }^{1)}(\mathrm{n}=4$ bestehend aus jeweils 50 Pfanzen). Unterschiedliche Buchstaben kennzeichnen statistisch signifikante Befallshäufigkeits- (LSD $p \leq 0,05)$ bzw. Befallswertunterschiede (Mann-Whitney Median-Test $p \leq 0,05$ ) zwischen den Bodenbearbeitungs-/Saatterminvarianten. Die gesamte Versuchsfläche wurde vor der Aussaat mit Verticillium-befallenem Stoppelmaterial in Höhe von $15 \mathrm{~g} / \mathrm{m}^{2}$ inokuliert. 1) Bodenbearbeitung: Pflug bzw. Grubber; Saattermine: 17.08. (früh) bzw. 01.09.2006 (spät).

Im dritten Versuchsjahr (2007/2008) sollten Effekte variierender Saattermine auf den Befall von Raps mit $V$. longisporum bei unterschiedlich hohem Kohlfliegenbefall untersucht werden, um eine differenzierte Risikoabschätzung bzgl. $V$. longisporum abgeben zu können. Der Faktor Bodenbearbeitung wurde hier nicht mehr variiert (nur Pflugsaat). Der Versuch umfasste verschiedene Insektizid/Netzvarianten, um Effekte von Saatzeit und Kohlfliegenbefall auf $V$. longisporum sowohl in Kombination, als auch einzeln betrachten zu können. In Abb. 18 sind die Ergebnisse der Stoppelbonitur dargestellt, wobei wie beim Sortenversuch ausschließlich Befallsparameter von inokulierten Varianten berücksichtigt wurden. Im Versuch, der einheitlich mit der Hybridsorte Trabant bestellt worden war, verzeichneten die früh gesäten Varianten (Saattermin 14.08.2007) im Vergleich zu den später gesäten Varianten (Saattermin 31.08.2007) deutlich höhere Befallsparameter. Die festgestellten Unterschiede ließen sich mit Ausnahme des Parameters BH der Variante „Netz im Herbst“ bei allen anderen Varianten statistisch absichern. Zwischen den Netz-/Insektizidvarianten, die gleichzeitig unterschiedlich hohen Kohlfliegenbefall repräsentieren, ließen sich tendenzielle Unterschiede ausmachen. Bei den Frühsaatvarianten ohne Netzabdeckung ging die Reduktion des Kohlfliegenbefalls mit einer tendenziellen Verringerung des Verticillium-Befalls einher. Die Variante „ohne Netz/Oftanol + Nexion Neu“, bei der Kohlfliegenbefall im Herbst gegenüber der Variante „ohne Netz/Chinook“ um etwa 50\% verringert werden konnte, zeigte 
dabei den geringsten Verticillium-Befall an. Wie beim Sortenversuch führten Netzabdeckungen trotz sehr geringen Kohlfliegenbefalls nicht zu einer weiteren Senkung des Verticillium-Befalls gegenüber der Variante „ohne Netz/ Oftanol + Nexion Neu“. Dieses Ergebnis bestätigt Hinweise des Sortenversuchs (vgl. 3.1.3.1), wonach Netzeffekte den Befall von Raps mit $V$. longisporum positiv beeinflussen können.
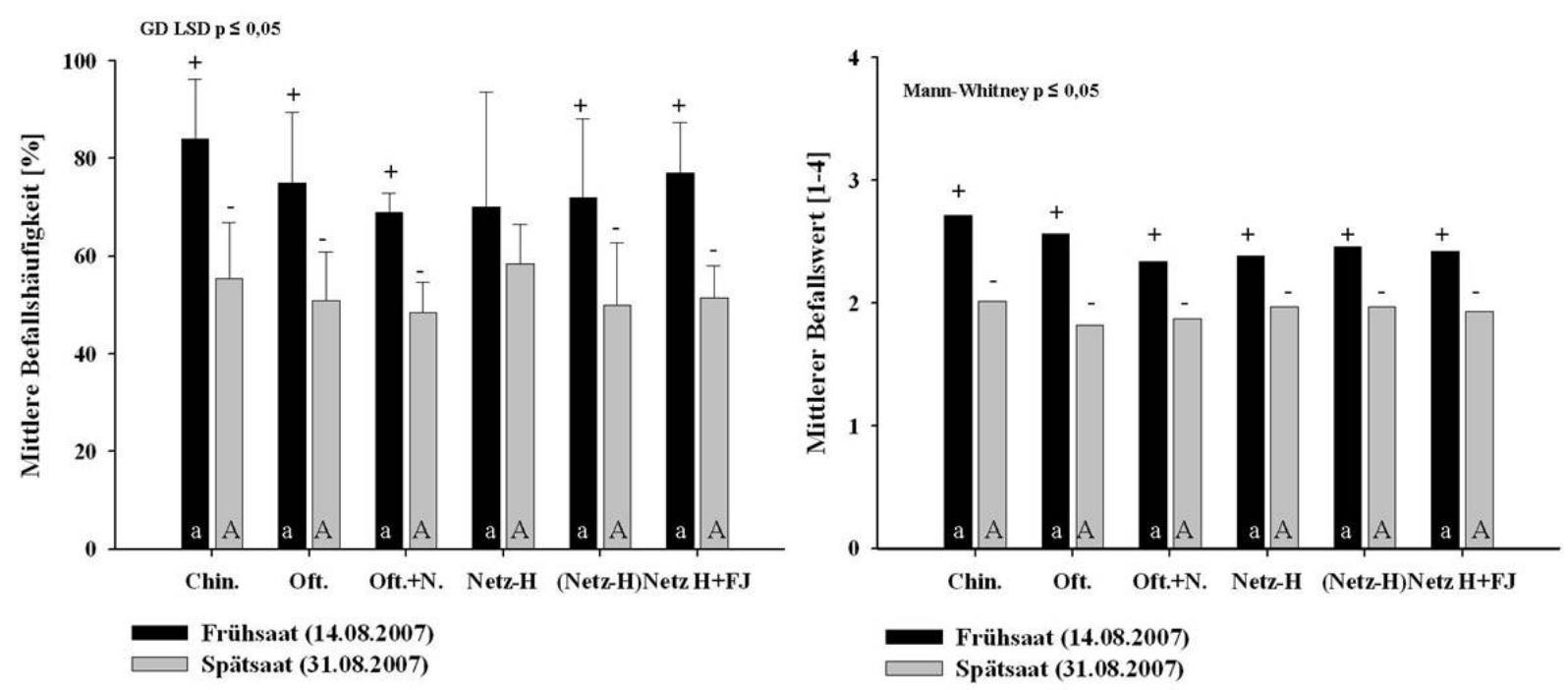

Abb. 18: Auftreten von V. longisporum an Winterraps der Sorte Trabant am Standort Weende (Schlag Dragoneranger) nach visueller Bonitur in $\mathrm{BBCH}$ 92; Versuchsjahr 2007/2008. Aufgeführt sind mittlere Befallshäufigkeiten [\%] sowie mittlere Befallswerte [1 (kein Befall) - 4 (sehr starker Befall)] von Varianten mit Verticillium-Inokulation ${ }^{1)}(\mathrm{n}=4$ bestehend aus jeweils 50 Pfanzen). Unterschiedliche Buchstaben kennzeichnen statistisch signifikante Befallshäufigkeits- (LSD p $\leq 0,05$ ) bzw. Befallswertunterschiede (Mann-Whitney Median-Test $\mathrm{p} \leq 0,05)$ zwischen den Netz-/Insektizidvarianten bei Frühsaat bzw. Spätsaat. (+/-) zeigen signifikante Unterschiede zwischen den Saatterminen bei den jeweiligen Netz-/Insektizidvarianten an. Netz/Insektizidvarianten: Chin. $=$ Saatgutbehandlung mit Chinook; Oft. = Saatgutbehandlung mit Oftanol T; Oft. + N. = Saatgutbehandlung mit Oftanol T + Austreuen des insektiziden Granulats Nexion Neu nach der Saat $\left(10 \mathrm{~g} / \mathrm{m}^{2}\right)$; Netz-H = Netz im Herbst, Saatgutbehandlung mit Chinook; (Netz-H) = Netz im Herbst teilweise offen (Auflage eines Kulturschutznetzes von Mitte August bis Anfang September und Mitte September bis Mitte Oktober 2007), Saatgutbehandlung mit Chinook; Netz H +FJ = Netz im Herbst + Frühjahr, Saatgutbehandlung mit Chinook. 1) Vorsaat-Bodeninokulation mit stark Verticilliumbefallenem Stoppelmaterial in Höhe von $15 \mathrm{~g} / \mathrm{m}^{2}$ ). 


\subsubsection{Erfassung des Befalls von Raps mit P. lingam}

Die Erfassung des Befalls von Raps mit $P$. lingam erfolgte gleichzeitig mit der Erhebung des Kohlfliegenbefalls im Frühjahr zu BBCH 85. Im Sortenversuch wurde der Frage nachgegangen, ob eine mit Hilfe von Insektiziden oder Kulturschutznetzabdeckungen herbeigeführte Abstufung des Kohlfliegenbefalls auch unterschiedlich starken Phoma-Befall zur Folge hat. In Tab. 19 sind die mittleren Phoma-Befallswerte an Wurzelhals- und Stängel für die einzelnen Varianten des ersten Versuchsjahres 2005/2006 aufgelistet. Bei insgesamt moderatem Befallsniveau waren sowohl Sorteneffekte als auch Inokulationseffekte zu erkennen. Die Sorte Caiman setzte sich im Vergleich zu den übrigen Sorten mit dem erwartungsgemäß niedrigsten Phoma-Befall ab. Im Herbst durchgeführte Sprühinokulationen führten bei den Sorten Lion und Oase zu einer signifikanten Erhöhung des Befalls am Wurzelhals im Vergleich zur Kontrolle. Bei der Sorte Laser waren nur tendenzielle Effekte festzustellen. Der Stängelbefall zeigte keine signifikanten Inokulationseffekte an. Beim Vergleich beider Insektizidvarianten waren wie beim Kohlfliegenbefall keine Befallsunterschiede auszumachen. Mögliche Effekte von Kohlfliegenbefall auf $P$. lingam ließen sich vor dem Hintergrund eines indifferenten Kohlfliegenbefalls nicht ableiten. Die Tatsache, dass die gering Phoma-anfällige Sorte Caiman trotz eines insgesamt hohen Kohlfliegenbefalls nur sehr geringe Phoma-Befallswerte aufwies, deutet hier bereits darauf hin, dass das Resistenzniveau von Caiman durch Kohlfliegenbefall nicht beeinflusst wird. 
Tab. 19: Auftreten von P. lingam an Winterraps bei verschiedenen Sorten am Standort Weende (Schlag Große Breite) nach visueller Bonitur in BBCH 85; Versuchsjahr 2005/2006. Aufgeführt sind mittlere Befallswerte (BW 1 (kein Befall) - BW 9 (sehr starker Befall)) der verschiedenen Inokulationsvarianten (Kontrolle, Phoma-Herbstinokulation, Verticillium-Inokulation) an Wurzelhals und Stängel ( $\mathrm{n}=4$ bestehend aus jeweils 25 Pflanzen). Unterschiedliche Buchstaben kennzeichnen statistisch signifikante Differenzen zwischen den Inokulationsvarianten bei den jeweiligen Insektizidvarianten (Mann-Whitney Median-Test $\mathrm{p} \leq 0,05$ ). Kruskall-Wallis $\mathrm{p}$-Werte geben die Irrtumswahrscheinlichkeit für statistisch signifikante Unterschiede zwischen den Insektizidvarianten bei den jeweiligen Inokulationsvarianten an.

\begin{tabular}{|c|c|c|c|c|c|c|}
\hline \multirow{2}{*}{$\begin{array}{l}\text { Sorte Laser } \\
\text { Insektizidvarianten }^{3)}\end{array}$} & \multicolumn{3}{|c|}{ BW Wurzelhals } & \multicolumn{3}{|c|}{ BW Stängel } \\
\hline & Kontrolle & $\mathrm{Ph}-\mathrm{H}^{1)}$ & Vert. $^{2)}$ & Kontrolle & $\mathrm{Ph}-\mathrm{H}^{1)}$ & Vert. ${ }^{2)}$ \\
\hline Chinook & $3,51 \mathrm{a}$ & $3,74 \mathrm{a}$ & $3,42 \mathrm{a}$ & $2,40 \mathrm{a}$ & $2,42 \mathrm{a}$ & $2,32 \mathrm{a}$ \\
\hline Elado + Nexion Neu & $3,72 \mathrm{~A}$ & $3,91 \mathrm{~A}$ & $3,64 \mathrm{~A}$ & $2,10 \mathrm{~A}$ & $2,52 \mathrm{~A}$ & $2,31 \mathrm{~A}$ \\
\hline Kruskall-Wallis $\mathrm{p} \leq 0,05$ & $0,51 \mathrm{n} . \mathrm{s}$. & 0,66 n.s. & 0,43 n.s. & 0,33 n.s. & 0,59 n.s. & 0,89 n. s. \\
\hline Sorte Lion & \multicolumn{3}{|c|}{ BW Wurzelhals } & \multicolumn{3}{|c|}{ BW Stängel } \\
\hline Insektizidvarianten ${ }^{3)}$ & Kontrolle & $\mathrm{Ph}-\mathrm{H}^{1)}$ & Vert. ${ }^{2)}$ & Kontrolle & $\mathrm{Ph}-\mathrm{H}^{1)}$ & Vert. ${ }^{2)}$ \\
\hline Chinook & $3,74 \mathrm{a}$ & $4,42 \mathrm{~b}$ & $3,53 \mathrm{a}$ & $2,25 \mathrm{a}$ & $2,70 \mathrm{a}$ & $2,79 \mathrm{a}$ \\
\hline Elado + Nexion Neu & $3,81 \mathrm{~A}$ & $4,41 \mathrm{~B}$ & $3,41 \mathrm{~A}$ & $2,12 \mathrm{~A}$ & $2,62 \mathrm{~A}$ & $2,39 \mathrm{~A}$ \\
\hline Kruskall-Wallis $\mathrm{p} \leq 0,05$ & 0,65 n.s. & 0,82 n. s. & 0,74 n.s. & 0,71 n.s. & 0,64 n.s. & 0,21 n. s. \\
\hline Sorte Oase & \multicolumn{3}{|c|}{ BW Wurzelhals } & \multicolumn{3}{|c|}{ BW Stängel } \\
\hline Insektizidvarianten $^{3)}$ & Kontrolle & $\mathrm{Ph}-\mathrm{H}^{1)}$ & Vert. $^{2)}$ & Kontrolle & $\mathrm{Ph}-\mathrm{H}^{1)}$ & Vert. $^{2)}$ \\
\hline Chinook & $3,10 \mathrm{a}$ & $3,72 \mathrm{~b}$ & $3,28 \mathrm{ab}$ & $2,23 \mathrm{a}$ & $2,34 \mathrm{a}$ & $2,53 \mathrm{a}$ \\
\hline Elado + Nexion Neu & $3,44 \mathrm{~A}$ & $4,01 \mathrm{~B}$ & $3,31 \mathrm{~A}$ & $2,25 \mathrm{~A}$ & $2,74 \mathrm{~A}$ & $2,52 \mathrm{~A}$ \\
\hline Kruskall-Wallis $\mathrm{p} \leq 0,05$ & 0,34 n.s. & 0,28 n. s. & 0,87 n.s. & 0,85 n.s. & 0,59 n. s. & 0,89 n. s. \\
\hline Sorte Caiman & \multicolumn{3}{|c|}{ BW Wurzelhals } & \multicolumn{3}{|c|}{ BW Stängel } \\
\hline Insektizidvarianten ${ }^{3)}$ & Kontrolle & $\mathrm{Ph}-\mathrm{H}^{1)}$ & Vert. $^{2)}$ & Kontrolle & $\mathrm{Ph}-\mathrm{H}^{1)}$ & Vert. $^{2)}$ \\
\hline Chinook & $1,91 \mathrm{a}$ & $1,94 \mathrm{a}$ & $2,02 \mathrm{a}$ & $1,83 \mathrm{a}$ & $2,10 \mathrm{a}$ & $2,02 \mathrm{a}$ \\
\hline Elado + Nexion Neu & $1,83 \mathrm{~A}$ & $1,91 \mathrm{~A}$ & $1,82 \mathrm{~A}$ & $2,01 \mathrm{~A}$ & $1,91 \mathrm{~A}$ & $1,92 \mathrm{~A}$ \\
\hline Kruskall-Wallis $\mathrm{p} \leq 0,05$ & 0,91 n.s. & 0,87 n.s. & 0,79 n. s. & 0,64 n.s. & 0,25 n.s. & 0,87 n.s. \\
\hline
\end{tabular}

1) Ph-H: Phoma-Sprühinokulation an den Wurzelhals im Herbst (BBCH 15)

2) Vert.: Bodeninokulation mit Verticillium-befallenen Stoppelmaterial vor der Saat $\left(15 \mathrm{~g} / \mathrm{m}^{2}\right)$

3) Insektizidbehandlungen: Saatgutbehandlung mit Chinook bzw. Saatgutbehandlung mit Elado sowie

Austreuen des Insektiziden Granulats Nexion Neu nach der Saat $\left(10 \mathrm{~g} / \mathrm{m}^{2}\right)$ 
Im zweiten Versuchsjahr 2006/2007 wurden nach den Erfahrungen des ersten Versuchsjahres einige Anpassungen in der Versuchsmethodik vorgenommen. Die für die Untersuchung von Interaktionseffekten notwendige Abstufung des Kohlfliegenbefalls sollte mit Hilfe von Kulturschutznetzabdeckungen erreicht werden. Zusätzlich zu einer Phoma-Sprühinokulation im Herbst sah der Versuch eine weitere Phoma-Sprühinokulation im Frühjahr vor, um auch Effekte eines späten Phoma-Befalls beurteilen zu können. Die Phoma-anfällige Sorte Viking sowie die gering anfällige Sorte Caiman wurden neben einer Kontrolle beiden PhomaInokulationsvarianten unterzogen. Die beiden Sorten Laser und Lion wurden im Hinblick auf mögliche Interaktionseffekte zwischen Kohlfliege und $V$. longisporum ausgewählt und kamen aufgrund von Versuchskapazitäten auch nur in den Varianten Kontrolle bzw. Verticillium-Bodeninokulation vor.

Die Ergebnisse der Phoma-Befallsbonitur sind für das Versuchsjahr 2006/2007 in Tab. 20 aufgeführt. Phoma-Sprühinokulationen im Herbst bzw. Frühjahr führten bei der Sorte Viking gegenüber der Kontrolle zu einer signifikanten Zunahme der Befallswerte an Wurzelhalsund Stängel. Die Sorte Caiman wies wie im Versuchsjahr 2005/2006 sehr geringen PhomaBefall auf, der von den Inokulationsvarianten unbeeinflusst blieb. Bei Betrachtung der Befallswerte der Sorten Laser und Lion wird deutlich, dass die Bodeninokulation mit Verticillium-befallenem Stoppelmaterial zugleich auch zu einer Erhöhung des Phoma-Befalls geführt hat. Bei der Sorte Lion kam es in allen Varianten zu einer signifikanten Erhöhung der Befallswerte an Wurzelhals- bzw. Stängel. Bei Laser war der Befall am Wurzelhals erhöht. Die Variante „Netz im Herbst“, bei der Kohlfliegenbefall im Herbst effektiv ausgeschlossen werden konnte, wies bei den Phoma- bzw. Verticillium-inokulierten Varianten der Sorten Viking, Laser und Lion tendenziell niedrigere Befallswerte am Wurzelhals auf als die stark durch Kohlfliegen geschädigte Variante ohne Netz. Durch einen zusätzlichen Ausschluss der Frühjahrsgeneration der Kohlfliege in der Netzabdeckungsvariante „Netz im Herbst + Frühjahr“ ließ sich die Tendenz eines reduzierten Phoma-Befalls nicht bekräftigen. Die Effekte fielen i. d. R. geringer aus als bei der Variante „Netz im Herbst.“ Dieses Ergebnis deutet darauf hin, dass es durch Netzeffekte auch zu einer Förderung von $P$. lingam kommen kann. 
Tab. 20: Auftreten von P. lingam an Winterraps verschiedener Sorten am Standort Weende (Schlag Große Lage) nach visueller Bonitur in BBCH 85; Versuchsjahr 2006/07. Aufgeführt sind mittlere Befallswerte (BW 1 (kein Befall) - BW 9 (sehr starker Befall)) der verschiedenen Inokulationsvarianten (Kontrolle, Phoma-Herbstinokulation, Phoma-Frühjahrsinokulation, Verticillium-Stoppelinokulation) an Wurzelhals und Stängel ( $\mathrm{n}=4$ bestehend aus jeweils 25 Pflanzen). Unterschiedliche Buchstaben kennzeichnen statistisch signifikante Differenzen zwischen den Inokulationsvarianten bei den jeweiligen Netzvarianten. (+/-) zeigen signifikante Unterschiede zwischen den Netzvarianten bei den jeweiligen Inokulationsvarianten an (Mann-Whitney Median-Test $\mathrm{p} \leq 0,05$ ). Kruskall-Wallis $\mathrm{p}$ Werte geben die Irrtumswahrscheinlichkeit für statistisch signifikante Unterschiede zwischen den Netzvarianten bei den jeweiligen Inokulationsvarianten an.

\begin{tabular}{|c|c|c|c|c|c|c|}
\hline \multirow{2}{*}{$\begin{array}{l}\text { Sorte Viking } \\
\text { Netzvarianten }{ }^{4)}\end{array}$} & \multicolumn{3}{|c|}{ BW Wurzelhals } & \multicolumn{3}{|c|}{ BW Stängel } \\
\hline & Kontrolle & $\mathrm{Ph}-\mathrm{H}^{1)}$ & $\mathrm{Ph}-\mathrm{FJ}^{2)}$ & Kontrolle & $\mathrm{Ph}-\mathrm{H}^{1)}$ & $\mathrm{Ph}-\mathrm{FJ}^{2)}$ \\
\hline ohne Netz & $2,83 \mathrm{a}$ & $3,88 \mathrm{~b}$ & $3,75 \mathrm{~b}$ & $2,95 \mathrm{a}$ & $4,25 \mathrm{~b}$ & $4,28 \mathrm{~b}+$ \\
\hline Netz im Herbst & $2,88 \mathrm{~A}$ & $3,56 \mathrm{~B}$ & $3,48 \mathrm{~B}$ & $2,83 \mathrm{~A}$ & $4,28 \mathrm{~B}$ & $4,05 \mathrm{~B}+/-$ \\
\hline Netz im Herbst + Frühjahr & $2,95 \alpha$ & $3,48 \beta$ & $3,30 \alpha \beta$ & $2,68 \alpha$ & $4,02 \beta$ & $3,45 \alpha \beta-$ \\
\hline Kruskall-Wallis $\mathrm{p} \leq 0,05$ & $0,35 \mathrm{n} . \mathrm{s}$ & \multicolumn{2}{|l|}{0,14 n.s. } & 0,24 n.s. & 0,33 n.s. & 0,04 \\
\hline Sorte Caiman & \multicolumn{3}{|c|}{ BW Wurzelhals } & \multicolumn{3}{|c|}{ BW Stängel } \\
\hline Netzvarianten ${ }^{4)}$ & Kontrolle & $\mathrm{Ph}-\mathrm{H}^{1)}$ & $\mathrm{Ph}-\mathrm{FJ}^{2)}$ & Kontrolle. & $\mathrm{Ph}-\mathrm{H}^{1)}$ & $\mathrm{Ph}-\mathrm{FJ}^{2)}$ \\
\hline ohne Netz & $2,32 \mathrm{a}$ & $2,34 \mathrm{a}$ & $2,31 \mathrm{a}$ & $2,40 \mathrm{a}$ & $2,46 \mathrm{~b}$ & $2,50 \mathrm{~b}$ \\
\hline Netz im Herbst & $2,22 \mathrm{~A}$ & $2,32 \mathrm{~A}$ & $2,52 \mathrm{~A}$ & $2,15 \mathrm{~A}$ & $2,46 \mathrm{~B}$ & $2,20 \mathrm{~B}$ \\
\hline Netz im Herbst + Frühjahr & $2,30 \alpha$ & $2,35 \alpha$ & $2,52 \alpha$ & $2,28 \alpha$ & $2,40 \beta$ & $2,38 \alpha \beta$ \\
\hline Kruskall-Wallis $\mathrm{p} \leq 0,05$ & 0,78 n.s. & $0,81 \mathrm{n} . \mathrm{s}$ & $0,79 \mathrm{n} . \mathrm{s}$ & 0,34 n.s. & $0,73 \mathrm{n} . \mathrm{s}$ & 0,33 n.s. \\
\hline Sorte Laser & & BW W & zelhals & & BW Stäı & gel \\
\hline Netzvarianten ${ }^{4)}$ & & trolle & Vert. $^{3)}$ & Kont & & Vert. ${ }^{3)}$ \\
\hline ohne Netz & & & $4,45 \mathrm{~b}$ & 3,22 & & $3,12 \mathrm{a}$ \\
\hline Netz im Herbst & & & $3,73 \mathrm{~B}$ & 3,12 & & $3,32 \mathrm{~A}$ \\
\hline Netz im Herbst + Frühjahr & & & $4,18 \beta$ & 3,25 & & $3,35 \beta$ \\
\hline Kruskall-Wallis $\mathrm{p} \leq 0,05$ & & & 0,06 n.s. & $0,67 \mathrm{r}$ & & $0,52 \mathrm{n} . \mathrm{s}$ \\
\hline Sorte Lion & & $\mathrm{BW} \mathrm{W}$ & rzelhals & & BW Stän & \\
\hline Netzvarianten ${ }^{4)}$ & & ntrolle & Vert. $^{3)}$ & Kontr & & Vert. $^{3)}$ \\
\hline ohne Netz & & & $4,53 \mathrm{~b}$ & $3,15 \mathrm{a}$ & & $4,10 \mathrm{~b}$ \\
\hline Netz im Herbst & & $0 \mathrm{~A}$ & $4,08 \mathrm{~B}$ & $2,50 \mathrm{~A}$ & & $3,93 \mathrm{~B}$ \\
\hline Netz im Herbst + Frühjahr & & $8 \alpha$ & $4,25 \beta$ & 2,850 & & $3,58 \beta$ \\
\hline Kruskall-Wallis $p \leq 0,05$ & & n.s. & 0,18 n.s. & $0,14 \mathrm{n}$ & & $0,33 \mathrm{n} \cdot \mathrm{s}$ \\
\hline
\end{tabular}

1) Ph-H.: Phoma-Sprühinokulation an den Wurzelhals im Herbst (BBCH 15)

2) Ph-FJ.: Phoma-Sprühinokulation an den Wurzelhals im Frühjahr (BBCH 63)

3) Vert.: Bodeninokulation mit Verticillium-befallenem Stoppelmaterial vor der Saat (15 g/ $\left.\mathrm{m}^{2}\right)$

4) Netzvarianten: ohne Netz; Netz im Herbst (Auflage eines Kulturschutznetzes von Mitte August bis Mitte Oktober 2006); Netz im Herbst + Frühjahr (Netz im Herbst + Netzkäfigkonstruktion von Ende März bis Mitte Juni 2007) 
In Tab. 21 sind die mittleren Phoma-Befallswerte für das Versuchsjahr 2007/2008 angegeben. Die Phoma-anfälligen Sorten Lion, Laser und NK Fair sowie die weniger anfälligen Sorten Aviso und Caiman wurden hierbei in einer Kontrolle bzw. einer Variante mit Verticillium-Bodeninokulation überprüft. Die Abstufung des Kohlfliegenbefalls erfolgte nicht nur mit Kulturschutznetzen sondern auch mit Hilfe von Insektiziden, um mögliche Befallseffekte eines verringerten Kohlfliegenbefalls ohne das Vorhandensein von Netzeffekten untersuchen zu können.

Bei insgesamt moderatem Befallsniveau entsprach die Sortenrangfolge bzgl. P. lingam (Lion $>$ Laser, NK Fair $>$ Aviso $>$ Caiman) der Einstufung nach Bundessortenliste. Im Gegensatz zum Vorjahr kam es im Versuchsjahr 2007/2008 durch die Bodeninokulation mit Verticillium-befallenem Stoppelmaterial nicht zu einer Erhöhung des Phoma-Befalls. Zwischen den Netz-/Insektizidvarianten waren teilweise signifikante Befallswertunterschiede auszumachen. In der Variante „ohne Netz/Oftanol + Nexion Neu“, bei der Kohlfliegenbefall im Herbst gegenüber der Variante „ohne Netz/Chinook“ um etwa 50\% reduziert werden konnte, ging die Reduktion des Kohlfliegenbefalls bei den Sorten Lion, Laser und NK Fair mit einer signifikanten Senkung der Befallswerte am Wurzelhals einher. Bei der weniger anfälligen Sorte Aviso waren nur tendenzielle Effekte, bei Caiman wie in den Vorjahren keine Effekte festzustellen. In der Variante „Netz im Herbst“, bei der Kohlfliegenbefall im Herbst gegenüber der Variante „ohne Netz/Chinook“ nahezu ausgeschlossen werden konnte, zeigten sich keine signifikanten Befallswertunterschiede. Die Tatsache, dass eine 50\%ige Reduktion des Kohlfliegenbefalls in der Variante „ohne Netz/Oftanol + Nexion Neu“, nicht jedoch eine 85\%ige Reduktion des Kohlfliegenbefall in der Variante „Netz im Herbst“ zu einer signifikanten Verringerung des Phoma-Befalls am Wurzelhals führte, bestätigt die Vermutung des Vorjahres, wonach die Kulturschutznetze den Befall mit $P$. lingam nicht nur indirekt über eine Senkung des Kohlfliegenbefalls verringern sondern auch direkt über Netzeffekte erhöhen können. 
Tab. 21: Auftreten von P. lingam an Winterraps verschiedener Sorten am Standort Weende (Schlag Dragoneranger) nach visueller Bonitur in BBCH 85; Versuchsjahr 2007/08. Aufgeführt sind mittlere Befallswerte (BW 1 (kein Befall) - BW 9 (sehr starker Befall)) der verschiedenen Inokulationsvarianten (Kontrolle, Verticillium-Inokulation) an Wurzelhals und Stängel $(\mathrm{n}=4$ bestehend aus jeweils 25 Pflanzen). Unterschiedliche Buchstaben kennzeichnen statistisch signifikante Differenzen zwischen den Inokulationsvarianten bei den jeweiligen Netz-/Insektizidvarianten. (+/-) zeigen signifikante Unterschiede zwischen den Netz-/Insektizidvarianten bei den jeweiligen Inokulationsvarianten an (Mann-Whitney Median-Test $\mathrm{p} \leq 0,05$ ). Kruskall-Wallis $\mathrm{p}$-Werte geben die Irrtumswahrscheinlichkeit für signifikante Unterschiede zwischen den Netz-/Insektizidvarianten bei den jeweiligen Inokulationsvarianten an. 1) Bodeninokulation mit Verticillium-Stoppeln $\left(15 \mathrm{~g} / \mathrm{m}^{2}\right)$.

\begin{tabular}{|c|c|c|c|c|}
\hline \multirow{2}{*}{$\begin{array}{l}\text { Sorte Laser } \\
\text { Netz-/ Insektizidvarianten }\end{array}$} & \multicolumn{2}{|c|}{ BW Wurzelhals } & \multicolumn{2}{|c|}{ BW Stängel } \\
\hline & Kontrolle & Vert. ${ }^{1)}$ & Kontrolle & Vert. $^{1)}$ \\
\hline ohne Netz/ Chinook & $4,04 \mathrm{a}+/-$ & $4,17 \mathrm{a}$ & $3,40 \mathrm{a}$ & $3,80 \mathrm{a}$ \\
\hline ohne Netz/ Oftanol + Nexion Neu & $3,47 \mathrm{~A}-$ & $3,48 \mathrm{~A}$ & $3,20 \mathrm{~A}$ & $3,48 \mathrm{~A}$ \\
\hline Netz im Herbst/ Chinook & $4,37 \alpha+$ & $4,12 \alpha$ & $3,71 \alpha$ & $3,71 \alpha$ \\
\hline Kruskall-Wallis $\mathrm{p} \leq 0,05$ & 0,05 & 0,09 & 0,12 n.s. & 0,79 n.s. \\
\hline Sorte Lion & \multicolumn{2}{|c|}{ BW Wurzelhals } & \multicolumn{2}{|c|}{ BW Stängel } \\
\hline Netz-/ Insektizidvarianten & Kontrolle & Vert. ${ }^{1)}$ & Kontrolle & Vert. $^{1)}$ \\
\hline ohne Netz/ Chinook & $4,80 \mathrm{a}+$ & $4,99 \mathrm{a}+$ & $3,29 \mathrm{a}$ & 3,65 a \\
\hline ohne Netz/ Oftanol + Nexion Neu & $4,07 \mathrm{~A}-$ & $4,20 \mathrm{~A}-$ & $3,00 \mathrm{~A}$ & $3,45 \mathrm{~A}$ \\
\hline Netz im Herbst/ Chinook & $4,43 \alpha+/-$ & $4,70 \alpha+/-$ & $3,18 \alpha$ & $3,16 \alpha$ \\
\hline Kruskall-Wallis $\mathrm{p} \leq 0,05$ & 0,04 & 0,02 & 0,12 n.s. & 0,34 n.s. \\
\hline Sorte Caiman & \multicolumn{2}{|c|}{ BW Wurzelhals } & \multicolumn{2}{|c|}{ BW Stängel } \\
\hline Netz-/ Insektizidvarianten & Kontrolle & Vert. ${ }^{1)}$ & Kontrolle & Vert. $^{1)}$ \\
\hline ohne Netz/ Chinook & $2,55 \mathrm{a}$ & $2,49 \mathrm{a}$ & $2,48 \mathrm{a}$ & $2,44 \mathrm{a}$ \\
\hline ohne Netz/ Oftanol + Nexion Neu & $2,45 \mathrm{~A}$ & $2,64 \mathrm{~A}$ & $2,28 \mathrm{~A}$ & $2,50 \mathrm{~A}$ \\
\hline Netz im Herbst/ Chinook & $2,45 \alpha$ & $2,50 \alpha$ & $2,45 \alpha$ & $2,18 \alpha$ \\
\hline Kruskall-Wallis $\mathrm{p} \leq 0,05$ & 0,43 n.s. & $0,28 \mathrm{n} . \mathrm{s}$ & 0,52 n.s. & 0,16 n.s. \\
\hline Sorte NK Fair & \multicolumn{2}{|c|}{ BW Wurzelhals } & \multicolumn{2}{|c|}{ BW Stängel } \\
\hline Netz-/ Insektizidvarianten & Kontrolle & Vert. ${ }^{1)}$ & Kontrolle & Vert. ${ }^{1)}$ \\
\hline ohne Netz/ Chinook & 4,10 a +/- & $4,02 \mathrm{a}$ & $3,78 \mathrm{a}$ & $3,37 \mathrm{a}$ \\
\hline ohne Netz/ Oftanol + Nexion Neu & $3,58 \mathrm{~A}-$ & $3,64 \mathrm{~A}$ & $3,20 \mathrm{~A}$ & $3,46 \mathrm{~A}$ \\
\hline Netz im Herbst/ Chinook & $4,55 \alpha+$ & $4,70 \alpha$ & $3,50 \alpha$ & $3,36 \alpha$ \\
\hline Kruskall-Wallis $\mathrm{p} \leq 0,05$ & 0,02 & 0,14 n.s. & 0,40 n.s. & 0,88 n.s. \\
\hline Sorte Aviso & \multicolumn{2}{|c|}{ BW Wurzelhals } & \multicolumn{2}{|c|}{ BW Stängel } \\
\hline Netz-/ Insektizidvarianten & Kontrolle & Vert. ${ }^{1)}$ & Kontrolle & Vert. $^{1)}$ \\
\hline ohne Netz/ Chinook & $3,45 \mathrm{a}$ & $3,62 \mathrm{a}$ & $2,72 \mathrm{a}$ & $2,80 \mathrm{a}$ \\
\hline ohne Netz/ Oftanol + Nexion Neu & $3,14 \mathrm{~A}$ & $3,37 \mathrm{~A}$ & $2,70 \mathrm{~A}$ & $2,62 \mathrm{~A}$ \\
\hline Netz im Herbst/ Chinook & $3,68 \alpha$ & $3,69 \alpha$ & $2,88 \alpha$ & $2,71 \alpha$ \\
\hline Kruskall-Wallis $\mathrm{p} \leq 0,05$ & 0,12 n.s. & 0,47 n.s. & 0,73 n.s. & 0,59 n.s. \\
\hline
\end{tabular}


Um eine genauere Beurteilung abgeben zu können, inwieweit Larvenfraß der Kohlfliege Phoma-Befall am Wurzelhals beeinflusst, ist es notwendig, Befallswerte in Abhängigkeit von der Art der Fraßschädigung zu analysieren. In Tab. 22 sind die Phoma-Befallswerte am Wurzelhals getrennt nach Fraßschädigungskategorien dargestellt. Hierbei wird zwischen Pflanzen ohne Fraßschädigung, Pflanzen mit Fraßschädigung im Wurzelbereich und Pflanzen mit Fraßschädigung im Hypokotylbereich differenziert. Aufgrund von Netzeffekten sind bei der Auswertung ausschließlich Pflanzen von Varianten ohne Netzabdeckung berücksichtigt worden. Aus der Tabelle geht hervor, dass eine Fraßschädigung des Hypokotyls mit Ausnahme der Sorte Caiman bei allen anderen Sorten zu einer signifikanten Erhöhung des Phoma-Befalls am Wurzelhals gegenüber nicht oder nur im Wurzelbereich geschädigten Pflanzen führte. Die Bedeutung von Kohlfliegenbefall für $P$. lingam hängt demnach maßgeblich vom Anteil am Hypokotyl geschädigter Pflanzen ab. Im Versuchsjahr 2007/2008 wiesen durchschnittlich $38 \%$ der durch die Kohlfliege geschädigten Pflanzen auch Fraßschädigungen im Hypokotylbereich auf.

Tab. 22: Befall von P. lingam am Wurzelhals bei verschiedenen Rapssorten am Standort Weende (Schlag Dragoneranger) nach visueller Bonitur in BBCH 85; Versuchsjahr 2007/08. Aufgeführt sind mittlere Befallswerte (BW 1 (kein Befall) - BW 9 (sehr starker Befall)) von unterschiedlich durch Kohlfliegen geschädigte Pflanzen. Für die Untersuchung wurden alle Pflanzen von Varianten ohne Netzabdeckung herangezogen (je Sorte $n=400$ ). Unterschiedliche Buchstaben kennzeichnen statistisch signifikante Differenzen zwischen den Fraßschädigungskategorien bei den jeweiligen Sorten (Mann-Whitney Median-Test $\mathrm{p} \leq 0,05$ ). Kruskall-Wallis $\mathrm{p}$-Werte geben die Irrtumswahrscheinlichkeit für statistisch signifikante Unterschiede zwischen den Fraßachädigungskategorien an.

\begin{tabular}{llllll}
\hline & \multicolumn{5}{c}{ Phoma-Befallswert am Wurzelhals } \\
\cline { 2 - 6 } Schädigung durch Kohlfliegenfraß & Lion & Laser & NK Fair & Aviso & Caiman \\
\hline ohne Kohlfliegenfraß & $3,8 \mathrm{a}$ & $3,4 \mathrm{~A}$ & $3,4 \mathrm{x}$ & $3,2 \mathrm{X}$ & $2,5 \alpha$ \\
Kohlfliegenfraß an der Wurzel & $4,1 \mathrm{a}$ & $3,5 \mathrm{~A}$ & $3,6 \mathrm{x}$ & $3,3 \mathrm{X}$ & $2,5 \alpha$ \\
Kohlfliegenfraß an Wurzel + Hypokotyl & $5,4 \mathrm{~b}$ & $4,5 \mathrm{~B}$ & $4,6 \mathrm{y}$ & $3,7 \mathrm{Y}$ & $2,6 \alpha$ \\
\hline Kruskall-Wallis $\mathrm{p} \leq 0,05$ & 0,01 & 0,02 & 0,01 & 0,04 & 0,65 n.s. \\
\hline
\end{tabular}

\subsubsection{Ertragsparameter}

Der Sorten- bzw. Anbaufaktorenversuch sah eine Erhebung von Ertragsparametern vor, um mögliche Schadeffekte beteiligter Schaderreger genauer beurteilen zu können. Im Sortenversuch wurden die bereits Ende Juni gescheitelten Parzellen einzeln mit einem Mähdrescher beerntet. Mittlere Erträge [dt/ha] sowie Tausendkorngewichte [g] sind für das erste Versuchsjahr 2005/2006 in Tab. 23 aufgeführt. Nach Auswertung der Ernteergebnisse konnten bei 
insgesamt hohem Ertragsniveau keine signifikanten Ertragseffekte von Phoma- bzw. Verticillium-Inokulationen gegenüber der Kontrolle festgestellt werden. Zwischen den Insektizidvarianten Chinook und Elado + Nexion $\mathrm{Neu}$, bei denen keine oder nur geringe Unterschiede im Kohlfliegen-, Phoma- und Verticillium-Befall auftraten, zeigten sich ebenfalls keine signifikanten Unterschiede im Ertrags sowie Tausendkorngewicht.

Tab. 23: Mittlere Erträge [dt/ha] sowie Tausendkorngewichte (TKG) [g] verschiedener Winterrapssorten am Standort Weende (Schlag Große Breite); Versuchsjahr 2005/2006. Dargestellt sind die hochgerechneten Hektarerträge (Parzellengröße: $15 \mathrm{~m}^{2}$ ) auf Basis von $9 \%$ Kornfeuchte $(\mathrm{n}=4)$. Es liegen keine statistisch signifikanten Differenzen zwischen den Inokulationsvarianten bei den jeweiligen Insektizidvarianten (Saatgutbehandlung mit Chinook bzw. Saatgutbehandlung mit Elado + Austreuen des insektiziden Granulats Nexion Neu (N.) nach der Saat $\left.\left(10 \mathrm{~g} / \mathrm{m}^{2}\right)\right)$ vor $(\operatorname{LSD} \mathrm{p} \leq 0,05)$.

\begin{tabular}{|c|c|c|c|c|}
\hline \multirow{2}{*}{$\begin{array}{l}\text { Sorte Laser } \\
\text { Inokulationsvarianten }\end{array}$} & \multicolumn{2}{|c|}{ Ertrag [dt/ha] } & \multicolumn{2}{|c|}{ TKG [g] } \\
\hline & Chinook & Elado $+\mathrm{N}$ & Chinook & Elado $+\mathrm{N}$ \\
\hline Kontrolle & 50,20 & 52,80 & 4,30 & 4,26 \\
\hline Phoma-Herbst ${ }^{1)}$ & 51,28 & 50,64 & 4,15 & 4,21 \\
\hline Verticillium $^{2)}$ & 48,88 & 50,96 & 4,25 & 4,24 \\
\hline GD LSD $p \leq 0,05$ & 4,16 n.s. & 6,24 n.s. & 0,31 n.s. & 0,29 n.s. \\
\hline Sorte Lion & \multicolumn{2}{|c|}{ Ertrag [dt/ha] } & \multicolumn{2}{|c|}{ TKG $[\mathrm{g}]$} \\
\hline Inokulationsvarianten & Chinook & Elado $+\mathrm{N}$ & Chinook & Elado $+\mathrm{N}$ \\
\hline Kontrolle & 51,20 & 52,00 & 4,05 & 4,11 \\
\hline Phoma-Herbst ${ }^{1)}$ & 48,96 & 48,80 & 3,87 & 3,98 \\
\hline Verticillium $^{2)}$ & 48,24 & 50,16 & 3,96 & 4,02 \\
\hline GD LSD $p \leq 0,05$ & 5,52 n.s. & 4,88 n.s. & 0,41 n.s. & $0,31 \mathrm{n} \cdot \mathrm{s}$ \\
\hline Sorte Caiman & \multicolumn{2}{|c|}{ Ertrag [dt/ha] } & \multicolumn{2}{|c|}{ TKG [g] } \\
\hline Inokulationsvarianten & Chinook & Elado $+\mathrm{N}$ & Chinook & Elado $+\mathrm{N}$ \\
\hline Kontrolle & 51,52 & 51,84 & 3,98 & 4,11 \\
\hline Phoma-Herbst ${ }^{1)}$ & 50,56 & 53,00 & 4,05 & 4,08 \\
\hline Verticillium $^{2)}$ & 52,08 & 52,92 & 4,02 & 4,05 \\
\hline GD LSD $p \leq 0,05$ & 3,84 n.s. & 6,40 n.s. & 0,27 n.s. & 0,33 n.s. \\
\hline Sorte Oase & \multicolumn{2}{|c|}{ Ertrag [dt/ha] } & \multicolumn{2}{|c|}{ TKG $[\mathrm{g}]$} \\
\hline Inokulationsvarianten & Chinook & Elado $+\mathrm{N}$ & Chinook & Elado $+\mathrm{N}$ \\
\hline Kontrolle & 52,48 & 55,20 & 4,15 & 4,12 \\
\hline Phoma-Herbst ${ }^{1)}$ & 52,56 & 55,60 & 4,11 & 4,00 \\
\hline Verticillium $^{2)}$ & 53,92 & 53,84 & 4,07 & 4,01 \\
\hline GD LSD $p \leq 0,05$ & 4,72 n.s. & 6,32 n.s. & 0,28 n.s. & 0,41 n.s. \\
\hline
\end{tabular}

1) Phoma-Herbst: Phoma-Sprühinokulation an den Wurzelhals im Herbst (BBCH 15)

2) Verticillium: Bodeninokulation mit Verticillium-befallenem Stoppelmaterial vor der Saat $\left(15 \mathrm{~g} / \mathrm{m}^{2}\right)$ 
In Tab. 24 a sowie Tab. 24 b sind die Ernteergebnisse des zweiten Versuchsjahres 2006/2007 zusammengefasst. Die ermittelten Erträge lagen auf einem für diesen Standort niedrigen Niveau, insbesondere wenn man berücksichtigt, dass die auf Hektarbasis hochgerechneten Parzellenerträge durch Randeffekte etwas überschätzt werden. Bei der Sorte Laser, wo bereits vier Wochen vor der Ernte etwa 50\% der Pflanzen in der inokulierten Variante VerticilliumSymptome aufwiesen, konnte ein deutlich verminderter Ertrag (bis zu 20\%) gegenüber der Kontrolle festgestellt werden, was sich bei der Variante ohne Netz sowie der kombinierten Herbst- und Frühjahrsabdeckung auch absichern ließ. Hingegen waren bei der Sorte Lion, wo eine verstärkte Ausbildung von Symptomen erst kurz vor der Ernte einsetzte, keine vergleichbaren Ertragseffekte zu beobachten. Beim Vergleich der Netzvarianten wies die Variante mit Frühjahrsabdeckung i.d. R. die signifikant niedrigsten Erträge sowie Tausendkorngewichte auf. Inwieweit Kohlfliegenbefall zu einer Erhöhung der Schadwirkung von $V$. longisporum bei der Sorte Laser beigetragen hat, lässt sich aufgrund von direkten Netzeffekten nicht eindeutig bestimmen. Phoma-Inokulationen übten keinen signifikanten Einfluss auf den Ertrag aus.

Tab. 24 a: Mittlere Erträge [dt/ha] sowie Tausendkorngewichte (TKG) [g] verschiedener Winterrapssorten am Standort Weende (Schlag Große Lage); Versuchsjahr 2006/2007. Dargestellt sind die hochgerechneten Hektarerträge (Parzellengröße: $20 \mathrm{~m}^{2}$ ) auf Basis von 9\% Kornfeuchte $(\mathrm{n}=4)$. Unterschiedliche Buchstaben kennzeichnen statistisch signifikante Differenzen zwischen den Inokulationsvarianten bei den jeweiligen Netzabdeckungsvarianten. (ohne Netz; Netz-H (Netzabdeckung im Herbst); Netz-H + FJ (Netzabdeckung im Herbst + Frühjahr). (+/-) zeigen signifikante Unterschiede zwischen den Netzabdeckungsvarianten der jeweiligen Inokulationsvarianten an (LSD $\mathrm{p} \leq 0,05)$.

\begin{tabular}{|c|c|c|c|c|c|c|}
\hline \multirow{2}{*}{$\begin{array}{l}\text { Sorte Laser } \\
\text { Inokulationsvarianten }\end{array}$} & \multicolumn{3}{|c|}{ Ertrag [dt/ha] } & \multicolumn{3}{|c|}{ TKG $[\mathrm{g}]$} \\
\hline & ohne Netz & Netz-H & Netz-H + FJ & ohne Netz & Netz-H & Netz-H + FJ \\
\hline Kontrolle & $38,16 b+$ & $40,28 \mathrm{~A}+$ & $33,00 \beta-$ & $3,70 \mathrm{a}+$ & $3,46 \mathrm{~A}+$ & $3,06 \alpha-$ \\
\hline Verticillium $^{1)}$ & $30,48 a+/-$ & $34,68 \mathrm{~A}+$ & $28,08 \alpha-$ & $3,47 \mathrm{a}+$ & $3,57 \mathrm{~A}+$ & $2,99 \alpha-$ \\
\hline GD LSD $p \leq 0,05$ & 7,04 & 8,11 n.s. & 4,41 & 0,45 n.s. & 0,23 n.s. & 0,29 n.s. \\
\hline Sorte Lion & \multicolumn{3}{|c|}{ Ertrag $[\mathrm{dt} / \mathrm{ha}]$} & \multicolumn{3}{|c|}{$\mathrm{TKG}[\mathrm{g}]$} \\
\hline Inokulationsvarianten & ohne Netz & Netz-H & Netz-H + FJ & ohne Netz & Netz-H & Netz-H + FJ \\
\hline Kontrolle & $35,92 \mathrm{a}+$ & $34,32 \mathrm{~A}+$ & $29,20 \alpha-$ & $3,70 \mathrm{a}+$ & $3,64 \mathrm{~A}+$ & $3,40 \alpha-$ \\
\hline Verticillium $^{1)}$ & $34,76 \mathrm{a}+$ & $32,76 \mathrm{~A}+$ & $26,92 \alpha-$ & $3,60 \mathrm{a}$ & $3,63 \mathrm{~A}$ & $3,63 \alpha$ \\
\hline GD LSD $p \leq 0,05$ & 4,32 n.s. & 4,61 n.s. & 5,14 n.s. & 0,29 n.s. & $0,32 \mathrm{n} . \mathrm{s}$ & 0,31 n.s. \\
\hline
\end{tabular}

1) Verticillium: Bodeninokulation mit Verticillium-befallenen Stoppelmaterial vor der Saat $\left(15 \mathrm{~g} / \mathrm{m}^{2}\right)$

2) Phoma-Herbst: Phoma-Sprühinokulation an den Wurzelhals im Herbst (BBCH 15)

3) Phoma-Frühjahr.: Phoma-Sprühinokulation an den Wurzelhals im Frühjahr (BBCH 63) 
Tab. 24 b: Mittlere Erträge [dt/ha] sowie Tausendkorngewichte (TKG) [g] verschiedener Winterrapssorten am Standort Weende (Schlag Große Lage); Versuchsjahr 2006/2007. Dargestellt sind die hochgerechneten Hektarerträge (Parzellengröße: $20 \mathrm{~m}^{2}$ ) auf Basis von 9\% Kornfeuchte $(\mathrm{n}=4)$. Unterschiedliche Buchstaben kennzeichnen statistisch signifikante Differenzen zwischen den Inokulationsvarianten bei den jeweiligen Netzabdeckungsvarianten. (ohne Netz; Netz-H (Netzabdeckung im Herbst); Netz-H + FJ (Netzabdeckung im Herbst + Frühjahr). (+/-) zeigen signifikante Unterschiede zwischen den Netzabdeckungsvarianten der jeweiligen Inokulationsvarianten an (LSD $\mathrm{p} \leq 0,05)$.

\begin{tabular}{|c|c|c|c|c|c|c|}
\hline \multirow{2}{*}{$\begin{array}{l}\text { Sorte Viking } \\
\text { Inokulationsvarianten }\end{array}$} & \multicolumn{3}{|c|}{ Ertrag [dt/ha] } & \multicolumn{3}{|c|}{ TKG [g] } \\
\hline & ohne Netz & Netz-H & Netz-H + FJ & ohne Netz & Netz-H & Netz-H + FJ \\
\hline Kontrolle & $34,80 \mathrm{a}+$ & $37,24 \mathrm{~A}+$ & $29,80 \alpha-$ & $3,24 \mathrm{a}$ & $3,13 \mathrm{~A}$ & $3,32 \alpha$ \\
\hline Phoma-Herbst ${ }^{2)}$ & $34,88 \mathrm{a}+$ & $32,48 \mathrm{~A}+$ & $26,48 \alpha-$ & $3,45 \mathrm{a}+$ & $3,16 \mathrm{~A}-$ & $3,12 \alpha-$ \\
\hline Phoma-Frühjahr ${ }^{3)}$ & $31,20 \mathrm{a}+/-$ & $35,76 \mathrm{~A}+$ & $26,40 \alpha-$ & $3,41 \mathrm{a}+$ & $3,38 \mathrm{~A}+$ & $3,05 \alpha-$ \\
\hline GD LSD $\mathrm{p} \leq 0,05$ & 5,1 n.s. & $5,8 \mathrm{n} \cdot \mathrm{s}$ & 4,9 n.s. & 0,28 n.s. & 0,31 n.s. & 0,34 n.s. \\
\hline \multirow{2}{*}{$\begin{array}{l}\text { Sorte Caiman } \\
\text { Inokulationsvarianten }\end{array}$} & \multicolumn{3}{|c|}{ Ertrag [dt/ha] } & \multicolumn{3}{|c|}{ TKG $[\mathrm{g}]$} \\
\hline & ohne Netz & Netz-H & Netz-H + FJ & ohne Netz & Netz-H & Netz-H + FJ \\
\hline Kontrolle & $42,64 \mathrm{a}$ & $41,04 \mathrm{~A}$ & $37,64 \alpha$ & $3,21 \mathrm{a}+$ & $3,16 \mathrm{~A}+$ & $2,90 \alpha-$ \\
\hline Phoma-Herbst ${ }^{2)}$ & $40,12 \mathrm{a}$ & $37,40 \mathrm{~A}$ & $34,72 \alpha$ & $3,23 \mathrm{a}+$ & $3,09 \mathrm{~A}+/-$ & $2,87 \alpha-$ \\
\hline Phoma-Frühjahr ${ }^{3)}$ & $37,48 \mathrm{a}$ & $39,08 \mathrm{~A}$ & $36,52 \alpha$ & $3,11 \mathrm{a}+/-$ & $3,21 \mathrm{~A}+$ & $2,92 \alpha-$ \\
\hline GD LSD $p \leq 0,05$ & 6,43 n.s. & 4,82 n.s. & 5,11 n.s. & 0,18 n.s. & 0,22 n.s. & 0,24 n.s. \\
\hline
\end{tabular}

1) Verticillium: Bodeninokulation mit Verticillium-befallenen Stoppelmaterial vor der Saat $\left(15 \mathrm{~g} / \mathrm{m}^{2}\right)$

2) Phoma-Herbst: Phoma-Sprühinokulation an den Wurzelhals im Herbst (BBCH 15)

3) Phoma-Frühjahr.: Phoma-Sprühinokulation an den Wurzelhals im Frühjahr (BBCH 63)

Im dritten Versuchsjahr 2007/2008 wurde keine Ertragserfassung vorgenommen, da ein Hagelereignis vom 20.07.2008 keine Variantenvergleiche zuließ.

Im Anbaufaktorenversuch erfolgte die Ertragsermittlung im ersten Versuchsjahr 2005/2006 mittels Kerndrusch, wobei je Parzelle eine Mähdruschbreite auf der gesamten Parzellenlänge $(30 \mathrm{~m})$ abgeerntet wurde (Tab. 25). Ein bei der spät gesäten Pflugvariante zu verzeichnender Mehrertrag von annähernd $5 \mathrm{dt} / \mathrm{ha}$ ließ sich gegenüber den übrigen Varianten nicht absichern. Beim Parameter Tausendkorngewicht waren ebenfalls keine Unterschiede auszumachen. 
Tab. 25: Mittlere Kerndruscherträge [dt/ha] sowie Tausendkorngewichte [g] von Winterraps der Sorte Oase am Standort Weende hochgerechnet in Erträge je Hektar; Versuchsjahr 2005/06. Dargestellt sind die mittleren Erträge der verschiedenen Versuchsvarianten aus jeweils $2 \mathrm{Wdh}$. Signifikante Unterschiede zwischen den Versuchsvarianten traten nicht auf (LSD $p \leq 0,05)$.

\begin{tabular}{lcc}
\hline Varianten & $\varnothing$ Ertrag [dt/ha] & $\varnothing$ TKG [g] \\
\hline Pflug/ Frühsaat & $45,23 \mathrm{a}$ & $4,15 \mathrm{~A}$ \\
Pflug/ Spätsaat & $50,12 \mathrm{a}$ & $4,25 \mathrm{~A}$ \\
Grubber/ Frühsaat & $45,51 \mathrm{a}$ & $4,08 \mathrm{~A}$ \\
Grubber/ Spätsaat & $44,62 \mathrm{a}$ & $4,15 \mathrm{~A}$ \\
\hline GD LSD p $\leq 0,05$ & 10,15 n.s. & 0,35 n.s. \\
\hline
\end{tabular}

Im zweiten Versuchsjahr 2006/2007 musste in Folge trockenheitsbedingter Bestandesdichteunterschiede, im dritten Versuchsjahr 2007/2008 aufgrund des bereits erwähnten Hagelschadens auf eine Ertragserfassung verzichtet werden.

\subsubsection{Einfluss von Netzabdeckungen auf die Pflanzenmorphologie}

Neben der bereits angeführten negativen Beeinflussung von Ertrag und Tausendkorngewicht durch eine Netzabdeckung im Frühjahr wurde zudem überprüft, ob Netzabdeckungen im Herbst (Mitte August bis Mitte Oktober) Auswirkungen auf die Wurzel- und Sprossentwicklung von Raps haben. Hierzu wurden die zur Kohlfliegenbonitur im November entnommenen Pflanzen nach Reinigung der Wurzeln gewogen, um die Pflanzenfrischmasse zu erheben. Nach der Trocknung erfolgte zusätzlich eine Bestimmung der Wurzeltrockenmasse. In Tab. 26 sind die mittleren Pflanzenfrischmasse- sowie Wurzeltrockenmassewerte von Varianten mit und ohne Netzabdeckung angegeben. In der Gesamtbetrachtung aller Sorten und Inokulationsvarianten führten Netzabdeckungen im Vergleich zu Varianten ohne Abdeckung zu einer Erhöhung der Pflanzenfrischmasse um etwa 12\%, was sich insbesondere auf eine Förderung des Blattwachstums zurückführen lässt. Das Wurzelwachstum, repräsentiert durch den Parameter Wurzeltrockenmasse, wurde durch Netzabdeckungen nicht beeinflusst. 
Tab. 26: Mittlere Pflanzenfrischmasse [FM/Pflanze [g]] bzw. Wurzeltrockenmasse [WTM/Pflanze [g]] von Winterraps im Herbst (November) 2006 am Standort Weende (Schlag Große Lage) bei Göttingen. Dargestellt sind die über alle Sorten (Laser, Lion, Caiman, Viking) und Inokulationsvarianten (Kontrolle, Verticillium-Inokulation, Phoma-Herbstinokulation, Phoma-Frühjahrsinokulation) gemittelten Werte für Varianten ohne Netzabdeckung (40 Parzellenmittelwerte bestehend aus jeweils 25 Pflanzen) bzw. Varianten mit Netzabdeckung ${ }^{1)}$ (80 Parzellenmittelwerte bestehend aus jeweils 25 Pflanzen). Unterschiedliche Buchstaben kennzeichnen statistisch signifikante Differenzen zwischen den Netzvarianten (LSD $\mathrm{p} \leq 0,05$ ).

\begin{tabular}{lcc}
\hline Netzvarianten & FM/Pflanze $[\mathrm{g}]$ & WTM/Pflanze $[\mathrm{g}]$ \\
\hline ohne Netzabdeckung & $59,16 \mathrm{a}$ & $2,11 \mathrm{~A}$ \\
Netzabdeckung im Herbst & $66,18 \mathrm{~b}$ & $2,06 \mathrm{~A}$ \\
\hline GD LSD $\mathrm{p} \leq 0,05$ & 5,41 & 0,20 n.s. \\
\hline
\end{tabular}

1) Netz im Herbst (Auflage eines Kulturschutznetzes von Mitte August bis Mitte Oktober 2006)

Im dritten Versuchsjahr 2007/2008 erfolgte eine vergleichbare Datenerhebung im Anbaufaktorenversuch, um Effekte von Netzabdeckungen im Herbst auch vor dem Hintergrund variierender Saattermine untersuchen zu können (Tab. 27). Wiederum kam es durch die Netzabdeckung im Herbst zu einer Erhöhung der Pflanzenfrischmasse, was allerdings nur bei der Spätsaat abzusichern war. Der Parameter Wurzeltrockenmasse zeigte wie 2006/2007 keine Unterschiede zwischen Varianten mit und ohne Netzabdeckung. Sehr deutliche Wuchsunterschiede kamen beim Vergleich von Frühsaat (14.08.2007) und Spätsaat (31.08.2007) zum Vorschein. Die Pflanzenfrischmasse war bei der Frühsaat gegenüber der Spätsaat in etwa doppelt, die Wurzeltrockenmasse etwa viermal so hoch.

Tab. 27: Mittlere Pflanzenfrischmasse [FM/Pflanze [g]] bzw. Wurzeltrockenmasse [WTM/Pflanze [g]] von Winterraps der Sorte Trabant im Herbst (November) 2007 am Standort Weende (Schlag Dragoneranger) bei Göttingen. Dargestellt sind die über beide Inokulationsvarianten (Kontrolle, Verticillium-Inokulation) gemittelten Werte für Varianten ohne Netzabdeckung $(\mathrm{n}=16$ Parzellenmittelwerte bestehend aus jeweils 25 Pflanzen) bzw. Varianten mit Netzabdeckung ${ }^{1)}(\mathrm{n}=24$ Parzellenmittelwerte bestehend aus jeweils 25 Pflanzen). Unterschiedliche Buchstaben kennzeichnen statistisch signifikante Differenzen zwischen den Netzabdeckungsvarianten im Herbst. (+/-) zeigen signifikante Unterschiede zwischen Frühsaat (Saattermin 14.08.2007) und Spätsaat (Saattermin 31.08.2007) bei den jeweiligen Netzabdeckungsvarianten an (LSD $\mathrm{p} \leq 0,05)$.

\begin{tabular}{lcccccc}
\hline & \multicolumn{2}{c}{ FM/Pflanze $[\mathrm{g}]$} & & & \multicolumn{2}{c}{ WTM/Pflanze $[\mathrm{g}]$} \\
\cline { 2 - 3 } Netzvarianten & Frühsaat & & Spätsaat & & Frühsaat & Spätsaat \\
\hline ohne Netzabdeckung & $63,21 \mathrm{a}+$ & $26,39 \mathrm{~A}-$ & & $2,20 \mathrm{a}+$ & $0,49 \mathrm{~A}-$ \\
Netzabdeckung im Herbst & $68,80 \mathrm{a}+$ & $31,54 \mathrm{~B}-$ & & $2,03 \mathrm{a}+$ & $0,55 \mathrm{~A}-$ \\
\hline GD LSD $\mathrm{p} \leq 0,05$ & 7,8 n.s. & 4,32 & & & 0,32 n.s. & 0,21 n.s. \\
\hline
\end{tabular}




\subsubsection{Monitoring}

Abgesehen von eigenen Feldversuchen am Standort Göttingen wurden von 2005 bis 2007 zusätzlich Befallserhebungen der Kohlfliege und $V$. longisporum an einigen Standorten innerhalb Deutschlands durchgeführt, wo beide Schaderreger natürlich auftreten. Im Versuchsjahr 2005/2006 wurden insgesamt fünf Versuchsstandorte eines Kohlfliegenringversuchs, bei dem die Wirksamkeit verschiedener insektizider Saatgutbehandlungsmittel gegenüber den Larven der Kohlfliege überprüft wurde, beprobt. Eine Erfassung des Kohlfliegenbefalls wurde im Herbst 2005 von den jeweiligen Versuchsanstellern vorgenommen. In Tab. 28 sind die Ergebnisse der Kohlfliegenbonitur im Herbst für die Saatgutbehandlungsvarianten Chinook und Elado aufgelistet. Bei insgesamt hohem Kohlfliegenbefall traten mit Ausnahme des Standortes Dedelow kaum Unterschiede zwischen den Saatgutbehandlungsvarianten auf. Starkbefall war nur am Standort Veelböken von Bedeutung. Durch eine Saatgutbehandlung mit Elado ließ sich dieser Starkbefall gegenüber Chinook um etwa die Hälfte reduzieren.

Tab. 28: Mittlere Befallshäufigkeit [BH \%], prozentual geschädigte Wurzeloberfläche [GW \%] sowie Anteil stark befallener Pflanzen mit $\mathrm{GW} \geq 50 \%$ [SB \%] von Winterraps (Sorte Talent) mit der Kleinen Kohlfliege nach visueller Bonitur im Herbst (November) 2005. Dargestellt sind die Befallswerte der Saatgutbehandlungsvarianten Chinook bzw. Elado an verschiedenen Standorten. Je Variante wurden 100 Pflanzen untersucht. Die Datenerhebung wurde von den Versuchsanstellern vorgenommen.

\begin{tabular}{lccccccc}
\hline & \multicolumn{3}{c}{ Chinook } & & \multicolumn{3}{c}{ Elado } \\
\cline { 2 - 3 } \cline { 7 - 8 } Standorte & BH [\%] & GW [\%] & SB [\%] & & BH [\%] & GW [\%] & SB [\%] \\
\hline Nesow (MV) & 72 & 19,6 & 4 & & 67 & 19,2 & 5 \\
Veelböken (MV) & 74 & 20,4 & 15 & & 70 & 18,1 & 7 \\
Schackendorf (SH) & 61 & 16,5 & 0 & & 52 & 15,6 & 0 \\
Dedelow (BB) & 93 & 20,1 & 0 & & 69 & 19,5 & 0 \\
Leipzig (SN) & 65 & 17,5 & 0 & & 47 & 17,1 & 2 \\
\hline
\end{tabular}

Im Versuchsjahr 2006/2007 wurden Befallserhebungen auf vier Praxisflächen in Prohnsdorf (SH), Veelböken (MV), Nesow (MV) sowie Dedelow (BB) durchgeführt, die nur unweit von den vorjährigen Schlägen entfernt waren. Nachdem sich das insektizide Saatgutbehandlungsmittel Elado im Versuchsjahr 2005/2006 als unzureichend erwiesen hatte, Kohlfliegenbefall gegenüber Chinook zu verringern, wurde im Versuchsjahr 2006/2007 auch an den Monitoringstandorten versucht, Kohlfliegenbefall mit Hilfe von Kulturschutznetzen gezielt auszuschließen. In Tab. 29 sind die Ergebnisse der Kohlfliegenbefallsbonitur für die 
offenen, nicht abgedeckten Bereiche aufgeführt. An allen Standorten konnte nur ein sehr geringer Kohlfliegenbefall festgestellt werden. Bei den mit Kulturschutznetzen abgedeckten Bereichen wiesen keine der untersuchten Pflanzen Kohlfliegenfraß auf, so dass auf eine vergleichende Darstellung verzichtet wurde.

Tab. 29: Mittlere Befallshäufigkeit [BH \%], prozentual geschädigte Wurzeloberfläche [GW \%] sowie Anteil stark befallener Pflanzen mit GW $\geq 50 \%$ [SB \%] von Winterraps mit der Kleinen Kohlfliege nach visueller Bonitur im Herbst (November) 2006. Dargestellt sind die Befallswerte der nicht mit einem Kulturschutznetz abgedeckten Parzelle an verschiedenen Standorten. Je Variante wurden 100 Pflanzen untersucht.

\begin{tabular}{llccc}
\hline Standorte & Sorten & BH [\%] & GW [\%] & SB [\%] \\
\hline Veelböken (MV) & PR 45 D 01 & 25 & 6 & 3 \\
Dedelow (BB) & Artus & 31 & 8 & 6 \\
Prohnsdorf (SH) & Taurus & 26 & 7 & 4 \\
Nesow (MV) & Titan & 29 & 6 & 0 \\
\hline
\end{tabular}

Die Erhebung des Befalls der Rapspflanzen mit $V$. longisporum erfolgte wie beim Sortenund Anbaufaktorenversuch im Rahmen einer Stoppelbonitur nach der Ernte. In Abb. 19 sind die Befallsparameter der jeweiligen Standorte für das Versuchsjahr 2005/2006 dargestellt. Zwischen einzelnen Standorten traten deutliche Befallsunterschiede auf, der höchste Befall war in Nesow bei Schwerin, der geringste Befall bei Leipzig auszumachen. Zwischen den beiden Saatgutbehandlungsvarianten, die im Kohlfliegenbefall kaum differierten, gab es nur an einem Standort signifikante Unterschiede bzgl. $V$. longisporum. In Veelböken wies die mit Chinook behandelte Variante im Vergleich zur Eladovariante einen signifikant höheren Verticillium-Befall auf. Bei Betrachtung der Befallsstärke, wiedergegeben durch den Befallswert, war hingegen nur noch ein Standorteffekt erkennbar. Zwischen den Saatgutbehandlungsvarianten traten hier keine signifikanten Unterschiede mehr auf.

In Abb. 20 sind die Stoppelboniturergebnisse des zweiten Versuchsjahres 2006/2007 für die verschiedenen Netzvarianten dargestellt. Zwischen einzelnen Standorten (Sorten) traten deutliche Befallsunterschiede auf, der höchste Befall war in Veelböken, der geringste Befall in Nesow auszumachen. Eindeutige Effekte von Kohlfliegenbefall auf $V$. longisporum ließen sich vor dem Hintergrund des geringen Kohlfliegenbefalls im Herbst anhand der vorliegenden Ergebnisse nicht ableiten. 

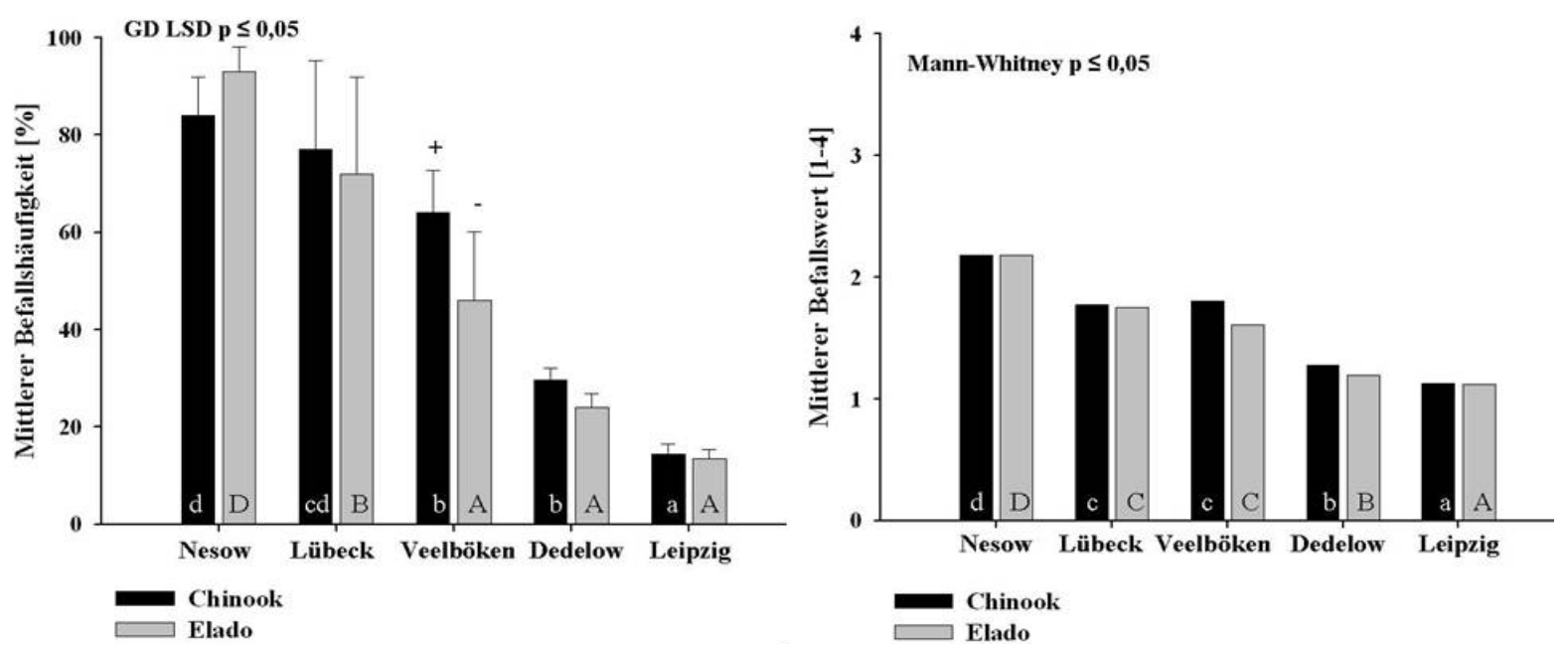

Abb. 19: Auftreten von $V$. longisporum an Winterraps der Sorte Talent nach visueller Bonitur in BBCH 92; Versuchsjahr 2005/2006. Aufgeführt sind mittlere Befallshäufigkeiten [\%] sowie mittlere Befallswerte [1 (kein Befall) - 4 (sehr starker Befall)] der verschiedenen Saatgutbehandlungsvarianten Chinook bzw. Elado an verschiedenen Standorten ( $n=4$ bestehend aus jeweils 25 Pfanzen). Unterschiedliche Buchstaben kennzeichnen statistisch signifikante Befallshäufigkeits- (LSD $p \leq 0,05)$ bzw. Befallswertunterschiede (Mann-Whitney Median-Test $\mathrm{p} \leq 0,05)$ zwischen den Standorten. (+/-) zeigen signifikante Unterschiede zwischen den Insektizidvarianten an den jeweiligen Standorten.
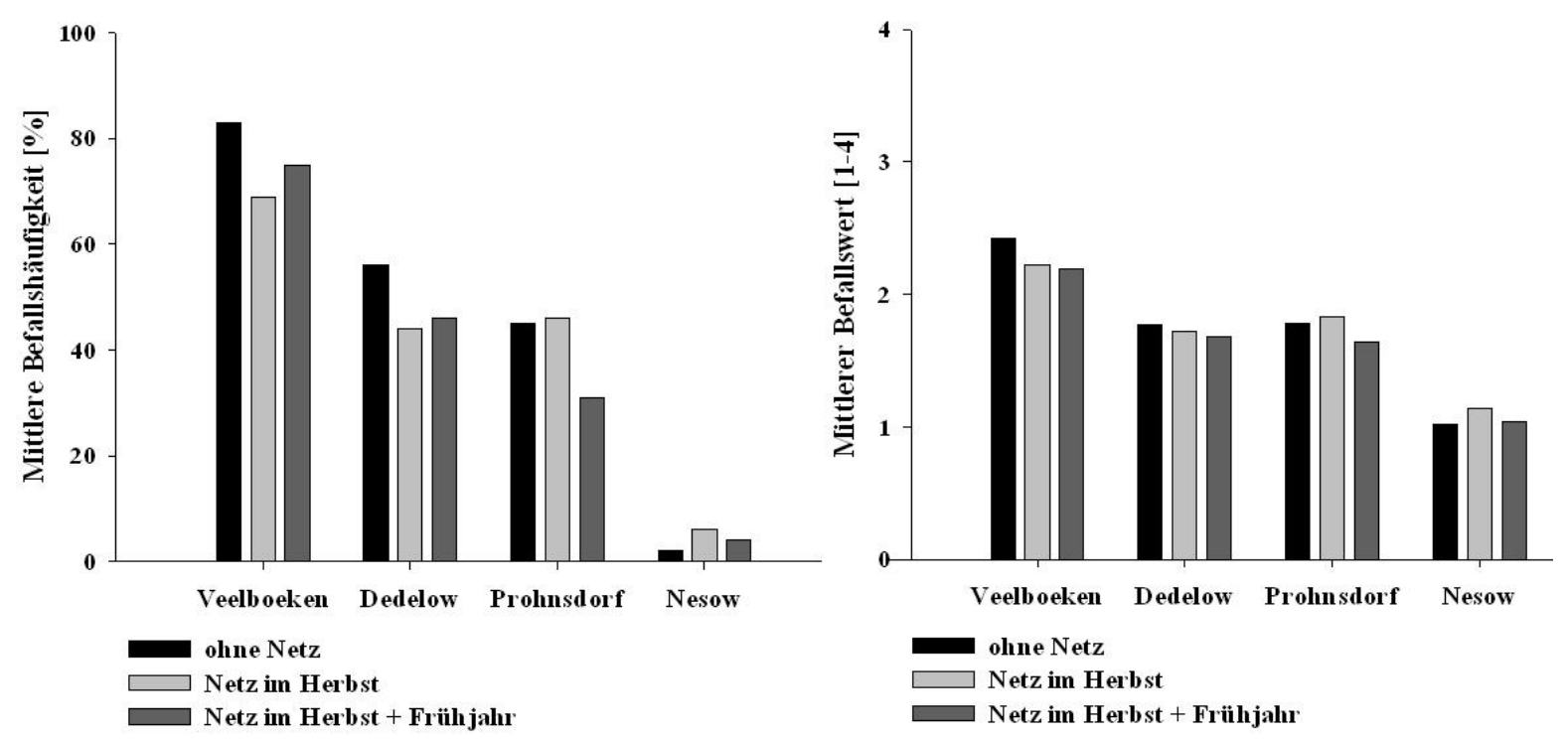

Abb. 20: Auftreten von $V$. longisporum an Winterraps nach visueller Bonitur in $\mathrm{BBCH}$ 92; Versuchsjahr 2006/2007. Aufgeführt sind mittlere Befallshäufigkeiten [\%] sowie mittlere Befallswerte [1 (kein Befall) - 4 (sehr starker Befall)] der verschiedenen Netzabdeckungsvarianten an (bei) unterschiedlichen Standorten (Sorten) $(\mathrm{n}=1$ bestehend aus jeweils 100 Pfanzen). (Veelböken (MV)/Sorte PR 45 D 01 „Halbzwerg Pioneer“; Dedelow(BB)/Sorte Artus; Prohnsdorf (SH)/Sorte Taurus; Nesow (MV)/Sorte Titan). 


\subsection{Halbfreilandversuche}

In den Halbfreilandversuchen wurden in den Jahren 2006 und 2007 am Standort „Institutsgarten" bei Göttingen Interaktionsuntersuchungen zwischen der Kohlfliege und $V$. longisporum bei gezieltem Kohlfliegenbesatz durchgeführt. Es sollte überprüft werden, ob Larvenfraß der Kleinen Kohlfliege Einfluss auf den Befall von Sommerraps mit $V$. longisporum hat und zudem geklärt werden, ob mögliche Effekte von der Höhe des Bodeninokulums abhängen. In Tab. 30 und 31 sind die Kohlfliegenbefallsparameter für Varianten mit und ohne Kohlfliegen(ei)besatz aufgeführt. In beiden Versuchsjahren wiesen nahezu alle mit Kohlfliegeneiern besetze Pflanzen Wurzelfraß auf. Mit durchschnittlich 24\% geschädigter Wurzeloberfläche und einem Anteil stark befallener Pflanzen von etwa 5\% war die Schädigung moderat. Die nicht mit Kohlfliegeneiern besetzen Varianten waren hingegen nur zu einem sehr geringen Anteil (ca. 3\% der Pflanzen) geschädigt, so dass sich die Varianten unter sonst gleichen Bedingungen nur im Kohlfliegenbefall (ja/nein) unterschieden.

Tab. 30: Mittlere Befallshäufigkeit [BH \%], prozentual geschädigte Wurzeloberfläche [GW \%] sowie Anteil stark befallener Pflanzen mit GW $\geq 50 \%$ [SB \%] von Sommerraps (Sorte Heros) mit der Kleinen Kohlfliege nach visueller Bonitur in BBCH 90 am Standort Institutsgarten bei Göttingen; Versuchsjahr 2006. Unterschiedliche Buchstaben kennzeichnen statistisch signifikante Differenzen zwischen den Inokulationsvarianten ${ }^{1)}$ bei Varianten ohne bzw. mit Kohlfliegenbesatz ${ }^{2}$ ( $\mathrm{n}=4$ bestehend aus jeweils 35 Pflanzen). (+/-) zeigen signifikante Unterschiede zwischen den Kohlfliegenvarianten bei den jeweiligen Inokulationsvarianten an (LSD p $\leq 0,05)$. Datenerhebung Müller (2007).

\begin{tabular}{|c|c|c|c|c|c|c|}
\hline \multirow{2}{*}{$\begin{array}{l}2006 \\
\text { Inokulationsvarianten }\end{array}$} & \multicolumn{3}{|c|}{ ohne Kohlfiegenbesatz } & \multicolumn{3}{|c|}{ mit Kohlfliegenbesatz } \\
\hline & $\mathrm{BH}[\%]$ & $\mathrm{GW}[\%]$ & SB [\%] & $\mathrm{BH}[\%]$ & GW [\%] & $\mathrm{SB}[\%]$ \\
\hline Kontrolle & $1,6 \mathrm{a}-$ & $0,1 \mathrm{~A}-$ & $0 \alpha-$ & $96,6 \mathrm{a}+$ & $23,0 \mathrm{~A}+$ & $2,4 \alpha+$ \\
\hline V1 (15 g) & $3,6 \mathrm{a}-$ & $0,3 \mathrm{~A}-$ & $0 \alpha-$ & $92,2 \mathrm{a}+$ & $21,3 \mathrm{~A}+$ & $6,6 \alpha+$ \\
\hline V2 (100 g) & $2,7 \mathrm{a}-$ & $0,3 \mathrm{~A}-$ & $0 \alpha-$ & $93,0 \mathrm{a}+$ & $22,2 \mathrm{~A}+$ & $4,8 \alpha+$ \\
\hline GD LSD $p \leq 0,05$ & 5,6 n.s. & $0,5 \mathrm{n} . \mathrm{s}$ & n.s. & 8,9 n.s. & 9,61 n.s. & 10,3 n.s. \\
\hline
\end{tabular}

1) Inokulationsvarianten $\left(\mathrm{je} \mathrm{m}^{2}\right)$ : Kontrolle $=100 \mathrm{~g}$ Kontrollsubstrat; V1 (15 g) = Bodeninokulation mit $15 \mathrm{~g}$ Verticillium-befallenem Stoppelmaterial + 85 g Kontrollsubstrat; V2 (100 g) = Bodeninokulation mit $100 \mathrm{~g}$ Verticillium-befallenem Stoppelmaterial. 2) Kohlfliegenvarianten $=$ ohne Kohlfliege; mit Kohlfliege $=$ Ansatz von 10 Eiern an den Wurzelhals zu BBCH 15. 
Tab. 31: Mittlere Befallshäufigkeit [BH \%], prozentual geschädigte Wurzeloberfläche [GW \%] sowie Anteil stark befallener Pflanzen mit GW $\geq 50 \%$ [SB \%] von Sommerraps (Sorte Heros) mit der Kleinen Kohlfliege nach visueller Bonitur in BBCH 90 am Standort Institutsgarten bei Göttingen, Versuchsjahr 2007. Unterschiedliche Buchstaben kennzeichnen statistisch signifikante Differenzen zwischen den Inokulationsvarianten ${ }^{1)}$ bei Varianten ohne bzw. mit Kohlfliegenbesatz ${ }^{2)}$ ( $n=4$ bestehend aus jeweils 35 Pflanzen). (+/-) zeigen signifikante Unterschiede zwischen den Kohlfliegenvarianten bei den jeweiligen Inokulationsvarianten an (LSD $p \leq 0,05)$.

\begin{tabular}{|c|c|c|c|c|c|c|}
\hline \multirow{2}{*}{$\begin{array}{l}2007 \\
\text { Inokulationsvarianten }\end{array}$} & \multicolumn{3}{|c|}{ ohne Kohlfiegenbesatz } & \multicolumn{3}{|c|}{ mit Kohlfliegenbesatz } \\
\hline & $\mathrm{BH}[\%]$ & GW [\%] & $\mathrm{SB}[\%]$ & $\mathrm{BH}[\%]$ & GW [\%] & SB [\%] \\
\hline Kontrolle & $2,1 \mathrm{a}-$ & $0,2 \mathrm{~A}-$ & $0 \alpha-$ & $90,3 \mathrm{a}+$ & $22,9 \mathrm{~A}+$ & $4,5 \alpha+$ \\
\hline V1 (10 g) & $1,6 \mathrm{a}-$ & $0,1 \mathrm{~A}-$ & $0 \alpha-$ & $96,3 \mathrm{a}+$ & $24,1 \mathrm{~A}+$ & $4,1 \alpha+$ \\
\hline $\mathrm{V} 2(50 \mathrm{~g})$ & $2 \mathrm{a}-$ & $0,1 \mathrm{~A}-$ & $0 \alpha-$ & $96,8 \mathrm{a}+$ & $27,9 \mathrm{~A}+$ & $8,3 \alpha+$ \\
\hline GD LSD $p \leq 0,05$ & 3,6 n.s. & $0,4 \mathrm{n} . \mathrm{s}$ & n.s. & 10,9 n.s. & 12,8 n.s. & 13,9 n.s. \\
\hline
\end{tabular}

1) Inokulationsvarianten $\left(\mathrm{je} \mathrm{m}^{2}\right)$ : Kontrolle $=100 \mathrm{~g}$ Kontrollsubstrat; V1 $(15 \mathrm{~g})=$ Bodeninokulation mit $10 \mathrm{~g}$ Verticillium-befallenem Stoppelmaterial $+40 \mathrm{~g}$ Kontrollsubstrat; V2 $(50 \mathrm{~g})=$ Bodeninokulation mit $50 \mathrm{~g}$ Verticillium-befallenem Stoppelmaterial). 2) Kohlfliegenvarianten $=$ ohne Kohlfliege; mit Kohlfliege $=$ Ansatz von 10 Eiern an den Wurzelhals zu BBCH 15.

Eindeutige Verticillium-Symptome ließen sich wie bei Winterraps erst mit beginnender Abreife beobachten, wobei der Anteil symptomatischer Pflanzen ab BBCH 85 deutlich zunahm. In der Vegetationsperiode wurden von Mai bis Ende August in vierwöchigem Abstand jeweils acht Pflanzen pro Variante aus der Versuchsanlage entnommen und mittels Druckkammermethode Xylemflüssigkeit gewonnen, $\mathrm{um} \mathrm{zu}$ überprüfen, ob sich $V$. longisporum bereits in der Pflanze nachweisen lässt. In Tab. 32 sind die Nachweishäufigkeiten aufgeführt. Im Jahr 2006 ließ sich V. longisporum ab BBCH 77 in einigen Pflanzen nachweisen, wobei die stärker inokulierten Varianten sowie die durch Kohlfliegen geschädigte Variante „V1 $+\mathrm{KF}^{“}$ höhere Nachweishäufigkeiten verzeichneten als die Variante „V1“ ohne Kohlfliegenbefall. Im Jahr 2007 konnten erste positive Nachweise trotz niedrigerer Bodeninokulummengen bereits ab BBCH 55 festgestellt werden. Ab BBCH 77 kam es zu einer deutlichen Zunahme positiver Befunde. Unterschiede zwischen Varianten mit und ohne Kohlfliegenbefall deuteten sich wiederum nur bei der geringeren Bodeninokulationsstufe „V1“" an. 
Tab. 32: Nachweishäufigkeiten von $V$. longisporum in Xylemflüssigkeit im unterem Pflanzenbereich (Wurzel + Hypokotyl + Sprossbasis) untersuchter Sommerrapspflanzen zu BBCH 55 bzw. BBCH 77; Versuchsjahr 2006 und 2007; Standort Institutsgarten (Göttingen). Aufgeführt ist die Anzahl positiv getesteter Pflanzenproben und die Anzahl jeweils untersuchter Rapspflanzen (n gesamt) der verschiedenen Versuchsvarianten. ${ }^{1)}$

\begin{tabular}{|c|c|c|c|c|}
\hline \multirow{2}{*}{$\begin{array}{l}2006 \\
\text { Inokulationsvarianten }\end{array}$} & \multicolumn{2}{|c|}{ BBCH 55} & \multicolumn{2}{|c|}{ BBCH 77} \\
\hline & positiv & $\mathrm{n}$ gesamt & positiv & $\mathrm{n}$ gesamt \\
\hline Kontrolle & 0 & 4 & 1 & 4 \\
\hline Kohlfliege (KF) & 0 & 4 & 1 & 4 \\
\hline V1 (15 g) & 0 & 8 & 2 & 8 \\
\hline $\mathrm{V} 1+\mathrm{KF}$ & 0 & 8 & 5 & 8 \\
\hline V2 $(100 \mathrm{~g})$ & 0 & 8 & 6 & 8 \\
\hline $\mathrm{V} 2+\mathrm{KF}$ & 0 & 8 & 5 & 8 \\
\hline 2007 & \multicolumn{2}{|c|}{ BBCH 55} & \multicolumn{2}{|c|}{ BBCH 77} \\
\hline Inokulationsvarianten & positiv & $\mathrm{n}$ gesamt & positiv & $\mathrm{n}$ gesamt \\
\hline Kontrolle & 0 & 4 & 1 & 4 \\
\hline Kohlfliege (KF) & 0 & 4 & 1 & 4 \\
\hline V1 (10 g) & 0 & 8 & 3 & 8 \\
\hline $\mathrm{V} 1+\mathrm{KF}$ & 0 & 8 & 5 & 8 \\
\hline V2 $(50 \mathrm{~g})$ & 2 & 8 & 6 & 8 \\
\hline $\mathrm{V} 2+\mathrm{KF}$ & 2 & 8 & 7 & 8 \\
\hline
\end{tabular}

1) Inokulationsvarianten (je m²) 2006 (2007): Kontrolle $=100$ g (50 g) Kontrollsubstrat; V1 = Bodeninokulation mit $15 \mathrm{~g} \mathrm{(10} \mathrm{g)} \mathrm{Verticillium-befallenem} \mathrm{Stoppelmaterial} \mathrm{+} 85 \mathrm{~g} \mathrm{(40} \mathrm{g)} \mathrm{Kontrollsubstrat;} \mathrm{V2} \mathrm{=} \mathrm{Boden-}$ inokulation mit $100 \mathrm{~g}(50 \mathrm{~g})$ Verticillium-befallenem Stoppelmaterial. Kohlfliegenvarianten $=$ ohne Kohlfliege (ohne KF); mit Kohlfliege (mit KF) = Ansatz von 10 Eiern an den Wurzelhals zu BBCH 15.

Die Ergebnisse der visuellen Befallsbonitur, bei der alle Pflanzen nach der Abreife untersucht wurden, sind für die Versuchsjahre 2006 sowie 2007 in Abb. 21 bzw. 22 dargestellt. Aus den Abbildungen ist ersichtlich, dass die mit Kohlfliegeneiern besetzte Variante der niedrigeren Bodeninokulationsstufe V1 in beiden Versuchsjahren einen deutlich höheren VerticilliumBefall aufwies als die vergleichbare Variante ohne Kohlfliegenbefall. Mit zunehmender Inokulummenge stieg der Anteil symptomatischer Pflanzen erwartungsgemäß an, wobei die Unterschiede zwischen den Varianten mit und ohne Kohlfliegenbefall hier geringer ausfielen.

Die Verticillium-Befallswerte erreichten im Jahr 2007 trotz geringerer Inokulummengen ein höheres Niveau als 2006. Signifikant höhere Befallswerte bei Varianten mit Kohlfliegenbefall waren im Jahr 2006 bei der Variante V1 $\left(15 \mathrm{~g} / \mathrm{m}^{2}\right)$, im Jahr 2007 sowohl bei V1 $\left(10 \mathrm{~g} / \mathrm{m}^{2}\right)$ als auch bei V2 $\left(50 \mathrm{~g} / \mathrm{m}^{2}\right)$ festzustellen. 

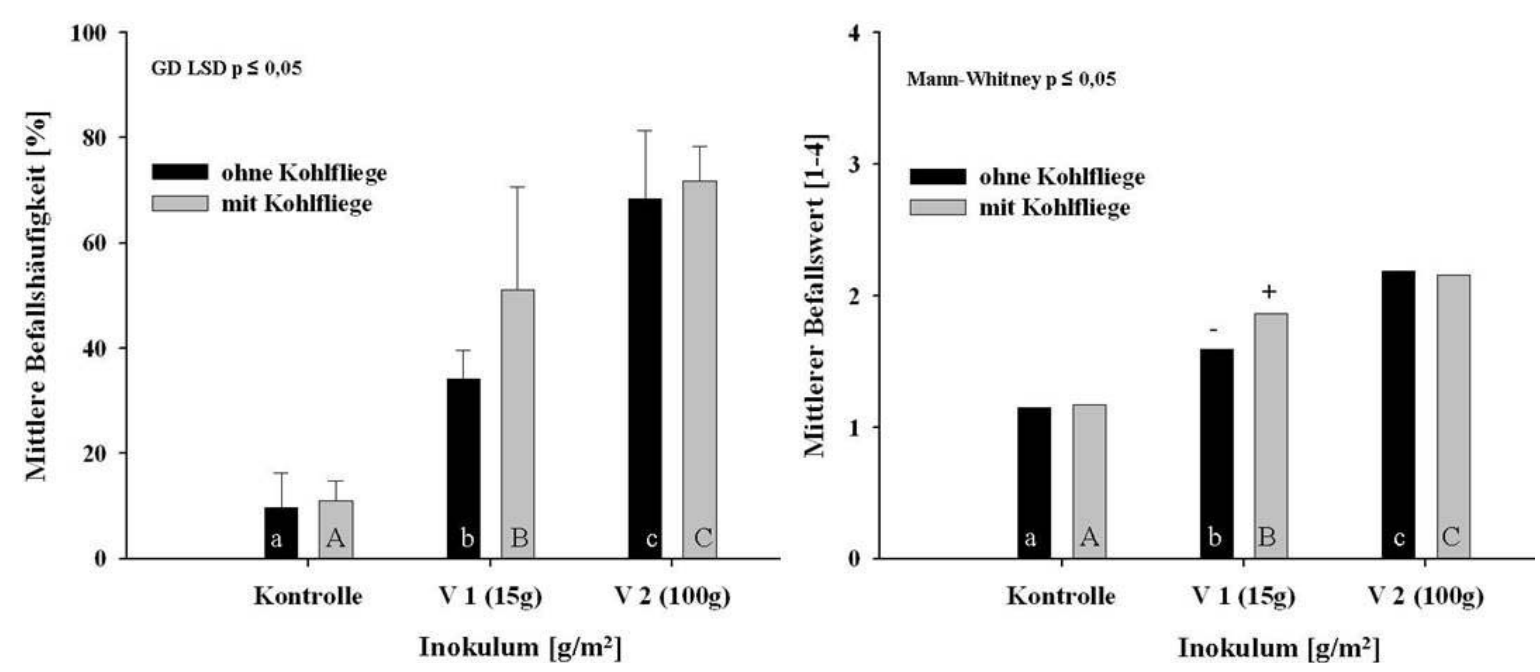

Abb. 21: Auftreten von $V$. longisporum an Sommerraps der Sorte Heros (Saatgutbehandlung mit Chinook) am Standort Institutsgarten bei Göttingen nach visueller Bonitur in BBCH 90; Versuchsjahr 2006. Aufgeführt sind mittlere Befallshäufigkeiten [\%] sowie mittlere Befallswerte [1 (kein Befall) 4 (sehr starker Befall)] der verschiedenen Inokulations/Kohlfliegenvarianten $\left.{ }^{1}\right)(n=4$ Parzellen bestehend aus jeweils 35 Pfanzen). Unterschiedliche Buchstaben kennzeichnen statistisch signifikante Befallshäufigkeits- (LSD $\mathrm{p} \leq 0,05)$ bzw. Befallswertunterschiede (Mann-Whitney Median-Test $\mathrm{p} \leq$ $0,05)$ zwischen den Inokulationsvarianten bei den jeweiligen Kohlfliegenvarianten. (+/-) zeigen signifikante Unterschiede zwischen den Kohlfliegenvarianten bei den jeweiligen Inokulationsvarianten an. 1) Inokulationsvarianten: Kontrolle $=100 \mathrm{~g}$ Kontrollsubstrat; V1 (15 g) = Bodeninokulation mit 15 g Verticillium-befallenem Stoppelmaterial + 85 g Kontrollsubstrat; V2 (100 g) = Bodeninokulation mit $100 \mathrm{~g}$ Verticillium-befallenem Stoppelmaterial). Kohlfliegenvarianten $=$ ohne Kohlfliege; mit Kohlfliege = Ansatz von 10 Eiern an den Wurzelhals zu BBCH 15. Datenerhebung Müller (2007). 

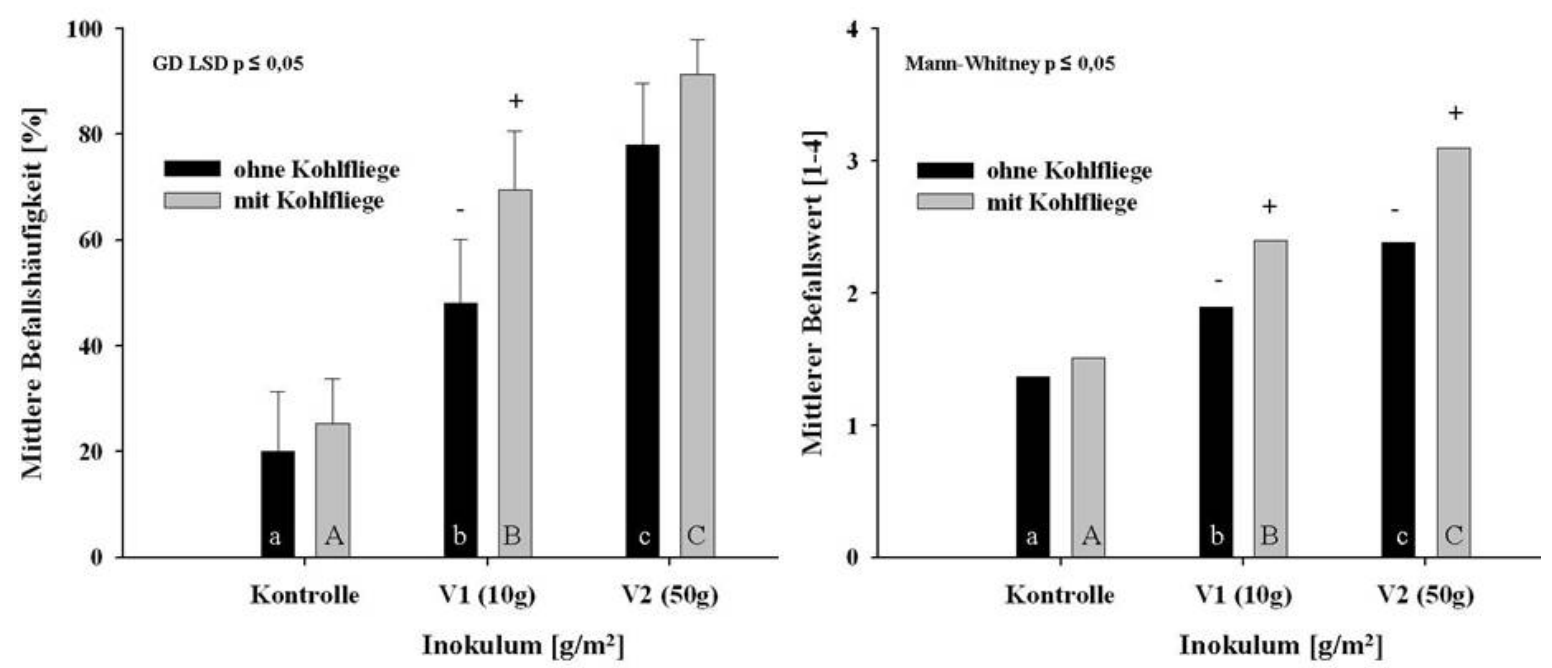

Abb. 22: Auftreten von $V$. longisporum an Sommerraps der Sorte Heros (Saatgutbehandlung mit Chinook) am Standort Institutsgarten bei Göttingen nach visueller Bonitur in BBCH 90; Versuchsjahr 2007. Aufgeführt sind mittlere Befallshäufigkeiten [\%] sowie mittlere Befallswerte [1 (kein Befall) - 4 (sehr starker Befall)] der verschiedenen Inokulations/Kohlfliegenvarianten ${ }^{1)}$ ( $\mathrm{n}=4$ Parzellen bestehend aus jeweils 35 Pfanzen). Unterschiedliche Buchstaben kennzeichnen statistisch signifikante Befallshäufigkeits- (LSD $\mathrm{p} \leq 0,05$ ) bzw. Befallswertunterschiede (Mann-Whitney Median-Test $\mathrm{p} \leq 0,05)$ zwischen den Inokulationsvarianten bei den jeweiligen Kohlfliegenvarianten. $(+/-)$ zeigen signifikante Unterschiede zwischen den Kohlfliegenvarianten bei den jeweiligen Inokulationsvarianten an. 1) Inokulationsvarianten: Kontrolle $=50 \mathrm{~g}$ Kontrollsubstrat; V1 (10 g) = Bodeninokulation mit $10 \mathrm{~g}$ Verticillium-befallenem Stoppelmaterial $+40 \mathrm{~g}$ Kontrollsubstrat; V2 $(50 \mathrm{~g})=$ Bodeninokulation mit $50 \mathrm{~g}$ Verticillium-befallenem Stoppelmaterial). Kohlfliegenvarianten $=$ ohne Kohlfliege; mit Kohlfliege = Ansatz von 10 Eiern an den Wurzelhals zu BBCH 15.

\subsection{Gewächshausversuche}

\subsubsection{Einfluss der Kleinen Kohlfliege auf den Befall von Raps mit V. longisporum}

\subsubsection{Sortenversuch}

In einem Gewächshausversuch wurden im Jahr 2006 kontrollierte Interaktionsuntersuchungen zwischen der Kleinen Kohlfliege und $V$. longisporum bei Winterraps der Sorten Laser und Lion durchgeführt. Im Vordergrund der Untersuchungen stand dabei die Beantwortung der Frage, ob Larvenfraß der Kohlfliege einen Einfluss auf den VerticilliumBefall sowie dessen Schadwirkung haben, und wenn ja, inwieweit sich hierbei eine anfällige (Laser) von einer weniger anfälligen Sorte (Lion) unterscheidet. Darüber hinaus sollte überprüft werden, ob etwaige Interaktionseffekte vom Zeitpunkt des Erscheinens der

Kohlfliege sowie der Höhe des Bodeninokulums abhängen. In Tab. 33 ist der am Versuchsende bonitierte Wurzelfraß der verschiedenen Kohlfliegenvarianten angegeben. Zwischen den Inokulationsvarianten traten keine Unterschiede im Kohlfliegenbefall auf, so 
dass hier nur zwischen den Kohlfliegenvarianten differenziert wird. Pflanzen ohne Kohlfliegenbesatz zeigten erwartungsgemäß keine Fraßschädigungen, Pflanzen mit Kohlfliegenbesatz hingegen immer Fraßschädigungen auf. Varianten, bei denen Kohlfliegeneier zu einem frühen Zeitpunkt angesetzt worden waren, wiesen mit annähernd 50\% geschädigter Wurzeloberfläche eine vergleichsweise hohe Fraßschädigung auf, die sich signifikant von der Variante mit spätem Eiansatz absetzte. Zwischen den Sorten Laser und Lion waren keine Unterschiede auszumachen. Mit den verschiedenen Kohlfliegenvarianten konnte die vorgesehene Abstufung des Kohlfliegenbefalls (kein Befall; früher Befall (Simulierung der Herbstgeneration); später Befall (Simulierung der Frühjahrsgeneration)) sehr gut erreicht werden.

Tab. 33: Prozentual geschädigte Wurzeloberfläche der Sorten Laser bzw. Lion durch die Larven der Kleinen Kohlfliege nach visueller Bonitur 150 dpi (BBCH 90). Dargestellt sind die über alle Inokulationsvarianten (Kontrolle, Bodeninokulation mit 0,05 mg bzw. 0,25 mg Mikrosklerotien/g Boden) gemittelten Werte für die verschiedenen Kohlfliegenvarianten (ohne Kohlfliegenbesatz, Ansatz von 8 Kohlfliegeneiern zu BBCH 15 (früh) bzw. zu BBCH 61 (spät)) (n=45). Unterschiedliche Buchstaben kennzeichnen statistisch signifikante Differenzen zwischen den Kohlfliegenvarianten bei den jeweiligen Sorten (LSD $\mathrm{p} \leq 0,05$ ).

\begin{tabular}{lcc}
\hline & \multicolumn{2}{c}{ Fraßschädigung [\%] } \\
\cline { 2 - 3 } Kohlfliegenvarianten & Laser & Lion \\
\hline ohne Kohlfliegenbesatz & $0 \mathrm{a}$ & $0 \mathrm{~A}$ \\
Kohlfliegenbesatz zu BBCH 15 & $49,2 \mathrm{c}$ & $48,1 \mathrm{C}$ \\
Kohlfliegenbesatz zu BBCH 61 & $34,1 \mathrm{~b}$ & $36,9 \mathrm{~B}$ \\
\hline GD LSD $\mathrm{p} \leq 0,05$ & 8,41 & 7,76 \\
\hline
\end{tabular}

In Tab. 34 sind die nach visueller Ganzpflanzenbonitur zu BBCH 90 ermittelten VerticilliumBefallswerte inokulierter Rapspflanzen der Sorten Laser und Lion angegeben. Bei den zugehörigen Kontrollvarianten konnte kein Verticillium-Befall festgestellt werden, so dass auf eine vergleichende Darstellung verzichtet wurde. Die anfällige Sorte Laser reagierte auf eine Bodeninokulation erwartungsgemäß mit stärkerem Befall als die moderat anfällige Sorte Lion, auch wenn nicht alle Varianten signifikante Unterschiede zeigten. Die höhere Bodeninokulationsstufe führte bei beiden Sorten zu steigenden Befallswerten. Varianten, bei denen Kohlfliegeneier zu einem frühen Zeitpunkt angesetzt worden waren, verzeichneten bei beiden Sorten höchste Befallswerte bei der jeweiligen Inokulationsstufe. Jedoch lediglich bei der Sorte Lion führte eine frühe Kohlfliegenfraßschädigung auch zu einer signifikanten Erhöhung der Befallswerte gegenüber der Variante ohne Kohlfliegenbefall. Varianten mit spät angesetzten Kohlfliegeneiern zeigten bei Lion einen gewissen Befallswerteffekt, der 
allerdings nicht abzusichern war. Die Untersuchungsergebnisse stimmen mit den Ergebnissen der Feldversuche (Sortenversuch 2006/2007) darin überein, dass es insbesondere durch eine frühe Kohlfliegenfraßschädigung zu einer Förderung des Verticillium-Befalls kommen kann, eine später auftretende Schädigung zur Blüte hingegen keine Auswirkungen mehr hat. Deutlichere Effekte bei der moderat anfälligen Sorte Lion im Vergleich zur anfälligen Sorte Laser entsprechen ebenfalls den Beobachtungen der Feldver- suche (vgl. 3.1.3.1).

Tab. 34: Mittlerer Befallswert [1 (kein Befall)- 4 (starker Befall)] Verticillium-inokulierter Rapspflanzen der Sorten Laser und Lion mit $V$. longisporum 150 dpi $(n=15)$. Statistisch signifikante Differenzen zwischen den Versuchsvarianten ${ }^{1)}$ sind für jeweilige Sorten durch unterschiedliche Buchstaben gekennzeichnet (Kruskall-Wallis $p \leq 0,05)$. (+/-) zeigen signifikante Sortenunterschiede bei den jeweiligen Inokulationsvarianten an (Mann-Whitney $\mathrm{p} \leq 0,05$ ).

\begin{tabular}{llll}
\hline \multirow{2}{*}{ Inokulum } & & \multicolumn{2}{c}{ Befallswert [1-4] } \\
\cline { 3 - 4 } $0,05 \mathrm{mg} \mathrm{MS}$ & Kohlfliege & $2,1 \mathrm{a}+$ & $1,3 \mathrm{~A}$ - \\
& ohne Kohlfliege & $2,4 \mathrm{ab}$ & $1,9 \mathrm{~B}$ \\
& Kohlfliege-früh & $2,1 \mathrm{a}+$ & $1,5 \mathrm{AB}$ - \\
& Kohlfliege-spät & $2,8 \mathrm{ab}+$ & $1,8 \mathrm{~B}-$ \\
& & $3,1 \mathrm{~b}+$ & $2,2 \mathrm{C}-$ \\
$0,25 \mathrm{mg}$ MS & ohne Kohlfliege & $2,6 \mathrm{ab}+$ & $1,9 \mathrm{BC}-$ \\
\hline Kruskall-Wallis $\mathrm{p} \leq 0,05$ & Kohlfliege-früh & 0,01 & 0,02 \\
\hline
\end{tabular}

1) Bodeninokulation mit Mikrosklerotiengemisch der V. longisporum-Isolate VL $40+\mathrm{VL} 43$ in Höhe von 0,05 bzw. 0,25 mg Mikrosklerotien (MS)/g Boden (1050 g Boden/Topf). Kohlfliegenvarianten: Kontrolle $=$ ohne Eiansatz, Kohlfliege-früh bzw. Kohlfliege-spät = Ansatz von 8 Eiern an den Wurzelhals zu BBCH 15 bzw. BBCH 61.

Am Versuchsende mit dem ELISA gemessene OD (Optische Dichte)-Werte [E $405 \mathrm{~nm}$ ] sind in Tab. 35 aufgeführt. Die Quantifizierung von $V$. longisporum in der Pflanze deckt sich nur teilweise mit den Ergebnissen der visuellen Bonitur. Bei insgesamt hohem OD-Wertniveau lag sortenübergreifend höherer Stängel- als Wurzelbefall vor. In Übereinstimmung mit der visuellen Bonitur wies die frühe Kohlfliegenvariante der Sorte Lion die höchsten OD-Werte im sortenspezifischen Vergleich auf, die mit einer Ausnahme auch signifikant gegenüber der Variante ohne Kohlfliegenbefall waren. Bei der Sorte Laser war kein Effekt von Kohlfliegenbefall auf die Besiedlung am Versuchsende zu erkennen. Beim Vergleich der Sorten konnten im Gegensatz zur visuellen Bonitur nur wenige signifikante Unterschiede, i. d. R. bei Varianten ohne Kohlfliegenbefall festgestellt werden. 
Tab. 35: Mittlere mit dem ELISA gemessene OD-Werte [Extinktion (E) $405 \mathrm{~nm}$ ] in Stängel bzw. Wurzel bei Verticillium-inokulierten Rapspflanzen der Sorten Laser und Lion 150 dpi (BBCH 90). Je Versuchsvariante ${ }^{1)}$ wurden 15 Pflanzen in Mischgruppen gleicher Boniturnote untersucht. Dargestellt sind die mittleren OD-Werte bereinigt um Negativkontrollwerte. Statistisch signifikante Differenzen zwischen den Versuchsvarianten sind für die jeweiligen Sorten durch unterschiedliche Buchstaben gekennzeichnet (Kruskall-Wallis $\mathrm{p} \leq 0,05)$. (+/-) zeigen signifikante Sortenunterschiede bei den jeweiligen Inokulationsvarianten an (Mann-Whitney $\mathrm{p} \leq 0,05$ ).

\begin{tabular}{|c|c|c|c|c|c|}
\hline \multirow[b]{2}{*}{ Inokulum } & \multirow[b]{2}{*}{ Kohlfliege } & \multicolumn{2}{|c|}{ OD-Stängel } & \multicolumn{2}{|c|}{ OD-Wurzel } \\
\hline & & Laser & Lion & Laser & Lion \\
\hline \multirow{3}{*}{$0,05 \mathrm{mg}$ MS } & ohne Kohlfliege & $1,32 \mathrm{a}+$ & $0,50 \mathrm{~A}-$ & $0,65 \mathrm{a}+$ & $0,30 \mathrm{~A}-$ \\
\hline & Kohlfliege-früh & $1,31 \mathrm{a}$ & $1,05 \mathrm{BC}$ & $0,73 \mathrm{ab}$ & $0,60 \mathrm{~B}$ \\
\hline & Kohlfliege-spät & $1,20 \mathrm{a}+$ & $0,59 \mathrm{~A}-$ & $0,59 \mathrm{a}$ & $0,54 \mathrm{AB}$ \\
\hline \multirow{3}{*}{$0,25 \mathrm{mg}$ MS } & ohne Kohlfliege & $1,51 \mathrm{a}$ & $1,27 \mathrm{C}$ & $1,00 \mathrm{~b}+$ & $0,57 \mathrm{AB}-$ \\
\hline & Kohlfliege-früh & $1,42 \mathrm{a}$ & $1,47 \mathrm{C}$ & $0,84 \mathrm{ab}$ & $0,96 \mathrm{C}$ \\
\hline & Kohlfliege-spät & $1,30 \mathrm{a}$ & $1,01 \mathrm{BC}$ & $0,70 \mathrm{ab}$ & $0,59 \mathrm{AB}$ \\
\hline \multicolumn{2}{|c|}{ Kruskall-Wallis $\mathrm{p} \leq 0,05$} & 0,21 n.s. & 0,01 & 0,03 & 0,01 \\
\hline
\end{tabular}

1) Bodeninokulation mit Mikrosklerotiengemisch der $V$. longisporum-Isolate VL $40+$ VL 43 in Höhe von 0,05 bzw. 0,25 mg Mikrosklerotien (MS)/g Boden (1050 g Boden/Topf). Kohlfliegenvarianten: Kontrolle $=$ ohne Eiansatz, Kohlfliege-früh bzw. Kohlfliege-spät = Ansatz von 8 Eiern an den Wurzelhals zu BBCH 15 bzw. BBCH 61.

Neben der Erfassung von Kohlfliegen- und Verticillium-Befall wurden die Pflanzenlänge, Spross- und Wurzeltrockenmasse erhoben, um die Schadwirkungen genauer zu beurteilen. Da ein alleiniger Kohlfliegenbefall keine pflanzenmorphologischen Effekte zur Folge hatte, sind in Tab. 36 ausschließlich Werte inokulierter Varianten in Relation zu den jeweiligen Kontrollwerten [100\%] angegeben. Die absoluten Werte sind im Anhang dargestellt (Abb. 1A). Bei der Sorte Laser nahm die mittlere Pflanzenlänge bei allen Kohlfliegenvarianten mit zunehmender Bodeninokulation ab. Aufgrund einer relativ hohen Variabilität konnte ein signifikanter Inokulationseffekt gegenüber den Kontrollvarianten erst bei der höheren Bodeninokulationsstufe festgestellt werden. Die Sorte Lion zeigte eine von der Kohlfliegenvariante abhängige Reaktion der Pflanzenlänge. Varianten ohne Kohlfliegenbefall bzw. mit spätem Eiansatz reagierten erst bei der höheren Bodeninokulationsstufe mit reduzierten Pflanzenlängen. Die frühe Kohlfliegenvariante verzeichnete hingegen schon bei der niedrigeren Bodeninokulationsstufe eine gegenüber der Kontrolle, sowie den anderen Kohlfliegenvarianten signifikant niedrigere Pflanzenlänge. Bei der Sprosstrockenmasse wies die Sorte Laser bereits bei der niedrigeren Bodeninokulation signifikante Inokulationseffekte auf. Eine höhere Bodeninokulation führte zu stärker abnehmenden Werten, wobei allerdings nur die frühe Kohlfliegenvariante eine weitere signifikante Reduktion aufzeigte. Bei der 
Sorte Lion führte die niedrigere Bodeninokulationsstufe wiederum nur bei der frühen Kohlfliegenvariante $\mathrm{zu}$ einer signifikanten Sprossmasse- reduktion. Bei höherer Bodeninokulation zeigten auch die anderen Kohlfliegenvarianten signifikante Inokulationseffekte an. Reaktionen der Wurzeltrockenmasse entsprachen denen der Sprossmasse. Zwischen einzelnen Varianten differierende Inokulationseffekte ließen sich bei allen untersuchten pflanzenmorphologischen Parametern relativ gut mit der visuellen Befallswertabstufung in Übereinstimmung bringen.

Tab. 36: Mittlere Pflanzenlänge [PFL], Sprosstrockenmasse [STM] sowie Wurzeltrockenmasse [WTM] Verticillium-inokulierter Rapspflanzen der Sorten Laser bzw. Lion in Relation zu den jeweiligen Kontrollvarianten 150 dpi (BBCH 90). Statistisch signifikante Differenzen zwischen den Inokulationsvarianten $^{1)}$ sind für die jeweiligen Kohlfliegenvarianten ${ }^{2)}$ durch unterschiedliche Buchstaben gekennzeichnet. (+/-) zeigen signifikante Unterschiede zwischen den Kohlfliegenvarianten bei den jeweiligen Inokulationsvarianten an (LSD $\leq p 0,05 ; \mathrm{n}=15)$.

\begin{tabular}{|c|c|c|c|c|c|c|}
\hline \multirow{2}{*}{$\begin{array}{l}\text { rel. PFL [\%] } \\
\text { Inokulationsvarianten }\end{array}$} & \multicolumn{3}{|c|}{ Sorte Laser } & \multicolumn{3}{|c|}{ Sorte Lion } \\
\hline & ohne KF & KF-früh & KF-spät & ohne KF & KF-früh & KF-spät \\
\hline Kontrolle & $100 \mathrm{~b}$ & $100 \mathrm{~B}$ & $100 \alpha$ & $100 \mathrm{~b}$ & $100 \mathrm{~B}$ & $100 \beta$ \\
\hline $0,05 \mathrm{mg} \mathrm{MS}$ & $84,5 \mathrm{ab}$ & $82 \mathrm{AB}$ & $86,5 \alpha \beta$ & $94,5 \mathrm{ab}+$ & $81,7 \mathrm{~A}-$ & $98,4 \beta+$ \\
\hline $0,25 \mathrm{mg} \mathrm{MS}$ & $72,1 \mathrm{a}$ & $60,1 \mathrm{~A}$ & $73,8 \alpha$ & 86,0 a & $79,1 \mathrm{~A}$ & $82,8 \alpha$ \\
\hline GD LSD $p \leq 0,05$ & 16,6 & 21,2 & 14,2 & 8,7 & 13,2 & 8,9 \\
\hline rel. STM [\%] & \multicolumn{3}{|c|}{ Sorte Laser } & \multicolumn{3}{|c|}{ Sorte Lion } \\
\hline Inokulationsvarianten & ohne KF & KF-früh & KF-spät & ohne KF & KF-früh & KF-spät \\
\hline Kontrolle & $100 \mathrm{~b}$ & $100 \mathrm{C}$ & $100 \beta$ & $100 \mathrm{~b}$ & $100 \mathrm{C}$ & $100 \beta$ \\
\hline $0,05 \mathrm{mg} \mathrm{MS}$ & 79,1 a & $74,1 \mathrm{~B}$ & $74,2 \alpha$ & $110,7 \mathrm{~b}+$ & $84,8 \mathrm{~B}-$ & $105,9 \beta+/-$ \\
\hline $0,25 \mathrm{mg} \mathrm{MS}$ & $66,1 \mathrm{a}$ & $52,7 \mathrm{~A}$ & $61,5 \alpha$ & $78,5 \mathrm{a}$ & $65,0 \mathrm{~A}$ & $70,6 \alpha$ \\
\hline GD LSD $p \leq 0,05$ & 17,5 & 16,1 & 17,2 & 17,9 & 14,6 & 15,9 \\
\hline rel. WTM [\%] & \multicolumn{3}{|c|}{ Sorte Laser } & \multicolumn{3}{|c|}{ Sorte Lion } \\
\hline Inokulationsvarianten & ohne KF & KF-früh & KF-spät & ohne KF & KF-früh & KF-spät \\
\hline Kontrolle & $100 \mathrm{~b}$ & $100 \mathrm{C}$ & $100 \beta$ & $100 \mathrm{~b}$ & $100 \mathrm{~B}$ & $100 \beta$ \\
\hline $0,05 \mathrm{mg} \mathrm{MS}$ & $80,8 \mathrm{ab}$ & $78,5 \mathrm{~B}$ & $81,7 \alpha \beta$ & $101,5 b+$ & $72,3 \mathrm{~A}-$ & $89,3 \alpha \beta+/-$ \\
\hline $0,25 \mathrm{mg} \mathrm{MS}$ & 72,9 a & $54,5 \mathrm{~A}$ & $75,5 \alpha$ & $80,2 \mathrm{a}$ & $67,4 \mathrm{~A}$ & $78,5 \alpha$ \\
\hline GD LSD $\mathrm{p} \leq 0,05$ & 22,7 & 18,9 & 21,1 & 16,5 & 18,3 & 18 \\
\hline
\end{tabular}

1) Bodeninokulation mit Mikrosklerotiengemisch der $V$. longisporum-Isolate VL $40+$ VL 43 in Höhe von 0,05 bzw. 0,25 mg Mikrosklerotien (MS)/g Boden (1050 g Boden/Topf). 2) Kohlfliegenvarianten: Kontrolle $=$ ohne Eiansatz, Kohlfliege-früh bzw. Kohlfliege-spät $=$ Ansatz von 8 Eiern an den Wurzelhals zu BBCH 15 bzw. BBCH 61 


\subsubsection{Inokulationsstufenversuch}

In einem weiteren Gewächshausversuch wurden kontrollierte Interaktionsuntersuchungen zwischen der Kohlfliege und $V$. longisporum an Sommerraps der Sorte Heros (moderat anfällig gegenüber $V$. longisporum) durchgeführt. Es sollte überprüft werden, ob die durch Kohlfliegen bedingte Förderung des Verticillium-Befalls von der Höhe des Bodeninokulums abhängt. Neben einer Kontrolle wurden entweder 0,25, 0,5, 1, 2 oder $4 \mathrm{~g}$ stark mit Verticillium-befallenes, klein gemahlenes Stoppelmaterial vor der Saat in den Boden eingemischt. Jede Inokulationsstufe kam einmal in einer Variante ohne und einmal in einer Variante mit Kohlfliegenbefall vor. Bei letztgenannter Variante wiesen alle Pflanzen am Versuchsende Kohlfliegenbefall auf. Mit durchschnittlich 33\% geschädigter Wurzeloberfläche war die Fraßschädigung moderat. Die im Rahmen der Endbonitur erhobenen mittleren Verticillium-Befallswerte sind für Varianten mit und ohne Kohlfliegenbefall in Abb. 23 aufgeführt. Nahezu alle inokulierten Pflanzen zeigten am Versuchsende MS-Besatz auf. Sowohl bei Varianten mit, als auch bei Varianten ohne Kohlfliegenbefall stiegen die mittleren Befallswerte mit zunehmendem Bodeninokulum an. Mit Kohlfliegeneiern besetzte Pflanzen wiesen ab 0,5 g Bodeninokulum etwas höhere Verticillium-Befallswerte als Pflanzen ohne Kohlfliegenbefall auf, absichern ließen sich diese Unterschiede allerdings nicht.

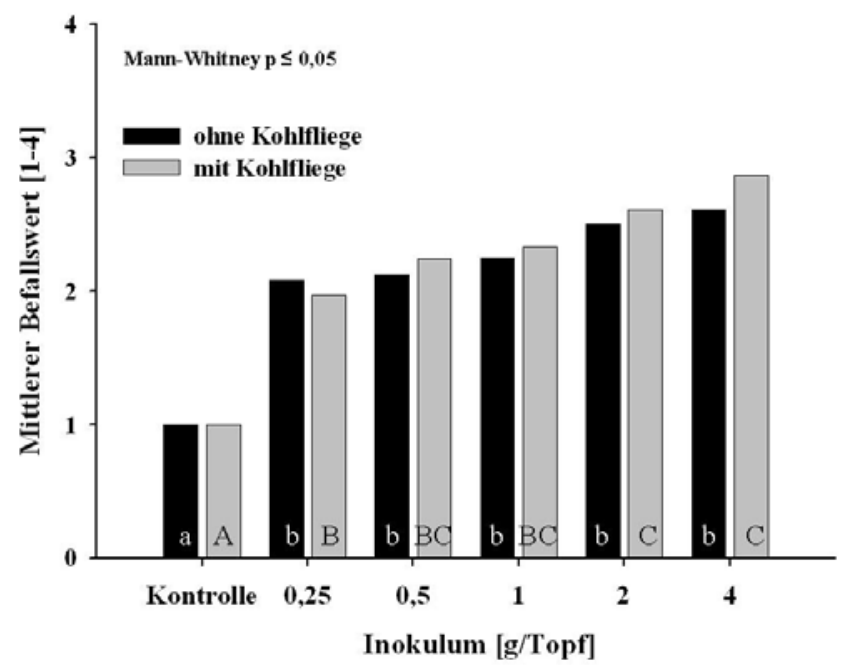

Abb. 23: Mittlerer Befallswert [1 (kein Befall) - 4 (starker Befall)] von Sommerraps (Sorte Heros) mit $V$. longisporum 155 dpi $(\mathrm{BBCH} 90)(\mathrm{n}=12)$. Statistisch signifikante Differenzen zwischen den Bodeninokulationsstufen sind für Varianten mit und ohne Kohlfliegenbefall durch unterschiedliche Buchstaben gekennzeichnet (Mann-Whitney Median-Test $\mathrm{p} \leq 0,05$ ). Bodeninokulation mit stark Verticillium-befallenem, klein gemahlenem Stoppelmaterial in Höhe von 0 (Kontrolle), 0,25, 0,5, 1, 2 oder 4 g/Topf (1050 g Boden/Topf). Kohlfliegenvarianten = ohne Kohlfliege; mit Kohlfliege: Ansatz von 8 Eiern an den Wurzelhals zu BBCH 15. 
Nach Abreife des Rapses erfolgte eine destruktive Endbonitur, bei der neben der Beurteilung von Kohlfliegen- und Verticillium-Befall auch eine Reihe von pflanzenmorphologischen Parametern erhoben wurden, um Schadeffekte $\mathrm{zu}$ beurteilen. Da ein alleiniger Kohlfliegenbefall keine pflanzenmorphologischen Auswirkungen zur Folge hatte, sind in Tab. 37 ausschließlich Werte inokulierter Varianten in Relation zu den jeweiligen Kontrollwerten [100\%] angegeben. Absolute Werte sind im Anhang zu finden (Tab. 17A). Bei den Parametern Pflanzenlänge, Sprosstrockenmasse sowie Wurzeltrockenmasse konnten bereits bei geringer Bodeninokulation signifikant niedrigere Werte im Vergleich zur Kontrolle ausgemacht werden. Ein signifikanter Inokulationseffekt ließ sich beim Einzelpflanzenertrag erst ab 1 g Bodeninokulum bei Varianten ohne Kohlfliegenbefall, bzw. ab 0,5 g Bodeninokulum bei Varianten mit Kohlfliegenbefall absichern. Der größte Inokulationseffekt war beim Parameter Wurzeltrockenmasse zu erkennen, wo der Unterschied zwischen der Kontrolle und der am stärksten inokulierten Variante etwa 50\% (ohne Kohlfliege) bzw. 60\% (mit Kohlfliege) betrug. Kohlfliegenbefall führte ab $1 \mathrm{~g}$ Bodeninokulum zu einer Erhöhung von Inokulationseffekten gegenüber Varianten ohne Kohlfliegenbefall. Ein signifikanter Unterschied konnte allerdings erst bei $4 \mathrm{~g}$ Bodeninokulum absichert werden.

Tab. 37: Mittlere Pflanzenlänge [PFL], Sprosstrockenmasse [STM], Wurzeltrockenmasse [WTM] sowie Einzelpflanzenkornertrag inokulierter Rapspflanzen der Sorte Heros in Relation zu den jeweiligen Kontrollvarianten 155 dpi (BBCH 90). Statistisch signifikante Differenzen zwischen den Inokulationsvarianten ${ }^{1)}$ sind für die jeweiligen Kohlfliegenvarianten ${ }^{2)}$ durch unterschiedliche Buchstaben gekennzeichnet. (+/-) zeigen signifikante Unterschiede zwischen den Kohlfliegenvarianten bei den jeweiligen Inokulationsvarianten an (LSD $\leq p 0,05 ; n=12$ ).

\begin{tabular}{|c|c|c|c|c|c|c|c|c|}
\hline \multirow[b]{2}{*}{ Inokulum [g] } & \multicolumn{2}{|c|}{ rel. PFL [\%] } & \multicolumn{2}{|c|}{ rel. STM [\%] } & \multicolumn{2}{|c|}{ rel. WTM [\%] } & \multicolumn{2}{|c|}{ rel. Ertrag [\%] } \\
\hline & ohne KF & mit KF & ohne KF & mit KF & ohne KF & mit KF & ohne KF & mit KF \\
\hline 0 & $100 \mathrm{c}$ & $100 \mathrm{C}$ & $100 \mathrm{~b}$ & $100 \mathrm{D}$ & $100 \mathrm{c}$ & $100 \mathrm{D}$ & $100 \mathrm{~b}$ & $100 \mathrm{C}$ \\
\hline 0,25 & $95,2 \mathrm{~b}$ & $94,7 \mathrm{BC}$ & 86,2 a & $87,6 \mathrm{C}$ & $67,1 \mathrm{~b}$ & $69,2 \mathrm{C}$ & $86,8 \mathrm{ab}$ & $89,2 \mathrm{BC}$ \\
\hline 0,5 & $93,6 \mathrm{ab}$ & $92,7 \mathrm{~B}$ & $85,4 \mathrm{a}$ & $81,6 \mathrm{BC}$ & $65,8 \mathrm{~b}$ & $57,5 \mathrm{BC}$ & $88,7 \mathrm{ab}$ & $84,8 \mathrm{~B}$ \\
\hline 1 & $95,1 \mathrm{~b}$ & $89,1 \mathrm{AB}$ & $83,3 \mathrm{a}$ & $76,7 \mathrm{~B}$ & $58,2 \mathrm{ab}$ & $54,4 \mathrm{ABC}$ & $86,7 \mathrm{ab}$ & $83,5 \mathrm{~B}$ \\
\hline 2 & $90,3 \mathrm{a}$ & $89,9 \mathrm{AB}$ & 79,3 a & $74,8 \mathrm{AB}$ & $59,1 \mathrm{ab}$ & $47,2 \mathrm{AB}$ & $79,5 \mathrm{a}$ & $71,2 \mathrm{~A}$ \\
\hline 4 & $90,1 \mathrm{a}+$ & 84,7 A - & $75,8 \mathrm{a}+$ & 66,4 A - & $50,2 \mathrm{a}+$ & $41,2 \mathrm{~A}-$ & $80,1 \mathrm{a}+$ & $62,2 \mathrm{~A}-$ \\
\hline GD LSD $p<0,05$ & 4.7 & 5,9 & 11.7 & 9,1 & 13,1 & 12,4 & 13,5 & 12,3 \\
\hline
\end{tabular}

1) Bodeninokulation mit stark Verticillium-befallenem, klein gemahlenem Stoppelmaterial in Höhe von 0 (Kontrolle), 0,25, 0,5, 1, 2 oder 4 g/Topf (1050 g Boden/Topf). 2) Kohlfliegenvarianten: ohne KF = ohne Kohlfliege; mit KF = mit Kohlfliege, Ansatz von 8 Eiern an den Wurzelhals zu BBCH 15. 
Die Höhe der Inokulationseffekte ließ sich relativ gut mit der Befallswertabstufung (Abb. 23) in Überereinstimmung bringen. Signifikant höhere Inokulationseffekte bei Varianten mit im Vergleich zu Varianten ohne Kohlfliegenbefall bei $4 \mathrm{~g}$ Bodeninokulum gingen allerdings nur mit einem tendenziellen Befallswertunterschied am Versuchsende einher. Mögliche Unterschiede in der Befallsdynamik wurden daher in einem weiterführenden Versuch (vgl. 3.3.1.3) untersucht.

\subsubsection{Befallsdynamikversuch}

Im Befallsdynamikversuch wurde im Jahr 2007 überprüft, inwieweit Larvenfraß der Kohlfliege Einfluss auf die Ausbreitung von $V$. longisporum in der Pflanze nimmt und welche Rolle hierbei die Höhe des Bodeninokulums spielt. In Übereinstimmung mit dem Inokulationsstufenversuch wurden die Interaktionsuntersuchungen an Sommerraps der Sorte Heros durchgeführt, wobei neben einer Kontrolle eine Bodeninokulation mit 0,2, 1 oder $5 \mathrm{~g}$ stark mit Verticillium befallenem Stoppelmaterial erfolgte. Varianten, bei denen Kohlfliegeneier angesetzt worden waren, zeigten mit durchschnittlich 35\% geschädigter Wurzeloberfläche eine moderate Fraßschädigung.

In Tab. 38 ist die nach visueller Ganzpflanzenbonitur erhobene BH mit $V$. longisporum aufgeführt. $\mathrm{Zu}$ den ersten beiden Boniturterminen wurden Blattsymptome zum letzten Boniturtermin MS-Besatz als Kriterium für Verticillium-Befall herangezogen. Zu 56 dpi (BBCH 55) waren nur bei wenigen Pflanzen eindeutige Verticillium-Symptome zu erkennen. Zum zweiten Boniturtermin (84 dpi; BBCH 75) nahm der Anteil symptomatischer Pflanzen deutlich zu, wobei chlorotische Blätter mit beginnender Schwarzadrigkeit insbesondere bei Varianten der höheren Bodeninokulationsstufen auftraten. Aus der Tabelle ist zudem ersichtlich, dass Larvenfraß ab $1 \mathrm{~g}$ Bodeninokulum zu einer verstärkten Symptomentwicklung geführt hat. Beim Vergleich von Varianten mit und ohne Kohlfliegenbefall kam der Unterschied bei $5 \mathrm{~g}$ Bodeninokulum besonders zum Vorschein. Zum letzten Boniturtermin (125 dpi; BBCH 90) wies ein Großteil inokulierter Pflanzen MS-Besatz auf. Zwischen den inokulierten Varianten waren hier nur noch geringe Unterschiede beim Parameter BH auszumachen.

Die im Rahmen der Endbonitur (125 dpi) erhobenen mittleren Verticillium-Befallswerte sind in Abb. 24 dargestellt. Bei insgesamt moderatem Befallsniveau war eine Zunahme mittlerer Befallswerte mit ansteigendem Bodeninokulum zu beobachten. Mit Kohlfliegeneiern besetzte 
Varianten wiesen etwas höhere Verticillium-Befallswerte als Varianten ohne

Kohlfliegenbefall auf. Absichern ließen sich diese Unterschiede allerdings nicht.

Tab. 38: Mittlere Befallshäufigkeit [\%] von Sommerraps (Sorte Heros) mit V. longisporum 56 dpi (BBCH 55), 84 dpi $(\mathrm{BBCH} 75)$ sowie 125 dpi $(\mathrm{BBCH} 90)(\mathrm{n}=12)$. Aufgeführt ist der Anteil symptomatischer Pflanzen der verschiedenen Inokulationsvarianten ${ }^{1)}$ mit bzw. ohne Kohlfliegenbefall. $\left.{ }^{2}\right) \mathrm{Zu}$ den ersten beiden Boniturterminen wurden Pflanzen mit eindeutigen Blattsymptomen, zum letzten Boniturtermin Pflanzen mit MS-Besatz als Kriterium für Verticillium-Befall herangezogen.

\begin{tabular}{|c|c|c|c|c|c|c|}
\hline \multirow{2}{*}{$\begin{array}{l}\text { Befallshäufigkeit [\%] } \\
\text { Inokulum [g/Topf] }\end{array}$} & \multicolumn{2}{|c|}{56 dpi (BBCH55) } & \multicolumn{2}{|c|}{84 dpi (BBCH 75) } & \multicolumn{2}{|c|}{125 dpi (BBCH 90) } \\
\hline & ohne KF & mit KF & ohne KF & mit KF & ohne KF & mit KF \\
\hline 0 & 0 & 0 & 0 & 0 & 0 & 0 \\
\hline 0,2 & 0 & 0 & 16,7 & 16,7 & 66,7 & 75 \\
\hline 1 & 0 & 0 & 33,3 & 50 & 91,7 & 100 \\
\hline 5 & 8,3 & 16,7 & 50 & 83,3 & 100 & 100 \\
\hline
\end{tabular}

1) Bodeninokulation mit Verticillium-befallenem, klein gemahlenem Stoppelmaterial in Höhe von 0 (Kontrolle), 0,2, 1 oder $5 \mathrm{~g}$ /Topf (1050 g Boden/Topf). 2) Kohlfliegenvarianten: ohne $\mathrm{KF}=$ ohne Kohlfliege; mit $\mathrm{KF}=$ mit Kohlfliege, Ansatzvon 8 Eiern an den Wurzelhals zu BBCH 15).

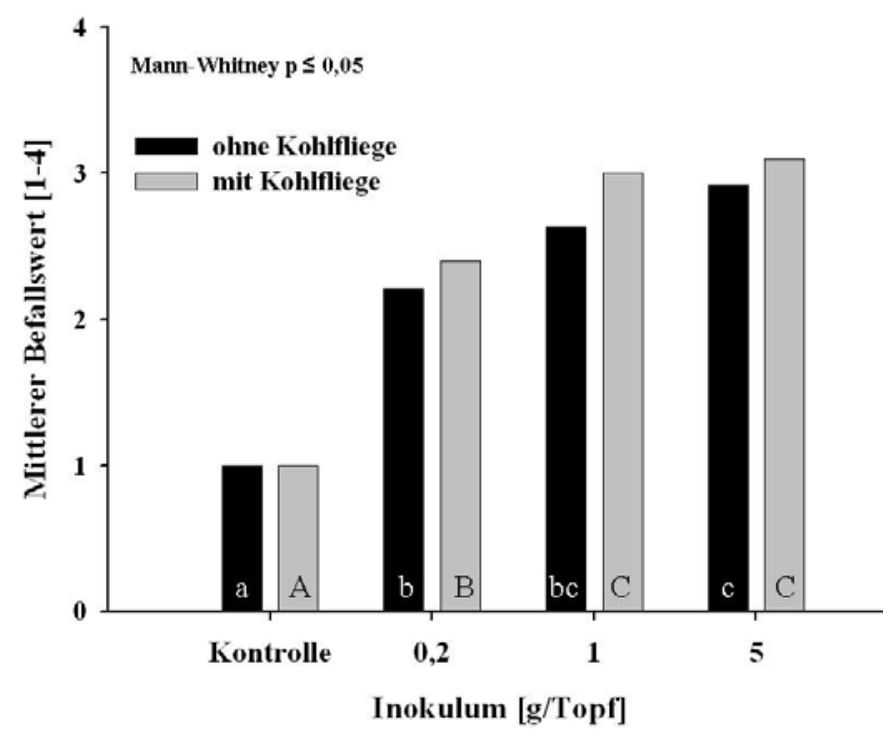

Abb. 24 : Mittlerer Befall [1 (kein Befall) - 4 (starker Befall)] von Sommerraps (Sorte Heros) mit $V$. longisporum 125 dpi $(\mathrm{BBCH} 90)(\mathrm{n}=12)$. Statistisch signifikante Differenzen zwischen den Inokulationsstufen sind für Varianten mit und ohne Kohlfliegenbefall durch unterschiedliche Buchstaben gekennzeichnet (Mann-Whitney Median-Test $\mathrm{p} \leq 0,05$ ). Bodeninokulation mit stark Verticillium-befallenem, klein gemahlenem Stoppelmaterial in Höhe von 0 (Kontrolle), 0,2, 1 oder 5 g/Topf (1050 g Boden/Topf). Kohlfliegenvarianten $=$ ohne Kohlfliege; mit Kohlfliege: Ansatz von 8 Eiern an den Wurzelhals zu BBCH 15. 
Zusätzlich zur visuellen Befallsbonitur erfolgten Real-Time PCR-Untersuchungen, um die Ausbreitungsdynamik von $V$. longisporum erfassen zu können. In Abb. 25 ist die mittlere Verticillium-DNA [ng/g TM] im Hypokotyl bzw. unterem Stängelbereich zu den unterschiedlichen Boniturterminen dargestellt. Bei den Kontrollpflanzen konnte kein Verticillium-Befall detektiert werden, so dass nur Messwerte inokulierter Varianten angegeben sind.
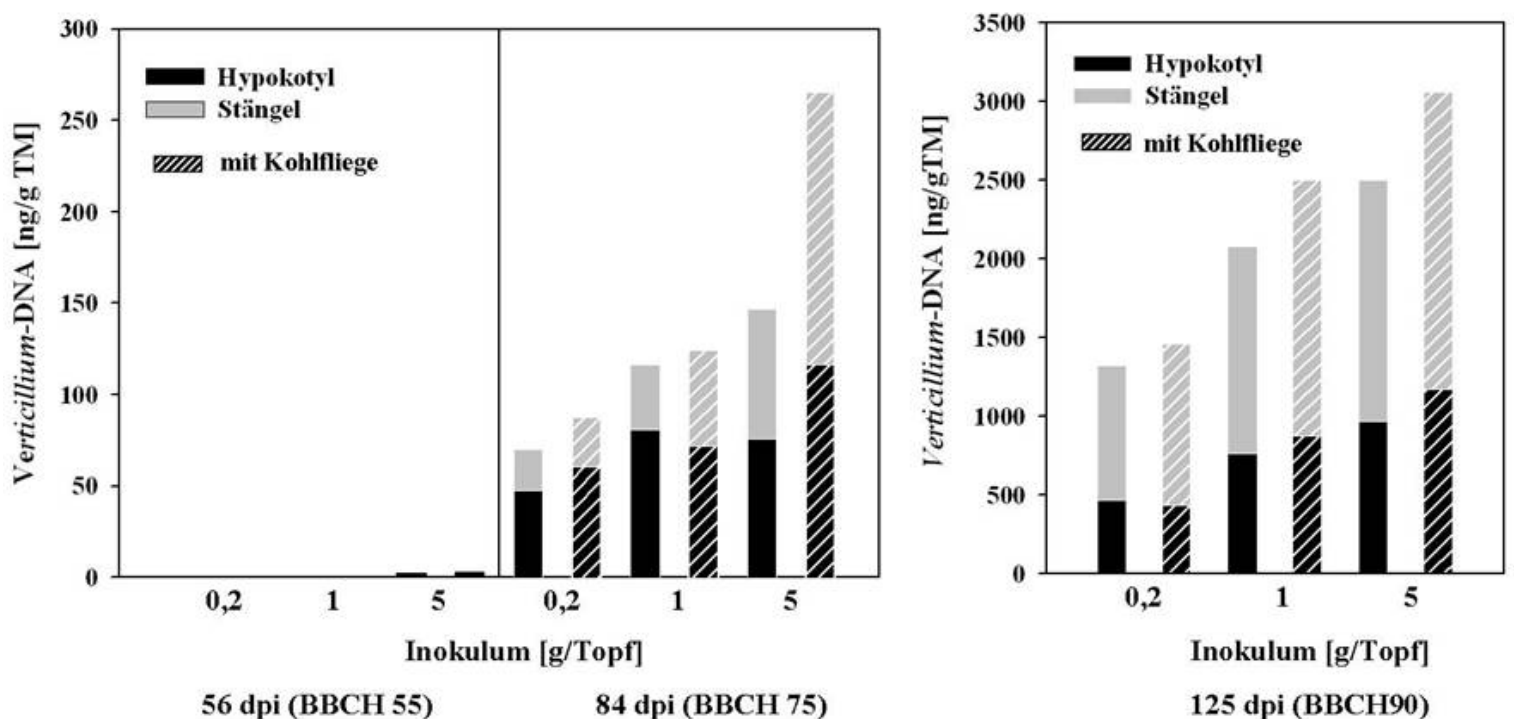

Abb. 25: Quantifizierung von Verticillium-DNA [ng/g TM] im Hypokotyl bzw. unterem Stängelbereich Verticillium-inokulierter Sommerrapspflanzen der Sorte Heros 56 dpi (BBCH 55), 84 dpi (BBCH 75) sowie 125 dpi (BBCH 90) mit Real-Time PCR. Dargestellt sind die Mittelwerte $(\mathrm{n}=6$ bestehend aus jeweils 2 Pflanzen) für Varianten mit und ohne Kohlfliegenbefall. Bodeninokulation mit stark Verticillium-befallenem, klein gemahlenem Stoppelmaterial in Höhe von 0,2, 1 oder 5 g/Topf (1050 g Boden/Topf). Kohlfliegenvarianten = ohne Kohlfliege; mit Kohlfliege: Ansatz von 8 Eiern an den Wurzelhals zu BBCH 15.

Zum ersten Boniturtermin (56 dpi; BBCH 55) konnten lediglich in zwei Hypokotylmischproben geringe Mengen Verticillium-DNA nachgewiesen werden. Zu 84 dpi (BBCH 75) ließ sich in allen untersuchten Mischproben Verticillium-Befall feststellen. DNA-Mengen im Hypokotyl lagen hierbei mit Ausnahme einer Variante (5 g Inokulum mit Kohlfliegenbefall) über denen des Stängelbereichs. Varianten mit Kohlfliegenbefall wiesen bei 0,2 und $1 \mathrm{~g}$ Bodeninokulum etwas höhere Messwerte gegenüber Varianten ohne Kohlfliegenbefall auf. Bei 5 g Bodeninokulum verzeichnete die Kohlfiegen geschädigte Variante deutlich stärkeren Verticillium-Befall als die nicht Kohlfliegen geschädigte Variante. Dieses Ergebnis lässt sich gut mit der in Tab. 38 dokumentierten dynamischeren Symptomentwicklung in Übereinstimmung bringen. Die zum letzten Boniturtermin verstärkt einsetzende MS-Bildung ging mit einer deutlichen Zunahme von Verticillium-DNA im Pflanzengewebe einher. Gegenüber 
84 dpi waren die Werte zwölf bis zwanzigfach erhöht (beachte unterschiedliche Skalierung). Bei insgesamt hohem Besiedlungsniveau von $V$. longisporum lag Stängelbefall nun deutlich über dem des Hypokotyls. Die Varianten mit Kohlfliegenbefall zeigten im Vergleich zu Varianten ohne Kohlfliegenbefall nach wie vor höhere Verticillium-DNA-Mengen an, wobei die Unterschiede bei $1 \mathrm{~g}$ und $5 \mathrm{~g}$ stärker zum Tragen kamen als bei 0,2 $\mathrm{g}$ Bodeninokulum.

Die zur Beurteilung von Schadwirkungseffekten herangezogenen pflanzenmorphologischen Parameter (Pflanzenlänge, Sprossfrischmasse, Wurzeltrockenmasse) sind in Tab. 39 angegeben. Hierbei handelt es sich um Werte inokulierter Varianten in Relation zu den jeweiligen Kontrollwerten. Absolute Werte sind im Anhang dokumentiert (Tab. 18A). Bereits zu 56 dpi ließen sich einige Inokulationseffekte ausmachen, obgleich PCR-Nachweis und Symptombonitur zu diesem Zeitpunkt kaum Befall anzeigten. Varianten ohne Kohlfliegenbefall verzeichneten bei $1 \mathrm{~g}$ sowie $5 \mathrm{~g}$ Bodeninokulum bei der Sprossfrischmasse signifikant niedrigere Werte als die Kontrolle. Bei Varianten mit Kohlfliegenbefall ließen sich signifikante Inokulationseffekte bei allen Parametern feststellen. Die zum zweiten Boniturzeitpunkt (84 dpi) berechneten Inokulationseffekte spiegeln die Situation des ersten Boniturtermins wider. Trotz stärkerer Ausbreitung in der Pflanze (vgl. Abb. 25) ließ sich keine höhere Schadwirkung gegenüber 56 dpi feststellen. Am Versuchsende zeigten Varianten ohne Kohlfliegenbefall bei 5 g Bodeninokulum signifikante Inokulationseffekte bei den Parametern Sprossfrischmasse sowie Wurzeltrockenmasse an. Varianten mit Kohlfliegenbefall wiesen bei diesen Parametern bereits ab 1 g Bodeninokulum signifikant niedrigere Werte gegenüber der Kontrolle auf. Kohlfliegenfraß führte bei den Parametern Sprossfrischmasse (1 g, $5 \mathrm{~g})$ und Pflanzenlänge (5 g) zu einem signifikanten Anstieg der Schadwirkung von $V$. longisporum. Eine vergleichsweise geringe Bodeninokulation mit 0,2 g Inokulummaterial hatte keine signifikanten Inokulationseffekte zur Folge. Auffällig war, dass die Variante ohne Kohlfliegenbefall hier bei allen Parametern tendenziell positive Inokulationseffekte aufwies, während die Variante mit Kohlfliegenbefall tendenziell niedrigere Werte im Vergleich zur Kontrolle verzeichnete. 
Tab. 39: Mittlere Pflanzenlänge [PFL], Sprossfrischmasse [SFM] sowie Wurzeltrockenmasse [WTM] Verticillium-inokulierter Rapspflanzen der Sorte Heros in Relation $\mathrm{zu}$ den jeweiligen Kontrollvarianten (100\%) 56 dpi (BBCH 55), 84 dpi (BBCH 75) sowie 125 dpi (BBCH 90). Statistisch signifikante Differenzen zwischen den Inokulationsvarianten ${ }^{1)}$ sind für die jeweiligen Kohlfliegenvarianten ${ }^{2}$ durch unterschiedliche Buchstaben gekennzeichnet. (+/-) zeigen signifikante Unterschiede zwischen den Kohlfliegenvarianten bei den jeweiligen Inokulationsvarianten an $(\operatorname{LSD} \mathrm{p} \leq 0,05 ; \mathrm{n}=12)$.

\begin{tabular}{|c|c|c|c|c|c|c|}
\hline \multirow{2}{*}{$\begin{array}{l}\text { rel. PFL [\%] } \\
\text { Inokulum [g/Topf] }\end{array}$} & \multicolumn{2}{|c|}{56 dpi (BBCH 55) } & \multicolumn{2}{|c|}{84 dpi (BBCH 75) } & \multicolumn{2}{|c|}{125 dpi (BBCH 90) } \\
\hline & ohne KF & mit KF & ohne KF & mit KF & ohne KF & mit KF \\
\hline 0 & $100 \mathrm{a}$ & $100 \mathrm{~B}$ & $100 \mathrm{a}$ & $100 \mathrm{~B}$ & $100 \mathrm{a}$ & $100 \mathrm{~B}$ \\
\hline 0,2 & $116,3 \mathrm{a}$ & $90,3 \mathrm{AB}$ & $104,3 \mathrm{a}$ & $94,3 \mathrm{AB}$ & $100,2 \mathrm{a}$ & $95,5 \mathrm{AB}$ \\
\hline 1 & 96,2 a & $86,8 \mathrm{AB}$ & 96,8 a & $98,1 \mathrm{~B}$ & $94,8 \mathrm{a}$ & $90,4 \mathrm{AB}$ \\
\hline 5 & $95,7 \mathrm{a}$ & $74,3 \mathrm{~A}$ & $96,5 \mathrm{a}$ & $84,2 \mathrm{~A}$ & $96,1 \mathrm{a}+$ & $85,4 \mathrm{~A}-$ \\
\hline GD LSD $\mathrm{p} \leq 0,05$ & 26,8 n.s. & 20,9 & 11,1 n.s. & 13,1 & 5,5 n.s. & 7,8 \\
\hline rel. SFM [\%] & \multicolumn{2}{|c|}{56 dpi (BBCH 55) } & \multicolumn{2}{|c|}{84 dpi (BBCH 75) } & \multicolumn{2}{|c|}{125 dpi (BBCH 90) } \\
\hline Inokulum [g/Topf] & ohne KF & mit KF & ohne KF & mit KF & ohne KF & mit KF \\
\hline 0 & $100 \mathrm{~b}$ & $100 \mathrm{~B}$ & $100 \mathrm{bc}$ & $100 \mathrm{~B}$ & $100 \mathrm{bc}$ & $100 \mathrm{~B}$ \\
\hline 0,2 & $100,3 \mathrm{~b}$ & $99 \mathrm{~B}$ & $106,8 \mathrm{c}$ & $91,2 \mathrm{AB}$ & $108,6 \mathrm{c}$ & $87,9 \mathrm{~B}$ \\
\hline 1 & 87,7 a & $87,5 \mathrm{~A}$ & $91 \mathrm{ab}$ & $92,1 \mathrm{AB}$ & $90,3 \mathrm{ab}+$ & $73,34 \mathrm{~A}-$ \\
\hline 5 & $73,8 \mathrm{a}$ & 80,9 A & $82,1 \mathrm{a}$ & $78,2 \mathrm{~A}$ & $85,8 \mathrm{a}+$ & $70,23 \mathrm{~A}-$ \\
\hline GD LSD $\mathrm{p} \leq 0,05$ & 10,9 & 10,5 & 13,1 & 14,8 & 12,18 & 19,7 \\
\hline rel. WTM [\%] & \multicolumn{2}{|c|}{56 dpi (BBCH 55) } & \multicolumn{2}{|c|}{84 dpi (BBCH 75) } & \multicolumn{2}{|c|}{125 dpi (BBCH 90) } \\
\hline Inokulum [g/Topf] & ohne KF & mit KF & ohne KF & mit KF & ohne KF & mit KF \\
\hline 0 & $100 \mathrm{a}$ & $100 \mathrm{~B}$ & $100 \mathrm{ab}$ & $100 \mathrm{~B}$ & $100 \mathrm{~b}$ & $100 \mathrm{~B}$ \\
\hline 0,2 & $105,4 \mathrm{a}$ & $101,8 \mathrm{~B}$ & 117,7 b & $87,4 \mathrm{AB}$ & $105,9 \mathrm{~b}$ & $86,6 \mathrm{AB}$ \\
\hline 1 & $103,1 \mathrm{a}$ & $88,5 \mathrm{AB}$ & $101,8 \mathrm{ab}$ & $92,1 \mathrm{~B}$ & $87,67 \mathrm{ab}$ & $76,4 \mathrm{~A}$ \\
\hline 5 & $89,8 \mathrm{a}+$ & $72,6 \mathrm{~A}-$ & $91,4 \mathrm{a}+$ & $72,6 \mathrm{~A}-$ & $68,8 \mathrm{a}$ & $59,1 \mathrm{~A}$ \\
\hline GD LSD $p \leq 0,05$ & 22,8 n.s. & 21,34 & 20,6 & 17,5 & 19,0 & 23,4 \\
\hline
\end{tabular}

1) Bodeninokulation mit stark Verticillium-befallenem, klein gemahlenem Stoppelmaterial in Höhe von 0 (Kontrolle), 0,2, 1 oder $5 \mathrm{~g} / \operatorname{Topf}$ (1050 g Boden/Topf). 2) Kohlfliegenvarianten: ohne $\mathrm{KF}=$ ohne Kohlfliege; mit KF $=$ mit Kohlfliege, Ansatz von 8 Eiern an den Wurzelhals zu BBCH 15.

Die dem Inokulationsstufenversuch (vgl. 3.3.1.2) zugrunde liegende Vermutung, wonach Inokulationseffekte möglicherweise von der Befallsdynamik mit V. longisporum abhängen, können anhand der vorliegenden Ergebnisse gestützt werden. Kohlfliegenbefall führte insbesondere bei hohem Bodeninokulum zu einer verstärkten Besiedlung von $V$. longisporum in der Pflanze, was neben einer beschleunigten Symptomentwicklung (Tab. 38) auch in einer Erhöhung beobachteter Inokulationseffekte resultierte. 


\subsubsection{Resistenzversuch}

Nachdem eine durch Kohlfliegen bedingte Förderung von Verticillium-Befall in den zuvor beschriebenen Versuchen festgestellt worden war, sollte in einem weiterführenden Gewächshausversuch überprüft werden, ob es durch Wurzelfraß der Kohlfliege auch zu einer Abschwächung von Sortenresistenz gegenüber $V$. longisporum kommt. Hierzu wurde neben der moderat anfälligen Winterrapssorte Express zusätzlich eine Rapsslinie (Sem 05-500256) mit hoher Verticillium-Resistenz getestet. Neben einer Kontrolle wurde eine Bodeninokulation mit $1 \mathrm{~g}$ stark Verticillium-befallenem Stoppelmaterial je Topf in einer Variante mit bzw. einer Variante ohne Kohlfliegenbefall eingestellt. Varianten, wo Kohlfliegeneier angesetzt worden waren, zeigten mit durchschnittlich 69\% geschädigter Wurzeloberfläche eine sehr hohe Fraßschädigung auf. Im Vergleich zu den vorher durchgeführten Gewächshausversuchen, wo vergleichbare Bedingungen vorlagen (Ansatz von acht Kohlfliegeneiern zu BBCH 15), war das Schädigungsniveau etwa doppelt so hoch.

In Tab. 40 ist die nach visueller Ganzpflanzenbonitur erhobene $\mathrm{BH}$ mit $V$. longisporum aufgeführt. $\mathrm{Zu}$ den ersten beiden Boniturterminen wurden Blattsymptome, zum letzten Boniturtermin Gefäßbündelverbräunungen im Wurzelhals als Kriterium für VerticilliumBefall herangezogen. $48 \mathrm{dpi}(\mathrm{BBCH}$ 65) waren noch keine typischen Blattsymptome festzustellen. 80 dpi (BBCH 75) zeigten sich vermehrt Blattsymptome bei der Sorte Express, wobei die BH bei Vorliegen von Kohlfliegenbefall etwas höher war als bei einer alleinigen Bodeninokulation. Beim Genotyp Sem ließen sich nur bei einigen Pflanzen der durch Kohlfliegen geschädigten Inokulationsvariante Verticillium-Blattsymptome beobachten. Zum letzten Boniturtermin wiesen bei der Sorte Express von jeweils zwölf untersuchten Pflanzen sechs (ohne Kohlfliegenbefall) bzw. acht (mit Kohlfliegenbefall) Pflanzen charakteristische Verticillium-Symptome auf. Im Gegensatz dazu führte eine Verticillium-Inokulation bei Sem nur bei gleichzeitiger Kohlfliegenschädigung zu vermehrtem Auftreten von Gefäßbündelverbräunungen. Bei Varianten ohne Kohlfliegenbefall waren lediglich bei einer Pflanze Symptome festzustellen. 
Tab. 40: Mittlere Befallshäufigkeit [\%] von Winterrapspflanzen der Sorte Express bzw. der Rapslinie Sem 05-500256 mit $V$. longisporum 48 dpi (BBCH 65), 80 dpi (BBCH 75) sowie 115 dpi (BBCH 85; $\mathrm{n}=12$ ). Aufgeführt ist der Anteil symptomatischer Pflanzen verschiedener Inokulationsvarianten ${ }^{1)}$ mit bzw. ohne Kohlfliegenbefall. ${ }^{2)} \mathrm{Zu}$ den ersten beiden Boniturterminen wurden Pflanzen mit eindeutigen Blattsymptomen, zum letzten Boniturtermin Pflanzen mit Gefäßbündelverbräunung im Hypokotyl als Kriterium für Verticillium-Befall herangezogen.

\begin{tabular}{lcccccccc}
\hline Befallshäufigkeit [\%] & \multicolumn{2}{c}{48 dpi (BBCH 65) } & & \multicolumn{2}{c}{80 dpi (BBCH 75) } & & \multicolumn{2}{c}{115 dpi (BBCH 85) } \\
\cline { 2 - 3 } Inokulum [g/Topf] & Express & Sem & & Express & Sem & & Express & Sem \\
\hline Kontrolle & 0 & 0 & & 0 & 0 & & 0 & 0 \\
Kohlfliege (KF) & 0 & 0 & & 0 & 0 & & 0 & 0 \\
Verticillium & 0 & 0 & & 33,3 & 0 & & 50 & 8,3 \\
Verticillium + KF & 0 & 0 & & 41,7 & 25 & & 66,7 & 50 \\
\hline
\end{tabular}

1) Bodeninokulation mit stark Verticillium-befallenem, klein gemahlenem Stoppelmaterial in Höhe von 0 (Kontrolle) oder $1 \mathrm{~g}$ /Topf (1050 g Boden/Topf). 2) Kohlfliegenvarianten: ohne Kohlfliege; mit Kohlfliege, Ansatz von 8 Eiern an den Wurzelhals zu BBCH 15.

Die anhand von Real-Time PCR Messungen erfassten Mengen an Verticillium-DNA [ng/g TM] in Wurzel, Hypokotyl sowie unterem Stängelbereich sind in Abb. 26 dargestellt. Bei den geprüften Kontrollpflanzen konnte kein Verticillium-Befall detektiert werden, so dass ausschließlich Messwerte inokulierter Varianten angegeben sind. Zum ersten Boniturtermin (48 dpi; BBCH 65) ließen sich nur geringe Mengen Verticillium-DNA im Wurzel- und Hypokotylbereich nachweisen. Im weiteren Zeitverlauf nahm die Besiedlung der Pflanzen deutlich zu, wobei Varianten mit Kohlfliegenbefall generell höheren Verticillium-Befall als Varianten ohne Kohlfliegenbefall aufzeigten. Bei der Betrachtung des letzten Boniturtermins (115 dpi; BBCH 85) ist deutlich zu erkennen, dass Kohlfliegenbefall bei Sem einen starken Befallsanstieg mit $V$. longisporum zur Folge hatte, was insbesondere durch eine verstärkte Besiedlung des Wurzel- und Hypokotylbereichs hervorgerufen wurde. Der Befall des Stängels lag bei Sem im Vergleich zu Express jedoch nach wie vor auf einem relativ niedrigen Niveau. 


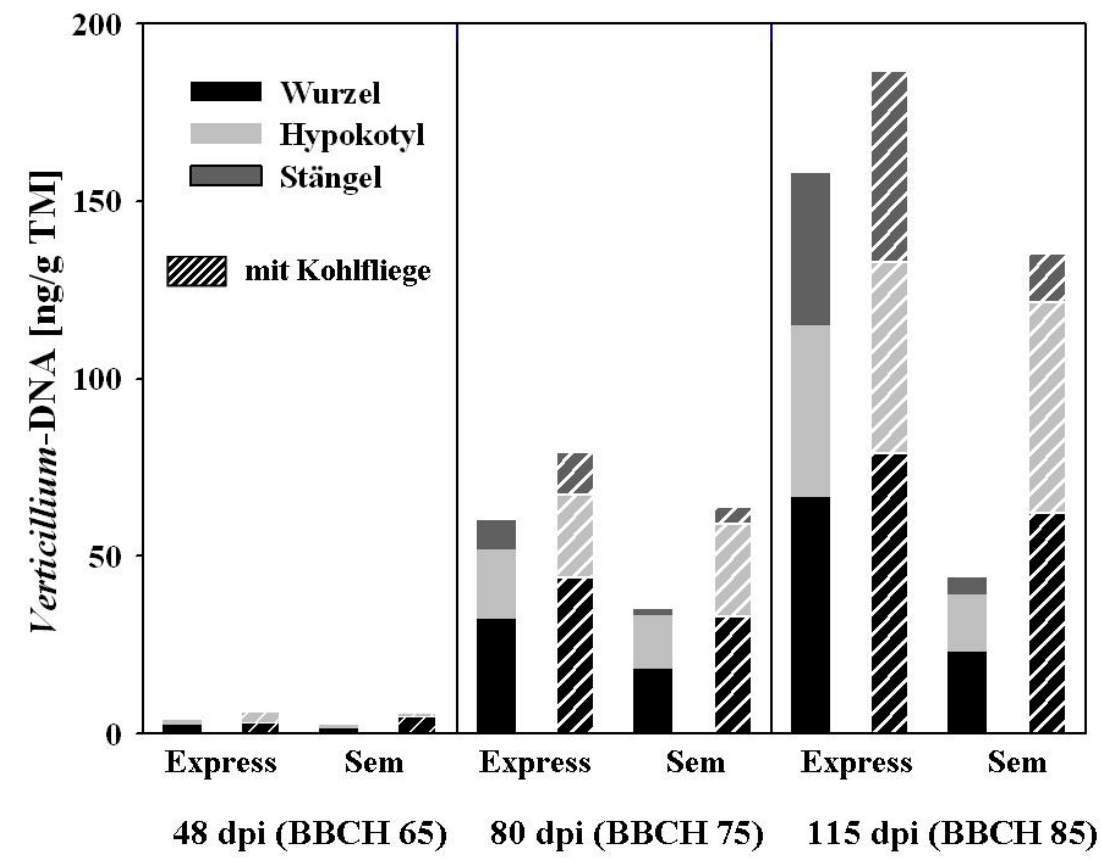

Abb. 26: Quantifizierung von Verticillium-DNA [ng/g TM] in Wurzel, Hypokotyl bzw. unterem Stängelbereich Verticillium-inokulierter Winterrapspflanzen der Sorte Express bzw. der Rapslinie Sem (05-500256) 48 dpi (BBCH 65), 80 dpi (BBCH 75) sowie 115 dpi (BBCH 85) mit Real-Time PCR. Dargestellt sind die Mittelwerte ( $n=6$ bestehend aus jeweils 2 Pflanzen) für Varianten mit und ohne Kohlfliegenbefall. Bodeninokulation mit stark Verticillium-befallenem, klein gemahlenem Stoppelmaterial in Höhe von $1 \mathrm{~g} /$ Topf (1050 g Boden/Topf). Kohlfliegenvarianten: ohne Kohlfliege (Balken ohne Striche); mit Kohlfliege (gestrichelte Balken): Ansatz von 8 Eiern an den Wurzelhals zu $\mathrm{BBCH} 15$.

In Tab. 41 sind die zu den jeweiligen Boniturterminen erhobenen pflanzenmorphologischen Parameter (Pflanzenlänge, Sprossfrischmasse, Wurzeltrockenmasse) der verschiedenen Versuchsvarianten in Relation zu Kontrollwerten (100\%) aufgeführt. Eine Auflistung absoluter Werte wird im Anhang vorgenommen (Tab. 19A). Der in der Tabelle mit angegebene Interaktionsparameter „ఎ Interaktion“ gibt Auskunft über mögliche Interaktionseffekte von Kohlfliegen- und Verticillium-Befall. Werte über Null deuten auf eine synergistische Interaktion hin, da die Schadwirkung eines kombinierten Kohlfliegen- und Verticillium-Befalls größer sind als die Summe der jeweils einzelnen Schadwirkungen. Werte im Bereich von Null kennzeichnen additive Effekte (Kombinierte Schadwirkung $=\sum$ einzelner Schadwirkungen), Werte kleiner Null weisen auf eine antagonistische Beziehung hin (Kombinierte Schadwirkung $<$ Eeinzelner Schadwirkungen). 
Zum ersten Boniturtermin (48 dpi; $\mathrm{BBCH}$ 65) kam es in der Variante mit alleinigem Kohlfliegenbefall trotz einer starken Fraßschädigung nur bei Sem, nicht jedoch bei Express $\mathrm{zu}$ einer signifikanten Reduktion von Wurzeltrockenmasse sowie Sprossfrischmasse gegenüber der Kontrolle. Verticillium-Inokulationen führten bei beiden Sorten zu Inokulationseffekten, obgleich Real-Time PCR-Untersuchungen zu diesem Zeitpunkt nur geringen Befall anzeigten. Kohlfliegenbefall resultierte in einer weiteren Erhöhung von Inokulationseffekten inokulierter Varianten, was sich bei Sem für alle Parameter, bei Express jedoch nur für den Parameter Pflanzenlänge absichern ließ. Interaktionsanalysen deuteten beim Parameter Pflanzenlänge auf eine synergistische Interaktion, bei den übrigen Parametern auf eine additive Interaktion hin. Ab 80 dpi ließen sich keine Schadwirkungseffekte eines alleinigen Kohlfliegenbefalls mehr feststellen. Eine Bodeninokulation ohne Kohlfliegenbefall zeigte bei Sem Inokulationseffekte an, nicht jedoch bei Express. Die im Variantenvergleich jeweils größten Inokulationseffekte waren in der Variante „Verticillium + Kohlfliege“ auszumachen. Bei Express ließen sich diese Effekte gegenüber der Kontrolle, bei Sem gegenüber allen anderen Varianten absichern. Interaktionsanalysen wiesen ausschließlich Werte größer null aus, was auf eine synergistische Schadwirkung von Kohlfliegen- und Verticillium-Befall hindeutet. Inokulationseffekte des letzten Boniturtermins (115 dpi; BBCH 85) entsprachen weitgehend den Ergebnissen des zweiten Boniturtermins. Abweichend davon ließen sich am Versuchsende bei der Sorte Express auch signifikante Inokulationseffekte eines alleinigen Verticillium-Befalls absichern. Auf der anderen Seite zeigten sich bei Sem bei dieser Inokulationsvariante für den Parameter Wurzeltrockenmasse im Gegensatz zu den ersten beiden Boniturterminen keine Inokulationseffekte mehr. 
Tab. 41: Mittlere Pflanzenlänge [PFL], Sprossfrischmasse [SFM] sowie Wurzeltrockenmasse [WTM] von Kohlfliegen geschädigten und/oder Verticillium-inokulierten Rapspflanzen der Sorte Express bzw. der Rapslinie Sem (05-500256) 48 dpi (BBCH 65), 80 dpi (BBCH 75) sowie 115 dpi (BBCH 85 ) in Relation $\mathrm{zu}$ den Kontrollvarianten. Statistisch signifikante Differenzen zwischen den Versuchsvarianten $^{2)}$ sind für die jeweiligen Sorten durch unterschiedliche Buchstaben gekennzeichnet. (+/-) zeigen signifikante Unterschiede zwischen den Sorten bei den jeweiligen Versuchsvarianten an (LSD $\mathrm{p} \leq 0,05 ; \mathrm{n}=12)$.

\begin{tabular}{|c|c|c|c|c|c|c|}
\hline \multirow{2}{*}{$\begin{array}{l}\text { rel. PFL [\%] } \\
\text { Versuchsvarianten }\end{array}$} & \multicolumn{2}{|c|}{48 dpi (BBCH 65) } & \multicolumn{2}{|c|}{80 dpi (BBCH 75) } & \multicolumn{2}{|c|}{115 dpi (BBCH 85) } \\
\hline & Express & Sem & Express & Sem & Express & Sem \\
\hline Kontrolle & $100 \mathrm{c}$ & $100 \mathrm{C}$ & $100 \mathrm{ab}$ & $100 \mathrm{C}$ & $100 \mathrm{~b}$ & $100 \mathrm{C}$ \\
\hline Kohlfliege (KF) & $101,2 \mathrm{c}$ & $88,3 \mathrm{BC}$ & $102,4 \mathrm{~b}$ & $94,8 \mathrm{BC}$ & $93,3 \mathrm{ab}$ & $95,8 \mathrm{BC}$ \\
\hline Verticillium & $90,5 b+$ & $77,1 \mathrm{~B}-$ & $98,4 \mathrm{ab}+$ & $87,8 \mathrm{~B}-$ & $91,9 \mathrm{a}$ & $88,5 \mathrm{~B}$ \\
\hline Verticillium + KF & $81,3 \mathrm{a}+$ & $56,4 \mathrm{~A}-$ & $95,4 \mathrm{a}+$ & $64,4 \mathrm{~A}-$ & $87,3 \mathrm{a}+$ & $79,1 \mathrm{~A}-$ \\
\hline$\Delta$ Interaktion $^{l)}$ & 10,4 & 9 & 5,4 & 18,2 & $-2,1$ & 5,2 \\
\hline GD LSD $p \leq 0,05$ & 9,1 & 11,9 & 6,2 & 9,9 & 7,1 & 7,6 \\
\hline rel. SFM [\%] & \multicolumn{2}{|c|}{48 dpi (BBCH 65) } & \multicolumn{2}{|c|}{80 dpi (BBCH 75) } & \multicolumn{2}{|c|}{115 dpi (BBCH 85) } \\
\hline Versuchsvarianten & Express & Sem & Express & Sem & Express & Sem \\
\hline Kontrolle & $100 \mathrm{~b}$ & $100 \mathrm{C}$ & $100 \mathrm{c}$ & $100 \mathrm{C}$ & $100 \mathrm{c}$ & $100 \mathrm{C}$ \\
\hline Kohlfliege (KF) & $94,8 \mathrm{~b}+$ & $83,2 \mathrm{~B}-$ & $87,4 \mathrm{ab}$ & $90 \mathrm{C}$ & $89,6 \mathrm{~b}$ & $87 \mathrm{~B}$ \\
\hline Verticillium & $83,2 \mathrm{a}+$ & $66,2 \mathrm{~B}-$ & $97,4 \mathrm{bc}+$ & 75,7 B - & $90,6 \mathrm{~b}$ & $83,3 \mathrm{~B}$ \\
\hline Verticillium + KF & $75,1 \mathrm{a}+$ & $50,6 \mathrm{~A}-$ & $77,9 \mathrm{a}+$ & $42,7 \mathrm{~A}-$ & $69,8 \mathrm{a}$ & $65,5 \mathrm{~A}$ \\
\hline$\Delta$ Interaktion $^{l)}$ & 2,9 & $-1,2$ & 6,9 & 23 & 10,4 & 4,8 \\
\hline GD LSD $p \leq 0,05$ & 9,5 & 8,7 & 10,1 & 13,8 & 9,5 & 12,6 \\
\hline rel. WTM [\%] & \multicolumn{2}{|c|}{48 dpi (BBCH 65) } & \multicolumn{2}{|c|}{80 dpi (BBCH 75) } & \multicolumn{2}{|c|}{115 dpi (BBCH 85) } \\
\hline Versuchsvarianten & Express & Sem & Express & Sem & Express & Sem \\
\hline Kontrolle & $100 \mathrm{a}$ & $100 \mathrm{C}$ & $100 \mathrm{~b}$ & $100 \mathrm{C}$ & $100 \mathrm{c}$ & $100 \mathrm{~B}$ \\
\hline Kohlfliege (KF) & $102,1 \mathrm{a}+$ & $78 \mathrm{~B}-$ & $88,1 \mathrm{~b}$ & $90 \mathrm{BC}$ & $85,3 \mathrm{~b}$ & $97,9 \mathrm{~B}$ \\
\hline Verticillium & $98,3 \mathrm{a}+$ & $65 \mathrm{~B}-$ & $97,8 \mathrm{~b}+$ & $76,5 \mathrm{~B}-$ & $78,5 \mathrm{~b}+$ & $106 \mathrm{~B}-$ \\
\hline Verticillium + KF & $90,1 \mathrm{a}+$ & $44,3 \mathrm{~A}-$ & $72,1 \mathrm{a}+$ & $35,6 \mathrm{~A}-$ & $50,3 \mathrm{a}$ & $51,3 \mathrm{~A}$ \\
\hline$\Delta$ Interaktion $^{l)}$ & 10,3 & 0,7 & 13,8 & 30,9 & 13,5 & 52,6 \\
\hline GD LSD $p \leq 0,05$ & 19,7 n.s. & 16,7 & 12,2 & 16,2 & 12,3 & 22,3 \\
\hline
\end{tabular}

1) $\Delta$ Interaktion $=[100-($ Verticillium $+\mathrm{KF})]-[200-(($ Verticillium $)+($ Kohlfliege $))]$ :

Werte $>0=$ Schadwirkung von kombiniertem Kohlfliegen- und Verticillium-Befall ist synergistisch

Werte $=0=$ Schadwirkung von kombiniertem Kohlfliegen- und Verticillium-Befall ist additiv

Werte $<0=$ Schadwirkung von kombiniertem Kohlfliegen- und Verticillium-Befall ist antagonistisch

2) Bodeninokulation mit stark Verticillium-befallenem, klein gemahlenem Stoppelmaterial in Höhe von 0 (Kontrolle) oder $1 \mathrm{~g} /$ Topf (1050 g Boden/Topf). 2) Kohlfliegenvarianten: ohne Kohlfliege; mit Kohlfliege, Ansatz von 8 Eiern an den Wurzelhals zu BBCH 15. 


\subsubsection{Mechanismen der Interaktion zwischen der Kohlfliege und V. longisporum}

\subsubsection{Stängelinokulationsversuch}

In einem 2008 durchgeführten Stängelinokulationsversuch wurde der Einfluss von Kohlfliegenbefall auf $V$. longisporum bei räumlicher Trennung beider Schaderreger untersucht, um mögliche pflanzenphysiologische Interaktionseffekte identifizieren zu können. Mit der moderat anfälligen Sorte Express und der resistenten Rapslinie Sem 05-500256 wurden dieselben Sorten wie beim Resistenzversuch (vgl. 3.3.1.4) ausgewählt, um Effekte mit und ohne räumliche Trennung miteinander vergleichen $\mathrm{zu}$ können. Bei Varianten mit Kohlfliegenbefall wurden zu BBCH 55 acht Kohlfliegeneier an den Wurzelhals angesetzt. Die Verticillium-Inokulation des direkt oberhalb des Hypokotyls befindlichen unteren Stängelbereichs erfolgte zehn Tage später (BBCH 60). Der im Rahmen einer destruktiven Endbonitur 28 dpi bzw. 38 Tage nach Eiansatz erhobene Kohlfliegenfraß zeigte mit durchschnittlich 38\% geschädigter Wurzeloberfläche ein moderates Schädigungsniveau an. Varianten ohne Kohlfliegenbesatz wiesen keinen Wurzelfraß auf.

Ergebnisse der visuellen Bonitur des Verticillium-Befalls, die 7, 14, 21 und 28 dpi anhand von Blattsymptomen vorgenommen wurde, sind in Abb. 27 zusammengefasst. Da bei den Kontrollpflanzen keine Symptome auftraten, wurde auf eine vergleichende Darstellung verzichtet. Erste charakteristische Blattsymptome mit beginnender Schwarzadrigkeit waren ab 14 dpi festzustellen. Bei der Sorte Express wiesen hierbei von insgesamt zwölf Pflanzen vier (ohne Kohlfliegenbefall) bzw. fünf (mit Kohlfliegenbefall) Symptome auf. Bei Sem lag die BH mit zwei (ohne Kohlfliegenbefall) bzw. drei (mit Kohlfliegenbefall) symptomatischen Pflanzen etwas niedriger. 21 dpi konnten an nahezu allen Pflanzen Blattsymptome beobachtet werden, die sich in einer Erhöhung abgebildeter Befallswerte niederschlug. Hierbei verzeichnete die Sorte Express im Vergleich mit Sem etwas stärkeren Befall. Absichern ließen sich diese Unterschiede allerdings nicht. Zum letzten Boniturtermin (28 dpi) war eine fortgeschrittene Symptomentwicklung $\mathrm{zu}$ beobachten, die bei Express dynamischer verlief als bei Sem. Befallswertunterschiede von 0,83 (ohne Kohlfliegenbefall) bzw. 0,75 (mit Kohlfliegenbefall) zwischen Express und Sem ließen sich nun absichern. Ein Vergleich von Varianten mit und ohne Kohlfliegenbefall ergab keine signifikanten Unterschiede. 


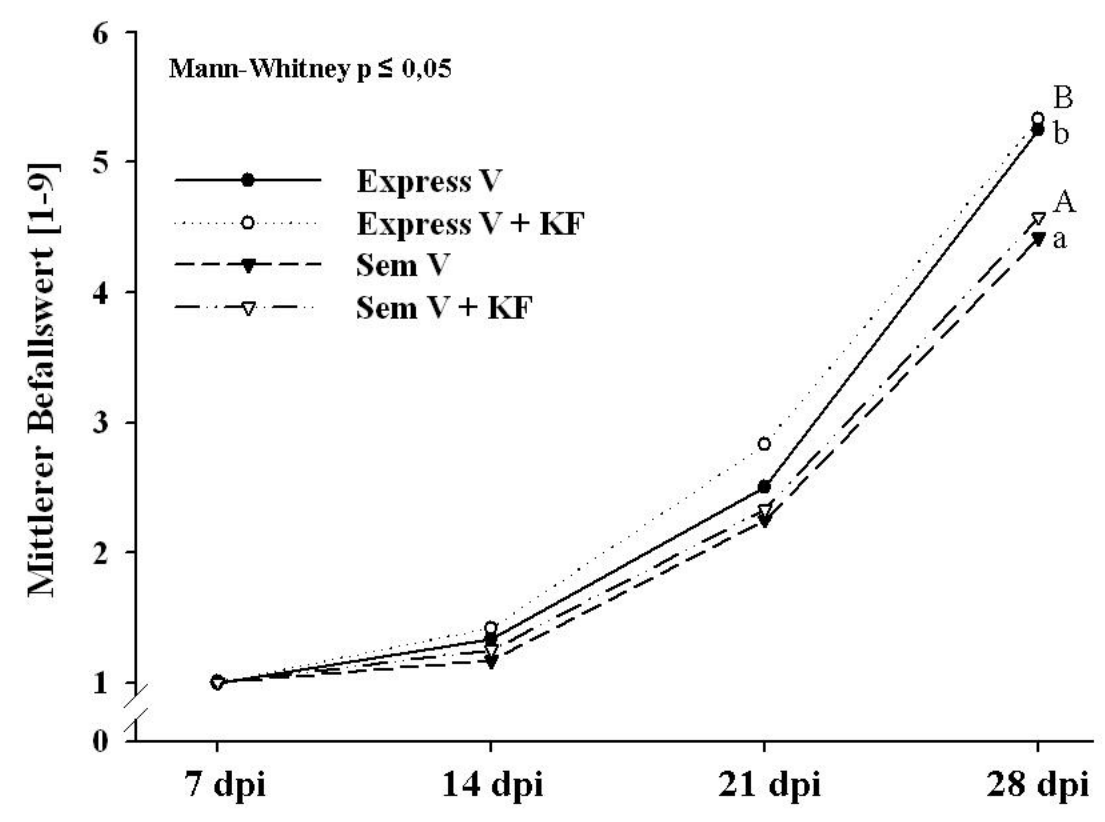

Abb. 27: Mittlerer Befallswert [1 (kein Befall) - 9 (sehr starker Befall)] von Winterraps der Sorte Express bzw. der Rapslinie Sem 05-500256 mit $V$. longisporum 7, 14, 21 und 28 Tage nach Stängelinokulation $(\mathrm{n}=12)$ (Boniturschlüssel nach Zeise (1992) basierend auf Blattsymptomen). Statistisch signifikante Differenzen zwischen den Sorten sind für Varianten mit und ohne Kohlfliegenbefall durch unterschiedliche Buchstaben gekennzeichnet (Mann-Whitney $p \leq 0,05$ ). Varianten: V (Stängelinokulation mit $V$. longisporum zu BBCH 60); V + KF (Ansatz von 8 Kohlfliegeneiern an den Wurzelhals zu BBCH $55+$ Stängelinokulation mit $V$. longisporum zu BBCH 60). Stängelinokulation $3 \mathrm{~cm}$ oberhalb des Hypokotyls mit 2 x $5 \mu$ l eines Sporensuspensionsgemischs der beiden $V$. longisporum-Isolate VL $40+\mathrm{VL} 43\left(1 \times 10^{6}\right.$ Sporen $\left./ \mathrm{ml}\right)$.

Nach dem letzten Boniturtermin (28 dpi) wurden zusätzlich Real-Time PCR-Untersuchungen durchgeführt, um den Befall von $V$. longisporum im Pflanzengewebe quantifizieren zu können. Für die Untersuchungen wurden je Pflanze zwei $5 \mathrm{~cm}$ lange Stängelabschnitte aus den Bereichen 5-10 cm (unterer Stängel) bzw. 30-35 cm (oberer Stängel) oberhalb der Inokulationsstelle herangezogen. In Abb. 28 ist die mittlere Verticillium-DNA [ng/g TM] beider Stängelabschnitte für Varianten mit und ohne Kohlfliegenbefall dargestellt. Aus der Abbildung ist ersichtlich, dass die Sorte Express etwa drei- bis vierfach höhere Mengen an Verticillium-DNA im Vergleich zu Sem aufwies. Kohlfliegenbefall führte bei beiden Sorten zu einer leichten Erhöhung des Befalls im unteren Stängelbereich. 


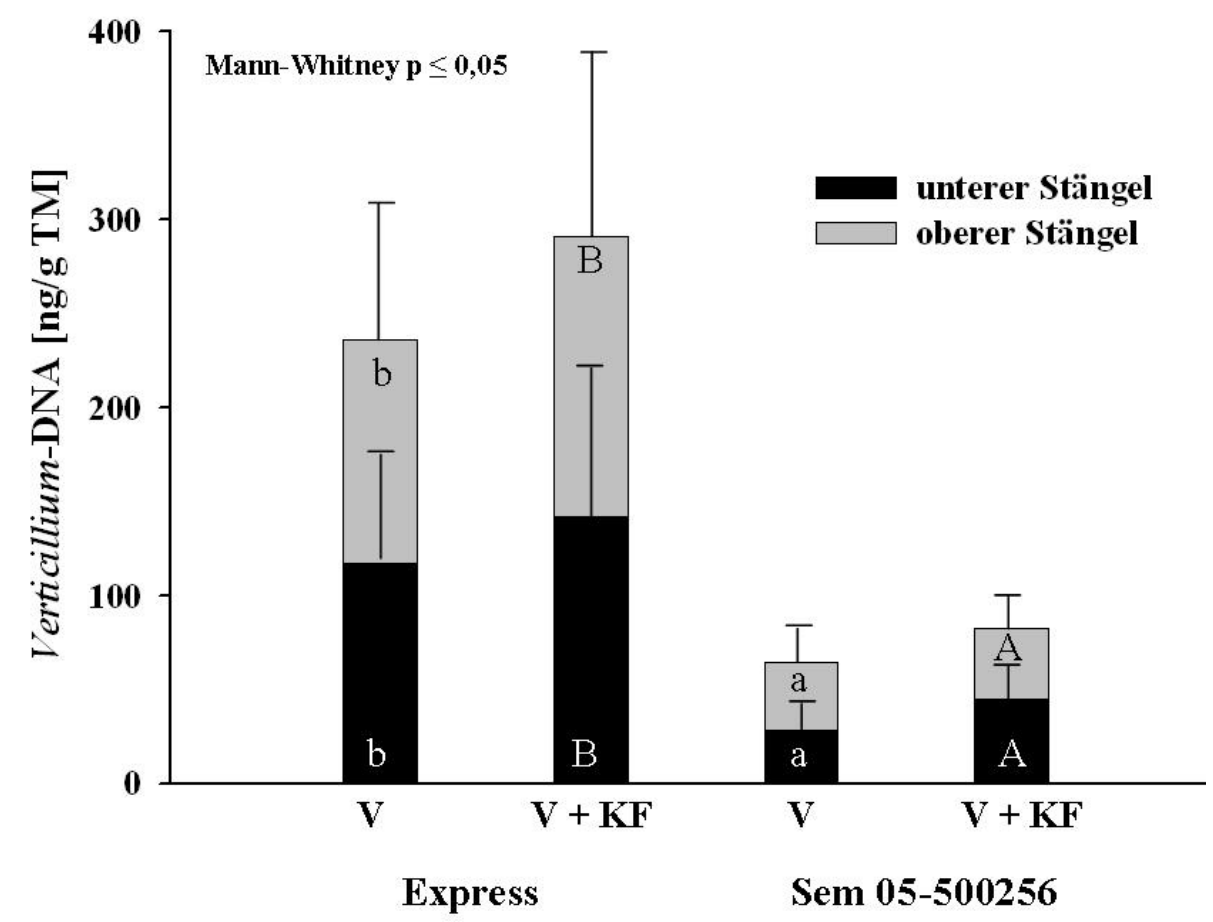

Abb. 28: Quantifizierung von Verticillium-DNA [ng/g TM] im unterem Stängelbereich (Abschnitt 5 $\mathrm{cm}$ bis $10 \mathrm{~cm}$ oberhalb der Inokulationsstelle) bzw. oberem Stängelbereich (Abschnitt $30 \mathrm{~cm}$ bis 35 cm oberhalb der Inokulationsstelle) von Winterraps der Sorte Express bzw. der Rapslinie Sem (05500256) 28 Tage nach Stängelinokulation. Dargestellt sind die Mittelwerte und Standardfehler $(\mathrm{n}=12)$ verschiedener Versuchsvarianten nach Messung mit Real-Time PCR. Unterschiedliche Buchstaben kennzeichnen signifikante Unterschiede zwischen den Sorten bei den jeweiligen Varianten (Mann-Whitney $\mathrm{p} \leq 0,05$ ). Varianten: $\mathrm{V}$ (Stängelinokulation mit $V$. longisporum zu BBCH 60 ); V + KF (Ansatz von 8 Kohlfliegeneiern an den Wurzelhals zu BBCH 55 + Stängelinokulation mit $V$. longisporum zu BBCH 60). Stängelinokulation $3 \mathrm{~cm}$ oberhalb des Hypokotyls mit $2 \times 5 \mu 1$ eines Sporensuspensionsgemischs der beiden $V$. longisporum-Isolate VL $40+$ VL $43\left(1 \times 10^{6}\right.$ Sporen $/ \mathrm{ml})$.

Im Vergleich zur visuellen Befallsbonitur führte die Quantifizierung von Verticillium-DNA im Pflanzengewebe zu einer deutlicheren Differenzierung von Express und Sem. Anhand der vorliegenden Ergebnisse kann nicht ausgeschlossen werden, dass Kohlfliegenbefall u. a. auch pflanzenphysiologische Befallseffekte auf $V$. longisporum ausübt. Die im Resistenzversuch (vgl. 3.3.1.4) aufgezeigte wesentlich stärkere durch Kohlfliegen bedingte Förderung des Verticillium-Befalls, insbesondere bei Sem, deutet allerdings auch darauf hin, dass lokale Wundeffekte hierbei von größerer Bedeutung sind als pflanzenphysiologische Effekte. 


\subsubsection{Wurzelteilungsversuch}

Im Rahmen eines 2008 durchgeführten Wurzelteilungsversuchs wurden Interaktionsuntersuchungen an Sommerraps der Sorte Heros durchgeführt. Es sollte überprüft werden, ob die in den vorhergehenden Versuchen aufgezeigte durch Kohlfliegen bedingte Förderung des Verticillium-Befalls eher auf lokale und/oder pflanzenphysiologische Effekte zurückzuführen ist. Zur Testung beider Hypothesen erfolgten die Untersuchungen an Rapspflanzen, deren Wurzelsysteme in zwei Hälften geteilt worden waren. Neben einer Kontrolle wurden die beiden Versuchsfaktoren Kohlfliegenbefall und Verticillium-Inokulum entweder einzeln (nur Kohlfliegenbefall bzw. Verticillium-Inokulum), separat (Kohlfliegenbefall und Verticllium-Inokulum auf unterschiedlichen Topf-/Wurzelhälften) oder zusammen (Kohlfliegenbefall und Verticllium-Inokulum auf derselben Topf-/Wurzelhälfte) überprüft.

Bonituren des Kohlfliegenbefalls zeigten, dass die schlüpfenden Larven neben Lateralwurzelfraß zum Teil auch Schädigungen am Hypokotyl hervorriefen. Auf der gegenüberliegenden Topf-/Wurzelseite, wo keine Eier angesetzt worden waren, ließen sich in keinem Fall Fraßschädigungen beobachten, so dass die im Versuch vorgesehene Beschränkung des Kohlfliegenbefalls auf einer Wurzelseite erreicht wurde. Eine genaue prozentuale Schätzung von Fraßschädigungen ließ sich aufgrund des vorrangig an Lateralwurzelen vorzufindenden Fraßes nicht abgeben. In Tab. 42 ist die zu den jeweiligen Boniturterminen erhobene BH mit $V$. longisporum aufgeführt. Erste typische Blattsymptome waren erst ab Mitte Blüte zu beobachten. Zum ersten Boniturtermin (58 dpi; BBCH 69) wies die Variante „V+KF/0“, bei der Kohlfliegenbefall und Verticillium-Inokulum auf einer Topf-/Wurzelhälfte gemeinsam vorkamen, eine etwas höhere $\mathrm{BH}$ im Vergleich zu den übrigen Varianten auf. Am Versuchsende (84 dpi; BBCH 85), wo Gefäßbündelverbräunung sowie MS-Besatz als Befallskriterien dienten, setzte sich o. a. Variante „V+KF/0“ mit jeweils höchsten Befallswerten ab. Zwischen den Varianten „V/0“ und „V/KF“ konnten keine Unterschiede festgestellt werden. 
Tab. 42: Mittlere Befallshäufigkeit [\%] von Sommerraps der Sorte Heros mit $V$. longisporum 58 dpi (BBCH 69) sowie 84 dpi (BBCH 85) $(n=12)$. Aufgeführt ist der Anteil symptomatischer Pflanzen verschiedener Versuchsvarianten ${ }^{1)}$ eines Doppeltopfversuchs mit zwei getrennten Wurzelsystemen. Zum ersten Boniturtermin wurden Pflanzen mit eindeutigen Blattsymptomen, zum zweiten Boniturtermin Pflanzen mit Gefäßbündelverbräunung im Hypokotyl bzw. Mikrosklerotienbesatz als Kriterium für Verticillium-Befall herangezogen.

\begin{tabular}{lcccc}
\hline Befallshäufigkeit [\%] & 58 dpi (BBCH 69) & & \multicolumn{2}{c}{84 dpi (BBCH 85) } \\
\cline { 2 - 3 } Versuchsvarianten* & Blattsymptome & & Gefäßverbräunung & Mikrosklerotien \\
\hline $0 / 0$ & 0 & 0 & 0 \\
/ KF & 0 & 8,3 & 0 \\
V / 0 & 25 & & 58,3 & 16,7 \\
V / KF & 16,7 & & 75 & 8,3 \\
V+KF/ 0 & 33,3 & 100 & 41,7 \\
\hline
\end{tabular}

1) Versuchsvarianten: $0 / 0=$ Kontrolle; $0 / \mathrm{KF}=$ Kohlfliegebefall $(\mathrm{KF})$ auf einer Wurzelhälfte; $\mathrm{V} / 0=$ Verticillium-Inokulum $(\mathrm{V})$ auf einer Wurzelhälfte; $\mathrm{V} / \mathrm{KF}=$ Verticillium-Inokulum $(\mathrm{V})$ und Kohlfliegenbefall $(\mathrm{KF})$ separat; $\mathrm{V}+\mathrm{KF} / 0=$ Verticillium-Inokulum $(\mathrm{V})$ und Kohlfliegenbefall (KF) zusammen. $\mathrm{V}=$ Bodeninokulation mit stark Verticillium-befallenem, klein gemahlenem Stoppelmaterial in Höhe von $1 \mathrm{~g} / \mathrm{Topf}(1050 \mathrm{~g}$ Boden/ Topf). KF = Ansatz von 5 Eiern im mittleren Wurzelbereich zu BBCH 17-18).

Die anhand von Real-Time PCR Messungen erfassten Mengen an Verticillium-DNA [ng/g TM] in Wurzel, Hypokotyl sowie unterem Stängelbereich sind in Abb. 29 dargestellt. Bei den geprüften Kontrollpflanzen konnte kein Verticillium-Befall detektiert werden, so dass ausschließlich Messwerte inokulierter Varianten angegeben sind. Zum ersten Boniturtermin (58 dpi (BBCH 69)) ließ sich bereits in allen untersuchten Proben Verticillium-DNA nachweisen. Mit der Variante „,V+KF/0“ zeigte diejenige Variante signifikant höchsten Befall in der Wurzel auf, bei der auch am meisten Blattsymptome beobachtet worden waren. Geringe Variantenunterschiede im Hypokotyl- bzw. Stängelbereich ließen sich zu diesem Zeitpunkt noch nicht feststellen. Zum zweiten Boniturtermin (84 dpi; BBCH 85) nahm die Besiedlung der Pflanzen deutlich zu (beachte Skalierung). In allen Pflanzenabschnitten verzeichnete die Variante „V+KF/0“, bei der zu diesem Zeitpunkt bereits fünf von zwölf Pflanzen MS-Besatz aufwiesen, deutlich höheren Verticillium-Befall als die übrigen Varianten. Zwischen den Varianten „V/0“ und „V/KF ließen sich keine klaren Unterschiede feststellen. 

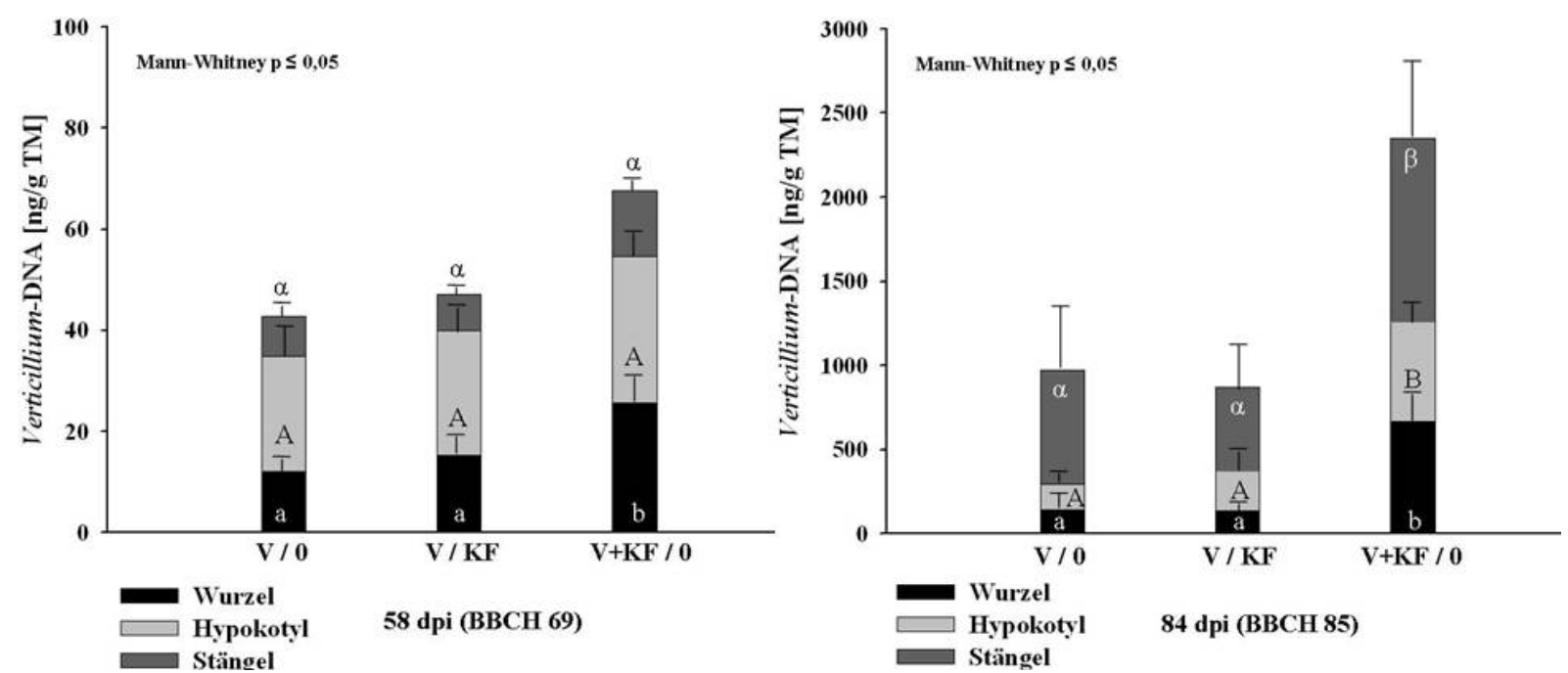

Abb. 29: Quantifizierung von Verticillium-DNA [ng/g TM] in Wurzel, Hypokotyl bzw. unterem Stängelbereich Verticillium-inokulierter Sommerrapspflanzen der Sorte Heros 58 dpi (BBCH 69) sowie 84 dpi (BBCH 85) mit Real-Time PCR. Dargestellt sind die Mittelwerte und Standardfehler ( $n=6$ bestehend aus jeweils 2 Pflanzen) verschiedener Versuchsvarianten eines Doppeltopfversuchs mit zwei getrennten Wurzelsystemen. Unterschiedliche Buchstaben kennzeichnen signifikante Differenzen zwischen den Versuchsvarianten (Mann-Whitney $\mathrm{p} \leq 0,05$ ). Versuchsvarianten: $\mathrm{V} / 0=$ Verticillium-Inokulum (V) auf einer Wurzelhälfte; V/KF $=$ Verticillium-Inokulum (V) und Kohlfliegenbefall (KF) separat; $\mathrm{V}+\mathrm{KF} / 0=\operatorname{Verticillium}$-Inokulum (V) und Kohlfliegenbefall (KF) zusammen. $\mathrm{V}=$ Bodeninokulation mit Verticillium-befallenem, klein gemahlenem Stoppelmaterial in Höhe von $1 \mathrm{~g} /$ Topf (1050 g Boden/Topf). KF = Ansatz von 5 Eiern im mittleren Wurzelbereich zu BBCH 17-18.

In Tab. 43 sind die zu den jeweiligen Boniturterminen erhobenen pflanzenmorphologischen Parameter (Pflanzenlänge, Sprosstrockenmasse, Wurzeltrockenmasse) in Relation zu Kontrollwerten (100\%) aufgeführt. Eine Auflistung absoluter Werte erfolgt im Anhang (Tab. 20A). Die in der Tabelle mit angegebenen Interaktionsparameter „, Interaktion $I^{\text {“ }}$

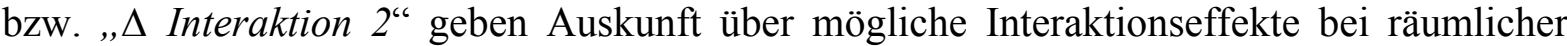
Trennung bzw. gleichzeitigem Vorhandensein beider Schaderreger. Zum ersten Boniturtermin (58 dpi; BBCH 69) konnten keine Schadwirkungen von Kohlfliegenbefall und/oder Verticillium-Befall ausgemacht werden. Am Versuchsende (84 dpi; BBCH 85) wiesen alle Varianten, bei denen eine Verticillium-Inokulation erfolgt war, signifikant niedrigere Spross- sowie Wurzeltrockenmassewerte gegenüber der Kontrolle auf. Die Variante „, $\mathrm{V}+\mathrm{KF} / 0^{\prime \prime}$ verzeichnete höchste Inokulationseffekte, die sich beim Parameter Wurzeltrockenmasse gegenüber den Varianten „,V/0“ und „,V/KF“ absichern ließen. Im Wurzelteilungsversuch konnte eine durch Kohlfliegen bedingte Förderung von VerticilliumBefall und eine darauf zurückzuführende Erhöhung von Schadeffekten lediglich dann festgestellt werden, wenn Kohlfliegenbefall und Verticillium-Inokulum auf derselben Topf-/ 
Wurzelhälfte zusammentrafen. Eine Befallsförderung war bei einer räumlichen Trennung beider Schaderreger nicht zu erkennen. Dieses Ergebnis deckt sich mit den Untersuchungsergebnissen der vorherigen Versuche (Resistenzversuch, Stängelinokulationsversuch), wonach lokale Wundeffekte in der Befallsförderung offenbar eine größere Rolle spielen als pflanzenphysiologische Effekte.

Tab. 43: Mittlere Pflanzenlänge [PFL], Sprosstrockenmasse [STM] sowie Wurzeltrockenmasse [WTM] von Sommerraps der Sorte Heros bei verschiedenen Versuchsvarianten eines Doppeltopfversuchs mit zwei getrennten Wurzelsystemen 58 dpi (BBCH 69) sowie 84 dpi (BBCH 85) in Relation zur Kontrollvariante $(\mathrm{n}=12)$. Statistisch signifikante Differenzen zwischen den Versuchsvarianten sind für die jeweiligen Parameter durch unterschiedliche Buchstaben gekennzeichnet. (LSD $\mathrm{p} \leq 0,05)$. Versuchsvarianten: $\mathrm{V} / 0=$ Verticillium-Inokulum $(\mathrm{V})$ auf einer Wurzelhälfte; V/KF $=$ Verticillium-Inokulum (V) und Kohlfliegenbefall (KF) separat; V+KF/0 =Verticillium-Inokulum (V) und Kohlfliegenbefall (KF) zusammen. V = Bodeninokulation mit Verticillium-befallenem, klein gemahlenem Stoppelmaterial in Höhe von $1 \mathrm{~g} /$ Topf (1050 g Boden/Topf). KF = Ansatz von 5 Eiern im mittleren Wurzelbereich zu BBCH 17-18.

\begin{tabular}{|c|c|c|c|c|c|c|}
\hline \multirow[b]{2}{*}{ Versuchsvarianten } & \multicolumn{2}{|c|}{ rel. PFL [\%] } & \multicolumn{2}{|c|}{ rel. STM [\%] } & \multicolumn{2}{|c|}{ rel. WTM [\%] } \\
\hline & 58 dpi & 84 dpi & 58 dpi & 84 dpi & $58 \mathrm{dpi}$ & $84 \mathrm{dpi}$ \\
\hline $0 / 0$ & $100 \mathrm{a}$ & $100 \mathrm{~A}$ & $100 \mathrm{a}$ & $100 \mathrm{C}$ & $100 \mathrm{a}$ & $100 \mathrm{C}$ \\
\hline $0 / \mathrm{KF}$ & $99,0 \mathrm{a}$ & $101,6 \mathrm{~A}$ & $110,5 \mathrm{a}$ & $92,2 \mathrm{BC}$ & $96,1 \mathrm{a}$ & $93,5 \mathrm{BC}$ \\
\hline $\mathrm{V} / 0$ & $99,1 \mathrm{a}$ & $101,6 \mathrm{~A}$ & $102,2 \mathrm{a}$ & $82,5 \mathrm{AB}$ & $93,2 \mathrm{a}$ & $77,6 \mathrm{~B}$ \\
\hline $\mathrm{V} / \mathrm{KF}$ & $101,4 \mathrm{a}$ & $95,1 \mathrm{~A}$ & $101,2 \mathrm{a}$ & $77,8 \mathrm{AB}$ & $95,1 \mathrm{a}$ & $84,1 \mathrm{BC}$ \\
\hline $\mathrm{V}+\mathrm{KF} / 0$ & $96,9 \mathrm{a}$ & $95 \mathrm{~A}$ & $100,1 \mathrm{a}$ & $70,5 \mathrm{~A}$ & $90,2 \mathrm{a}$ & $59,8 \mathrm{~A}$ \\
\hline$\Delta$ Interaktion 1 & $-3,3$ & 8,1 & 11,5 & $-3,1$ & $-5,8$ & -13 \\
\hline$\Delta$ Interaktion 2 & 1,3 & 8,2 & 12,6 & 4,2 & $-0,9$ & 11,3 \\
\hline GD LSD $p \leq 0,05$ & 5,6 n.s. & 11,2 n.s. & 11,5 n.s. & 14,4 & 21,6 n.s. & 18,7 \\
\hline
\end{tabular}

1) $\Delta$ Interaktion $=[100-(\mathrm{V} / \mathrm{KF})]-[200-((\mathrm{V} / 0)+(0 / \mathrm{KF}))]$

2) $\Delta$ Interaktion $=[100-(\mathrm{V}+\mathrm{KF} / 0)]-[200-((\mathrm{V} / 0)+(0 / \mathrm{KF}))]$

Werte $>0=$ Schadwirkung von kombiniertem Kohlfliegen- und Verticillium-Befall ist synergistisch

Werte $=0=$ Schadwirkung von kombiniertem Kohlfliegen- und Verticillium-Befall ist additiv

Werte $<0=$ Schadwirkung von kombiniertem Kohlfliegen- und Verticillium-Befall ist antagonistisch

\subsubsection{Wurzelverletzungsversuch}

Ergänzend $\mathrm{zu}$ den beschriebenen Interaktionsuntersuchungen wurde in einem weiteren Gewächshausversuch im Jahr 2008 überprüft, welche Rolle einer mechanischen Wurzelverletzung im Vergleich zu einer durch Kohlfliegen bedingten Wurzelschädigung bzgl. $V$. longisporum zukommt. Die Untersuchungen wurden an Winterraps der Sorte Express durchgeführt. Der im Rahmen einer destruktiven Endbonitur 35 dpi bzw. 45 Tage 
nach Eiansatz erhobene Kohlfliegenfraß zeigte mit durchschnittlich 31\% geschädigter Wurzeloberfläche ein moderates Schädigungsniveau. Varianten ohne Kohlfliegenbesatz wiesen keinen Wurzelfraß auf. Ergebnisse der visuellen Bonitur des Verticillium-Befalls, die 7, 14, 21, 28 und 35 dpi anhand von Blattsymptomen vorgenommen wurde, sind in Abb. 30 zusammengefasst. Da bei den Kontrollpflanzen keine Symptome auftraten, wurde auf eine vergleichende Darstellung verzichtet. Aus der Abbildung geht hervor, dass die einzelnen Versuchsvarianten in der Dynamik des Verticillium-Befalls stark differierten. In der Variante „V $\mathrm{V}$ M“, bei der eine mechanische Verletzung von Haupt- und Feinwurzeln vor der Inokulation herbeigeführt worden war, setzte die Entwicklung von Symptomen früher ein als bei den übrigen Varianten. Den mit Abstand langsamsten Befallsverlauf verzeichnete die unverletzte Variante „V“. Am Versuchsende (35 dpi) waren hier bei fünf von zwölf Pflanzen Symptome festzustellen, wo hingegen in der durch Kohlfliegen geschädigten Variante „V + $\mathrm{KF}^{\text {“ }}$ neun von zwölf und in der o. a. Variante mit mechanischer Verletzung elf von zwölf Pflanzen charakteristische Symptome aufwiesen. Nach der Berücksichtigung einzelner Boniturnoten spiegelte sich der unterschiedliche Befallsverlauf auch in den mittleren Befallswerten wider. Eine Abstufung des Befalls in der Reihenfolge „,V $+\mathrm{M}^{“}>$ „,V $+\mathrm{KF}^{\circ}>$ „V“" konnte ab 28 dpi abgesichert werden.
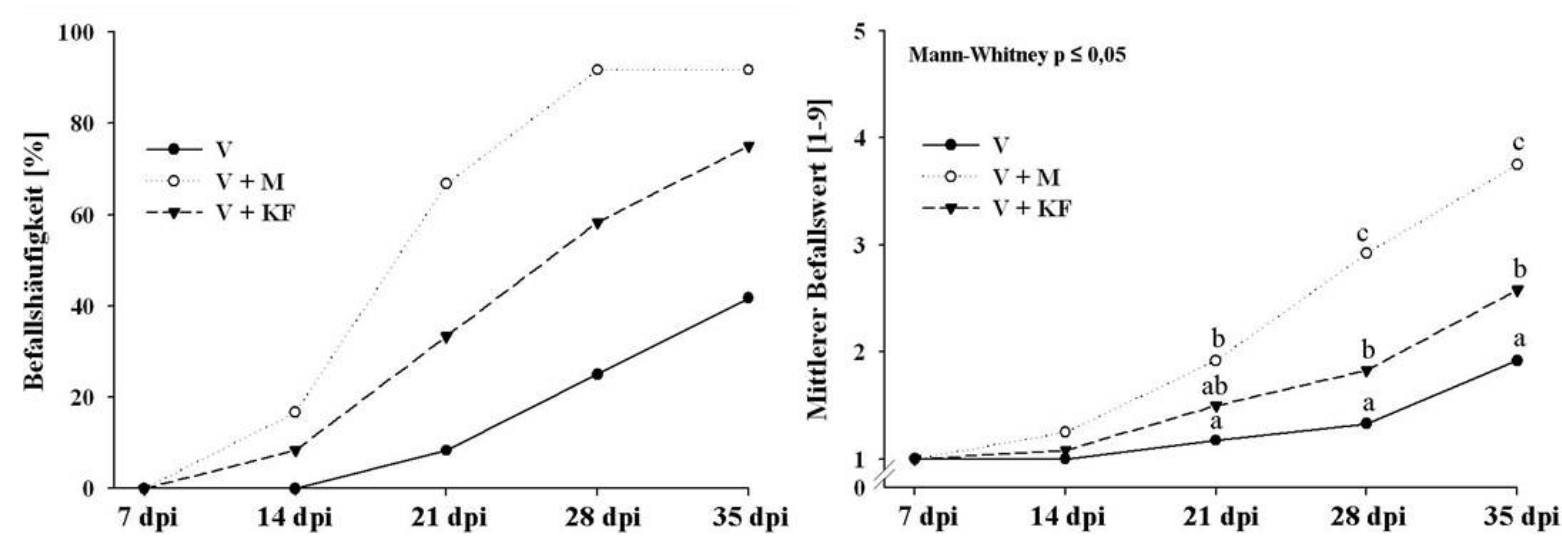

Abb. 30: Befallshäufigkeit [\%] sowie mittlerer Befallswert [1 (kein Befall) - 9 (sehr starker Befall)] von Winterraps der Sorte Express mit $V$. longisporum 7, 14, 21,28 und 35 Tage nach Bodengießinokulation ( $\mathrm{n}=12)$ (Boniturschlüssel nach Zeise (1992) basierend auf Blattsymptomen). Statistisch signifikante Befallswertdifferenzen zwischen den Versuchsvarianten sind durch unterschiedliche Buchstaben gekennzeichnet (Mann-Whitney $\mathrm{p} \leq 0,05$ ). Versuchsvarianten: $\mathrm{V}=$ Bodengießinokulation mit $100 \mathrm{ml}$ einer Sporensuspension der V. longisporum-Isolate VL $40 \mathrm{bzw}$. VL 43 (1 x $10^{5}$ Sporen/ml) zu BBCH 60; V + M= Mechanische Verletzung von Hauptwurzel (mit Skalpell) sowie Feinwurzeln (mit Nadel) unmittelbar vor der Bodengießinokulation (vgl. V); V $+\mathrm{KF}=$ Ansatz von 8 Kohlfliegeneiern an den Wurzelhals zu BBCH 55 + Bodengießinokulation. 
In Tab. 44 ist die nach dem letzten Boniturtermin (35 dpi) erhobene Wurzeltrockenmasse inokulierter Versuchsvarianten in Relation $\mathrm{zu}$ den jeweiligen Kontrollwerten (100\%) aufgelistet. Absolute Werte sind im Anhang angegeben (Tab. 21A). Eine Bodengießinokulation führte bei allen Versuchsvarianten zu einer signifikanten Reduktion der Wurzeltrockenmasse. Entsprechend den o. a. Unterschieden im Verticillium-Befall waren die höchsten Inokulationseffekte bei einer mechanischen Wurzelverletzung, die geringsten bei der unverletzten Variante auszumachen.

Tab. 44: Mittlere Wurzeltrockenmasse [WTM] von Rapspflanzen der Sorte Express nach Bodengießinokulation mit $V$. longisporum in Relation zu den jeweiligen Kontrollvarianten (100\%) 35 dpi (BBCH 75). Statistisch signifikante Differenzen zwischen den Inokulationsvarianten ${ }^{1)}$ sind für die jeweiligen Wurzelverletzungsvarianten ${ }^{2)}$ durch unterschiedliche Buchstaben gekennzeichnet. (+/-) zeigen signifikante Unterschiede zwischen den Wurzelverletzungsvarianten an (LSD $\mathrm{p} \leq 0,05 ; \mathrm{n}=$ 12).

\begin{tabular}{lccc}
\hline rel. WTM [\%] & \multicolumn{3}{c}{ Wurzelverletzung } \\
\cline { 2 - 4 } Inokulationsvarianten & Ohne & Mechanisch & Kohlfliege \\
\hline Kontrolle & $100 \mathrm{~b}$ & $100 \mathrm{~B}$ & $100 \beta$ \\
Verticillium-Inokulation & $83,3 \mathrm{a}+$ & $59,5 \mathrm{~A}-$ & $73,9 \mathrm{\alpha}+$ - \\
\hline GD LSD p $\leq 0,05$ & 14,5 & 18,7 & 11 \\
\hline
\end{tabular}

1) Bodengießinokulation mit $100 \mathrm{ml}$ einer Sporensuspension der $V$. longisporum-Isolate VL 40 bzw. VL 43 (1 x $10^{5}$ Sporen $/ \mathrm{ml}$ ) zu BBCH 60. 2) Wurzelverletzungsvarianten: Ohne; Mechanisch = Mechanische Verletzung von Hauptwurzel (mit Skalpell) sowie Feinwurzeln (mit Nadel) unmittelbar vor der Bodengießinokulation; Kohlfliege $=$ Ansatz von 8 Kohlfliegeneiern an den Wurzelhals zu BBCH 55.

Ergebnisse des Wurzelverletzungsversuchs bestätigen, dass nicht nur Kohlfliegenbefall, sondern auch mechanische Wurzelverletzungen zu einer Begünstigung von VerticilliumBefall führen können. Im vorliegenden Versuch kam es durch eine mechanische Verletzung von Hauptwurzel sowie Feinwurzeln unmittelbar vor der Inokulation zu einer stärkeren Symptomentwicklung als bei einer Schädigung durch Larvenfraß der Wurzel. 


\subsubsection{Einfluss der Kleinen Kohlfliege auf den Befall von Raps mit $P$. lingam}

Im Versuchsjahr 2007 wurden in einem Gewächshausversuch Interaktionen zwischen der Kohlfliege und $P$. lingam an Winterraps untersucht. Im Vordergrund der Untersuchungen stand dabei die Beantwortung der Frage, ob Larvenfraß der Kohlfliege einen Einfluss auf den Phoma-Befall hat und inwieweit sich hierbei eine anfällige (Oase) von einer resistenten Sorte (Caiman) unterscheidet. Darüber hinaus sollte überprüft werden, ob die Interaktion von der Aggressivität der Phoma-Isolate abhängt und wie der Kohlfliegenfraß im Vergleich zu einer nicht biotisch verursachten, mechanischen Schädigung im Hinblick auf Phoma-Befall zu bewerten ist. Unverletzte, mechanisch verletzte oder durch Kohlfliegen geschädigte Varianten wurden zu BBCH 55 mit einem aggressiven bzw. einem weniger aggressiven (mild) Isolatgemisch verschiedener Phoma-Isolate oberhalb des Wurzelhalses inokuliert. Zu 49 dpi erfolgte eine destruktive Endbonitur, bei der Phoma-Befall des Wurzelhalses anhand von verschiedenen Läsionsparametern (Länge, Tiefe und Umfang) bonitiert wurde.

In Tab. 45 sind die Ergebnisse für inokulierte Varianten der Sorte Oase dargestellt. Erwartungsgemäß hatte die Inokulation aggressiver Phoma-Isolate eine stärkere Symptomausprägung als eine Inokulation weniger aggressiver Phoma-Isolate zur Folge. Generell konnte selbst bei großen Phoma-Läsionen nur eine geringe Läsionstiefe beobachtet werden, so dass die VDT-Werte, die das Volumen erkrankten Gewebes repräsentieren, auf einem insgesamt niedrigen Niveau lagen. Die mechanische Verletzung und Fraßschädigungen der Kohlfliege (Ø 41\% geschädigte Wurzeloberfläche) führten gegenüber der nicht verletzten Kontrollvariante zu einem deutlichen Anstieg von Symptomhäufigkeit sowie Befallsstärke. Im Versuch war die Förderung von $P$. lingam durch Larvenfraß der Kohlfliege tendenziell stärker ausgeprägt als bei der mechanischen Nadelverletzungsvariante, was u. a. auf größere Wunden zurückzuführen ist (Abb. 31). Bei der resistenten Sorte Caiman konnten keine Phoma-Symptome beobachtet werden, was darauf hindeutet, dass eine Resistenz gegenüber den verwendeten Phoma-Isolaten vorliegt, die durch mechanische Verletzungen bzw. Fraßschädigungen der Kohlfliege offenbar nicht beeinflusst wird. 
Tab. 45: Befallshäufigkeit [\%], Gesamtboniturwert [GBW 0-9] sowie Volume of Diseased Tissue [VDT 0-9] von Winterraps der Sorte Oase mit $P$. lingam am Wurzelhals zu $49 \mathrm{dpi}^{1)}(\mathrm{BBCH} 85 ; \mathrm{n}=$ 15). Unterschiedliche Buchstaben zeigen statistisch signifikante Differenzen zwischen den Verletzungsvarianten bei den jeweiligen Phoma-Isolaten (aggressiv/mild) an (Mann-Whitney Median-Test $\mathrm{p} \leq 0,05)$.

\begin{tabular}{|c|c|c|c|c|c|c|}
\hline \multirow{2}{*}{$\begin{array}{l}\text { Sorte Oase } \\
\text { Läsionsparameter }\end{array}$} & \multicolumn{3}{|c|}{ Phoma-aggressiv } & \multicolumn{3}{|c|}{ Phoma-mild } \\
\hline & Ohne & Mechanisch $^{2)}$ & Kohlfliege $^{3)}$ & Ohne & Mechanisch $^{2)}$ & Kohlfliege $^{3)}$ \\
\hline $\mathrm{BH}[\%]$ & 50 & 87,5 & 100 & 6,7 & 18,8 & 37,5 \\
\hline GBW [0-9] & $1,67 \mathrm{a}$ & $3,8 \mathrm{~b}$ & $5,21 \mathrm{~b}$ & $0,07 \mathrm{a}$ & $0,4 \mathrm{a}$ & $1,69 \mathrm{~b}$ \\
\hline VDT [0-9] & $0,3 \mathrm{~A}$ & $1,05 \mathrm{~B}$ & $1,54 \mathrm{~B}$ & $0 \mathrm{~A}$ & $0,03 \mathrm{~A}$ & $0,19 \mathrm{~B}$ \\
\hline
\end{tabular}

1) Inokulation: $1 \mathrm{ml}$ eines aggressiven oder weniger aggressiven (mild) Phoma-Isolatgemischs $\left(1 \times 10^{6}\right.$ Sporen/ml) wurden zu BBCH 55 mit einer Pipette oberhalb des Wurzelhalses aufgetragen. 2) Verletzungsvarianten: Ohne; Mechanisch = unmittelbar vor der Inokulation wurde die Stängeloberfläche oberhalb des Wurzelhalses mit einer sterilen Nadel auf einer Länge von $1 \mathrm{~cm}$ flach eingeritzt. 3) Kohlfliege $=$ Ansatz von 8 Kohlfliegeneiern an den Wurzelhals zu BBCH 39. $\left[\mathrm{GBW}=(\mathrm{L}[1-9] \times \mathrm{U}[1-9])^{1 / 2} ; \mathrm{VDT}=\left(\left(1-\mathrm{HR}^{2}\right) \times \mathrm{U} / 9 \times \mathrm{L}\right)\right.$; (HR = 1-T/9); L = Läsionslänge [mm] 1-9; U = Läsionsumfang [\%] 1-9; T = Läsionstiefe [\%] 1-9]
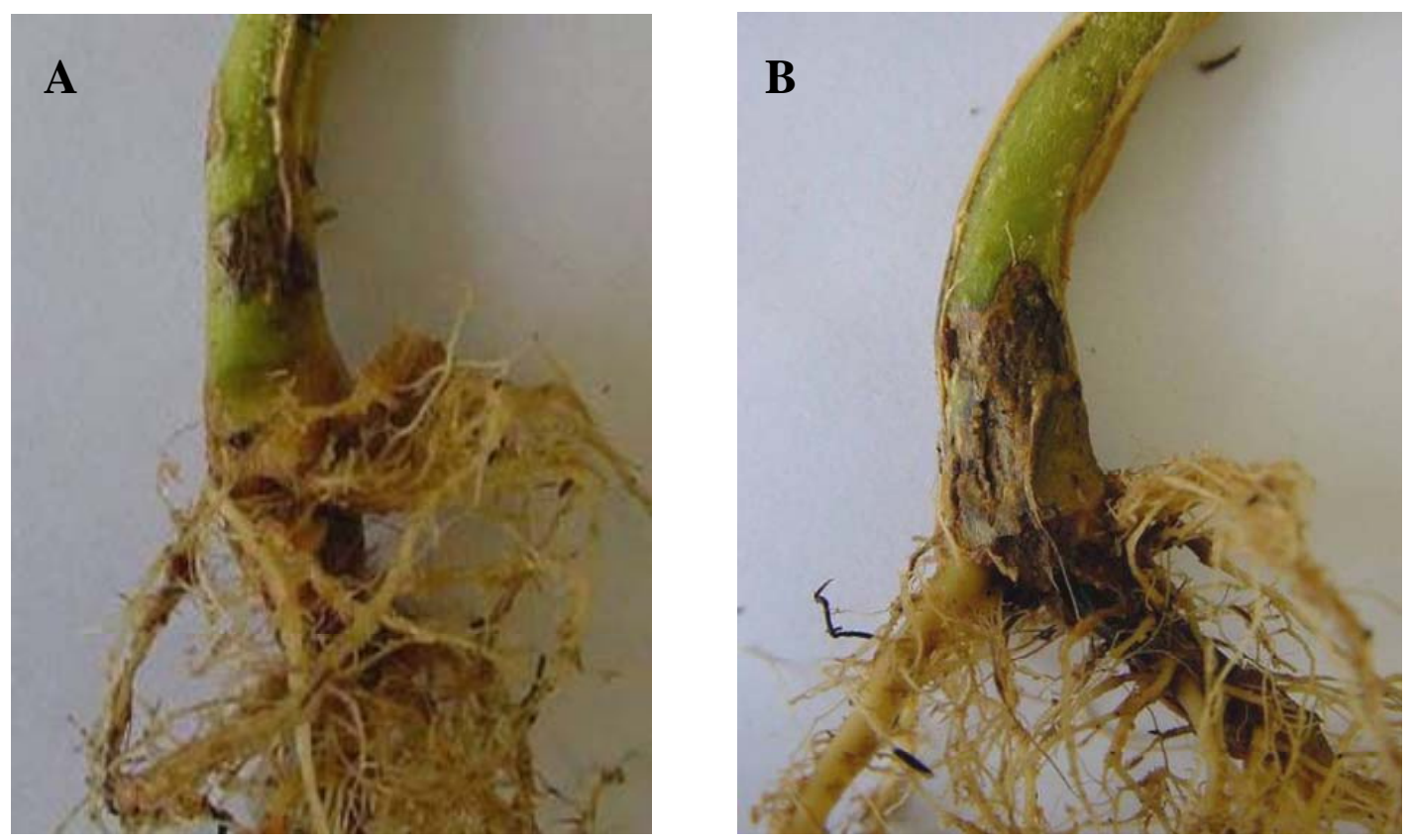

Abb. 31: Phoma-Läsion am Wurzelhals 49 dpi (Sorte Oase) nach einer mechanischen Nadelverletzung (A) sowie Larvenfraß der Kohlfliege (B). 


\section{Diskussion}

Im Rahmen der vorliegenden Arbeit wurde der Einfluss von Kohlfliegenbefall auf die Infektion und Schadwirkung von $V$. longisporum und P. lingam an Raps untersucht. Die folgende Diskussion setzt sich zunächst mit der Bedeutung einzelner Faktoren für den Befall und die Schadwirkung der Kleinen Kohlfliege (4.1) und $V$. longisporum (4.2) auseinander, bevor in den Kapiteln 4.3 sowie 4.4 auf die Interaktion beider Schaderreger und zugrunde liegende Mechanismen eingegangen wird. Den Abschluss der Diskussion bilden die Kapitel 4.5 und 4.6, in denen Befallsfaktoren von P. lingam unter Berücksichtigung von Kohlfliegenbefall näher beleuchtet werden.

\subsection{Befall und Schadwirkung der Kleinen Kohlfliege}

Während die Kleine Kohlfliege im Kohlanbau bereits seit vielen Jahren als bedeutender Schädling gilt, wird sie im Rapsanbau erst seit Mitte der 90er Jahre verstärkt wahrgenommen. Der Eiablage wird hierbei die entscheidende Rolle für Auftreten und Ausmaß von Larvenfraß an der Wurzel zugeschrieben. Ob es zu einer Eiablage kommt, hängt dabei nicht nur vom Vorhandensein einer ausreichend hohen Kohlfliegenpopulation, sondern auch einer Reihe weiterer Faktoren ab. Die Wahl der Wirtspflanze wird durch olfaktorische sowie optische Reize stimuliert. Abgesehen von den für Kruziferen charakteristischen Senfölen, die durch Hydrolyse von Glucosinolaten gebildet werden und einen starken olfaktorischen Reiz auslösen (Traynier, 1965; Finch, 1978; Nottingham \& Coaker, 1985; Nottingham, 1988; Tuttle et al., 1988; Baur et al., 1996a, 1996b), spielen optische Faktoren wie Pflanzengröße und Auffälligkeit bei der Ortung einer Wirtspflanze ebenfalls eine wichtige Rolle (Yaman, 1960; Traynier, 1967; Prokopy et al., 1983a, 1983b; Roessingh \& Städler, 1990; Kostal, 1993). Nach der Landung reifer Weibchen auf der Pflanze kommt es nach Zohren (1968) und Städler (1978) zu einer weiteren chemotaktilen Stimulation der Kohlfliege, die über Chemorezeptoren an den Sinneshaaren der Tarsen wahrgenommen wird. Weiterführende Untersuchungen von Roessingh et al. (1992, 1997), Baur et al. (1998), Marazzi \& Städler (2004) sowie De Jong (2000) liefern Hinweise, dass nicht nur Glucosinolate, sondern auch andere stoffliche Verbindungen für diese Stimulierung verantwortlich sind. Nach dem Blattspreitenlauf, der von Zohren (1968) als Indiz für eine erfolgreiche Stimulierung angesehen wird, begibt sich das Kohlfliegenweibchen an die Pflanzenbasis, wo mit einem Legebohrer, dem so genannten Oviposator, Eier an den Wurzelhals oder in nahe gelegene Bodenrisse abgelegt werden. 
Eine Reihe von Versuchen an Raps und anderen Brassica-Arten zeigen, dass Kohlfliegenweibchen bei Wahlmöglichkeit größere Pflanzen gegenüber kleineren Pflanzen bei der Eiablage bevorzugen (Finch, 1989). Ob es allerdings zu einer Eiablage kommt, hängt auch vom Entwicklungsstadium der Wirtspflanze ab. In Freilanduntersuchungen von Swailes (1958) und Maack (1977) konnte eine Eiablage an Blumenkohl erst ab dem dritten bis vierten Laubblattstadium festgestellt werden, obgleich keine weiter entwickelten Witspflanzen in unmittelbarer Nähe vorzufinden waren. Als Begründung führten die Autoren einen zu geringen Pflanzenbedeckungsgrad des Bodens und eine damit verbundene zu geringe optische sowie olfaktorische Stimulierung der Kohlfliege an. Die gezielte Wahl des Saattermins bietet eine Möglichkeit, Kohlfliegenbefall zu verringern, in dem der Saattermin so gelegt wird, dass das anfällige Entwicklungsstadium einer Wirtspflanze nicht mit dem Höhepunkt der Eiablage zusammenfällt (Maack, 1977; Coaker, 1987; Finch, 1989; Dosdall et al., 1995, 2006). Beobachtungen aus der Praxis haben gezeigt, dass früh gesäte Winterrapsbestände bei der Eiablage im Herbst gegenüber später gesäten Beständen häufig präferiert und demzufolge stärker geschädigt werden (Erichsen \& Hünmörder, 2005; Ulber et al., 2006).

Um in eigenen Versuchen am Standort Göttingen einen möglichst hohen Befallsdruck zu gewährleisten, erfolgte die Aussaat mit Ausnahme einer Spätsaatvariante (Aussaat Ende August) in der ersten Augusthälfte. Bei den früh gesäten Varianten, in denen keine Kontrolle des Kohlfliegenbefalls vorgesehen war, wiesen im Untersuchungszeitraum 2005-2007 im Herbst durchschnittlich 60-70\% der untersuchten Wurzeln Kohlfliegenbefall auf, während in der Spätsaatvariante des Anbaufaktorenversuchs maximal 20\% der Wurzeln befallen waren. Nennenswerter Starkbefall (12-15\%) trat ebenfalls nur nach einer Frühsaat auf. Zum Zeitpunkt des anhand von Gelbschalenfängen kontrollierten Hauptzufluges der Kohlfliege Mitte September hatten die früh gesäten Bestände bereits vier bis fünf Laubblätter entwickelt, während sich der später gesäte Raps erst im zweiten Laubblattstadium befand. Die für eine hohe Eiablage erforderliche Koinzidenz zwischen starkem Kohlfliegenflug und attraktiven Wirtspflanzenstadium war demnach nur für die Frühsaaten gegeben. Ein Zusammenhang zwischen Saattermin und Kohlfliegenbefall war auch an den Monitoringstandorten festzustellen, wo die Versuchsflächen im ersten Jahr in der ersten Augusthälfte, im zweiten Jahr aufgrund von ungünstigen Witterungsbedingungen jedoch erst Ende August bestellt werden konnten. Der Anteil durch die Kohlfliege befallener Pflanzen im Herbst variierte je nach Standort zwischen 50-90\% im ersten und 25-32\% im zweiten Versuchsjahr. Auch wenn 
mögliche jahresbedingte Populationsschwankungen der Kohlfliege nicht ausgeschlossen werden können, so deutet sich auch hier ein Effekt des Saattermins an.

Nach eigenen Untersuchungen können Bodenbearbeitungseffekte Kohlfliegenbefall im Herbst ebenfalls beeinflussen. Im Anbaufaktorenversuch, bei dem in den ersten beiden Versuchsjahren neben dem Faktor Saattermin (früh/spät) auch die Art der Grundbodenbearbeitung (Grubber/ Pflug) variiert worden war, wiesen die vor der Aussaat gepflügten Varianten nach einer Frühsaat deutlich höheren Kohlfliegenbefall auf als gegrubberte Varianten. Die unterschiedliche Entwicklung des Rapses nach Pflug- bzw. Grubberbearbeitung kann hier als möglicher Grund angeführt werden. In den gepflügten Parzellen lief der Raps zügiger auf, wodurch es zu einem Entwicklungsvorsprung kam, der sich bis Ende September beobachten ließ. Aufgrund der bereits erwähnten Präferenz größerer Pflanzen bei der Eiablage waren die Pflanzen nach einer Pflugsaat offenbar attraktiver. Ein weiterer Grund für den geringeren Kohlfliegenbefall nach einer Grubberbearbeitung lässt sich möglicherweise auf Erntereste der Vorfrucht (Wintergerste) zurückführen, die nach einer mischenden Bodenbearbeitung an der Bodenoberfläche verbleiben. Zahlreiche Untersuchungen haben gezeigt, dass Unkräuter (Dosdall et al., 2003), Mischanbau mit Nichtwirtspflanzen (Ryan et al., 1980; Tukahirwa \& Coaker, 1982; Björkman et al., 2007) sowie Untersaaten (Finch, 1996) zu einer Störung des Wirtsfindungsvermögens der Kohlfliege führen können. In unseren Untersuchungen waren Pflug- und Grubbervarianten direkt nebeneinander angeordnet. Fraglich ist, ob die Befallsunterschiede zwischen beiden Varianten auch bei einem Vergleich in größerem Maßstab (Schlagebene) aufgetreten wären, da geringe Attraktivitätsunterschiede von der Kohlfliege nach Finch \& Skinner (1975) nur über kurze Distanzen wahrgenommen werden können. Generell wird der Faktor Bodenbearbeitung als wichtiges Instrument einer integrierten Kohlfliegenbekämpfung betrachtet (Finch, 1989), wobei hier nicht die Bodenbearbeitung vor, sondern insbesondere die Bodenbearbeitung nach dem Anbau einer anfälligen Wirtspflanze im Vordergrund steht. In Versuchen von Finch \& Skinner (1980) sowie Dosdall et al. (1996) führte eine Bodenbearbeitung mit Pflug bzw. Scheibenegge nach dem Anbau von Raps zu einer Verminderung des Kohlfliegenschlupfes um bis zu 75\%, was vornehmlich auf eine mechanische Zerstörung der Kohlfliegenpuppen zurückgeführt wurde.

Neben den bisher erörterten indirekten Kontrollmaßnahmen, die auf eine Beeinflussung der Populationsgröße, sowie das Eiablageverhalten ausgerichtet sind, stellt ein Insektizideinsatz eine direkte Form der Bekämpfung dar. Versuche zur Kontrolle der Imagines sowie Larven 
mittels Spritzapplikation haben dabei häufig nur geringe Wirkungsgrade erzielen können (Erichsen et al., 2004; Erichsen \& Hünmörder, 2005). Teilweise führte eine Spritzapplikation sogar zu einer Erhöhung des Kohlfliegenbefalls, was mit einer möglichen Nebenwirkung auf Gegenspieler begründet wurde (Coaker \& Williams, 1963; Erichsen \& Hünmörder, 2005). Im Kohlanbau wurden Insektizide in der Vergangenheit häufig als Gießapplikationen oder in Granulatform in den Boden eingebracht. Eine Saatgutbehandlung mit Insektiziden, die auf eine Bekämpfung der Kohlfliegenlarven abzielt, stellt im Rapsanbau die einzig praktikable Bekämpfungsmaßnahme dar. Unter der Voraussetzung, dass eine effektive Kontrolle der Larven gewährleistet wird, bietet diese prophylaktische Maßnahme sowohl aus Kostengründen, als auch aus umwelttoxikologischen Gründen Vorteile, da hier im Vergleich zu Spritzapplikationen nur sehr geringe Wirkstoffmengen je Flächeneinheit ausgebracht werden (Heitefuss, 2000). Insektizide Wirkstoffe, die im Rapsanbau für eine Saatgutbehandlung in Frage kommen, haben in bisher durchgeführten Untersuchungen unterschiedlich hohe Wirkungsgrade erkennen lassen. Während das seit 2003 zugelassene Standardpräparat Chinook (Wirkstoffe: Imidacloprid + Beta-Cyfluthrin) nur eine sehr geringe Wirkung gegenüber den Larven der Kohlfliege aufweist (Ester et al., 2003; Haarstrich, 2007), konnten mit dem seit 2005 zur Verfügung stehenden Präparat Elado (Wirkstoffe: Clothianidin + BetaCyfluthrin) in Versuchen von Erichsen \& Hünmörder (2005) deutlich höhere Wirkungsgrade erzielt werden. Eine Saatgutbehandlung mit Elado führte gegenüber einer Saatgutbehandlung mit Chinook in einem an dreizehn Standorten in Mecklenburg-Vorpommern im Herbst 2004 durchgeführten Praxisversuch $\mathrm{zu}$ einer Verringerung fraßgeschädigter Pflanzen um durchschnittlich 45\% sowie einer Senkung des Starkbefalls um etwa 80\%.

In eigenen Versuchen (Sortenversuch 2005/2006) wurde daraufhin versucht, mit Hilfe von Elado in Kombination mit dem insektiziden Streumittel Nexion Neu (Wirkstoff: Chlorpyriphos) ein im Vergleich zu Chinook deutlich geringeren Kohlfliegenbefall im Herbst einzustellen. Zwischen den beiden Insektizidvarianten traten bei insgesamt hohem Befallsdruck allerdings lediglich geringe Unterschiede im Starkbefall auf. Bei der Befallshäufigkeit $(\mathrm{BH})$ waren keine Unterschiede auszumachen. An den Monitoringstandorten ließen sich im Versuchsjahr 2005/2006 ebenfalls nur geringe Befallsunterschiede zwischen den Insektizidvarianten Chinook und Elado erkennen. Deutlich geringere Wirkungsgrade des Präparats Elado im Vergleich zu den von Erichsen \& Hünmörder (2005) durchgeführten Untersuchungen lassen auf eine begrenzte Wirkung von Elado bei hohem Kohlfliegenbefall schließen. Haarstrich (2007) testete die Wirkung verschiedener insektizider Saatgutbehandlungsmittel gegenüber den Larven der Kohlfliege an Raps im Gewächshaus. Eine 
Teilwirkung des Präparates Elado konnte hier ebenso bestätigt werden wie die unzureichende Wirkung des Präparates Chinook. Auffällig war, dass das bis zum Jahr 2003 zugelassene Präparat Oftanol T (Wirkstoff: Isofenphos) den mit Abstand höchsten Wirkungsgrad erzielte.

Im dritten Versuchsjahr 2007/2008 wurde daraufhin versucht, Herbstbefall der Kohlfliege mit Hilfe von Chinook und Oftanol $\mathrm{T}$ abzustufen. In einer Variante wurde in den mit Oftanol T behandelten Parzellen zusätzlich das insektizide Streumittel Nexion Neu in die Saatreihen ausgestreut. In der Insektizidvariante „Oftanol T + Nexion Neu“ ließen sich Häufigkeit und Stärke des Kohlfliegenbefalls um etwa 50\% gegenüber Chinook reduzieren. Eine alleinige Saatgutbehandlung mit Oftanol T führte zu einer Verringerung des Befalls um etwa 30\%. Die mit den Organophosphorsäureestern Isofenphos und Chlorpyriphos erreichte Verringerung des Kohlfliegenbefalls steht im Einklang mit Untersuchungsergebnissen von Thompson et al. (1979), Ester et al. (1993) sowie Ester (1994), die im Kohlanbau vergleichbar hohe Effekte feststellten. Unterschiedliche Wirkungsgrade des insektiziden Streumittels Nexion Neu im ersten und dritten Versuchsjahr hängen möglicherweise mit der Ausbringtechnik zusammen. Nach Untersuchungen von Bevan \& Kelly (1975) führt eine flache Einarbeitung der insektiziden Granulate zu einer effektiveren Larvenbekämpfung als eine Ausbringung auf der Bodenoberfläche, was auf eine höhere Bodenfeuchte, die eine stärkere Wirkstofffreisetzung bedingt, zurückgeführt wurde. Eine weitere Ursache geringer Wirkungsgrade bei Oberflächenausbringung könnte eine zu geringe Wirkstoffakkumulation am Fraßort sein, da die Larven nach dem Schlupf i. d. R. nur kurze Distanzen bis zur Wurzel zurücklegen (Hassan, 1969). Während im ersten Versuchsjahr 2005/2006 eine breitflächige Ausbringung erfolgte, wurde Nexion Neu im dritten Versuchsjahr 2007/2008 ausschließlich in die Saatreihenvertiefungen des in Einzelkornsaat bestellten Rapses ausgestreut. Dieses hatte vermutlich eine höhere Wirkstoffakkumulation im Bereich des Samens zur Folge. Eigene Untersuchungen sowie die von Haarstrich (2007) erhobenen Daten lassen die Vermutung zu, dass die mit dem Ende der Zulassung von Oftanol T im Jahr 2003 einhergehende Erhöhung des Kohlfliegenbefalls im Raps auch auf eine geringe Kohlfliegenwirkung der seitdem verwendeten Saatgutbehandlungsmittel zurückzuführen ist.

Abgesehen von den bisher beschriebenen Maßnahmen, Kohlfliegenbefall zu verringern, bieten Kulturschutznetze eine Möglichkeit, Kohlfliegenbefall auszusschließen. Während Kulturschutznetze im ökologischen Kohlanbau häufig erforderlich sind, um einen wirtschaftlichen Anteil marktfähiger Ware zu produzieren (Crüger et al., 2002; Merz, 2005), kommt ein Einsatz im Rapsanbau aus Kostengründen nicht in Betracht. In eigenen Feld- 
versuchen kamen Kulturschutznetze (Rantai K 1,35 mm x 1,35 mm Maschenweite) zur Anwendung, um Kohlfliegenbefall effektiv ausschließen zu können. Durch verschiedene Netzabdeckungsvarianten im Herbst und Frühjahr bot sich hier zudem die Gelegenheit, auch den Einfluss von Kohlfliegenbefall im Frühjahr zu untersuchen, was mit Insektiziden, die nur den Befall im Herbst beeinflussen können, nicht möglich ist. In Übereinstimmung mit Untersuchungen an Kohl (Lukoschik, 1990; Merz, 2005) konnte Kohlfliegenbefall mit Hilfe von Netzabdeckungen effektiv ausgeschlossen werden. Ein geringer Anteil geschädigter Pflanzen trotz Netzabdeckung lässt sich vermutlich auf kleine Lücken am Rand der Befestigung zurückführen, wodurch Eintrittspforten entstanden sein könnten. Netzabdeckungen führten allerdings auch $\mathrm{zu}$ einer Beeinflussung des Mikroklimas, was pflanzenmorphologische Effekte zur Folge hatte. Im Vergleich zu den nicht abgedeckten Parzellen war die Bodentemperatur unter den Netzen im Untersuchungszeitraum August bis Oktober 2007 um durchschnittlich 1,1 ${ }^{\circ} \mathrm{C}$ erhöht. Eine Netzabdeckung im Herbst führte zu einer Förderung des Blattwachstums, wodurch es zu einer Erhöhung der Pflanzenfrischmasse von $10-20 \%$ gegenüber nicht abgedeckten Parzellen vor Winter kam. Eine Beeinflussung des Wurzelwachstums war hingegen nicht festzustellen.

Netzabdeckungen übten teilweise auch einen Einfluss auf den Ertrag aus. Im Versuchsjahr 2006/2007 wies die Variante „Netz im Herbst + Frühjahr“ signifikant niedrigere Ertragssowie TKG-Werte im Vergleich zu den anderen Netzabdeckungsvarianten (,ohne Netz“; „Netz im Herbst") auf. Es ist vorstellbar, dass die während des gesamten Blühzeitraumes errichteten Netzkäfige trotz einer relativ großen Maschenweite $(1,35 \mathrm{~mm})$ zu einer geringeren Bestäubungsleistung geführt haben. Da es sich bei Raps um eine vorwiegend selbstbefruchtende Kultur mit partieller Fremdbefruchtung handelt (Becker et al., 1992), deren Bestäubung maßgeblich über Wind erfolgt, liegt die Vermutung nahe, dass die Luftbewegung in den Netzkäfigen vermindert war. Ob auch ein gewisser Anteil des Ertragsverlustes auf den Ausschluss blütenbestäubender Insekten, wie der Honigbiene, zurückzuführen ist, bleibt ungewiss, da Angaben zur Bedeutung von Bienen für den Rapsertrag von gering (Langridge \& Goodman, 1982) bis hoch (Fries \& Stark, 1983; Williams et al., 1987) reichen.

Flugbeginn und Flugverlauf der Kohlfliege wurden an den Göttinger Feldversuchsstandorten anhand von Gelbschalenfängen kontrolliert. Der Zuflug der dritten Kohlfliegengeneration im Herbst fand im Untersuchungszeitraum 2005-2008 zwischen Ende August und Anfang Oktober statt. Im Frühjahr setzte erster Zuflug der ersten Generation ab Ende April ein und dauerte bis Ende Mai/Anfang Juni an. Flughöhepunkte lagen im September bzw. Mai. Die 
Populationsdynamik entsprach den Ausführungen anderer Autoren (Collier \& Finch., 1983a, 1983b; Crüger, 2002; Hoffmann \& Schmutterer, 2002). In den ersten beiden Versuchsjahren wiesen nach dem Zuflug der ersten Generation im Frühjahr nahezu alle untersuchten Wurzeln, die aus nicht abgedeckten Parzellen stammten, Larvenfraß der Kohlfliege auf und zwar unabhängig von der Höhe des Herbstbefalls. Dieses Ergebnis stimmt mit Beobachtungen von Hünmöder (2003) überein, wonach im Frühjahr häufig mehr Pflanzen geschädigt werden als im Herbst. Finch \& Jones (1987) halten Kohlfliegenbefall von Winterraps im Frühjahr nur dann für möglich, wenn es bereits im Herbst zu Larvenfraß an der Wurzel gekommen ist. Eine über Winter einsetzende starke Verhärtung des Wurzelgewebes wurde hierfür verantwortlich gemacht. In eigenen Versuchen konnte jedoch gezeigt werden, dass sogar in Varianten, bei denen Kohlfliegenbefall im Herbst mit einer Netzabdeckung ausgeschlossen worden war, fast alle Pflanzen im Frühjahr befallen wurden. Im dritten Versuchsjahr 2007/2008 war der Kohlfliegenbefall im Frühjahr nicht mit der Befallssituation der Vorjahre zu vergleichen. Trotz eines im Vergleich zu den Vorjahren nur geringfügig niedrigeren Kohlfliegenzufluges im Mai 2008 wurden nur wenige Pflanzen im Frühjahr befallen. Eine mit dem Kohlfliegenflug im Mai koinzidierende sechswöchige Trockenperiode ist möglicherweise ein Grund für geringen Kohlfliegenbefall, da Untersuchungen von Mukerji (1971) darauf hinweisen, dass es bei Bodentrockenheit zu einer hohen Ei- und Junglarvenmortalität kommen kann.

Kohlfliegenbefall wurde in den Halbfreilandversuchen sowie im Gewächshaus durch das Ansetzen von Kohlfliegeneiern gezielt gesteuert. In der mit einem Kulturschutznetz abgedeckten Betonkastenrahmenanlage wiesen in den Versuchsjahren 2006 und 2007 nahezu alle Sommerrapspflanzen, bei denen zehn Kohlfliegeneier an den Wurzelhals angesetzt worden waren, Larvenfraß an der Wurzel auf. Mit durchschnittlich 24\% geschädigter Wurzeloberfläche und einem Anteil stark befallener Pflanzen von etwa 5\% war die Schädigung moderat. Im Gewächshaus erfolgte die Simulierung des Kohlfliegenbefalls in ähnlicher Weise wie bei den Halbfreilandversuchen, wobei jedoch anstatt zehn i. d. R. acht Kohlfliegeneier an den Wurzelhals angesetzt wurden. Trotz dieser geringeren Eizahl lag das durchschnittliche Fraßschädigungsniveau mit 41,4\% geschädigter Wurzeloberfläche deutlich über dem der Halbfreilandversuche. Dieses Ergebnis deutet auf eine höhere Larvenentwicklungsrate im Gewächshaus hin, die ihre Ursache in einer geringeren Mortalität haben könnte. Im Freiland entwickeln sich gewöhnlich nicht mehr als zehn bis zwanzig Prozent der abgelegten Kohlfliegeneier zu Larven und schließlich zu Puppen (Mukerji, 1971; Maack, 1977). Eine besonders hohe Mortalität tritt im Ei- sowie ersten Larvenstadium auf, was 
insbesondere auf eine zu geringe Bodenfeuchtigkeit, hohe Bodentemperaturen, Starkregenereignisse und ein fehlendes Penetrationsvermögen von Junglarven in die Wurzel der Wirtspflanze zurückgeführt wird (Finch \& Coaker, 1969; Mukerji, 1971; Vereecke \& Hertveldt, 1970). Neben witterungs- und dichteabhängiger Mortalität (Zohren, 1968) werden weitere Verluste natürlichen Gegenspielern zugeschrieben. Von Bedeutung sind u. a. Käfer und Larven der Kurzflügler Aleochara bilineata und Aleochara bipustulata. Während die Käfer als Ei-, Larven und Puppenräuber auftreten, können die Käferlarven als Puppenparasitoide agieren (Coaker \& Williams, 1963; Bromand, 1980). Als Eiräuber fungierende kleine Laufkäferarten wie bspw. Bembidion lampris und Amara familiaris (Hughes, 1959; Mitchell, 1963; Coaker \& Williams, 1963; Finch \& Elliott, 1992) sowie die Gallwespe Trybliograha rapae (Reader \& Jones, 1990; Hemachandra et al., 2007), welche ihre Eier in Kohlfliegenlarven legt, gelten als weitere bedeutende Gegenspieler der Kohlfliege.

Der Anbau von resistenten Sorten wäre eine weitere Möglichkeit, Kohlfliegenbefall vorzubeugen. Eine geringere Fraßschädigung an der Wurzel kann dabei entweder auf einer verminderten Eiablage aufgrund von Nicht-Präferenz (Antixenosis) oder auf einer gehemmten Larvenentwicklung (Antibiosis) beruhen (Birch, 1988). In einer Reihe von Wahlversuchen wurden bei einigen Brassica-Arten Sortenunterschiede im Kohlfliegenbefall beobachtet, die sich vornehmlich auf eine differierende Präferenz bei der Eiablage zurückführen ließen (Swailes, 1960; Schnitzler, 1969; Ellis \& Hardman, 1975, 1983). Beim Besatz von Pflanzen mit einer festgelegten Anzahl von Eiern bzw. Larven fielen die Sortenunterschiede gering aus. Nur vereinzelt war bei Sorten mit einer vergleichsweise hohen Wurzeltrockenmasse [\%] auch eine leichte Reduktion des Wurzelfraßes zu erkennen, was auf Antibiosiseffekte schließen lässt (Birch, 1988; Hopkins et al., 1999; Felkl et al., 2005). In eigenen Feldversuchen waren nur geringe Sortenunterschiede beim Herbstbefall der Kohlfliege festzustellen. Hierbei setzten sich in den jeweiligen Versuchsjahren die Sorten mit relativ niedrigem (hohen) Kohlfliegenbefall von den übrigen Sorten ab, die auch gleichzeitig die langsamste (zügigste) Entwicklung vollzogen. Beim Kohlfliegenbefall im Frühjahr konnten keine Sortenunterschiede mehr festgestellt werden. Im Gewächshaus, wo alle Pflanzen gleichen Bedingungen (Anzahl Kohlfliegeneier) ausgesetzt waren, zeigten sich keine Sortenunterschiede im Fraßschädigungsniveau. Antibiosiseffekte können hier ausgeschlossen werden. Inwieweit die in Canada verfolgten Ansätze zur Erhöhung von Kohlfliegenresistenz bei Raps (Dosdall et al., 2000; Ekuere et al., 2005) Aussicht auf Erfolg haben, erscheint fraglich, insbesondere wenn man berücksichtigt, dass die im Wesentlichen 
auf Antixenosis beruhenden Sortenunterschiede ausschließlich in Versuchen mit Wahlmöglichkeit gewonnen worden sind.

Die direkte Schadwirkung von Kohlfliegenbefall lässt sich nur schwer vorhersagen. Ob es durch Larvenfraß an Haupt-, Seitenwurzel und Hypokotyl zu einer Beeinträchtigung des Pflanzenwachstums kommt, hängt dabei nicht nur vom Ausmaß der Fraßschädigung, sondern auch vom Entwicklungszustand und Regenerationsvermögen der Pflanze (Wurzel) ab. Untersuchungen an Blumenkohl haben gezeigt, dass starker Kohlfliegenbefall zu einem frühen Entwicklungsstadium massive Pflanzenausfälle zur Folge haben kann, während ein vergleichbar hoher Befall bei fortgeschrittener Pflanzenentwicklung weitaus besser toleriert wird (Maack, 1977; El Titi, 1977a, 1977b, 1979; Bligaard, 1999). Bei Winterraps wird der im September/Oktober erscheinenden dritten Kohlfliegengeneration die größte Bedeutung beigemessen, da Larven an jungen Rapspflanzen starke Fraßschädigungen hervorrufen können, die bei Kappung der Hauptwurzel häufig zum Absterben der Pflanze führen (Erichsen et al., 2004). Der ersten Kohlfliegengeneration im Frühjahr wird nur eine untergeordnete Schadrelevanz zugeschrieben, da sich Winterraps zu Beginn de Zufluges bereits im Stadium der Blüte befindet und i. d. R. in der Lage ist, Larvenfraß an der Pfahlwurzel besser zu tolerieren. Bei Sommerraps liegt eine andere Situation vor. Aufgrund des mit der Jugendphase zusammenfallenden Frühjahrszufluges kommt der ersten Kohlfliegengeneration hier die entscheidende Bedeutung zu (McDonald \& Sears, 1991; Morgan, 1992; Dosdall et al., 2004).

Bislang existieren nur wenige Untersuchungen, die sich mit der Schadwirkung eines nicht letalen Kohlfliegenbefalls auseinandergesetzt haben. Generell wird davon ausgegangen, dass eine durch Larvenfraß bedingte Zerstörung des Wurzelsystems zu einer Beeinträchtigung der Wasser- und Nährstoffaufnahme führt, die sich letztlich in einer geringeren Biomassproduktion niederschlägt (Richard \& Thurling, 1978; McDonald \& Sears 1991; Morgen, 1992). Je nach Versuchsansatz schwankten befallsinduzierte Verluste von Wurzel- und Sprossmasse zwischen 0 und 47\%, wobei die Effekte mit ansteigender Befallsintensität i. d. R. zunahmen. In Klimakammerversuchen von McDonald \& Sears (1991) war eine Reduktion der Pflanzenbiomasse um 19\% lediglich bei einem hohen Fraßschädigungsgrad der Wurzel (> 50\%) zu verzeichnen, während geringere Schädigungen keine signifikanten Effekte zur Folge hatten. Hopkins et al. (1999) konnten in Gewächshausversuchen bei moderater Fraßschädigung ebenfalls keine Biomasseverluste feststellen. 
Schadeffekte eines alleinigen Kohlfliegenbefalls (ohne Pathogenbefall) traten in eigenen Gewächshausuntersuchungen lediglich in einem Versuch (Resistenzversuch) auf, bei dem die Fraßschädigung mit durchschnittlich 69\% geschädigter Wurzeloberfläche auf einem sehr hohen Niveau lag. Gegenüber nicht geschädigten Kontrollpflanzen waren am Versuchsende (BBCH 85) signifikante Reduktionen bei der Sprossmasse (bis 13\%) sowie Wurzeltrockenmasse (bis 14,7\%) festzustellen. In den übrigen Versuchen, bei denen durchschnittlich 3050\% der Wurzeloberfläche Fraßschädigungen aufwiesen und Rapspflanzen auf Befall mit einer verstärkten Seitenwurzelbildung reagierten, ließen sich keine Schadeffekte eines alleinigen Kohlfliegenbefalls erkennen. DieseErgebnisse deuten darauf hin, dass Raps nicht nur den Befall von Blüten- und Schotenschädlingen durch regeneratives Wachstum ausgleichen kann (William \& Free, 1979; Tatchell, 1983), sondern offenbar auch in der Lage ist, Wurzelfraß in Abwesenheit weiterer biotischer oder abiotischer Stressfaktoren ohne nennenswerte Biomasseverluste zu kompensieren.

Nach Müller (1991) führt ein durch Larvenfraß bedingter Verlust an Wurzelmasse zu einer verstärkten Ressourcenallokation in der Wurzel, wodurch das regenerative Wachstum von Seitenwurzeln stimuliert wird. Inwieweit das regenerative Wurzelwachstum allerdings ausreicht, Biomasseverlusten entgegen zuwirken, hängt auch vom physiologischen Zustand der Pflanze ab. Untersuchungen zur Schadwirkung des Maiswurzelbohrers (Diabrotica virgifera) zeigen, dass das regenerative Wurzelwachstum bei einer geringen Fraßschädigung wesentlich stärker ausgeprägt ist als bei einer hohen Fraßschädigung (Painter, 1951; Assabgui et al., 1995). Dem kompensatorischen Potenzial sind zudem Grenzen gesetzt, wenn neben der eigentlichen Fraßschädigung weitere Stressfaktoren wie bspw. Bodentrockenheit oder Nährstoffmangel auftreten, die ein regeneratives Wachstum nicht zulassen (Spike \& Tollefson, 1989a, 1989b). Für Raps liegen bislang keine Versuchsergebnisse vor, die das kompensatorische Wurzelwachstum von Kohlfliegen geschädigten Pflanzen näher untersucht haben. Ausführungen von Erichsen \& Hünmörder (2005) zufolge, nach denen insbesondere bei trockenen Bodenbedingungen und Starkbefall mit einer eingeschränkten Kompensationsfähigkeit zu rechnen ist, weisen auf ähnliche Gegebenheiten hin.

Im Rahmen einer Masterarbeit von Müller (2007) sollten im Halbfreilandversuch (Versuchsjahr 2006) auch Schadeffekte eines alleinigen Kohlfliegenbefalls an Sommerraps näher untersucht werden. Eine nach gezieltem Eibesatz festgestellte moderate Fraßschädigung (Ø $23 \%$ geschädigte Wurzeloberfläche, Ø 2,4\% Starkbefall) hatte keine negativen, sondern teilweise sogar positive pflanzenmorphologische Effekte zur Folge. Gegenüber Pflanzen 
ohne Kohlfliegenbefall wiesen Pflanzen mit Kohlfliegenbefall tendenziell höhere Werte bei der Sprossfrischmasse $(+6,6 \%)$ und beim Einzelpflanzenertrag $(+10 \%)$ auf. Die Wurzeltrockenmasse wurde durch Kohlfliegenbefall um durchschnittlich 23,7\% erhöht, was sich gegenüber der Kontrolle auch statistisch absichern ließ. Diese Ergebnisse deuten darauf hin, dass Rapspflanzen unter günstigen Bedingungen in der Lage sind, geringen Larvenfraß an der Wurzel nicht nur zu kompensieren, sondern sogar überzukompensieren. Unklar ist, warum das kompensatorische Wurzelwachstum hier nicht gleichzeitig $\mathrm{zu}$ einer reduzierten Sprossmasse geführt hat, was nach der Theorie einer verstärkten Ressourcenallokation in der Wurzel (Müller, 1991) zu erwarten wäre. Ein möglicher Erklärungsansatz beruht auf der Annahme, dass Pflanzen mit einer größeren Wurzel über ein höheres Nährstoff- und Wasseraneignungsvermögen verfügen (Ehlers, 1996), wodurch eine höhere Biomasseproduktion ermöglicht wird.

Das Ergebnis, dass Pflanzen nach einer geringen Schädigung mit einer Überkompensation reagieren können, wird durch eine Reihe von Untersuchungen gestützt. Obermeyer \& Bledsoe (2004) berichten, dass es nach einer geringen Wurzelfraßschädigung an Mais, hervorgerufen durch Larven des Westlichen Maiswurzelbohrers (Diabrotica virgifera), bei ausreichender Bodenfeuchtigkeit zu einem überkompensatorischen Wurzelwachstum kam. In Halbfreilandversuchen von Müller (1991) reagierte die Gefleckte Flockenblume (Centaurea maculosa) nach Wurzelfraß durch eine Rüsselkäferlarve (Cyphocleonus achates) ebenfalls mit einer verstärkten Wurzelneubildung. Eine Überkompensation war hier allerdings nur festzustellen, wenn die Pflanze keinen weiteren Stressfaktoren wie Nährstoffmangel oder interspezifischer Pflanzenkonkurrenz ausgesetzt war. Untersuchungen, wonach sich geringer Fraß an der Wurzel positiv auf die Biomasseproduktion auswirken kann, sind insbesondere für Grasland-Ökosysteme beschrieben worden (Blossey \& Hunt-Joshi, 2003). Darüber hinaus gibt es Hinweise, dass auch oberirdischer Schädlingsbefall Überkompensationsreaktionen bedingen kann. Bünger (2004) beobachtete an Gurken bei geringem Blattlausbefall eine Förderung des Wachstums. Zahlreiche Untersuchungen haben sich mit der Schadwirkung des Rapsglanzkäfers (Meligethes aeneus) an Raps auseinandergesetzt und übereinstimmend festgestellt, dass Knospenschädigungen häufig keine Ertragsverluste nach sich ziehen, da geschädigte Pflanzen mit einer verstärkten Neubildung von Knospen an Nebentrieben reagieren (Tatchell, 1983; Williams \& Free, 1979; Nilsson, 1994). In von Wahmhoff (2000) durchgeführten Versuchen, bei denen eine Schädigung des Rapsglanzkäfers simuliert worden war, ließen sich teilweise sogar ertragserhöhende Schädigungseffekte beobachten. 
Schadeffekte von Kohlfliegenbefall an Raps wurden bisher ausschließlich auf Einzelpflanzenebene beleuchtet. Inwieweit Pflanzenausfälle oder das Vorhandensein von stärker befallenen Pflanzen zu Gesamtertragsverlusten auf Schlagebene führen, hängt jedoch auch vom ausgeprägten Kompensationspotential des Bestandes ab. Wenn Pflanzen aufgrund von Kohlfliegenbefall absterben oder im Wuchs zurückbleiben, findet gleichzeitig auch eine indirekte Förderung des Wachstums gesunder Nachbarpflanzen statt, die einen größeren Anteil an bestandesdichteabhängigen Wachstumsfaktoren nutzen können. Dieses kompensatorische Wachstum, das sich bei Raps in geringeren Reduktionsprozessen von Nebentrieben, Schoten und Körnern ausdrückt (Grosse et al., 1987; McGregor 1980, Diepenbrock, 2000), ist ausschlaggebend dafür, dass ein gewisser Anteil stärker befallenen Pflanzen ohne Gesamtertragseinbußen toleriert werden kann. Dem kompensatorischen Potenzial sind allerdings Grenzen gesetzt, wenn der Anteil nicht oder nur gering geschädigter Pflanzen als Folge des hohen Befallsdrucks gering ist. Falls Bedingungen vorherrschen, die eine Kompensation zusätzlich erschweren, sind Ertragseinbußen von bis zu 20\% nach Griffiths $(1986,1991)$ nicht auszuschließen. Schadeffekte eines Kohlfliegenbefalls konnten aus den eigenen Feldversuchen nicht abgeleitet werden. Eine zu geringe Abstufung des Befalls im ersten Versuchsjahr (2005/2006), ertragsbeeinflussende Netzabdeckungen im zweiten Versuchsjahr (2006/2007) und eine im dritten Versuchsjahr (2007/2008) aufgrund von Hagel unterlassene Ertragserfassung lassen keine eindeutigen Schlüsse zu.

\subsection{Befall und Schadwirkung von V. longisporum}

Das folgende Kapitel setzt sich mit der Bedeutung einzelner Faktoren (u. a. Bodeninokulum, Sorte, Saattermin, Klima) für den Befall und die Schadwirkung von V. longisporum an Raps auseinander, bevor im Kapitel 4.3 näher auf den Zusammenhang zwischen Kohlfliegenbefall und $V$. longisporum eingegangen wird.

Die Feldversuche am Standort Göttingen wurden auf Flächen durchgeführt, auf denen bis dato kein oder nur einmal Raps angebaut worden war und folglich mit einem geringen natürlichen Befallsdruck mit $V$. longisporum gerechnet werden konnte. Vor der Aussaat des Rapses erfolgte eine Bodeninokulation mit Verticillium-befallenem Stoppelmaterial, um neben einer befallsfreien Kontrolle möglichst einheitlichen Befallsdruck einzustellen. In den Feldversuchen wurden im dreijährigen Versuchszeitraum (2005-2008) zwei Bodeninokulationsstufen, in den Halbfreilandversuchen $(2006,2007)$ jeweils drei unterschiedliche Bodeninokulationsstufen eingestellt. Der Versuchsansatz basierte auf Eigenschaften von 
$V$. longisporum als boden- und schlagbürtige Krankheit, die von im Boden befindlichen MS initiiert wird. In zahlreichen Untersuchungen konnten bei Kulturpflanzen, die von Verticillium spp. befallen werden, eindeutige Beziehungen zwischen der Höhe des Bodeninokulums und dem Befall hergestellt werden (Ashworth et al., 1979; Pulmann \& DeVay, 1982; Nicot \& Rouse, 1987; Xiau \& Subbarao, 1998). Der Befall von Winterraps mit $V$. longisporum wird ebenfalls maßgeblich von der der Höhe des Bodeninokulums beeinflusst. In von Heppner (1995) durchgeführten Gewächshausversuchen zeigte sich mit zunehmender Inokulumkonzentration eine Erhöhung des Befalls, wobei ab einer bestimmten Bodeninokulumhöhe keine weitere Befallssteigerung zu verzeichnen war. Dunker (2006) beobachtete eine Zunahme symptomatischer Pflanzen bei ansteigenden Inokulummengen unter Feldbedingungen. Die Relevanz des Bodenverseuchungsgrades wird deutlich, wenn man sich vor Augen führt, dass $V$. longisporum verstärkt in Regionen mit hoher Anbaukonzentration von Raps vorkommt, wo mit einer Anreicherung von MS im Boden zu rechnen ist (Svensson \& Lerenius, 1987; Daebeler \& Seidel, 1989; Amelung et al., 1996; Sadowski \& Zielinski, 1995; Steinbach et al., 2005).

Bei der am MS-Besatz ausgerichteten visuellen Befallserfassung von $V$. longisporum lagen mittlere Befallsparameter (Befallshäufigkeit $(\mathrm{BH})$ und Befallswert $(\mathrm{BW})$ ) inokulierter Varianten $(\mathrm{BH} \leq 90 \%$; $\mathrm{BW} \leq 3,5)$ im gesamten Versuchszeitraum immer signifikant über den der Kontrollvarianten $(\mathrm{BH} \leq 25 \%$; $\mathrm{BW} \leq 1,3)$, wobei die Werte zwischen Sorten und Jahren differierten. In den Halbfreilandversuchen (Sommerrapssorte Heros) entsprachen die Befallsparameter einzelner Versuchsvarianten der Mengenabstufung des vor Saat ausgebrachten Inokulummaterials. Mittlere BH (ohne Kohlfiegenbefall) variierten zwischen 9,8\% (Kontrolle) und 68\% (100 g Inokulum $\left./ \mathrm{m}^{2}\right)$ im ersten bzw. 18\% (Kontrolle) und 76\% (50 g Inokulum $/ \mathrm{m}^{2}$ ) im zweiten Versuchsjahr. In den Kontrollparzellen zu verzeichnender Befall lässt sich eventuell auf Verwehungen von Inokulummaterial während, oder nach dem Ausstreuen zurückführen. Nicht auszuschließen ist, dass der am Feldversuchsstandort Weende regelmäßig als Zwischenfrucht vor Rüben angebaute Ölrettich sowie andere kruzifere Unkräuter zu einer Bodenverseuchung mit $V$. longisporum beigetragen haben, von der die gesamte Versuchsfläche betroffen war. Eine Verschleppung von Inokulummaterial über Bodenbearbeitungsgeräte und Mähdrescher ist nach Ausführungen von Kreye \& Dölger (2007) sowie Fradin \& Thomma (2006) ebenfalls möglich.

In einigen Gewächshausversuchen (Sorten-, Inokulationsstufen- und Befallsdynamikversuch) wurden unterschiedliche Mengen von Verticillium-Inokulummaterial vor der Saat in den 
Boden eingemischt, um die Rolle des Faktors Bodeninokulum unter kontrollierten Bedingungen untersuchen zu können. In Übereinstimmung mit den Halbfreilandversuchen stiegen Befallswerte mit zunehmenden Bodeninokulum an. Die im Rahmen des Befallsdynamikversuchs (Sorte Heros) erfolgte Quantifizierung von Vericillium-DNA mittels RealTime PCR konnte dabei eindeutig aufzeigen, dass hohe Befallswerte (visuelle Bonitur) auf einer stärkeren und dynamischeren Besiedlung des Pflanzengewebes beruhten. Ein proportionaler Zusammenhang zwischen dem Bodeninokulum und der Besiedlungsstärke ließ sich allerdings nicht feststellen.

Der Anbau resistenter Sorten stellt ein wichtiges Instrument zur Kontrolle von Verticillium spp. dar. Resistenz wird in diesem Zusammenhang nicht als vollständige Immunität verstanden, sondern durch den Grad der Symptomausprägung definiert, da auch bei Sorten mit vergleichsweise hoher Resistenz eine gewisse Besiedlung der Pflanze erfolgen kann. (Pegg \& Brady, 2002). Eine qualitative Resistenz (Majorgenresistenz), bei der Pflanzen lediglich im Stängelbasisbereich besiedelt werden und i. d. R. keine Symptome ausbilden, sind bisher für Baumwolle, Sonnenblume und Tomate beschrieben worden (Schaible et al., 1951; Lynch et al., 1997; Jansky et al., 2004). Eine genaue Charakterisierung des zugrunde liegenden Resistenzgens liegt für Tomate (Ve-Gen: receptor-like protein) vor (Kruijt et al., 2005). Das Resistenzniveau derzeit zugelassene Rapssorten gegenüber $V$. longisporum ist als gering zu bezeichnen, da alle Sorten mehr oder weniger stark besiedelt werden und Symptome ausbilden. Inokulationsversuche im Gewächshaus (Zeise, 1992; Zeise \& Tiedemann, 2002; Steventon et al., 2002; Happstadius et al., 2003; Keunecke, 2005; Eynck, 2008) sowie Befallserhebungen im Feld (Heppner, 1995; Zeise \& Steinbach, 2004; Eynck, 2008) haben jedoch gezeigt, dass es Anfälligkeitsunterschiede zwischen den Sorten gibt. Im Rahmen der vorliegenden Arbeit konnten ebenfalls Sortenunterschiede festgestellt werden. Erwartungsgemäß wies die als besonders anfällig eingestufte Sorte Laser im Feld in allen drei Versuchsjahren signifikant höhere Befallsparameter als die Sorte Lion auf, welche als moderat anfällig charakterisiert worden war. Diese Anfälligkeitsunterschiede ließen sich auch unter Gewächshausbedingungen (Sortenversuch) wiederfinden. Das Befallsniveau anderer im Feld getesteter Sorten lag i. d. R. zwischen dem von Laser und Lion, wobei sich die jeweiligen Unterschiede nur teilweise absichern ließen. Eine Ausnahme bildete die im letzten Versuchsjahr (2007/2008) angebaute Sorte Aviso, bei der lediglich 14\% der untersuchten Stoppeln MS-Besatz anzeigten. Damit wies Aviso den mit Abstand niedrigsten Befall im Versuch (5 Sorten) auf. 
In einem von Eynck im Jahr 2006/2007 (2008) sowie Knüfer im Jahr 2007/2008 (persönl. Mitteilung, 2008) am Standort Göttingen unter vergleichbaren Bedingungen (Standort Weende, 15 g Inokulummaterial $/ \mathrm{m}^{2}$, Pflugsaat) durchgeführten Sortenversuch, bei dem 24 Sorten/Genotypen in ihrer Anfälligkeit gegenüber $V$. longisporum getestet worden waren, hatte sich die Sorte Aviso ebenfalls mit jeweils niedrigsten Befallsparametern von den übrigen Prüfgliedern absetzen können. Grenzen dieser Resistenz werden allerdings deutlich, wenn man sich Sortenversuchsergebnisse o. g. Autoren vergegenwärtigt, die auf Standorten mit hohem natürlichen Befallsdruck erhoben worden sind. Auf Fehmarn, einem traditionellen Rapsstandort, waren im betreffenden Versuchszeitraum kaum Befallsunterschiede zwischen den 24 Sorten/Genotypen festzustellen. Nahezu alle nach der Ernte untersuchten Stoppeln (BH 86-100\%), auch die der Sorte Aviso, wiesen hier starken MS-Besatz im Wurzel- und Stängelbereich auf. Diese Untersuchungsergebnisse lassen die Vermutung zu, dass die Sortenresistenz von Aviso bei hohem Befallsdruck abnimmt. Vergleichbare Ergebnisse liegen auch für andere Kulturpflanzen (u. a. Baumwolle, Kartoffel, Kakao), die von Verticillium spp. befallen werden, vor. Übereinstimmend kommen die Autoren zu dem Schluss, dass Sorten mit hoher quantitativer Resistenz, die bei moderatem Befallsdruck nur selten Symptome ausbilden, bei zunehmenden Befallsdruck stärker befallen werden, auch wenn der Befallsverlauf gegenüber anfälligen Sorten weniger dynamisch verläuft (Berry \& Thomas, 1961; Schnathorst \& Mathre, 1966; Bell \& Mace, 1981; Francl et al., 1975; Resende et al., 1995). Mögliche Sortenunterschiede in der Befallsdynamik am Standort Fehmarn lassen sich aus den Untersuchungsergebnissen von Eynck (2008) bzw. Knüfer (persönl. Mitteilung, 2008) nicht ableiten, da aus versuchstechnischen Gründen keine Bonituren vor der Ernte vorgenommen werden konnten.

In den letzten Jahren sind einige Brassica-Genotypen identifiziert worden, die ein höheres quantitatives Resistenzniveau gegenüber $V$. longisporum aufweisen (Happstadius et al., 2003; Dixelius et al., 2005; Rygulla et al., 2007, 2008; Eynck, 2008). In zwei Gewächshausversuchen (Resistenzversuch, Stängelinokulationsversuch) wurde neben der moderat anfälligen Sorte Express zusätzlich eine Rapslinie mit hoher Verticillium-Resistenz getestet (Sem 05500256). Nach einer Bodeninokulation wiesen von jeweils zwölf untersuchten Pflanzen sechs bei der Sorte Express und lediglich eine bei Sem Verticillium-Symptome am Versuchsende (BBCH 85) auf. Die anhand von Real-Time PCR-Messungen erfassten Mengen an Verticillium-DNA ergaben ein ähnliches Bild. Bei der Sorte Express, die häufig als gering anfälliger Standard verwendet wird, waren am Versuchsende im Vergleich mit Sem dreifach höhere Mengen an Verticillium-DNA im Wurzel und Hypokotyl bzw. siebenfach höhere 
DNA-Mengen im unteren Sprossbereich festzustellen. Nach einer Stängelinokulation (Stängelinokulationsversuch) des direkt oberhalb des Hypokotyls befindlichen unteren Stängelbereichs zeigten am Versuchsende (28 dpi) alle Pflanzen charakteristische Blattsymptome, wobei sich die Sorte Express mit signifikant höherem Befallswert $(5,4)$ von Sem $(4,2)$ absetzte. Real-Time PCR- Untersuchungen von unterem und oberem Stängelbereich (28 dpi) konnten dabei aufzeigen, dass Express drei- bis vierfach höhere Mengen an VerticilliumDNA aufwies als Sem. Unabhängig davon, welche Resistenzmechanismen hierfür verantwortlich sein könnten, liefern diese Ergebnisse Hinweise, dass diese Resistenzmechanismen nicht ausschließlich auf den Wurzel- und Hypokotylbereich beschränkt sind, sondern offenbar auch im Sprossbereich operieren. Andere Autoren, die nach einer Stängelinokulation mit $V$. dahliae visuelle Befallsunterschiede zwischen einzelnen Sorten bei Minze (Berry \& Thomas, 1961), Baumwolle (Erwin et al., 1965) und Kakao (Resende et al., 1995) beobachteten, kamen ebenfalls zu dem Schluss, dass Resistenzreaktionen auch im Stängelbereich stattfinden.

Im Rahmen dieser Arbeit wurden Anbaufaktorenversuche angelegt, um den Effekt variierender Saattermine auf Kohlfliegen- und Verticillium-Befall untersuchen zu können. Ergebnisse des ersten Versuchsjahres (2005/2006) hatten gezeigt, dass eine frühe Aussaat (Saattermin 12.08.05) von Winterraps (Sorte Oase) sowohl signifikant höheren Kohlfliegenbefall im Herbst, als auch signifikant höheren Verticillium-Befall aufwies als eine spätere Aussaat (Saattermin 25.08.05). Im dritten Versuchsjahr (2007/2008) wurden Effekte variierender Saattermine auf den Befall von Raps (Sorte Trabant) mit $V$. longisporum bei unterschiedlich hohem Kohlfliegenbefall untersucht, um eine differenzierte Risikoabschätzung der Faktoren Kohlfliegenbefall und Saattermin bzgl. V. longisporum abgeben zu können. Kohlfliegenbefall wurde hierbei mit Hilfe von Netzen bzw. Insektiziden abgestuft, um Effekte von Saatzeit und Kohlfliegenbefall sowohl in Kombination als auch einzeln betrachten zu können. Die früh gesäten Varianten (Saattermin 14.08.07; BH 71-84\%) wiesen im Vergleich mit den später gesäten Varianten (Saattermin 31.08.07; BH 49-58\%) deutlich höhere Befallsparameter auf, und zwar sowohl bei Varianten mit hohem als auch bei Varianten mit niedrigen Kohlfliegenbefall im Herbst. Diese Ergebnisse deuten darauf hin, dass eine frühe Aussaat von Winterraps Verticillium-Befall nicht nur indirekt, über eine Erhöhung des Kohlfliegenbefalls, sondern auch direkt begünstigen kann. Ein Vergleich eigener mit den von Eynck (2008) und Knüfer (2008, persönliche Mitteilung) durchgeführten Versuchen liefert zudem weitere Hinweise, dass ein früher Saattermin Verticillim-Befall beeinflusst. Im ersten sowie dritten Versuchsjahr wurden beide Versuche auf der gleichen Ver- 
suchsfläche angelegt. Unter sonst identischen Bedingungen (15 g Inokulummaterial $/ \mathrm{m}^{2}$, Pflugsaat) unterschieden sich beide Versuche lediglich in der Saatzeit. Eigene Sortenversuche wurden am 11.08.05 bzw. 14.08.07 ausgesät, während angrenzende Versuchsflächenbereiche der o. g. Autoren am 25.08.05 bzw. 27.08.07 bestellt wurden. Beim Vergleich der Boniturergebnisse fiel auf, dass die BH der in beiden Versuchen vorkommenden Sorten Laser und Lion nach einer frühen Aussaat (2005/2006 = Laser (64\%), Lion (38\%); 2007/2008 = Laser (88\%), Lion (65\%)) deutlicher höher waren als nach einer späteren Aussaat (2005/2006 = Laser (28\%), Lion (20\%); 2007/2008 = Laser (40\%), Lion (38\%)).

In der Literatur wird auf den Zusammenhang zwischen Saatzeit und dem Befall bodenbürtiger Pathogene hingewiesen. Der Befall von Rhizoctonia solani (Sumner \& Dowler, 1983) an Mais sowie Fusarium oxysporum an Erbse (Landa et al., 2004) ließ sich durch eine Verschiebung des Saattermins verringern. Die Autoren führten den befallsmindernden Effekt einer späteren Aussaat dabei im Wesentlichen auf veränderte Bodentemperaturverhältnisse zurück, die gleichzeitig ungünstigere Infektionsbedingungen für die Pathogene darstellten. Der Zeitraum günstiger Infektionsbedingungen konnte somit vermieden oder zumindest verkürzt werden. Vergleichbare Saattermineffekte sind auch für den Befall von Raps mit $V$. longisporum vorstellbar.

Gewächshausuntersuchungen von Zhou et al. (2006) sowie Eynck et al. (2007) haben gezeigt, dass $V$. longisporum in der Lage ist, Raps im Jungpflanzenstadium zu infizieren. Unter Feldbedingungen sind bislang allerdings keine entsprechenden Nachweise erbracht worden. Im Freiland von Zeise \& Seidel (1990) durchgeführte Untersuchungen, in denen Winterrapspflanzen aus Verticillium-inokulierten Kleinparzellen zu unterschiedlichen Terminen in Töpfe mit inokulumfreier, gedämpfter Komposterde gepflanzt wurden, liefern Hinweise, dass Infektionen bereits im Herbst stattfinden, da 38\% der sechzehn Wochen nach Aussaat im Dezember umgesetzten Pflanzen zur Reife Symptome aufwiesen. Untersuchungen, wonach die MS-Keimung von $V$. longisporum in einem weiten Temperaturbereich möglich ist, sich jedoch optimalerweise zwischen $15^{\circ} \mathrm{C}$ und $28^{\circ} \mathrm{C}$ vollzieht (Pegg \& Brady, 2002), sind ein weiteres Indiz dafür, dass im Herbst günstige Infektionsbedingungen vorliegen. Vor diesem Hintergrund lassen die Versuchsergebnisse den Schluss zu, dass eine durch Frühsaat bedingte Verlängerung des Infektionszeitraumes im Herbst Hauptgrund stärkeren Verticillium-Befalls zur Ernte ist. Aus diesen Ergebnissen können allerdings keine uneingeschränkten Empfehlungen für eine späte Aussaat im September abgeleitet werden, da hier aufgrund einer unzureichenden Vorwinterentwicklung mit Ertragseinbußen zu rechnen ist (Hodgson, 1979; 
Mendhem et al., 1981a, 1981b; Scarisbrick et al., 1981; Yousaf et al., 2002). In eigenen (Anbaufaktorenversuch 2005/2006) sowie von Dunker (2006) am Standort Göttingen Weende durchgeführten Versuchen waren keine signifikanten Ertragsunterschiede zwischen Saatterminen im Zeitraum 10.08-27.08 festzustellen. Eine Aussaat Ende August bietet somit eventuell eine Möglichkeit, dass Verticillium-Befallsrisiko gegenüber einer Frühsaat zu begrenzen und gleichzeitig eine ausreichende Vorwinterentwicklung zu gewährleisten.

In Übereinstimmung mit Beobachtungen anderer Autoren (Hornig, 1987; Wolf \& Weinert, 2003; Zeise \& Steinbach, 2004; Dunker, 2006) traten Verticillium-Symtome im Feld erst mit Abreifebeginn in Form halbseitiger, wässriger Stängelverbräunungen auf. Eine eindeutige Differenzierung gegenüber $P$. lingam bedingten Verbräunungserscheinungen war erst mit der Diagnose von MS möglich. Das Symptombild des Verticillium-Befalls entsprach dem einer vorzeitigen Abreife und nicht dem einer Welke. Bei stärker befallenen Pflanzen war ein massives Absterben von Seitentrieben, eine geringe Schoten- sowie Kümmerkornausbildung zu erkennen. Ein reduziertes Längenwachstum, das bei stark $V$. longisporum-befallenem Rosen- und Blumenkohl (Isaac, 1957; Koike et al., 1999) sowie $V$. dahliae-erkrankter Baumwolle (De-Vay \& Pullmann, 1984) im Feld beobachtet wurde, war in eigenen Feldversuchen an Raps nicht auszumachen.

Spät im Bestand auftretende Symptome von $V$. longisporum entsprachen den im ersten Versuchsjahr (2005/2006) durchgeführten ELISA-Untersuchungen, die Befall erst mit beginnender Abreife nachweisen konnten. Andere Autoren (Wolf \& Weinert, 2003; Steinbach et al., 2005; Dunker et al., 2008) kamen zu ähnlichen Ergebnissen. Nach wie vor ist unklar, warum sich die nach Zeise \& Seidel (1990) indirekt nachgewiesenen frühen Infektionen im Herbst mit dem ELISA nicht detektieren lassen. Eine zu geringe Sensitivität gegenüber latenten Infektionen mit nur schwacher Pilzproteinkonzentration könnte nach Holtschulte (1992) ein möglicher Grund sein. Mit den im Rahmen der Halbfreilandversuche durchgeführten Untersuchungen von Xylemsaft ließ sich $V$. longisporum im Jahr 2006 ab BBCH 77, im Jahr 2007 vereinzelt ab BBCH 55 nachweisen. Eine verstärkte Besiedlung des Pflanzengewebes durch $V$. longisporum findet offenbar erst nach der Blüte statt. Diese späte Ausbreitung ist auch für eine Reihe anderer Pflanzen (Arabidopsis, Baumwolle, Kartoffel), die von Verticillium spp. befallen werden, beschrieben worden (Robinson et al., 1957; Koike et al., 1994; Steventon et al., 2001; Veronese et al., 2003; Debode et al., 2005). Nach Zhou et al (2006) kommt dem Übergang vom vegetativen zum generativen Wachstum eine entscheidende Bedeutung für die Ausbreitung von V. longisporum bei Raps zu. Mit Beginn der 
Blühphase einsetzende Stoffwechselprozesse, die durch eine verstärkte Assimilattranslokation in Blüten- und Schotenanlagen gekennzeichnet sind (Keiller \& Morgan, 1988; Diepenbrock \& Grosse, 1995), werden auch von Zeise \& Seidel (1990) als mögliche Ursache dieser späten Symptomexpression angesehen. Khatib et al. (1974) führten die späte Symptomausprägung von $V$. dahliae bei Tomatenpflanzen auf eine reduzierte Bildung von Polyphenolen nach der Blüte zurück. Untersuchungsergebnisse von Eynck (2008) deuten ebenfalls auf einen Zusammenhang zwischen Polyphenolbildung im Hypokotyl und der Ausbreitungsdynamik von $V$. longisporum in der Rapspflanze hin. Die Versuche beziehen den Zeitraum nach der Blüte allerdings nicht mit ein, so dass keine Aussage möglich ist, ob die stärkere Besiedlung nach der Blüte mit einem Abfall der Polyphenole einhergeht.

Beim Vergleich einzelner Versuchsjahre (2005-2008) fiel auf, dass Auftreten und Stärke des Verticillium-Befalls nicht nur von den Faktoren Bodeninokulum, Sorte und Saattermin bestimmt wurde, sondern auch von Jahreseffekten abhing. In den Halbfreilandversuchen (2006, 2007) lagen die Befallsparameter im Jahr 2007 auf einem höheren Niveau als 2006, obgleich die Bodeninokulationsstufen verringert worden waren. Im Sortenversuch waren im Versuchsjahr 2006/2007 ebenfalls deutlich höhere Befallsparameter festzustellen als 2005/2006. Zudem kam es im Versuchsjahr 2006/2007 zu einer vergleichsweise frühen Ausbildung von Symptomen. Bei der anfälligen Sorte Laser wiesen bereits vier Wochen vor der Ernte (BBCH 83-85) etwa 50\% der untersuchten Pflanzen MS-Besatz auf. In den anderen beiden Versuchsjahren waren zu diesem Zeitpunkt maximal 25\% der Pflanzen befallen. Die Tatsache, dass ein besonders starker und früher Verticillium-Befall in einem Jahr (2006/2007) mit außergewöhnlich milder Witterung aufgetreten ist, weist darauf hin, dass Umweltfaktoren Verticillium-Befall beeinflussen können. Bei der Betrachtung möglicher Einflussgrößen kommt den Parametern Temperatur und Bodenfeuchte im Hinblick auf MS-Keimung, Besiedlung und Symptomausprägung hier eine besondere Bedeutung zu.

Untersuchungen an Winterraps in Polen haben gezeigt, dass die MS-Keimung in einem weiten Temperaturbereich möglich ist, sich jedoch optimalerweise zwischen 15 und $28^{\circ} \mathrm{C}$ vollzieht (Pegg \& Brady, 2002). Soesanto \& Termorshuizen (2001) ermittelten einen ähnlichen Optimalbereich $\left(20-28^{\circ} \mathrm{C}\right)$ für das Myzelwachstum von $V$. dahliae. Temperaturen oberhalb von $30^{\circ} \mathrm{C}$ wirken sich dagegen hemmend auf Mycelwachstum und Symptomausprägung aus. Epidemiologische Untersuchungen, die den Faktor Temperatur mit einbeziehen, wurden insbesondere bei der durch $V$. dahliae verursachten Baumwollwelke durchgeführt (Pullmann \& DeVay, 1982; Gutierrez et al., 1983). Neben anderen Faktoren, die die Infektion 
und Besiedlung beeinflussen (Bodeninokulummenge, Pathotyp, Sortenresistenz), wird der Zeitpunkt und die Stärke der Symptomausbildung als eine Funktion von Gradtagen ( $\sum$ Tage $\mathrm{x}$ $\geq 12^{\circ} \mathrm{C}$ ) betrachtet. Die Erfüllung einer bestimmten Temperatursumme als Voraussetzung für Besiedlung und Symptomausprägung ist auch für andere von $V$. dahliae bzw. $V$. longisporum befallene Kulturpflanzen nahe liegend, da Symptome i. d. R. erst nach einer Periode wärmerer Temperaturen in Erscheinung treten. Eigene Untersuchungsergebnisse haben zudem gezeigt, dass eine Netzabdeckung im Herbst, die in einer Erhöhung der Bodentemperatur resultiert, Verticillium-Befall ebenfalls begünstigen kann. In Übereinstimmung mit den o. a. Studien anderer Autoren deuten eigene Ergebnisse darauf hin, dass der Befall von Raps mit $V$. longisporum durch höhere Temperaturen gefördert wird.

Inwieweit überdurchschnittlich hohe Niederschlagsmengen im Versuchsjahr 2006/2007 zu einer Erhöhung des Verticillium-Befalls beigetragen haben könnten, erscheint fraglich, da die für MS-Keimung und Infektion erforderliche Bodenfeuchte (Green, 1980) am Versuchsstandort Weende auch in den anderen Versuchsjahren kein limitierender Faktor war. Die in der Literatur beschriebene Begünstigung eines Verticillium-Befalls durch Bewässerungsmaßnahmen (Xiau et al., 1998; Arbogast \& Powelson, 1997; Lopez-Escurdo \& Blanco-Lopez, 2005) beruhen i. d. R. auf vergleichsweise trockenen Bodenbedingungen, die einer Infektion nicht zuträglich sind. Karaca et al. (1971) führten die Befallsförderung von $V$. dahiae an Baumwolle auf einen indirekten Bodentemperatureffekt der Bewässerung zurück. Hohe Bodentemperaturen von $33-34^{\circ} \mathrm{C}$, die keine Infektionen zuließen, konnten durch eine Bewässerung auf 28-29 $\mathrm{C}$ gesenkt werden, wodurch günstige Infektions- und Besiedlungsbedingungen geschaffen wurden. Im Gegensatz zu diesen Studien wird der Befall von $V$. dahliae an Kartoffeln nach Untersuchungen von Francl et al. (1988) insbesondere durch Trockenstress stark gefördert. Vergleichbare Bodentemperatur- bzw. Trockenstressbedingungen traten am Standort Weende nicht auf, so dass der Faktor Niederschlag eine untergeordnete Rolle für $V$. longisporum gespielt haben dürfte.

Bislang existieren nur wenige Untersuchungen, in denen die Schadwirkung von $V$. longisporum an Raps untersucht wurde. Je nach Versuchsansatz schwankten befallsinduzierte Ertragseffekte zwischen 0 und 44\%. Svensson \& Lerenius (1987) stellten bei der Winterrapssorte Jet Neuf nach einer Inokulation mit Verticillium-befallenen Stoppeln einen um 44\% reduzierten Ertrag fest. Angemerkt werden muss allerdings, dass bei diesem Versuch mit $350 \mathrm{~g}$ Inokulummaterial pro $0,94 \mathrm{~m}^{2}$ Parzellen eine extrem hohe Bodenverseuchung eingestellt wurde, die zu einer BH von 96\% führte. Günzelmann \& Paul (1990) berichten von 
einem Ertragsverlust von $10 \%$ bei einer $\mathrm{BH}$ von $24 \%$ nach einer Parzelleninokulation mit befallenem Stroh, wobei Inokulummenge und Versuchsansatz nicht genauer erörtert wurden. Dunker (2006) konnte auf einer mit unterschiedlichen Mengen Verticillium-befallenen Strohs inoklierten Versuchsfläche bei insgesamt niedrigem Befallsniveau ( $\mathrm{BH} \leq 54 \%$ ) keine Ertragseffekte feststellen. Hornig (1987) und Ahlers (1987) sehen den Haupteinfluss von $V$. longisporum in einer Reduktion des TKG. Diese Untersuchungen wurden jedoch an allgemein krankhaft abreifenden Pflanzen durchgeführt. Verticillium-spezifische Einzelpflanzenuntersuchungen werden seit Mitte der achtziger Jahre in Rostock-Biestow, einem Standort mit hohem natürlichen Befallsniveau durchgeführt (Daebeler et al., 1988; Zeise \& Steinbach, 2004). Einzelpflanzenerträge von zum Zeitpunkt der Mähdruschreife selektiv aus dem Bestand entnommenen befallenen Rapspflanzen ergaben mittlere Ertragsreduktionen von $20-85 \%$ gegenüber befallsfreien Pflanzen. Zwischen Jahren und Sorten schwankende Ertragsreduktionen waren bei hohen Befallswerten am stärksten.

Diese Untersuchungen verdeutlichen, dass $V$. longisporum $\mathrm{zu}$ einem hohen Schaden an Einzelpflanzen führen kann. Inwieweit das Vorhandensein von stärker befallenen Pflanzen zu Gesamtertragswirkungen auf Parzellen- oder Schlagebene führt, hängt jedoch auch noch vom sehr ausgeprägten Kompensationspotential des Winterrapses ab. In einem von Gutierrez et al. (1983) entwickelten Modell werden erwartete Ertragseffekte von $V$. dahliae an Baumwolle nicht nur isoliert von der BH oder dem Starkbefall abgeleitet, sondern vor dem pflanzenmorphologischen Hintergrund eines Gesamtbestandes betrachtet. Einige Modellannahmen lassen sich auch auf Winterraps übertragen. Ein Bestand besteht neben stark befallenen Pflanzen aus schwach bis mittelstark befallenen sowie gesunden Pflanzen. Krankheitsbedingt wird dabei nicht nur das Wachstum stark befallener Pflanzen negativ beeinflusst, sondern es findet auch eine indirekte Förderung des Wachstums gesunder Nachbarpflanzen statt, die einen größeren Anteil an bestandesdichteabhängigen Wachstumsfaktoren nutzen können. Dieses kompensatorische Wachstum, das sich bei Raps in geringeren Reduktionsprozessen von Nebentrieben, Schoten- und Kornzahl ausdrückt (Grosse et al., 1987), ist ausschlaggebend, dass ein gewisser Anteil stark befallener Pflanzen ohne Gesamtertragseinbußen toleriert werden kann. Bei schwach bis mittelstark befallenen Pflanzen, die keinen Bestandesdichteeffekt ausüben, findet dagegen kaum kompensatorisches Wachstum durch gesunde Nachbarpflanzen statt. Das gesamte Schadausmaß durch diese im Habitus kaum beeinträchtigten Pflanzen hängt maßgeblich vom Grad der Notreife ab (Daebeler et al., 1988). Dem kompensatorischen Potential eines Bestandes sind darüber hinaus Grenzen 
gesetzt, wenn der Anteil gesunder Pflanzen als Folge hohen Befallsdruckes gering ist (Gutierrez et al., 1983).

In eigenen Feldversuchen konnte lediglich in den ersten beiden Versuchsjahren eine Ertragserfassung vorgenommen werden, da ein Hagelereignis kurz vor der Ernte 2008 Variantenvergleiche unmöglich machte. Nach der Auswertung der Erträge ließen sich im ersten Versuchsjahr 2005/2006 bei moderatem Befallsniveau und später Symptomausprägung keine signifikanten Ertragsunterschiede zwischen Inokulations- und Kontrollvarianten feststellen. Im zweiten Versuchsjahr 2006/2007 verzeichnete die Inokulationsvariante der Sorte Laser (BH 88\%; BW 2,9), bei der bereits vier Wochen vor der Ernte etwa $50 \%$ der Pflanzen starke Verticillium-Symptome und Notreifeerscheinungen aufwiesen, einen signifikant niedrigeren Ertrag (bis -20\%) als die Kontrollvariante. Bei der Sorte Lion, wo vier Wochen vor der Ernte 18\% der Pflanzen MS-Besatz anzeigten, waren keine signifikanten Ertragseffekte eines Verticillium-Befalls auszumachen, obgleich der Anteil symptomatischer Pflanzen bis zur Ernte deutlich zunahm (BH 75\%, BW 2,7). Eine signifikante Beeinflussung des TKG trat bei keiner Sorte auf. Der unterschiedliche Befallsverlauf der Sorten Laser und Lion weist darauf hin, dass die Schadwirkung von $V$. longisporum nicht nur von der BH und der Befallsstärke bestimmt wird, sondern auch maßgeblich von der Dynamik des Befalls abhängt. Nach Untersuchungen von Pullmann \& DeVay (1982) sowie Gutierrez et al. (1983) ist die Schadwirkung von $V$. dahliae an Baumwolle in ähnlicher Weise vom Zeitpunkt des Erscheinens erster Symptome abhängig, da ein Eingriff in die Ertragsbildung etwa zwei Wochen vor dem Erscheinen der ersten Symptome eintritt. Je früher sich $V$. dahliae in der Pflanze ausbreitet und Symptome auftreten, desto stärker wirken sich befallsinduzierte Effekte auf den Gesamtertrag aus. Der Zusammenhang zwischen Befallsdynamik und Schadwirkung hat Auswirkungen auf die Bewertung von Sortenresistenz gegenüber $V$. longisporum. Um Sortenunterschiede in der Befallsdynamik erfassen zu können, ist es notwendig, nicht nur nach, sondern bereits in den Wochen vor der Ernte Befallsbonituren vorzunehmen.

Im Vergleich mit einem erst spät erkennbaren Krankheitsbild von $V$. longisporum im Feld zeigten sich unter kontrollierten Gewächshausbedingungen bereits früh charakteristische Symptome. Etwa zwei Wochen nach der Stängel- oder Bodengießinokulation bzw. acht Wochen nach der Topfbodeninokulation traten erste Blattsymptome mit beginnender Schwarzadrigkeit auf, die sich im Zeitverlauf akropetal ausbreiteten. Neben Blattsymptomen, die auch von anderen Autoren (Zeise, 1992; Steventon et al., 2002; Zeise \& Tiedemann, 
2002) nach einer Wurzeltauchinokulation von Winterraps beobachtet wurden, kam es als Folge des Befalls zu einer starken Bildung von MS im Spross, Mark- sowie Wurzelbereich. Teilweise ließen sich Schwarzadrigkeitssymptome an Schoten feststellen, ein Symptombild, welches von Keunecke (2005) in Gewächshausversuchen bereits beobachtet worden war. Das Symptombild entsprach in Übereinstimmung mit Niederleitner et al. (1991) nicht dem einer Welke. Zeitpunkt und Ausmaß der Symptomausprägung hing maßgeblich von der mittels Real-Time PCR erfassten Ausbreitungsdynamik von $V$. longisporum in der Pflanze ab, die u. a. zwischen Inokulationsmethoden, Sorten und der Höhe des Bodeninokulums differierte. Die Methode der Stängel- bzw. Bodengießinokulation führte zu einer früheren Symptomausprägung als eine Bodeninokulation mit MS, bei der Symptome erst zum Stadium der Blüte zu beobachten waren. Zuletzt genannte Methode, die der natürlichen Infektion im Feld nahe kommt, setzt für eine erfolgreiche Infektion zunächst die Keimung von im Boden in unmittelbarer Wurzelnähe befindlichen MS voraus, um anschließend mit Hilfe einer Infektionshyphe in die Wurzel eindringen zu können (Olsson \& Nordbring-Hertz, 1985). Im Vergleich zur Stängel- bzw. Bodengießinokulation, bei der das Pathogen direkt in den Stängel eingebracht wird bzw. die ganze Wurzel mit Konidien überzogen wird, finden hierbei nicht nur zeitlich verzögerte, sondern auch zahlenmäßig weniger Penetrationen statt. Da nur ein geringer Anteil dieser Wurzelpenetrationen letztlich zu einer erfolgreichen Xylembesiedlung führt (Garber \& Housten, 1966), ist nach einer Bodeninokulation mit MS mit einer weniger dynamischen Xylembesiedlung zu rechnen.

Im Zeitverlauf durchgeführte Real-Time PCR-Untersuchungen (Befallsdynamikversuch, Resistenzversuch) konnten eine verstärkte Besiedlung des Pflanzengewebes auch bei hohen Bodeninokulummengen von $5 \mathrm{~g}$ je Topf (1050 gTopfboden) erst nach der Blüte nachweisen. Nach der Ausbildung charakteristischer Blattsymptome waren im unteren Sprossbereich Messwerte zwischen 30 und 200 ng Verticillium-DNA/g TM festzustellen. Die am Ende der Pathogenese einsetzende MS-Bildung ging mit einer deutlichen Zunahme des Befalls einher. Messwerte lagen hier zwischen 500 und 2000 ng Verticillium-DNA/g TM. Mögliche Ursachen dieser späten Besiedlung des Pflanzengewebes wurden bereits diskutiert. Die im Vergleich zu Feldbedingungen relativ frühe Besiedlung und Ausbildung charakteristischer Symptome Mitte/Ende Blüte (im Feld erst zur Abreife) hängt möglicherweise mit dem bereits erörterten Faktor Temperatur zusammen. Im Gewächshausversuch lagen Temperaturen zwischen 15 und $25^{\circ} \mathrm{C}$, wodurch Infektion und Besiedlung vermutlich begünstigt wurden. 
Neben o. g. Symptomen kommt es nach einer Infektion mit Verticillium spp., insbesondere im Gewächshaus, häufig zu befallsinduzierten pflanzenmorphologischen Veränderungen (Pegg \& Brady, 2002). In mehreren Untersuchungen, in denen Wurzeltauchinokulationen an Winterraps vorgenommen wurden, zeigten sich im Vergleich mit Kontrollpflanzen deutliche Reduktionen der Pflanzenlänge, Blattanzahl, Spross- sowie Wurzeltrockenmasse. (Zeise, 1992; Karapapa et al., 1997; Zeise \& Tiedemann, 2002; Keunecke, 2005). In eigenen Versuchen wurde eine Reihe von pflanzenmorhologischen Parametern erhoben, um Schadeffekte von $V$. longisporum zu beurteilen. Das Ausmaß der am Versuchsende (Abreife) festzustellenden Schadeffekte ließ sich relativ gut mit Variantenunterschieden in der Befallsdynamik und Symptomausprägung in Übereinstimmung bringen. Effekte waren umso höher, je früher die Besiedlung und Symptomausprägung einsetzte. Bei geringem Bodeninokulum (0,2 g/Topf; Sorte Heros) konnten keine Schadeffekte eines alleinigen Verticillium-Befalls abgesichert werden. Im Gegensatz zu anderen Gewächshausversuchen (u.a. Zeise, 1992; Keunecke, 2005), in denen es nach einer Wurzeltauchinokulation zu starken Staucheeffekten kam, waren in eigenen Versuchen lediglich nach einer hohen Bodeninokulation mit künstlich angezogenen MS (vgl. 3.3.1.1) deutliche Staucheeffekte zu erkennen. Diese Ergebnisse unterstreichen die Bedeutung der Inokulationmethode für den Befall und die Schadwirkung von $V$. longisporum. Bei der Wurzeltauchinokulation handelt es sich um eine sehr stringente Methode, die hohen Inokulationserfolg, schnelle Besiedlung und hohe Mortalität anfälliger Kulturpflanzen zur Folge hat (Zeise, 1992). In eigenen Versuchen übte die zwischen einzelnen Varianten differierende Befallsdynamik größeren Einfluss auf andere pflanzenmorphologische Parameter aus. Am Versuchsende waren je nach Befallsausmaß deutliche Reduktionen von Einzelpflanzenertrag (bis 20\%), Sprossmasse (bis 34\%) und Wurzelmasse (bis 50\%) festzustellen.

Schadeffekte früher Boniturtermine stimmten nur teilweise mit der Besiedlungsdynamik und Symptomausprägung überein. Im Resistenzversuch waren bei der Rapslinie Sem zum ersten Boniturtermin (48 dpi; BBCH 65) hohe Inokulationseffekte bei der Sprossfrischmasse ($34 \%)$ sowie Wurzeltrockenmasse $(-35 \%) \mathrm{zu}$ verzeichnen, obgleich Real-Time PCRUntersuchungen $\mathrm{zu}$ diesem Zeitpunkt nur sehr geringen Wurzelbefall anzeigten. Am Versuchsende (115 dpi; BBCH 85) ließen sich bei der Sprossfrischmasse (-17\%) geringere, bei der Wurzeltrockenmasse $(+6 \%)$ keine Inokulationseffekte mehr erkennen. Diese Ergebnisse deuten darauf hin, dass Jungpflanzeninfektionen, ohne starke Besiedlung, bereits einen hemmenden Einfluss auf die Pflanzenentwicklung nehmen können. Darüber hinaus wird deutlich, dass eine Rapslinie wie Sem, bei der nur eine geringe Besiedlung des 
Pflanzengewebes stattfindet, offenbar in der Lage ist, eine anfängliche Hemmung der Pflanzenentwicklung im Laufe der Entwicklung weitgehend auszugleichen. Den Effekt einer zeitlich begrenzten Stauche konnte Eynck (2008) nach einer Wurzeltauchinokulation bei Sem ebenfalls beobachten.

\subsection{Einfluss von Kohlfliegenball auf die Infektion und Schadwirkung von $V$. longisporum}

In der Vergangenheit durchgeführte Untersuchungen haben gezeigt, dass Wurzelschädlinge den Befall bodenbürtiger Pathogene begünstigen können. Die meisten Untersuchungen, in denen eine Förderung vaskulärer Pathogene (Verticillium spp., Fusarium spp.) beschrieben worden ist, beziehen sich auf Nematoden (Fielding, 1959; Powell 1971; Mai \& Abawi, 1987; Back et al., 2002). Während gallenbildende Nematoden der Gattung Meloidogyne (M.) spp. insbesondere mit einer Begünstigung von Fusarium-Welkekrankheiten an Baumwolle (Garber et al., 1979; De Vay et al., 1997; Davis et al., 2006), Tomate (Bergeson et al., 1970; Abawi \& Barker, 1984), Kaffee (Bertrand et al., 2000) und Bohnen (France \& Abawi, 1994) in Verbindung gebracht werden, ist eine Förderung von Verticillium spp. an Kartoffel (Martin et al., 1982; Riedel et al., 1985; Rowe et al., 1985; MacGuidwin \& Rouse, 1990; Botseas \& Rowe, 1994; Wheeler et al., 1994; Bowers et al., 1996), Tomate (Conroy et al., 1972) und Minze (Faulkner \& Skotland, 1965; Faulkner \& Bolander, 1969; Faulkner et al., 1970; Johnson \& Santo, 2001) vornehmlich auf Wurzelschädigungen von Nematoden der Gattung Pratylenchus $(P$.$) spp. zurückgeführt worden. Im Nordamerikanischen Kartoffelanbau wird$ der Befallskomplex von $P$. penetrans und $V$. dahliae als Hauptursache krankhafter Abreifeerscheinungen (Potato Early Dying) angesehen (Bowers et al., 1996).

Untersuchungen zur Bedeutung tierischer Organismen für den Befall von Raps mit $V$. longisporum weisen ebenfalls auf befallsfördernde Effekte von Nematoden hin (Inszuna \& Eriksson, 1987). In Versuchen von Svensson \& Lerenius (1987) sowie Gröntoft \& Jonasson (1992) ließen sich bei hohen Inokulummengen jedoch keine Befallseffekte von Nematoden mehr erkennen. Abgesehen von Nematoden kann es auch durch Insekten, die Wurzelverletzungen hervorrufen, $\mathrm{zu}$ einer erhöhten Infektion und Schadwirkung bodenbürtiger Pathogene kommen (Beute \& Benson, 1979). Ein Zusammenhang zwischen Larvenfraß und Fusarium-Wurzelfäule ist u. a. für Sitona spp. (Kilpatrick, 1961; Leath \& Hower, 1993; Kalb et al., 1994) und Bradysia spp. (Leath \& Newton, 1969) an Leguminosen sowie Diabrotica spp. an Mais (Palmer \& Kommedahl, 1969) und Kürbis (Latin \& Reed, 1985) beschrieben 
worden. Nach Untersuchungen von Porter \& Smith (1974) ist Larvenfraß von Diabrotica spp. Hauptgrund der durch Phythium bedingten Erdnussfäule. Larvenfraß der Kohlfliege wird mit einer Förderung von Bakterienweichfäule (Doane \& Chapman, 1964 a, 1964 b) sowie $P$. lingam (Quanjer, 1907) an Kohlgewächsen in Zusammenhang gebracht. Griffiths (1986) beobachtete zudem ein verstärktes Auftreten von Fusarium-Infektionen an Kohlfliegen geschädigten Rapswurzeln in Canada.

Im Rahmen von Feld-, Freiland- sowie Gewächshausversuchen konnte nachgewiesen werden, dass Kohlfliegenbefall die Infektion, Besiedlung, Symptomausprägung und Schadwirkung von $V$. longisporum an Raps erhöhen kann. Die Bedeutung von Kohlfliegenbefall für $V$. longisporum hängt dabei maßgeblich von dem Entwicklungsstadium der Pflanze, der Sortenanfälligkeit (gegenüber $V$. longisporum) und der Bodeninokulumhöhe $a b$. Befallsfördernde Effekte von Kohlfliegenbefall sind insbesondere dann zu erwarten, wenn Wurzelfraß bereits im Jungpflanzenstadium auftritt. Mit Hilfe von Netzabdeckungen war es möglich, den Einfluss von Kohlfliegenbefall im Herbst bzw. Frühjahr differenziert zu betrachten. Im Sortenversuch (2006/2007) verzeichnete die nicht abgedeckte, bereits im Herbst stark durch die Kohlfliege geschädigte Sorte Lion zur Ernte signifikant höheren sowie stärkeren Verticillium-Befall als Varianten, in denen Kohlfliegenbefall im Herbst mit Netzen nahezu ausgeschlossen worden war. Der Befund, dass ein Ausschluss von Kohlfliegenbefall im Frühjahr in der Variante „Netz Herbst + Frühjahr“ keine weitere Reduktion des Verticillium-Befalls gegenüber der Variante „Netz Herbst“ herbeiführen konnte, deutet darauf hin, dass Kohlfliegenbefall im Herbst die größte Bedeutung in der Befallsförderung von $V$. longisporum beizumessen ist.

Im Gewächshaus (Sortenversuch vgl. 3.3.1.1) wurden Kohlfliegeneier entweder im Fünfblattstadium, oder zu Beginn Blüte angesetzt, um den Befall im Herbst bzw. Frühjahr simulieren zu können. In Übereinstimmung mit den Feldversuchen war eine signifikante Befallsförderung von $V$. longisporum durch die Kohlfliege nur dann zu erkennen, wenn Kohlfliegeneier im Fünfblattstadium angesetzt worden waren. Diese Ergebnisse zeigen einen deutlichen Zusammenhang zwischen Kohlfliegenbefall im Herbst und Verticillium-Befall auf. In Ergänzung zu der in Kapitel 4.2 erörterten Förderung von $V$. longisporum durch eine frühe Aussaat ergeben sich hieraus weitere Hinweise, dass Jungpflanzeninfektionen unter Feldbedingungen bereits im Herbst stattfinden können. Kohlfliegenbefall im Frühjahr, bei dem Winterraps ab dem Blütenstadium geschädigt wird, spielt nach eigenen Untersuchungen eine untergeordnete Rolle in der Befallsförderung von $V$. longisporum. Indirekte 
Befallseffekte sind jedoch auch hier nicht gänzlich auszuschließen. Nach Untersuchungen von Francl et al. $(1988,1990)$ sowie Saeed et al. $(1999,2007)$ wird die Symptomausprägung und Schadwirkung von $V$. dahliae im Kartoffelanbau durch Trockenstress stark erhöht. In eigenen Versuchen waren die Versuchspflanzen, weder im Feld, noch im Gewächshaus, Trockenstress ausgesetzt. Falls Kohlfliegenbefall im Frühjahr dazu beiträgt, Trockenstress zu induzieren, so ist auch hier eine vorzeitige Abreife mit früherer Symptomexpression möglich.

Abgesehen vom Zeitpunkt der Fraßschädigung hängt die Befallsförderung von $V$. longisporum durch Kohlfliegenbefall möglicherweise auch von der Höhe der Fraßschädigung ab. In Versuchen von Faulkner \& Skotland (1965), Conroy et al. (1972) sowie Müller (1973) resultierte eine höhere Nematodendichte auch gleichzeitig in einer stärkeren Zunahme des Verticillium-Befalls, wobei dieser Effekt nicht proportional war. Hingegen weisen Rotenberg et al. (2004) darauf hin, dass eine höhere Nematodenpopulation nicht immer zu einer Zunahme des Verticillium-Befalls führt. In Versuchen von Latin \& Reed (1985) war die Befallsförderung von Fusarium spp. durch Larven von Acalymma vittatum an Kürbis bereits bei einem Eibesatz von 5 Eiern maximal. Eibesätze von 10 oder 20 Eiern konnten hier keine weitere Befallssteigerung bewirken. Eigene Untersuchungen lassen lediglich eingeschränkte Aussagen zur Bedeutung der Fraßschädigungshöhe zu. Ergebnisse der Halbfreilandversuche zeigen, dass eine deutliche Befallsförderung von $V$. longisporum durch Kohlfliegenbefall bereits bei moderatem Wurzelfraß (Ø 24\% fraßgeschädigte Wurzeloberfläche) stattfindet. Im Sortenversuch 2005/2006 hatte eine geringe Reduktion des Larvenfraßes keine Senkung des Verticillium-Befalls zur Folge. Generell war die Variabilität des Kohlfliegenbefalls in einzelnen Versuchen bzw. Varianten gering, so dass keine eindeutigen Aussagen zur Bedeutung der Fraßintensität abgeleitet werden konnten.

Die Bedeutung von Kohlfliegenbefall für $V$. longisporum hängt auch von der Sortenanfälligkeit gegenüber $V$. longisporum ab. Während Kohlfliegenbefall in Feld-, Halbfreiland- sowie Gewächshausversuchen zu einer deutlichen Erhöhung des Verticillium-Befalls bei Sorten mit moderater Anfälligkeit (Lion, Heros) führte, waren bei der anfälligen Sorte Laser keine vergleichbaren Effekte festzustellen. Diese Ergebnisse stimmen mit einer Reihe von Untersuchungen überein, in denen Nematodenbefall bei moderat anfälligen Sorten, nicht jedoch bei Sorten mit hoher Anfälligkeit zu einer Erhöhung von Verticillium-Befall geführt hat (Back et al., 2002). Nachdem eine durch Larvenfraß der Kohlfliege bedingte Förderung von $V$. longisporum bei moderat anfälligen Sorten beobachtet worden war, sollte in einem Gewächshausversuch (Resistenzversuch) überprüft werden, ob Kohlfliegenbefall auch zu einer 
erhöhten Anfälligkeit resistenter Sorten führt. Hierzu wurde neben der moderat anfälligen Sorte Express zusätzlich eine Rapslinie mit hoher Verticillium-Resistenz (Sem 05-500256) getestet. Nach einer Bodeninokulation war eine verstärkte Symptomausbildung in der Variante ohne Kohlfliegenbefall nur bei Express (50\% BH), nicht jedoch bei Sem $(8,3 \% \mathrm{BH})$ zu beobachten. Die anhand von Real-Time PCR-Messungen ermittelten Mengen an Verticillium-DNA zeigten bei Sem eine sehr geringe Besiedlung des Pflanzengewebes an. Am Versuchsende (115 dpi; BBCH 85) wies die moderat anfällige Sorte Express in der Variante ohne Kohlfliegenbefall im Vergleich zu Sem etwa dreifach höhere Mengen an Verticillium-DNA in Wurzel und Hypokotyl sowie siebenfach höhere Mengen im Spross auf. Kohlfliegenbefall führte zu einer höheren Besiedlung des Pflanzengewebes, wobei dieser Effekt bei Sem $(+200 \%)$ deutlich stärker ausgeprägt war als bei Express $(+20 \%)$. Eine differenzierte Betrachtung einzelner Pflanzenbereiche zeigte, dass Kohlfliegenbefall bei Sem insbesondere zu einer verstärkten Besiedlung des Wurzel- und Hypokotylbereichs führte. Im Unterschied zur Variante ohne Kohlfliegenbefall lagen Verticillium-DNA-Werte hier auf einem mit Express vergleichbaren Niveau. Der Befall des Sprossbereichs, ein wichtiges Kriterium für Verticillium-Resistenz (Pegg \& Brady, 2002), war im Vergleich zu Express nach wie vor auf einem relativ niedrigen Niveau. Dieses Versuchsergebnis weist auf eine deutliche Abschwächung, nicht jedoch auf eine vollständige Aufhebung von Sortenresistenz durch Kohlfliegenbefall hin.

Eigene Untersuchungen zeigen, dass die relative Anfälligkeit von moderat bzw. gering anfälligen Sorten durch Kohlfliegenbefall zunimmt. Dieses Ergebnis steht im Einklang mit einer Reihe von Studien, in denen es durch Nematodenbefall ebenfalls zu einer Abschwächung von quantitativer Sortenresistenz gegenüber Verticillium spp. (Evans, 1983; Hide et al., 1984; Storey \& Evans, 1987) bzw. Fusarium spp. (Michel \& Powell, 1972; Abawi \& Barker, 1984; France \& Abawi, 1994) kam. Im Vergleich dazu existieren nur wenige Untersuchungen, die auf eine Abschwächung von Majorgenresistenz durch Wurzelschädlinge hindeuten. Einige Autoren (Bowman \& Bloom, 1966; Sidhu \& Webster, 1977) berichten, dass es unter Gewächshausbedingen nach einem Nematodenbefall an Tomate zu einem Bruch von Majorgenresistenz gegenüber Fusarium spp. gekommen ist. Die meisten Studien konnten keine entsprechenden Effekte feststellen. Über einen Bruch von Majorgenresistenz unter Feldbedingungen liegen keine Veröffentlichungen vor (Mai \& Abawi, 1979; Back et al., 2002). 
Auf die Bedeutung des Faktors Bodeninokulum für den Befall von Raps mit $V$. longisporum wurde bereits in Kapitel 4.2 hingewiesen. In Halbfreiland- sowie Gewächshausversuchen (Inokulationsstufen- und Befallsdynamikversuch) wurde der Einfluss von Kohlfliegenbefall auf $V$. longisporum bei variierenden Bodeninokulummengen untersucht, um Effekte bei niedrigem und hohem Befallsdruck erfassen zu können. In den Halbfreilandversuchen (Sorte Heros) wiesen Kohlfliegen geschädigte Varianten bei 10, 15 und $50 \mathrm{~g}$ Inokulum/ $\mathrm{m}^{2}$ deutlich höheren Verticillium-Befall auf als vergleichbare Varianten ohne Kohlfliegenbefall. Bei einer Bodeninokulation mit $100 \mathrm{~g}$ Inokulummaterial $/ \mathrm{m}^{2}$ waren keine Befallsunterschiede zwischen Varianten mit und ohne Kohlfliegenbefall festzustellen. Die Ergebnisse beider Versuchsjahre zeigen, dass Larvenfraß der Kohlfliege die Wahrscheinlichkeit einer Symptomausprägung bei geringem bis mittleren Bodeninokulum erhöht, bei hohem Bodeninokulum jedoch nur noch einen geringen Einfluss ausübt. Conroy et al. (1972) stellten vergleichbare Effekte in Interaktionsstudien zwischen $P$. penetrans und $V$. albo-atrum an Tomate fest. Ohne Nematodenbefall lag der $\mathrm{ED}_{50}$-Wert (Bodeninokulum für $50 \% \mathrm{BH}$ ) bei $41 \mathrm{MS} / \mathrm{g}$ Boden, bei gleichzeitigem Vorhandensein von $P$. penetrans jedoch bereits bei $26 \mathrm{MS} / \mathrm{g}$ Boden. Bei einer Bodeninokulation in Höhe von $200 \mathrm{MS} / \mathrm{g}$ Boden waren alle Versuchspflanzen (mit oder ohne Nematodenbefall) befallen.

Unter Gewächshausbedingungen, wo auch bei geringem Bodeninokulum mit einer Ausbildung von Symptomen zu rechnen ist, wurde überprüft, inwieweit Larvenfraß der Kohlfliege Einfluss auf die Befallsdynamik von $V$. longisporum in der Pflanze nimmt und welche Rolle hierbei die Höhe des Bodeninokulums spielt (Befallsdynamikversuch, Sorte Heros). Real-time PCR-Untersuchungen verzeichneten ab 84 dpi (BBCH 75) bei 0,2 g sowie $1 \mathrm{~g}$ Inokulummaterial/Topf leicht erhöhte Mengen an Verticillium-DNA bei Varianten mit im Vergleich zu Varianten ohne Kohlfliegenbefall. Bei $5 \mathrm{~g}$ Inokulummaterial/Topf führte Kohlfliegenbefall zu einer deutlichen Erhöhung der Besiedlung $(+100 \%$ gegenüber Variante ohne Kohlfliegenbefall), was sich auch in einer stärkeren Symptomausprägung ausdrückte. Am Versuchsende (125 dpi, BBCH 90) zeigten Varianten mit im Vergleich zu Varianten ohne Kohlfliegenbefall nach wie vor höhere Verticillium-DNA-Werte, wobei die Unterschiede bei $1 \mathrm{~g}$ und $5 \mathrm{~g}$ Inokulummaterial/Topf stärker zum Tragen kamen als bei $0,2 \mathrm{~g}$.

Halbfreiland- sowie Gewächshausversuche weisen darauf hin, dass es Wechselwirkungen zwischen Kohlfliegenbefall und der Bodeninokulumhöhe gibt, die sich in unterschiedlichem Maße auf die Parameter Befallshäufigkeit und Besiedlungsstärke auswirken. Die Wahrscheinlichkeit einer Symptomexpression wird durch Kohlfliegenbefall insbesondere bei 
geringem bis mittleren Bodeninokulum erhöht, während die Besiedlungsstärke offenbar bei hohem Bodeninokulum stärker begünstigt wird. Ursachen dieser auf den ersten Blick widersprüchlichen Effekte lassen sich anhand eines Modells von Baker (1971) veranschaulichen (Abb. 32). Das Modell geht davon aus, dass es mit zunehmendem Bodeninokulum auch zu einem höheren Anteil befallener Pflanzen kommt. Wurzelschädlinge tragen zu einer höheren Infektionswahrscheinlichkeit des vorhandenen Bodeninokulums bei und steigern somit die Inokulumeffizienz. Eine daraus abgeleitete, rein hypothetische Annahme, dass Kohlfliegenbefall die Infektionswahrscheinlichkeit von MS bspw. um 10\% erhöht, würde sich dann umso stärker auf die Besiedlung der Pflanze auswirken, je höher das Bodeninokulum ist.
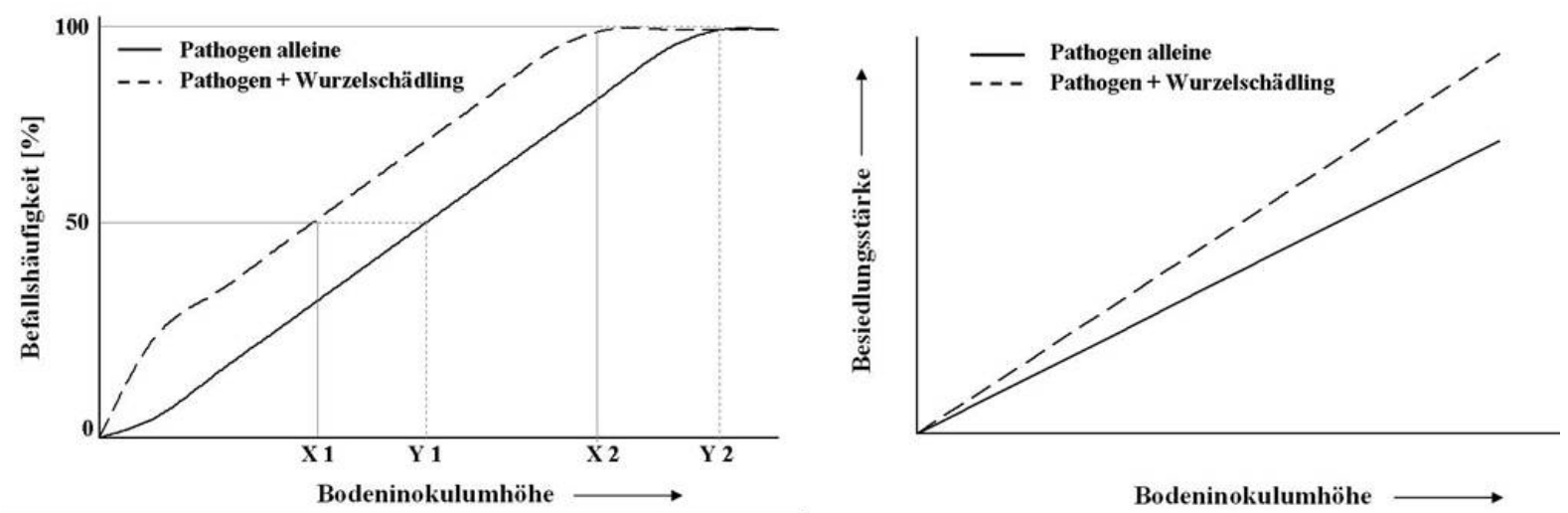

Abb. 32: Einfluss von Wurzelschädlingen auf die Befallshäufigkeit [\%] sowie Besiedlungsstärke von bodenbürtigen Pathogenen. Wurzelfraß erhöht die Inokulumeffizienz, so dass bereits bei einer Bodeninokulumhöhe von X1 50\% und X2 100\% der Pflanzen befallen sind, während ein alleiniger Pathogenbefall diese Befallshäufigkeiten erst bei Y1 und Y2 erreicht. Ab einer Bodeninokulumhöhe von Y2 werden alle Pflanzen befallen. Die Besiedlungsstärke wird durch Wurzelschädlinge umso stärker gefördert, je höher das Bodeninokulum ist (Schaubild nach Orientierung an Baker (1971)).

Im Rahmen der vorliegenden Arbeit wurden Schadeffekte von Kohlfliegen- und VerticilliumBefall sowohl getrennt, als auch zusammen untersucht, um mögliche synergistische Interaktionsbeziehungen identifizieren zu können. Eine synergistische Interaktion im Bezug auf die Schadwirkung liegt dann vor, wenn die Schadwirkung eines kombinierten Befalls beider Schaderreger größer ist als die Summe der Einzelschadwirkungen. Aus den Feldversuchen ließen sich keine eindeutigen Schlüsse ziehen, ob es zu einer synergistischen Schadwirkung von Kohlfliegen- und Verticillium-Befall gekommen ist. Signifikante Schadeffekte eines Verticillium-Befalls konnten hier lediglich in einem Versuchsjahr (2006/2007) bei der Sorte Laser festgestellt werden. In der stark durch Kohlfliegen geschädigten Variante „ohne Netz“ war der zu verzeichnende Ertragsverlust mit Ø 21\% etwas höher als in der Variante „Netz im 


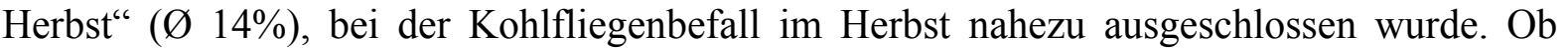
dieser Unterschied von 7\% ausschließlich auf den Ausschluss des Kohlfliegenbefalls zurückzuführen ist, erscheint fraglich. Unter Gewächshausbedingungen waren i. d. R. keine Schadwirkungen eines alleinigen Kohlfliegenbefalls zu beobachten. Die pflanzenmorphologischen Auswirkungen eines alleinigen Verticillium-Befalls hingen von der Stärke und Dynamik des Befalls, die zwischen Sorten und Bodeninokulmmengen differierte, ab (vgl. 4.2).

Das gleichzeitige Vorhandensein beider Schaderreger (Kohlfliegenbefall + Verticillium) hatte eine verstärkte Besiedlung des Pflanzengewebes zur Folge, wodurch Schadeffekte zunahmen. Im Befallsdynamikversuch (Sorte Heros) ließen sich signifikante Inokulationseffekte durch Kohlfliegenbefall bei der Sprossfrischmasse sowie Wurzeltrockenmasse bereits ab $1 \mathrm{~g}$ Inokulummaterial/Topf absichern, während signifikante Inokulationseffekte eines alleinigen Verticillium-Befalls erst bei $5 \mathrm{~g}$ Inokulummaterial/Topf festzustellen waren. Vergleichbare Effekte ließen sich auch im Inokulationsstufenversuch (Sorte Heros) beobachten. In beiden Versuchen konnten synergistische Schadeffekte identifiziert werden, wobei die jeweils größten Effekte bei hohem Bodeninokulum auftraten. Im Resistenzversuch (Sorte Express, Rapslinie Sem, $1 \mathrm{~g}$ Inokulummaterial/Topf) lagen die Schadeffekte eines kombinierten Kohlfliegen- und Verticillium-Befalls bei den Parametern Sprossfrischmasse sowie Wurzeltrockenmasse ebenfalls über der Summe der Einzelschadwirkungen. Die höchste synergistische Schadwirkung war bei der Wurzeltrockenmasse und hierbei insbesondere bei Sem festzustellen. Ein kombinierter Befall führte zu einer Reduktion der Wurzeltrockenmasse um -48,7\% (gegenüber der Kontrolle), während die Summe der Einzelschadwirkungen (Kohlfliege: $-2,1 \%$; Verticillium: $+6 \%$ ) mit einem Wert von $+3,9 \%$ keine Schadwirkung aufzeigte.

In der Literatur lassen sich eine Vielzahl von Studien finden, die von synergistischen Schadwirkungseffekten zwischen Nematoden und Verticillium spp. bzw. Fusarium spp. berichten, da die Ertragsverluste eines kombinierten Befalls höher waren als die Summe der Einzelschadwirkungen (Mai \& Abawi, 1987; Back et al., 2002). Die Tatsache, dass ein kombinierter Befall eine mehr als additive Schadwirkung zur Folge hat, ist allerdings noch kein hinreichender Beweis für eine vorhandene Interaktion. In Anlehnung an Ausführungen von Pedigo et al. (1986) sowie Peterson \& Higley (2001) wird davon ausgegangen, dass Pflanzen ein gewisses Maß an Stress, bspw. hervorgerufen durch Nematodenbefall oder Verticillium-Befall, ohne nennenswerte Ertragsverluste tolerieren können (Abb. 33). Das 
Vorhandensein beider Stressfaktoren (Nematodenbefall + Verticillium-Befall) führt möglicherweise zu einem kumulierten Gesamtstress, welcher Ertragsverluste zur Folge hat, obgleich sich beide Schaderreger nicht bedingen. Die Schadwirkung kommt in diesem Fall nicht durch eine Interaktion, sondern durch eine Assoziation beider Schaderreger zustande. Auf der anderen Seite sind additive oder antagonistische Schadwirkungseffekte eines kombinierten Schaderregerbefalls auch kein hinreichender Beweis dafür, dass keine Interaktion vorliegt. Falls einzelne Schaderreger bereits hohe Ertragsverluste hervorrufen (bspw. Nematodenbefall: $-60 \%$; Verticillium-Befall: $-60 \%=\sum-120 \%$ ), so wird die Analyse eines kombinierten Befalls (Schadwirkung $\leq 100 \%$ ) immer auf eine antagonistische Interaktion hindeuten. Eine mögliche gegenseitige Beeinflussung beider Schaderreger bleibt somit unerkannt. Nach Ausführungen von Mai \& Abawi (1979) ergeben sich gerade bei der Interpretation von Interaktionseffekten zwischen Nematoden und Verticillium spp. große Schwierigkeiten, da beide Schaderreger ähnliche Welkesymptome hervorrufen. Hieraus ergibt sich die Notwendigkeit, Verticillium-Befall im Pflanzengewebe zu quantifizieren. In eigenen Versuchen gingen synergistische Schadwirkungseffekte eines kombinierten Kohlfliegen- und Verticillium-Befalls mit einer stärkeren und dynamischeren Besiedlung des Pflanzengewebes einher, so dass sich hieraus das Vorhandensein einer „echten“ Interaktion ableiten lässt. Indirekte Schadwirkungseffekte aufgrund von höherem Gesamtstress können jedoch auch hier nicht gänzlich ausgeschlossen werden.

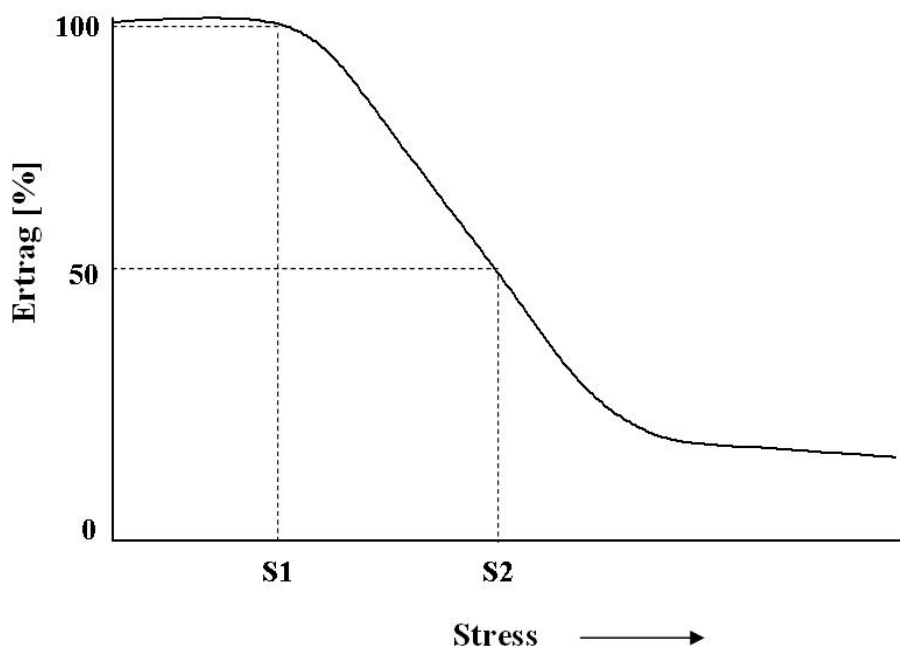

Abb. 33: Einfluss von Stress auf den Ertrag [\%] von Pflanzen. S1: Maximaler Gesamtstress ohne Ertragsverluste. S2: Gesamtstress der zu einem Ertragsverlust von 50\% führt. (Schaubild nach Orientierung an Pedigo et al. (1986) sowie Peterson \& Higley (2001)). 


\subsection{Mechanismen der Interaktion zwischen der Kleinen Kohlfliege und V. longisporum}

Vorliegende Untersuchungsergebnisse haben gezeigt, dass die Besiedlung, Symptomausprägung und Schadwirkung von $V$. longisporum an Raps durch Kohlfliegenbefall begünstigt wird. Die meisten Studien, in denen eine Förderung von Verticillium spp. bzw. Fusarium spp. durch Wurzelschädlinge festgestellt wurde, führten den zugrunde liegenden Mechanismus im Wesentlichen auf lokale Wundeffekte und/oder pflanzenphysiologische Effekte zurück (Fielding, 1959; Powell 1971; Beute \& Benson, 1979; Mai \& Abawi, 1987; Back et al., 2002). Die Bedeutung beider Faktoren für die Interaktion zwischen Kohlfliege und $V$. longisporum an Raps soll vor dem Hintergrund eigener Interaktionsstudien näher beleuchtet werden. Darüber hinaus wird auf weitere, im Rahmen der Arbeit nicht behandelte, mögliche Interaktionseffekte (Kohlfliege als Vektor; Effekt von $V$. longisporum auf die Kohlfliege) hingewiesen.

V. longisporum ist in der Lage, die Wurzel von Raps mittels Infektionshyphe direkt zu penetrieren. Zhou et al. (2006) berichten, dass die Infektionen hierbei vornehmlich von Wurzelhaaren und Seitenwurzeln ausgehen. Nach Interaktionsstudien von Eynck et al. (2007) interagiert $V$. longisporum mit den Wurzelhaaren, eine Penetration findet jedoch erst im Bereich der Wurzel statt. Beide Studien zeigen, dass sich $V$. longisporum nach der Penetration von Epidermiszellen über inter- und intrazelluläres Wachstum in Richtung Xylemgefäße orientiert. Zudem weisen beide Untersuchungen darauf hin, dass Infektionen der Wurzel auch ohne das Vorhandensein von Wunden möglich sind. Auf der anderen Seite haben eine Reihe von Versuchen zeigen können, dass die Infektionsrate, Dynamik der Gefäßbesiedlung sowie Symptomausprägung von Verticillium spp. durch eine mechanische Wurzelverletzung stark beschleunigt wird (Selman \& Buckley, 1959; Mountain \& McKeen, 1960; Müller, 1973). Vergleichbare Effekte waren in eigenen Versuchen ebenfalls festzustellen. Im Wurzelverletzungsversuch wurden Befallsdynamik und Symptomausprägung von $V$. longisporum bei einer moderat anfälligen Sorte (Express) sowohl durch Kohlfliegenbefall, als auch durch eine mechanische Wurzelverletzung stark gefördert. Nach einer Bodengießinokulation verzeichnete die unverletzte Variante den mit Abstand langsamsten Befallsverlauf. Am Versuchsende (35 dpi) zeigten hier lediglich fünf von insgesamt zwölf Pflanzen Blattsymptome, wo hingegen in der Variante mit Kohlfliegenbefall neun und in der mechanischen Verletzungsvariante elf von zwölf Pflanzen charakteristische Blattsymptome aufwiesen. 
Eine durch Wurzelverletzungen oder Wurzelfraß hervorgerufene stärkere Gefäßbesiedlung von $V$. longisporum lässt sich möglicherweise mit einer Beeinträchtigung von Abwehrreaktionen, die in der prevaskulären Phase operieren, begründen. Zahlreiche histologische Untersuchungen (Garber \& Housten, 1966; Bishop \& Cooper, 1983a; Zhou et al., 2006; Eynck et al., 2007) stellten übereinstimmend fest, dass lediglich ein sehr geringer Anteil der Wurzelpenetrationen von Verticillium spp. in einer erfolgreichen Besiedlung des Xylems resultiert. Verschiedene Abwehrmechanismen werden hierfür verantwortlich gemacht. Erste nach einer Penetration zu verzeichnende anatomische Veränderungen im Rindengewebe sind Zellwandverdickungen in unmittelbarer Umgebung der penetrierenden Hyphe (Talboys, 1958). Griffiths (1971) beobachtete in histologischen Untersuchungen $V$. dahliae infizierter Tomaten und Erbsen die Einkapselung penetrierender Hyphen durch die Akkumulation von vesikulärem Material (lignituber) zwischen Zellwand und Plasmalemma, wodurch weiteres Hyphenwachstum unterbunden wurde. Die Endodermis stellt für die Hyphe i. d. R. die zweite Barriere auf dem Weg ins Xylem dar, weil die Pflanze wiederum mit Zellwandverdickungen (Suberinauflagerung) auf eine Penetration reagiert. Nach Talboys (1958) sowie Bishop \& Cooper (1983b) treten Resistenzunterschiede bei Hopfen und Tomate insbesondere im Bereich der Endodermis auf, die bei resistenten Sorten eine weitaus effektivere Barriere darstellt als bei anfälligen Sorten. Eine verstärkte Besiedlung der Xylemgefäße findet demzufolge nur dann statt, wenn die Endodermis beschädigt wird oder wenn das Pathogen über den Streckungszonenbereich der Wurzelspitze, wo keine Endodermis vorliegt, ausweicht. Eine durch Kohlfliegenbefall oder mechanische Verletzungen hervorgerufene Beschädigung der Endodermis ist möglicherweise ein Grund dafür, dass Pflanzen stärker und schneller besiedelt werden.

Abgesehen von direkten Wundeffekten sind weitere, indirekte Modifikationen in der Rhizosphäre vorstellbar, die Einfluss auf die Infektion und anschließende Besiedlung nehmen könnten. Eine Wurzelinfektion von Verticillium spp. wird von Wurzelexsudaten, die die MSKeimung auslösen, beeinflusst (Schreiber \& Green, 1963; Mol \& van Riessen, 1995). Die Keimrate von MS nimmt dabei mit zunehmender Wurzelentfernung stark ab (Olsson \& Nordbring-Hertz, 1985). Larvenfraß der Kohlfliege trägt möglicherweise zu quantitativen und/oder qualitativen Veränderungen der Wurzelexsudation bei. Eine vermehrte Absonderung von Wurzelexsudaten könnte in einer größeren Anzahl gekeimter MS resultieren und somit zu einer höheren Infektionsrate führen. Nach Aussagen von Bergeson (1972) können Wurzelschädlinge auch zu einer qualitativen Veränderung der Wurzelexsudation führen, wodurch Pathogenbefall begünstigt wird. In Interaktionsstudien von van Gundy et al. (1977) 
reagierten Tomatenpflanzen nach einer Inokulation mit Rhizoctonia solani mit starken Wurzelnekrosen, wenn Wurzelexsudate nematodenbefallener (M. incognita) Pflanzen hinzu gegeben wurden. Eine entsprechende Behandlung mit Wurzelexsudaten von Kontrollpflanzen (ohne Nematodenbefall) hatte hingegen keine Wurzelnekrosen zur Folge. Wurzelexsudate von Nematoden befallenen Pflanzen wiesen einen erhöhten Anteil von Stickstoffverbindungen auf, die nach Weinhold et al. (1972) einen bedeutenden Virulenzfaktor von $R$. solani darstellen. Bergeson et al. (1970) beobachteten eine deutliche Zunahme von Fusarium oxysporum-Sporen bei Tomatenpflanzen, die mit $M$. javanica befallen waren. In einer Folgestudie konnte Bergeson (1972) nachweisen, dass die vermehrte Sporenbildung mit einer Abnahme von Fusarium-Antagonisten einherging. Falls Kohlfliegenbefall zu einer qualitativen Veränderung der Wurzelexsudation führt, so ist auch hier eine Beeinflussung von Verticillium-Antagonisten (Berg \& Ballin, 1994; Alström, 1999) nicht auszuschließen.

Die Infektionsrate bodenbürtiger Pathogene hängt nicht nur vom Bodeninokulum ab, sondern wird auch maßgeblich von der Durchwurzelung des Bodens bestimmt (Huisman, 1982; Ashworth et al., 1979b). Da MS nahezu stationär im Boden vorliegen, ist für die Keimung und Infektion das Vorhandensein von Wurzeln in unmittelbarer MS-Nähe Voraussetzung. Die Infektionswahrscheinlichkeit ist bei konstantem Bodeninokulum dabei umso höher, je mehr Wurzeln in die Nähe von MS wachsen (Olsson \& Nordbring-Hertz, 1985; Mol, 1995). Rapspflanzen reagieren auf Kohlfliegenbefall i. d. R. mit einer verstärkten regenerativen Seitenwurzelbildung (vgl. 4.1). Bei moderatem Wurzelfraß kann es dabei, wie im Halbfreilandversuch 2006, zu einer überkompensatorschen Wurzelneubildung kommen, wodurch Keimrate und Infektionswahrscheinlichkeit vorhandener MS vermutlich erhöht werden.

Zahlreiche Autoren weisen darauf hin, dass die Befallsförderung bodenbürtiger Pathogene nicht ausschließlich auf lokale Wundeffekte, sondern auch auf eine Beeinflussung der Pflanzenphysiologie zurückzuführen ist. Entsprechende Berichte beziehen sich dabei i. d. R. auf den Befallskomplex Meloidogyne spp. und Fusarium spp. (Abawi \& Barker, 1979; Back et al., 2002). Das von Meloidogyne spp. produzierte, nährstoffreiche Gallengewebe wird dabei sowohl mit einer lokalsystemischen Infektionsförderung als auch mit einer physiologischen Beeinträchtigung der Wirtspflanze in Verbindung gebracht. Mechanistische Interaktionsuntersuchungen, in denen es bei räumlicher Trennung von Meloidogyne spp. und Fusarium spp. (Bowman \& Bloom, 1966; Powell, 1971; Hillocks, 1986; Marley \& Hillocks, 1994) zu einem stärkeren Fusarium-Befall kam als bei einer alleinigen Fusarium-Inokulation, deuten auf das Vorhandensein pflanzenphysiologischer Befallseffekte hin. Im 
Vergleich zu Meloidogyne spp. liegen nur wenige Untersuchungsergebnisse vor, die eine Befallsförderung von Fusarium spp. bzw. Verticillium spp. durch Pratylenchus spp. im Wesentlichen pflanzenphysiologischen Effekten zuschreiben. Eine Befallsförderung von $V$. albo-atrum durch P. penetrans an Tomate (Conroy et al., 1972) sowie Impatiens balsamina (Müller, 1973) war in Wurzelteilungsversuchen lediglich dann zu erkennen, wenn beide Schaderreger räumlich zusammen vorkamen. In einem Stängelinokulationsversuch mit $V$. albo-atrum an Pfefferminze (Faulkner et al., 1970) führte Nematodenbefall mit $P$. minyus bei räumlicher Trennung beider Schaderreger $\mathrm{zu}$ einem höheren Anteil symptomatischer Pflanzen (Verticillium alleine: 19\% BH ; Verticillium/Nematodenbefall: 38\% BH), was auf eine pflanzenphysiologische Beeinflussung hindeutet. Die Tatsache, dass die mit Abstand höchste $\mathrm{BH}$ bei räumlichem Zusammensein beider Schaderreger zu verzeichnen war $(81 \%$ $\mathrm{BH})$, weist allerdings auch auf die weitaus größere Bedeutung lokaler Wundeffekte hin.

Die Befallsförderung von $V$. longisporum durch Kohlfliegenbefall beruht nach eigenen Untersuchungen ebenfalls maßgeblich auf lokalen Wundeffekten. Im Wurzelteilungsversuch (Sorte Heros) führte Kohlfliegenbefall bei räumlichem Zusammentreffen beider Schaderreger $\mathrm{zu}$ einer deutlich stärkeren Besiedlung und Symptomausprägung gegenüber einer Variante ohne Kohlfliegenbefall. Bei räumlicher Trennung beider Schaderreger ließen sich hingegen keine Effekte von Kohlfliegenbefall auf $V$. longisporum feststellen. Mit dem Stängelinokulationsversuch (Sorte Express, Rapslinie Sem) wurde ein weiterer Versuch angelegt, um mögliche pflanzenphysiologische Effekte von Kohlfliegenbefall auf $V$. longisporum bei räumlicher Trennung beider Schaderreger identifizieren zu können. Zwischen stängelinokulierten Varianten mit bzw. ohne Kohlfliegenbefall waren keine visuellen Befallsunterschiede zu erkennen. Bei der am Versuchsende (28 dpi) durchgeführten Real-Time PCRUntersuchung wiesen Varianten mit Kohlfliegenbefall etwas höhere Mengen an VerticilliumDNA auf als vergleichbare Varianten ohne Kohlfliegenbefall, was sich allerdings auf den unteren Stängelabschnitt beschränkte. Anhand dieser Ergebnisse ist eine geringe pflanzenphysiologische Begünstigung von $V$. longisporum durch Kohlfliegenbefall nicht auszuschließen. Die im Resistenzversuch (Sorte Express, Rapslinie Sem) bei räumlichen Zusammensein beider Schaderreger aufgezeigte wesentlich stärkere Förderung von $V$. longisporum durch Kohlfliegenbefall, insbesondere bei Sem, weist allerdings auch darauf hin, dass lokale Wundeffekte hierbei von größerer Bedeutung sind als pflanzenphysiologische Effekte. 
Die im Stängelinokulationsversuch bei räumlicher Trennung beider Schaderreger zu verzeichnenden Befallseffekte lassen sich möglicherweise auf eine Beeinträchtigung von Abwehrreaktionen, die in der vaskulären Phase operieren, zurückführen. Erreicht Verticillium spp. die Xylemgefäßwände, so können physikalische Barrieren eine laterale und vertikale Ausbreitung hemmen. Newcombe \& Robb (1988) stellten bei Luzerne, kurz nach einer Wurzeltauchinokulation mit $V$. albo-atrum, suberinartige Gefäßwandauflagerungen fest, die zu einer gehemmten lateralen Pathogenausbreitung führten. Da Gefäßwandauflagerungen bei der resistenten Sorte am stärksten ausgeprägt waren, sahen die Autoren darin einen Resistenzmechanismus. In den Xylemgefäßen kann es als Reaktion auf eine Infektion zur Ansammlung von granulärem Material (Gel) kommen, welches vermutlich von Porenmembranen der Perforationsplatten stammt. Diese Gelbildung wird durch ein Verstopfen der Porenmembran und Perforationsplatten für eine gehemmte laterale und vertikale Ausbreitung von Verticillium spp. bei resistenten Sorten verantwortlich gemacht (Bishop \& Cooper, 1983b). Darüber hinaus reagieren einige Kulturpflanzen mit einer Thyllenbildung auf Gefäßinfektionen. Hierbei dringen benachbarte Xylemparenchymzellen über Porenmembranen in Xylemgefäße ein, schwellen durch Vakuolation an und stellen somit ebenfalls eine Besiedlungsbarriere dar (Beckmann, 1984). Die Rolle physikalischer Abwehrreaktionen als Resistenzfaktoren ist jedoch umstritten, da sie sowohl bei resistenten, als auch anfälligen Kulturpflanzen vorkommen und häufig auch durch mechanische Verletzungen hervorgerufen werden können. Nach Beckmann (1984) zeichnet sich eine resistente gegenüber einer anfälligen Sorte oftmals dadurch aus, dass physikalische Abwehrreaktionen zu einem früheren Zeitpunkt ablaufen und somit effektive Ausbreitungsbarrieren darstellen.

Neben physikalischen werden chemische Abwehrreaktionen der Wirtspflanze als mögliche Ursache von Resistenz diskutiert. Dabei stehen neben der Induktion von PR-Proteinen (Pathogenesis-Related Proteins) wie Chitinase und $\beta$ 1,3 Glucanase (Dubery \& Slater, 1997) insbesondere die Akkumulation von phenolischen Komponenten sowie Phytoalexinen im Vordergrund. Die im Gewebe vorliegenden Phenole können nach Infektion vermehrt ins Xylem abgegeben werden, wo es in Anwesenheit von Polyphenoloxidasen zur Oxidation und anschließenden Polymerisation mit Xylemparenchymzellen, Gels, Tylosen sowie pilzlichen Strukturen kommt. Als Folge dieser Reaktion findet eine sichtbare Verbräunung der Leitbündel statt (Beckmann, 1984). Darüber hinaus werden den Phenolen enzymbeeinflussende sowie phytoalexinfördernde Eigenschaften zugeschrieben (Nicholson \& Hammerschmidt, 1992). In von Eynck (2008) durchgeführten Untersuchungen konnten nach einer Wurzeltauchinokulation bei der resistenten Rapslinie Sem im Vergleich zu einer 
anfälligen Sorte (Falcon) höhere Konzentrationen löslicher und zellwandgebundener Phenole festgestellt werden. Ähnliche Effekte sind auch für andere von Verticillium spp. befallene Kulturpflanzen beschrieben worden (Pegg \& Brady, 2002).

Phytoalexine repräsentieren von der Wirtspflanze gebildete Metabolite, die vermehrt bei abiotischem oder biotischem Stress synthetisiert werden. Neben den zuvor aufgeführten physikalischen Abwehrreaktionen werden Resistenzerscheinungen u.a. mit fungitoxischen Wirkungen dieser Phytoalexine begründet. Baumwollresistenz gegenüber $V$. dahliae basiert nach Bell (1969), Mace (1978) sowie Mace et al. (1985) auf einer kombinierten Wirkung von Tylosen und Phytoalexinen. Die nach einer Stängelinokulation einer resistenten Sorte auf den unteren Pflanzenbereich beschränkte Ausbreitung von $V$. dahliae wurde von den Autoren primär mit einer sehr früh einsetzenden Tylosenbildung in Verbindung gebracht. Der Tod nahezu aller $V$. dahliae-Konidien an den Infektionsorten und die gleichzeitig festgestellte starke Akkumulation von terpenoiden aldehyden Phytoalexinen ließen die Autoren auf einen Zusammenhang schließen. In vitro-Untersuchungen zur Phytotoxizität und Wasserlöslichkeit aus Baumwolle isolierter Phytoalexine von Mace et al. (1985) zeigten allerdings, dass lediglich eines der vier getesteten Phytoalexine, Desoxyhemigossypol, in der Lage war, fungitoxische Konzentrationen im Stängel zu bilden. Die Autoren sehen eine frühe Tylosenbildung an den Infektionsorten als essentiell für die Akkumulation fungitoxischer Konzentrationen an. Die Resistenz von Kakao und Tomate gegenüber $V$. dahliae wird mit elementarem Schwefel, einem anorganischen Phytoalexin, in Verbindung gebracht (Cooper et al., 1996; Resende et al., 1996; Williams et al., 2002; Cooper \& Williams, 2004). Die Autoren konnten nachweisen, dass elementarer Schwefel, bei dem es sich um ein altes, im Weinanbau häufig angewandtes Fungizid handelt, nach einer Verticillium-Infektion in fungitoxischen Konzentrationen (im Xylem) angereichert werden kann. Die Rolle von Phytoalexinen in der Pathogenese von $V$. longisporum an Winterraps wurde bislang nicht untersucht.

Die Beeinträchtigung vaskulärer Resistenzreaktionen durch Wurzelschädlinge ist für den Befallskomplex Meloidogyne spp. und Fusarium spp. beschrieben worden. In einem von Hillocks (1985) durchgeführten Stängelinokulationsversuch an Baumwolle ging die durch Nematodenbefall hervorgerufene stärkere Besiedlung und Symptomausprägung von Fusarium oxysporum mit einer verlangsamten und verringerten Tylosenbildung einher. Khan \& Milton (1979) berichten von einer verminderten Phytoalexin-Akkumulation Fusarium infizierter Luzernepflanzen nach einem Nematodenbefall. Das hohe Resistenzniveau der 
Erbsensorte ICP 9145 gegenüber Fusarium udum basiert nach Untersuchungen von Marley \& Hillocks (1993) auf einer rapiden Akkumulation des isoflavonoiden Phytoalexins Cajanol. In einer Folgestudie (Marley \& Hillocks, 1994) wurde der Einfluss von Meloidogyne incognita auf die Akkumulation von Cajanol bei dieser Sorte in einem Stängelinokulationsversuch untersucht. Räumlich getrennter Schaderregerbefall führte dazu, dass zwei Drittel der Pflanzen Symptome ausbildeten, während bei einer alleinigen Stängelinokulation keine Symptome zu beobachten waren. Nach einer Analyse des vaskulären Stängelgewebes wiesen die Autoren eine auf Nematodenbefall zurückzuführende Verminderung des Phytoalexins Cajanol um 50 bis 70\% nach. Versuche von Katsantonis et al. (2005), in denen Nematodenbefall an Baumwolle zu einer stärkeren Konidienbildung von $F$. oxysporum im Xylem führte, deuten ebenfalls auf eine reduzierte Resistenz hin.

Abwehrreaktionen von Pflanzen werden nicht nur durch Pathogenbefall, sondern auch durch mechanische Verletzungen oder Herbivorie ausgelöst (Karban \& Myers, 1989). Beispielsweise reagieren einige Solanaceen auf eine Fraßschädigung mit einer de novo Synthese von Proteinase-Inhibitoren, die sich negativ auf die Fraßtätigkeit und Entwicklung von Insekten auswirken (Ryan, 1990). Generell kommt es nach einer Fraßschädigung zu einer vermehrten Bildung von Phenolen (Nicholson \& Hammerschmidt, 1992). Zahlreiche Studien haben sich mit den Effekten eines Kohlfliegenbefalls (Delia radicum, Delia floralis) auf die Bildung von Glucosinolaten auseinandergesetzt (Birch et al., 1990, 1992; Griffiths et al., 1994; Hopkins et al., 1998; van Dam \& Raaijmakers, 2006). Übereinstimmend kommen die Autoren zu dem Schluss, dass Larvenfraß insbesondere zu einer lokalen Erhöhung von Indol-Glucosinolaten (Glucobrassicin, Neoglucobrassicin) im Wurzelbereich führt. Ob es sich hierbei um einen effektiven Abwehrmechanismus gegenüber der Kohlfliege handelt, der in einer geringeren Fraßtätigkeit resultiert, ist allerdings fraglich. Neveu et al. (2002) sehen in der Anlockung von Parasitoiden einen indirekten Kontrolleffekt der Kohlfliege. Auf der anderen Seite belegen eine Vielzahl von Untersuchungen (Traynier, 1965; Finch, 1978; Nottingham \& Coaker, 1985; Nottingham, 1988, Tuttle et al., 1988; Baur et al., 1996 a, 1996 b), dass Abbauprodukte der Indol-Glucosinolate sowohl die Eiablage als auch den Fraß der Larven stark stimulieren. Glucosinolate, deren vermehrte Synthese auch durch Pathogenbefall induziert wird, werden mit Resistenz gegenüber Phoma lingam, Sclerotinia sclerotiorum sowie Alternaria brassicae an Raps in Verbindung gebracht (Wretblad \& Dixelius, 2000; Mithen, 1992). Im Gegensatz dazu weisen Untersuchungen von Müller et al. (1997) darauf hin, dass Indol-Glucosinolate die Symptomentwicklung von Plasmodiophora brassicae (Kohlhernie) begünstigen. Die Bedeutung von Glucosinolaten für Resistenz bzw. 
Pathogenese von Verticillium spp. ist bislang nicht nachgewiesen worden (Karapapa et al., 1997 b; Pegg \& Brady, 2002). Es kann daher keine Bewertung abgegeben werden, ob eine stärkere Synthese von Indol-Glucosinolaten nach Larvenfraß Effekte auf $V$. longisporum ausübt.

Abwehrreaktionen von Pflanzen gegenüber Insektenbefall, mechanischen Verletzungen oder Pathogenbefall werden über verschiedene durch Phytohormone gesteuerte Signalwege induziert. Die nach Herbivorie bzw. mechanischen Verletzungen ausgelösten Abwehrreaktionen werden vornehmlich mit den Phytohormonen Jasmonsäure und Ethylen in Beziehung gesetzt, während dem Phytohormon Salicylsäure regulierende Eigenschaften in der Pathogenabwehr zugeschrieben werden (Maleck \& Dietrich, 1999; Leon et al., 2001). Untersuchungen von Thaler et al. (2004), in denen Jasmonsäure defiziente bzw. Jasmonsäure insensitive Tomatenpflanzen stärkeren Verticillium-Befall aufwiesen, deuten jedoch darauf hin, dass Jasmonsäure nicht nur Abwehrreaktionen gegenüber Insekten reguliert, sondern auch eine Rolle in der Pathogenabwehr hat. Zahlreiche Studien (Felton et al., 1999; Maleck \& Dietrich, 1999; Hunter, 2001; Taylor et al., 2004) berichten, dass Abwehrreaktionen nach Insektenund Pathogenbefall nicht unabhängig voneinander ablaufen, sondern häufig antagonistisch interagieren. Eine antagonistische Beziehung liegt dann vor, wenn bspw. Abwehrreaktionen nach Insektenbefall zu einer Hemmung der Pathogenabwehr führen. Vergleichbare antagonistische Effekte sind auch für einen kombinierten Kohlfliegen- und Verticillium-Befall nicht auszuschließen.

Eine zusammenfassende Beurteilung durchgeführter Interaktionsstudien lässt den Schluss zu, dass die Befallsförderung von $V$. longisporum durch Kohlfliegenbefall maßgeblich auf lokale Wundeffekte zurückzuführen ist. Eine entscheidende physiologische Beeinflussung von $V$. longisporum durch Kohlfliegenbefall konnte nicht festgestellt werden. Es muss allerdings erwähnt werden, dass vorliegende Ergebnisse unter Bedingungen generiert wurden, in denen die Versuchspflanzen keinen abiotischen Stressfaktoren ausgesetzt wurden. Nach Untersuchungen von Francl et al. (1988, 1990) wird die Besiedlung und Symptomexpression von $V$. dahliae an Kartoffel durch Trockenstress stark erhöht. Ayres (1984) weist ebenfalls auf die Bedeutung von Umweltstress für Pathogenbefall hin. Falls Kohlfliegenbefall dazu beiträgt, Trockenstress zu induzieren, so ist auch eine stärkere pflanzenphysiologische Beeinflussung von $V$. longisporum möglich. 
Abschließend soll noch kurz auf weitere mögliche Interaktionseffekte zwischen der Kohlfliege und $V$. longisporum eingegangen werden. Beute \& Benson (1979) weisen auf die Möglichkeit hin, dass passiver Pathogentransport der Bodenfauna zu einer Akkumulation von Inokulum im Wurzelbereich führen kann. Darüber hinaus werden Insekten als oberirdische Vektoren von bodenbürtigen Pathogenen (Fusarium spp.; V. albo-atrum) angesehen, die sekundäres Inokulum (Sporen) bilden. Als potenzielle Vektoren von $V$. albo-atrum an Luzerne wurden Blattläuse (Huang et al., 1983), Blattschneiderwespen (Huang et al., 1986) sowie Trauermücken (Kalb \& Millar, 1986) genannt. Die Verbreitung von Inokulum erfolgt hier auf mechanischem Wege durch außen am Insektenkörper anhaftende Sporen. In Zwangsfraßversuchen konnten Price (1975) und El-Hamalawi (2007) neben einer Oberflächenkontamination auch eine Aufnahme vitaler Sporen von $V$. albo-atrum bei Spinnmilben sowie Küstenfliegen nachweisen. Inwieweit es sich bei der Kohlfliege um einen effektiver Vektor für $V$. longisporum handelt, erscheint fraglich. Eine Verbreitung von Inokulum setzt voraus, dass Larven, die an Verticillium-befallenen Wurzeln fressen, in der Lage sind, Inokulum aufzunehmen und anschließend über die Stadien Puppe, Imagino, Ei sowie Larve weiterzugeben.

Bisher erörterte Mechanismen der Interaktion haben sich mit dem Einfluss von Kohlfliegenbefall auf $V$. longisporum auseinandergesetzt. Effekte von $V$. longisporum auf Kohlfliegenbefall stellen eine weitere mögliche Form der Interaktion dar. Die meisten Versuche, in denen Effekte bodenbürtiger Pathogene auf Wurzelschädlinge untersucht worden sind, beziehen sich auf Nematoden. In Interaktionsstudien zwischen Pratylenchus spp. und Verticillium spp. wiesen Verticillium-inokulierte Varianten entweder höheren (Mountain \& McKeen, 1962; Faulkner \& Skotland, 1965; Morsink \& Rich, 1968) oder vergleichbar hohen Nematodenbefall (Population) wie entsprechende Kontrollvarianten auf (Conroy et al., 1972). Als mögliche Ursache des durch Pathogenbefall bedingten Anstiegs der Nematodenpopulation führten die Autoren phytohormonelle Veränderungen an, die in einer höheren Attraktivität der Wurzel resultiert haben könnten. Im Gegensatz zu wandernden Wurzelnematoden wie Pratylenchus spp. wirkt sich ein Pathogenbefall i. d. R. negativ auf die Entwicklung von sedentären Wurzelnematoden (Meloidogyne spp., Heterodera spp., Globodera spp.) aus (Powell, 1971). In Versuchen von Ketudat (1969) wurde die Entwicklung von Heterodera spp.-Weibchen durch einen Befall mit Verticillium spp., Rhizoctonia spp. sowie Fusarium spp. stark gehemmt. Ryder \& Crittenden (1965) berichten, dass Meloidogyne hapla bei gleichzeitigem Befall von Kohl mit Plasmodiophora brassicae (Kohlhernie) nicht in der Lage war, ein Riesenzellensystem zu etablieren. Der Zusammen- 
hang zwischen Verticillium spp. und Insektenbefall wurde an Baumwolle und Luzerne untersucht. Karban et al. (1987) stellten an Verticillium-inokulierter Baumwolle eine um etwa $50 \%$ reduzierte Spinnmilbenpopulation fest. In Laboruntersuchungen von Kingsley et al. (1983) führte Verticillium-Befall an Luzerne zu einer verringerten Verwertungseffizienz aufgenommenen Gewebes bei Larven von Spodoptera eridania. Eine verminderte Wirtspflanzenqualität wurde in beiden Studien als Grund nachteiliger Befallswirkungen angegeben.

Während die Förderung von Nematoden (Pratylenchus spp.) durch Verticillium-Befall eine Interaktion nach der so genannten „Pflanzen-Stress-Hypothese“ darstellt, folgen zuletzt genannte Beispiele der „Pflanzen-Vitalitäts-Hypothese“, die davon ausgeht, dass gesunde, kräftige Pflanzen bessere Nahrungs- und Entwicklungsmöglichkeiten bieten als geschwächte Pflanzen (Inbar et al., 2001). Teilweise nach einem Pathogenbefall zu beobachtende stärkere Fraßschädigungen sind demnach auch nicht auf eine höhere, sondern auf eine geringere Nahrungsqualität zurückzuführen. Das Insekt (Larve) muss mehr Nahrung aufnehmen, um seinen Energiebedarf zu decken. Mögliche Interaktionseffekte zwischen $V$. longisporum und der Kohlfliege beziehen sich auf die Faktoren Eiablage, Fraßschädigung sowie Entwicklung von Larven und Puppen. In Feldversuchen ließen sich weder im Herbst, noch im Frühjahr, Unterschiede im Kohlfliegenbefall zwischen Inokulations- und Kontrollvarianten feststellen. Unter Gewächshausbedingungen lagen Fraßschädigungswerte inokulierter Varianten ebenfalls auf dem Niveau von Kontrollpflanzen. Larven und Puppengewichte wurden nicht ermittelt, so dass sich keine Aussagen zu Entwicklungsparametern ableiten lassen. Untersuchungen, wonach größere, vitalere Pflanzen bei der Eiablage bevorzugt werden und auch bessere Entwicklungsbedingungen für Kohlfliegenlarven bieten (vgl. 4.1) entsprechen der „Pflanzen-Vitalitäts-Hypothese.“ Ein negativer Effekt von Verticillium-Befall auf die Entwicklung von Kohlfliegenlarven (Puppen) unter Feldbedingungen ist vorstellbar, wenn Larven der zweiten Generation im Juli an stark Verticillium-befallenen, verrotteten Wurzeln fressen und hierbei möglicherweise nicht genug Nahrung aufnehmen können, um sich weiter zu entwickeln.

\subsection{Befall und Schadwirkung von Phoma lingam}

Die Untersuchung des Befallskomplexes Kohlfliege/ $V$. longisporum bildete den Schwerpunkt in der vorliegenden Arbeit. Darüber hinaus sollte in Feld- und Gewächshausuntersuchungen der Frage nachgegangen werden, ob Larvenfraß der Kohlfliege auch Auswirkungen auf den 
Befall von Raps mit P. lingam hat. Im Rahmen des Sortenversuchs (2005-2008) wurden die Faktoren Sortenanfälligkeit (gegenüber $P$. lingam) und Inokulum variiert, um Effekte bei unterschiedlich hohem Befallsdruck zu analysieren. Ergebnisse der Phoma-Befallsbonitur weisen auf ein moderates Befallsniveau im Untersuchungszeitraum hin. Je nach Sorte bzw. Inokulationsvariante variierten mittlere Befallswerte (BW) am Wurzelhals- und Stängel zwischen 1,8 und 5. Festgestellte Sortenunterschiede entsprachen der Anfälligkeitseinstufung nach Bundessortenliste (BSL 1-9), die auf bundesweit durchgeführten Sortenprüfungen basiert (Anonymus, 2008). Die in allen drei Versuchsjahren angebauten Sorten Lion (BSL 6) und Laser (BSL 5) wiesen dabei signifikant höhere BW auf als die Sorte Caiman (BSL 2), bei der lediglich kleine Befallsflecken ohne Einschnürung zu beobachten waren. Andere in jeweils einem der drei Versuchsjahre bestellte Sorten (Oase (BSL 5), Viking (BSL 5), NK Fair (BSL 5), Aviso (BSL 3) zeigten ebenfalls eine ihrer Einstufung entsprechende Befallsreaktion.

Das Phoma-Resistenzniveau derzeit zugelassener Sorten ist vergleichsweise hoch. Sortenresistenz gegenüber $P$. lingam beruht dabei sowohl auf monogener als auch polygener Resistenz. Eine durch einzelne Resistenzgene $\left(\mathrm{R}_{\mathrm{x}}\right)$ gesteuerte Majorgenresistenz ist bei Raps auf das Jungpflanzenstadium (Keim- bzw. Laubbätter) beschränkt (Pongam et al., 1998; Balesdent et al., 2001; Rouxel \& Balesdent, 2005). Die Infektion sowie Ausbildung von Blattsymptomen wird verhindert, falls angreifende Pathogenrassen über Avirulenzgene $\left(A v r L m_{x}\right)$ verfügen, die den Resistenzgenen $\left(R m_{x}\right)$ von Raps entsprechen. Hierbei handelt es sich um eine rassenspezifische, qualitative, durch Hypersensitivität bedingte Resistenz, die sehr effektiv ist, solange vorwiegend avirulente Pathogenrassen vorhanden sind (AnsanMelayah et al., 1998). Eine weit verbreitete Nutzung spezifischer Resistenzgene erhöht allerdings auch den Selektionsdruck virulenter Pathogenrassen, die keine korrespondierenden Avirulenzgene aufweisen. Untersuchungen aus Frankreich (Rouxel et al., 2003) sowie Australien (Li et al., 2003, 2004; Sprague et al., 2006) belegen, dass Majorresistenz gegenüber $P$. lingam binnen weniger Jahre gebrochen werden kann.

Polygene, quantitative Resistenz operiert erst nach einer erfolgreichen Infektion von P. lingam. Das systemische Wachstum vom Blattstiel in den Wurzelhals wird gehemmt, wodurch es letztlich zu einer geringeren Ausbildung von Wurzelhalsnekrosen kommt (Ferreira et al., 1995; Pilet et al., 1998; Rouxel et al., 2003; Huang et al., 2009). Über zugrunde liegende Mechanismen dieser partiellen, quantitativen Resistenz herrscht nach wie vor Unklarheit. Als mögliche Ursachen werden Zellwandauflagerungen durch Lignin und 
Kallose, Kambiumbildung (Hammond \& Lewis, 1987a) sowie die Akkumulation von Calcium (Hammond \& Lewis, 1986a) und Phytoalexinen (Rouxel et al., 1991; Pfähler, 1998) genannt. Das Risiko eines Bruchs polygener Sortenresistenz wird allgemein als weniger wahrscheinlich angesehen als das der monogenen Resistenz. Die Sorte Jet Neuf (Zulassungsjahr 1977) wird hierbei häufig als Musterbeispiel für eine Sorte angeführt, deren quantitative Resistenz auch nach langjährigem Anbau Bestand hatte und auch heute noch in vielen Sorten implementiert ist (Rimmer \& van den Berg, 1992; Pilet et al., 1998; Rouxel \& Balesdent, 2005). Bei der im Sortenversuch 2007/2008 mit getesteten Sorte Aviso (BSL 3) handelt es sich ebenfalls um eine Sorte mit stabiler, vergleichsweise hoher quantitativer Resistenz. Den mit Abstand geringsten Phoma-Befall wies die Sorte Caiman (BSL 2) auf, deren Resistenz nach Angaben von Cetiom (Anonymus, 2008 c) ausschließlich auf dem Majorresistenzgen LmR7 basiert. Vereinzelt in den Versuchsparzellen zu beobachtende Blattsymptome deuten darauf hin, dass es bereits einige Pathogenrassen gibt, die von dieser Resistenz nicht erfasst werden. Ahlers (2008) isolierte einige dieser Pathogenrassen (avr7) und führte anschließend Inokulationsstudien an wundinokulierten Keimblättern, Laubblättern sowie Blattstielen durch. Hierbei waren avr7-Isolate lediglich in der Lage, Symptome an Keimblättern hervorzurufen. Neben der Erkenntnis einer organspezifischen Interaktion, die auch von anderen Autoren beschrieben wurde (Kutscher et al., 1993; Kuswinanti, 1996), weisen diese Untersuchungen darauf hin, dass die Resistenz von Caiman nicht ausschließlich auf Majorgenresistenz, sondern möglicherweise auch auf quantitativer Resistenz beruht.

In einigen Versuchsvarianten des Sortenversuchs wurden Phoma-Inokulationen durchgeführt, um den Befallsdruck gegenüber natürlichem Befall zu erhöhen. Im Herbst (BBCH 15) in den ersten beiden Versuchsjahren erfolgte Sprühinokulationen des Wurzelhalses führten bei den Sorten Lion (BSL 6), Oase (BSL 5) sowie Viking (BSL 5) zu einer signifikanten Erhöhung des Wurzelhalsbefalls im Vergleich zu einer nicht inokulierten Kontrolle. Befallswerterhöhungen variierten zwischen 0,6 und 1. Bei der Sorte Caiman (BSL 2) waren in beiden Versuchsjahren keine Inokulationseffekte festzustellen. Ergebnisse dieser Versuche stimmen mit Untersuchungen von Ndimande (1976) überein, wonach Pyknidiosporen, die zum Wurzelhals gespült werden, zu einer direkten Infektion des Wurzelhalses führen können. Die trotz Verwendung besonders aggressiver Isolate relativ geringe Befallswerterhöhung zeigt allerdings auch die Grenzen des Inokulationserfolges auf. Ein möglicher Grund könnte die im Vergleich zu Ascosporen vergleichsweise geringe Infektiösität von Pyknidiosporen sein (Wood \& Barbetti, 1977; Hammond \& Lewis, 1987b; Li et al., 2006). Im Gegensatz zu Ascosporen, die über die Stomata infizieren können, ist das Vorhandensein von Wunden 
nach Aussagen von Hammond et al. (1985) sowie Huang et al. (2003) häufig Voraussetzung für eine erfolgreiche Infektion mit Pyknidiosporen. Nach Untersuchungen von Vanniasingham \& Gilligan (1988) setzt eine Infektion mit Pyknidiosporen zudem eine mindestens sechzehnstündige Feuchteperide voraus und vollzieht sich optimalerweise in einem Temperaturbereich von 20 bis $25^{\circ} \mathrm{C}$. Zum Zeitpunkt der Inokulation lagen Temperaturen in einem Bereich von 10 bis $12^{\circ} \mathrm{C}$. Diese suboptimalen Bedingungen haben möglicherweise $\mathrm{zu}$ einer geringen Infektionsrate beigetragen.

Im Rahmen des Sortenversuchs ließen sich in einem Versuchsjahr auch Inokulationseffekte nach einer Bodeninokulation mit Verticillium-befallenem Stoppelmaterial erkennen. Stoppelinokulierte Varianten der Sorten Lion sowie Laser verzeichneten im Versuchsjahr 2006/2007 signifikant höhere Phoma-Befallswerte als vergleichbare Kontrollvarianten. BW am Wurzelhals waren um bis zu 1,8 (Sorte Lion) erhöht. Bereits im Herbst wiesen 15\% der zur Kohlfliegenbonitur entnommenen Pflanzen der Sorte Lion Wurzelhalsnekrosen auf, was auf eine frühe direkte Hypokotylinfektion schließen lässt. Direkte Jungpflanzeninfektionen des Hypokotyls gelten als Hauptgrund massiver Pflanzen ausfälle in Australien, während die Bedeutung in Europa als gering angesehen wird (West et al., 2001). Die größere Relevanz dieses Infektionsweges in Australien wird neben einem stärkeren Ascosporenflug u. a. damit begründet, dass trockene Witterungsverhältnisse, insbesondere in West-Australien, den Abbau von Inokulummaterial im Boden verzögern, so dass selbst nach einer mehrjährigen Anbaupause noch mit infektiösem Stoppelmaterial zu rechnen ist (Barbetti \& Khangura, 1999; Fitt et al., 2006; Sosnowski et al., 2006). Unter europäischen Verhältnissen nimmt das Inokulumpotenzial bereits nach einem Jahr stark ab (West et al., 2001; Huang et al., 2003; Fitt et al., 2006). Im Sortenversuch waren in den Versuchsjahren 2005/2006 sowie 2007/2008 keine mit 2006/2007 vergleichbaren Inokulationseffekte nach einer Stoppelinokulation zu beobachten. Als möglicher Grund könnte hier das Alter des verwendeten Materials angeführt werden. Während im Versuchsjahr 2006/2007 Stoppelmaterial herangezogen wurde, welches aus der Ernte 2006 stammte, wurde in den anderen beiden Jahren jeweils Inokulummaterial vom Vorjahr verwendet. Die einjährige Lagerung hat hierbei möglicherweise zu einer Abnahme des Inokulumpotenzials geführt, auch wenn keine Stoppelrotte erfolgte.

Die Wurzelhals- und Stängelfäule ist eine weltweit verbreitete Rapskrankheit, deren jährliche Ertragsverluste sich nach Schätzung von Fitt et al. (2008) auf einen monetären Wert von über 900 Mio. US \$ beziffern lassen. Dem Wurzelhalsbefall wird dabei die größte Bedeutung zugeschrieben, da er neben den bereits erwähnten massiven Ausfällen im Jungpflanzen- 
stadium (Salisbury et al., 1995; Khangura \& Barbetti, 1999) auch bei späterer Symptomausprägung zu Lager, Stängelbruch und einer vorzeitigen Abreife führen kann (Hall, 1992; Fitt et al., 1999; West et al., 2001; Fitt et al., 2006). Angaben über Phoma-bedingte Ertragseinbußen reichen von 5-56\%, wobei geschätzte bzw. errechnete Verlustwerte in den meisten Fällen zwischen 5 und 20\% liegen (Cook \& Evans, 1978; Petrie, 1985; Hall, 1992; Gugel \& Petrie, 1992; West et al., 2001). Insbesondere bei frühem, massiven Blattbefall im Herbst und anhaltend warmfeuchten Witterungsbedingungen kann es zu erheblichen Ertragsverlusten kommen, weil $P$. lingam dann optimale Bedingungen vorfindet, um systemisch über den Blattstiel bis zum Wurzelhals vorzudringen (Fitt et al., 1999; West et al., 2001; Wherrett et al., 2004). Ein starker Blattbefall resultiert aber nicht immer in starkem Wurzelhalsbefall im Frühjahr, so dass dieser Parameter keine Prognose des zu erwartenden Ertragsausfalls erlaubt. Zuverlässige Befalls-Verlustrelationen sind erst wenige Wochen vor der Ernte möglich, wenn das Ausmaß des Wurzelhalsbefalls und die damit verbundenen Notreifeerscheinungen sichtbar geworden sind (Thürwächter, 1995; Zhou et al., 1999). Zu erwartende Ertragsverluste sind dabei umso stärker, je höher der Anteil stark befallener Pflanzen ist (McGee \& Emmett, 1977; Hall, 1992; Zhou et al., 1999; West et al., 2001).

In eigenen Feldversuchen lagen mittlere BW am Wurzelhals zwischen 1,8 und 5. Signifikante Ertragsunterschiede zwischen den Kontrollen und inokulierten Varianten ließen sich nicht feststellen. Aufgrund unterlassener Fungizidapplikationen trat auch in den Kontrollparzellen moderater Phoma-Befall auf, so dass eine Ertragswirkung von P. lingam nicht gänzlich ausgeschlossen werden kann. Das insgesamt niedrige Befallsniveau deutet jedoch darauf hin, dass $P$. lingam, wenn überhaupt, nur einen geringen Einfluss auf den Ertrag ausgeübt hat.

\subsection{Einfluss von Kohlfliegenbefall auf die Infektion und Schadwirkung von P. lingam}

Bei P. lingam handelt es sich um ein Pathogen, dessen Auftreten durch Wunden stark gefördert wird. Infektionen von Ascosporen über die Stomata sind zwar möglich (Hammond et al., 1985), eine mechanische Verletzung führt jedoch auch hier zu einer deutlichen Erhöhung von BH und Befallsstärke (Brunin \& Lacoste, 1970). Eine hohe Infektionsrate mit Pyknidiosporen setzt i. d. R. Wunden voraus (Hammond et al., 1985; Huang et al., 2003), so dass eine mechanische Verletzung zur Überprüfung von Sortenresistenz bzw. Isolat-Virulenz obligatorisch ist (Rimmer \& van den Berg, 1992). Unter Feldbedingungen können mechanische Verletzungen, die in einem stärkeren Phoma-Befall resultieren, u. a. durch Starkwinde 
(Barbetti \& Khangura, 1999), Frost- bzw. Wachstumsrisse (Heitefuss et al., 2000), Herbizidschäden (Petrie, 1973) oder tierische Schadorganismen hervorgerufen werden.

Zahlreiche Untersuchungen haben einen positiven Zusammenhang zwischen stängelminierenden Schadinsekten (Großer Rapsstängelrüssler, Gefleckter Kohltriebrüssler, Rapserdfloh) und Phoma-Befall am Stängel feststellen können (Ndimande, 1976; Krüger, 1982; Newman \& Plumridge, 1983; Schulz \& Daebeler, 1984; Newman, 1984; Schulz, 1992; Ulber, 1994; Hartleb et al., 1998). Die Förderung von P. lingam wurde in den Untersuchungen vornehmlich auf Larvenfraßgänge im Stängel sowie Ein- und Ausbohrlöcher zurückgeführt. Versuche von Krause et al. (2007) haben zudem nachweisen können, dass der Große Rapsstängelrüssler Phoma-Befall nicht nur durch die Schaffung von Eintrittspforten, sondern auch direkt als Vektor begünstigen kann. Neben einer Förderung von Stängelbefall wird Larvenfraß des Rapserdflohs auch mit einer Erhöhung von Phoma-Wurzelhalsbefall in Verbindung gebracht (Newman, 1984; Plumridge \& Newman, 1983; Schulz \& Daebeler, 1984). In von Newman (1984) angelegten Versuchen führte eine Kontrolle des Rapserdflohs mit Insektiziden zu einer deutlichen Verringerung des Phoma-Wurzelhalsbefalls.

Über die Bedeutung von Larvenfraß der Kohlfliege für den Befall von Raps mit P. lingam liegen bis dato noch keine Untersuchungsergebnisse vor. Die einzige Quelle, in der auf einen Zusammenhang hingewiesen wird, datiert aus dem Jahr 1907 (Quanjer, 1907) und bezieht sich auf Kohl. Als Ergebnis zweijähriger Studien in Nord-Holland kommt der Autor zu dem Schluss, dass Larvenfraß der Kohlfliege Hauptursache der im Jungpflanzenstadium auftretenden durch Phoma-bedingten „Fallsucht“ ist, die massive Pflanzenausfälle zur Folge haben kann. Quanjer sieht die Rolle von Kohlfliegenbefall in einer Prädisposition für $P$. lingam, indem die Pflanze durch Larvenfraß geschwächt und gleichzeitig durch die Schaffung von Eintrittspforten stärker infiziert wird. Bei $P$. lingam handelt es sich nach Quanjer um einen Schwächeparasiten, der nicht in der Lage ist, junge „energisch wachsende Individuen“ ohne das Vorhandensein von Wunden, hervorgerufen durch die Kohlfliege, oder durch das Umpflanzen, zu infizieren. Vom Befallskomplex Kohlfliege/P.lingam, der zur Fallsucht führt, sind nach Aussagen Quanjers insbesondere solche Kohlarten betroffen, die über ein schwach ausgebildetes Wurzelsystem verfügen. Quanjer bemerkt dazu folgendes: „Im Kampfe zwischen dem Pilz, der durch die Wundstellen einzudringen versucht und der Pflanze, die durch Wundgewebe und Adventivwurzeln zu verteidigen sich bestrebt, trägt der Wirsing den Sieg davon, während die besonders empfindlichen Rassen des Rotkrauts und des Blumenkohls unterliegen. “ 
In eigenen Versuchen ließ sich in Übereinstimmung mit der von Quanjer (1907) durchgeführten Studie an Kohl ebenfalls eine Förderung von Phoma-Wurzelhalsbefall durch die Kohlfliege an Raps feststellen, wobei allerdings keine vergleichbar hohe Schadwirkung (Fallsucht) auftrat. Aus den Feldversuchsergebnissen der ersten beiden Versuchsjahre konnten aufgrund eines indifferent hohen Kohlfliegenbefalls (2005/2006) bzw. nicht genau quantifizierbarer Netzeffekte (2006/2007) keine eindeutigen Aussagen abgeleitet werden, inwieweit es durch Kohlfliegenbefall zu einer Förderung von P. lingam kam. Erst die mit Hilfe des insektiziden Saatgutbehandlungsmittels Oftanol $\mathrm{T}$ im dritten Versuchsjahr (2007/2008) erreichte Abstufung des Kohlfliegenbefalls erlaubte unverzerrte Analysen. In der Variante „ohne Netz/Oftanol + Nexion Neu“, bei der Kohlfliegenbefall im Herbst gegenüber der Variante „ohne Netz/Chinook“ Variante um etwa 50\% verringert werden konnte, ging die Reduktion des Kohlfliegenbefalls bei den Sorten Lion, Laser und NK Fair mit einer signifikanten Senkung der BW am Wurzelhals einher. Bei der weniger anfälligen Sorte Aviso waren nur tendenzielle Effekte, bei Caiman wie in den Vorjahren keine Effekte festzustellen. Eine differenzierte Analyse verschiedener Fraßschädigungskategorien (ohne Larvenfraß; Larvenfraß an Wurzel; Larvenfraß an Wurzel + Hypokotyl) konnte dabei eindeutig aufzeigen, dass Larvenfraß am Hypokotyl mit Ausnahme der Sorte Caiman bei allen anderen Sorten zu einer signifikanten Erhöhung des Phoma-Wurzelhalsbefalls gegenüber nicht oder nur im Wurzelbereich geschädigten Pflanzen führte. Die stärkste Befallsförderung war bei der anfälligen Sorte Lion, die geringsten Effekte bei der weniger anfälligen Sorte Aviso festzustellen. Dieses Ergebnis weist auf eine von der Sortenanfälligkeit abhängige Befallsförderung hin.

Vorliegende Untersuchungsergebnisse zeigen, dass es insbesondere durch Larvenfraß am Hypokotyl zu einer Förderung von Phoma-Befall kommen kann. Larvenfraß am Wurzelbereichs spielt offenbar eine untergeordnete Rolle, auch wenn Studien von Sosnowski et al. (2001) sowie Sprague et al. (2007) belegen, dass P. lingam in der Lage ist, verletzte Wurzeln zu infizieren. Darüber hinaus erbrachte Sprague et al. (2007) den Nachweis, dass P. lingam von inokulierten Blattstielen aus systemisch über den Hypokotylbereich bis in die Wurzel vordringen kann. Im Gegensatz zum Hypokotyl, wo eine verstärkte Hyphenbesiedlung äußerer Gewebebereiche $\mathrm{zu}$ beobachten war, blieb das Wachstum von P. lingam im Wurzelbereich im Wesentlichen auf das Xylem beschränkt. Anatomische Gewebeunterschiede, u. a. ein stärker ausgebildetes sekundäres Phloem im Wurzelbereich, wurden hier als möglicher Grund der geringen Besiedlung angeführt. In eigenen Versuchen ließen sich im 
Untersuchungszeitraum (2005-2008) lediglich an fünf bonitierten Pflanzen PhomaSymptome im Hauptwurzelbereich erkennen. Die Symptome traten dabei jeweils in fraßgeschädigtem Gewebe auf. Diese Beobachtungen stimmen mit den von Sosnowski et al. (2001) und Sprague et al. (2007) durchgeführten Studien darin überein, dass P. lingam prinzipiell in der Lage ist, Raps über verletzte Wurzeln zu infizieren. Fraglich ist in diesem Zusammenhang, warum das Symptombild nicht häufiger zu beobachten war. Ein möglicher Grund könnte die fehlende Koinzidenz zwischen Wurzelverletzung und dem Vorhandensein von ausreichend Inokulum in unmittelbarer Nähe sein. In den o. a. Inokulationsstudien von Sosnowski et al. (2001) wurden Pyknidiosporen direkt in mechanisch verletzte Wurzeln inokuliert. Unter Feldbedingungen kommen Wurzeln allerdings nur dann mit einer größeren Menge Inokulum in Kontakt, wenn das Inokulum bereits im Boden in Form von infektiösem Stoppelmaterial vorliegt, da eine Einwaschung von Ascosporen- oder Pyknidiosporen über den Hypokotylbereich hinaus eher unwahrscheinlich ist. Aufgrund der bereits erwähnten zügigen Stoppelrotte ist unter europäischen Verhältnissen nach einer für Raps üblichen Anbaupause von zwei bis drei Jahren i. d. R. nicht mehr mit einem hohen Bodeninokulumpotenzial zu rechnen (West et al., 2001; Huang et al., 2003; Fitt et al., 2006).

Ergebnisse ergänzend durchgeführter Gewächshausuntersuchungen decken sich mit den Beobachtungen der Feldversuche. Unverletzte, mechanisch beschädigte oder durch Larvenfraß der Kohlfliege geschädigte Varianten der Sorten Oase (BSL 5) und Caiman (BSL 2) wurden zu BBCH 55 mit einem Isolatgemisch aggressiver bzw. nicht aggressiver Phoma-Isolate oberhalb des Wurzelhalses inokuliert. Eine stärkere Symptomausprägung war erwartungsgemäß nur bei einer Inokulation aggressiver Isolate $\mathrm{zu}$ verzeichnen. Die mechanische Verletzungsvariante, sowie Larvenfraß der Kohlfliege, führten bei der Sorte Oase zu einem deutlichen Anstieg von BH und Befallsstärke gegenüber der nicht verletzten Variante. Bei der Sorte Caiman ließen sich keine Symptome feststellen, was darauf hindeutet, dass eine Resistenz gegenüber den verwendeten Isolaten vorliegt, die nicht nur auf das Keimbzw. Laubblatt beschränkt ist, sondern offenbar auch am Wurzelhals operiert. In diesem Zusammenhang stellt sich die Frage, ob die Resistenz am Wurzelhals bei Caiman tatsächlich auf unspezifischen, partiellen Resistenzmechanismen beruht, oder ob hier möglicherweise auch eine vollständige Resistenz vorliegt, wie sie von Roy (1984) sowie Rimmer \& van den Berg (1992) für Brassica juncea bzw. Brassica carinata beschrieben worden ist.

Ergebnisse der Feld- und Gewächshausversuche haben übereinstimmend darlegen können, dass Larvenfraß am Hypokotyl den Phoma-Wurzelhalsbefall direkt begünstigen kann. Das 
Risiko eines Kohlfliegenbefalls hängt demnach maßgeblich vom Anteil der am Hypokotyl geschädigter Pflanzen ab. Der von Hammond et al. (1985) beschriebene systemische Infektionsweg von befallenen Blättern über den Blattstiel zum Wurzelhals bleibt von der Kohlfliege auf den ersten Blick unbeeinflusst. Anhand vorliegender Untersuchungsergebnisse kann allerdings nicht gänzlich ausgeschlossen werden, dass systemisch bedingte Wurzelhalsnekrosen durch Kohlfliegenbefall indirekt gefördert werden. Zur Klärung der Frage, ob Larvenfraß am Hypokotyl die Entwicklung und Ausprägung systemisch bedingter Wurzelhalsnekrosen indirekt begünstigt, sind weitere Gewächshausversuche erforderlich, in denen die Rolle von Kohlfliegenbefall nach Inokulation von Blattstielen untersucht wird. 


\section{Schlussfolgerungen}

Vorliegende Untersuchungsergebnisse belegen, dass Kohlfliegenbefall neben den Hauptrisikofaktoren Inokulum, Sortenanfälligkeit und Jahr ein weiterer Risikofaktor für die Infektion und Schadwirkung von $V$. longisporum und $P$. lingam an Raps ist. Vor dem Hintergrund fehlender bzw. unzureichender direkter Kontrollmöglichkeiten stehen dem Landwirt hier allerdings nur wenige Instrumente (Fruchtfolge, Sortenwahl) zur Verfügung, um das Befallsrisiko beteiligter Schaderreger zu begrenzen. Eine effektive Bekämpfung von Kohlfliegenlarven ist momentan nicht möglich. Da eine Befallsförderung von $V$. longisporum und $P$. lingam bereits bei geringem Larvenfraß auftritt, reicht eine alleinige Reduktion des Starkbefalls mit derzeit zur Verfügung stehenden insektiziden Saatgutbehandlungsmitteln hier nicht aus. Ziel muss es daher sein, den Anteil der durch Larvenfraß geschädigten Pflanzen insgesamt zu senken. Beobachtungen aus der Praxis sowie eigene Untersuchungen haben gezeigt, dass Frühsaaten (Saattermin vor dem 20. August) häufig stärker durch die Kohlfliege geschädigt werden als später gesäte Bestände, da größere Pflanzen bei der Eiablage bevorzugt werden. Zudem belegen die Versuchsergebnisse, dass eine frühe Aussaat VerticilliumBefall sowohl indirekt (über erhöhten Kohlfliegenbefall), als auch direkt (über günstigere Infektionsbedingungen) fördert. Mit der Wahl des Saattermins steht dem Landwirt daher ein Instrument zur Verringerung des Risikos beider Schaderreger zur Verfügung. Gleichzeitig wird damit auch das Risiko von Larvenfraß am Wurzelhals, der den Phoma-Befall begünstigt, gesenkt. Unter der Voraussetzung, dass Betriebsablauf sowie Feldarbeitstage einen gewissen Spielraum zulassen, sollten deshalb extreme Frühsaaten in der ersten Augusthälfte möglichst vermieden werden, da sie sowohl den direkten Kohlfliegenschaden, wie auch das Risiko von Verticillium- und Phoma-Infektionen im Herbst erhöhen. 


\section{Zusammenfassung}

Im Rahmen der vorliegenden Arbeit wurde der Einfluss von Kohlfliegenbefall auf die Infektion und Schadwirkung von $V$. longisporum und $P$. lingam an Raps untersucht. Es sollte überprüft werden, ob Wurzelfraß durch Larven der Kohlfliege einen bodenbürtigen Pilz wie $V$. longisporum, der Raps über die Wurzel infiziert, begünstigen. In Feld-, Halbfreilandsowie Gewächshausversuchen wurden die Faktoren Kohlfliegenbefall, Sortenanfälligkeit (gegenüber $V$. longisporum), Bodeninokulum, Saattermin sowie Bodenbearbeitung variiert, um neben der Identifizierung von Interaktionseffekten auch der Frage nachgehen zu können, welche Determinanten hierbei eine Rolle spielen. Neben visuellen Befallsbonituren dienten Nachweismethoden (ELISA, Real-Time PCR) für $V$. longisporum in der Rapspflanze dazu, Schadwirkungen beteiligter Schaderreger in Abhängigkeit von befallsdynamischen Aspekten (Zeitpunkt, Stärke und Ausbreitung des Pathogens) beurteilen zu können. Zur Untersuchung der Interaktionen wurden Gewächshausversuche $\mathrm{zu}$ den möglichen zugrunde liegenden Mechanismen durchgeführt, anhand derer die Bedeutung lokaler Wundeffekte bzw. pflanzenphysiologischer Effekte abgeschätzt werden konnte. Abgesehen von Untersuchungen, die auf den Schaderregerkomplex Kohlfliege/Verticillium ausgerichtet waren, wurde zusätzlich überprüft, ob Larvenfraß der Kohlfliege auch Auswirkungen auf den Befall von Raps mit $P$. lingam, den Erreger der Wurzelhals- und Stängelfäule, hat. Die Ergebnisse lassen sich wie folgt zusammenfassen:

An den Feldversuchsstandorten wurde Kohlfliegenbefall mit Hilfe von Insektiziden bzw. Kulturschutznetzen abgestuft. Zwischen den insektiziden Saatgutbehandlungsmitteln Elado und Chinook traten bei hohem Befallsdruck lediglich geringe Unterschiede im Starkbefall auf. Im Gegensatz dazu ließen sich mit dem Präparat Oftanol T sowohl Häufigkeit als auch Stärke des Kohlfliegenbefalls gegenüber Chinook um etwa 50\% reduzieren. Mit Kulturschutznetzen konnte Kohlfliegenbefall effektiv ausgeschlossen werden. Durch den Vergleich verschiedener Netzabdeckungsvarianten (ohne Netz, Netz im Herbst, Netz im Herbst + Frühjahr) war es hier zudem möglich, auch die Bedeutung von Larvenfraß im Herbst bzw. Frühjahr differenziert zu betrachten.

Im Rahmen von Anbaufaktorenversuchen wurden die Auswirkungen von Saattermin- und Bodenbearbeitungsvarianten auf Kohlfliegenbefall untersucht. Nach einer frühen Aussaat (Saattermin vor dem 20. August) wiesen im Untersuchungszeitraum 2005-2007 durchschnittlich $60-70 \%$ der untersuchten Wurzeln Kohlfliegenbefall im Herbst auf, während bei 
einer späteren Aussaat (Ende August) maximal 20\% der Wurzeln Fraßschädigungen aufzeigten. Diese Ergebnisse decken sich mit anderen Untersuchungen, die darauf hinweisen, dass größere Pflanzen bei der Eiablage bevorzugt werden. Ein teilweise nach einer Pflugsaat gegenüber einer Grubbersaat zu beobachtender stärkerer Kohlfliegenbefall ließ sich ebenfalls auf eine zügigere Herbstentwicklung und eine damit verbundene höhere Attraktivität bei der Eiablage zurückführen.

Kohlfliegenbefall wurde in den Halbfreilandversuchen sowie im Gewächshaus durch das Ansetzen von Kohlfliegeneiern an den Wurzelhals gezielt gesteuert. Nahezu alle mit Kohlfliegeneiern besetze Pflanzen wiesen Larvenfraß auf, wo hingegen Varianten ohne Besatz nur selten geschädigt wurden. Schadeffekte eines alleinigen Kohlfliegenbefalls (ohne Pathogenbefall) traten lediglich in einem Gewächshausversuch auf, bei dem die Fraßschädigung mit durchschnittlich 69\% geschädigter Wurzeloberfläche auf einem sehr hohen Niveau lag.

Befall und Schadwirkung von $V$. longisporum wurden maßgeblich durch die Faktoren Bodeninokulum, Sortenanfälligkeit, Saattermin und Jahr bestimmt. Die Verticillium-Befallsparameter stiegen mit zunehmenden Bodeninokulum deutlich an. Die höchsten Befallswerte waren bei der Sorte Laser, die geringsten bei der Rapslinie Sem 05-500256 zu verzeichnen. Unter Gewächshausbedingungen wies Sem gegenüber einer moderat anfälligen Sorte (Express) sowohl nach einer Bodeninokulation, als auch nach einer direkten Inokulation des Stängels, signifikant geringere Mengen an Verticillium-DNA im Pflanzengewebe auf. Diese Untersuchungsergebnisse liefern deutliche Hinweise, dass die zugrunde liegenden Resistenzmechanismen nicht ausschließlich auf den Wurzel- und Hypokotylbereich beschränkt sind, sondern offenbar auch im Sprossbereich operieren.

Als weiterer Risikofaktor von $V$. longisporum wurde eine frühe Aussaat im Herbst identifiziert. Frühe Aussaattermine in der ersten Augusthälfte zeigten im Vergleich zu einer späteren Aussaat Ende August signifikant höheren Verticillium-Befall zur Ernte an. Dieser Effekt konnte sowohl bei Varianten mit hohem, als auch bei Varianten mit niedrigem Kohlfliegenbefall festgestellt werden. Eine durch die Frühsaat bedingte Verlängerung des Infektionszeitraumes im Herbst wurde hierbei als möglicher Grund höheren VerticilliumBefalls in Betracht gezogen.

Beim Vergleich einzelner Versuchsjahre (2005-2008) fiel auf, dass Auftreten und Stärke des Verticillium-Befalls nicht nur von den Faktoren Bodeninokulum, Sorte und Saattermin 
bestimmt wurde, sondern auch von Jahreseffekten abhing. Im zweiten Versuchsjahr (2006/2007), welches durch eine außergewöhnlich milde Witterung geprägt war, lagen Befallsparameter deutlich über denen der anderen Versuchsjahre. Zudem kam es hier zu einer vergleichsweise frühen Ausbildung von Symptomen. Auf Verticillium-Befall zurückzuführende Ertragsverluste traten ebenfalls nur im Versuchsjahr 2006/2007 auf. Die stoppelinokulierte Variante der Sorte Laser, bei der bereits vier Wochen vor der Ernte etwa 50\% der Pflanzen starke Verticillium-Symptome und Notreifeerscheinungen aufwiesen, verzeichnete gegenüber der Kontrollvariante einen um etwa 20\% niedrigeren Ertrag. Bei der Sorte Lion, wo vier Wochen vor der Ernte 18\% der Pflanzen Mikrosklerotienbesatz anzeigten, waren keine signifikanten Ertragseffekte eines Verticillium-Befalls auszumachen, obgleich der Anteil symptomatischer Pflanzen bis zur Ernte deutlich zunahm. Der unterschiedliche Befallsverlauf der Sorten Laser und Lion weist darauf hin, dass die Schadwirkung eines Verticillium-Befalls nicht nur von den Parametern Befallshäufigkeit und Befallsstärke bestimmt wird, sondern auch entscheidend von der Dynamik des Befalls abhängt.

Im Vergleich zu einem erst spät erkennbaren Krankheitsbild von $V$. longisporum im Feld zeigten sich unter kontrollierten Gewächshausbedingungen bereits früh charakteristische Symptome. Zeitpunkt und Ausmaß der Symptomausprägung hing maßgeblich von der mittels Real-Time PCR erfassten Ausbreitungsdynamik von V. longisporum in der Pflanze ab, die zwischen Inokulationsmethoden, Sorten und der Höhe des Bodeninokulums differierte. In den Versuchen wurden eine Reihe von pflanzenmorphologischen Parametern erhoben, um Schadeffekte identifizieren zu können. Das Ausmaß der Schadeffekte ließ sich relativ gut mit Variantenunterschieden in Befallsdynamik und Symptomausprägung in Übereinstimmung bringen. Effekte waren umso höher, je früher und stärker die Besiedlung und Symptomausprägung einsetzte.

Im Rahmen von Feld-, Freiland- sowie Gewächshausversuchen konnte nachgewiesen werden, dass Kohlfliegenbefall die Infektion, Besiedlung, Symptomausprägung und Schadwirkung von $V$. longisporum an Raps erhöhen kann. Die Bedeutung von Kohlfliegenbefall für $V$. longisporum hängt dabei maßgeblich von dem Entwicklungsstadium der Pflanze, der Sortenanfälligkeit (gegenüber $V$. longisporum) und der Bodeninokulumhöhe ab. Befallsfördernde Effekte eines Kohlfliegenbefalls sind insbesondere dann zu erwarten, wenn Wurzelfraß bereits im Jungpflanzenstadium auftritt. Kohlfliegenbefall im Frühjahr, bei dem Winterraps ab dem Blütenstadium geschädigt wird, spielt nach eigenen Untersuchungen eine untergeordnete Rolle in der Befallsförderung. Während Kohlfliegenbefall bei Sorten mit 
moderater bzw. geringer Verticillium-Anfälligkeit zu einer deutlichen Erhöhung des Verticillium-Befalls führte, waren bei der hoch anfälligen Sorte Laser keine vergleichbaren Effekte festzustellen. Die stärkste Befallsförderung trat bei der resistenten Rapslinie Sem 05500256 auf. Die im Pflanzengewebe quantifizierten Mengen an Verticillium-DNA wurden hier durch Kohlfliegenbefall um durchschnittlich 200\% erhöht, was insbesondere auf eine verstärkte Besiedlung des Wurzel- und Hypokotylbereichs zurückzuführen war. Die Besiedlung des Sprossbereichs, ein wichtiges Kriterium für Verticillium-Resistenz, lag jedoch nach wie vor auf einem relativ niedrigen Niveau, was darauf hindeutet, dass Kohlfliegenbefall zu einer deutlichen Abschwächung, nicht jedoch $\mathrm{zu}$ einer vollständigen Aufhebung von Sortenresistenz führt.

Die Untersuchungsergebnisse weisen darauf hin, dass es Wechselwirkungen zwischen Kohlfliegenbefall und dem Bodeninokulum gibt, die sich in unterschiedlichem Maße auf die Parameter Befallshäufigkeit und Besiedlungsstärke auswirken. Die Wahrscheinlichkeit einer Symptomexpression (Befallshäufigkeit) wird durch Kohlfliegenbefall insbesondere bei geringem bis mittleren Bodeninokulum erhöht, während die Besiedlungsstärke bei hohem Bodeninokulum stärker begünstigt wird.

Im Rahmen der vorliegenden Arbeit wurden Schadeffekte von Kohlfliegen- und VerticilliumBefall sowohl getrennt, als auch zusammen untersucht, um mögliche synergistische Interaktionsbeziehungen identifizieren zu können. Aus den Feldversuchen ließen sich keine eindeutigen Schlüsse ziehen, ob es zu einer synergistischen Schadwirkung von Kohlfliegenund Verticillium-Befall gekommen ist. Unter Gewächshausbedingungen waren i. d. R. keine Schadeffekte eines alleinigen Kohlfliegenbefalls zu registrieren. Die pflanzenmorphologischen Auswirkungen eines alleinigen Verticillium-Befalls hingen von der Stärke und Dynamik des Befalls, die zwischen Sorten und Bodeninokulmmengen differierte, ab. Das gleichzeitige Vorhandensein beider Schaderreger (Kohlfliegenbefall + Verticillium) hatte eine verstärkte Besiedlung des Pflanzengewebes zur Folge, wodurch Schadeffekte i. d. R. zunahmen. Synergistische Schadeffekte waren dabei umso höher, je stärker Befallsdynamik und Besiedlungsstärke von $V$. longisporum durch Kohlfliegenbefall gefördert wurden.

Im Rahmen von Interaktionsstudien wurde der Frage nachgegangen, ob die durch Kohlfliegenbefall bedingte Förderung von $V$. longisporum im Wesentlichen auf lokale Wundeffekte und/oder pflanzenphysiologische Effekte zurückzuführen ist. Die Versuche konnten dabei übereinstimmend zeigen, dass eine deutliche Befallsförderung lediglich bei 
räumlichen Zusammentreffen beider Schaderreger (Kohlfliege $+V$. longisporum) gegeben ist. Bei räumlicher Trennung beider Schaderreger ließen sich hingegen keine (Wurzelteilungsversuch) oder nur sehr geringe (Stängelinokulationsversuch) Befallseffekte feststellen. Die Untersuchungsergebnisse lassen deshalb den Schluss zu, dass die Begünstigung von $V$. longisporum durch Kohlfliegenbefall insbesondere lokalen Wundeffekten zuzuschreiben ist.

In Feld- und Gewächshausversuchen wurde untersucht, ob Larvenfraß der Kohlfliege auch Auswirkungen auf den Befall von Raps mit P. lingam hat. Ergebnisse der Phoma-Befallsbonitur wiesen auf ein moderates Befallsniveau hin. Je nach Sorte bzw. Inokulationsvariante variierten mittlere Befallswerte am Wurzelhals- und Stängel zwischen 1,8 und 5. Festgestellte Sortenunterschiede entsprachen der Anfälligkeitseinstufung nach Bundessortenliste (BSL 1-9). Nach einer Sprüh- bzw. Stoppelinokulation ließen sich bei einigen Sorten Inokulationseffekte erkennen, wobei das niedrige Befallsniveau der Sorte Caiman (BSL 2) unbeeinflusst blieb. Signifikante Ertragsunterschiede zwischen Kontrollen und inokulierten Varianten waren nicht festzustellen.

Ergebnisse der Feld- und Gewächshausversuche haben übereinstimmend darlegen können, dass Larvenfraß der Kohlfliege Phoma-Wurzelhalsbefall durch Wundeffekte direkt begünstigt. Eine differenzierte Analyse verschiedener Fraßschädigungskategorien (ohne Larvenfraß; Larvenfraß an Wurzel; Larvenfraß an Wurzel + Hypokotyl) konnte dabei aufzeigen, dass Larvenfraß am Hypokotyl mit Ausnahme der Sorte Caiman bei allen anderen geprüften Sorten zu einer signifikanten Erhöhung des Phoma-Wurzelhalsbefalls gegenüber nicht oder nur im Wurzelbereich geschädigten Pflanzen führte. Die stärkste Befallsförderung war bei der anfälligen Sorte Lion, die geringsten Effekte bei der weniger anfälligen Sorte Aviso festzustellen. Dieses Ergebnis weist auf eine von der Sortenanfälligkeit abhängige Befallsförderung hin. Darüber hinaus lassen die Untersuchungen die Vermutung zu, dass Larvenfraß im Wurzelbereich offenbar eine untergeordnete Rolle für die Ausprägung von Phoma-Symptomen spielen. Das Risiko eines Kohlfliegenbefalls für $P$. lingam hängt demnach maßgeblich vom Anteil der am Hypokotyl geschädigten Pflanzen ab.

Vorliegende Untersuchungsergebnisse haben gezeigt, dass Larvenfraß der Kohlfliege das Befallsrisiko von $V$. longisporum und P. lingam an Raps erhöht. Strategien zur Kontrolle beider Pathogene sollten deshalb nicht nur die Hauptrisikofaktoren Inokulum, Sortenanfälligkeit und Jahr sondern auch Kohlfliegenbefall mit berücksichtigen. Aufgrund fehlender bzw. 
unzureichender direkter Bekämpfungsmöglichkeiten beteiligter Schaderreger gewinnen vorbeugende Maßnahmen (Fruchtfolge, Sortenwahl) hier an Bedeutung. Nach unseren Untersuchungen steht dem Landwirt mit der Wahl des Aussaattermins ein weiteres Kontrollinstrument zur Verfügung. Unter der Voraussetzung, dass Betriebsablauf sowie Feldarbeitstage einen gewissen Spielraum zulassen, sollten deshalb extreme Frühsaaten in der ersten Augusthälfte möglichst vermieden werden, da sie sowohl den direkten Kohlfliegenschaden, wie auch das Risiko von Verticillium- und Phoma-Infektionen im Herbst erhöhen.

\section{Summary}

The present work is dealing with the impact of cabbage root fly (Delia radicum) on infections and damage potential of $V$. longisporum and P. lingam on oilseed rape. Between 2005 and 2008 several field and greenhouse experiments were performed to determine the impact of root damage, caused by the feeding larvae of the cabbage root fly, on $V$. longisporum, which is a root infecting soilborne pathogen. In order to identify possible interactions and to study their importance several factors such as soil inoculum, cultivar susceptibility, sowing date and soil cultivation were varied. Visual scoring as well as serological (ELISA) and molecular (Real-time PCR) detection methods were used to assess disease incidence and disease severity respectively. Furthermore greenhouse experiments were conducted to elucidate mechanisms underlying the pest-disease-complex. Another objective of this work was to look for possible interactions between the cabbage root fly and P. lingam, the causal agent of Phoma stem canker. The main results are listed below.

In the field, either insecticides or meshes were used to achieve different levels of root fly damage. Under high pest pressure the insecticide Oftanol T, applied as a seed dressing, reduced incidence and severity of root fly damage by up to $50 \%$ as compared to the insecticide Chinook. Meshes effectively prevented root fly attack in autumn and spring. In another set of field experiments, the effect of sowing date and soil cultivation on root fly attack was investigated. Sowing early in autumn favoured root fly attack. This result is in accordance with other studies which indicate that the cabbage root fly generally prefers taller plants for egg laying. Ploughing field plots instead of cultivating prior to sowing promoted seedling emergence and subsequent plant growth. As a consequence of this, plants in ploughed plots were damaged to a higher extent than plants in the cultivated plots. 
Under semi controlled conditions in the field and controlled conditions in the greenhouse, root fly infestation was successfully adjusted by placing cabbage root fly eggs onto the root collar. Larval feeding (without pathogen attack) did not affect plant growth; except for one experiment with root damage being extremely high.

Disease incidence (DI) and disease severity (DS) of $V$. longisporum were mainly determined by soil inoculum, cultivar susceptibility, sowing date and climate conditions. Both DI and DS significantly increased with the amount of soil inoculum. In our studies, cultivar Laser was the most susceptible cultivar, whereas the genotype Sem was the least susceptible. Under greenhouse conditions following inoculation of the soil or the stem, Sem displayed substantially lower amounts of fungal DNA in plant tissue than the moderately susceptible cultivar Express. These results provide evidence that resistance mechanisms are not solely confined to the root and hypocotyl region, but do also operate in the stem.

Early sowing in autumn was identified to be a further risk factor of $V$. longisporum. Field experiments showed a clear relationship between early sowing and elevated levels of both DI and DS, irrespective of root fly damage in autumn. It was concluded that early sowing prolonged the infection period before wintertime and thus leading to more severe symptom expression.

Besides the amount of inoculum, cultivar susceptibility and sowing date, the climate conditions, which varied among years, had a significant impact on $V$. longisporum. In 2006/2007, a year with exceptionally mild climate conditions, disease levels (in inoculated plots) were elevated and symptoms appeared much earlier than in the other years. For the highly susceptible cultivar Laser, which displayed severe disease symptoms four weeks prior to harvest, whole plot yield was reduced by up to $20 \%$ as compared to control plots. In contrast the moderately susceptible cultivar Lion, in which symptom development was delayed, showed no significant yield effects, even though DI at harvest was comparably high. These results indicate the time point of symptom expression to be an important determinant of yield effects.

Under greenhouse conditions first typical symptoms of $V$. longisporum appeared earlier than in the field. The onset and extent of symptom expression was mainly governed by the colonization of the plant, which differed among inoculation methods, cultivar susceptibility and soil inoculum. Similarly the effect of $V$. longisporum on plant growth correlated well with the systemic spread in the plant. 
The results obtained clearly demonstrated that root damage, caused by the feeding larvae of the cabbage root fly do facilitate infection, colonization and symptom expression of $V$. longisporum in oilseed rape. Hence the probability to suffer yield loss from $V$. longisporum is increased. The importance of root fly attack to $V$. longisporum is mainly determined by the growth stage, at which the plant is exposed to root fly attack. Furthermore, cultivar susceptibility and the amount of soil inoculum take an influence on the magnitude of the interaction. Our results showed that early root fly infestation in autumn put plants at a higher risk to become infected by $V$. longisporum, whereas root fly attack in spring is of minor importance. The interaction between cabbage root fly and $V$. longisporum was most pronounced in moderately susceptible and resistant cultivars. Strongest effects were observed for the resistant genotype Sem 05-500256. The amount of fungal DNA, measured by RealTime PCR, was threefold higher in root fly damaged plants following soil inoculation with microsclerotia. The elevated amount of fungal DNA was primarily due to an enhanced colonization of the root and hypocotyl. The colonization of the stem remained low, irrespective of root fly attack. The spread to the upper plant part was still impaired. This leads to the conclusion that resistance to $V$. longisporum is reduced but not entirely broken by root fly damage.

The interaction between cabbage root fly and $V$. longisporum is dependent on the amount of soil inoculum. Our results point out that root fly attack particularly favours disease incidence at lower inoculum levels, whereas the infection rate will be accelerated to a greater extent at higher inoculum levels.

The effects of cabbage root fly and $V$. longisporum on plant growth were studied both separately and combined to identify possible synergistic interactions. Under greenhouse conditions the presence of both organisms resulted in plant damage exceeding the sum of the individual plant damage by cabbage root fly and $V$. longisporum. The magnitude of the synergistic interaction was dependant on the extent to which the colonization of the plant was elevated due to root fly attack.

Several greenhouse experiments were conducted to reveal the mechanisms underlying the pest-disease-complex. The data obtained consistently exhibit that the interaction between cabbage root fly and $V$. longisporum is most pronounced when both organisms are in close proximity in the rhizosphere. There was no clear effect observable when both organisms were spatially separated on the same plant in a split-root system. Thus the effect of cabbage root 
fly in this pest-disease-complex appears to be limited to providing more favourable infection courts or other similar changes in the root system which favour colonization by the fungus.

Both field and greenhouse experiments studying the impact of cabbage root fly on Phoma stem canker confirmed that larval feeding on the hypocotyl region generally facilitated the development of crown canker. The interaction was found to be cultivar dependent. Strongest effects were seen in the susceptible cultivar Lion, while the resistant cultivar Caiman remained unaffected. In contrast to damage inflicted on the hypocotyl, root damage did not have any effect on canker development.

Based on our results we conclude that cabbage root fly damage has to be taken into account when looking for control strategies to prevent oilseed rape from yield loss due to pathogen attack by $V$. longisporum and $P$. lingam. Because of the fact that effective means of control are lacking, preventive measures such as crop rotation, choice of cultivars and sowing date gain in importance. 


\section{Literaturverzeichnis}

Abawi, G. S. \& K. R. Barker, 1984: Effects of cultivar, soil temperature, and population levels of Meloidogyne incognita on root necrosis and Fusarium wilt of tomatoes. Phytopathology 74, 433-438.

Abu Yaman, J. K., 1960: Natural control in cabbage root fly populations and influence of chemicals. Mededel. Van de Landbouwhoogeschool te Wageningen 60, 1-57.

Ahlers, D., 1987: Untersuchungen über den Erreger der krankhaften Abreife an Winterraps. Gesunde Pflanzen 39, 375-383.

Ahlers, S., 2008: Untersuchungen zur Epidemiologie und zum Auftreten verschiedener Pathotypen von Phoma lingam an Brassica napus Varietäten mit unterschiedlicher Resistenzausstattung. Masterarbeit, Universität Göttingen.

Alström, S., 2000: Root-colonizing fungi from oilseed rape and their inhibition of Verticillium dahliae. J. Phytopathology 148, 417-423.

Amelung, D., R. R. Schulz \& F. Daebeler, 1996: Einfluss der Fruchtfolge auf Rapskrankheiten. Raps 2, 52-56.

Anonymus, 2005: Feldschätzkarte: Gemarkung Weende, Flur 12, Maßstab 1 : 2000. Finanzamt Göttingen.

Anonymus, 2008a: Homepage des BMVEL. (http://www.bmvel.de), besucht am 20.03.2009.

Anonymus, 2008b: Beschreibende Sortenliste 2008- Getreide, Mais, Ölfrüchte, Leguminosen, Hackfrüchte. Bundessortenamt, Hannover.

Anonymus, 2008c: Homepage von CETIOM. (http://www.cetiom.fr/fileadmin/cetiom/kiosque/ PDF_fiches_regions/west_est_co_phoma.pdf), besucht am 20.10.2008.

Ansan-Melayah, D., M. H. Balesdent, R. Delourme, M. L. Pilet, X. Tanguy, M. Renard \& T., Rouxel, 1998: Genes for race-specific resistance against blackleg disease in Brassica napus L. Plant Breed. 117, 373-378.

Arbogast, M. \& M. L. Powelson, 1997: Response of potato cultivars to plant available water and Verticillium dahliae. Proc. $7^{\text {th }}$ Int. Verticillium Symposium. Cape Sounion, Athens, Greece, 45.

Ashworth, L. J., Jr., O. C. Huismann, D. M. Harper, L. K. Stomberg \& D. M. Bassett, 1979a: Verticillium wilt disease of cotton: Influence of inoculum density in the field. Phytopathology 69, 483-489.

Ashworth, L. J., O. C. Huisman, D. M. Harper \& L. K. Stromberg, 1979b: Verticillium wilt disease of tomato: Influence of inoculum density and root extension upon disease severity. Phytopathology 69, 490-492.

Assabgui, R. A., R. I. Hamilton \& J. T. Arnason, 1995: Hydroxamic acid content and plant development of maize (Zea mays L.) in relation to the western corn rootworm, Diabrotica virgifera virgifera Le conte. Can. J. Plant Science. 75, 851-856.

Ayres, P. G., 1984: The interaction between environmental stress injury and biotic disease physiology. Annu. Rev. Phytopathol. 22, 53-75. 
Back, M. A., P. P. J. Haydock \& P. Jenkinson, 2002: Disease complexes involving plant parasitic nematodes and soilborne pathogens. Plant Pathol. 51, 683-697.

Baker, R., 1971: Analysis involving inoculum density of soil-borne plant pathogens in epidemiology. Phytopathology 61, 1280-1292.

Balesdent, M. H., A. Attard, D. Ansan-Melayah, R. Delourme, M. Renard \& T. Rouxel, 2001: Genetic control and host range of avirulence towards Brassica napus cvs. Quinta and Jet Neuf in Leptosphaeria maculans. Phytopathology 91, 70-76.

Barbetti M. J. \& R. K. Khangura, 1999: Managing blackleg in the disease-prone environment of Western Australia. Proceedings $10^{\text {th }}$ Int. Rapeseed Congress, Canberra, Australia, 100.

Barbetti, M. J., 1976: The role of pycnidiospores of Leptosphaeria maculans in the spread of blackleg disease in rape. Aust. J. Experim. Agric. Anim. Husbandry 16, 911-914.

Baur, R., V. Kostal \& E. Städler, 1996a: Root damage by conspecific larvae induces preference for oviposition in cabbage root flies. Entomol. Exp. Appl. 80, 224-227.

Baur, R., V. Kostal, B. Patrian \& E. Städler, 1996b: Preference for plants damaged by conspecific larvae in ovipositing cabbage root flies: influence from leaf surface and roots.

Entomol. Exp. Appl. 81, 353-364.

Baur, R., A. N. E. Birch, R. J. Hopkins, D. W. Griffiths, M. S. J. Simmonds \& E. Städler, 1996c: Oviposition and chemosensory stimulation of the root flies Delia radicum and D. floralis in response to plant and leaf surface extracts from resistant and susceptible Brassica genotypes. Entomol. Exp. Appl. 78, 61-75.

Becker, H. C., C. Damgaard \& B. Karlsson, 1992: Environmental variation for outcrossing rate in rapeseed (Brassica napus). Theor. Appl. Genet. 84, 303-306.

Beckmann, C. H., 1984: Modelling the succession of host-parasite interactions in vascular diseases of plants. Phytopath. Medit. 23, 109-129.

Bell, A. A. \& M. E. Mace, 1981: Biochemistry and physiology of resistance. In: Mace, M. E., A. A. Bell \& C. H. Beckman, eds. Fungal wilt diseases of Plants, New York: Academic Press, 431-466.

Bell, A. A., 1969: Phytoalexin production and Verticillium-wilt resistance in cotton. Phytopathology 59, 1119-1127.

Berg, G. \& G. Ballin, 1994: Bacterial Antagonists to Verticillium dahliae Kleb.. J. Phytopathology 141, 99-110.

Bergeson, G. B., 1972: Concepts of nematode-fungus associations in plant disease complexes: a review. Exp. Parasitol. 32, 301-314.

Bergeson, G. B., S. D. van Gundy \& I. J. Thomason, 1970: Effect of Meloidogyne javanica on rhizosphere microflora and Fusarium wilt of tomato. Phytopathology 60, 1245-1249.

Berry, S. Z. \& C. A. Thomas, 1961: Influence of soil temperature, isolates, and method of inoculation on resistance of mint to Verticillium wilt. Phytopathology 51, 169-174.

Bertrand, B., C. Nunez \& J. L. Sarah, 2000: Disease complex in coffee involving Meloidogyne arabicida and Fusarium oxysporum. Plant Pathol. 49, 383-388. 
Beute, M. K. \& D. M. Benson, 1979: Relation of small soil fauna to plant disease. Annu. Rev. Phytopathol. 17, 485-502.

Biddulph, J. E., B. D. L. Fitt \& P: K. Leech 1999: Effects of temperature and wetness duration on infection of oilseed rape leaves by ascospores of Leptosphaeria maculans (stem canker). Eur. J. of Plant Pathol. 105, 769-781.

Bieber, F., 1990 : Biotinylierung monoklonaler Antikörper. In: Peters, J. H. \& H. Baumgarten. Monoklonale Antikörper. Springer-Verlag, Berlin.

Birch, A. N. E., 1988: Field and glasshouse studies on components of resistance to root fly attack in swedes. Ann. Appl. Biol. 113, 89-100.

Bishop, C. D. \& R. M. Cooper, 1983a: An ultrastructural study of vascular colonization in three vascular wilt diseases. I. Colonization of susceptible cultivars. Physiol. Plant Pathol. 23, 323-343.

Bishop, C. D. \& R. M. Cooper, 1983b: An ultrastructural study of root invasion in three vascular wilt diseases. Physiol. Plant Pathol. 22, 15-27.

Björkman, M., P. A. Hambäck \& B. Rämert, 2007: Neighbouring monocultures enhance the effect of intercropping on the turnip root fly (Delia floralis). Entomol. Exp. Appl. 124, 319-326.

Bligaard, J., 1999: Damage thresholds for cabbage root fly (Delia radicum (L.)) in cauliflower assessed from pot experiments. Acta Agric. Scandin., Section B-Plant Soil Science 49, 57-64.

Blossey, B. \& T. M. Hunt-Joshi, 2003: Belowground herbivory by insects: Influence on plants and aboveground herbivores. Annu. Rev. Entomol. 48, 521-547.

Bosse, J., 2006: Untersuchungen zum Flugverhalten der Kleinen Kohlfliege (Delia radicum L.) und zum Befall von Winterraps in Abhängigkeit von Saattermin und Bodenbearbeitung im Frühjahr 2006. Bachelorarbeit, Universität Göttingen.

Botseas, D. D. \& R. C. Rowe, 1994: Development of potato early dying in response to infection by two pathotypes of Verticillium dahliae and coinfection by Pratylenchus penetrans. Phytopathology 84, 275-282.

Bowers, J. H., S. T. Nameth, R. M. Riedel \& R. C. Rowe, 1996: Infection and colonisation of potato roots by Verticillium dahliae as affected by Pratylenchus penetrans and P. crenatus. Phytopathology 86, 614-621.

Bowman, P. \& J. R. Bloom, 1966: Breaking of resistance of tomato varieties to Fusarium wilt by Meloidogyne incognita. Phytopathology 56, 871 (Abstr.).

Bromand, B., 1980: Investigations on the biological control of the cabbage root fly (Hylemya brassicae) with Aleochara bilineata. SROP/WPRS Bull. 3, 49-62.

Brunin, B. \& L. Lacoste 1970: Recherches sur la maladie du colza due à Leptosphaeria maculans (Desm.) Ces. et de Not. II. Pouvoir pathogene des ascospores. Ann. phytopathol. 3, 477-488.

Bugbee, W. A. \& W. P. Sappenfield, 1968: Varietal reaction of cotton after stem or root inoculation with Fusarium oxysporum f. sp. vasinfectum. Phytopathology 58, 212-214.

Bünger, I., 2004: Vermehrungs- und Schadpotential der grünen Gurkenlaus (Aphis gossypii Glover) an Gewächshausgurken (Cucumis sativus L.). Dissertation, Universität Hohenheim. 
Casper, R. \& S. Meyer, 1981: Die Anwendung des ELISA-Verfahrens zum Nachweis pflanzenpathogener Viren. Nachrichtenbl. Deutsch. Pflanzenschutzd. 33, 49-54.

Cernusco, R., 1996: Entwicklung und Erprobung enzymatischer und immunologischer Nachweismethoden für Verticillium dahliae Kleb. im Raps (Brassica napus L.). Dissertation, Universität Göttingen, Cuvillier Verlag, Göttingen.

Chevre, A.-M., H. Brun, F. Elber, F. C. Letanneur, P. Vallee, M. Ermel, I. Glais, H. Li, K. Sivasithamparam \& M. J. Barbetti, 2008: Stabilization of resistance to Leptosphaeria maculans in Brassica napus-B. juncea recombinant lines and its introgression into spring-type Brassica napus. Plant Disease 92, 1208-1214.

Clark, M. F. \& A. N. Adams, 1977: Characteristics of the microplate method of enzyme-linked immunosorbent assay for the detection of plant viruses. J. Gen. Virol. 34, 475- 483.

Coaker, R. H. \& D. A. Williams, 1963: The importance of some carabidae and staphylinidae as predators of the cabbage root fly, Erioischia brassicae (Bouché). Entomol. Exp. Appl. 6, 156-164.

Coaker, T. H., 1987: Cultural methods: The crop. In Integrated Pest Management, ed. A. J. Burn, T. H. Coaker, P. C. Jepsen, 69-99. London: Academic.

Collier R. H. \& S. Finch, 1983a: Completion of diapause in field populations of the cabbage root fly (Delia radicum). Entomol. Exp. Appl. 34, 186-192.

Collier R. H. \& S. Finch, 1983b: Effects of intensity and duration of low temperatures in regulating diapause development of the cabbage root fly (Delia radicum). Entomol. Exp. Appl. 34, 193-200.

Conroy, J. J., R. J. Green (Jr) \& J. M. Ferris, 1972: Interaction of Verticillium albo-atrum and the root lesion nematode, Pratylenchus penetrans, in tomato roots at controlled inoculum densities. Phytopathology 62, 362-366.

Cook, R. J. \& E. J. Evans, 1978: Build up of diseases with intensification of oilseed rape in England. Proc. $5^{\text {th }}$ Int. Rapeseed Conf. Malmö, Sweden 1, 333-337.

Cooper, R. M. \& J. S. Williams, 2004: Elemental sulphur as an induced antifungal substance in plant defence. J. Exp. Botany 55, 1947-1953.

Cooper, R. M., M. L. V. Resende, J. Flood, M. G. Rowan, M. H. Beale \& U. Potter, 1996: Detection and cellular localization of elemental sulphur in disease resistant genotypes of Theobroma cacao. Nature 246, 309-311.

Crüger G., G. F. Backhaus, M. Hommes, S. Smolka \& H.-J. Vetten, 2002: Pflanzenschutz im Gemüsebau. Verlag Eugen Ulmer, Stuttgart.

Daebeler, F. \& D. Seidel, 1989: Auswirkungen der Fruchtfolge auf Krankheitserreger des Winterrapses. Raps 3, 130.

Daebeler, F., D. Amelung \& K. Zeise, 1988: Verticillium-Welke an Winterraps- Auftreten und Bedeutung. Nachrichtenbl. Pflanzenschutz DDR 42, 71-73.

Daebeler, F., D. Amelung \& K.-H. Engel, 1985: Zur Verwechslungsmöglichkeit der durch Phoma lingam (Tode ex Fr.) Desm. verursachten Wurzelhalsfäule mit Rhizoctonia solani $\mathrm{K}$. und Verticillium dahliae Kleb.. Nachrichtenbl. Pflanzenschutz DDR, 39, 180-181. 
Davis, R. M., P. D. Colyer, C. S. Rothrock \& J. K. Kochman, 2006: Fusarium wilt of cotton: Population diversity and implications for management. Plant Disease 90, 692-703.

De Jong, R., N. Maher, E. Städler \& T. Winkler, 2000: Rutabaga roots, a rich source of oviposition stimulants fort he cabbage root fly. Chemoecology 9, 205-209.

De Vay, J. E., A. P. Gutierrez, G. S. Pulmann, R. J. Wakeman, R. H. Garber, D. P. Jeffers, S. N. Smith, P. B. Goodell \& P. A. Roberts, 1997: Inoculum densities of Fusarium oxysporum f. sp. vasinfectum and Meloidogyne incognita in relation to the development of Fusarium wilt and the phenology of cotton plants (Gossypium hirsutum). Phytopathology 87, 341-346.

Debode, J., B. Declercq \& M. Höfte, 2005: Identification of cauliflower cultivars that differ in susceptibility to Verticillium longisporum using different inoculation methods. J. Phytopathology 153, 257-263.

Delourme, R., A.-M. Chevre, H. Brun, T. Rouxel, M. H. Balesdent, J. S. Dias, P. Salisbury, M. Renard \& S. R. Rimmer, 2006: Major genes and polygenic resistance to Leptosphaeria maculans in oilseed rape (Brassica napus). Eur. J. Plant Pathol. 114, 41-52.

DeVay, J. E. \& G. S. Pullmann, 1984 : Epidemiology and ecology of diseases caused by Verticillium species, with emphasis on Verticillium wilt of cotton. Phytopatholoy Medi. 23, 95-108.

Diepenbrock, W., 2000: Yield analysis of winter oilseed rape (Brassica napus L.): a review. Field Crops Res. 67, 35-49.

Dixelius, C., I. Happstadius \& G. Berg, 2005: Verticillium wilt on Brassica oil crops-a swedish perspective. J. Swed. Seed Assoc. 115, 36-48.

Doane, J. F. \& R. K. Chapman, 1964a: The relation of the cabbage maggot, Hylemyia Brassicae (Bouché) to decay in some cruciferous crops. Entomol. Exp. Appl. 7, 1-8.

Doane, J. F. \& R. K. Chapman, 1964b: Development of the cabbage maggot Hylemyia Brassicae (Bouché) on aseptic and decaying rutabaga tissue. Entomol. Exp. Appl. 7, 115-119.

Dosdall, L. M., M. J. Herbut \& N. T. Cowle, 1994: Susceptibilities of species and cultivars of canola and mustard to infestation by root maggots (Delia spp.) (Diptera: Anthomyiidae). Can. Entomol. 126, 251-260.

Dosdall, L. M., M. J. Herbut, N. T. Cowle \& T. M. Micklich, 1995: The effect of seeding date and plant density on infestations of root maggots, Delia spp. (Diptera: Anthomyiidae in canola. Can. J. Plant Science 75, 169-177.

Dosdall, L. M., M. J. Herbut, N. T. Cowle \& T. M. Micklich, 1996: The effect of tillage regime on emergence of root maggots (Delia spp.) (Diptera: Anthomyiidae from canola. Can. Entomol. 128, $1157-1165$

Dosdall, L., A. Good, B. A. Keddie, U. Ekuere \& G. Stringham, 2000: Identification and evaluation of root maggot (Delia spp.) (Diptera: Anthomyiidae) resistance within Brassicaceae. Crop Protection 19, 245-253.

Dosdall, L. M., G. W. Clayton, K. N. Harker, J. O. Donovan \& F. C. Stevenson, 2003: Weed control and root maggots: making canola pest management strategies compatible. Weed Science 51, 576-585. 
Dosdall, L. M., G. W. Clayton, K. N. Harker, J. O. Donovan \& F. C. Stevenson, 2004: Integrated Pest Management- The effect of soil fertility and other agronomic factors on infestations of root maggots in canola. Agron. J. 96, 1306-1313.

Dosdall, L. M., G. W. Clayton, K. N. Harker, J. O. Donovan \& F. C. Stevenson, 2006: Effects of fall and spring seeding date and other agronomic factors on infestations of root maggots, Delia spp. (Diptera: Anthomyiidae), in canola. J. Econ. Entomol. 99, 1165-1674.

Dubery, I. A. \& V. Slater, 1997: Induced defence responses in cotton leaf discs by elicitors from Verticillium dahliae. Phytochemistry 44, 1429-1434.

Dunker, S, H. Keunecke, P. Steinbach \& A. von Tiedemann, 2008: Impact of Verticillium longisporum on yield and morphology of winter oilseed rape (Brassica napus) in relation to systemic spread in the plant. J. Phytopathology 156, 698-707.

Dunker, S., 2006: Untersuchungen zur Schadwirkung von Sclerotinia sclerotiorum (Lib. De Bary) und Verticillium longisporum (comb. Nov. Karapapa) in Winterraps (Brassica napus). Dissertation, Universität Göttingen.

Ehlers, W.,1996: Wasser in Boden und Pflanze: Dynamik des Wasserhaushaltes als Grundlage von Pflanzenwachstum und Ertrag. Verlag Eugen Ulmer, Stuttgart.

Ekuere, U. U., L. M. Dosdall, M. Hills, A. B. Keddie, L. Kott \& A. Good, 2005: Identification, mapping, and economic evaluation of QTLs encoding root maggot resistance in brassica. Crop Science 45, 371-378.

El Titi, A., 1977a: Die Ermittlung der wirtschaftlichen Schadensschwelle für die Kleine Kohlfliege (Erioischia brassicae Bouché) im Blumenkohlanbau. 1. Beziehung zwischen Schädlingsdichte, chemischer Bekämpfung und Ertrag. Z. Pflanzenkrankh. Pflanzenschutz 84, 65-77.

El Titi, A., 1977b: Die Ermittlung der wirtschaftlichen Schadensschwelle für die Kleine Kohlfliege (Erioischia brassicae Bouché) im Blumenkohlanbau. 2. Quantifizirung der Eimortalität. Z. Pflanzenkrankh. Pflanzenschutz 84, 78-83.

El Titi, A., 1979: Weitere Untersuchungen zur Frage der wirtschaftlichen Schadensschwelle für die Kleine Kohlfliege (Erioischia brassicae Bouché) im Blumenkohlanbau. 2. Quantifizirung der Eimortalität. Z. Pflanzenkrankh. Pflanzenschutz 86, 65-74.

El-Hamalawi, Z. A., 2007: Attraction, acquisition, retention and spatiotemporal distribution of soilborne plant pathogenic fungi by shore flies. Ann. Appl. Biol.,1-9.

Ellis, P. R. \& J. A. Hardman, 1975: Laboratory methods for studying non-preference resistance to cabbage root fly in cruciferous crops. Ann. Appl. Biol. 79, 253-264.

Ellis, P. R. \& J. A. Hardman, 1983: Investigations of the resistance in cruciferous crops to cabbage root fly at Wellesbourne, IOBC/WPRS Bulletin 11, 63-64.

Erichsen, E. \& S. Hünmörder, 2005: Kohlfliegenauftreten im Raps- Bericht über ein Gemeinschaftsprojekt von acht Landespflanzenschutzdiensten und der BBA. Ges. Pflanzen 57, 149-157.

Erichsen, E., 2006: Neue Rapsbeizen- Dargestellt am Beispiel der Kohlfliegenproblematik. Raps 3, 116-123.

Erichsen, E., S. Hünmörder \& C. Kruspe, 2004: Die Kohlfliege, Hauptschädling auf den Winterrapsflächen im Herbst 2003, Raps 1, 4-9. 
Erwin, D. C., D. Moje \& I. Malca, 1965: An assay of the severity of Verticillium wilt on cotton plants inoculated by stem puncture. Phytopathology 55, 663-665.

Ester, A., 2003: Filmcoating the seed cabbage (Brassica oleracea L. var. Botrytis L.) with imidacloprid and spinosad to control insect pests. Crop Protection 22, 761-768.

Ester, A., S. B. Hofstede, P. S. R. Kosters \& C. P. de Moel, 1994: Filmcoating of cauliflower seed (Brassica oleracea L. var. botrytis L.) with insecticides to control the cabbage root fly (Delia radicum). Crop Protection 13, 14-18.

Evans, K., 1983: Interactions between Globodera pallida, Globodera rostochiensis and Verticillium dahliae on four potato cultivars. Nematologica 28, 143-144.

Evans, K., 1987: The interactions of potato cyst nematodes and Verticillium dahliae on early and main crop potato cultivars. Ann. Appl. Biol. 110, 329-339.

Eynck, C., 2008: Identification of resistance sources and characterisation of resistance factors in Brassica species to Verticillium longisporum. Dissertation, Universität Göttingen.

Eynck, C., B. Koopmann, G. Grunewaldt-Stoecker, P. Karlovsky \& A. von Tiedemann, 2007: Differential interactions of Verticillium longisporum and Verticillium dahliae with Brassica napus detected with molecular and histological techniques. Eur. J. Plant Pathol. 118, 259-274.

Faulkner, L. R. \& C. B. Skotland, 1965: Interactions of Verticillium dahliae and Pratylenchus minyus in Verticillium wilt of peppermint. Phytopathology 55, 583-586.

Faulkner, L. R. \& W. J. Bolander, 1969: Interaction of Verticillium dahliae and Pratylenchus minyus in Verticillium wilt of peppermint: Effect of Soil Temperature. Phytopathology 59, 868-870.

Faulkner, L. R., W. J. Bolander \& C. B. Skotland, 1970: Interactions of Verticillium dahliae and Pratylenchus minyus in Verticillium wilt of peppermint: Influence of the nematode as determined by a double-root technique. Phytopathology 60, 100-103.

Felkl G., E. B. Jensen, K. Kristiansen \& S. B. Andersen, 2005: Tolerance and antibiosis resistance to cabbage root fly in vegetable Brassica species. Entomol. Exp. Appl. 116, 65-71.

Felton, G. W., K. L. Korth, J. L. Bi, S. V. Wesley, D. V. Huhman, M. C. Matews, J. B. Murphy, C. Lamb \& R. A. Dixon, 1999: Inverse relationship between systemic resistance of plants to microorganisms to insect herbivory. Current Biology 9, 317-320.

Ferreira, M. E., S. R. Rimmer, P. H. Williams \& T. C. Osborn, 1995: Mapping loci controlling Brassica napus resistance to Leptosphaeria maculans under different screening conditions. Phytopathology 85, 213-217.

Fielding, M. J., 1959: Nematodes in Plant Disease. Annu. Rev. Microbiol. 13, 239-254.

Finch, S. \& T. H. Coaker, 1969: A method for the continuous rearing of the cabbage root fly Erioschia brassicae (Bouché) and some observations on its biology. Bull. Entomol. Res. 58, 619-627.

Finch, S. \& G. Skinner, 1975: Dispersal of the cabbage root fly. Ann. App. Biol. 81, 1-19.

Finch, S. \& G. Skinner, 1980: Mortality of overwintering pupae of the cabbage root fly (Delia brassicae). J. Appl. Ecol. 17, 657-666. 
Finch, S. \& T. H. Jones, 1987: Factors influencing the severity of cabbage root fly infestations in crops of oilseed rape. IOBC/WPRS Bull. X/4, 85-92.

Finch, S., 1978: Volatile plant chemicals and their effect on host plant finding by the cabbage root fly (Delia brassicae). Entomol. Exp. Appl. 24, 150-159.

Finch, S., 1989: Ecological considerations in the management of Delia pest species in vegetable crops. Annu. Rev. Entomol. 34, 117-137.

Finch, S. \& M. S. Elliott, 1992: Predation of cabbage root fly eggs and larvae by Carabidae. IOBC/ WPRS Bull. Entomol. Res. XV/4, 176-183.

Finch, S., 1996: 'Appropriate/inappropriate landings', a mechanism for describing how undersowing with clover affects host-plant selection by pest insects of brassica crops. IOBC/WPRS Bulletin 19, 102-106.

Finch, S. \& R. H. Collier, 2000: Host plant selection by insects - a theory based on appropriate/inappropriate landings by pest insect of cruciferous plants. Entomol. Exp. Appl. 96, 91-102.

Fitt, B. D. L., P. Gladders, K. G. Sutherland, J. A. Turner \& S.J. Welham, 1999: Epidemology, forecasting and management of winter oilseed rape diseases in the UK. Proceedings of the $10^{\text {th }}$ International Rapeseed Congress, Canberra, Australia.

Fitt, B. D. L., H. Brun, M. J. Barbetti \& S. R. Rimmer, 2006: World-Wide importance of phoma stem canker (Leptosphaeria maculans and L. biglobosa) on oilseed rape (Brassica napus). Eur. J. Plant Pathol. 114, 3-15.

Fitt, B. D. L, B. C. Hu, Z. Q. Li, S. Y. Liu, R. M. Lange, P. D. Kharbandra, M. H. Butterworth \& R. P. White, 2008: Strategies to prevent spread of Leptosphaeria maculans (phoma stem canker) onto oilseed rape crops in China; costs and benefits. Plant Pathol. 57, 652-664.

Fradin, E. F. \& B. P. H. J. Thomma, 2006: Physiology and molecular aspects of Verticillium wilt diseases caused by $V$. dahliae and V. albo-atrum. Mol. Plant Pathol.7, 71-86.

France, R. A. \& G. S. Abawi, 1994: Interaction between Meloidogyne incognita and Fusarium oxysporum f. sp. phaseoli on selected bean genotypes. J. Nematol. 26, 467-474.

Francl, L. J., R. C. Rowe, R. M. Riedel \& L. V. Madden, 1988: Effects of three soil types on potato early dying disease and associated yield reduction. Phytopathology 78, 159-166.

Fries, I. \& J. Stark, 1983: Measuring the importance of honey bees in rape seed production. J. Apic. Res. 22, 272-276.

Gabrielson, R. L. 1983: Blackleg disease of crucifers caused by Leptosphaeria maculans (Phoma lingam) and its control. Seed Sci. Technol. 11, 749-780.

Garber, R. H. \& B. R. Housten, 1966: Penetration and development of Verticillium albo-atrum in the cotton plant. Phytopathology 56, 1121-1126.

Garber, R. H., E. C. Jorgenson, S. Smith \& A. H. Hyer, 1979: Interaction of population levels of Fusarium oxysporum f. sp. vasinfectum and Meloidogyne incognita on cotton. J. Nematol. 11, 133137. 
Gladders, P. \& T. M. Musa, 1980: Observations on the epidemiology of Leptosphaeria maculans stem canker in winter oilseed rape. Plant Pathol. 29, 28-37.

Green, R. J., 1980: Soil factors affecting survival of Verticillium dahliae. Phytopathology 70, 353355.

Griffiths, C. D., 1986: Phenology and dispersion of Delia radicum (L.) (Diptera: Anthomyiidae) in canola fields in Morinville, Alberta. Quaest. Entomol. 22, 29-50.

Griffiths, D. A., 1971: The development of lignitubers in roots after infection by Verticillium dahliae. Can. J. Microbiol. 17, 441-444.

Griffiths, G. C. D., 1991: Economic assessment of cabbage maggot damage in canola in Alberta. Proc. GCIRC $8^{\text {th }}$ Rapeseed Congress (Saskatoon, July 9-11, 1991) 2, 528-535.

Gröntoft, M. \& T. Jonasson, 1992: Influence of Heterodera schachtii on Verticillium wilt symptoms in oilseed rape. J. Phytopathology 134, 170-174.

Grosse, F., W. Diepenbrock \& G. Geisler, 1987: Ertragsbildung bei Winterraps. Raps 3, 125-130.

Gugel, R. K. \& G.A. Petrie, 1992: History, occurrence, impact, and control of blackleg of rapeseed. Can. J. Plant Pathol. 14, 36-45.

Günzelmann, H. \& V. H. Paul, 1990 : Zum Auftreten und zur Bedeutung der Verticillium-Welke an Raps in der Bundesrepublik Deutschland in 1989. Raps 1, 23-25.

Gutierrez, A. P., J. E. DeVay, G. S. Pullmann \& G. E. Friebertshauser, 1983: A model of Verticillium wilt in relation to cotton growth and development. Phytopathology 73, 89-94.

Haarstrich, F., 2007: Wirkung von insektiziden Saatgutbehandlungsmitteln auf den Befall der Kleinen Kohlfliege (Delia radicum L.) an Winterraps. Masterarbeit, Universität Göttingen.

Hall, R., 1992: Epidemiology of blackleg of oilseed rape. Can. J. Plant Pathol. 14, 46-55.

Hammond, K. E., B. G. Lewis \& T. M. Musa, 1985: A systemic pathway in the infection of oilseed rape plant by Leptosphaeria maculans. Plant Pathol. 34, 557-565.

Hammond, K. E.\& B. G. Lewis, 1986a: Ultrastructural studies of the limitation of lesions caused by Leptosphaeria maculans in stems of Brassica napus var. oleifera. Physiol. Mol. Plant Pathol. 28, 251265.

Hammond, K. E.\& B. G. Lewis, 1986b: The timing and sequence of events leading to stem canker disease in populations of Brassica napus var. oleifera in the field. Plant Pathol. 35, 551-564.

Hammond, K. E.\& B. G. Lewis, 1987a: Variation in stem infections caused by aggressive and nonaggressive isolates of Leptosphaeria maculans on Brassica napus var. oleifera. Plant Pathol. 36, 5365 .

Hammond, K. E. \& B. G. Lewis, 1987b: The establishment of systemic infection in leaves of oilseed rape by Leptosphaeria maculans. Plant Pathol. 36, 135-147.

Happstadius, I., A. Ljunberg, B. Kristiansson \& C. Dixelius, 2002: Identification of Brassica oleracea germplasm with improved resistance to Verticillium wilt. Plant Breed. 122, 30-34. 
Hartleb, H., C. Wolff, W. Kufeld \& H. Briswitz, 1998: Phoma-Spätbefall durch Triebrüsslerbekämpfung reduzieren. Raps 16, 26-31.

Hassan, S. A., 1969: Observations on the effect of insecticides on coleopterous predators of Erioischia brassicae (Diptera: Anthomyiidae). Entomol. Exp. Appl. 12, 157-168.

Heale, J. B. \& V. K. Karapapa, 1999 : The Verticillium threat to Canada's major oilseed crop canola. Can. J. Plant. Pathol. 21, 1-7.

Heitefuss, R., K. König, A. Obst \& M. Reschke, 2000: Pflanzenkrankheiten und Schädlinge im Ackerbau. DLG- Verlag, Frankfurt am Main, 4., überarbeitete und erweiterte Auflage.

Hemachandra, K. S., U. Kuhlmann, P. G. Mason \& N. J. Holliday, 2007: Spatial patterns of Trybliographa rapae parasitism of Delia radicum larvae in oilseed rape and califlower. J. Appl. Entomol. 131, 338-346.

Heppner, C. \& R. Heitefuss, 1995: Untersuchungen zum Auftreten von Verticillium dahliae Kleb. und anderen pilzlichen Erregern am Erntegut von Winterraps (Brassica napus L. var. oleifera Metzger). Nachrichtenbl. Deutsch. Pflanzenschutzd. 47, 57-61.

Heppner, C., 1995: Nachweis von Verticillium dahliae Kleb. im Boden mit Plattengussfahren und ELISA (enzyme-linked immunosorbent assay) sowie Untersuchungen zur Auswirkung des Inokulums auf den Befall von Winterraps (Brassica napus ssp. Oleifera Metzg.). Dissertation, Universität Göttingen, Cuvillier Verlag, Göttingen.

Hide, G. A., D. C. M. Corbett \& K. Evans, 1984: Effects of soil treatments and cultivars on 'early dying' disease of potatoes caused by Globodera rostochiensis and Verticillium dahliae. Ann. Appl. Biol. 104, 277-289.

Hillocks, R. J., 1985: The effect of root-knot nematode on vascular resistance to Fusarium oxysporum f. sp. vasinfectum in the stems of cotton plants. Ann. Appl. Biol. 107, 213-218.

Hillocks, R. J., 1986: Localised and systemic effects of root-knot nematode on the incidence and severity of Fusarium wilt in cotton. Nematologica 32, 202-208.

Hodgson, A. S., 1979: Rapeseed adaption in Northern New South Wales. III. Yield, yield components and grain quality of Brassica campestris and Brassica napus in relation to planting date. Aust. J. Agric. Res. 30, 19-27.

Hoffman, G. M. \& H. Schmutterer, 1999: Parasitäre Krankheiten und Schädlinge an landwirtschaftlichen Nutzpflanzen. Verlag Eugen Ulmer, Stuttgart.

Holtschulte, B., 1992: Untersuchungen zur Biologie und Bedeutung von Verticillium dahliae Kleb. und Leptosphaeria maculans (Desm.) Ces. et de Not. (Anamorph: Phoma lingam (Tode ex Fr.)) innerhalb des Erregerkomplexes der Krankhaften Abreife von Raps. Dissertation, Universität Göttingen.

Hopkins, R. J., D. W. Griffiths, A. N. E. Birch \& R. G. McKinlay, 1998: Influence of increasing herbivore pressure on modification of glucosinolate content of swedes (Brassica napus spp. rapifera). J. Chemic. Ecol. 24, 2003-2019.

Hopkins. R. J., D. W. Griffiths, R. G. McKinlay \& A. N. E. Birch, 1999: The relationship between cabbage root fly (Delia radicum) larval feeding and the freeze-dried matter and sugar content of brassica roots. Entomol. Exp. Appl. 92, 109-117. 
Hornig, H., 1987 : Weitere Untersuchungen und Erkenntnisse zur Krankhaften Abreife. Raps 1, 2430.

Hough-Goldstein, J. A., 1987: Tests of a spun polyester row cover as a barrier against seedcorn maggot (Diptera: Anthomyiidae) and cabbage pest infestations. J. Econ. Entomol. 80, 768-772.

Huang, H. C., A. M. Harper, E. G. Kokko \& R. J. Howard, 1983: Aphid transmission of Verticillium albo-atrum to alfalfa. Can. J. Plant Pathol. 5, 141-147.

Huang, H. C., K. W. Richards \& E. G. Kokko, 1986: The role of the leafcutter bee in dissemination of Verticillium albo-atrum in alfalfa. Phytopathology 76, 75-79.

Huang, Y. J., B. D. L. Fitt \& A. M. Hall, 2003: Survival of A-group and B-group Leptosphaeria maculans (phoma stem canker) ascospores in air and mycelium on oilseed rape debris. Assoc. Appl. Biologists 143, 359-369.

Huang, Y. J., E. J. Pirie, N. Evans, R. Delourme, G. J. King \& B. D. L. Fitt, 2009: Quantitative resistance to symptomless growth of Leptosphaeria maculans (phoma stem canker) in Brassic napus (oilseed rape). Plant Pathol. 58, 314-323.

Hughes, R. D., 1959: The natural mortality of Erioischia brassicae (Bouché) (Diptera: Anthomyiidae) during the egg stage of the first generation. J. Anim. Ecol. 28, 343-357.

Huisman, O. C., 1982: Interrelations of root growth dynamics to epidemiology of root invading fungi. Annu. Rev. Phytopathol. 20, 303-327.

Hünmörder, S., 2003: Untersuchungen zur Biologie, Ökologie und Bekämpfung der Kleinen Kohlfliege (Delia radicum L.) an Winterraps. Diplomarbeit, Universität Rostock.

Hunter, M. D., 2001: Mixed signals and cross-talk: interactions between plants, insect herbivores and plant pathogens. Agricultural and Forest Entomology 2, 155-160.

Inbar, M., H. Doostdar \& R. T. Mayer, 2001: Suitability of stressed and vigorous plants to various insect herbivores. Oikos 94, 228-235.

Inszuna, V. \& B. Eriksson, 1981: Betcsytnematod/ kransmögel/oljeväxter. Exempel pa markbiologiska samspel. SLU Växtskyddsrapporter, Jordbruk 16, 90-95.

Isaac, I., 1957: Verticillium wilt of brussels sprout. Ann. Appl. Biol. 45, 276-283.

Jansky, S., D. I. Rouse \& P. J. Kauth, 2004: Inheritance of resistance to Verticillium dahliae in diploid interspecific potato hybrids. Plant Disease 88, 1075-1078.

Johnson, D. A. \& G. S. Santo, 2001: Development of wilt in mint in response to infection by two pathotypes of Verticillium dahliae and co-infection by Pratyylenchus penetrans. Plant Disease 85, 1189-1192.

Jorgenson, E. C., 1970: Antagonistic interaction of Heterodera schachtii (Schmidt) and Fusarium oxysporum (Woll.) on sugar beet. J. Nematol. 2, 393-398.

Kalb, D. W. \& R. L. Millar, 1986: Dispersal of Verticillium albo-atrum by fungus gnat (Bradysia impatiens). Plant Disease 70, 752-753. 
Kalb, D. W., G. C. Bergstrom \& E. J. Shields, 1994: Prevalence, severity, and association of fungal crown and root rots with injury by the clover root curculio in Ney York alfalfa. Plant Disease 78, 491495.

Karaca, I., A. Karciloglu \& S. Ceylan, 1971: Wilt disease of cotton in the Ege region of Turkey. J. Turkish Phytopathology 1, 4-11.

Karapapa, V. K., B. W. Bainbridge \& J. B. Heale, 1997: Morphological and molecular characterization of Verticillium longisporum comb. nov., pathogenic to oilseed rape. Mycol. Res. 101, 1281-1294.

Karapapa, V. K., M. A. Baig, J. B. Heale \& J. T. Rossiter, 1997 b: Glucosinolate response in winter oilseed rape Brassuca napus ssp. oleifera to Verticillium dahliae (non-pathogenic) and $V$. longisporum comb. Nov. [Karapapa, Bainbridge \& Heale, 1997] (pathogenic). Proc. $7^{\text {th }}$ Int. Verticillium Symp. Cape Sounion, Athens, Greece, 50.

Karban, R. \& J. H. Myers, 1989: Induced plant responses to herbivory. Annu. Rev. Ecol. Syst. 20, 331-348.

Karban, R., R. Adamchak \& W. C. Schnathorst, 1987: Induced resistance and interspecific competition between spider mites and a vascular wilt fungus. Science 235, 678-680.

Kathib, A. El., A. Aramouni, A. Hassan \& A. Ravisé, 1974: Accumulation de composés phénoliques et de phytoalexines par des variétés de tomate cultivées sur des sols infectes au Liban. Phytopathol. Z. 81, 23-37.

Katsantonis, D., R. J. Hillocks \& S. Gowen, 2005: Enhancement of germination of spores of Verticillium dahliae and Fusarium oxysporum f. sp. vasinfectum in vascular fluid from cotton plants infected with the root-knot nematode. Phytoparasitica 33, 215-224.

Keiller, D. R. \& D. G. Morgan, 1988: Distribution of carbon labelled assimilates in flowering plants of oilseed rape (Brassica napus L.). J. Agric. Sci. Camb. 111, 347-355.

Ketudat, U., 1969: The effects of some soil-borne fungi on the sex ratio of Heterodera rostochiensis on tomato. Nematologica 15, 229-233.

Keunecke, H., 2005: Einfluss von Verticillium longisporum auf die Wurzel- und Sprossentwicklung von Winterraps unter Berücksichtigung von Fungizidapplikationen. Masterarbeit, Universität Göttingen.

Khan, F. Z. \& J. M. Milton, 1979: Some factors affecting the production of medicarpin and sativan by lucerne leaflets inresponse to Verticillium albo-atrum. Physiol. Plant Pathol. 14, 11-17.

Khangura, R. K. \& M. J. Barbetti, 1999: Chemical control of blackleg disease of canola in Western Australia. Proceedings $10^{\text {th }}$ Int. Rapeseed Congress, Canberra, Australia, 232.

Kilpatrick, R. A., 1961: Fungi associated with larvae of Sitona spp.. Phytopathology 51, 640-641.

Kingsley, P., J. M. Scriber, C. R. Grau \& P. A. Delwiche, 1983: Feeding and growth performance of Spodoptera eridania (Noctuidae: Lepidoptera) on vernal alfalfa, as influenced by Verticillium wilt. Protection Ecology 5, 127-134. 
Koch, E., H.M.A. Badawy and H.-H. Hoppe, 1989: Differences between aggressive and non aggressive single spore lines of Leptosphaeria maculans in cultural characteristics and phytotoxin production. J. Phytopathology 124, 52-62.

Koike, S. T., K. V. Subbarao, R. M. Davis, T. R. Gordon \& J. C. Hubbard, 1994: Verticillium wilt of cauliflower in California. Plant Disease 78, 1116-1121.

Kostal, V., 1991: Orientation behaviour of newly hatched larvae of the cabbage maggot, Delia radicum (L.) (Diptera: Anthomyiidae), to volatile plant metabolites. J. Insect Behaviour 5, 61-69.

Kostal, V., 1993: Physical and chemical factors influencing landing and oviposition by the cabbage root fly on host-plant models. Entomol. Exp. Appl. 66, 109-118.

Krahmer, U., V. Hennings, U. Müller und H.- P. Schrey, 1995: Ermittlung bodenphysikalischer Kennwerte in Abhängigkeit von Bodenart, Lagerungsdichte und Humusgehalt. Z. Pflanzenernähr. Bodenkd. 158, 323-331.

Krause, U., B. Koopmann \& B. Ulber, 2007: Phoma lingam an Winterraps. Eiablage des Rapsstängelrüsslers begünstigt frühe Stängelinfektionen. Raps 1, 32-34.

Kreye, H. \& D. Dölger, 2007: Anbautechnik im Produktionsverfahren, in Christen, O. \& W. Friedt, 2007: Winterraps- Das Handbuch für Profis. DLG-Verlag, Frankfurt am Main, 103-105.

Krüger, W., 1982: Die Wurzelhals- und Stängelfäule des Rapses, verursacht durch Phoma lingam (Leptosphaeria maculans), eine schwer bekämpfbare Krankheit. Z. Pflanzenkrankh. Pflanzenschutz 89, 489-507.

Krüger, W., 1989: Untersuchung zur Verbreitung von Verticillium dahliae Kleb. und anderen Krankheits- und Schaderregern bei Raps in der Bundesrepublik Deutschland. Nachrichtenbl. Deutsch. Pflanzenschutzd. 41, 49-56.

Kruijt, M., M. J. D. de Kock \& P. J. G. M. de Wit, 2005: Receptor-like proteins involved in plant disease resistance. Mol. Plant Pathol. 6, 85-97.

Kuswinanti, T., 1996: Die Population von Phoma lingam (Tode ex. Fr.) Desm. (Teleomorph: Leptosphaeria maculans (Desm.) Ces. et de Not.) dem Erreger der Wurzelhals-und Stängelfäule des Rapses: Virulenzunterschiede auf einem erweiterten Testsortiment, Kreuzungstypen, Physiologische Eigenschaften und geographische Verbreitung. Dissertation, Universität Göttingen.

Kutscher, H., C. van den Berg \& S. Rimmer, 1993: Variation in pathogenicity of Leptosphaeria maculans on brassica spp. based on cotyledons and stem reactions. Can. J. Plant Pathol. 15, 253-258.

Francl, L., V. Madden, R. C. Rowe \& R. M. Riedel, 1990: Correlation of Growing Season Environmental Variables and the Effect of Early Dying on Potato Yield. Phytopathology 80, 425-432.

Laine, P., J. Bigot, A. Ourry and J. Boucaud, 1994: Effects of low temperature on nitrate uptake, and xylem and phloem flows of nitrogen, in Secale cereale L. and Brassica napus L. New Phytol. 127, 675-683.

Landa, B. B., J. A. Navas-Cortés \& R. M. Jimenez-Déaz, 2004: Integrated management of Fusarium wilt of chickpea with sowing date, host resistance, and biological control. Phytopathology 94, 946960. 
Langridge, D. F. \& R. D. Goodman, 1982: Honeybee pollination of oilseed rape, cultivar Midas. Austr. J. Exp. Agric. and Anim. Husbandry 22, 124-126.

Latin, R. X. \& G. L. Reed, 1985: Effect of root feeding by striped cucumber beetle larvae on the incidence and severity of Fusarium wilt of muskmelon. Phytopathology 75, 209-212.

Leath, K. T. \& A. A. Hower, 1993: Interaction of Fusarium oxysporum f. sp. medicaginis with feeding activity of clover root curculio larvae in alfalfa. Plant Disease 77, 799-802.

Leath, K. T. \& R. C. Newton, 1969: Interaction of a fungus gnat, Bradysia spp. (Sciaridae) with Fusarium spp. on alfalfa and red clover. Phytopathology 59, 257-258.

Leon, J., E. Rojo \& J.J. Sanchez-Serrano, 2001: Wound signalling in plants. J. Exp. Botany 52, 1-9.

Lépez-Escudero, F. J. \& M. A. Blanco-Lopez, 2005: Effects of drip irrigation on population of Verticillium dahliae in olive orchard. J. Phytopathology 153, 238-239.

Li, H., K. Sivasithamparam \& M. J. Barbetti 2003: Breakdown of a Brassica rapa subsp. sylvestris single dominant blackleg resistance gene in B. napus rapeseed by Leptosphaeria maculans field isolates in Australia. Plant Disease 87, 752.

Li, H., L. Damour, K. Sivasithamparam \& M. J. Barbetti 2004: Increased virulence and physiological specialisation among Western Australian isolates of Leptosphaeria maculans breaking down existing single dominant gene-based resistance in six cultivars of Brassica napus. Brassica 6, 9-16.

Li, H., N. Tapper, N. Dean, M, Barbetti \& K. Sivasithamparam, 2006: Enhanced pathogenicity of Leptosphaeria maculans pycnidiospores from paired co-inoculation of Brassica napus cotyledons with ascospores. Ann. Bot. 97, 1151-1156.

Liu, H. J. \& R. A. Butts, 1982: Delia spp. (Diptera: Anthomyiidae) infesting canola in Alberta. Can. Entomol. 114, 651-653.

Lukoschik, A. 1990: Untersuchungen zur Biologie der Kleinen Kohlfliege, Delia radicum (L.), und der Möglichkeit einer Prognose ihres ersten Erscheinens im Kohl- und Rapsanbaugebiet um Glücksstadt/Schleswig-Holstein. Dissertation, Universität Hamburg.

Lynch, D. R., L. M. Kawchuck \& J. Hachey, 1997: Identification of a gene conferring high levels of resistance to Verticillium wilt in Solanum chacoense. Plant Disease 81, 1001-1014.

Maack, G., 1977: Schadwirkung der Kleinen Kohlfliege (Phorbia brassicae Bouché) und Möglichkeiten zur Reduzierung des Insektizidaufwandes bei der Bekämpfung. Mitteilungen aus der Biologischen Bundesanstalt für Land- und Forstwirtschaft, Berlin-Dahlem.

Mace, M. E., 1978 : Contributions of tyloses and terpenoid aldehyde phytoalexins to Verticillium wilt resistance in cotton. Physiol. Plant Pathol. 12, 1-11.

Mace, M. E., R. D. Stipanovic \& A. A. Bell, 1985: Toxicity and role of terpenoid phytoalexins in Verticillium wilt resistance in cotton. Physiol. Plant Pathology 26, 209-218.

MacGuidwin, A. E. \& D. I. Rouse, 1990: Role of Pratylenchus penetrans in the Potato Early Dying disease of Russet Burbank Potato. Phytopathology 80, 1077-1082.

Mai, W. F. \& G. S. Abawi, 1987: Interactions among root-knot nematodes and Fusarium wilt fungi on host plants. Annu. Rev. Phytopathol. 25, 317-338. 
Maleck, K. \& R. A. Dietrich, 1999: Defense on multiple fronts: how do plants cope with diverse enemies? Trends in plant science reviews 4, 215-218.

Marazzi, C. \& E. Städler, 2004: Arabidopsis thaliana leaf-surface extracts are detected by the cabbage root fly (Delia radicum) and stimulate oviposition. Physiol. Entomol. 29, 192-198.

Marcroft, S., S. Sprague, P. Salisbury \& B. Howlett, 2003: Survival and dissemination of Leptosphaeria maculans in southeastern Australia. Proceedings of the $11^{\text {th }}$ International Rapeseed Congress, Copenhagen, Denmark, 1157-1159.

Marley, P. S. \& R. J. Hillocks, 1993: The role of phytoalexins in resistance to Fusarium wilt in pigeon pea (Cajanus cajan). Plant Pathol. 42, 212-218.

Marley, P. S. \& R. J. Hillocks, 1994: The effect of root-knot nematodes on cajanol accumulation in the vascular tissues of pigeonpea after stem inoculation with Fusarium udum. Plant Pathol. 43, 172176.

Martin, M. J., R. M. Riedel \& R. C. Rowe, 1982: Verticillium dahliae and Pratylenchus penetrans: interactions in the early dying complex of potato in Ohio. Phytopathology 72, 640-644.

McDonald, R. S. \& M. K. Sears, 1991: Effects of root damage by cabbage root maggot, Delia radium (L.) (Diptera: Anthomyiidae), on yield of canola, Brassica campestris L., under laboratory conditions. Can. Entomol. 123, 861-867.

McGee, D, C. \& R. W. Emmett, 1977: Black leg (Leptosphaeria maculans (Desm.) Ces. Et de Not.) of rapeseed in Victoria: Crop losses and factors which affect disease severity. Aust. J. Agric. Res. 28, 47-51.

McGregor, D. I., 1987: Effect of plant density on development and yield of rapeseed and its significance to recovery from hail injury. Can. J. Plant Science 67, 43-51.

Mendhem, N. J., P. A. Shipway \& R. K. Scott, 1981a: The effects of delayed sowing and weather on growth, development and yield of winter oil-seed rape (Brassica napus L.). J. Agric. Sci. Camb. 96, 389-416.

Mendhem, N. J., P. A. Shipway \& R. K. Scott, 1981b: The effects of seed size, autumn nitrogen and population density on the response of delayed sowing in winter oil-seed rape (Brassica napus L.). J. Agric. Sci. Camb. 96, 417-428.

Merz, F., 2005: 18 Jahre Versuche mit Kulturschutznetzen gegen Schädlinge. In: Festschrift 50 Jahre Landesanstalt für Pflanzenschutz Stuttgart, 50 Jahre integrierter Pflanzenschutz Baden-Württemberg (1955-2005). Landesanstalt für Pflanzenschutz, Stuttgart.

Michel, R. E. \& W. M. Powell, 1972: Influence of Pratylenchus brachyurus on the incidence of Fusarium wilt in cotton. Phytopathology 62, 336-338.

Mitchell, B., 1963: Ecology of two carabid beetles, Bembidion lampros (Herbst.) and Trechus quadristriatus (Schrank). J. Anim. Ecol. 32, 377-392.

Mithen, R. F. \& R. Magrath, 1992: Glucosinolates and resistance to Leptosphaeria maculans in wild and cultivated Brassica species. Plant Breed. 108, 60-68.

Mithen, R. F., 1992: Leaf glucosinolate profiles and their relationship to pest and disease resistance in oilseed rape. Euphytica 63, 71-83. 
Mol, L. \& H. W. v. Riessen, 1995: Effect of plant roots on the germination of microsclerotia of Verticillium dahliae. I. Use of root observation boxes to assess differences among crops. Eur. J. Plant Pathol. 101, 673-678.

Mol, L.,1995: Effect of plant roots on the germination of microsclerotia of Verticillium dahliae. II. Quantitative analysis of the luring effect of crops. Eur. J. Plant Pathol. 101, 679-685.

Morsink, F. \& A. E. Rich, 1968: Interactions between Verticillium albo-atrum and Pratylenchus penetrans in the Verticillium wilt of potatoes. Phytopathology 58, 401 (Abstrakt).

Mountain, W. B. \& C. D. McKeen, 1960: Increase in the incidence of Verticillium wilt of eggplant in the presence of Pratylenchus penetrans. Phytopathology 50, 647.

Mountain, W. B. \& C. D. McKeen, 1962: Effect of Verticillium dahliae on the population of Pratylenchus penetrans. Nematologica 7, 261-266.

Mukerji, M. K., 1971: Major factors in survival of the immature stages of Hylemya brassicae on cabbage. Can. Entomol. 103, 717-728.

Müller, H., 1991: Pflanzenreaktionen auf Wurzelherbivoren- Variationen, Ursachen und Mechanismen: Experimente an zweijährigen Kompositen. In: Populationsbiologie der Pflanzen (B. Schmid und J. Stöcklin, eds.). Birkhäuser Verlag Basel; Kapitel 17, 281-297.

Müller, J. L., B. Schubert, K. Pieper, S. Ihmig \& W. Hilgenberg, 1997: Glucosinolate content in susceptible and resistant chinese cabbage varieties during development of clubroot disease. Phytochemistry 44, 407-414.

Müller, J., 1973: Zum Einfluss von Pratylenchus penetrans auf die Verticillium-Welke von Impatiens balsamina. Z. Pflanzenkrankh. Pflanzenschutz 5, 295-311.

Müller, K., 2007: Einfluss von Kohlfliegenbefall auf die Infektion und Schadwirkung von Verticillium longisporum an Sommerraps. Masterarbeit, Universität Göttingen.

Ndimande, B., 1976: Studies on Phoma lingam (Tode ex. Fr.) Desm. and the dry rot in oilseed rape, Brassica napus (L.) var. oleifera Metzger. PhD- Thesis, Agricultural College of Sweden, Uppsala, Sweden.

Neveu, N., J. Grandgirard, J. P. Nenon \& A. M. Cortesero, 2002: Systemic release of herbivoreinduced plant volatiles by turnips infested by concealed root-feeding larvae Delia radicum L.. J. Chemic. Ecol. 28, 1717-1732.

Newcombe G. \& J. Robb, 1988: The function and relative importance of the vascular coating response in highly resistant, moderately resistant and susceptible alfalfa infected by Verticillium alboatrum. Physiol. Mol. Plant Pathol. 33, 47-58.

Newman, P. L. \& H. Plumridge, 1983: The effect of insect damage on the incidence of infection of Phoma lingam in winter oilseed rape. Eucarpia: Cruciferae Newsletter No. 8, November 1983, 30-31.

Newman, P. L., 1984: The effects of insect larval damage upon the incidence of canker in winter oilseed rape. Proceedings of Brighton Crop Protection Conference- Pests and Diseases, 815-822.

Nicholson, R. L. \& R. Hammerschmidt, 1992: Phenolic compounds and their role in disease resistance. Annu. Rev. Phytopathol. 30, 369-389. 
Niederleitner, S., V. Zinkernagel \& H.-C. Bartscherer, 1991: Untersuchungen zur Pathogenese von Verticillium dahliae an Impatiens balsamina und Brassica napus. Z. Pflanzenkrankh. Pflanzenschutz 98, 484-489.

Nilsson, C., 1994: Pollen beetles (Meligethes spp) in oil seed rape crops (Brassica napus L.): Biological interactions and crop losses. Dissertation, Swedish University of Agricultural Sciences, Alnarp.

Nottingham, S. F. \& T. H. Coaker, 1985: The olfactory response of cabbage root fly Delia radicum to the host plant volatile allylisothiocyanate. Entomol. Exp. Appl. 39, 307-316.

Nottingham, S. F., 1988: Host-plant finding for oviposition by adult cabbage root fly, Delia radicum. J. Insect Physiol. 34, 227-234.

Obermeyer J. \& L. Bledsoe, 2004: Rootworm Feeding (Drowning) Time. Pest \& Crop 14, 1-2.

Olsson, S. \& B. Nordbring-Hertz, 1985: Microsclerotial germination of Verticillium dahliae as affected by rape rhizosphere. FEMS Microbiol. Ecol. 31, 297-303.

Painter, R. H., 1951: Insect Resistance in Crop Plants. New York: McMillan, 520pp.

Palmer, L. T. \& T. Kommedahl, 1969: Root-infecting Fusarium species in relation to rootworm infestations in corn. Phytopathology 59, 1613-1617.

Pedigo, L. P., S. H. Hutchins \& Higley, 1986: Economic injury levels in theory and practice. Annu. Rev. Entomol. 31, 341-368.

Pegg, G. F. \& B. L. Brady, 2002 : Verticillium Wilts. CAB International, Wallingford, UK.

Peterson, K. D. \& Higley, 2001: in Peterson, K. D. \& Higley, 2001: Biotic Stress and Yield Loss. CRC Press LLC, Boca Raton, Florida. Chapter 1: Iluminating the Black Box: The Relationship Between Injury and Yield, 1-11.

Petrie, G. A. \& T. C. Vanterpool, 1974: Infestation of crucifer seed in western Canada by the blackleg fungus Leptosphaeria maculans. Can. Plant Dis. Surv. 54, 119-123.

Petrie, G. A., 1973: Herbicide damage and infection of rape by the blackleg fungus, Leptosphaeria maculans. Can. Plant Dis. Surv. 53, 26-28.

Petrie, G. A., 1985: Yield losses in Saskatchawan rapeseed/canola crops from basal stem cankers of blackleg (Leptosphaeria maculans) in 1982, with notes to other diseases. Can. Plant Dis. Surv. 65, 4346.

Pfähler, B., 1996: Charakterisierung der Abwehrreaktionen von Rapspflanzen gegen Phoma lingam unter besonderer Berücksichtigung der Anreicherung von Phytoalexinen. Dissertation, Universität Göttingen.

Pilet, M. L., G. Duplan, M. Archipiano, P. Barret, C. Baron, R. Horvais, X. Tanguy, M. O. Lucas, M. Renard \& R.Delourme, 2001: Stability of QTL for field resistance to blackleg across two genetic backgrounds in oilseed rape. Crop Sci. 41, 197-205.

Pilet, M. L., R. Delourme, N. Foisset \& M. Renard, 1998: Identification of loci contributing to quantitative field resistance to blackleg disease, causal agent Leptosphaeria maculans (Desm.) Ces. Et de Not., in winter rapeseed (Brassica napus L.). Theor. Appl. Genet. 96, 23-30. 
Pongam, P., T. C. Osborn \& P. H. Williams, 1998: Genetic analysis and identification of Amplified Fragment Length Polymorphism markers linked to the alm1 avirulence gene of Leptosphaeria maculans. Phytopathology 88, 1068-1072.

Porter, D. M. \& J. C. Smith, 1974: Fungal colonization of peanut fruit as related to southern corn rootworm injury. Phytopathology 64, 249-251.

Powell, N. T., 1971: Interactions between nematodes and fungi in disease complexes. Annu. Rev. Phytopathol. 9, 253-274.

Price, D. W., 1975: Passage of Verticillium albo-atrum propagules through the alimentary canal of the bulb mite. Phytopathology 66, 46-50.

Prokopy, R. J., R. H. Collier \& S. Finch, 1983a: Visual detection of host plants by cabbage root flies. Entomol. Exp. Appl. 34, 85-89.

Prokopy, R. J., R. H. Collier \& S. Finch, 1983b: Leaf colour: a character used by cabbage root flies to distinguish among host plants. Science 221, 190-192.

Pullmann, G. S. \& J. E. DeVay, 1982: Epidemiology of Verticillium wilt of cotton : A relationship between inoculum density and disease progression. Phytopathology 72, 549-553.

Quanjer, H. M., 1907: Neue Kohlkrankheiten in Nord-Holland (Drehherzkrankheit, Fallsucht und Krebs). Z. Pflanzenkrankh. Pflanzenschutz 17, 258-267.

Reader, P. M. \& T. H. Jones, 1990: Interactions between an eucoilid (Hymenoptera) and a staphylinid (Coleoptera) parasitoid of the cabbage root fly. Entomophaga 35, 241-246.

Resende, M. L. V., J. Flood \& R. M. Cooper, 1995: Effect of method of inoculation, inoculum density and seedling age at inoculation on the expression of resistance of cocoa (Theobroma cacao L.) to Verticillium dahliae Kleb. Plant Pathol. 44, 374-383.

Resende, M. L. V., J. Flood, J. D. Ramsden, M. G. Rowan, M. H. Beale \& R. M. Cooper, 1996: Novel phytoalexins including elemental sulphur in the resistance of cocoa (Theobroma cacao L.) to Verticillium wilt (Verticillium dahliae Kleb.). Physiol. Mol. Plant Pathol. 48, 347-359.

Richards, R. A. \& N. Thurling, 1978: Variation between and within species of rapeseed (Brassica campestris and Brassica napus) in response to drought stress. 1. Sensitivity at different stages of development. Aust. J. Agric. Res. 29, 469-477.

Riedel, R. M., R. C. Rowe \& M. J. Martin, 1985: Differential interactions of Pratylenchus crenatus, Pratylenchus penetrans and Pratylenchus scribneri with Verticillium dahliae in potato early dying disease. Phytopathology 75, 419-422.

Rimmer, S. R. \& C. G. J. van den Berg, 1992: Resistance of oilseed rape Brassica spp. to blackleg caused by Leptosphaeria maculans. Can. J. Plant Pathol. 14, 56-66.

Robinson, D. B, R. H. Larson \& J. C. Walker, 1957: Verticillium wilt of potatos in relation to symptoms, epidemiology and variability of the pathogen. Bulletin of the Wisconsin Agricultural Experimental Station 202, 1-49.

Roessingh, P. \& E. Städler, 1990: Foliar form, colour and surface characteristics influence oviposition behaviour in the cabbage root fly, Delia radicum. Entomol. Exp. Appl. 57, 93-100. 
Roessingh, P., E. Städler, G. R. Fenwick, J. A. Lewis, J. K. Nielsen R., J. Hurter \& T. Ramp, 1992: Oviposition and tarsal chemoreceptors of the cabbage root fly are stimulated by glucosinolates and host plant extracts. Entomol. Exp. Appl. 65, 267-282.

Roessingh, P., E. Städler, R. Baur, J. Hurter \& T. Ramp, 1997: Tarsal chemoreceptors and oviposition behaviour of the cabbage root fly, Delia radicum. Physiol. Entomol. 22, 140-148.

Rotenberg, D., A. E. MacGuidwin, I. A. M. Saeed \& D. I. Rouse, 2004: Interaction of spatially separated Pratylenchus penetrans and Verticillium dahliae on potato measured by impaired photosynthesis. Plant Pathol. 53, 294-302.

Rouxel, T. \& M. H. Balesdent, 2005: The stem canker (blackleg) fungus, Leptosphaeria maculans, enters the genomic era. Mol. Plant Pathol. 6, 225-241.

Rouxel, T., A. Kollmann, L. Boulidard \& R. Mithen, 1991: Abiotic elicidation of indole pyytoalexins and resistance to Leptosphaeria maculans within brassicae. Planta 184, 271-278.

Rouxel, T., A. Penaud, X. Pinochet, H. Brun, L. Gout, R. Delourme, J. Schmit \& M.H. Balesdent, 2003: A 10-year survey of populations of Leptosphaeria maculans in France indicates a rapid adaption towards the Rlm1 resistance gene of oilseed rape. Eur. J. Plant Pathol. 109, 871-881.

Rowe, R. C., R. M. Riedel \& M. J. Martin, 1985: Synergistic interactions between Verticillium dahliae and Pratylenchus penetrans in potato early dying disease. Phytopathology 75, 412-418.

Roy, N. N., 1984: Interspecific transfer of Brassica juncea-type high blackleg resistance to Brassica napus. Euphytica 33, 295-303.

Ryan, C., 1990: Protease inhibitors in plants: genes for improving defences against insects and pathogens. Annu. Rev. Phytopathol. 28, 425-449.

Ryan, J., M. F. Ryan \& F. McNaeidhe, 1980: The effect of interrow plant cover on populations of the cabbage root fly, Delia brassicae (Wiedemann). J. Appl. Ecol. 17, 31-40.

Ryder, H. W. \& H. W. Crittenden, 1965: Relationship of Meloidogyne incognita acrita and Plasmodiophora brassicae in cabbage roots. Phytopathology 55, 506 (Abstract).

Rygulla, W., R. J. Snowdon, C. Eynck, A. von Tiedemann, W. Lühs \& W. Friedt, 2007: Broadening the genetic basis of Verticillium longisporum resistance in Brassica napus by interspecific hybridisation. Phytopathology 97, 1391-1396.

Rygulla, W., R. J. Snowdon, W. Friedt, I. Happstadius, W. Y. Ceung \& D. Chen, 2008: Identification of quantitative trait loci for resistance against Verticillium longisporum in oilseed rape (Brassica napus). Phytopathology 98, 215-221.

Sadowski C., D. Zielinski, J. Klepin \& K. Zawislak, 1995: The health status of winter rape cultivated for many years with monoculture and crop rotation. Proceedings of the 9th International Rapeseed Congress. Rapeseed today and tomorrow, 4 to 7 July 1995, Cambridge, UK, 1231-1233.

Saeed, I. A. M., A. E. MacGuidwin \& D. I. Rouse, 1997: Synergism of Pratylenchus penetrans and Verticillium dahliae manifested by reduced gas exchange in potato. Phytopathology 87, 435-439.

Saeed, I. A. M., A. E. MacGuidwin, D. I. Rouse \& C. Malek, 2007: A field study on the influence of Verticillium dahliae and Pratylenchus penetrans on gas exchange of potato. Plant Disease 91, 15311535. 
Salisbury, P. A., D. J. Ballinger, N. Wratten, K. M. Plummer \& B. J. Howlett, 1995: Blackleg disease on oilseed rape Brassica in Australia: a review. Aust. J. Exp. Agric. 35, 665-672.

Scarisbrick, D. H., R. W. Daniels \& M. Alcock, 1981: The effect of sowing date on the yield and yield components of spring oil-seed rape. J. Agric. Sci. Camb. 97, 189-195.

Schnathorst, W. C. \& D. E. Mathre, 1966: Host range and differentiation of a severe form of Verticillium albo- atrum in cotton. Phytopathology 56, 1155-1161.

Schnitzler, W. H., 1969: Über den Einfluss des Bodens, der Düngung, der Bewässerung, des Aussaattermins und der Sorten auf den Befall von Rettich und Radieschen durch die Kleine Kohlfliege, Phorbia brassicae Bouché (Diptera, Anthomyiidae). Z. Angew. Entomol. 64, 353-377.

Scholander, P. F., H.T. Hammel, E. D. Bradstreet \& E. A. Hemmingsen, 1965: Sap pressure in vascular plants. Science 148, 339-346.

Schreiber L. R. \& R. J. Green, 1963: Effect of root exudates on germination of conidia and microsclerotia of Verticillium albo-atrum inhibited by the soil fungistatic principle. Phytopathology $53,260-264$.

Schulz, R.-R. \& F. Daebeler, 1984: Zum Schaden durch den Rapserdfloh (Psylliodes chrysocephala L.), insbesondere seiner Imagines. Nachrichtenbl. Pflanzenschutz DDR 38, 113-115.

Schulz, R.-R., 1992: Einfluss von tierischen Schaderregern auf Ertragskomponenten und Pilzbefall von Winterraps. Raps 10, 37-39.

Schwantes, H.O., 1996 : Biologie der Pilze. Verlag Eugen Ulmer, Stuttgart.

Selman J. W. \& W. R. Buckley, 1959: Factors affecting the invasion of tomato roots by Verticillium albo-atrum. Trans. Br. Mycol. Soc. 42, 227-234.

Shoemaker, R. A. \& H. Brun, 2001: The teleomorph of the weakly aggressive segregate of Leptosphaeria maculans. Can. J. Botany 79, 412-419.

Sidhu, G. \& J. M. Webster, 1977: Predisposition of tomato to the wilt fungus (Fusarium oxysporum lycopersici) by the root-knot nematode (Meloidogyne incognita). Nematologica 23, 433-442.

Smith, H. \& B. Sutton, 1964: Leptosphaeria maculans the ascogenous state of Phoma lingam. Trans. Br. Mycol. Soc. 47, 159-164.

Soesanto, L. \& A. J. Termorshuizen, 2001: Effect of temperature on the formation of microsclerotia of Verticillium dahliae. J. Phytopathology 149, 685-691.

Sosnowski, M. R., E. S. Scott \& M. D. Ramsey, 2006: Survival of Leptosphaeria maculans in soil on residues of Brassica napus in South Australia. Plant Pathol. 55, 200-206.

Sosnowski, M., M. Ramsey, G. Murray, E. Scott \& C. Wilshurst, 2001: Symptoms of blackleg (Leptosphaeria maculans) on the roots of canola in Australia. Plant Pathol. 50, 808.

Spike, B. P. \& J. J. Tollefson, 1989a: Relationship of plant phenology to corn yield loss resulting from western corn rootworm (Coleoptera: Chrysomelidae). J. Econ. Entomol. 82, 226-231. 
Spike, B. P. \& J. J. Tollefson, 1989b: Relationship of root ratings, root size, and root regrowth to yield of corn injured by western corn rootworm (Coleoptera: Chrysomelidae). J. Econ. Entomol. 82, 17601763.

Sprague, S. J., M. H. Balesdent \& H. Brun, 2006: Major gene resistance in Brassica napus (oilseed rape) is overcome by changes in virulence of populations of Leptosphaeria maculans in France and Australia. Eur. J. Plant Pathol. 114, 33-40.

Sprague, S. J., M. Watt, J. A. Kirkegaard \& B. J. Howlett, 2007: Pathways of infection of Brassica napus roots by Leptosphaeria maculans. New Phytologist 176, 211-222.

Städler, E., 1978: Chemoreception of host plant chemicals by ovipositing females of Delia (Hylemya) brassicae. Entomol. Exp. Appl. 24, 511-520.

Steinbach, P., H. Kreye \& G. A. Wolf, 2005: Bundesweites Verticillium-Monitoring: Bewertung von Diagnosesicherheit und Risikofaktoren. Raps 1, 20-26.

Steventon, L. A., I. Happstadius, P. Okori \& C. Dixelius, 2002: Development of a rapid technique for the evaluation of the response of Brassica napus to Verticillium wilt. Plant Disease 86, 854-858.

Storey, G. W. \& K. Evans, 1987: Interactions between Globodera pallida juveniles, Verticillium dahliae and three potato cultivars, with descriptions of associated histopathologies. Plant Pathol. 36, 192-200.

Sumner, D. R. \& C. C. Dowler, 1983: Herbicide, planting date, and root disease interactions in corn. Plant Disease 67, 513-517.

Svensson, C. \& C. Lerenius, 1987: An investigation on the effect of Verticillium wilt (Verticillium dahliae Kleb.) on oilseed rape. Bulletin SROP 10, 30-34.

Swailes, G. E., 1958: Periods of flight and oviposition of the cabbage maggot, Hylemya brassicae (Bouché) (Diptera: Anthomyiidae), in southern Alberta. Can. Entomol. 90, 434-435.

Swailes, G. E., 1960: Laboratory evaluation of resistance in rutabaga varieties to the cabbage maggot, Hylemya brassicae (Bouché) (Diptera: Anthomyiidae). Can. Entomol. 92, 958-960.

Swailes, G. E., 1963: Effects of temperature on hatching and on longevity of starved first-instar larvae of Hylemya brassicae (Bouché) (Diptera: Anthomyiidae). Can. Entomol. 95, 878-881.

Talboys, P. W., 1958: Some mechanisms contributing to Verticillium-resistance in the hop root. Trans. Br. Mycol. Soc. 41, 227-241

Tatchel, G. M., 1983: Compensation in spring-sown oilseed rape (Brassica napus L.) plants in response to injury to their flower buds and pods. J. Agric. Sci. Camb. 101, 565-573.

Taylor, J. E., P. E. Hatcher \& N. D. Paul, 2004: Crosstalk between plant responses to pathogens and herbivores: a view from the outside in. J. Exp. Botany 55, 159-168.

Thaler, J. S., B. Owen \& V. J. Higgins, 2004: The role of the jasmonate response in plant susceptibility to diverse pathogens with a range of lifestyles. Plant Physiol. 135, 530-538.

Thompson, A. R., D. L. Suett \& A. L. Percivall, 1979: Protection of radish from cabbage root fly damage by seed treatment with organophosphorus and carbamate insecticides. Ann. Appl. Biol. 94, 110 . 
Thürwächter, F., 1995: Kriterien für die Bekämpfung von Rapskrankheiten unter besonderer Berücksichtigung der Wurzelhals- und Stängelfäule. Dissertation Universität Göttingen, Cuvillier Verlag Göttingen.

Travadon, R., L. Bousset, S. Saint-Jean, H. Brun \& I. Sache, 2007: Splash dispersal of Leptosphaeria maculans pycnidiospores and the spread of blackleg on oilseed rape. Plant Pathol. 56, 595-603.

Traynier, R. M. M., 1965: Chemostimulation of oviposition by the cabbage root fly, Erioischia brassicae. Nature 207, 218.

Traynier, R. M. M., 1967: Effect of host plant odour on the behaviour of the adult cabbage root fly, Erioischia brassicae. Entomol. Exp. Appl. 10, 321-328.

Tukahirwa, E. M. \& T. H. Coaker, 1982: Effect of missed cropping on some insect pests of brassicas; reduced Brevicoryne brassicae infestations and influences of epigeal predators and the disturbance of oviposition behaviour in Delia brassicae. Entomol. Exp. Appl. 32, 129-140.

Tuttle, A. F., D. N. Ferro \& K. Idoine, 1988: Role of visual and olfactory stimuli in host finding of cabbage root lies, Delia radium. Entomol. Exp. Appl. 47, 37-44.

Ulber, B., 1994: Wirkung des kombinierten Befalls von Winterraps mit dem Großen Rapsstängelrüssler (Ceutorhynchus napi Gyll.) und dem Gefleckten Kohltriebrüssler (Ceutorhynchus pallidactylus (Mrsh.) auf den Befall von Phoma lingam. Mitt. Biol. Bundesanst. Land- und Forstwirtsch. 301, 96.

Ulber, B., U. Jeche, H. Keunecke \& R. Wedemeyer, 2006: Einfluss der Bodenbearbeitung auf die Schlupfabundanz und Befallsstärke der Kleinen Kohlfliege (Delia radicum (L.)). Mitt. Biol. Bundesanst. Land- und Forstwirtsch. 400, 114.

Van Dam, N. M. \& C. E. Raaijmakers, 2006: Local and systemic induced responses to cabbage root fly larvae (Delia radicum) in Brassica nigra and B. oleracea. Chemoecology 16, 17-24.

Van Gundy, S. D., J. D. Kilpatrick \& J. Golden, 1977: The nature and role of metabolic leakage from root-knot nematode galls and infection by Rhicoctonia solani. J. Nematol. 9, 113-121.

Vanniasingham, V. M. \& C. A. Gillingan, 1988: Effects of biotic and abiotic factors on germination of pycnidiospores of Leptosphaeria maculans in vitro. Trans. Br. Mycol. Soc. 90, 415-420.

Vereecke, A. \& L. Hertveldt, 1970: Laboratory rearing of the cabbage maggot. J. Econ. Entomol. 64, 670-672.

Veronese, P., M. L. Narasimhan, R. A. Steventon, J. K. Zhu, S. C. Weller, K. V. Subbarao \& R. A. Bressan, 2003: Identification of a locus controlling Verticillium disease symptom response in Arabidopsis thaliana. Plant Journal 35, 574-587.

Wahmhoff, W., 2000: Integrierter Rapsanbau: Untersuchungen zur Entwicklung integrierter Produktionsverfahren am Beispiel des Winterrapses (Brassica napus L.). Erich Schmidt-Verlag, Berlin.

Weinhold, A. R., R. L. Dodman \& T. Bowman, 1972: Influence of exogenious nitrogen on virulence of Rhicoctonia solani. Phytopathology 62, 278-281. 
West, J. S., B. D. L. Fitt, P. K. Leech, J. E. Biddulph \& Y- J. Huang, 2002: Effects of timing of Leptosphaeria maculans ascospore release and fungicide regime on phoma leaf spot and phoma stem canker development on winter oilseed rape (Brassica napus) in southern England. Plant Pathol. 51, 454-463.

West, J. S., P. D. Kharbandra, M. J. Barbetti \& B. D. L. Fitt, 2001: Epidemiology and management of Leptosphaeria maculans (phoma stem canker) on oilseed rape in Australia, Canada and Europe. Plant Pathol. 50, 10-27.

Wheeler, T. A., L. V. Madden, R. M. Riedel \& R. C. Rowe, 1994: Distribution and yield-loss relations of Verticillium dahliae, Pratylenchus penetrans, P.scribneri, P. crenatus, and Meloidogyne hapla in commercial potato fields. Phytopathology 80, 843-852.

Wherrett, A. D., K. Sivasithamparam \& M. J. Barbetti, 2004: Establishing the relationship of ascospore loads with blackleg (Leptosphaeria maculans) severity on canola (Brassica napus). Aust. J. Agric. Res. 55, 849-854.

Wildhagen, V., 1972: Holozäne Bodenentwicklung, Sedimentbildung und Geomorphogenese im Flussauen-Bereich des Göttinger Leinegrabens, Dissertation, Universität Göttingen.

Williams, I. H. \& J. B. Free, 1979: Compensation of oilseed rape (Brassica napus L.) plants after damage to their buds and pods. J. Agric. Sci. Camb. 92, 53-59.

Williams, I. H., A. P. Martin \& R. P. White, 1987: The effect of insect pollination on plant development and seed production in winter oilseed rape (Brassica napus L.). J. Agric. Sci. Camb. 109, 135-139.

Williams, J., S. A. Hall, M. J. Hawkesford, M. H. Beale \& R. M. Cooper, 2002: Elemental sulphur and thiol accumulation in tomato and defence against a fungal vascular pathogen. Plant Physiol. 128, 150-159.

Williams, P., 1992: Biology of Leptosphaeria maculans. Can. J. Plant Pathol. 14, 30-35.

Williams, R. H. \& B. D.L. Fitt, 1999: Differentiating A and B groups of Leptosphaeria maculans. Can. J. Plant Pathol. 48, 161-175.

Wohlleben, S., 2001: Epidemie- und Schadensdynamik von pilzlichen Krankheitserregern (Leptosphaeria maculans, Sclerotinia sclerotiorum, Verticillium dahliae) an Winterraps (Brassica napus L. var. napus) in Schleswig-Holstein. Dissertation, Universität Kiel.

Wolf; G. A. \& J. Weinert, 2003: Problemschläge früh erkennen. DLG- Mitt. 7, 48-50.

Wood, P. Mcr. \& M. J.Barbetti, 1977: A study on the inoculation of rape seedlings with ascospores and pyknidiospores of the blackleg disease causal agent Leptosphaeria maculans. J. Inst. Agric. Sci. 43, 79-80.

Wretblad, S. \& C. Dixelius, 2000: B-genome derived resistance to Leptosphaeria maculans in near isogenic Brassica napus is independent of glucosinolate profile. Physiol. Plant. 110, 461-468.

Xiau, C. L. \& K. V. Subbarao, 1998: Relationships between Verticillium dahliae inoculum density and wilt incidence, severety, and growth of cauliflower. Phytopathology 88, 1108-1115. 
Xiau, C. L., K. V. Subbarao, K. F. Schulbach \& S. T. Koike, 1998: Effects of crop rotation and irrigation on Verticillium dahliae microslerotia in soil and wilt in cauliflower. Phytopathology 88, 1046-1055.

Yousaf, M., A. Ahmad, M. Jahangir \& T. Naseeb, 2002: Effect of different sowing dates on the growth and yield of canola (Sarson) varieties. Asian J. Pl. Sci. 1, 634-635.

Zeise, K., D. Seidel \& D. Amelung, 1990: Zum Befallsverlauf von Verticillium dahliae Kleb. an Winterraps. Arch. Phytopathol. Pflanzenschutz, Berlin 26, 205-207.

Zeise, K., 1992: Gewächshaustest zur Resistenzprüfung von Winterraps (Brassica napus L. var. oleifera Metzger) gegen den Erreger der Rapswelke Verticillium dahliae Kleb.. Nachrichtenbl. Deutsch. Pflanzenschutzd. 44, 125-128.

Zeise, K. \& M. Buchmüller, 1997: Studies on the susceptibility to Verticillium dahliae Kleb. var. longisporum Stark of six related Brassica species. Z. Pflanzenkrankh. Pflanzenschutz 104, 501-505.

Zeise, K. \& A. v. Tiedemann, 2002: Host specialization among vegetative compatibility groups of Verticillium dahliae in relation to Verticillium longisporum. J. Phytopathology 150, 112-119.

Zhou, L., Q. Hu, A. Johansson \& C. Dixelius, 2006: Verticillium longisporum and V. dahliae: infection and disease in Brassica napus. Plant Pathol. 55, 137-144.

Zhou, Y., B. D. L. Fitt, S. J. Welham, P. Gladders, C. E. Sansford \& J. S. West, 1999: Effects of severity and timing of stem canker (Leptosphaeria maculans) symptoms on yield of winter oilseed rape (Brassica napus) in the UK. Eur. J. Plant Pathol. 105, 715-728.

Zohren, E., 1968: Laboruntersuchungen zu Massenanzucht, Lebensweise, Eiablage und Eiablageverhalten der Kohlfliege, Chortophila brassicae Bouché (Diptera: Anthomyiidae). Z. Angew. Entomol. 62, 139-188. 


\section{Anhang}

Tab. 1A: Versuchsplan Sortenversuch 2005/2006 (Schlag „Große Breite“, Weende).

\begin{tabular}{|c|c|c|c|c|c|c|c|c|c|c|c|c|c|c|c|}
\hline \multicolumn{8}{|c|}{ Verticillium } & \multicolumn{8}{|c|}{$(P h \text {-Frühjahr })^{*}$} \\
\hline 1 & 1 & 2 & 2 & 3 & 3 & 4 & 4 & 1 & 1 & 2 & 2 & 3 & 3 & 4 & 4 \\
\hline 1 & 1 & 2 & 2 & 3 & 3 & 4 & 4 & 1 & 1 & 2 & 2 & 3 & 3 & 4 & 4 \\
\hline \multicolumn{8}{|c|}{$P h$-Herbst } & \multicolumn{8}{|c|}{ Kontrolle } \\
\hline 2 & 2 & 4 & 4 & 1 & 1 & 3 & 3 & 2 & 2 & 4 & 4 & 1 & 1 & 3 & 3 \\
\hline 2 & 2 & 4 & 4 & 1 & 1 & 3 & 3 & 2 & 2 & 4 & 4 & 1 & 1 & 3 & 3 \\
\hline \multicolumn{8}{|c|}{$(P h$-Frühjahr $) *$} & \multicolumn{8}{|c|}{ Ph-Herbst } \\
\hline 3 & 3 & 1 & 1 & 4 & 4 & 2 & 2 & 3 & 3 & 1 & 1 & 4 & 4 & 2 & 2 \\
\hline 3 & 3 & 1 & 1 & 4 & 4 & 2 & 2 & 3 & 3 & 1 & 1 & 4 & 4 & 2 & 2 \\
\hline \multicolumn{8}{|c|}{ Kontrolle } & \multicolumn{8}{|c|}{ Verticillium } \\
\hline 4 & 4 & 3 & 3 & 2 & 2 & 1 & 1 & 4 & 4 & 3 & 3 & 2 & 2 & 1 & 1 \\
\hline 4 & 4 & 3 & 3 & 2 & 2 & 1 & 1 & 4 & 4 & 3 & 3 & 2 & 2 & 1 & 1 \\
\hline \multicolumn{8}{|c|}{ Verticillium } & \multicolumn{8}{|c|}{$(P h \text {-Frühjahr })^{*}$} \\
\hline 3 & 3 & 1 & 1 & 4 & 4 & 2 & 2 & 1 & 1 & 2 & 2 & 3 & 3 & 4 & 4 \\
\hline 3 & 3 & 1 & 1 & 4 & 4 & 2 & 2 & 1 & 1 & 2 & 2 & 3 & 3 & 4 & 4 \\
\hline \multicolumn{8}{|c|}{$P h$-Herbst } & \multicolumn{8}{|c|}{ Kontrolle } \\
\hline 4 & 4 & 3 & 3 & 2 & 2 & 1 & 1 & 3 & 3 & 1 & 1 & 4 & 4 & 2 & 2 \\
\hline 4 & 4 & 3 & 3 & 2 & 2 & 1 & 1 & 3 & 3 & 1 & 1 & 4 & 4 & 2 & 2 \\
\hline \multicolumn{8}{|c|}{$(P h \text {-Frühjahr })^{*}$} & \multicolumn{8}{|c|}{ Ph-Herbst } \\
\hline 2 & 2 & 4 & 4 & 1 & 1 & 3 & 3 & 4 & 4 & 3 & 3 & 2 & 2 & 1 & 1 \\
\hline 2 & 2 & 4 & 4 & 1 & 1 & 3 & 3 & 4 & 4 & 3 & 3 & 2 & 2 & 1 & 1 \\
\hline \multicolumn{8}{|c|}{ Kontrolle } & \multicolumn{8}{|c|}{ Verticillium } \\
\hline 1 & 1 & 2 & 2 & 3 & 3 & 4 & 4 & 2 & 2 & 4 & 4 & 1 & 1 & 3 & 3 \\
\hline 1 & 1 & 2 & 2 & 3 & 3 & 4 & 4 & 2 & 2 & 4 & 4 & 1 & 1 & 3 & 3 \\
\hline
\end{tabular}

Parzelle:

1,25 m x 10 m (linke Parzelle: Ernteparzelle; rechte Parzelle: Probeparzelle)

Sorten:

1) Laser 2) Lion 3) Oase 4) Caiman

Saatgutbehandlung: $\quad$ Elado + Streumittel Nexion Neu (obere Blockreihe); Chinook (untere Blockreihe)

Inokulationsvarianten: Kontrolle; Verticillium-Bodeninokulation; Phoma-Herbstinokulation;

* Phoma-Frühjahrsinokulation wurde nicht durchgeführt. 
Tab. 2A: Versuchsplan Sortenversuch 2006/2007 (Schlag „Große Lage“, Weende).

\begin{tabular}{|c|c|c|c|c|c|c|c|c|c|c|c|c|c|c|c|}
\hline \multicolumn{4}{|c|}{ Verticillium } & \multicolumn{4}{|c|}{ Kontrolle } & \multicolumn{4}{|c|}{$P h$-Herbst } & \multicolumn{4}{|c|}{ Kontrolle } \\
\hline $1 \mathrm{a}$ & $1 \mathrm{a}$ & $2 b$ & $2 b$ & $3 a$ & $3 a$ & $4 b$ & $4 b$ & $4 c$ & $4 c$ & $3 b$ & $3 b$ & $4 b$ & $4 b$ & $4 a$ & $4 a$ \\
\hline $2 c$ & $2 c$ & $1 \mathrm{c}$ & $1 \mathrm{c}$ & $4 c$ & $4 c$ & $3 c$ & $3 c$ & $3 a$ & $3 a$ & $4 b$ & $4 b$ & $1 \mathrm{~b}$ & $1 \mathrm{~b}$ & $1 \mathrm{a}$ & $1 \mathrm{a}$ \\
\hline $1 \mathrm{~b}$ & $1 b$ & $2 \mathrm{a}$ & $2 \mathrm{a}$ & $3 b$ & $3 b$ & $4 a$ & $4 a$ & $4 a$ & $4 a$ & $3 c$ & $3 c$ & $1 \mathrm{c}$ & $1 \mathrm{c}$ & $4 c$ & $4 c$ \\
\hline \multicolumn{4}{|c|}{$P h$-Herbst } & \multicolumn{4}{|c|}{ Kontrolle } & \multicolumn{4}{|c|}{$P h$-Frühjahr } & \multicolumn{4}{|c|}{ Verticillium } \\
\hline $4 a$ & $4 a$ & $3 c$ & $3 c$ & $2 \mathrm{c}$ & $2 \mathrm{c}$ & $1 \mathrm{~b}$ & $1 \mathrm{~b}$ & $4 c$ & $4 c$ & $3 b$ & $3 b$ & $1 b$ & $1 b$ & $2 a$ & $2 \mathrm{a}$ \\
\hline $3 b$ & $3 b$ & $4 c$ & $4 c$ & $1 \mathrm{a}$ & $1 \mathrm{a}$ & $2 b$ & $2 b$ & $3 a$ & $3 a$ & $4 b$ & $4 b$ & $2 \mathrm{~b}$ & $2 \mathrm{~b}$ & $1 \mathrm{a}$ & $1 \mathrm{a}$ \\
\hline $3 a$ & $3 \mathrm{a}$ & $4 b$ & $4 b$ & $2 \mathrm{a}$ & $2 \mathrm{a}$ & $1 \mathrm{c}$ & $1 \mathrm{c}$ & $4 a$ & $4 a$ & $3 c$ & $3 c$ & $1 \mathrm{c}$ & $1 \mathrm{c}$ & $2 \mathrm{c}$ & $2 \mathrm{c}$ \\
\hline \multicolumn{4}{|c|}{$P h$-Frühjahr } & \multicolumn{4}{|c|}{ Verticillium } & \multicolumn{4}{|c|}{ Kontrolle } & \multicolumn{4}{|c|}{$P h$-Herbst } \\
\hline $3 b$ & $3 b$ & $4 a$ & $4 a$ & $2 \mathrm{a}$ & $2 \mathrm{a}$ & $1 \mathrm{c}$ & $1 \mathrm{c}$ & $4 a$ & $4 a$ & $2 \mathrm{c}$ & $2 \mathrm{c}$ & $3 a$ & $3 a$ & $4 b$ & $4 b$ \\
\hline $4 b$ & $4 b$ & $3 a$ & $3 a$ & $1 b$ & $1 b$ & $2 c$ & $2 c$ & $2 b$ & $2 b$ & $4 c$ & $4 c$ & $4 c$ & $4 c$ & $3 c$ & $3 c$ \\
\hline $3 c$ & $3 c$ & $4 c$ & $4 c$ & 1a & $1 \mathrm{a}$ & $2 b$ & $2 b$ & $2 \mathrm{a}$ & $2 a$ & $4 b$ & $4 b$ & $3 b$ & $3 b$ & $4 a$ & $4 a$ \\
\hline \multicolumn{4}{|c|}{ Kontrolle } & \multicolumn{4}{|c|}{ Ph-Herbst } & \multicolumn{4}{|c|}{ Kontrolle } & \multicolumn{4}{|c|}{$P h$-Frühjahr } \\
\hline $3 b$ & $3 b$ & $4 a$ & $4 a$ & $3 b$ & $3 b$ & $4 a$ & $4 a$ & $3 a$ & $3 a$ & $1 \mathrm{~b}$ & $1 \mathrm{~b}$ & $4 a$ & $4 a$ & $3 c$ & $3 c$ \\
\hline $4 b$ & $4 b$ & $3 a$ & $3 a$ & $4 b$ & $4 b$ & $3 a$ & $3 a$ & $1 \mathrm{c}$ & $1 \mathrm{c}$ & $3 c$ & $3 c$ & $3 b$ & $3 b$ & $4 c$ & $4 c$ \\
\hline $3 c$ & $3 c$ & $4 c$ & $4 c$ & $3 c$ & $3 c$ & $4 c$ & $4 c$ & $3 b$ & $3 b$ & $1 \mathrm{a}$ & $1 \mathrm{a}$ & $3 a$ & $3 a$ & $4 b$ & $4 b$ \\
\hline \multicolumn{2}{|c|}{ Kontrolle } & & & \multicolumn{4}{|c|}{$P h$-Frühjahr } & \multicolumn{4}{|c|}{ Verticillium } & \multicolumn{4}{|c|}{ Kontrolle } \\
\hline $1 \mathrm{a}$ & $1 \mathrm{a}$ & $2 \mathrm{~b}$ & $2 \mathrm{~b}$ & $3 a$ & $3 a$ & $4 \mathrm{~b}$ & $4 b$ & $2 \mathrm{c}$ & $2 \mathrm{c}$ & $1 \mathrm{~b}$ & $1 \mathrm{~b}$ & $3 b$ & $3 \mathrm{~b}$ & $2 \mathrm{a}$ & $2 \mathrm{a}$ \\
\hline $2 c$ & $2 c$ & $1 \mathrm{c}$ & $1 \mathrm{c}$ & $4 c$ & $4 c$ & $3 c$ & $3 c$ & $1 \mathrm{a}$ & 1a & $2 b$ & $2 b$ & $2 b$ & $2 b$ & $3 a$ & $3 a$ \\
\hline $1 b$ & $1 b$ & $2 \mathrm{a}$ & $2 \mathrm{a}$ & $3 b$ & $3 b$ & $4 a$ & $4 a$ & $2 \mathrm{a}$ & $2 \mathrm{a}$ & $1 \mathrm{c}$ & $1 \mathrm{c}$ & $3 c$ & $3 c$ & $2 c$ & $2 c$ \\
\hline
\end{tabular}

Parzelle: $\quad$ Doppelparzelle $2 \times(1,25 \mathrm{~m} \times 10 \mathrm{~m})$

Netzabdeckungsvarianten: a) ohne Netzabdeckung

b) Netzabdeckung im Herbst

c) Netzabdeckung im Herbst + Frühjahr

Sorten:

1) Laser

2) Lion

3) Viking

4) Caiman

Inokulationsvarianten: Kontrolle (alle Sorten)

Verticillium-Bodeninokulation (Laser und Lion)

Phoma-Herbstinokulation (Viking und Caiman)

Phoma-Frühjahrsinokulation (Viking und Caiman) 
Tab. 3A: Versuchsplan Sortenversuch 2007/2008 (Schlag „Dragoneranger“, Weende).

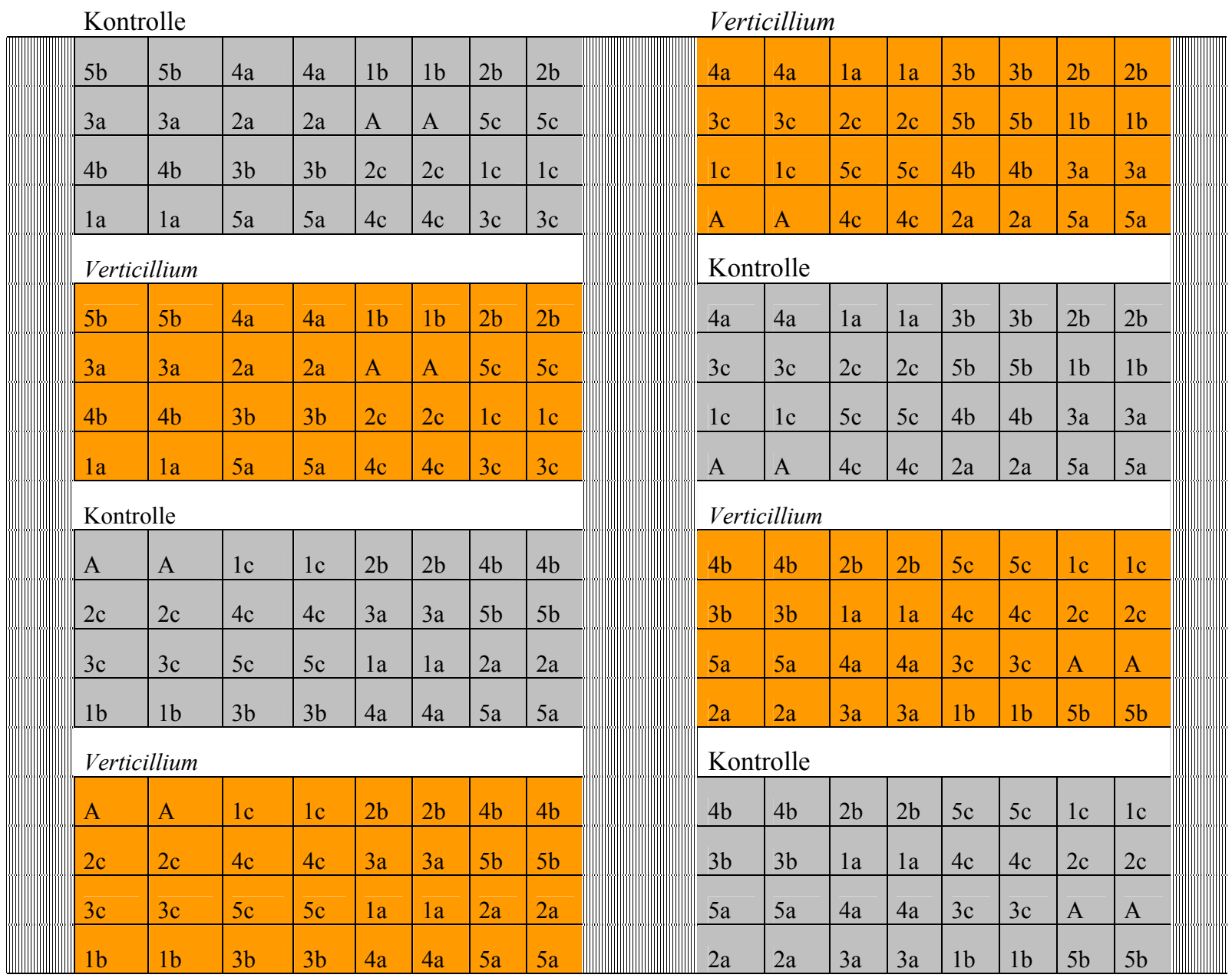

Parzelle:

Doppelparzelle $2 \times(1,25 \mathrm{~m} \times 10 \mathrm{~m})$

Netzabdeckung/Insektizide: a) ohne Netzabdeckung/ Chinook

b) Netzabdeckung im Herbst/ Chinook

c) ohne Netzabdeckung/ Oftanol T + Nexion Neu

Sorten:
1) Laser
2) Caiman
3) Lion
4) NK Fair
5) Aviso

Inokulationsvarianten: Kontrolle

Verticillium-Bodeninokulation 
Tab. 4A: Versuchsplan Anbaufaktorenversuch 2005/2006 (Schlag „Große Breite“, Weende) und 2006/2007 (Schlag „Wäldchen“, Angerstein).

\begin{tabular}{|c|c|c|c|}
\hline$P$ & $G$ & $P$ & $G$ \\
\hline$P$ & $G$ & $P$ & $G$ \\
\hline
\end{tabular}

Parzelle:

Sorte:

Grundbodenbearbeitung:

Saattermin:
Frühsaat

Spätsaat

\section{$\underline{2005 / 2006}$}

$30 \mathrm{~m} \times 30 \mathrm{~m}$

Oase

$\mathrm{P}=$ Pflug

$\mathrm{G}=$ Grubber

Frühsaat

Spätsaat

\section{$2006 / 2007$}

$15 \mathrm{~m} \times 15 \mathrm{~m}$

Smart

$\mathrm{P}=$ Pflug

$\mathrm{G}=$ Grubber

Frühsaat

Spätsaat

Vorsaat-Inokulation der gesamten Versuchsfläche mit Verticillium-Inokulummaterial

Tab. 5A: Versuchsplan Anbaufaktorenversuch 2007/2008 (Schlag „Dragoneranger“, Weende).

\begin{tabular}{|c|c|c|c|c|c|c|c|c|c|c|c|c|c|c|c|}
\hline \multicolumn{4}{|c|}{ Kontrolle } & \multicolumn{4}{|c|}{ Verticillium } & \multicolumn{4}{|c|}{ Kontrolle } & \multicolumn{4}{|c|}{ Verticillium } \\
\hline $\mathrm{e}$ & $\mathrm{e}$ & $\mathrm{f}$ & $\mathrm{f}$ & $\mathrm{b}$ & $\mathrm{b}$ & $\mathrm{d}$ & d & e & e & $\mathrm{f}$ & $\mathrm{f}$ & $\mathrm{b}$ & $\mathrm{b}$ & d & d \\
\hline $\mathrm{a}$ & $\mathrm{a}$ & $\mathrm{c}$ & $\mathrm{c}$ & $\mathrm{e}$ & $\mathrm{e}$ & $\mathrm{f}$ & $\mathrm{f}$ & $\mathrm{a}$ & $\mathrm{a}$ & $\mathrm{c}$ & $\mathrm{c}$ & $\mathrm{e}$ & e & $\mathrm{f}$ & $\mathrm{f}$ \\
\hline $\mathrm{b}$ & $\mathrm{b}$ & d & d & $\mathrm{a}$ & $\mathrm{a}$ & $\mathrm{c}$ & $\mathrm{c}$ & $\mathrm{b}$ & $\mathrm{b}$ & $\mathrm{d}$ & d & $\mathrm{a}$ & $\mathrm{a}$ & $\mathrm{c}$ & $\mathrm{c}$ \\
\hline \multicolumn{8}{|c|}{ Verticillium } & \multicolumn{4}{|c|}{ Verticillium } & \multicolumn{4}{|c|}{ Kontrolle } \\
\hline $\mathrm{c}$ & $\mathrm{c}$ & $\mathrm{a}$ & $\mathrm{a}$ & $\mathrm{f}$ & $\mathrm{f}$ & $\mathrm{e}$ & $\mathrm{e}$ & $\mathrm{c}$ & $\mathrm{c}$ & $\mathrm{a}$ & $\mathrm{a}$ & $\mathrm{f}$ & $\mathrm{f}$ & $\mathrm{e}$ & $\mathrm{e}$ \\
\hline $\mathrm{b}$ & $\mathrm{b}$ & $\mathrm{d}$ & $\mathrm{d}$ & $\mathrm{c}$ & $\mathrm{c}$ & $\mathrm{a}$ & $\mathrm{a}$ & $b$ & $\mathrm{~b}$ & $\mathrm{~d}$ & d & $\mathrm{c}$ & $\mathrm{c}$ & $\mathrm{a}$ & $\mathrm{a}$ \\
\hline $\mathrm{f}$ & $\mathrm{f}$ & $\mathrm{e}$ & e & $\mathrm{b}$ & $\mathrm{b}$ & $\mathrm{d}$ & $\mathrm{d}$ & $\mathrm{f}$ & $\mathrm{f}$ & e & e & $\mathrm{b}$ & $\mathrm{b}$ & d & $\mathrm{d}$ \\
\hline \multicolumn{4}{|c|}{ Kontrolle } & \multicolumn{4}{|c|}{ Verticillium } & \multicolumn{4}{|c|}{ Kontrolle } & \multicolumn{4}{|c|}{ Verticillium } \\
\hline d & d & $\mathrm{b}$ & $\mathrm{b}$ & $\mathrm{c}$ & $\mathrm{c}$ & $\mathrm{a}$ & $\mathrm{a}$ & $\mathrm{d}$ & $\mathrm{d}$ & $\mathrm{b}$ & $\mathrm{b}$ & $\mathrm{c}$ & $\mathrm{c}$ & $\mathrm{a}$ & $\mathrm{a}$ \\
\hline $\mathrm{f}$ & $\mathrm{f}$ & $\mathrm{e}$ & $\mathrm{e}$ & d & $\mathrm{d}$ & $\mathrm{b}$ & $\mathrm{b}$ & $\mathrm{f}$ & $\mathrm{f}$ & $\mathrm{e}$ & $\mathrm{e}$ & d & d & $b$ & $\mathrm{~b}$ \\
\hline $\mathrm{c}$ & $\mathrm{c}$ & $\mathrm{a}$ & $\mathrm{a}$ & $\mathrm{f}$ & $\mathrm{f}$ & $\mathrm{e}$ & e & $\mathrm{c}$ & $\mathrm{c}$ & $\mathrm{a}$ & $\mathrm{a}$ & $\mathrm{f}$ & $\mathrm{f}$ & e & $\mathrm{e}$ \\
\hline \multicolumn{8}{|c|}{ Verticillium } & \multicolumn{4}{|c|}{ Verticillium } & \multicolumn{4}{|c|}{ Kontrolle } \\
\hline $\mathrm{a}$ & $\mathrm{a}$ & $\mathrm{c}$ & $\mathrm{c}$ & $\mathrm{b}$ & $\mathrm{b}$ & $\mathrm{d}$ & $\mathrm{d}$ & $\mathrm{a}$ & $\mathrm{a}$ & $\mathrm{c}$ & $\mathrm{c}$ & $\mathrm{b}$ & $\mathrm{b}$ & $\mathrm{d}$ & $\mathrm{d}$ \\
\hline $\mathrm{b}$ & $\mathrm{b}$ & $\mathrm{d}$ & $\mathrm{d}$ & $\mathrm{e}$ & $\mathrm{e}$ & $\mathrm{f}$ & $\mathrm{f}$ & $\mathrm{b}$ & $\mathrm{b}$ & $\mathrm{d}$ & $\mathrm{d}$ & $\mathrm{e}$ & $\mathrm{e}$ & $\mathrm{f}$ & $\mathrm{f}$ \\
\hline $\mathrm{e}$ & $\mathrm{e}$ & $\mathrm{f}$ & $\mathrm{f}$ & $\mathrm{a}$ & $\mathrm{a}$ & $\mathrm{c}$ & $\mathrm{c}$ & $\mathrm{e}$ & $\mathrm{e}$ & $\mathrm{f}$ & $\mathrm{f}$ & $\mathrm{a}$ & $\mathrm{a}$ & $\mathrm{c}$ & $\mathrm{c}$ \\
\hline
\end{tabular}

Parzelle:

Doppelparzelle $2 \times(1,25 \mathrm{~m} \times 8 \mathrm{~m})$

Sorte:

Trabant

Netzabdeckung/Insektizide: a) offen/ Chinook

b) Netzabdeckung Herbst/Chinook

c) Netzabdeckung Herbst (teilw. offen)/ Chinook

d) Netzabdeckung Herbst + Frühjahr/ Chinook

e) offen/ Oftanol T + Nexion Neu

f) offen/ Oftanol T

Saattermin:

Frühsaat oder Spätsaat

Inokulationsvarianten:

Kontrolle; Verticillium-Bodeninokulation 
Tab. 6A: Acker- und pflanzenbauliche Maßnahmen im Sortenversuch 2005/2006 (Schlag „Große Breite“, Weende).

\begin{tabular}{|c|c|c|}
\hline Vorfrucht & 14.07 .05 & Ernte Wintergerste \\
\hline Grundbodenbearbeitung & 10.08 .05 & Pflug \\
\hline Verticillium-Bodeninokulation & 11.08 .05 & Verticillium-Stoppeln per Hand ausgestreut \\
\hline Saatbettbereitung & 11.08 .05 & Walze + Kreiselegge \\
\hline Aussaattermin & 11.08 .05 & Parzellendrillmaschine ( $\mathrm{Fa}$. Hege) \\
\hline Aussaatstärke & & verschiede Sorten, $60 \mathrm{kf} \mathrm{K} / \mathrm{m}^{2}$ \\
\hline Saatgutbehandlung & & Chinook + TMTD bzw. Elado + TMTD \\
\hline Pflanzeninokulation & 15.09 .05 & Phoma-Sprühinokulation \\
\hline \multicolumn{3}{|l|}{ N- Düngung } \\
\hline $\mathrm{N}_{\min }$ & 08.03 .06 & $37,9 \mathrm{~kg} \mathrm{~N} / \mathrm{ha}$ \\
\hline 1. N- Düngung & 23.03 .06 & EC 23: SSA $(180 \mathrm{~kg} / \mathrm{ha})=37,8 \mathrm{~kg} \mathrm{~N} / \mathrm{ha}$ \\
\hline 2. N-Düngung & 29.03 .06 & EC 25: $80 \mathrm{~kg} \mathrm{~N}(\mathrm{AHL})$ \\
\hline 3. N- Düngung & 21.04 .06 & EC 39: $70 \mathrm{~kg} \mathrm{~N}(\mathrm{AHL})$ \\
\hline $\mathrm{N}_{\text {gesamt }}$ (inkl. $\mathrm{N}_{\min }$ ) & & $225,7 \mathrm{~kg} \mathrm{~N} / \mathrm{ha}$ \\
\hline S- Düngung & & EC 23: SSA $(180 \mathrm{~kg} / \mathrm{ha})=43,2 \mathrm{~kg} \mathrm{~S} / \mathrm{ha}$ \\
\hline \multicolumn{3}{|l|}{ Herbizide } \\
\hline 1. Herbizid & 12.08 .05 & VA: 2,5 1/ha Nimbus \\
\hline 2. Herbizid & 21.09 .05 & EC 16: 0,5 1/ha Agil \\
\hline \multicolumn{3}{|l|}{ Wachstumsregler } \\
\hline 1.Wachstumsregler & 21.09 .05 & EC 16: 0,6 1/ha Moddus $+0,3$ 1/ha CCC 720 \\
\hline 2.Wachstumsregler & 19.04.06 & EC 37: 0,6 1/ha Moddus $+0,3$ 1/ha CCC 720 \\
\hline \multicolumn{3}{|l|}{ Insektizide } \\
\hline 1. Insektizid & 12.08 .05 & VA: Nexion Neu gestreut in Elado-Varianten $\left(10 \mathrm{~g} / \mathrm{m}^{2}\right)$ \\
\hline 2. Insektizid & 19.04 .06 & EC 37: 0,1 1/ha Fastac \\
\hline \multicolumn{3}{|l|}{ Schneckenkorn } \\
\hline 1. Schneckenkorn & & $5 \mathrm{~kg} / \mathrm{ha}$ Pro Limax \\
\hline Scheiteln & 29.06 .06 & \\
\hline Ernte & 28.07 .06 & \\
\hline
\end{tabular}


Tab. 7A: Acker- und pflanzenbauliche Maßnahmen im Sortenversuch 2006/2007 (Schlag „Große Lage“, Weende).

\begin{tabular}{|c|c|c|}
\hline Vorfrucht & 13.07.06 & Ernte Wintergerste \\
\hline Grundbodenbearbeitung & 02.08 .06 & Pflug mit Packer \\
\hline Verticillium-Bodeninokulation & 14.08 .06 & Verticillium-Stoppeln per Hand ausgestreut \\
\hline Saatbettbereitung & 14.08 .06 & Walze + Kreiselegge \\
\hline Aussaattermin & 14.08 .06 & Einzelkornsaat (Fa. Hege) \\
\hline Aussaatstärke & & verschiede Sorten, $52 \mathrm{kf} \mathrm{K} / \mathrm{m}^{2}$ \\
\hline Saatgutbehandlung & & Chinook + TMTD \\
\hline \multirow[t]{2}{*}{ Pflanzeninokulation } & 12.10 .06 & EC 15: Phoma-Sprühinokulation im Herbst \\
\hline & 14.05 .07 & EC 65: Phoma-Sprühinokulation im Frühjahr \\
\hline \multirow[t]{2}{*}{ Netzabdeckung } & 22.08 .06 & Netzabdeckung im Herbst bis zum 15.10.06 \\
\hline & 26.03 .07 & Netzabdeckung im Frühjahr bis zum 18.06.07 \\
\hline \multicolumn{3}{|l|}{ N- Düngung } \\
\hline 1. N- Düngung & 12.03 .07 & EC 45: SSA $(150 \mathrm{~kg} / \mathrm{ha})=31,5 \mathrm{~kg} \mathrm{~N} / \mathrm{ha}$ \\
\hline 2. N- Düngung & 13.03 .07 & EC 45: $150 \mathrm{~kg} \mathrm{~N}$ (AHL) \\
\hline $\mathrm{N}_{\text {gesamt }}$ & & $171,5 \mathrm{~kg} / \mathrm{ha}$ \\
\hline S- Düngung & & EC 45: SSA $(150 \mathrm{~kg} / \mathrm{ha})=36 \mathrm{~kg} \mathrm{~S} / \mathrm{ha}$ \\
\hline \multicolumn{3}{|l|}{ Herbizide } \\
\hline 1. Herbizid & 16.08 .06 & VA: 1,7 1/ha Brasan $+0,7$ l/ha Butisan \\
\hline 2. Herbizid & 12.10 .06 & EC 16: 0,5 1/ha Agil \\
\hline \multicolumn{3}{|l|}{ Wachstumsregler } \\
\hline 1.Wachstumsregler & 12.10 .06 & EC 16: 0,7 1/ha Moddus + 0,4 1/ha CCC 720 \\
\hline 2.Wachstumsregler & 12.03 .07 & EC 37: 0,6 1/ha Moddus $+0,3$ 1/ha CCC 720 \\
\hline Insektizide & 12.03 .07 & EC 37: 0,1 1/ha Fastac \\
\hline \multicolumn{3}{|l|}{ Schneckenkorn } \\
\hline 1. Schneckenkorn & 18.08 .06 & $6 \mathrm{~kg} / \mathrm{ha}$ Metarex \\
\hline 2. Schneckenkorn & 25.08 .06 & $5 \mathrm{~kg} / \mathrm{ha}$ Pro Limax \\
\hline Scheiteln & 19.06.07 & \\
\hline Ernte & 17.07 .07 & \\
\hline
\end{tabular}


Tab. 8A: Acker- und pflanzenbauliche Maßnahmen im Sortenversuch 2007/2008 (Schlag „Dragoner Anger", Weende).

\begin{tabular}{|c|c|c|}
\hline Vorfrucht & 15.07 .07 & Ernte Wintergerste \\
\hline Grundbodenbearbeitung & 13.08 .07 & Pflug mit Packer \\
\hline Verticillium-Bodeninokulation & 13.08 .07 & Verticillium-Stoppeln per Hand ausgestreut \\
\hline Saatbettbereitung & 13.08 .07 & Walze + Kreiselegge \\
\hline Aussaattermin & 14.08 .08 & Einzelkornsaat (Fa. Hege) \\
\hline Aussaatstärke & & verschiede Sorten, $52 \mathrm{kf} \mathrm{K} / \mathrm{m}^{2}$ \\
\hline Saatgutbehandlung & & Chinook + TMTD bzw. Oftanol T \\
\hline Netzabdeckung & 23.08 .07 & Netzabdeckung im Herbst bis zum 10.10.06 \\
\hline \multicolumn{3}{|l|}{ N- Düngung } \\
\hline $\mathrm{N}_{\min }$ & 20.02 .08 & $30,8 \mathrm{~kg} \mathrm{~N} / \mathrm{ha}$ \\
\hline 1. N- Düngung & 25.02 .08 & EC 18: SSA $(170 \mathrm{~kg} / \mathrm{ha})=35,7 \mathrm{~kg} \mathrm{~N} / \mathrm{ha}$ \\
\hline 2. N- Düngung & 28.02 .08 & EC 18: $80 \mathrm{~kg} \mathrm{~N}$ (AHL) \\
\hline 3. N- Düngung & 09.04.08 & EC 51: $80 \mathrm{~kg} \mathrm{~N}$ (AHL) \\
\hline $\mathrm{N}_{\text {gesamt }}\left(\right.$ inkl. $\left.\mathrm{N}_{\min }\right)$ & & $226,5 \mathrm{~kg} / \mathrm{ha}$ \\
\hline S- Düngung & & EC 18: SSA $(170 \mathrm{~kg} / \mathrm{ha})=40,8 \mathrm{~kg} \mathrm{~S} / \mathrm{ha}$ \\
\hline \multicolumn{3}{|l|}{ Herbizide } \\
\hline 1. Herbizid & 20.08 .07 & EC 10: 2 1/ha Butisan Top \\
\hline 2. Herbizid & 11.10 .07 & EC 16: 0,5 1/ha Gallant Super \\
\hline \multicolumn{3}{|l|}{ Wachstumsregler } \\
\hline 1.Wachstumsregler & 11.10 .07 & EC 16: $0,71 /$ ha Moddus $+0,4$ 1/ha CCC 720 \\
\hline 2.Wachstumsregler & 01.04 .08 & EC 39: $0,61 /$ ha Moddus $+0,31 /$ ha CCC 720 \\
\hline \multicolumn{3}{|l|}{ Insektizide } \\
\hline 1. Insektizid & 11.10 .07 & EC 16: 0,1 1/ha Karate Zeon \\
\hline 2. Insektizid & 01.04 .08 & EC 37: 0,1 1/ha Fastac \\
\hline Schneckenkorn & 30.08 .07 & $6 \mathrm{~kg} / \mathrm{ha}$ Pro Limax \\
\hline Mäusegift & 11.10 .07 & 10 kg/ha Ratron Feldmausköder \\
\hline Scheiteln & 19.06 .08 & \\
\hline Ernte & 25.07 .08 & keine Ertragserfassung wegen Hagelschäden \\
\hline
\end{tabular}


Tab. 9A: Acker- und pflanzenbauliche Maßnahmen im Anbaufaktorenversuch 2005/2006 (Schlag „Große Breite“, Weende).

\begin{tabular}{|c|c|c|}
\hline Vorfrucht & 14.07 .05 & Ernte Wintergerste \\
\hline Grundbodenbearbeitung & 10.08 .05 & Pflug bzw. Grubber \\
\hline Verticillium-Bodeninokulation & 11. bzw. 24.08 .05 & Verticillium-Stoppeln per Hand ausgestreut \\
\hline Saatbettbereitung & 11. bzw. 24.08 .05 & Walze + Kreiselegge \\
\hline Aussaattermin & 12. bzw. 25.08 .05 & Scheibenschardrillmaschine "Hassia" \\
\hline Aussaatstärke & & Sorte Oase, $60 \mathrm{kf} \mathrm{K} / \mathrm{m}^{2}$ \\
\hline Saatgutbehandlung & & Chinook + TMTD \\
\hline \multicolumn{3}{|l|}{ N- Düngung } \\
\hline $\mathrm{N}_{\min }$ & 08.03 .06 & $37,9 \mathrm{~kg} \mathrm{~N} / \mathrm{ha}$ \\
\hline 1. N- Düngung & 23.03 .06 & EC 23: SSA $(180 \mathrm{~kg} / \mathrm{ha})=37,8 \mathrm{~kg} \mathrm{~N} / \mathrm{ha}$ \\
\hline 2. N- Düngung & 29.03 .06 & EC 25: $80 \mathrm{~kg} \mathrm{~N}(\mathrm{AHL})$ \\
\hline 3. N- Düngung & 21.04 .06 & EC 39: $70 \mathrm{~kg} \mathrm{~N}$ (AHL) \\
\hline $\mathrm{N}_{\text {gesamt }}\left(\right.$ inkl. $\left.\mathrm{N}_{\min }\right)$ & & $225,7 \mathrm{~kg} \mathrm{~N} / \mathrm{ha}$ \\
\hline S- Düngung & & EC 23: SSA $(180 \mathrm{~kg} / \mathrm{ha})=43,2 \mathrm{~kg} \mathrm{~S} / \mathrm{ha}$ \\
\hline \multicolumn{3}{|l|}{ Herbizide } \\
\hline 1. Herbizid & 12.08 .05 & VA: 2,5 1/ha Nimbus \\
\hline 2. Herbizid & 21.09 .05 & EC 16: 0,5 1/ha Agil \\
\hline \multicolumn{3}{|l|}{ Wachstumsregler } \\
\hline 1.Wachstumsregler & 21.09 .05 & EC 16: 0,6 1/ha Caramba (Fungizid) \\
\hline 2.Wachstumsregler & 19.04.06 & EC 37: 0,6 1/ha Folicur (Fungizid) \\
\hline Insektizide & 19.04 .06 & EC 37: 0,1 1/ha Fastac \\
\hline Schneckenkorn & 22.08 .05 & $5 \mathrm{~kg} / \mathrm{ha}$ Pro Limax \\
\hline Ernte & 28.07 .06 & \\
\hline
\end{tabular}


Tab. 10A: Acker- und pflanzenbauliche Maßnahmen im Anbaufaktorenversuch 2006/2007 (Schlag „Wäldchen“, Angerstein).

\begin{tabular}{|c|c|c|}
\hline Vorfrucht & 01.08 .06 & Ernte Winterweizen \\
\hline Grundbodenbearbeitung & 11.08 .06 & Pflug bzw. Grubber \\
\hline Verticillium-Bodeninokulation & 17. bzw. 31.08 .06 & Verticillium-Stoppeln per Hand ausgestreut \\
\hline Saatbettbereitung & 17. bzw. 31.08 .06 & Walze + Kreiselegge \\
\hline Aussaattermin & 17. bzw. 31.08 .06 & Scheibenschardrillmaschine " Hassia" \\
\hline Aussaatstärke & & Sorte Smart, $60 \mathrm{kf} \mathrm{K} / \mathrm{m}^{2}$ \\
\hline Saatgutbehandlung & & Chinook + TMTD \\
\hline \multicolumn{3}{|l|}{ N- Düngung } \\
\hline \multicolumn{3}{|l|}{$\mathrm{N}_{\min }$} \\
\hline 1. N- Düngung & 26.09 .06 & EC 13: $25 \mathrm{~kg} \mathrm{~N} / \mathrm{ha}(\mathrm{KAS})$ \\
\hline 2. N- Düngung & 12.03.07 & EC 45: SSA $(170 \mathrm{~kg} / \mathrm{ha})=35,7 \mathrm{~kg} \mathrm{~N} / \mathrm{ha}$ \\
\hline 3. N- Düngung & 13.03.07 & $\mathrm{EC} 45: 80 \mathrm{~kg} \mathrm{~N}(\mathrm{AHL})$ \\
\hline 4. N- Düngung & 29.03 .07 & EC 50: $70 \mathrm{~kg} \mathrm{~N}(\mathrm{AHL})$ \\
\hline $\mathrm{N}_{\text {gesamt }}\left(\right.$ inkl. $\left.\mathrm{N}_{\text {min }}\right)$ & & $210,7 \mathrm{~kg} \mathrm{~N} / \mathrm{ha}$ \\
\hline S- Düngung & & EC 23: SSA $(170 \mathrm{~kg} / \mathrm{ha})=40,8 \mathrm{~kg} \mathrm{~S} / \mathrm{ha}$ \\
\hline \multicolumn{3}{|l|}{ Herbizide } \\
\hline 1. Herbizid & 17.08 .06 & VA: 1,7 1/ha Brasan $+0,71 /$ ha Butisan \\
\hline 2. Herbizid & 12.10 .06 & EC 16: 0,5 1/ha Agil \\
\hline \multicolumn{3}{|l|}{ Wachstumsregler } \\
\hline 1.Wachstumsregler & 12.10 .06 & EC 16: 0,6 1/ha Caramba (Fungizid) \\
\hline 2.Wachstumsregler & 15.03.07 & EC 45: 0,6 1/ha Folicur (Fungizid) \\
\hline Insektizide & 15.03.07 & EC 45: 0,15 1/ha Trafo \\
\hline Schneckenkorn & 04.09 .06 & $5 \mathrm{~kg} / \mathrm{ha}$ Pro Limax \\
\hline Ernte & 20.07 .07 & keine Ertragsermittlung \\
\hline
\end{tabular}


Tab. 11A: Acker- und pflanzenbauliche Maßnahmen im Anbaufaktorenversuch 2007/2008 (Schlag „Dragoner Anger“, Weende).

\begin{tabular}{|c|c|c|}
\hline Vorfrucht & 15.07 .07 & Ernte Wintergerste \\
\hline Grundbodenbearbeitung & 13.08 .07 & Pflug mit Packer \\
\hline Verticillium-Bodeninokulation & 13.08 .07 & Verticillium-Stoppeln per Hand ausgestreut \\
\hline Saatbettbereitung & 14. bzw. 31.08 .07 & Walze + Kreiselegge \\
\hline Aussaattermin & 17. bzw. 31.08 .07 & Einzelkornsaat (Fa. Hege) \\
\hline Aussaatstärke & & Sorte Trabant, $52 \mathrm{kf} \mathrm{K} / \mathrm{m}^{2}$ \\
\hline Saatgutbehandlung & & Chinook + TMTD bzw. Oftanol T \\
\hline \multirow[t]{2}{*}{ Netzabdeckung } & 23.08 .07 & Netzabdeckung im Herbst bis zum 10.10.07 \\
\hline & 22.04 .08 & Netzabdeckung im Frühjahr bis zum 12.06.08 \\
\hline \multicolumn{3}{|l|}{ N- Düngung } \\
\hline $\mathrm{N}_{\min }$ & 20.02 .08 & $30,8 \mathrm{~kg} \mathrm{~N} / \mathrm{ha}$ \\
\hline 1. N- Düngung & 25.02 .08 & EC 18: SSA $(170 \mathrm{~kg} / \mathrm{ha})=35,7 \mathrm{~kg} \mathrm{~N} / \mathrm{ha}$ \\
\hline 2. N- Düngung & 28.02 .08 & EC 18: $80 \mathrm{~kg} \mathrm{~N}(\mathrm{AHL})$ \\
\hline 3. N- Düngung & 09.04 .08 & EC 50: $80 \mathrm{~kg} \mathrm{~N}(\mathrm{AHL})$ \\
\hline $\mathrm{N}_{\text {gesamt }}$ (inkl. $\left.\mathrm{N}_{\text {min }}\right)$ & & $226,5 \mathrm{~kg} \mathrm{~N} / \mathrm{ha}$ \\
\hline S- Düngung & 25.02 .08 & EC 18: SSA $(170 \mathrm{~kg} / \mathrm{ha})=40,8 \mathrm{~kg} \mathrm{~S} / \mathrm{ha}$ \\
\hline \multicolumn{3}{|l|}{ Herbizide } \\
\hline 1. Herbizid & 20.08 .07 & EC 10: 2 1/ha Butisan \\
\hline 2. Herbizid & 11.10 .07 & EC 16: 0,5 1/ha Gallant Super \\
\hline \multicolumn{3}{|l|}{ Wachstumsregler } \\
\hline 1.Wachstumsregler & 11.10 .07 & EC 16: 0,7 1/ha Moddus $+0,4$ 1/ha CCC 720 \\
\hline 2.Wachstumsregler & 01.04 .08 & EC 39: 0,6 1/ha Folicur (Fungizid) \\
\hline Fungizide & 01.10 .07 & EC 16: 2 1/ha Eria \\
\hline \multicolumn{3}{|l|}{ Insektizide } \\
\hline 1. Insektizid & 11.10 .07 & EC 16: 0,1 1/ha Karate Zeon \\
\hline 2. Insektizid & 01.04 .08 & EC 37: 0,1 1/ha Fastac \\
\hline Schneckenkorn & 30.08 .07 & $6 \mathrm{~kg} / \mathrm{ha}$ Pro Limax \\
\hline Mäusegift & 11.10 .07 & $10 \mathrm{~kg} / \mathrm{ha}$ Ratron Feldmausköder \\
\hline Ernte & 25.07 .08 & keine Ertragsermittlung wegen Hagelschaden \\
\hline
\end{tabular}


Tab. 12A: Acker- und pflanzenbauliche Maßnahmen im Halbfreilandversuch 2006 (Schlag „Garten“, Weende).

\begin{tabular}{|c|c|c|}
\hline Grundbodenbearbeitung & 05.04 .06 & Umgraben der Parzellen mit Spaten \\
\hline Saatbettbereitung & 21.04 .06 & Handrechen \\
\hline Verticillium-Bodeninokulation & 21.04 .06 & Inokulummaterial per Hand ausgestreut und eingeharkt \\
\hline Aussaattermin & 21.04 .06 & Einzelkornsaat mit Säschablone per Hand \\
\hline Aussaatstärke & & Sorte Heros, $64 \mathrm{kf} \mathrm{K} / \mathrm{m}^{2}$ \\
\hline Saatgutbehandlung & & Chinook + TMTD \\
\hline Netzabdeckung der Anlage & 27.04 .06 & Kulturschutznetz Rantai K (1,35 mm x 1,35 mm) \\
\hline Bestandesdichteregulierung & 24.05 .06 & 40 Pflanzen $/ \mathrm{m}^{2}$ \\
\hline Ansatz von Kohlfliegeneiern & $29.05-2.06 .06$ & 10 Eier/Pflanze bei Varianten mit Kohlfliegenbefall \\
\hline \multicolumn{3}{|l|}{ Düngung } \\
\hline $\mathrm{N}_{\min }$ & 20.03 .06 & $33 \mathrm{~kg} \mathrm{~N} / \mathrm{ha}$ \\
\hline 1. Düngung & 21.04 .06 & VS : $400 \mathrm{~kg} / \mathrm{ha}$ 40er Kornkali, $152 \mathrm{~kg} / \mathrm{ha}$ Harnstoff \\
\hline & & $175 \mathrm{~kg} / \mathrm{ha} \mathrm{N} / \mathrm{P}(18 / 46)$ \\
\hline 2. Düngung & 01.06 .06 & EC 25: $70 \mathrm{~kg} / \mathrm{ha}$ Bittersalz $+3 \mathrm{~kg} / \mathrm{ha}$ Nutribor \\
\hline 3. Düngung & 19.06 .06 & EC 60: $120 \mathrm{~kg} / \mathrm{ha}$ KAS \\
\hline Düngung kg/ha (gesamt) & & $166,9 \mathrm{~N} ; 80,5 \mathrm{P}_{2} \mathrm{O} 5 ; 160 \mathrm{~K}_{2} \mathrm{O} ; 40 \mathrm{MgO} ; 25,1 \mathrm{~S} ; 0,24 \mathrm{~B}$ \\
\hline Herbizide & 09.05 .06 & EC 10: 2 1/ha Butisan Top \\
\hline \multicolumn{3}{|l|}{ Insektizide } \\
\hline 1. Insektizid & 26.06 .06 & EC 65: 0,1 1/ha Fastac gegen Rapsglanzkäfer \\
\hline 2. Insektizid & 29.06 .06 & EC 65: 0,075 1/ha Karate Zeon gegen Rapsglanzkäfer \\
\hline Schneckenkorn & & gezielt zu verschiedenen Terminen \\
\hline \multirow[t]{3}{*}{ Bewässerung } & 01.06 .06 & $21 / \mathrm{m}^{2}$ \\
\hline & 09.06 .06 & $21 / \mathrm{m}^{2}$ \\
\hline & 13.06.06 & $41 / \mathrm{m}^{2}$ \\
\hline Ernte & 01.09 .06 & per Hand \\
\hline
\end{tabular}


Tab. 13A: Acker- und pflanzenbauliche Maßnahmen im Halbfreilandversuch 2007 (Schlag „Garten“, Weende).

\begin{tabular}{|c|c|c|}
\hline Bodenaustausch & 10.-12.10.06 & Bodenaustausche der Bodenschicht 0-40 cm \\
\hline Grundbodenbearbeitung & 13.04 .07 & Umgraben der Parzellen mit Spaten \\
\hline Verticillium-Bodeninokulation & 19.04 .07 & Inokulummaterial per Hand ausgestreut und eingeharkt \\
\hline Saatbettbereitung & 19.04 .07 & Handrechen \\
\hline Aussaattermin & 20.04 .07 & Einzelkornsaat mit Säschablone per Hand \\
\hline Aussaatstärke & & Sorte Heros, $64 \mathrm{kf} \mathrm{K} / \mathrm{m}^{2}$ \\
\hline Saatgutbehandlung & & Chinook + TMTD \\
\hline Netzabdeckung der Anlage & 25.04 .07 & Kulturschutznetz Rantai K (1,35 mm x 1,35 mm) \\
\hline Bestandesdichteregulierung & 20.05 .07 & 40 Pflanzen $/ \mathrm{m}^{2}$ \\
\hline Ansatz von Kohlfliegeneiern & 31.05-04.06.07 & EC 15: 10 Eier/Pflanze bei Varianten mit Kohlfliegenbefall \\
\hline \multicolumn{3}{|l|}{ Düngung } \\
\hline $\mathrm{N}_{\min }$ & 12.03 .07 & $21 \mathrm{~kg} \mathrm{~N} / \mathrm{ha}$ \\
\hline \multirow[t]{2}{*}{ 1. Düngung } & 19.04.07 & VS : $300 \mathrm{~kg} / \mathrm{ha}$ 40er Kornkali, $152 \mathrm{~kg} / \mathrm{ha}$ Harnstoff \\
\hline & & $90 \mathrm{~kg} / \mathrm{ha} \mathrm{N} / \mathrm{P}(18 / 46)$ \\
\hline 2. Düngung & 26.06 .07 & EC 63: $100 \mathrm{~kg} / \mathrm{ha}$ Bittersalz $+100 \mathrm{~kg} / \mathrm{ha} \mathrm{KAS}+3 \mathrm{~kg} / \mathrm{ha}$ Nutribor \\
\hline Düngung kg/ha (gesamt) & & $134,2 \mathrm{~N} ; 41,4 \mathrm{P}_{2} \mathrm{O} 5 ; 120 \mathrm{~K}_{2} \mathrm{O} ; 38 \mathrm{MgO} ; 25 \mathrm{~S} ; 0,24 \mathrm{~B}$ \\
\hline Fungizid & 27.06 .07 & EC 63: $0,5 \mathrm{~kg} / \mathrm{ha}$ Cantus \\
\hline Insektizid & 27.06 .07 & EC 63: 0,1 1/ha Fastac gegen Rapsglanzkäfer \\
\hline Schneckenkorn & & gezielt zu verschiedenen Terminen \\
\hline Mäusegift & 01.06 .07 & 10 kg/ha Ratron Feldmausköder \\
\hline Bewässerung & 28.04-08.05.07 & $41 / \mathrm{m}^{2} / \mathrm{Tag}$ \\
\hline Ernte & 04.09 .07 & keine Ertragserfassung \\
\hline
\end{tabular}


Tab. 14A: Mittlere Befallshäufigkeit [BH \%], prozentual geschädigte Wurzeloberfläche [GW \%] sowie Anteil stark befallener Pflanzen mit $\mathrm{GW} \geq 50 \%$ [SB \%] von Winterraps mit der Kleinen Kohlfliege nach visueller Bonitur im Herbst 2005 bzw. Frühjahr 2006 am Standort Weende (Schlag Große Breite) bei Göttingen. Dargestellt sind die über alle Inokulationsvarianten (Kontrolle, Verticillium-Inokulation, Phoma-Herbstinokulation) gemittelten Boniturwerte ( $\mathrm{n}=12$ Parzellenmittelwerte bestehend aus jeweils 25 Pflanzen). Unterschiedliche Buchstaben kennzeichnen statistisch signifikante Differenzen zwischen den Sorten bei den jeweiligen Insektizidvarianten ${ }^{1)}$ im Herbst bzw. Frühjahr. (+/-) zeigen signifikante Unterschiede zwischen den Insektizidvarianten der jeweiligen Sorten an (LSD $\mathrm{p} \leq 0,05)$.

\begin{tabular}{|c|c|c|c|c|c|c|}
\hline \multirow{2}{*}{$\begin{array}{l}\text { Herbst } 2005 \\
\text { Sorten }\end{array}$} & \multicolumn{2}{|c|}{$\mathrm{BH}[\%]$} & \multicolumn{2}{|c|}{ GW [\%] } & \multicolumn{2}{|c|}{$\mathrm{SB}[\%]$} \\
\hline & Chinook & Elado $+\mathrm{N}$ & Chinook & Elado $+\mathrm{N}$ & Chinook & Elado $+\mathrm{N}$ \\
\hline Laser & $66,8 \mathrm{a}$ & $68,8 \mathrm{AB}$ & $23,8 \mathrm{a}$ & $21,9 \mathrm{AB}$ & $17,3 \mathrm{ab}$ & $14,8 \mathrm{~A}$ \\
\hline Lion & $70,0 \mathrm{a}$ & $66,0 \mathrm{AB}$ & $22,3 \mathrm{a}$ & $20,5 \mathrm{~A}$ & $11,0 \mathrm{a}$ & $11,0 \mathrm{~A}$ \\
\hline Oase & $79,8 \mathrm{~b}$ & $72,8 \mathrm{~B}$ & $29,7+$ & $24,2 \mathrm{~B}-$ & $24,2 \mathrm{c}+$ & $14,3-$ \\
\hline Caiman & $65,5 \mathrm{a}$ & $63,5 \mathrm{~A}$ & $26,5 a b+$ & $21,3 \mathrm{AB}-$ & $21,5 b c+$ & $13,3 \mathrm{~A}-$ \\
\hline GD LSD $p \leq 0,05$ & 8,1 & 7,2 & 4,6 & 3,7 & 6,9 & 4,4 n.s. \\
\hline Frühjahr 2006 & \multicolumn{2}{|c|}{$\mathrm{BH}[\%]$} & \multicolumn{2}{|c|}{ GW [\%] } & \multicolumn{2}{|c|}{ SB [\%] } \\
\hline Sorten & Chinook & Elado $+\mathrm{N}$ & Chinook & Elado $+\mathrm{N}$ & Chinook & Elado $+\mathrm{N}$ \\
\hline Laser & $99,5 \mathrm{a}$ & $99,7 \mathrm{~A}$ & $38,6 \mathrm{ab}$ & $37,0 \mathrm{AB}$ & $25,0 \mathrm{~b}$ & $21,7 \mathrm{~A}$ \\
\hline Lion & $98,7 \mathrm{a}$ & $98,3 \mathrm{~A}$ & $37,3 \mathrm{ab}$ & $35,8 \mathrm{AB}$ & $20,3 \mathrm{a}$ & $21,7 \mathrm{~A}$ \\
\hline Oase & $98,7 \mathrm{a}$ & $99,0 \mathrm{~A}$ & $39,4 \mathrm{~b}$ & $37,9 \mathrm{~B}$ & $29,3 \mathrm{c}$ & $26,7 \mathrm{~B}$ \\
\hline Caiman & $97,0 \mathrm{a}$ & $97,0 \mathrm{~A}$ & $36,3 \mathrm{a}$ & $34,8 \mathrm{~A}$ & $26,0 \mathrm{bc}+$ & $20,3 \mathrm{~A}-$ \\
\hline GD LSD $p \leq 0,05$ & 2,7 n.s. & 2,7 n.s. & 2,8 & 2,4 & 4,2 & 4,1 \\
\hline
\end{tabular}

1) Insektizidvarianten: Saatgutbehandlung mit Chinook bzw. Saatgutbehandlung mit Elado + Austreuen des insektiziden Granulats Nexion Neu (N.) nach der Saat $\left(10 \mathrm{~g} / \mathrm{m}^{2}\right)$. 
Tab. 15A: Mittlere Befallshäufigkeit [BH \%], prozentual geschädigte Wurzeloberfläche [GW \%] sowie Anteil stark befallener Pflanzen mit GW $\geq 50 \%$ [SB \%] von Winterraps mit der Kleinen Kohlfliege nach visueller Bonitur im Herbst 2006 bzw. Frühjahr 2007 am Standort Weende (Schlag Große Lage) bei Göttingen. Dargestellt sind die über alle Inokulationsvarianten (Kontrolle. Verticillium-Inokulation, Phoma-Herbstinokulation, Phoma-Frühjahrsinokulation) gemittelten Boniturwerte ( $\mathrm{n}=12$ bei den Sorten Viking und Caiman, $\mathrm{n}=8$ bei den Sorten Laser und Lion (Parzellenmittelwerte bestehend aus jeweils 25 Pflanzen)). Unterschiedliche Buchstaben zeigen statistisch signifikante Differenzen zwischen den Sorten bei den jeweiligen Netzabdeckungsvarianten ${ }^{1)}$ im Herbst bzw. Frühjahr an (LSD p $\leq 0,05)$.

\begin{tabular}{|c|c|c|c|c|c|c|c|c|c|}
\hline \multirow{2}{*}{$\begin{array}{l}\text { Herbst } 2006 \\
\text { Sorten }\end{array}$} & \multicolumn{3}{|c|}{$\mathrm{BH}[\%]$} & \multicolumn{3}{|c|}{ GW [\%] } & \multicolumn{3}{|c|}{$\mathrm{SB}[\%]$} \\
\hline & $\begin{array}{l}\text { ohne } \\
\text { Netz }\end{array}$ & $\begin{array}{c}\text { Netz } \\
\mathrm{H}\end{array}$ & $\begin{array}{c}\text { Netz } \\
\mathrm{H}+\mathrm{FJ}\end{array}$ & $\begin{array}{l}\text { ohne } \\
\text { Netz }\end{array}$ & $\begin{array}{c}\text { Netz } \\
\mathrm{H}\end{array}$ & $\begin{array}{c}\text { Netz } \\
\mathrm{H}+\mathrm{FJ}\end{array}$ & $\begin{array}{l}\text { ohne } \\
\text { Netz }\end{array}$ & $\begin{array}{c}\text { Netz } \\
\mathrm{H}\end{array}$ & $\begin{array}{c}\text { Netz } \\
\mathrm{H}+\mathrm{FJ}\end{array}$ \\
\hline Laser & 60,9 a & $6,8 \mathrm{~A}$ & $8,5 \alpha$ & $22,5 \mathrm{a}$ & $1,9 \mathrm{~A}$ & $2,2 \alpha$ & $15,5 \mathrm{a}$ & 0,5 & $1 \alpha$ \\
\hline Lion & $75,4 \mathrm{~b}$ & $8,0 \mathrm{~A}$ & $7,0 \alpha$ & $27,6 \mathrm{a}$ & $1,9 \mathrm{~A}$ & $1,2 \alpha$ & $17,5 \mathrm{a}$ & 0,5 & $0 \alpha$ \\
\hline Viking & $72,8 \mathrm{~b}$ & $8,3 \mathrm{~A}$ & $5,8 \alpha$ & $27,6 \mathrm{a}$ & $2,0 \mathrm{~A}$ & $1,2 \alpha$ & $17,1 \mathrm{a}$ & 0,3 & $0 \alpha$ \\
\hline Caiman & $66,2 \mathrm{ab}$ & $6,2 \mathrm{~A}$ & $6,7 \alpha$ & $24,3 \mathrm{a}$ & $1,7 \mathrm{~A}$ & $1,5 \alpha$ & $17,5 \mathrm{a}$ & 0,3 & $0,3 \alpha$ \\
\hline GD LSD $p \leq 0,05$ & 9,97 & 3,1 n. s. & $3,4 \mathrm{n} . \mathrm{s}$ & $6,1 \mathrm{n} . \mathrm{s}$. & 2,4 n.s & $2,8 \mathrm{n} . \mathrm{s}$. & 2,9 n. s. & 2,6 n.s. & 2,5 n. s. \\
\hline Frühjahr 2007 & \multicolumn{3}{|c|}{$\mathrm{BH}[\%]$} & \multicolumn{3}{|c|}{ GW [\%] } & \multicolumn{3}{|c|}{ SB [\%] } \\
\hline Sorten & $\begin{array}{l}\text { ohne } \\
\text { Netz }\end{array}$ & $\begin{array}{c}\text { Netz } \\
\mathrm{H}\end{array}$ & $\begin{array}{c}\text { Netz } \\
\mathrm{H}+\mathrm{FJ}\end{array}$ & $\begin{array}{l}\text { ohne } \\
\text { Netz }\end{array}$ & $\begin{array}{c}\text { Netz } \\
\mathrm{H}\end{array}$ & $\begin{array}{c}\text { Netz } \\
\mathrm{H}+\mathrm{FJ}\end{array}$ & $\begin{array}{l}\text { ohne } \\
\text { Netz }\end{array}$ & $\begin{array}{c}\text { Netz } \\
\mathrm{H}\end{array}$ & $\begin{array}{c}\text { Netz } \\
\mathrm{H}+\mathrm{FJ}\end{array}$ \\
\hline Laser & $99,5 \mathrm{a}$ & $97,0 \mathrm{~A}$ & $7,5 \alpha$ & $40,5 \mathrm{c}$ & $38,9 \mathrm{~B}$ & $0,9 \alpha$ & $28,5 \mathrm{~b}$ & $30,5 \mathrm{~B}$ & $0 \alpha$ \\
\hline Lion & $98,4 \mathrm{a}$ & $98,0 \mathrm{~A}$ & $6,5 \alpha$ & $34,0 \mathrm{ab}$ & $32,2 \mathrm{~A}$ & $1,4 \alpha$ & $20,6 \mathrm{a}$ & $16,5 \mathrm{~A}$ & $0 \alpha$ \\
\hline Viking & $97,9 \mathrm{a}$ & $98,3 \mathrm{~A}$ & $5,0 \alpha$ & $36,3 \mathrm{abc}$ & $32,1 \mathrm{~A}$ & $1,2 \alpha$ & $19,6 \mathrm{a}$ & $15,8 \mathrm{~A}$ & $0 \alpha$ \\
\hline Caiman & $97,6 \mathrm{a}$ & $97,7 \mathrm{~A}$ & $7,7 \alpha$ & $31,6 \mathrm{a}$ & $32,2 \mathrm{~A}$ & $1,2 \alpha$ & $18,2 \mathrm{a}$ & $14,3 \mathrm{~A}$ & $0 \alpha$ \\
\hline GD LSD $p \leq 0,05$ & 2,5 n. s. & $2,4 \mathrm{n} . \mathrm{s}$. & $3,1 \mathrm{n} . \mathrm{s}$. & 5,16 & 6,1 & $2,1 \mathrm{n} . \mathrm{s}$. & 7,11 & 9,72 & n. s. \\
\hline
\end{tabular}

1) Netzvarianten $=$ ohne Netz; Netz im Herbst $(\mathrm{H})$ : Auflage eines Kulturschutznetzes von Mitte August bis Mitte Oktober 2006; Netz im Herbst (H) + Frühjahr (FJ): Netz im Herbst + Netzkäfigkonstruktion von Ende März bis Mitte Juni 2007. 
Tab. 16A: Mittlere Befallshäufigkeit [BH \%], prozentual geschädigte Wurzeloberfläche [GW \%] sowie Anteil stark befallener Pflanzen mit GW $\geq 50 \%$ [SB \%] von Winterraps mit der Kleinen Kohlfliege nach visueller Bonitur im Herbst 2007 bzw. Frühjahr 2008 am Standort Weende (Schlag Dragoneranger) bei Göttingen. Dargestellt sind die über alle Inokulationsvarianten (Kontrolle. Verticillium-Inokulation) gemittelten Boniturwerte $(\mathrm{n}=8$ Parzellenmittelwerte bestehend aus jeweils 25 Pflanzen). Unterschiedliche Buchstaben zeigen statistisch signifikante Differenzen zwischen den Sorten bei den jeweiligen Netzabdeckungs-/Insektizidvarianten ${ }^{1)}$ im Herbst bzw. Frühjahr an (LSD $\mathrm{p} \leq 0,05)$.

\begin{tabular}{|c|c|c|c|c|c|c|c|c|c|}
\hline \multirow{2}{*}{$\begin{array}{l}\text { Herbst } 2007 \\
\text { Sorten }\end{array}$} & \multicolumn{3}{|c|}{$\mathrm{BH}[\%]$} & \multicolumn{3}{|c|}{ GW [\%] } & \multicolumn{3}{|c|}{ SB [\%] } \\
\hline & Chin. & Oft. $+\mathrm{N}$. & Netz-H & Chin. & Oft. $+\mathrm{N}$ & Netz-H & Chin. & Oft. $+\mathrm{N}$ & Netz-H \\
\hline Laser & $66,7 \mathrm{ab}$ & $33,3 \mathrm{~A}$ & $7,5 \alpha$ & $23,6 \mathrm{ab}$ & $8,5 \mathrm{~A}$ & $0,9 \alpha \beta$ & $18,9 \mathrm{a}$ & 2,9 A & $0 \alpha$ \\
\hline Caiman & $58,9 \mathrm{ab}$ & $30,8 \mathrm{~A}$ & $5,0 \alpha$ & $18,9 \mathrm{a}$ & $9,6 \mathrm{~A}$ & $0,4 \alpha$ & $13,3 \mathrm{a}$ & $6,7 \mathrm{~A}$ & $0 \alpha$ \\
\hline Lion & $67,0 \mathrm{ab}$ & $36,7 \mathrm{~A}$ & $11,7 \alpha$ & $25,0 \mathrm{ab}$ & $11,0 \mathrm{~A}$ & $2,7 \beta$ & $24,2 \mathrm{a}$ & $5,8 \mathrm{~A}$ & $0,8 \alpha$ \\
\hline NK Fair & $74,6 \mathrm{~b}$ & $39,1 \mathrm{~A}$ & $8,3 \alpha$ & $28,7 \mathrm{~b}$ & $13,6 \mathrm{~A}$ & $2,2 \alpha \beta$ & $28,5 \mathrm{a}$ & $9,5 \mathrm{~A}$ & $2,5 \alpha$ \\
\hline Aviso & $56,7 \mathrm{a}$ & $31,7 \mathrm{~A}$ & $9,2 \alpha$ & $20,5 \mathrm{a}$ & $8,9 \mathrm{~A}$ & $1,2 \alpha \beta$ & $17,5 \mathrm{a}$ & $6,7 \mathrm{~A}$ & $0,1 \alpha$ \\
\hline GD LSD $p \leq 0,05$ & 15,3 & 15,68 n.s. & 8,95 n.s. & 8,25 & 6,36 n.s. & 2,13 & 14,2 n.s. & 7,8 n.s. & 2,45 n. s. \\
\hline \multirow{2}{*}{$\begin{array}{l}\text { Frühjahr } 2008 \\
\text { Sorten }\end{array}$} & \multicolumn{3}{|c|}{$\mathrm{BH}[\%]$} & \multicolumn{3}{|c|}{$\mathrm{GW}[\%]$} & \multicolumn{3}{|c|}{ SB [\%] } \\
\hline & Chin. & Oft.+ N. & Netz-H & Chin. & Oft.+ N. & Netz-H & Chin. & Oft. $+\mathrm{N}$. & . Netz-H \\
\hline Laser & $61,7 \mathrm{ab}$ & $43,3 \mathrm{AB}$ & $30,8 \alpha$ & $23,3 \mathrm{bc}$ & $13,2 \mathrm{BC}$ & $10,1 \beta$ & $14,2 \mathrm{a}$ & $2,5 \mathrm{AB}$ & $3,3 \alpha$ \\
\hline Caiman & $62,2 \mathrm{ab}$ & $40,0 \mathrm{AB}$ & $18,1 \alpha$ & $16,3 a b$ & $9,8 \mathrm{AB}$ & $4,0 \alpha$ & $4,4 \mathrm{a}$ & $0,8 \mathrm{~A}$ & $0 \alpha$ \\
\hline Lion & $73,3 \mathrm{~b}$ & $45,0 \mathrm{AB}$ & $29,1 \alpha$ & $27,0 \mathrm{c}$ & $12,7 \mathrm{BC}$ & $8,6 \beta$ & $10,8 \mathrm{a}$ & $1,7 \mathrm{~A}$ & $0,8 \alpha$ \\
\hline NK Fair & $60,0 \mathrm{ab}$ & $46,7 \mathrm{~B}$ & $25,8 \alpha$ & $20,2 \mathrm{bc}$ & $14,5 \mathrm{~B}$ & $9,2 \beta$ & $8,6 \mathrm{a}$ & $5,8 \mathrm{~B}$ & $1,7 \alpha$ \\
\hline Aviso & $54,3 \mathrm{a}$ & $36,7 \mathrm{~A}$ & $28,6 \alpha$ & $15,3 \mathrm{a}$ & $8,9 \mathrm{~A}$ & $6,9 \alpha \beta$ & $6,7 \mathrm{a}$ & $0 \mathrm{~A}$ & $0 \alpha$ \\
\hline GD LSD $p \leq 0,05$ & 15,69 & 9,26 & 12,9 n. s. & 7,55 & 3,43 & 4,14 & $12,05 \mathrm{n.s}$ & 3,81 & $4 \mathrm{n} . \mathrm{s}$ \\
\hline
\end{tabular}

1) Netz/ Insektizidvarianten = Chinook (Chin.): ohne Netz/ Saatgutbehandlung mit Chinook; Oftanol T + Nexion Neu (Oft. + N.): ohne Netz/ Saatgutbehandlung mit Oftanol T + Austreuen des insektiziden Granulats Nexion Neu nach der Saat $\left(10 \mathrm{~g} / \mathrm{m}^{2}\right)$; Netz im Herbst $(\mathrm{H})$ : Auflage eines Kulturschutznetzes von Mitte August bis Mitte Oktober 2007/ Saatgutbehandlung mit Chinook). 

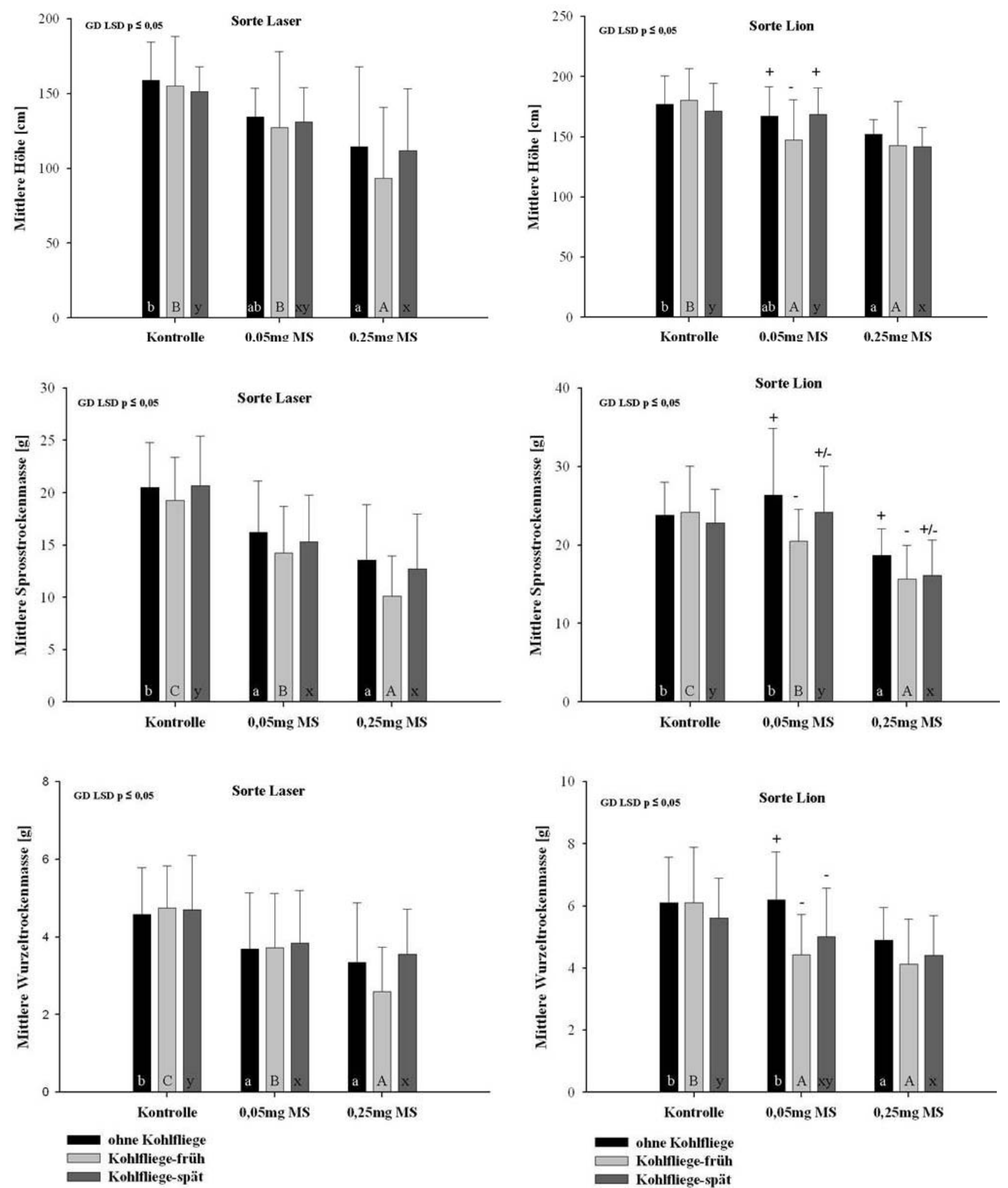

Abb. 1A: Mittlere Höhe [cm], Sprosstrockenmasse [g] sowie Wurzeltrockenmasse $[\mathrm{g}]$ verschiedener Versuchsvarianten der Winterrapssorten Laser bzw. Lion 150 dpi (BBCH 90). Statistisch signifikante Differenzen zwischen den Inokulationsvarianten sind für die jeweiligen Kohlfliegenvarianten durch unterschiedliche Buchstaben gekennzeichnet $(n=15)$. Signifikante Unterschiede zwischen den Kohlfliegenvarianten sind für die jeweiligen Inokulationsvarianten durch $(+)$ bzw. $(-)$ Zeichen gekennzeichnet (LSD $\mathrm{p} \leq 0,05$ ). Bodeninokulation mit Mikrosklerotiengemisch der $V$. longi-sporumIsolate VL 40 + VL 43 in Höhe von 0 (Kontrolle), 0,05 oder 0,25 mg Mikrosklerotien (MS)/g Boden. Kohlfliegenvarianten: Kontrolle $=$ ohne Eiansatz, Kohlfliege-früh bzw. Kohlfliege-spät $=$ Ansatz von 8 Eiern an den Wurzelhals zu BBCH 15 bzw. BBCH 61. 
Tab. 17A Mittlere Pflanzenlänge [PFL], Sprosstrockenmasse (STM), Wurzeltrockenmasse (WTM) sowie Einzelpflanzenkornertrag (Ertrag/Pfl.) Verticillium-inokulierter Sommerrapspflanzen der Sorte Heros 155 dpi (BBCH 90). Statistisch signifikante Differenzen zwischen den Inokulationsvarianten ${ }^{1)}$ sind für die jeweiligen Kohlfliegenvarianten ${ }^{2}$ durch unterschiedliche Buchstaben gekennzeichnet $(+/-)$ zeigen signifikante Unterschiede zwischen den Kohlfliegenvarianten bei den jeweiligen Inokulationsvarianten an (LSD $\mathrm{p} \leq 0,05 ; \mathrm{n}=12)$.

\begin{tabular}{|c|c|c|c|c|c|c|c|c|}
\hline \multirow[b]{2}{*}{ Inokulum [g] } & \multicolumn{2}{|c|}{ PFL $[\mathrm{cm}]$} & \multicolumn{2}{|c|}{ STM $[\mathrm{g}]$} & \multicolumn{2}{|c|}{ WTM [g] } & \multicolumn{2}{|c|}{ Ertrag/Pfl. [g] } \\
\hline & ohne KF & mit KF & ohne KF & mit KF & ohne KF & mit KF & ohne KF & mit KF \\
\hline 0 & $147,8 \mathrm{c}$ & $144,9 \mathrm{C}$ & $35,3 \mathrm{~b}$ & $34,5 \mathrm{D}$ & $3,1 \mathrm{c}$ & $3,2 \mathrm{D}$ & $9,6 \mathrm{~b}$ & $9,3 \mathrm{C}$ \\
\hline 0,25 & $140,4 \mathrm{~b}$ & $137,3 \mathrm{BC}$ & $30,4 \mathrm{a}$ & $30,2 \mathrm{C}$ & $2,1 \mathrm{~b}$ & $2,2 \mathrm{C}$ & $8,3 \mathrm{ab}$ & $8,3 \mathrm{BC}$ \\
\hline 0,5 & $138,4 \mathrm{ab}$ & $134,3 \mathrm{~B}$ & $30,1 \mathrm{a}$ & $28,2 \mathrm{BC}$ & $2,1 \mathrm{~b}$ & $1,8 \mathrm{BC}$ & $8,5 \mathrm{ab}$ & 7,9 B \\
\hline 1 & $140,5 \mathrm{~b}$ & $129,2 \mathrm{AB}$ & $29,4 \mathrm{a}$ & $26,5 \mathrm{~B}$ & $1,8 \mathrm{ab}$ & $1,7 \mathrm{ABC}$ & $8,1 \mathrm{a}$ & $7,8 \mathrm{~B}$ \\
\hline 2 & $133,6 \mathrm{a}$ & $130,3 \mathrm{AB}$ & $28,0 \mathrm{a}$ & $25,8 \mathrm{AB}$ & $1,9 \mathrm{ab}$ & $1,5 \mathrm{AB}$ & $7,6 \mathrm{a}$ & $6,7 \mathrm{~A}$ \\
\hline 4 & $133,3 \mathrm{a}+$ & $122,8 \mathrm{~A}-$ & $26,7 \mathrm{a}+$ & $22,9 \mathrm{~A}-$ & $1,6 \mathrm{a}+$ & $1,3 \mathrm{~A}-$ & $7,7 \mathrm{a}+$ & $5,8 \mathrm{~A}-$ \\
\hline GD LSD $p \leq 0,05$ & 6,9 & 8,6 & 4,1 & 3,2 & 0,4 & 0,5 & 1,3 & 1,2 \\
\hline
\end{tabular}

1) Bodeninokulation mit Verticillium-befallenem, klein gemahlenem Stoppelmaterial in Höhe von 0 (Kontrolle), 0,25, 0,5, 1, 2 oder $4 \mathrm{~g}$ /Topf (1050 g Boden/Topf). 2) Kohlfliegenvarianten = ohne Kohlfliege (ohne KF); mit Kohlfliege (mit KF): Ansatz von 8 Eiern an den Wurzelhals zu BBCH 15. 
Tab. 18A: Mittlere Pflanzenlänge [PFL], Sprossfrischmasse (SFM) sowie Wurzeltrockenmasse (WTM) Verticillium-inokulierter Sommerrapspflanzen der Sorte Heros 155 dpi (BBCH 90). Statistisch signifikante Differenzen zwischen den Inokulationsvarianten ${ }^{1)}$ sind für die jeweiligen Kohlfliegenvarianten ${ }^{2}$ durch unterschiedliche Buchstaben gekennzeichnet. (+/-) zeigen signifikante Unterschiede zwischen den Kohlfliegenvarianten bei den jeweiligen Inokulationsvarianten an (LSD $p$ $\leq 0,05 ; \mathrm{n}=12$ ).

\begin{tabular}{|c|c|c|c|c|c|c|}
\hline \multirow{2}{*}{$\begin{array}{l}\text { PFL [cm] } \\
\text { Inokulum [g/Topf] }\end{array}$} & \multicolumn{2}{|c|}{56 dpi (BBCH 55) } & \multicolumn{2}{|c|}{84 dpi (BBCH 75) } & \multicolumn{2}{|c|}{125 dpi (BBCH 90) } \\
\hline & ohne KF & mit KF & ohne KF & mit KF & ohne KF & mit KF \\
\hline 0 & $80,8 \mathrm{a}$ & $103,5 \mathrm{~B}$ & 168,4 & $165,8 \mathrm{~B}$ & 169,3 & 170,1 \\
\hline 0,2 & $93,9 \mathrm{a}$ & $93,5 \mathrm{AB}$ & 175,7 & $156,2 \mathrm{AB}$ & 169,6 & 162,6 \\
\hline 1 & $77,6 \mathrm{a}$ & $89,83 \mathrm{AB}$ & 163,1 & $162,5 \mathrm{~B}$ & 160,5 & 153,6 \\
\hline 5 & $76,3 \mathrm{a}$ & $76,9 \mathrm{~A}$ & $162,4+$ & $139,6 \mathrm{~A}-$ & $162,6+$ & $145,3-$ \\
\hline GD LSD $p \leq 0,05$ & 21,6 n.s. & 21,6 & 18,7 n.s. & 21,7 & 9,3 n.s. & 12,9 \\
\hline SFM [g] & \multicolumn{2}{|c|}{56 dpi (BBCH 55) } & \multicolumn{2}{|c|}{84 dpi (BBCH 75) } & \multicolumn{2}{|c|}{125 dpi (BBCH 90) } \\
\hline Inokulum [g/Topf] & ohne KF & mit KF & ohne KF & mit KF & ohne KF & mit KF \\
\hline 0 & $130,2 \mathrm{~b}$ & $131,9 \mathrm{~B}$ & $107 \mathrm{bc}$ & 94,4 B & $27,4 \mathrm{bc}$ & $29,6 \mathrm{~B}$ \\
\hline 0,2 & $130,5 \mathrm{~b}$ & $130,5 \mathrm{~B}$ & $114,2 \mathrm{c}+$ & $90,7 \mathrm{AB}-$ & $29,7 \mathrm{c}$ & $27,8 \mathrm{~B}$ \\
\hline 1 & $114,2 \mathrm{a}$ & $115,4 \mathrm{~A}$ & $94,5 \mathrm{ab}$ & $91,6 \mathrm{AB}$ & $24,7 \mathrm{ab}$ & $21,7 \mathrm{~A}$ \\
\hline 5 & $115,4 \mathrm{a}$ & $106,5 \mathrm{~A}$ & $87,9 \mathrm{a}$ & $77,9 \mathrm{~A}$ & $23,5 \mathrm{a}$ & $20,8 \mathrm{~A}$ \\
\hline GD LSD $p \leq 0,05$ & 14,2 & 13,9 & 14 & 14,7 & 3,3 & 5,8 \\
\hline WTM [g] & \multicolumn{2}{|c|}{56 dpi (BBCH 55) } & \multicolumn{2}{|c|}{84 dpi (BBCH 75) } & \multicolumn{2}{|c|}{125 dpi (BBCH 90) } \\
\hline Inokulum [g/Topf] & ohne KF & mit KF & ohne KF & mit KF & ohne KF & mit KF \\
\hline 0 & $1,34 \mathrm{a}$ & $1,39 \mathrm{~B}$ & $2,26 \mathrm{ab}$ & $2,20 \mathrm{~B}$ & $2,53 \mathrm{~b}$ & $2,61 \mathrm{~B}$ \\
\hline 0,2 & $1,41 \mathrm{a}$ & $1,32 \mathrm{~B}$ & $2,66 \mathrm{~b}$ & $1,92 \mathrm{AB}$ & $2,68 \mathrm{~b}$ & $2,55 \mathrm{AB}$ \\
\hline 1 & $1,38 \mathrm{a}$ & $1,27 \mathrm{AB}$ & $2,30 \mathrm{ab}$ & $2,02 \mathrm{~B}$ & $2,21 \mathrm{ab}$ & $1,99 \mathrm{~A}$ \\
\hline 5 & $1,21 \mathrm{a}$ & $1,02 \mathrm{~A}$ & $2,07 \mathrm{a}$ & $1,58 \mathrm{~A}$ & $1,74 \mathrm{a}$ & $1,55 \mathrm{~A}$ \\
\hline GD LSD $p \leq 0,05$ & $0,31 \mathrm{n} . \mathrm{s}$. & 0,30 & 0,46 & 0,38 & 0,48 & 0,61 \\
\hline
\end{tabular}

1) Bodeninokulation mit stark Verticillium-befallenem, klein gemahlenem Stoppelmaterial in Höhe von 0 (Kontrolle), 0,2, 1 oder 5 g/Topf (1050 g Boden/Topf). 2) Kohlfliegenvarianten: ohne KF = ohne Kohlfliege, mit KF $=$ mit Kohlfliege, Ansatz von 8 Eiern an den Wurzelhals zu BBCH 15. 
Tab. 19A: Mittlere Pflanzenlänge [PFL], Sprossfrischmasse [SFM] sowie Wurzeltrockenmasse [WTM] von Raps der Sorte Express bzw. der Rapslinie Sem (05-500256) 48 dpi (BBCH 65), 80 dpi (BBCH 75) sowie 115 dpi (BBCH 85). Statistisch signifikante Differenzen zwischen den Versuchsvarianten ${ }^{1)}$ sind für die jeweiligen Sorten durch unterschiedliche Buchstaben gekennzeichnet. (+/-) zeigen signifikante Unterschiede zwischen den Sorten bei den jeweiligen Versuchsvarianten an (LSD $\mathrm{p} \leq 0,05 ; \mathrm{n}=12)$.

\begin{tabular}{|c|c|c|c|c|c|c|}
\hline \multirow{2}{*}{$\begin{array}{l}\text { PFL [cm] } \\
\text { Versuchsvarianten }\end{array}$} & \multicolumn{2}{|c|}{48 dpi (BBCH 65) } & \multicolumn{2}{|c|}{80 dpi (BBCH 75) } & \multicolumn{2}{|c|}{115 dpi (BBCH 85) } \\
\hline & Express & Sem & Express & Sem & Express & Sem \\
\hline Kontrolle & $93,1 \mathrm{c}$ & $97,7 \mathrm{C}$ & $162,9 \mathrm{ab}$ & $156,8 \mathrm{C}$ & $172,9 \mathrm{~b}$ & $161,8 \mathrm{C}$ \\
\hline Kohlfliege (KF) & $94,2 \mathrm{c}$ & $86,3 \mathrm{BC}$ & $167,2 b+$ & 148,7 BC - & $161,5 \mathrm{ab}$ & $155,3 \mathrm{BC}$ \\
\hline Verticillium & $84,3 \mathrm{~b}$ & $75,3 \mathrm{~B}$ & $160,4 \mathrm{ab}+$ & $137,7 \mathrm{~B}-$ & $159,1 \mathrm{a}+$ & $143,2 \mathrm{~B}-$ \\
\hline Verticillium + KF & $75,7 \mathrm{a}+$ & $55,1 \mathrm{~A}-$ & $155,5 \mathrm{a}+$ & $100,8 \mathrm{~A}-$ & $150,8 \mathrm{a}+$ & $127,6 \mathrm{~A}-$ \\
\hline GD LSD $p \leq 0,05$ & 8,5 & 11,4 & 10,1 & 15,5 & 12,3 & 12,3 \\
\hline SFM [g] & \multicolumn{2}{|c|}{48 dpi (BBCH 65) } & \multicolumn{2}{|c|}{80 dpi (BBCH 75) } & \multicolumn{2}{|c|}{115 dpi (BBCH 85) } \\
\hline Versuchsvarianten & Express & Sem & Express & Sem & Express & Sem \\
\hline Kontrolle & $64 \mathrm{~b}$ & $64,7 \mathrm{D}$ & $68,5 \mathrm{c}$ & $70,7 \mathrm{C}$ & $61,3 \mathrm{~d}$ & $54,8 \mathrm{C}$ \\
\hline Kohlfliege (KF) & $60,6 \mathrm{~b}$ & $53,8 \mathrm{C}$ & $59,9 \mathrm{ab}$ & $63,6 \mathrm{C}$ & $48,8 \mathrm{~b}$ & $47,8 \mathrm{BC}$ \\
\hline Verticillium & $53,2 \mathrm{a}+$ & $42,8 \mathrm{~B}-$ & $66,7 \mathrm{bc}+$ & $53,5 \mathrm{~B}-$ & $55,5 \mathrm{c}+$ & $45,6 \mathrm{~B}-$ \\
\hline Verticillium $+\mathrm{KF}$ & $48 \mathrm{a}+$ & $32,6 \mathrm{~A}-$ & $53,4 \mathrm{a}+$ & $30,2 \mathrm{~A}-$ & $42,8 \mathrm{a}$ & $35,9 \mathrm{~A}$ \\
\hline GD LSD $\mathrm{p} \leq 0,05$ & 6,1 & 5,6 & 6,9 & 9,8 & 5,8 & 6,9 \\
\hline WTM [g] & \multicolumn{2}{|c|}{48 dpi (BBCH 65) } & \multicolumn{2}{|c|}{80 dpi (BBCH 75) } & \multicolumn{2}{|c|}{115 dpi (BBCH 85) } \\
\hline Versuchsvarianten & Express & Sem & Express & Sem & Express & Sem \\
\hline Kontrolle & $0,61 \mathrm{ab}-$ & $0,84 \mathrm{C}+$ & $1,23 \mathrm{~b}$ & $1,30 \mathrm{C}$ & $1,55 \mathrm{~d}+$ & $1,30 \mathrm{~B}-$ \\
\hline Kohlfliege (KF) & $0,73 \mathrm{c}$ & $0,66 \mathrm{~B}$ & $1,08 \mathrm{~b}$ & $1,17 \mathrm{BC}$ & $1,32 \mathrm{c}$ & $1,27 \mathrm{~B}$ \\
\hline Verticillium & $0,62 \mathrm{ab}$ & $0,55 \mathrm{~B}$ & $1,19 b+$ & $0,99 \mathrm{~B}-$ & $1,06 \mathrm{~b}-$ & $1,38 \mathrm{~B}+$ \\
\hline Verticillium $+\mathrm{KF}$ & $0,54 \mathrm{a}+$ & $0,37 \mathrm{~A}-$ & $0,88 \mathrm{a}+$ & $0,52 \mathrm{~A}-$ & $0,78 \mathrm{a}$ & $0,67 \mathrm{~A}$ \\
\hline GD LSD $p \leq 0,05$ & 0,12 & 0,14 & 0,15 & 0,21 & 0,19 & 0,29 \\
\hline
\end{tabular}

1) Bodeninokulation mit Verticillium-befallenem, klein gemahlenem Stoppelmaterial in Höhe von 0 (Kontrolle; Kohlfliege) oder 1 g/Topf (1050 g Boden/Topf) (Verticillium, Verticillium + KF). Kohlfliegenvarianten: ohne Kohlfliege (Kontrolle, Verticillium); mit Kohlfliege (Kohlfliege (KF), Verticillium + KF); Ansatz von 8 Eiern an den Wurzelhals zu BBCH 15). 
Tab. 20A: Mittlere Pflanzenlänge [PFL], Sprosstrockenmasse [STM] sowie Wurzeltrockenmasse [WTM] von Sommerraps der Sorte Heros bei verschiedenen Versuchsvarianten ${ }^{1)}$ eines Doppeltopfversuchs mit zwei getrennten Wurzelsystemen 58 dpi $(\mathrm{BBCH} 69)$ sowie 84 dpi $(\mathrm{BBCH} 85 ; \mathrm{n}=12)$. Statistisch signifikante Differenzen zwischen den Versuchsvarianten sind für die jeweiligen Parameter durch unterschiedliche Buchstaben gekennzeichnet. (LSD $\mathrm{p} \leq 0,05)$.

\begin{tabular}{|c|c|c|c|c|c|c|}
\hline \multirow[b]{2}{*}{ Versuchsvarianten } & \multicolumn{2}{|c|}{ PFL $[\mathrm{cm}]$} & \multicolumn{2}{|c|}{ STM $[\mathrm{g}]$} & \multicolumn{2}{|c|}{ WTM [g] } \\
\hline & 58 dpi & 84 dpi & $58 \mathrm{dpi}$ & 84 dpi & 58 dpi & 84 dpi \\
\hline $0 / 0$ & $155,4 \mathrm{a}$ & $151,6 \mathrm{~A}$ & $16,9 \mathrm{a}$ & $19,1 \mathrm{C}$ & $1,02 \mathrm{a}$ & $1,07 \mathrm{C}$ \\
\hline $0 / \mathrm{KF}$ & 153,9 a & $154 \mathrm{~A}$ & $18,7 \mathrm{a}$ & $17,6 \mathrm{BC}$ & $0,95 \mathrm{a}$ & $1 \mathrm{BC}$ \\
\hline $\mathrm{V} / 0$ & $154,1 \mathrm{a}$ & $155,5 \mathrm{~A}$ & $17,3 \mathrm{a}$ & $15,8 \mathrm{AB}$ & $0,95 \mathrm{a}$ & $0,83 \mathrm{AB}$ \\
\hline $\mathrm{V} / \mathrm{KF}$ & $157,6 \mathrm{a}$ & $144,2 \mathrm{~A}$ & $17,1 \mathrm{a}$ & $14,9 \mathrm{AB}$ & $0,97 \mathrm{a}$ & $0,9 \mathrm{BC}$ \\
\hline $\mathrm{V}+\mathrm{KF} / 0$ & $150,6 \mathrm{a}$ & $144 \mathrm{~A}$ & $16,9 \mathrm{a}$ & $13,5 \mathrm{~A}$ & $0,92 \mathrm{a}$ & $0,64 \mathrm{~A}$ \\
\hline GD LSD $p \leq 0,05$ & 8,6 n.s. & 17 n.s. & 1,9 n.s. & 2,8 & $0,22 \mathrm{n} \cdot \mathrm{s}$ & 0,2 \\
\hline
\end{tabular}

1) Versuchsvarianten: $\mathrm{V} / 0=$ Verticillium-Inokulum $(\mathrm{V})$ auf einer Wurzelhälfte; $\mathrm{V} / \mathrm{KF}=$ Verticillium-Inokulum (V) und Kohlfliegenbefall (KF) separat; $\mathrm{V}+\mathrm{KF} / 0=$ Verticillium-Inokulum (V) und Kohlfliegenbefall (KF) zusammen. $\mathrm{V}=$ Bodeninokulation mit Verticillium-befallenem, klein gemahlenem Stoppelmaterial in Höhe von $1 \mathrm{~g} /$ Topf. KF= Ansatz von 5 Eiern im mittleren Wurzelbereich zu BBCH 17-18.

Tab. 21A: Mittlere Wurzeltrockenmasse [WTM] von Rapspflanzen der Sorte Express nach Bodengießinokulation ${ }^{1)}$ mit $V$. longisporum 35 dpi (BBCH 75). Statistisch signifikante Differenzen zwischen den Inokulationsvarianten sind für die jeweiligen Wurzelverletzungsvarianten durch unterschiedliche Buchstaben gekennzeichnet. (+/-) zeigen signifikante Unterschiede zwischen den Wurzelverletzungsvarianten an (LSD $\mathrm{p} \leq 0,05 ; \mathrm{n}=12$ ).

\begin{tabular}{lccc}
\hline WTM [g] & \multicolumn{3}{c}{ Wurzelverletzung } \\
\cline { 2 - 4 } Inokulationsvarianten & Ohne & Mechanisch $^{2)}$ & Kohlfliege $^{3)}$ \\
\hline Kontrolle & $0,84 \mathrm{~b}$ & $0,87 \mathrm{~B}$ & $0,82 \mathrm{y}$ \\
Verticillium -Inokulation & $0,70 \mathrm{a}+$ & $0,52 \mathrm{~A}-$ & $0,61 \mathrm{x}+/-$ \\
\hline GD LSD $\leq 0,05$ & 12,18 & 16,27 & 9,02 \\
\hline
\end{tabular}

1) Bodengießinokulation mit $100 \mathrm{ml}$ einer Sporensuspension der V. longisporum-Isolate VL $40 \mathrm{bzw}$. VL 43 (1 x $10^{5}$ Sporen/ml) zu BBCH 60. Wurzelverletzungsvarianten: Ohne; Mechanisch= Mechanische Verletzung von Hauptwurzel (mit Skalpell) sowie Feinwurzeln (mit Nadel) unmittelbar vor der Bodengießinokulation; Kohlfliege $=$ Ansatz von 8 Kohlfliegeneiern an den Wurzelhals zu BBCH 55. 


\section{Danksagung}

Ich möchte mich ganz besonders bei Herrn Prof. Dr. Andreas von Tiedemann für die Überlassung des Themas, die Diskussions- und Hilfsbereitschaft sowie die gewährte Freiheit bei der Bearbeitung des Projektes bedanken.

Herrn Prof. Dr. Stefan Vidal danke ich für die Übernahme des Koreferates.

Herrn Dr. Bernd Ulber gilt mein besonderer Dank für die Unterstützung in allen Entomologischen Angelegenheiten.

Bei Katharina Müller bedanke ich mich ganz herzlich für die konstruktive Zusammenarbeit im Rahmen ihrer Masterarbeit.

Vielen Dank an Evelin Vorbeck, Jutta Scharper, Claudia Nordmann, Hubertus Reintke und Eugen Hodyl für die tatkräftige Unterstützung im Feld und Gewächshaus. Bei Frank Gremmes und Herrn Kussatz danke ich für die technische Unterstützung jeglicher Art.

Bei Herrn Prof. Dr. Petr Karlovsky, Heike Rollwage und Dagmar Tacke bedanke ich mich für die Hilfe bei molekularbiologischen Fragestellungen.

Bei Frau Martina Bode möchte ich mich für die pragmatische, unbürokratische Hilfe in allen administrativen Angelegenheiten bedanken.

Ich möchte mich bei einer ganzen Reihe von Hiwis, Ziwis und weiteren freiwilligen Helfern bedanken, die mich sehr unterstützt haben: Fried Rathing, Mareen Gollnow, Christine Venjakop, Ansgar Poloczek, Jennifer Hüpenden, Oliver Wisser, Laura Hartman, Johannis Thiemann, Ali Haydar Oezen, Jan-Eike Krämer, Steffi Nehrlich und Lucie de Combret.

Der Abteilung Pflanzenzüchtung und hierbei insbesondere Herrn Gerald Miotke gilt mein Dank für die Durchführung der Einzelkornsaat in den letzten beiden Versuchsjahren.

Bei den Kooperationspartnern an den Monitoringstandorten, Frau Weiske, Herrn Kaak, Herrn Meißner, Herrn Kruse, Herrn Dr. Verch und Herrn Dr. Steinbach danke ich für die Zusammenarbeit.

Bei der Union zur Förderung von Öl- und Proteinpflanzen (UFOP) bedanke ich mich für die Finanzierung des Projektes.

Beim FG Pflanzenpathologie und Pflanzenschutz und hierbei insbesondere der Abteilung Allgemeine Pflanzenpathologie und Pflanzenschutz möchte ich mich für die herausragende Arbeitsatmosphäre und stetige Hilfsbereitschaft bedanken.

Abschließend möchte ich mich ganz besonders bei meiner Familie und Birte Wassmuth bedanken, die mich immer unterstützt haben. 


\section{Lebenslauf:}

Name: $\quad$ Harald Keunecke

Geboren am: $\quad$ 08. März 1978 in Mettmann

Familienstand: $\quad$ Ledig

08/84- 08/88 Besuch der Grundschule Kirchendellerweg in Mettmann

08/88- 07/97 Besuch des Heinrich-Heine Gymnasiums in Mettmann. Abschluss: Abitur

07/97-05/98 Wehrdienst im FüUstgRgt30 in Hilden

10/98-10/00 Grundstudium der Agrarwissenschaften an der Georg-August-Universität Göttingen.

07/00-07/01 Landwirtschaftliches Praktikum auf einem Ackerbau-Schweinemastbetrieb in Essen. Abschluss: Praktikantenprüfung NRW

07/03-10/03 Landwirtschaftliches Praktikum auf einem Milchviehbetrieb in Cork (Irland)

10/01-03/04 Hauptstudium der Agrarwissenschaften (Fachrichtung Pflanzenproduktion) an der Georg-August-Universität-Göttingen sowie an der University of Nottingham (UK)

04/04-09/05 Anfertigung einer Masterarbeit am Institut für Pflanzenpathologie und Pflanzenschutz Thema: "Einfluss von Verticillium longisporum auf die Wurzel- und Sprossentwicklung von Winterraps unter Berücksichtigung von Fungizidapplikationen." Abschluss: Master of Science

Seit $10 / 05$

Doktorand am Department für Nutzpflanzenwissenschaften, Fachgebiet Pflanzenpathologie und Pflanzenschutz der Georg-August-Universität Göttingen. Dissertationsthema: „Einfluss von Kohlfliegenbefall auf die Infektion und Schadwirkung von Verticillium longisporum und Phoma lingam an Raps.“ 